Martin Müller, Christoph Neubert (Hg.)

STANDARDISIERUNG UND NATURALISIERUNG 
SCHRIFTENREIHE DES GRADUIERTENKOLLEGS

\title{
„AUTOMATISMEN“
}

\author{
Herausgegeben von \\ Hannelore Bublitz, Norbert Otto Eke, \\ Reinhard Keil, Christoph Neubert und \\ Hartmut Winkler
}

Wissenschaftlicher Beirat

Ulrike Bergermann, Michael Nagenborg, Bettina Wahrig, Heike Weber 
Martin Müller, Christoph Neubert (Hg.)

\section{Standardisierung und Naturalisierung}

Wilhelm Fink 
Gedruckt mit Unterstützung der Deutschen Forschungsgemeinschaft Umschlagabbildung: Jürgen Gebhard (picturepress)

\section{Online-Ausgabe 2021}

Bibliografische Information der Deutschen Nationalbibliothek

Die Deutsche Nationalbibliothek verzeichnet diese Publikation in der Deutschen

Nationalbibliografie; detaillierte bibliografische Daten sind im Internet über http://dnb.d-nb.de abrufbar.

Alle Rechte vorbehalten. Dieses Werk sowie einzelne Teile desselben sind urheberrechtlich geschützt. Jede Verwertung in anderen als den gesetzlich zugelassenen Fällen ist ohne vorherige schriftliche Zustimmung des Verlags nicht zulässig.

(C) 2019 Wilhelm Fink Verlag, ein Imprint der Brill-Gruppe (Koninklijke Brill NV, Leiden, Niederlande; Brill USA Inc., Boston MA, USA; Brill Asia Pte Ltd, Singapore; Brill Deutschland GmbH, Paderborn, Deutschland)

Internet: www.fink.de

Lektorat und Satz: Margret Westerwinter, Düsseldorf; www.lektorat-westerwinter.de Einband: Evelyn Ziegler, München

Herstellung: Brill Deutschland GmbH, Paderborn

ISSN 2629-7574

ISBN 978-3-7705-6229-9 (paperback)

ISBN 978-3-8467-6229-5 (e-book) 


\section{INHALT}

MARTIN MÜLLER

Standardisierung und Naturalisierung - zur Einleitung

\section{AUTOMATISMEN DER STANDARDISIERUNG: \\ METRIKEN, FORMBILDUNG, SCHEMATA}

FLORIAN SPRENGER

Standards und Standarten

ANNA ECHTERHÖLTER

Red and Black Boxes.

Koloniale Standardisierung als Metroklasmus

STEFAN RIEGER

Stille Post. Automatismen der Formerzeugung

SUSANNE JANY

Die Fabrikation des Betriebsunfalls

NICOLE M. WILK

„Das ist kein neuer Kalter Krieg“ -

zum Zusammenhang von Metadiskurs und Standardbildung aus diskurslinguistischer Sicht 
ROLAND BLESS

Standardisierung im Internet -

wer gestaltet das Internet der Zukunft?

\section{EFFEKTE DER NATURALISIERUNG: LEBEN, KÖRPER, PRAKTIKEN}

ANTONIO LUCCI UND THOMAS MACHO

,Vivete sani e amatemi“.

Paolo Mantegazza und das Gespenst der Biopolitik

ANNE SCHREIBER

Standards for Group Action.

Anfänge des US-amerikanischen Managements zwischen

Biochemie, Sozialtheorie und Wissenschaftsgeschichte

LAURA MOISI

Zurück in die Zukunft:

Theorie und Geschichte der Frankfurter Küche

TOBIAS EICHINGER

Authentische Amputationen.

Zum Umgang mit extremen Wünschen in der Medizin

zwischen körperlicher Integrität und Normalität

PATRICIA RIBAULT

Körper bei der Arbeit. Geste, Norm und Technik

MARTIN MÜLLER

Universale Konstrukteure?

Vom $\alpha$ vós des Lebendigen zur Affirmation der synthetischen

Biologie als universale Ingenieurswissenschaft 
Thesen:

Zum Eigenleben statistischer Instrumente und die Reduzierung des Ökologischen

THORBEN MÄMECKE

These 1: Automatismen sind unberechenbar.

Naturalisierungen emergenter Prozesse sind Versuche, dies zu kaschieren.

PAUL BUCKERMANN

These 2: Die formelle Standardisierung von Maßeinheiten ermöglicht ungeplante Strukturbildung.

Eine vergleichssoziologische Skizze zum Ecological Footprint.

ABBILDUNGSNACHWEISE 



\section{MARTIN MÜLLER}

\section{STANDARDISIERUNG UND NATURALISIERUNG - ZUR EINLEITUNG}

Ein Hauptmotiv der Automatismen-Forschung lässt sich als Faszination (für den Nachvollzug) eines spezifischen Typus von Prozessen beschreiben, wel-

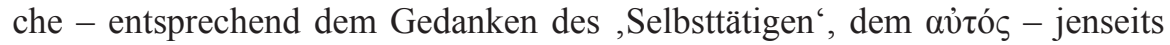
menschlicher Handlungsmacht, Planung und Kontrolle wirksam sind. Das Denken von und mit Automatismen steht im Zeichen des Opaken, des Rätselund Geisterhaften, oder technisch gewendet, im Denkbild der Black Box. Mit dieser Fokussierung widmet es sich dem Verstehen dessen, was vor der Etablierung etwaiger Ordnung und Konstellationen, was hinter dem Sicht- und Sagbaren, was vor der Stabilisierung von Praktiken und Schemata und im Prozess der Bildung materieller Strukturen und Gefüge operativ tätig ist.

Standardisierung und Naturalisierung erscheinen vor diesem Hintergrund als zwei unterschiedliche und doch komplementäre Prozesse, durch die kulturell bedingte Praktiken, Wahrnehmungen und Technologien in einen Zustand der Selbstverständlichkeit übergehen. ${ }^{1}$ Zwischen den beiden Begriffen finden sich vielfältige Parallelen und Überlappungen: Während es für die Naturalisierung als Konstruktion von Natürlichkeit charakteristisch scheint, dass sie sich auf einer unbewussten Ebene vollzieht, gibt es gleichzeitig Standardisierungsprozesse, in denen das Ideal des ,Natürlichen ' bewusst angestrebt wird. Die natürlich erscheinende Norm und das Selbstverständlich-Natürliche sind gerade deshalb so wirksam, weil sie ihre historische Genese, ihre Zufälligkeit, ihre Künstlichkeit wie auch ihre Kontingenz verschleiern und verdecken. Genau darin liegt ihre (kultur-)technische und (macht-)historische Relevanz und Bedeutung.

Der Beginn einer umfassenden Standardisierung im modernen Europa lässt sich in Frankreich zum Ende des Ancien régime ausmachen. Die Einführung der einheitlichen Standards des metrischen Systems sollte im gewissen Sinne ein ,epistemisches Leid' lindern, das sich aus der überbordenden Vielzahl tradierter Standards und lokaler Normen ergab: ,[T]he existence of French men and women around 1790 was made miserable by [...] 700 or 800 diffe-

\footnotetext{
Geoffrey C. Bowker und Susan Leigh Star, Sorting Things Out: Classification and Its Consequences, Cambridge, MA, 2000, S. 10-19. Neben dieser Monografie zur Theorie der Klassifizierung und Sortierung ist unlängst ein weiteres Standardwerk zur Geschichte der Standardisierung in den Ingenieurswissenschaften entstanden: JoAnne Yates/Craig N. Murphy, Engineering Rules. Global Standard Setting since 1880, Baltimore, MD, 2019.
} 
rently named measures and untold units of the same name but different sizes." 2 Im Auftrag der Académie des Sciences wurde deshalb ein standardisiertes Maßsystem erarbeitet. Dem Gestus der Aufklärung entsprechend, präsentierte der berühmte Rapport sur le choix d'une unité de mesure aus dem Jahr 1791 eine Reihe von ,universal gültigen ' sowie ,natürlichen Normalmaßen' der Längen, Gewichte und Zeiteinteilungen. Im Zeichen der Universalität wurde der Erdkörper selbst als ,maßgebende' Entität erkoren. Dementsprechend betrug ein Meter ein Zehnmillionstel der Entfernung vom Nordpol zum Äquator, freilich gemessen über Paris. ${ }^{3}$ Die neuen Maße, so das Ansinnen der Académie, sollten kurzfristig die lokalen Metriken Frankreichs ersetzen und mittelfristig zum internationalen und weltweiten Standard erhoben werden.

Bei genauerer Betrachtung war jene Vereinheitlichung der Standards - beschlossen am 30. März 1791 durch die Nationalversammlung - weit mehr als die Einführung von Kilogramm und Meter zur Erleichterung der alltäglichen Vollzüge. Ihr macht- und diskurshistorischer Effekt, so lässt sich aus der Perspektive der Automatismen-Forschung andeuten, lag in der Ermöglichung einer neuen, staatlichen Empirie. ${ }^{4}$ Die Etablierung des natürlichen Standards war auf Engste verknüpft mit dem Aufkommen der modernen Biopolitik um 1800 - als eine Geschichte der Erfassung, Normalisierung und Steigerung von individuellen Körpern und kollektiver Vitalität. ${ }^{5}$ Die Setzung von Normen, Metriken und Standards bildete erst eine fundamentale Möglichkeitsbedingung zur intervenierenden Regulierung des Bevölkerungskörpers und zur Modulierung natürlich-künstlicher environments sowie zur freien Zirkulation von Menschen, Waren und Kapitalen innerhalb eines Territoriums. ${ }^{6}$ Jene Implementierung der mesure naturelle geriet - unversehens - zur Geburtshilfe der Normalisierungsgesellschaft. Der ,Lebensstandard' ist demnach nicht lediglich ein beschreibender Begriff, sondern eine durchgreifende Regierungstechnologie, die seit dem 19. Jahrhundert ihre Wirkung im Feld der Fremdund Selbstdisziplinierung entfaltet. ${ }^{7}$

2 John L. Heilbron, „The Measure of Enlightenment“, in: Tore Frängsmyr (Hg.), The Quantifying Spirit in the $18^{\text {th }}$ Century, Berkeley, CA, 1990, S. 207. Zum Zusammenhang von Natürlichkeitsdenken und Metrisierung siehe Maurice Crosland, „Nature and Measurement in Eighteenth-Century France“, in: Theodore Bestermann (Hg.), Studies on Voltaire and the Eighteenth Century, Banbury, 1973, S. 277-309.

3 Siehe Académie des sciences, Rapport sur le choix d'uneunité de mesure, Paris, 1791, S. 3 f. Im Jahr 1983 wurde der französische Urmeter neu definiert. Seitdem wird ein Meter durch die Naturkonstante der Lichtgeschwindigkeit bestimmt. Erst in diesem Jahr wurde das zylinderförmige, aus Platin-Iridium gefertigte Urkilogramm aus seinem Dienst entlassen. Ein Kilogramm beruht seit dem 20. Mai 2019 auf dem Planckschen Wirkungsquantum.

4 Siehe Joseph Vogl, Kalkül und Leidenschaft. Poetik des ökonomischen Menschen, Berlin, 2002, S. 54-80.

5 Michel Foucault, In Verteidigung der Gesellschaft, Frankfurt/M., 2001, S. 282-310.

6 Florian Sprenger, Epistemologien des Umgebens. Zur Geschichte, Ökologie und Biopolitik künstlicher environments, Bielefeld, 2019.

7 Bernhard Kleeberg, Lebensstandard. Geschichte eines Konzepts im 19. Jahrhundert, Habilitationsschrift, Universität Konstanz, 2015. 
Die Metrisierung Frankreichs zeigt also: Standards vermitteln die Beziehungen zwischen Menschen, Dingen und Zeichen - besonders wirksam dort, wo sie nicht als Konvention, sondern als ,natürlich ${ }^{\star}$ erscheinen. Prozesse der Standardisierung und Naturalisierung haben in zeitgenössischen Gesellschaften eine hohe Relevanz, sei es im Bereich der Ökonomie, des Selbstmanagements, der Bio- und Materialwissenschaften sowie der Informatik. In technischen Bereichen wird Standardisierung zuweilen als Top-down-Prozess verstanden, der durch Institutionen zentralgesteuert wird. Wie stellt sich eine ,Ökonomie der Standards' dar und welche Machtkonstellationen zeichnen sich in ihr ab? Wie reversibel und flexibel können etablierte Standards sein? Im Bereich der Wissenschaften sind Naturalisierungsdiskurse zu beobachten, in denen Standardisierungen Unhinterfragbarkeit begründen. ${ }^{8}$ Wie stabil sind diese Naturalisierungen, und inwiefern dienen sie übergeordneten Strategien? In welchem Verhältnis stehen unbewusst ablaufende Black-Boxing-Prozesse $\mathrm{zu}$ gesteuerten Naturalisierungsbestrebungen?

Technik gilt als ,zweite Natur', wenn ihre Nutzung sich so weit in das Alltagsleben integriert hat, dass sie nicht mehr als Fremdkörper wahrgenommen wird. Diese Form der Naturalisierung wird durch ubiquitous computing, ,intuitive' Interfaces und digitale Nahkörpertechnologien aktiv vorangetrieben. ${ }^{9}$ Gleichzeitig setzt man in der Technikentwicklung auf das Nachempfinden der Natur sowie auf den Nachvollzug der intrinsischen ,Selbst'-Aktivität der Materie - etwa im Bereich komplexer Algorithmen oder im Feld einer interdisziplinär agierenden Geistes- und Materialwissenschaft. ${ }^{10}$

Ein anderer Bereich, in dem Standardisierungen und Naturalisierungen eine maßgebliche Rolle spielen, ist zweifelsohne der (menschliche) Körper. ${ }^{11}$ Wie kommt es zur Etablierung von Körperstandards - beispielsweise in der wissenschaftlichen wie alltagspraktischen Konstruktion von Geschlecht, etwa in der Medizin? Inwiefern fließen standardisierende und naturalisierende Momente in das Management des Körpers und des Selbst mit ein? An welche hegemonialen Diskurse sind die Körper in der Gegenwart rückgebunden? Inwiefern bedingt die durchgreifende Digitalisierung von Wissenschaft, Kultur und Gesellschaft eine Revision der Kategorien Leben, Körper und Natur? Teils bezugnehmend auf diesen Fragenkatalog, teils anhand eigener Beobach-

8 Vgl. Tom Knight, Idempotent Vector Design for Standard Assembly of Biobricks, Cambridge, MA, 2003. Zu den Prozesslogiken der synthetischen Biologie im Allgemeinen und den Herstellungsverfahren mit molekularen Standardbauteilen im Speziellen, den sogenannten Biobricks, siehe: Martin Müller „Zoë als Téchne. Zum Paradox möglicher Menschen in der synthetischen Biologie“, in: Antonio Lucci/Thomas Skowronek (Hg.), Potential regieren. Zur Genealogie des möglichen Menschen, Paderborn, 2018, S. 239-252.

9 Timo Kaerlein, Smartphones als digitale Nahkörpertechnologien. Zur Kybernetisierung des Alltags, Bielefeld, 2018, S. 35-96.

10 Horst Bredekamp/Wolfgang Schäffner (Hg.), Haare hören - Strukturen wissen - Räume agieren. Berichte aus dem Interdisziplinären Labor Bild Wissen Gestaltung, Bielefeld, 2015.

11 Hannelore Bublitz, Das Archiv des Körpers. Konstruktionsapparate, Materialitäten und Phantasmen, Bielefeld, 2019, S. 129-187. 
tungen und Fragestellungen, haben sich die Autorinnen und Autoren des vorliegenden Bandes auf sehr originäre Weise mit den historischen, theoretischen, technischen und ethischen Dimensionen von Standardisierung und Naturalisierung auseinandergesetzt. Im Zuge dessen sind vierzehn Texte entstanden, die nun im Einzelnen und in gebührender Ausführlichkeit vorgestellt werden.

I.

Der erste Teil des Bandes versammelt sechs Beiträge aus verschiedenen Disziplinen - der Medien- und Kulturwissenschaft, der Wissenschaftsgeschichte, der Linguistik und der Informatik - zu Fragen nach den Automatismen der Standardisierung mit einer Fokussierung auf die Genese von Metriken, Prozesse der Formbildung und die Entstehung von Schemata.

Florian Sprengers Text zur Geschichte des Begriffs „Standard“ bildet den Auftakt des Bandes. Entlang einer begriffsgeschichtlichen Denkbewegung verbindet der Autor den Begriff des „Standards“ mit dem der mittelalterlichen Standarten, um sich auf die englischen Schlachtfelder jenes battle of standards ins Jahr 1138 in die Nähe von Yorkshire zu begeben. Das kriegs- und medientechnische Novum dieser Schlacht bildet der Einsatz eines auf einem Wagen befestigten Schiffsmastes, standard genannt, der hier zum ersten Mal unter diesem Namen ins Schlachtgetümmel geführt wurde. Die beweglichen standards hatten die Aufgabe, die Ordnung des Heeres aufrechtzuerhalten, den Kriegern Mut zuzusprechen, die Insignien des englischen Königs jederzeit sichtbar zu machen sowie den Feldherren mit dem Schlachtgeschehen auf dem Feld zu vernetzen. Die Konstellation aus Standarten und Masten etablierte eine mittelalterliche Kulturtechnik, welche nun zum operativen Zentrum des Schlachtgeschehens wurde. Dieses immer sichtbare Zentrum sollte eine neue Ebene der Taktiken und Effekte der Kontingenzreduktion ermöglichen.

Anna Echterhölter widmet sich einer Problematisierung des Metroklasmus als eine spezifische Machttechnologie der Kolonialisierung. Die Autorin analysiert die Standardisierungseffekte in der von Preußen annektierten Inselregion ,Deutsch-Neuguinea', in welcher mit dem metrischen System eines der hegemonialen Instrumetarien kolonialer Macht selbst fehlte: Zwar verfügte die Region über eine große Vielzahl an ökonomischen Institutionen mit ihren diversen Teil- und Zeremonialwährungen, es gab jedoch keine eigene Währung, keine Schrift, kein kodifiziertes Recht und keine einheitlichen Gewichte und Maße. In einer kultur- und wissensgeschichtlichen Auseinandersetzung mit den Finanzpolitiken der Kolonisatoren im Verhältnis zu den indigenen, teils animistischen Tausch- und Bezahlsystemen nimmt Anna Echterhölter die sogenannte „Black Box westlicher monetärer Standards“ in den Blick, um die unsichtbaren Automatismen der Wahrnehmungsroutinen des Globalen Nordens offenzulegen. 
Stefan Rieger beschäftigt sich in seinem Beitrag mit den Automatismen der Formerzeugung als ein Zusammenwirken von Persistenz und Transformationen. Oder als Frage gewendet: Wie lassen sich Konstanz und Persistenzen überhaupt denken, die es erlauben, Transformationen, also Veränderungen jedweder Art, an Bildern als solche überhaupt wahrzunehmen? Mit Referenz zum Spiel von der Stillen Post geht es dem Autor dabei um ein Modell für die Beschreibung von Prozessen der Transformation, das Momente von Intentionalität und Gesteuertheit, die bewusste Planung und Kontrolle gezielt außer Kraft setzt. Dieser Fragekomplex wird anhand von fünf Fallgeschichten aus der Sprachwissenschaft, der Kunstgeschichte, der Neurologie, der Wissenschaftsgeschichte und der zeitgenössischen Neurowissenschaft verhandelt. Vor dem Hintergrund von Aby Warburgs Bildatlas werden die Befunde aus den Fallstudien auf ihre kulturtheoretische Bedeutung hin befragt. Mit Warburg skizziert Stefan Rieger eine Kulturtheorie, die Konstanz und Veränderung von Formen auf ein übergreifendes Gedächtnismodell zurückzuführen vermag. In den Fokus rücken dabei die Experimentalanordnungen, welche erklären, wie kulturelle Formüberlieferung funktioniert. In dieser Konstellation firmieren die beteiligten Wissenschaften und ihre Experimentalanordnungen nicht als Beiwerk zur Kulturtheorie, sondern als ihr Fundament.

Susanne Janys Text über die Fabrikation des Betriebsunfalls um 1900 ist ein wichtiger Beitrag zur kulturwissenschaftlichen Architekturforschung. Als prägendes Element der europäischen Hochindustrialisierung gilt der technische Unfall, der seine spezifische Ereignishaftigkeit im Verkehrsunfall oder der Dampfkesselexplosion offenbart. Mit dem Betriebsunfall in der Industrie taucht jedoch ein neuer Ereignistypus auf, dessen Spezifikum darin liegt, dass er nicht allein auf technische Fehler, menschliches Versagen oder eine Verkettung unglücklicher Umstände zurückgeführt werden kann. Er erscheint vielmehr als ein betrieblicher Komplex, der sich aus Arbeitsabläufen, Menschen, Maschinen und Architekturen zusammensetzt. Ab den 1890er Jahren tritt der Betriebsunfall als Störung und in Differenz zum Normalbetrieb immer deutlicher in Erscheinung. In den Betriebsvorschriften, Unfallversicherungsgesetzen und Sicherheitsarchitekturen sind Strategien wirksam, die darauf zielen, das betriebliche Dispositiv von innen heraus abzusichern. Aus Janys infrastruktureller Analyseperspektive wird deutlich: Der Betriebsunfall ist zugleich Normalisierungseffekt und Normalisierungsinstrument.

Nicole M. Wilks Text mit dem Titel „Das ist kein neuer Kalter Krieg“ exploriert den Zusammenhang von Metadiskurs und Standardbildung aus diskurslinguistischer Perspektive. Standardbildung tritt einmal als Folge einer Verfestigung sprachlicher Muster und einmal als Ergebnis von Entautomatisierung in Prozessen normreflektierender und normbildender Sprachaufmerksamkeit in Erscheinung. Mittels eines framesemantischen Fallbeispiels werden Standardisierungsprozesse aus korpuslinguistischer Sicht analysiert. Wilk zeigt, wie anhand der Schema-Aktualisierung (Kalter Krieg) im Diskurs zur russischen Krim-Annexion die Herausbildung re-standardisierter Werte und 
ihre naturalisierenden Effekte als Teil einer semantischen Transformation in Diskursen beschreibbar werden. Auf theoretischer Ebene stellt sich die Frage, wie (Be-)Deutung im Diskurs entsteht und wie spezifische Elemente des impliziten Wissens als Katalysatoren soziopolitischer Deutungsmuster fungieren, und inwiefern sich die besagten Elemente an andere diskursrelevante Frames, Topoi und Metaphern anschließen.

Roland Bless widmet sich den Aushandlungsprozessen der Standardisierung im Internet aus der Perspektive der Informatik und geht dabei der Frage nach, wer das Internet der Zukunft gestaltet. Bless zeigt, dass der 1986 gegründeten Internet Engineering Task Force (IETF) eine tragende Rolle in dieser Frage zukommt. Die Organisation ist verantwortlich für die technologische Weiterentwicklung im Internet und die offene Standardisierung der heutigen Internetprotokolle. Ausgehend von der Leitformel „Rough consensus and running code" produziert die Task Force Protokolle, die in fundamentaler Weise beeinflussen sollen, wie das Internet entworfen, benutzt und verwaltet wird. Kurzum: Das erklärte Ziel der Organisation ist es, das Internet ,besser zu machen. Bless argumentiert: Obwohl die IETF sich vornehmlich auf technische Aspekte konzentriert, muss sie realisieren, dass ihre Arbeit zugleich auch immer eine politische Wirkung zeitigt - etwa in Hinblick auf Fragen zu Privatsphäre und Menschenrechten.

II.

Der zweite Teil des Buches versammelt sechs Beiträge aus dem Feld der Medien- und Kulturwissenschaft, der Wissenschaftsgeschichte, der medizinischen Ethik und der Gestaltungstheorie. Ausgehend von der Trias Leben, Körper, Praktiken werden hier - mal historisch-kritisch, dann wieder theoretisch - die Effekte der Naturalisierung in den Blick genommen.

Antonio Luccis und Thomas Machos Beitrag mit dem Titel „Vivete Sani e Amatemi“ fragt nach den biopolitischen Implikationen und Unheimlichkeiten im Werk des italienischen Neuro-, Physio- und Ethnologen Paolo Mantegazza (1831-1910). Die kulturgeschichtliche Studie beschreibt das polyvalente Schaffen und das umfangreiche Euvre Mantegazzas, der heute unter anderem für die erste Extraktion des Alkaloid Kokain aus dem Kokosblatt im Jahr 1859 und für seine zahlreichen Selbstexperimente mit verschiedenen Drogen bekannt ist. Lucci und Macho geht es jedoch um die Extrapolation und die Problematisierung einer bisher wenig beachteten Seite jenes, liebenswürdigen Epikureer und Drogenkenners': Denn sowohl seine belletristischen und populärwissenschaftlichen als auch seine wissenschaftlichen Schriften weisen Mantegazza vielmehr als eine höchst umtriebige und ebenfalls streitbare Figuration der Biopolitik im modernen Italien und Europa aus. Seine populärwissenschaftliche Aufklärungstätigkeit, so zeigen die Autoren, war geradezu getrieben von einem Willen zur medizinisch-hygienischen Standardisierung, der 
sehr deutlich in seinen Plädoyers für die Durchsetzung einer naturalisierenden Staats-Hygienik und einer strengen Eugenik zum Ausdruck kam.

Anne Schreiber geht in ihrem Aufsatz mit dem Titel „Standards for Group Action" dem komplexen Zusammenspiel von Biochemie, Sozialtheorie und Wissenschaftsgeschichte in den Anfängen des US-amerikanischen Managementdenkens um 1920 nach. Der US-Biochemiker Lawrence Joseph Henderson und der Industriepsychologe Elton Mayo waren herausragende Akteure in dieser historischen Konstellation. Im Jahr 1927 gründete Henderson das Harvard Fatigue Laboratory, wo er sich der Untersuchung der Faktoren körperlicher Ermüdung in Arbeitssituationen widmete. Zur selben Zeit leitete Mayo die berühmten Hawthorne-Experimente, eine Untersuchungsreihe in den Werkstätten des Telekommunikationsunternehmens AT\&T in Chicago. Die Verhaltensexperimente bildeten den Auftakt der sogenannten Human-Relations-Schule als einen neuen Diskurs des modernen Managements, das nun als Reaktion auf die in dieser Zeit einsetzende Kritik an den Arbeitsbedingungen und dem Erstarken von Gewerkschaften - im Zeichen einer Humanisierung der Arbeit stand. An die Stelle von Top-down-Methoden trat nun ein horizontaler und netzwerkartiger Typus der Organisation, der auf wechselseitiger Abstimmung zwischen dem Management und den Mitarbeiter_innen beruhte. Infolge dessen, so zeigt Anne Schreiber, wurden die Techniken der Disziplinierung der Körper immer häufiger überlagert durch die gouvernementalen Techniken der kooperativen Organisation und den Praktiken der Selbst- und Fremdreflexion. Dem Management ging es nun nicht mehr um die Standardisierung der Bewegungsabläufe der Körper, sondern um die Kommunikationsweisen und damit letztlich die Regulierung und Kontrolle der Beziehungen in sozialen Netzwerken. All dies markiert den Übergang von der Disziplinar- zur Kontrollgesellschaft, in der Wissenselemente der Chemie, der Biologie und der Sozialtheorie ein neues, aber nicht weniger ambivalentes Wechselverhältnis eingehen und hierin auch ein Vorspiel gegenwärtiger Erscheinungen des Ökonomischen darstellen, wie etwa der des „Plattformkapitalismus".

Laura Moisi beschäftigt sich mit den kulturwissenschaftlichen und geschlechtertheoretischen Implikationen der Frankfurter Küche (1926) - als einem mustergültigen Ort des Standardisierungsdenkens in der Moderne. Der nach rationalistischen Maßstäben gestaltete Küchenraum, so zeigt die Autorin, wurde zum kulturellen Ort spezifischer Imaginationen von Geschlecht und Effizienz, von Instruktion und Verausgabung, welche den Diskurs der Haushaltsführung zu Beginn des 20. Jahrhunderts in fundamentaler Weise prägten. Nach den Vorstellungen ihrer Erfinderin, der Architektin Margarete SchütteLihotzki, sollte die moderne Küche nichts anderes sein als ein fabrikartiges Laboratorium. Die Standardisierungsprozesse, aus denen der neue Küchentypus hervorgeht, implizieren spannungsreiche Verflechtungen zwischen Abstraktion und Verkörperung, Technik und Naturalisierung. Kurzum: Hausarbeit wurde den Dispositiven der Leistungssteigerung unterworfen, wie man sie aus 
Fabriken und Betrieben kannte. Die Frankfurter Küche erscheint aus historisch-kritischer Perspektive als ein konkreter Ort zur Produktion normierter Weiblichkeit.

Tobias Eichinger widmet sich in seinem Beitrag der Denkfigur der authentischen Amputation aus der Perspektive der medizinischen Ethik, um daran den Umgang mit extremen Patientenwünschen zwischen persönlicher Integrität und körperlicher Normalität zu problematisieren. In einem traditionellen Sinne war und ist das ärztliche Ethos vornehmlich auf therapeutische Ziele bezogen. In diesem Paradigma ist die medizinische Praxis in erster Linie eine kurative, präventive, palliative und rehabilitative Tätigkeit. Doch heute werden zunehmend Techniken und Praktiken nachgefragt, die eher in das Register der Optimierung, des Enhancement, der Verbesserung und der Gestaltung des eigenen Selbst mit medizinischen Mitteln fallen. Im Zuge dessen wird Medizin immer stärker als wunscherfüllende Medizin verstanden und betrieben. Die Beispiele sind zahlreich und verschieden: von Pränataldiagnostik und Reproduktionsmedizin über operative Eingriffe mittels plastischer Chirurgie bis hin zu neurostimulierenden Interventionen. Während die ethischen Ambivalenzen der wunscherfüllenden Medizin umfangreich diskutiert wurden, exploriert Eichinger nun ein neues Forschungsfeld, das er mit dem Begriff der extremen wunscherfüllenden Medizin kennzeichnet. Beispiele dafür, so wird gezeigt, sind Wünsche nach Amputationen physiologisch gesunder Gliedmaßen, welche auf sogenannte Körper-Integritäts-Identitäts-Störungen (BIID) zurückgehen. Die Betroffenen empfinden dabei bestimmte Körperteile - meist eine Extremität - als nicht zu ihrem eigenen Körper gehörig. Eichinger zufolge wird das Leiden am unerfüllten Amputationswunsch dann im Einzelfall als schwerwiegender erlebt und eingestuft, als das Leiden an der gewünschten körperlichen Beeinträchtigung nach der Amputation. So gesehen bedeuten solch extreme, und doch ethisch legitimierbare Wünsche der BIID-Betroffenen nicht nur eine weitere Verunsicherung des traditionellen ärztlichen Ethos und seiner normativen Kopplung von Gesundheit und Krankheit; der Wunsch lässt sich auch als eine Aufforderung zur Reflexion herkömmlicher Standards von körperlicher Natürlichkeit im Zeichen einer vermeintlich medizinischen Objektivität interpretieren.

Patricia Ribaults theoretischer Text mit dem Titel „Körper bei der Arbeit. Geste, Norm und Technik" beschäftigt sich mit der Denkfigur des ,offenen", technisch gegliederten und verfassten Körper, der uns auch unter der Chiffre des ,Technokörpers' begegnet. Hier ist jedoch nicht der durch (Bio-)Ingenieure ersonnene und hergestellte Körper gemeint. Der Text liest sich vielmehr als eine doppelte Absage, zum einen an ideelle Standardisierungsstrategien und zum anderen an Natürlichkeitsvorstellungen eines der Technik vorgeordneten Körpers. Ribaults Überlegungen zum Körper nehmen vielmehr Ausgang von Gilbert Simondons Beschreibungen jener vorindustriellen „déformations professionelles" der Handwerker. An dieser Denkbewegung zeigt die Autorin die reziproke Formung von Arbeit und Körper, Praktiken und Material. So 
produzieren Menschen nicht nur Artefakte durch Werkzeuge und Techniken. Letztere formen, de-formieren, kon-figurieren den arbeitenden Körper unablässig. Die Technik wird dabei als Mittel des pouvoir ins Auge gefasst. Im Hinblick auf den Doppelsinn von Technik - als Handlung und Herrschaft, aber auch als Potenzial - lässt sich fragen: Was kann die Technik? Und in welchem Verhältnis zum Vermögen der Technik steht die materielle, formgebende Arbeit und der Eigensinn der Materie und des Materials? Mit Verweis auf Jean-Luc Nancys Philosophie der „Ökotechnie der Körper“ verweist Patricia Ribault auf die Rolle des Berührens. Erst im Vollzug des Berührens entstehen jene Technizität und Formbarkeit, die unsere Lage als Menschen ,ohne Eigenschaften ' bestimmt. Dankenswerterweise wurde der Text von Peter Geble aus dem Französischen übertragen. Peter Geble ist bekannt für seine Übersetzungen von u. a. Michel Foucault, Roland Barthes, Gilles Deleuze und zuletzt Roger Caillios.

Martin Müllers Beitrag geht den neusten Entwicklungen im Feld der Biotechnologien nach und fragt nach den wissensgeschichtlichen und biopolitischen Implikationen der synthetischen Biologie und der neuen GenomEditierungstechnologie CRISPR. Stand das Humangenomprojekt noch unter der Zielsetzung einer Enträtselung des genetischen Codes, den es im Medium der Schrift zu ,lesen' galt, so ist heute aus dieser codebasierten Epistemologie eine molekulare Ingenieurswissenschaft geworden, die darauf zielt, den vermeintlich universalen Code allen Lebens radikal ,umzuschreiben'. Neben der Neu-Konstruktion biologischer Entitäten und der Re-Konstruktion bereits ausgestorbener Arten, konzentrieren sich die synthetischen Biologen immer stärker auf die Editierung des Humangenoms und die Manipulation der menschlichen Keimbahn. Vor diesem Hintergrund fragt der Autor, welcher Lebensbegriff der synthetischen Biologie zugrunde liegt, mittels dessen ein fast uneingeschränktes Schalten und Walten auf der Ebene des Genoms möglich zu sein scheint? Ein zentraler, genealogischer Moment der synthetischen Biologie liegt im Aufkommen des kybernetischen und vermeintlich universellen Lebensbegriffs, welcher in Erwin Schrödingers Spekulationen zur Frage "What is Life?" im Jahr 1943 - eine Urszene der heutigen Formel von der ,Biologie als Technologie' - skizziert wurde. Der genetische Code war Schrödinger zufolge „Gesetzbuch und ausübende Gewalt, Plan des Architekten und Handwerker des Baumeisters" zugleich. Müller zeigt, dass Schrödingers Spekulationen über jenen materiellen konstitutiven Grund lebender Entitäten ganz im Zeichen des Selbsttätigen und des Autogenerativen stehen. Indem die synthetische Biologie den av̉ós des Lebendigen zu einer Art universellem Organon erklärt, versucht sie sich an einer technowissenschaftlichen Aneignung von Schrödingers Denkfigur. Die molekularen, Automatismen des Lebendigen' werden zu neuen Standards, Programmen und Protokollen einer ,Evolution in Menschenhand ' - an die Stelle von Schrödingers Baumeister rückt die Figur des Lebensingenieurs. 
III.

Der letzte Abschnitt widmet sich dem Eigenleben statistischer Instrumente und der Reduzierung des Ökologischen aus soziologischer Perspektive. Die beiden Beiträge verstehen sich als Thesen zur Automatismen-Forschung.

Thorben Mämecke diskutiert am Beispiel von Quantified Self-Communities spezifische Praktiken der technologiebasierten Selbst-Vermessung. Die SelbstQuantifizierung und Messung des eigenen Verhaltens lässt sich als Suche nach biologischen und sozialen Gesetzmäßigkeiten verstehen, die sich bewusster Wahrnehmung entziehen, aber als Ergebnisse einer wiederholten Messung vermeintlich , aufgedeckt ${ }^{\star}$ und beeinflusst werden können. Mämecke zufolge stehen die heutigen Self-Tracking-Communities für eine Aktualisierung eines positivistischen Wirklichkeitsverständnisses. In dem Moment, in dem die statistischen Werte vermeintlich ,aufgedeckter' Muster als ,natürlich' erscheinen, geraten die unkontrollierbaren Eigendynamiken statistischer Instrumente aus dem Blick.

Paul Buckermann zeigt mit seinem vergleichssoziologischen Ansatz, wie Standardisierungsverfahren nicht einfach etwaige Ordnungen abbilden, sondern diese erst hervorbringen und wie diese dann über ihren eigenen Rahmen hinaus Grundlage für weitere Strukturbildung sein können. Als paradigmatisches Beispiel dient ihm dabei der Ecological Footprint, für den der Maßstandard globale Hektar (gha) implementiert wurde, um auf globaler Ebene komplexe Fragen des Ressourcenverbrauchs auf einen einzelnen, messbaren Wert zu reduzieren. Das Beispiel des ökologischen Fußabdrucks zeigt, wie eine quasi-objektive Evidenz des quantitativen Vergleichs Grundlage für weitere ungeplante Standardisierungen und Vergleiche werden kann, indem vergleichbare Messstandards eingerichtet werden.

\section{Literatur}

Académie des sciences, Rapport sur le choix d'uneunité de mesure, Paris, 1791.

Bowker, Geoffrey C./Star, Susan Leigh, Sorting Things Out. Classification and Its Consequences, Cambridge, MA, 2000.

Bredekamp, Horst/Schäffner, Wolfgang (Hg.), Haare hören - Strukturen wissen Räume agieren. Berichte aus dem Interdisziplinären Labor Bild Wissen Gestaltung, Bielefeld, 2015.

Bublitz, Hannelore, Das Archiv des Körpers. Konstruktionsapparate, Materialitäten und Phantasmen, Bielefeld, 2019.

Crosland, Maurice, „Nature and Measurement in Eighteenth-Century France“, in: Theodore Bestermann (Hg.), Studies on Voltaire and the Eighteenth Century, Banbury, 1973, S. 277-309. 
Foucault, Michel, In Verteidigung der Gesellschaft, Frankfurt/M., 2001.

Heilbron, John L., „The Measure of Enlightenment", in: Tore Frängsmyr (Hg.), The Quantifying Spirit in the $18^{\text {th }}$ Century, Berkeley, CA, 1990, S. 207-242.

Kaerlein, Timo, Smartphones als digitale Nahkörpertechnologien. Zur Kybernetisierung des Alltags, Bielefeld, 2018.

Kleeberg, Bernhard, Lebensstandard. Geschichte eines Konzepts im 19. Jahrhundert, Habilitationsschrift, Konstanz, 2015.

Knight, Tom, Idempotent Vector Design for Standard Assembly of Biobricks, Cambridge, MA, 2003.

Müller, Martin, „Zoë als Téchne. Zum Paradox möglicher Menschen in der synthetischen Biologie", in: Antonio Lucci/Thomas Skowronek (Hg.), Potential regieren. Zur Genealogie des möglichen Menschen, Paderborn, 2018, S. 239-252.

Sprenger, Florian, Epistemologien des Umgebens. Zur Geschichte, Ökologie und Biopolitik künstlicher environments, Bielefeld, 2019.

Vogl, Joseph, Kalkül und Leidenschaft. Poetik des ökonomischen Menschen, Berlin, 2002.

Yates, JoAnne/Murphy, Craig N., Engineerig Rules. Global Standard Setting since 1880, Baltimore, MD, 2019. 

AUTOMATISMEN DER STANDARDISIERUNG:

METRIKEN, FORMBILDUNG, SCHEMATA 



\section{FLORIAN SPRENGER}

\section{STANDARDS UND STANDARTEN}

Die Geschichte der in diesem Buch verhandelten Gegenstände kann man als Geschichte der Prozesse der Standardisierung, der Skalierung sowie der Normung schreiben und dabei die Techniken und Aushandlungsprozesse, die Institutionen und Praktiken, die Dispositive und Netzwerke ins Zentrum stellen, welche dafür verantwortlich sind, dass wir heute in einer bis ins Detail und gerade in den Details - standardisierten Welt leben. Nimmt man jedoch die Geschichte des Begriffs Standard in den Blick, stößt man auf eine Begebenheit, die zunächst äußerst unwahrscheinlich und abwegig erscheint. Geradezu verwegen mag es wirken, vom blutigen Schlachtfeld des battle of the standard im Jahr 1138 zu den hochkomplexen Standardisierungsprozessen der Gegenwart übergehen zu wollen. Und doch zeigt sich auf diesem Weg, allen Diskontinuitäten zum Trotz, dass die signalgebende und versammelnde Funktion, die ein Schiffsmast im Getümmel mittelalterlicher Schlachtfelder hatte', von einem noch für die Gegenwart aufschlussreichen Verhältnis von Sichtbarkeit und Unsichtbarkeit, von Ordnung und Unordnung geprägt ist: Die Aufgabe des mittelalterlichen standards war es, die Ordnung des Heeres angesichts ihrer drohenden Auflösung aufrechtzuerhalten, den Kriegern Mut zuzusprechen und den Feldherren mit dem Geschehen auf dem Feld zu vernetzen.

\section{Schlachtfelder}

Im ungeklärten Interregnum nach dem Tod Henry I. und vielen blutigen Auseinandersetzungen steht in den frühen Morgenstunden des 22. August 1138 ein zwölf Meter hoher Schiffsmast auf einem nebeligen Schlachtfeld in Cowton Moor bei Northallerton in Yorkshire. ${ }^{2}$ Die englischen Truppen unter Thurstan, dem Erzbischof von York, und seinem Stellvertreter William of Aumale haben ihn im Kampf gegen die einmarschierten Schotten unter David I. errichtet, die ihnen zahlenmäßig weit überlegen, aber schlechter ausgerüstet und organisiert sind. Die Schlacht wird von den Engländern gewonnen und fortan, anders als

\footnotetext{
Zum Überblick über die Forschung zur Kriegsführung im Mittelalter vgl. Jörg Rogge, „Das Kriegswesen im späten Mittelalter und seine Erforschung. Neuere englische und deutsche Arbeiten zu Krieg, Staat und Gesellschaft", in: Militär und Gesellschaft in der Frühen Neuzeit, 8 (2004), S. 20-33.

2 Zum Ort dieser Schlacht vgl. Jim Bradbury, „Battles in England and Normandy 1066-1154“, in: Matthew Strickland (Hg.), Anglo-Norman Warfare. Studies in Late Anglo-Saxon and Anglo-Norman Military Organisation and Warfare, Suffolk, 1992, S. 182-193: 191.
} 
sonst üblich, nicht auf den Ort des Schlachtfelds getauft, sondern battle of the standard genannt. Darüber berichtet der Chronist Richard, Abt von Hexham, einem Kloster in der Gegend, die von den Schotten heimgesucht wird, um 1140 in „De gestis regis Stephani et de bello standardii“":

Some of them soon erected, in the centre of a frame which they brought, the mast of a ship, to which they gave the name of the Standard; whence those lines of Hugh Sotevagina, archdeacon of York:

Our gallant stand by all confest,

Be this the Standard's fight;

Where death or victory the test,

That proved the warriors' might. ${ }^{3}$

Auf Latein lauten die letzten Zeilen weniger poetisch als in der modernen Übersetzung durch Joseph Stephenson:

Dicitur a stando standardum, quod stetit illic,

Militiae probatis vincere sive mori. ${ }^{4}$
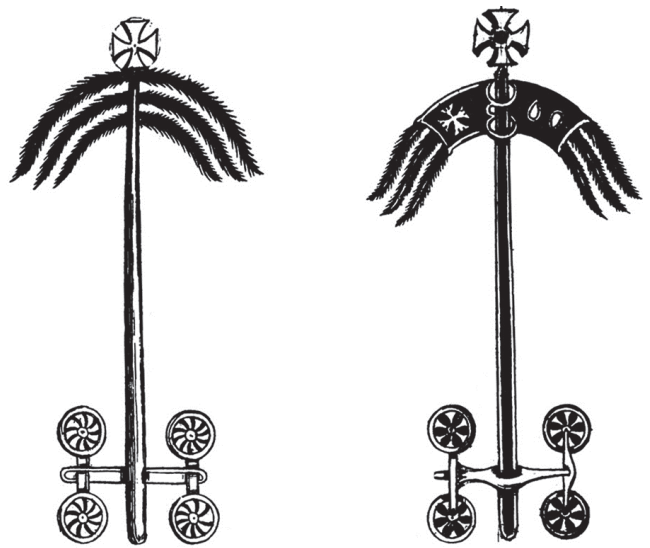

2.1 - Die Abbildung zeigt eine Zeichnung aus Roger Twysdens

Historiae Anglicanae Scriptores Decem von 1648, der die heute verschollene

Handschrift Richard of Hexhams veröffentlichte und die Abbildung vermutlich von dort abzeichnete

3 Zit. n. der Übersetzung durch Joseph Stephenson: Richard of Hexham, „History of the Acts of King Stephen and the Battle of the Standard", in: Joseph Stephenson (Hg.), Contemporary Chronicles of the Middle Ages, Felinfach, Dyfed, 1988, S. 61. Neben Hexhams Bericht gibt es mit „Relatio de Standardo“ von Aelred of Rievaulx nur noch eine weitere Quelle, auf die sich die folgenden Ausführungen stützen. Im Gegensatz zu Richard geht Aelred aber kaum auf die konkrete Rolle des standard ein: Aelred of Rievaulx, „Relatio de Standardo“, in: Richard Howlett (Hg.), Chronicles of the Reigns of Stephen, Henry II., and Richard I., London, 1964, S. 179-199.

4 Richard of Hexham, „De Gestis regis Stephani et de Bello Standardii“, in: Richard Howlett (Hg.), Chronicles of the Reigns of Stephen, Henry II., and Richard I., London, 1964, S. 163. 
Der Schiffsmast ist in die Wogen der Schlacht geraten, und so wie er auf See bei den zu dieser Zeit üblichen einmastigen Schiffen nicht nur das Segel im Wind hält, sondern auch Fahnen und Insignien trägt, so hilft er auch auf dem Land dabei, das Chaos und die Wirren des blutigen Feldes in einer Zeit zu kontrollieren, die als The Anarchy in die Geschichte eingegangen ist. König Stephen ist zu diesem Zeitpunkt in einen zum Bürgerkrieg zu eskalieren drohenden Konflikt mit seiner Cousine Matilda verwickelt, die von ihrem 1135 verstorbenen Vater Heinrich I. zur Thronfolgerin bestimmt wurde. Dies wird von Stephen, dem Neffen Heinrichs, nicht anerkannt. Während Stephen im Süden des Landes gebunden ist, will der schottische König David, Onkel von Matilda, diese Gelegenheit ausnutzen, um die von den Anglonormannen eingenommenen Gebiete zurückzuerobern. Seine Truppen überfallen die Grenzregionen, plündern die Ortschaften und planen schließlich einen großen gemeinsamen Angriff. In Abwesenheit von Stephen übernimmt auf Seiten der Engländer mit Thurstan ein hoher Geistlicher die Befehlsgewalt über die versprengten, einander nicht immer wohlgesonnenen Truppen im Norden des Landes und vereint die vorhandenen Ritter und Bogenschützen mit einer großen Anzahl von Bauern. Da der Erzbischof selbst zu alt ist, um auf das Feld zu ziehen, besteht er darauf, dass statt dessen sein persönliches Kreuz und eine Reihe von Bannern an einem Mast befestigt mit in die Schlacht geführt werden. Die Lücken des abwesenden Königs und des greisen Bischofs übernimmt dieser standard.

An der Spitze dieses Mastes, der stets hinter der Frontlinie bleiben soll, werden das Kreuz, ein Gefäß mit Hostien namens Phyxis sowie die Banner von St. John of Beverly, St. Wilfrid of Ripon und von St. Peter of York befestigt. Vor allem das letztere Abzeichen, das vexillum sancti petri, gilt als wichtiges Kennzeichen für die kirchliche Billigung eines Krieges. ${ }^{5}$ Vor der Schlacht findet im Schatten des Mastes ein kollektives Gebet statt, wird den Kämpfern die Absolution erteilt, das Abendmahl eingenommen und ein gemeinsamer Schwur über den bedingungslosen Zusammenhalt geleistet. In seiner Schlachtenrede unterstreicht einer der Befehlshaber namens Walter of Espec mit markigen Worten, die Heiligen würden an der Seite der Truppen kämpfen und selbst Christus sei unter ihnen. Schließlich wird der Mast, auf einem Ochsenkarren stehend - von den erfahrensten Kämpfern umgeben und von einer Schar Priestern, Ärzten und Trompetern begleitet - auf das Feld gezogen.

Mit standard ist vor allem der auf dem Wagen bewegliche, geschmückte und weithin sichtbare Mast gemeint. Der Begriff taucht in Varianten erstmals im Kontext der Kreuzzüge auf. Etwa von Petrus Tudebodus und Albert von Aachen, zwei Chronisten der Kreuzzüge, wird der Begriff standarum bzw. standart bereits einige Jahre vor Richard verwendet, um Fahnen mit Abzei-

5 Vgl. Carl Erdmann, „Kaiserliche und Päpstliche Fahnen im hohen Mittelalter“, in: Quellen und Forschungen aus italienischen Archiven (1933/34), S. 1-48. 
chen der Herrschenden zu benennen und die Eroberer als Christen zu kennzeichnen. ${ }^{6}$ Zugleich traf man dabei auf eine reiche arabische Tradition an Flaggen und Abzeichen, die sicherlich die Vielfalt der europäischen Heraldik beeinflusst hat. ${ }^{7}$ Lanzen mit Fahnen, welche im Gegensatz zu Bannern lang und spitz zulaufend sind, werden erst im 14. Jahrhundert als standard oder Standarte bezeichnet ${ }^{8}$, ebenso wie später direkt auf dem Kirchenboden stehende große Kerzen oder die aufragenden Reste von Baumstümpfen nach dem Fällen. ${ }^{9}$ Wer der Schlacht von 1138 ihren Namen gegeben hat, lässt sich nicht mehr feststellen. Doch ist der neue Begriff standard bzw. standardum seit Richards Text in der lateinischen und der englischen Sprache verbreitet. Im anonymen und undatierten, aber aus der gleichen Zeit stammenden „Brevis relatio de origine Willelmi Conquestoris", einem kurzen Lebensbericht über die ersten Jahre unter William the Conqueror, fällt der Begriff in einer anderen Schreibweise und zeigt, dass diese Kulturtechnik von Nordfrankreich aus nach England gebracht wurde: „Heraldi standarium ibi videbat" ${ }^{10}$

Fällt der fortan in den meisten Kriegen der nächsten beiden Jahrhunderte eingesetzte standard, ist die Schlacht verloren. Sein Untergang ist nahezu unwiderruflich das Ende der Auseinandersetzung. Ihn zu erobern ist größter Triumph für die Sieger und größte Schmach für die Unterlegenen. Die Fahnen und Insignien freiwillig zu senken ist ein Zeichen für die Kapitulation und geschieht entsprechend selten. Dem standard gilt daher die Aufmerksamkeit aller: Er ist Indikator für den Verlauf der Schlacht, Ziel und Orientierungspunkt, Beute und Schutz, gesucht und gefürchtet, ein Ort der Versammlung, der Kommunikation, der Kommunion und des Kommandos. Er ermöglicht, in anderen Worten, als operatives Zentrum der Schlacht eine neue Ebene der

6 Tudeborus schreibt: „Unus autem nostrorum accepit standarum Ammiravisi, desuper quod erat pomum aureum, hast vero tota cooperta argento." Zit. n. Charles Fresne Du Cange, Glossarium Ad Scriptores Mediae et Infimae Latinitatis, Frankfurt/M., 1710, S. 1043. Ein weiterer früher Beleg aus diesem Kontext findet sich im Chronicon Hierosolymitanum von Albert von Aachen: „Longissima hasta argento operta per totum, quod vocant standart, et quod signum regis Babyloniae exercitui preferebatur et circa quod precipua virtus densabatur capta est.“" Zit. n. Herbert Meyer, „Sturmfahne und Standarte“, in: Zeitschrift der Savigny-Stiftung für Rechtsgeschichte, 51 (1931), S. 204-257.

7 So Phyllis Ackerman, „Standards, Banners and Badges“, in: Arthur Upham Pope/Phyllis Ackerman (Hg.), A Survey of Persian Art from Prehistoric Times to the Present, London, 1938, S. 2766-2782.

8 Vgl. Malte Prietzel, Kriegführung im Mittelalter. Handlungen, Erinnerungen, Bedeutungen, Bd. 32, Paderborn, 2006, S. 199.

9 Artikel „standard“, auf: OED Online, online unter: http://www.oed.com/view/Entry/188962, zuletzt aufgerufen 12.12.2018. Der Artikel „standard“"im Oxford English Dictionary listet viele verschiedene Verwendungen auf und dient zahlreichen anderen Wörterbüchern als Vorlage, ist aber historisch ungenau, wie Frankwalt Möhren herausgestellt hat: Als erste Nennung von „standard“ im modernen Sinn gibt das OED 1450 statt 1274 an. Vgl. ders., „Englisch standard. Ein Beispiel französisch-englischer Wort- und Sachgeschichte“, in: Wolfgang Dahmen (Hg.), Englisch und Romanisch, Tübingen, 2005, S. 53-75.

10 Anonym, „Brevis relatio de origine Willelmi Conquestoris“, in: I. A. Giles (Hg.), Scriptores Rerum Gestarum Willelmi Conquestoris, London, 1845, S. 1-21: 7. 
Taktik, die, wenn man dem Bericht Richards Glauben schenken darf, allein durch ihre Einführung Einfluss auf den Verlauf der Auseinandersetzung gehabt hat. Auch wenn Angaben über die genauere Verwendung in den Quellen spärlich sind und daher vieles Spekulation bleiben muss, kann man den standard doch als wichtiges Element in die Geschichte dessen einordnen, was Martin van Crefeldt $C^{3}$ genannt hat: Command, Control und Communications. ${ }^{11}$

Warum diese in anderer Form bereits von den Römern verwendete Kulturtechnik um das Jahr 1100 im Norden wieder auflebt, wie sie als ars militaris den Weg nach England gefunden hat und ob sie für den Sieg in der Schlacht mit - will man den sicherlich übertreibenden Quellen glauben - mehr als 10.000 Toten tatsächlich so hilfreich war, wie es Richards auf die damals übliche Weise idealisierender Bericht darlegt, kann nicht mehr mit Bestimmtheit gesagt werden. Doch die Schlacht firmiert nunmehr unter dem Titel des standard. Der battle of the standard prägt mithin in maßgeblicher Weise einen Begriff für das Englische, der in der Folge im Zuge einer Bedeutungsverschiebung in alle europäischen Sprachen wandert, im 20. Jahrhundert bis ins Japanische übergreift und von einer überaus verwinkelten, aber sehr aufschlussreichen Geschichte geprägt ist.

Dieser Geschichte zu folgen, den standard als mittelalterliche Kulturtechnik zu begreifen und zugleich dem Übergang zum heutigen, in diesem Band verhandelten Verständnis von Standards nachzuspüren, kann dabei helfen, einige neue Gesichtspunkte in die gegenwärtigen Debatten um Standards sowie Standardisierungen einzubringen und sie zugleich historisch zu erden. Während angesichts der enormen Breite der in den jüngsten Veröffentlichungen unter dem Titel „Standard“ zusammengefassten Phänomene nur Fallstudien weiterzuhelfen scheinen und analytische Definitionsversuche zumeist unbefriedigend geblieben sind, soll an dieser Stelle die in der Literatur zwar gelegentlich angesprochene, aber bislang nicht ausführlicher diskutierte Geschichte des battle of the standard ins Zentrum gerückt werden. Eine eingehende etymologische oder quellenkundliche Untersuchung kann und muss angesichts der einschlägigen Literatur und der schwierigen Quellenlage nicht geleistet werden. ${ }^{12}$ Meine Überlegungen sind daher in drei Abschnitte unterteilt: in Kulturtechniken des standard, in Begriffsgeschichte von standard zu Standard sowie in einige Bemerkungen zu Standards und Standardisierungen.

Die Entwicklung von Standardisierungen seit dem 19. Jahrhundert ist gut bekannt und aus verschiedenen Perspektiven etwa anhand der Etablierung des

11 Vgl. Martin van Creveld, Command in War, Cambridge, 1985.

12 Wichtige Vorarbeiten wurden bereits veröffentlicht: Möhren (2005), Englisch standard; Ernst Voltmer, „Standart, Carroccio, Fahnenwagen. Zur Funktion der Feld- und Herrschaftszeichen mittelalterlicher Städte am Beispiel der Schlacht von Worringen 1288“, in: Blätter für deutsche Landesgeschichte (1988), S. 187-209 sowie Ernst Voltmer, Il carroccio, Torino, 1994. Auf die Bedeutung dieser Geschichte für die Standardisierung geht die Literatur allerdings nicht ein. 
Meters, des Ohms und der Standardzeit beschrieben worden. ${ }^{13}$ Doch scheint bei aller Konzentration auf Praktiken der Standardisierung, die dafür nötigen Netzwerke und ihre Rolle in technischen Prozessen - ein Schritt zurück sinnvoll, um einen Blick auf die Anfänge des Begriffs zu werfen. Bislang wurden Standards als transversales Phänomen, das quer durch verschiedenste Gebiete verläuft und Technik, Politik, Wirtschaft, Industrie, Wissenschaft, Arbeit und Kultur gleichermaßen betrifft ${ }^{14}$, fast ausschließlich als Errungenschaft der einsetzenden Rationalisierung von Arbeitsprozessen, der Verwissenschaftlichung von Ingenieurstätigkeiten sowie in ihrer Bedeutung für die Datenverarbeitung beschrieben. Letztere kann neben der Logistik als Anlass für den Aufschwung des Interesses an Standards in den 1990er Jahren gelten, denn in digitalen Netzwerken sind diese von grundlegender Bedeutung für die Distribution von Daten und die Kompatibilität von Hardware. Der historische Ort der Frage, die dieser Sammelband stellt, scheint daher recht eindeutig bestimmbar. Die Begriffsgeschichte lässt jedoch erahnen, dass einige Charakteristika von Standards durchaus mit der Vergangenheit des battle of the standard in Verbindung gebracht werden können. Denn der standard von Northallerton ist zugleich Orientierungs- wie Ausgangspunkt, er verleiht symbolische wie operative Macht durch Sichtbarkeit und Kontingenzminimierung, er sammelt Symbole, Insignien sowie Reliquien und fügt sie zu einer neuen Ordnung zusammen, er erlangt gleichsam nomothetische Kraft im Spiel der Akteure, und da diese Funktionen sich auf heutige Standards übertragen lassen, lohnt sich - trotz der Gefahr von Diskontinuitäten überspringenden Analogisierungen - die Reise zurück auf das Schlachtfeld von Northallerton auch für die gegenwärtige Beschäftigung mit Standards und Normen, über die Friedrich Kittler einst schrieb: „Die ungeschriebene Geschichte technischer Normen ist demnach eine Kriegsgeschichte." ${ }^{15}$

13 Vgl. Janet Abbate/Amy Slaton, „The Hidden Lives of Standards. Prescriptions and Transformations of Work in America", in: Michael Thad Allen/Gabrielle Hecht (Hg.), Technologies of Power, Cambridge, 2001, S. 95-143; Bruce Hunt, „The Ohm is Where the Art Is. British Telegraph Engineers and the Development of Electrical Standards", in: Osiris, 9 (1994), S. 48-63; Martha Lampland/Susan Leigh Star, The Hidden Life of Standards. How Quantifying, Classifying, and Formalizing Practices Shape Everyday Life, Ithaca, NY, 2009; Benjamin Singer, „Towards a Sociology of Standards. Problems of a Criterial Society“, in: The Canadian Journal of Sociology, 21 (2006), S. 203-221; Stefan Timmermanns/Steven Epstein, „A World of Standards but Not a Standard World. Toward a Sociology of Standards and Standardization“, in: Annual Review of Sociology, 36 (2010), S. 69-89; Aashish Velkar, „Transactions, Standardisation and Competition. Establishing Uniform Sizes in the British Wire Industry c.1880“, in: Business History, 51 (2009), S. 222-247.

14 Vgl. zur Übersicht Andrew Russell, ,Standardization in History. A Review Essay with an Eye to the Future", in: Sherry Bolin (Hg.), The Standards Edge. Future Generation, Ann Arbor, MI, 2005.

15 Friedrich Kittler, „Gleichschaltungen. Über Normen und Standards der elektronischen Kommunikation“, in: Klaus Peter Dencker (Hg.), Interface. Elektronische Medien und künstlerische Kreativität, Hamburg, 1992, S. 175-183: 175. 


\section{Signum, carroccio und standard}

Wie neben Richard auch der Mönch Aelred of Rievaulx aus einem in der Nähe von Northallerton gelegenen, einige Jahre vor der Schlacht von erwähntem Walter of Espec gegründeten Zisterzienserkloster in seinem Text „Relatio de Standardo" um 1150 berichtet, ist das Vorbild dieser Kriegstechnik der italienische carroccio (wörtlich: großer Wagen), der zu diesem Zeitpunkt seit gut 100 Jahren verwendet wird. ${ }^{16}$ Zunächst in den römisch oder byzantinisch geprägten Ländern, später dann auch im Norden, ersetzt diese Art der Schlachtorganisation durch beflaggte Masten auf Karren Reiter, die an Lanzen befestigte, aber nur schwer aus der Ferne sichtbare Fahnen trugen. Aufgrund seines Gewichts ist der Mast zwar fixiert, aber durch den Wagen doch beweglich.

In der Lombardei wurden Masten auf mit Heiligenfiguren bemalten Ochsenkarren nachweislich schon seit 1039 in der Kriegsführung zur Präsentation von Flaggen und zur Organisation der Truppen verwendet. Noch heute kommen carroccios mit ihrer gemeinschaftsstiftenden Funktion in Teilen Italiens bei festlichen Umzügen zum Einsatz. ${ }^{17}$ Sie stärkten, wie der Mittelalterhistoriker Ernst Voltmer gezeigt hat, die politische Organisation der zahlreichen untereinander verfeindeten Stadtstaaten und lieferten ihnen zugleich ein Mittel der Integration und der Identifikation..$^{18} \mathrm{Da}$ die Heere der Kommunen größtenteils aus schlecht ausgebildeten Fußtruppen bestanden, war deren Organisation von besonderer Bedeutung. Carroccios regelten, so könnte man sagen, ihr gegenseitiges Begehren, indem sie ihm Zeichen und Zentrum gaben. Den Mast transportierte man in waagerechter Lage zum Schlachtfeld, um ihn erst dort aufzurichten. ${ }^{19}$ Ihn begleiteten Trompeter, die mit ihren Signalen die Truppen leiten sollten, sowie Notare, deren Aufgabe darin bestand, Befehle aufzuschreiben und Notizen über den Verlauf der Schlacht zu machen. Priester segneten vor der Schlacht vom Wagen aus die Truppen, versorgten in seinem Schutz Verwundete und erteilten Sterbenden die Absolution. Oft waren am Mast Glocken befestigt, welche die Heeresbewegungen akustisch leiten sollten.

Über all dies wird in England jedoch 1138 noch nicht berichtet. Aelreds Text, der zu den wenigen zeitgenössischen Zeugnissen für die Grausamkeit einer Schlacht zählt ${ }^{20}$ und neben Richards Werk die einzige Quelle für die frühe Geschichte des standard ist, erzählt von seiner ersten Verwendung auf englischem

16 Vgl. of Rievaulx (1964), Relatio de Standardo.

17 Vgl. Voltmer (1988), Standart, Carroccio, Fahnenwagen, S. 227.

18 Ebd.

19 Vgl. Alwin Schultz, Das höfische Leben zur Zeit der Minnesinger. Zweiter Band, Leipzig, 1889, S. 231.

20 Vgl. John Bliese, „Aelred of Rievaulx's Rhetoric and Morale at the Battle of the Standard, 1138“, in: Albion: A Quarterly Journal Concerned with British Studies, 20 (1988), S. 543556. Berichtet wird durch von Pfeile durchbohrten Körpern, erbeuteten Köpfen und zerschmetterten Gesichtern. 
Boden und der sicherlich größten Schlacht, in der ein solcher Wagen jemals eingesetzt wurde. Von diesem Zeitpunkt an ist er im 12. und 13. Jahrhundert verbreitet, verschwindet jedoch im folgenden Jahrhundert weitgehend, wohl aufgrund der schwierigen Manövrierbarkeit der Wagen und Veränderungen der Taktik. ${ }^{21}$ Der standard sorgt für eine Ausdifferenzierung der Aufgaben auf dem Schlachtfeld, welche die im frühen Mittelalter eher chaotisch organisierten Truppen im Laufe der Zeit zu professionalisieren hilft.

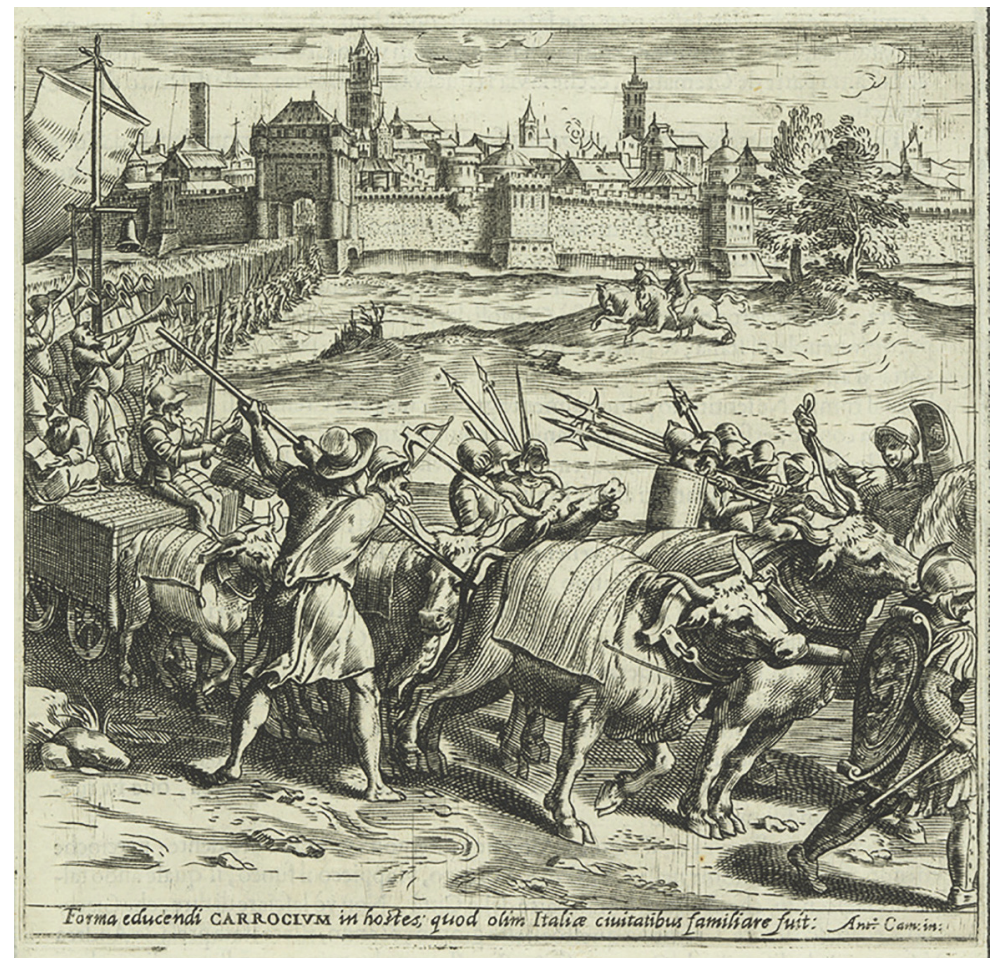

2.2 - Agostino Carracci, Stecher, nach Antonio Campi, ZeichnerDer Carroccio von Cremona wird in die Schlacht geführt, 1585

Vermutlich werden bereits 1086 in der Schlacht von Pleichfeld in Sachsen ${ }^{22}$, sicher aber seit Anfang des 13. Jahrhunderts carroccios auch in Deutschland

21 Vgl. Voltmer (1988), Standart, Carroccio, Fahnenwagen, S. 199.

22 Vgl. Meyer (1931), Sturmfahne und Standarte, S. 246. Der Text Meyers, im August 1931 veröffentlicht, ist trotz seiner guten Quellenangaben allerdings mit Vorsicht zu rezipieren, will der Autor doch ganz explizit möglichst alle Entwicklungen von Fahnen auf deutsche Ursprünge zurückführen. 
verwendet und kurze Zeit später als standhart bezeichnet. ${ }^{23}$ Im 14. Jahrhundert, als standards im englischen Sinne nahezu verschwunden sind, versteht man unter Standarten bereits etwas anderes: Lanzen, die mit Bannern und Wappen geschmückt waren und die keinesfalls als Waffen verwendet werden durften. ${ }^{24}$ Trotz des begrifflichen Übergangs ist der standard keine solche Standarte und sollte von ihr unterschieden werden, weil sonst die Gefahr besteht, seine kulturtechnische Funktion zu übersehen. Die Verwendung von carroccios und standards ist somit durchaus eine historische Episode geblieben, weil, so die These, seine Funktionen mit der zunehmenden Professionalisierung des Kriegswesens seit dem 14. Jahrhundert auf andere Weise erfüllt werden konnten.

Die Kulturtechnik des standard ist selbstredend älter als der neue Begriff. Man schließt in Italien mit diesem überaus zeremoniell genutzten, mobilen Kriegsaltar an die für einige Jahrhunderte vergessene Tradition der römischen signa oder vexilla an, Feldzeichen auf Stoff, die an Lanzen oder Speeren befestigt waren. ${ }^{25}$ Die Größe, Farbe und Verzierung gaben Michael Rostovtzeff zufolge Aufschluss über den Rang des Anführers der jeweiligen Truppen und wurden oft von Reitern, die man signifer nannte, neben den Fußtruppen an der Frontlinie getragen. Diese Rolle wurde im Laufe der Zeit immer prestigeträchtiger, so dass im Mittelalter sogar ein Amt daraus erwuchs. Auch wenn über die Schlachten zwischen dem Untergang des Römischen Reichs und dem Beginn des ersten Jahrtausends kaum etwas bekannt ist, hat sich das Wissen um das römische Signalwesen in den auf Latein verfassten Berichten über den battle of the standard gehalten.

Die Gestalt von Feldzeichen hat sich im Lauf der Jahrhunderte häufig geändert, und obwohl die Römer noch deutlich zwischen vexillum und signum unterschieden, wurden ihre Differenzen mit der Zeit verwischt. Das vexillum, von velum für Schiffssegel, war ein Feldzeichen mit kommunikativer Funktion, das etwa die Abzeichen einer Abteilung oder eines Regiments beinhaltete und als solches besonders prominent von Cicero beschrieben wurde. ${ }^{26}$ Es handelte sich zunächst um eine Lanze mit einer an einer Querstange befestigten, viereckigen Fahne für Abteilungen und Gesandtschaften, die sich vom Hauptheer entfernten. ${ }^{27}$ Auf dem Feldherrenzelt angebracht, gab das vexillum das

23 Vgl. Prietzel (2006), Kriegführung im Mittelalter, S. 199; Hans Delbrück, Geschichte der Kriegskunst im Rahmen der politischen Geschichte. Das Mittelalter, Berlin, 1907, S. 149 sowie Schultz (1889), Das höfische Leben, S. 228.

24 Vgl. Prietzel (2006), Kriegführung im Mittelalter, S. 323 sowie J. F. Verbruggen, The Art of Warfare in Western Europe during the Middle Ages. From the Eighth Century to 1340, Suffolk, 1997, S. 69.

25 Vgl. Michael Rostovtzeff, „Vexillum and Victory“, in: The Journal of Roman Studies, 32 (1942), S. 92-106 sowie Eiliv Skard, „Vexillum virtutis“, in: Symbolae Osloenses: Norwegian Journal of Greek and Latin Studies, 25 (1947), S. 26-30.

26 Ebd., S. 26. Für den Hinweis auf die Nähe zum signum danke ich Wolfgang Hagen/Lüneburg.

27 Vgl. Alfred Domaszewski, „Die Fahnen im römischen Heere“, in: Abhandlungen des archäologisch-epigraphischen Instituts der Universität Wien (1885), S. 1-80. 
Signal zum Angriff. Damit hatte es eher temporären Charakter und wurde auch für Abteilungen mit Verwundeten oder Veteranen eingesetzt. Um vexilla handelt es sich bei dem Mast auf dem Ochsenkarren jedoch nicht. Richard bezeichnet lediglich die befestigten Banner als „vexilla“".28 Der standardum ist vom vexillum also eindeutig unterschieden. Letzteres tauchte in großen Mengen auf, während es nur einen oder sehr wenige standards gibt, deren Funktion in der Schlacht anders gelagert ist.

Eine eingehende Studie des mit sign und signal verwandten Begriffs signum, die einerseits die Schließung hin zum technisch definierten Signal und andererseits die Öffnung hin zum Zeichen berücksichtigen müsste, kann an dieser Stelle nicht geleistet werden. Signum bezeichnet zunächst bestimmte Kleidungsstücke oder Uniformen, dann Abzeichen auf dieser Kleidung, schließlich Feldzeichen, die aus Fahnenstangen mit verzierten Bannern, Kränzen und Tierfiguren an der Spitze bestehen ${ }^{29}$, sowie letztlich generell Erkennungsmerkmale, wie sie jede Legion und ihre einzelnen Abteilungen mit sich trugen. ${ }^{30}$ Während die vexilla für die Truppen sichtbar sein und sich deshalb zusätzlich zu Trompetern nahe der Frontlinie befinden müssen, verbleiben die signa in Sicherheit. Für die Zeit Caesars wird in der Literatur ein „Wandel des Feldzeichenbegriffs vom Werkzeug der Befehlsgebung zum Palladium““31 beschrieben. Aus dem Signal wird ein Zeichen, das wie der berühmte Legionsadler für die Legion steht und als solches einen kultischen Wert besitzt, den die Soldaten mit ihrem Leben zu verteidigen bereit sind. Die Rolle des signum wird damit in eine operationale und eine symbolische aufgespalten: Einerseits dient es, von sogenannten conicines geschwenkt, zur Weitergabe von Befeh$l^{1 e n}{ }^{32}$, andererseits fungiert der Legionsadler als magische, an den Totemismus gemahnende Übertragung der Kräfte des Tieres auf die Kämpfer. Auch wenn die semiotisch zu nennende Tendenz des signum nicht aus dem Heereswesen abgeleitet werden kann und vielmehr auch in den antiken Zeichenlehren verhandelt wird, scheint, so viel sei hier angedeutet, die Begriffsprägung von dort zu stammen. Von hier aus ließe sich die überaus komplexe Geschichte des Zeichenbegriffs in der Antike aufrollen, wie sie in Augustinus De Dialectica im Jahr 426 erstmals systematisiert wird.

Der mittelalterliche standard hat zwar ähnliche operationale und symbolische Funktionen, wird aber vom signum unterschieden: Für Richard ist stan-

28 Richard of Hexham, De Gestis regis Stephani et de Bello Standardii, S. 165.

29 Vgl. ebd., S. 55.

30 Ein Indikator für diesen Bedeutungswandel ist folgendes Zitat Leon Battista Albertis von 1435: „Ich nenne alles das ein Zeichen, was sich auf einer Oberfläche befindet und mit dem Auge wahrgenommen werden kann.“ Im Original: „Signum hoc loco appello quicquid in superficie ita insit ut possit ocula conspici." Leon Battista Alberti, On Painting and on Sculpture. The Latin Texts of De Pictura and De Statua, London, 1972, S. 37.

31 Johannes Kromayer/Georg Veith, Heerwesen und Kriegführung der Griechen und Römer, Bd. 4, München, 1928, S. 402.

32 Vgl. Graham Webster, The Roman Imperial Army of the First and Second Centuries A.D., 3. Aufl., Norman, 1998, S. 134. 
dardum das „evidens et certum signum““33 zur Organisation der Truppen und damit zwar in der Klasse der signa, aber doch etwas Eigenständiges. Der standard unterscheidet sich in einigen bedeutenden Punkten von den römischen Feldzeichen, seien es signa oder vexilla.

Eine antike und in geringerem Ausmaß auch eine mittelalterliche Schlacht war mithin von einem dichten Geflecht aus Zeichen geprägt. Ihrer operativen und ihrer symbolischen Funktion gemeinsam ist die bezeichnende Funktion, deren Einordnung jedoch leicht in die Irre führen kann. Das moderne Zeichenverständnis darf weder leichtfertig in die Antike noch ins Mittelalter projiziert werden. Denn signa und vexilla galten nicht als Signifikanten für die jeweiligen Truppen im heutigen Sinne, sondern zum einen als begleitende Kennzeichen, insofern sie in Anwesenheit der Truppen getragen wurden, um ihre Position an den Feldherren zu übermitteln und im Gegenzug für Befehle adressierbar zu sein. Zum anderen waren die signa selbst Gegenstand kultischer Verehrung. Sie waren nicht eigenständig und austauschbar, sondern an konkrete Kontexte gebundene Unikate. ${ }^{34}$ Die Bedeutung, so Malte Prietzel, hing am Einzelexemplar als solchem, das allerdings selbst etwas zeigen konnte, seien es Wappentiere oder Symbole. Diese Einschränkungen machen deutlich, dass signa kein Abbildungsverhältnis bildeten, sondern eine Beziehung zwischen dem signum und seinem Träger. Vom militärischen signum als Zeichen im modernen Sinne kann man daher noch nicht sprechen. Dass auf Fahnen und Bannern Wappen abgebildet werden, die Herrscher repräsentieren, mag heute selbstverständlich erscheinen, ist aber der Entwicklung einer Zeichenverwendung geschuldet, die zur Zeit des battle of the standard erneut virulent zu werden scheint. Der standard kann durchaus als ein sogar relativ frühes Symptom des Übergangs zu auf bestimmten Farben, Figuren und Formen basierenden Codes der Repräsentation gelten, die hier nur kurz angerissen werden können. Etwa in der Symbolik des Hissens einer Fahne auf den Mauern einer eroberten Stadt wird diese Zeichenverwendung um 1100 etabliert. Bis dahin waren signa und vexilla als Zeichen an die tragende Person oder Gruppe gebunden. Statt als Einzelstücke mit dem Träger verbunden zu sein, zeichnet sich mit dem standard eine von Prietzel herausgearbeitete Tendenz ab, nach der seit dem 11. Jahrhundert Fahnen „,durch ihr charakteristisches Aussehen als Zeichen für den Fürsten und seinen Besitz stehen. ${ }^{\text {" }}{ }^{35}$ Ihre Reproduzierbarkeit und Austauschbarkeit, die sich langsam durchsetzen, bedeute, dass zwei ähnliche Fahnen gleichermaßen ihren Besitzer bezeichnen, anstatt als Unikate mit ihm verbunden zu sein.

Über diese Funktionen als Zeichenträger hinaus, waren schon die antiken Feldzeichen von operativer Bedeutung. Befehle wurden durch die Bewegung von vexilla übertragen, wobei die genaue Ausführung von einstudierten Manö-

33 of Hexham (1964), De Gestis regis Stephani et de Bello Standardii, S. 163.

34 Vgl. zum Folgenden Prietzel (2006), Kriegführung im Mittelalter, S. 194.

35 Ebd., S. 236. 
vern, Rückzügen, Gefechtspausen und Bewegungen an der Front umstritten ist. ${ }^{36}$ Indem ihre Träger an der Frontlinie standen und diese gemäß der strengen römischen Schlachtordnung sichtbar machten, dienten sie dem Feldherren zum Manöver. Seine Befehle wurden den signiferi mittels Trompeten erteilt. Wie vexilla dienten signa im römischen Heer als Kennzeichen. Das römische Heer war in einzelne Abteilungen gegliedert - in Legionen, Zenturien, Manipel und Kohorten -, die eigene Kommandeure hatten und bis zu einem gewissen Grad autark agieren konnten. Vor allem beherrschten sie einstudierte Manöver, die mit den anderen Truppenteilen abgestimmt werden mussten. $\mathrm{Zu}$ diesem Zweck wurden signa verwendet. Sie hatten also nicht die Funktion einer spontanen Bekundung eines Interesses, sondern waren strikt generalisiert, ohne jedoch etwas zu symbolisieren. Erst aus der Perspektive ihres operativen Einsatzes wird die Entwicklung des signum einsichtig.

\section{Kulturtechniken des standard}

Die Ritter der Zeit des battle of the standard sind stets lose gruppierte Einzelkämpfer, zumeist zu Pferd und selbst als Gruppen nicht streng koordiniert, weshalb sie auf andere Weise taktisch agieren als die später sogenannten ,taktischen Körper ${ }^{6}{ }^{37}$ aus Gruppen von Fußsoldaten. Derartige Verbände gibt es Matthew Strickland zufolge in den nordeuropäischen Schlachten der Epoche des standard nicht, weshalb dessen vereinigende Funktion die beschriebenen Auswirkungen haben konnte. Der Zweck des standard liegt zwar nicht darin, solche ,taktischen Körper' zu produzieren - dafür fehlt es an Organisation und Ausbildung der Soldaten. Seine Funktion ist vielmehr, das den Reitern grundsätzlich unterlegene Fußvolk so zu vereinen und zu steuern, dass seine Linien nicht länger einfach zu sprengen sind. Eine weitere Besonderheit des battle of the standard kommt hinzu: Untypisch für die damalige Zeit steigen die Ritter von ihren Pferden und rücken zu Fuß an ${ }^{38}$ Die Kavallerie ist ihrer Schlagkraft zum Trotz grundsätzlich schwierig zu organisieren und ungeeignet zur Bildung eines ,taktischen Körpers'. Im Verlauf der Schlacht erweist sich das zurückhaltende Vorgehen der Engländer als Schlüssel zum Sieg.

In den historischen Schriften wird der standard hervorgehoben, weil er die Organisation und Formation der englischen Truppen bestimmt, die durch ihre Waffentechnik - Bogenschützen und gepanzerte Kavallerie - den Schotten überlegen sind, welche jedoch durch die vorangegangenen Scharmützel über mehr Übung verfügen als die vielen Bauern im englischen Heer. Die Befehlsstrukturen innerhalb des englischen Heeres sind stärker als bei den Gegnern

36 Vgl. ebd., S. 207 sowie Kromayer/Veith (1928), Heerwesen und Kriegführung, S. 408.

37 Vgl. zu diesem Begriff Hans Delbrück, Geschichte der Kriegskunst im Rahmen der politischen Geschichte. Das Altertum, Berlin, 1900.

38 Vgl. Matthew Strickland, War and Chivalry. The Conduct and Perception of War in England and Normandy, Cambridge, 1996, S. 23. 
symbolisch reguliert, was, wie Richard festhält, vor allem am standard als psychologischer wie logistischer Zentrale liegt:

By this means they also provided for their men, that, in the event of their being cut off and separated from them, they might observe some certain and conspicuous rallying-point, by which they might rejoin their comrades, and where they would receive succour. ${ }^{39}$

Der standard auf Seiten der Engländer macht die Schlacht asymmetrisch. Es ist weniger der Anblick ihrer Truppen als der des standard, vor dem die angreifenden Schotten Richard zufolge erzittern, auch weil er ihnen vor Augen führt, dass die Engländer besser auf die Schlacht vorbereitet sind. Um den standard als ,Fels in der Brandung' sammeln sich die englischen Truppen und überstehen die erste Angriffswelle der Schotten, bei denen die Pikten aus Galloway gegen den Willen Davids auf ihrem angestammten Recht beharren, in erster Linie zu kämpfen und bittere Verluste einfahren. ${ }^{40}$ Die von ihren Pferden gestiegenen englischen Ritter verteidigen die Bogenschützen gegen die anstürmenden Schotten, deren Nachhut im Pfeilhagel zu Boden sinkt: „,[A]s a hedgehog is covered with spines, so were the Galwegians with arrows". ${ }^{41}$

Der Träger der Zeichen der Truppen, deren Weg er folgt, reicht in seiner symbolischen Funktion für diesen ersten Schlag gegen die Moral der feindlichen Kräfte aus:

As they advanced [...] to the battle, the standard with its banners became visible at no great distance; and at once the hearts of the king [David I.] and his followers were overpowered by extreme terror and consternation; yet, persisting in their wickedness, they pressed on to accomplish their bad ends. ${ }^{42}$

Inwieweit man diesen Angaben des Chronisten glauben kann, bleibt fraglich. Dennoch zeigen diese Sätze, für wie bedeutsam die englische Seite den standard hält. Einen Gegenangriff starten die Engländer nicht und ein volles Aufeinandertreffen der Heere wird vermieden, da die Schotten schnell merken, dass ihnen die englischen Ritter im Verbund mit den Bogenschützen überlegen sind. ${ }^{43}$

Aus diesem Bericht lassen sich mehrere Schlussfolgerungen für die Wirksamkeit des standard ziehen, der vor allem durch die Verbindung mit heraldischen Zeichen wirkt. Als Medien der Heraldik - auf die Nähe zum höfischen Protokoll kann hier nur hingewiesen werden - und seit Mitte des 20. Jahrhunderts von der eher antiquarisch orientierten Vexillologie untersucht, sind Flag-

39 Zit. n. of Hexham (1988), History of the Acts of King Stephen, S. 61.

40 Vgl. J. Douglas Drummond, Studien zur Kriegsgeschichte Englands im 12. Jahrhundert, Berlin, 1905, S. 60.

41 of Rievaulx (1964), Relatio de Standardo, S. 196.

42 Zit. n. Hexham (1988), History of the Acts of King Stephen, S. 62.

43 Vgl. Drummond (1905), Studien zur Kriegsgeschichte Englands, S. 64. 
gen und Banner feste Bestandteile mittelalterlicher Politik. ${ }^{44}$ In der Schlacht markieren sie - mit dem standard auf neuartige Weise - den Mittelpunkt der jeweils bezeichneten Truppen oder Einheiten und zeigen die Insignien der Herrschenden und der Kirche. Sie dienen zur Ermutigung und zur Erbauung. In ihrer religiösen Funktion besetzen sie, von hochrangigen Geistlichen geweiht, ein Territorium der Kirche gegenüber äußeren Eindringlingen. In seiner Funktion als nomos, als Setzung einer Ordnung, steht der standard innerhalb der Repräsentationsordnung des Mittelalters an der Seite des Souveräns und seiner Zeichen. Er ersetzt jedoch nicht den König oder den Feldherren, der ebenfalls von Bannern auf Lanzen begleitet ins Feld zieht.

In diesem Sinne ist der standard als zentrales Feldzeichen der identitätsstiftende Ort der Versammlung von Individuen, stellt diesen über andere Ordnungen, markiert ihn nach außen und bewegt eine zentrale Position über das Schlachtfeld. Mit seiner Hilfe gewinnt, so könnte man sagen, das Symbolische operative Kraft und das Operative eine symbolische Dimension. Der standard organisiert einerseits die eigenen Truppen, die seine signa lesen können, als Wissende und grenzt diese durch die gleichen Symbole nach außen hin gegenüber jenen ab, die ihre genaue Bedeutung nicht kennen oder ihr jedenfalls eher abgeneigt gegenüberstehen. Er motiviert, verbreitet Schrecken und erzeugt eine „Stimmung der Entschlossenheit und des Vertrauens auf den Sieg“. ${ }^{45} \mathrm{Er}$ trennt zwischen denen, die ihm unterworfen sind und über Wissen sowie Zugehörigkeit verfügen, und jenen, die nicht in seine Reichweite fallen. Zwischen ihnen muss eine Hierarchie von Wissen und Wissenden aufrechterhalten werden. Anders gesagt: Als Kulturtechnik verknüpft er Form, Inhalt und Medium, indem er eine geteilte, materielle und bewegliche Einheit bereitstellt, die von allen wahrgenommen werden kann und zugleich über anderen derartigen Funktionsträgern steht.

Der standard markiert all das, was die andere Seite erobern will. Er ist zugleich für die eigene Seite ein zentrales Element der Selbstkonstitution und damit schützenswert, eben weil er ausgestellt und sichtbar ist. Er muss für beide Seiten deutlich - mitunter durch Glocken und Trompeter auch akustisch wahrnehmbar sein, denn nur dann kann er seine operativen Funktionen erfüllen. Aber wenn er sichtbar ist, ist er zugleich angreifbar und muss gesichert werden. Dass die erfahrensten Krieger nicht in vorderster Reihe kämpfen, sondern um den standard stehen, ist charakteristisch für diese Verkreuzung: was ausgestellt wird, gefährdet sich dadurch selbst. Es ist eben diese Logik aus Operationalität, Sichtbarkeit und Begehren, die mit dem singulären und sichtbaren standard ins Feld einzieht.

Der battle of the standard markiert damit, so kann man aus Richards und Aelreds Aufzeichnungen schließen, das Aufkommen einer überaus wirksamen

\footnotetext{
44 Vgl. zu Heeresfahnen im Mittelalter Schultz (1889), Das höfische Leben, S. 224 sowie in breiterem Kontext Prietzel (2006), Kriegführung im Mittelalter.

45 Delbrück (1889), Geschichte der Kriegskunst, S. 375.
} 
Praxis der Kontingenzminimierung unter widrigen Umständen. Die Kontingenz von 26.000 todesmutigen Männern wird in diesem Fall reduziert, indem der standard die Geschlossenheit der Verbände sicher- und Einheiten zur Übersetzung bereitstellt: unter den eigenen Truppen zur Vermittlung ihrer $\mathrm{Zu}$ gehörigkeit, Anordnung und Motivation, sowie zwischen den Engländern und den Schotten zur Aushandlung ihrer Feindseligkeit. Er verhilft den Zeichen zur Sichtbarkeit und breitet sie über das Schlachtfeld und die Frontlinie hinweg aus. Ohne den Masten wären die Feldzeichen nahezu wirkungslos. Aufrecht stehend und weithin sichtbar trägt er sie über die Wogen der Schlacht hinweg und sorgt für einen Rest von Ordnung. Fällt er, löst sich der $\mathrm{Zu}-$ sammenhalt seiner Orientierung und seines Schutzes auf. Dabei haftet er nicht am Boden, sondern wird, dem Fortgang der Schlacht entsprechend, durchaus im Sinne von Bruno Latours immutable mobiles ${ }^{46}$ als bewegliche Konstante, von den Ochsen über das Feld gezogen. Von dort, wo er sichtbar ist, macht er vergleichbar und hilft als zentraler Ort bei der Orientierung und Bewegung der Truppenteile. Dass der standard auf dem Feld zur Kontingenzminimierung dient, heißt nicht, dass die Lage durch ihn einfacher würde. Komplexitätsreduktion kann neue Möglichkeiten eröffnen, welche die Gesamtsituation mitunter komplexer machen als den vorherigen Zustand. Der Akt der Komplexitätsreduktion als solcher kann die Komplexität steigern, weil er eine neue Beobachtungsebene einführt. Als taktisches Zentrum der englischen Truppen ermöglicht der standard in seiner symbolisch-operativen Funktion eine Steigerung der gleichzeitig bewältigbaren Aufgaben zwischen Kooperation und Konkurrenz.

\section{Begriffsgeschichte von standard zu Standard}

Diese Beschreibung der Kulturtechniken des standard wird von der Geschichte des Begriffs gestützt. Das Wort standardum für eine Lanze mit Flaggen kennt nur das mittelalterliche, nicht aber das antike Latein. Richard verwendet es, wie gezeigt, um 1150 und mit dem Namen der für die Geschichte Englands so wichtigen Schlacht breitet es sich aus. Der französische Einfluss auf die englische Sprache legt es in einer ersten Annäherung nahe, das französische estandard für eine Lanze mit Bannern als Ursprung anzusehen. Dieser altfranzösische Begriff ist um 1100 verbreitet und wird ab 1279 auch, parallel zur englischen Erweiterung und grob übersetzt, zur Benennung eines Maßes für Münzen verwendet. ${ }^{47}$ Er ist verwandt mit dem heutigen etendard für Standarte. Später wird Standard in der neueren Bedeutung und in der gleichen Schreib-

\footnotetext{
46 Vgl. Bruno Latour, „Drawing things together. Die Macht der unveränderlich mobilen Elemente", in: Andréa Belliger/David Krieger (Hg.), ANThology. Ein einführendes Handbuch zur Akteur-Netzwerk-Theorie, Bielefeld, 2006, S. 259-309.

47 Vgl. Möhren (2005), Englisch standard, S. 59.
} 
weise auch ins Deutsche übernommen, während Standarte ebenfalls bestehen bleibt. ${ }^{48}$ Das Englische kennt diese Unterscheidung nicht. Im Französischen hingegen ist heute eher von normalisation als von standardisation die Rede.

Vermutlich, so legen die etymologischen Wörterbücher verschiedener Sprachen nahe, ist die Lage jedoch komplizierter. In standard vermischen sich zwei Linien auf eine bemerkenswerte Weise: das englische standard und das mittelhochdeutsche stanthart, das im späten 13. Jahrhundert auftaucht, kommen tendenziell - starke Belege sind allerdings, darauf hat der Romanist Frankwalt Möhren hingewiesen, nicht nachweisbar - als substantivierte Form vom germanischen stande für Stand sowie in einer Deutung von hart für kühn oder $f e s t^{49}$, in einer anderen Deutung vom altfranzösischen standale mit ähnlicher Bedeutung. Das altfranzösisch-provenzalische estandard oder estendard hingegen stammen eher von estendre und dem lateinischen extendere für ausdehnen, ausstrecken. ${ }^{50}$ Sowohl große Fahnen wie die des standard werden ausgebreitet als auch dessen Sichtbarkeit auf dem Feld. Für die Ableitung von stande statt von estandard spricht auch, dass Richard in seiner Chronik an der eingangs zitierten Stelle den standard mit to stand in Verbindung bringt und den stehenden Masten mit den stehenden Soldaten assoziiert. ${ }^{51}$

Wie der Übergang zur heutigen Bedeutung im Einzelnen geschieht, wird sich nicht mehr eindeutig bestimmen lassen. Doch wird diese Etymologie besonders aufschlussreich, wenn man sie auf den weiteren Fortlauf von Standardisierungsprozessen bezieht. Diese doppelte Etymologie scheint treffend zwei heute wirksame Funktionen des Standards zu überkreuzen. Versteht man die neuere Bedeutung von Standard als figurativen Gebrauch des alten standard, macht diese Überkreuzung durchaus Sinn. Die heutige Verwendung lässt sich weder eindeutig von Stand noch von Ausdehnung her begreifen. Vielmehr bringen die verbundenen Kulturtechniken, wie bereits angedeutet wurde, beides zusammen: den Stand, der durch die Vertikale für Sichtbarkeit sorgt, und die durch ihn ermöglichte Ausdehnung über die Horizontale des Schlachtfelds, aber eben nicht nur zum Zweck der Verbreitung, sondern, um die untergeordneten Elemente zu ordnen. Ausgedehnt wird sowohl in die Höhe als auch auf die Fläche.

All dies ist, das sei nochmals unterstrichen, noch nicht mit der heutigen Verwendung von Standard gleichzusetzen. Wie es dazu kommt, dass der Begriff auch im Sinne eines Maßes oder einer Einheit verwendet wird, bleibt,

48 Häufig wird im Mittelhochdeutschen aber auch von Karrotsche gesprochen. Vgl. hierzu Schultz (1889), Das höfische Leben, S. 228.

49 Vgl. zu dieser Deutung Meyer (1931), Sturmfahne und Standarte, S. 230.

50 Vgl. die Einträge zu standard in: Ernst Klein, Comprehensive Etymological Dictionary of the English Language, Amsterdam, 1971 sowie Walter W. Skeat, An Etymological Dictionary of the English language, Oxford, 1958. Auch Raymond Williams hat in Keywords den Ursprung von standard als ,source of authority' im 15. Jahrhundert verortet: Raymond Williams, Keywords. A Vocabulary of Culture and Society, London, 1976, S. 296.

51 Vgl. auch Tom MacArthur, The English Languages, Cambridge, 1998, S. 103. 
wie das Oxford English Dictionary schreibt, "somewhat obscure“.52 Diese Etymologie ist auch deswegen von besonderer Bedeutung, weil, wie Möhren ausgeführt hat, in England nach der normannischen Invasion und dem Battle of Hastings 1066 eine besondere Sprachentwicklung stattgefunden hat: Stark vom Französischen beeinflusst, aber auf der Insel relativ isoliert, entwickelt sich das Englische eigenständig. In der Magna Carta, so Möhren weiter, die 1215 als früher Feudalvertrag zwischen verschiedenen Stufen des Adels auch in Reaktion auf die Jahre der Anarchie auf Latein und Französisch verfasst wird, wird zur gerechten Besteuerung durch die Feststellung von Maßen und Gewichten etwa für Wein, Getreide, Tuch oder Gewichte das lateinische mensura bzw. das französische la mesure verwendet. ${ }^{53}$ Weder von standard noch von estandard ist die Rede. Parallel zur Fortentwicklung der Gesetze und Regelungen über Besitzverhältnisse werden jedoch in den 1270er Jahren standardum auf Latein sowie estaundard auf Anglonormannisch im Sinne von Maßeinheit oder Maßstab verwendet. Die Begriffe helfen, in den Wirren der vergangenen Dekaden beschlagnahmte Güter zu berechnen und neu zu verteilen. Diese Festsetzung von Maßen hat historisch eine bedeutende Stabilisierungsfunktion in den aus den Fugen geratenen Ökonomien des Landes. Spätestens 1327 ist für das Mittelenglische die Bezeichnung im Sinne von standard measures of volume nachgewiesen. ${ }^{54}$ Möhren führt diese frühe und im internationalen Vergleich einmalige Entwicklung auf die politische Lage nach eben jenen Jahren der Anarchie zurück, die durch französischen Einfluss geprägt waren und letztlich zur Notwendigkeit einer neuen, Verfassung' geführt haben, für die wiederum die Festlegung von Maßen und Gewichten nach dem Maßstab des Königs viel früher notwendig war als in anderen Ländern.

Im Fleta, einem auf Latein verfassten Gesetzeskommentar aus England, ist 1290 in einer frühen Verwendung in dieser Bedeutung von „standardis et exemplaribus mensurarum regni“"55 die Rede, von „Standards“ und Vorlagen für die Maße des Reiches. Seit etwa 1450 nennt man die Flagge des Königs, unter der sich die Truppen versammeln sollen, den King's Standard. Der König übertrifft als Inhaber höchster Macht andere Befehle und manifestiert daher mit seinem standard die am weitesten reichende Macht. Später fallen unter den King's Standard auch Größen und Längen: „The sayd Burgese schall haffe ye standard $[\ldots]$ the qwhyche measures schuld agre with the kynges

52 Artikel ,standard“, auf: OED Online, online unter: http://www.oed.com/view/Entry/188962? rskey $=$ P3CJaw\&result $=1$ \&isAdvanced $=$ false, zuletzt aufgerufen am 12.12.2018.

53 Magna Carta, auf: The Latin Library, online unter: http://www.thelatinlibrary.com/magnacarta. $\mathrm{html}$, zuletzt aufgerufen am 12.12.2018.

54 Vgl. Möhren (2005), Englisch standard, S. 60.

55 Der Kontext lautet wie folgt: „Committitur alicui clerico vel laico cura et custodia mensurarum regiarum quae pro standardis et exemplaribus mensurarum regni habentur, ulnarum videlicet lagenarum, ponderum et cetera." Zit. n. Du Cange (1710), Glossarium Ad Scriptores Mediae, S. 1043. 
standard." "56 Der König hat das Recht, Maße und Gewichte festzusetzen, vor allem für den Feingehalt einer Münze, das heißt das Verhältnis von echtem und unechtem Metall. Seine Standards sollen regeln, wie etwas austauschbar wird, indem sie eine gemeinsame Größe oder Einheit darstellen, die aber - im Gegensatz zur Norm - nicht ausgehandelt, sondern festgelegt wird. Der Maßstab des standard ist dabei wörtlich zu nehmen. Den standard foot gibt es ab 1650 , standard silver ab 1690, standard value ab 1700, standard pint ab 1825, standard error ab 1895 und standard cable ab 1900.57 In der Literatur wird der Begriff seit dem frühen 19. Jahrhundert verwendet, um Kanonisierungen zu kennzeichnen, aber auch eine gemeinsam geteilte Sprache, das Standard English. Im 19. Jahrhundert ist zudem vermehrt vom standard of living die Rede. Für die exakter werdenden Wissenschaften des 19. Jahrhunderts sind Standards als Laborbedingungen oder Maßeinheiten von enormer Bedeutung. Wie diese wenigen Hinweise andeuten und eine Worthäufigkeitsanalyse mit Google Ngram belegt, steigt die Verwendungsfrequenz des Begriffs seit Mitte des 19. Jahrhunderts rasant an und löst sich gänzlich von dem aufrecht stehenden Mast auf dem Ochsenkarren, der allenfalls als mittelalterliche Kuriosität auftaucht.

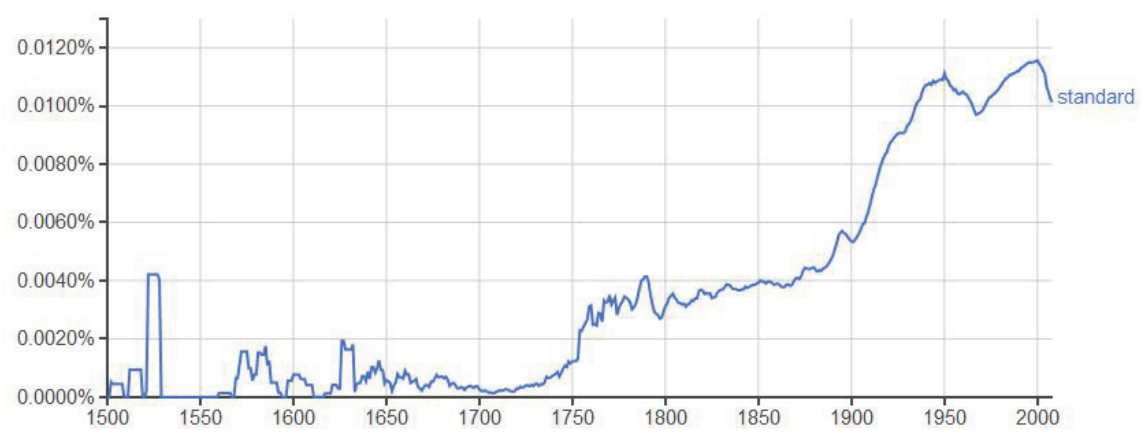

2.3 - Google Ngram Analyse für den Begriff standard

\section{Standards und Standardisierung}

Wohin führt also der Rückblick auf die verwinkelte Geschichte des Begriffs? Abschließend soll kurz auf einige Aspekte der Standardisierung näher eingegangen werden, um sie auf den battle of the standard zu beziehen. Ein Standard wird, das verbindet in einem ersten Punkt beide Verwendungen, durch

56 Artikel ,standard“, auf: OED Online, online unter: http://www.oed.com/view/Entry/188962? rskey $=$ P3CJaw\&result $=1$ \&isAdvanced=false, zuletzt aufgerufen am 12.12.2018.

57 Vgl. MacArthur (1998), The English Languages. 
weltliche Macht festgelegt und ist nicht zwangsläufig Gegenstand von offenen Verhandlungen. Regulierung durch Standards gelingt nur dann, wenn sie nicht mehr kontrovers ist. Sie ist konservativ. Standards sind keine Aushandlungssache - darauf weist schon die Tatsache hin, dass sie zunächst allein Herrschenden und Königen zugesprochen wurden. Standards brauchen aber zugleich Öffentlichkeit und müssen allen zugänglich sein. Diese Öffentlichkeit muss eigens hergestellt werden: durch Sichtbarkeit, Verordnungen oder Befehle. Es darf im Umkehrschluss keine Hermetik des Standards geben. Als wesentlicher Bestandteil der Ökonomisierung und der Effizienzsteigerung, zunächst von Produktionsprozessen und dann von Produkten und Einheiten, dienen technische Standards durch diese Öffentlichkeit der Dissemination von Expertenwissen ohne Status, weil es für jeden gleichermaßen zugänglich sein muss, aber doch mit Hierarchie, weil nicht jeder über das nötige Wissen oder die nötigen Werkzeuge verfügen kann. Standards teilen aber auch Verantwortung auf, weil jeder in ihrer Reichweite sich an ihnen orientieren soll.

Standards erfordern zweitens die Herstellung von Einheiten, die über Raum und Zeit hinweg konstant bleiben und darin über die Grenzen einer Gruppe hinausgehen. Ein Standard muss durch Dauerhaftigkeit gesichert werden, aber trotzdem mobil sein. Daher wird er zumeist von besagten staatlichen Instanzen oder einflussreichen Organisationen gestützt. ${ }^{58}$ Eben die dadurch gewährleistete Konstanz erlaubt eine Vergleichbarkeit und Austauschbarkeit, die in verschiedener Hinsicht ausgenutzt wird: zur Vereinheitlichung von Maßen und Größen, die wiederum in Produktionsverfahren zur Herstellung austauschbarer Bauteile, zur Präzision von Messungen oder zur Vergleichbarkeit von Vorgängen dienlich sind. Standardisierungen sind aus diesem Grund nicht oder nur äußerst aufwendig rückgängig zu machen. Sie sind daher meist Geschichten der Sieger oder zumindest dessen, was zum Sieger gemacht wird. Was nicht passt, überlebt auch nicht. ${ }^{59}$

Die Abgrenzung von Standards und Normen mag, so viel sei an dieser Stelle gesagt, zwar unscharf sein, doch sollte man sie nicht miteinander und schon gar nicht mit normal oder normativ verwechseln. ${ }^{60}$ Während Normen anhand von Durchschnitten verschiedener Art berechnet oder ausgehandelt werden, richtet sich ein Standard nicht im Sinne eines Schnittes nach einer Menge von Faktoren. Vielmehr stellt er sich selbst über die Köpfe der Beteiligten. Standardisierung und Normierung sind zwei verschiedene Praktiken und zwei verschiedene juristische und politische Akte. Normen sind, so könnte man sagen, bedeutsam innerhalb des Regelwerks für einen Standard. Sie sind aber

58 Vgl. dazu Marc Olshan, ,Standards-Making Organizations and the Rationalization of American Life", in: The Sociological Quarterly, 34 (1992), S. 319-335.

59 Ian Inkster (Hg.), History of Technology. Special Issue: By Whose Standards? Standardization, Stability and Uniformity in the History of Information and Electrical Technologies, London, 2008.

60 Vgl. zur Norm Jürgen Link, Versuch über den Normalismus. Wie Normalität produziert wird, 2. Aufl., Opladen, 1999. 
keine notwendige Bedingung für diesen. Einer Norm gehorcht, was wie anderes ist. Dies gilt nicht notwendigerweise für einen Standard.

Bei aller Nähe zum standard von Northallerton sind beide Begriffsverwendungen selbstverständlich nicht gleichzusetzen. Die Geschichten der Standardisierung, wie sie etwa von Ken Alder, David Hounshell oder Peter Berz dargestellt wurden ${ }^{61}$, zeigen, dass es vielmehr um die Etablierung eines Systems der Produktion geht, um die Bereitstellung universal gültiger Maße für, wie Stefan Timmermanns und Stephen Epstein ausgeführt haben, design, terminology, performance und procedure. ${ }^{62}$ Darin ist der Standard etwas zutiefst Modernes und der standard auf dem Schlachtfeld einer anderen Zeit zugehörig. Dennoch erlauben die Kontinuitäten zwischen beiden Verwendungen einen neuen Blick auf die Macht der gegenwärtigen Standardisierungen.

In industriellen Prozessen bedeutet Komplexitätsreduktion durch Standards, so haben Amy Slaton und Janet Abbate gezeigt, Kostenverringerung, Reduktion von Aufwand und Material sowie Ersetzung von Vielfalt. ${ }^{63}$ Industrielle Standards sollen die Qualität der Materialien, die Austauschbarkeit der Elemente und die allgemeine Funktionstüchtigkeit sicherstellen. Sie vereinfachen Verfahren und machen Arbeitskraft billiger. Standardisierung ist daher eng mit dem Aufstieg kapitalistischer Produktionsweisen verbunden. Sie besteht aus komplexen Aushandlungsprozessen, die zahlreiche Akteure integrieren und nur durch die gemeinsame Betrachtung von Technik, Wissenschaft und Ökonomie beschrieben werden können. ${ }^{64}$ Und doch macht es, so hoffe ich gezeigt zu haben, durchaus Sinn, sich die Geschichte des battle of the standard und die mit ihm einhergehenden Kulturtechniken noch einmal näher anzusehen. Denn auch, wenn sie das Martialische einer mittelalterlichen Schlacht verloren haben, sind gegenwärtige battles of standards auf eine ähnliche Weise radikal. Für die englischen Feldherren ist der standard, so können wir vermuten, einer der Schlüssel zum Sieg. Die Schotten haben keinen standard. Sie können ihn auch nicht erobern, sondern sind hoffnungslos unterlegen.

Die abschließende Bemerkung lautet daher, dass in einer so durchstandardisierten Welt wie der unseren Standardisierungen nicht mehr als Kämpfe erscheinen, weil die Standardisierung schon gewonnen hat. C. A. Adams, Mitarbeiter des 1903 aus dem Bureau of Weights and Measures entstandenen Bureau of Standards in Washington, schreibt 1919 in einem Selbstverständnispapier über die Rolle der Standardisierung für den Aufstieg der USA: „It might

61 Vgl. Ken Alder, The Measure of all Things, London, 2004.; David A. Hounshell, From the American System to Mass Production, 1800-1932. The Development of Manufacturing Technology in the United States, Bd. 4Baltimore, MD, 1985 sowie Peter Berz, 08/15. Ein Standard des 20. Jahrhunderts, München, 2001.

62 Timmermanns/Epstein (2010), A World of Standards, S. 72.

63 Abbate/Slaton (2001), The Hidden Lives of Standards sowie Joseph O'Connell, „Metrology. The Creation of Universality by the Circulation of Particulars“, in: Social Studies of Science (1990), S. 129-173.

64 Vgl. Thomas P. Hughes, Networks of Power, London, 1993. 
be almost said that the degree of standardization in any nation is a measure of its civilization, certainly in the material sense of the word." 65 Adams propagiert die Vorteile der durch Organisationen wie seine eigene kontrollierten Standards, die in der Folge - sieht man vom imperialen Maßsystem ab, das sich glücklicherweise nicht gegen das metrische durchsetzen konnte - den Globus kolonisieren. In diesem Sinne lassen die letzten Zeilen seines Textes nur den Schluss zu, dass Frieden in der Sphäre der Standards nur Krieg mit anderen Mitteln sein kann und dies auch nur gegen die Rolle von Standards und Normen für das Militär und seine Technik:

In the broad sense, international standardization means a common industrial language and the removal of one of those barriers which tend to separate nations and to give rise to misunderstandings. The more of those barriers we can remove and the more we come to realize that our interests are after all in common, the more likely we are to attain that lasting peace for which the world longs. ${ }^{66}$

Der Kampf gegen die überlieferte Anarchie, den Standards führen, kann nur mit ihrem Sieg ein Ende finden, der nie endgültig sein wird.

Ich danke dem Banff Centre, dem Programm BRiC: Dock(ing); or New Economies of Exchange und besonders Imre Szeman für die Möglichkeit, in den kanadischen Bergen dem Mittelalter nachzuspüren.

\section{Literatur}

Anonym, „Brevis relatio de origine Willelmi Conquestoris“, in: I. A. Giles (Hg.), Scriptores Rerum Gestarum Willelmi Conquestoris, Nutt, 1845, S. 1-21.

Abbate, Janet/Slaton, Amy, „The Hidden Lives of Standards. Prescriptions and Transformations of Work in America“, in: Michael Thad Allen/Gabrielle Hecht (Hg.), Technologies of Power, Cambridge, 2001, S. 95-143.

Ackerman, Phyllis, „Standards, Banners and Badges“, in: Arthur Upham Pope/Phyllis Ackerman (Hg.), A Survey of Persian Art from Prehistoric Times to the Present, London, 1938, S. 2766-2782.

Adams, C. A., „Industrial Standardization“, in: Annals of the American Academy of Political and Social Science, 82 (1919), S. 289-299.

Alberti, Leon Battista, On Painting and on Sculpture. The Latin Texts of De Pictura and De Statua, London, 1972.

Alder, Ken, The Measure of All Things, London, 2004.

Berz, Peter, 08/15. Ein Standard des 20. Jahrhunderts, München, 2001.

65 C. A. Adams, „Industrial Standardization“, in: Annals of the American Academy of Political and Social Science, 82 (1919), S. 289-299: 298. Selbstredend können Adams Aussagen angesichts der vielschichtigen militärischen Bedeutung von Standards nicht als pars pro toto gelten, sind aber doch bemerkenswert, weil sie direkt aus der zuständigen Institution kommen.

66 Ebd. 
Bliese, John, „Aelred of Rievaulx's Rhetoric and Morale at the Battle of the Standard, 1138“, in: Albion: A Quarterly Journal Concerned with British Studies, 20 (1988), S. 543-556.

Bradbury, Jim, „Battles in England and Normandy 1066-1154“, in: Matthew Strickland (Hg.), Anglo-Norman Warfare. Studies in Late Anglo-Saxon and Anglo-Norman Military Organisation and Warfare, Boydell, 1992, S. 182-193.

Delbrück, Hans, Geschichte der Kriegskunst im Rahmen der politischen Geschichte. Das Altertum, Berlin, 1900.

Ders., Geschichte der Kriegskunst im Rahmen der politischen Geschichte. Das Mittelalter, Berlin, 1907.

Domaszewski, Alfred, „Die Fahnen im römischen Heere“, in: Abhandlungen des archäologisch-epigraphischen Instituts der Universität Wien (1885), S. 1-80.

Drummond, J. Douglas, Studien zur Kriegsgeschichte Englands im 12. Jahrhundert, Berlin, 1905.

Epstein, Steven/Timmermanns, Stefan, „A World of Standards but Not a Standard World. Toward a Sociology of Standards and Standardization“, in: Annual Review of Sociology, 36 (2010), S. 69-89.

Du Cange, Charles Fresne, Glossarium Ad Scriptores Mediae et Infimae Latinitatis, Frankfurt/M., 1710.

Erdmann, Carl, „Kaiserliche und Päpstliche Fahnen im hohen Mittelalter“, in: Quellen und Forschungen aus italienischen Archiven (1933/34), S. 1-48.

of Hexham, Richard, „De Gestis regis Stephani et de Bello Standardii“, in: Richard Howlett (Hg.), Chronicles of the Reigns of Stephen, Henry II., and Richard I., London, 1964.

Ders., „History of the Acts of King Stephen and the Battle of the Standard“, in: Joseph Stephenson (Hg.), Contemporary Chronicles of the Middle Ages, Felinfach, Dyfed, 1988.

Hounshell, David A., From the American System to Mass Production, 1800-1932. The Development of Manufacturing Technology in the United States, Bd. 4, Baltimore, MD, 1985.

Hughes, Thomas P., Networks of Power, London, 1993.

Hunt, Bruce, ,The Ohm is Where the Art Is. British Telegraph Engineers and the Development of Electrical Standards“, in: Osiris, 9 (1994), S. 48-63.

Inkster, Ian (Hg.), History of Technology. Special Issue: By Whose Standards? Standardization, Stability and Uniformity in the History of Information and Electrical Technologies, London, 2008.

Kittler, Friedrich, ,Gleichschaltungen. Über Normen und Standards der elektronischen Kommunikation“, in: Klaus Peter Dencker (Hg.), Interface. Elektronische Medien und künstlerische Kreativität, Hamburg, 1992, S. 175-183.

Klein, Ernst, Comprehensive Etymological Dictionary of the English Language, Amsterdam, 1971.

Kromayer, Johannes/Veith, Georg, Heerwesen und Kriegführung der Griechen und Römer, Bd. 4, München, 1928.

Lampland, Martha/Star, Susan Leigh, The Hidden Life of Standards. How Quantifying, Classifying, and Formalizing Practices Shape Everyday Life, Ithaca, NY, 2009.

Latour, Bruno, „Drawing things together. Die Macht der unveränderlich mobilen Elemente", in: André Belliger/David Krieger (Hg.), ANThology. Ein einführendes Handbuch zur Akteur-Netzwerk-Theorie, Bielefeld, 2006, S. 259-309.

Link, Jürgen, Versuch über den Normalismus. Wie Normalität produziert wird, 2. Aufl., Opladen, 1999. 
MacArthur, Tom, The English Languages, Cambridge, 1998.

Meyer, Herbert, „Sturmfahne und Standarte“, in: Zeitschrift der Savigny-Stiftung für Rechtsgeschichte, 51 (1931), S. 204-257.

Möhren, Frankwalt, „Englisch standard. Ein Beispiel französisch-englischer Wort- und Sachgeschichte“, in: Wolfgang Dahmen, (Hg.), Englisch und Romanisch, Tübingen, 2005, S. 53-75.

O'Connell, Joseph, „Metrology. The Creation of Universality by the Circulation of Particulars", in: Social Studies of Science (1990), S. 129-173.

Olshan, Marc, „Standards-Making Organizations and the Rationalization of American Life", in: The Sociological Quarterly, 34 (1992), S. 319-335.

Prietzel, Malte, Kriegführung im Mittelalter. Handlungen, Erinnerungen, Bedeutungen, Bd. 32, Paderborn, 2006.

of Rievaulx, Aelred, „Relatio de Standardo“, in: Richard Howlett (Hg.), Chronicles of the Reigns of Stephen, Henry II., and Richard I., London, 1964, S. 179-199.

Rogge, Jörg, „Das Kriegswesen im späten Mittelalter und seine Erforschung. Neuere englische und deutsche Arbeiten zu Krieg, Staat und Gesellschaft", in: Militär und Gesellschaft in der Frühen Neuzeit, 8 (2004), S. 20-33.

Rostovtzeff, Michael, „Vexillum and Victory“, in: The Journal of Roman Studies, 32 (1942), S. 92-106.

Russell, Andrew, „Standardization in History. A Review Essay with an Eye to the Future“, in: Sherry Bolin (Hg.), The Standards Edge. Future Generation, Sheridan, 2005.

Schultz, Alwin, Das höfische Leben zur Zeit der Minnesinger. Zweiter Band, Leipzig, 1889.

Singer, Benjamin, „Towards a Sociology of Standards. Problems of a Criterial Society“, in: The Canadian Journal of Sociology, 21 (2006), S. 203-221.

Skard, Eiliv, „Vexillum virtutis“, in: Symbolae Osloenses: Norwegian Journal of Greek and Latin Studies, 25 (1947), S. 26-30.

Skeat, Walter W., An Etymological Dictionary of the English Language, Oxford, 1958.

Strickland, Matthew, War and Chivalry. The Conduct and Perception of War in England and Normandy, Cambridge, 1996.

Twysden, Roger, Historiae Anglicanae Scriptores Decem, London, 1648.

van Creveld, Martin, Command in War, Cambridge, 1985.

Velkar, Aashish, „Transactions, Standardisation and Competition. Establishing Uniform Sizes in the British Wire Industry c.1880", in: Business History, 51 (2009), S. 222-247.

Verbruggen, J. F., The Art of Warfare in Western Europe during the Middle Ages. From the Eighth Century to 1340, Suffolk, 1997.

Voltmer, Ernst, ,Standart, Carroccio, Fahnenwagen. Zur Funktion der Feld- und Herrschaftszeichen mittelalterlicher Städte am Beispiel der Schlacht von Worringen 1288“, in: Blätter für deutsche Landesgeschichte (1988), S. 187-209.

Voltmer, Ernst, Il carroccio, Torino, 1994.

Webster, Graham, The Roman Imperial Army of the First and Second Centuries A.D., 3. Aufl., Norman, 1998.

Williams, Raymond, Keywords. A Vocabulary of Culture and Society, London, 1976. 



\section{ANNA ECHTERHÖLTER \\ RED AND BLACK BOXES. Koloniale Standardisierung ALs Metroklasmus}

In der Region der ehemaligen Kolonie Deutsch-Neuguinea sind später CargoKulte entstanden. Diese Ritualformen reagieren auf die rapide Veränderung der Gesellschaft durch Technik und Industrie. Kopfhörer aus Holz und Flugzeuge aus Bast kommen zum Einsatz und symbolisieren die vermeintlich rein technischen Maschinen. An den Höhenzügen des Mount Hagen existiert um das Jahr 1970 der kurzlebige ,Red Box Money-Cult‘. Anhänger beschwören die Geister der Ahnen, kleine Geldsummen zu vermehren, die in roten Boxen gesammelt, vor den Blicken verborgen und kultisch gepflegt werden. Auf Fluchen, Stehlen und Sexualität im Umfeld der roten Boxen wird verzichtet. Durch Wässerung wird die Fruchtbarkeit des Geldes begünstigt; Gesänge beschwören die Windgeister wie die Weltbank gleichermaßen. ${ }^{1}$ Das Anfangskapital für das intendierte Wachstum wird in Form von Wetten zusammengebracht, entweder in der Landeswährung Kina oder australischen Dollars. Viele reagierten skeptisch. Oganka, einer der respektierten Big Men der Region, setzte sein wertvollstes Schwein gegen das Gelingen dieses Unterfangens. Er gewinnt die Wette. Die fieberhaft erwartete Öffnung der Boxen führte ins Leere und ruinierte nicht wenige. Der Kult zerstreute sich. Einige Gruppen gehen so weit, den Festplatz langfristig zu vermeiden.

Der Red Box Money-Cult steht für eine spiritistisch-vitalistische Geldauffassung, die wenig mit den typischerweise neutralen Konzepten des westlichen Geldes gemeinsam hat. Dies zeigt, wie groß die Unterschiede in der kulturellen Codierung des sozialen Mediums ausfallen können. Andrew Strathern, als ethnologischer Beobachter dieser Geldwetten, gibt zu bedenken, dass die rituelle Reaktion auf die Einführung einer normierten Standardwährung und westlichen Bargeldes in einer Hinsicht das Medium korrekt beschreibt: Das Münzund Papiergeld verselbstständigte sich in der Erfahrung der Hochlandbewohner unkontrollierbar und gleicht daher einer fremden Macht:

1 Andrew Strathern, „The Red Box Money-Cult in Mount Hagen 1968-71. (Part I)“, in: Oceania 50, 2 (1979), S. 88-102, sowie ders., „The Red Box Money-Cult in Mount Hagen 1968-71. (Part II)“, in: Oceania 51,3 (1980), S. 162-175: 166. Vgl. Pamela J. Stewart/Andrew Strathern, „Introduction. Latencies and Realizations in Millennial Practices", in: Ethnohistory 47, 1 (2000), S. 3-27: 13. Vgl. zudem die Autobiografie des Kawelka Anführers Ru, Biography of a Western Highlander, Port Moresby, 1993, S. 85. Die von Strathern aufgezeichneten Gesänge lauten beispielsweise: „My brother, do you think as I do, / My brother, do you see what I see? / I look up, and behold / The world bank breaks open and comes to us." (Anführer der Kawelka) Strathern (1980), Red Box Money-Cult, S. 166. 
Money was also the medium of exchange, which Europeans themselves used, and it came, as Hageners knew, from Australia. They did not however, understand its true source, and therefore felt that they did not properly control it. Indeed, this perception was accurate: they could not fix rates of exchange for goods they sold and were dependent on the mystery of the ,world market ${ }^{6}$.

Man sah sich einem Automatismus ausgesetzt, der autorlos Strukturen hervorbrachte und das Leben zu ergreifen begann - von Einkaufsläden über Lohnarbeit, Cash Cropping bis hin zu Truck-Systemen der Plantagen. Der Versuch, diesen neuen Agenten zu manipulieren, entbehrt nicht ganz der Folgerichtigkeit. Die Hoffnung auf Geldvermehrung tendiert dabei zum Irrationalen, wie dies von Wetten auf das ganz persönliche Glück, etwa in Schneeballsystemen oder Pferderennen bekannt ist.

Im Kontrast zeigt die spirituelle oder spiritistische Bewältigung jedoch hinlänglich, worum es in dieser Untersuchung gehen soll: Um die vom Standardisierungsprozess ersetzten und marginalisierten Routinen bzw. um einen komplexeren Blick auf die monetäre Infrastruktur der Industriegesellschaft, die den Kolonien oktroyiert wurde. Denn der Red Box Money-Cult enthält den Hinweis, dass es vielen Anwohnern des Mount Hagen nicht einleuchten wollte, Geld als neutral einzustufen und in seinen gesellschaftlichen Auswirkungen auszublenden. An diesem Beispiel aus den 1970er Jahren lässt sich verdeutlichen, dass zwar ein westliches Bezahlungsobjekt eingeführt wurde, nicht jedoch der vollständige westliche monetäre Standard, zu dem Verhaltensweisen, Regeln, Gesetze und Codierungen gehören. In der folgenden Auseinandersetzung mit der Finanzpolitik der deutschen Kolonisatoren geht es vor allem um die Black Box westlicher monetärer Standards.

Um die Wahrnehmungsroutinen der sicheren, stabilen, technisch erzeugten Welt des Globalen Nordens zu verlernen, den Blick für die Spätphase integrierter Standardisierungskaskaden zu lockern und den ,spell of cognition and language ${ }^{63}$ zu umgehen, folgt er einer besonderen Strategie. Wie in der literalen Bedeutung der ,Black Box “ im militärischen Kontext, kann das aufgefundene ,piece of enemy equipment“ nur entschlüsselt werden, wenn sich ein Team mit offener und explorativer Haltung nähert. Andrew Pickering fordert diese Analyseform für die technisch gewordene Welt, die nicht als Setzung verstanden, sondern prozedural aufgeschlüsselt werden sollte. ${ }^{4}$

2 Strathern (1979), Red Box Money-Cult, S. 96.

3 Andrew Pickering, ,Islands of Stability. Engaging Emergence from Cellular Automata to the Occupy Movement", in: ZKM 5, 1 (2014), S. 124-134: 123; Bruno Latour, Science in Action. How to Follow Scientists and Engineers through Society, Cambridge, MA, 1987; mit Dank an Hartmut Winkler, „Black Box und Blackboxing - Zur Einführung. Vortrag im Graduiertenkolleg ,Automatismen', Universität Paderborn, 14.10.2014“, auf: Open Desk, online unter: http://homepages.uni-paderborn.de/winkler/gk-black.pdf, zuletzt aufgerufen am 20.05.2019.

4 Pickering (2014), Islands of Stability, S. 123. In seinen Worten: ,[A] chancy and emergent performative achievement of fragile and local stabilizations in a world of becoming." (Ebd.). 
Gegenstand eines solchen ,reverse engineering“ ist im Folgenden der Prozess der Standardisierung der monetären Sphäre. ${ }^{5}$ Im kolonialen Kontext soll der Standard nicht als Anker, sondern als Auflösungsmittel für die durch ihn neu vermittelten Verhältnisse verhandelt werden. An die Stelle empirischer Versicherung über die Welt der messbaren Dinge treten die Aktivierung, Adaption und Konkurrenz unterschiedlicher Quantifizierungsregime. Der Prozess der Standardisierung geht als Metroklasmus vor sich, zumal in Ozeanien - eine der heterogensten Regionen der Welt was Sprachen, Wertmessungs- und Zählsysteme angeht. ${ }^{6}$

Metroklasmen lassen sich beobachten, als gut 80 Jahre vor dem Red Box Money-Cult von 1970 preußische Beamte und Pflanzer die Inselwelten des heutigen Papua-Neuguinea annektierten. Sie hissten Flaggen, unterzeichneten Papiere in Gegenwart des Papstes oder europäischer Großmächte, sie führten ihre Schulen, Kataster und Götter ein und beginnen insbesondere, die metrische Sphäre in ihrem Sinne zu verändern. Dies betrifft die Zeitrechnung, die Maße und Gewichte sowie die Formen des Geldes. All dies sollte angeschlossen werden an die Reichsmark bzw. das metrische System, das damals auf wenige Objekte in einem Safe in Sèvres bei Paris zurückging. ${ }^{7}$

Die Auswirkung dieser Normale der metrischen Standards ist von technischer $^{8}$, wissenschaftstheoretischer ${ }^{9}$, wirtschaftsethnologischer ${ }^{10}$, infrastruktu-

5 Karl Polanyi, „Über den Stellenwert wirtschaftlicher Institutionen in der Antike am Beispiel Athen, Mykene und Alalakh“, in: ders. (Hg.), Ökonomie und Gesellschaft, übers. v. Heinrich Jelinek, Frankfurt/M., 1979 [engl. OA 1957], S. 387-413: 392.

6 Kay Owens, History of Number. Evidence from Papua New Guinea and Oceania, Heidelberg, 2018.

7 Vermittelt wurde die Norm über die nationalen Maßnormale. Der Meter Nr. 18 und das Kilogramm Nr. 22 waren erst 1889 per Verlosung an Deutschland gefallen. Das letztere Objekt ist, mit kriegsbedingten Einschränkungen, bis dato an der Eichung der Gewichte beteiligt. Die Bestimmung des Meters beruht seit 1960 nicht länger auf einem physischen Körper, sondern einer der Wellenlängen des Lichtes, wie die Konstanten des Systeme Internationale (SI) inzwischen mehrheitlich auf Naturkonstanten zurückgeführt werden. Nr. 22, der deutsche Prototyp des Kilogramms, wurde im Zweiten Weltkrieg beschädigt und wird in Braunschweig (PTB) durch weitere Schwesternkopien des Urkilogramms von Sèvres entlastet (Nr. 52, Nr. 55 [DDR], Nr. 70). Am 20.05.2019 wurden die physischen Massenormale abgesetzt. Seitdem ist das Kilogramm durch die Planck-Konstante definiert und kann auf unterschiedliche Arten experimentell realisiert werden. Vgl. zur Institutionengeschichte der Standardisierung: Terry Quinn, From Artefacts to Atoms. The BIPM and the Search for Ultimate Measurement Standards, Oxford, 2012, S. 145 f.; David Cahan, An Institute for an Empire. The Physikalisch-Technische Reichsanstalt, 1871-1918, Cambridge, 1989; Cornelia Meyer-Stoll, Die Maß- und Gewichtsreformen in Deutschland im 19. Jahrhundert unter besonderer Berücksichtigung der Rolle Carl August Steinheils und der Bayerischen Akademie der Wissenschaften, München, 2010; Dieter Hind/Manfred Kochsiek, Herausforderung Metrologie. Die Physikalisch-Technische Bundesanstalt und die Entwicklung seit 1945, Bremerhaven, 2002.

8 Ken Alder, The Measure of the World, Washington, D.C, 2003; Peter Berz, 08/15. Ein Standard des 20. Jahrhunderts, München, 2001.

9 Graeme Gooday/James Sumner (Hg.), By Whose Standards? Standardization, Stability and Uniformity in the History of Information and Electrical Technologies, History of Technology, Vol. 28, London, 2008; Hasok Chang, Inventing Temperature. Measurement and Scientific Progress, New York, NY, 2004; Eran Tal, „Measurement in Science“, auf: The Stanford En- 
reller $^{11}$ und rechtlicher ${ }^{12}$ Seite aufgearbeitet worden. Die Wissenschaftsgeschichte der Quantifizierung geht von einer Koproduktion des Messens durch naturwissenschaftliche und ökonomische Praktiken aus ${ }^{13}$, sowie von einem Ineinandergreifen der Wirtschafts- und Technikgeschichte. ${ }^{14}$

In diesem Beitrag wird der Prozess der Standardisierung anhand einer Region analysiert, in der mit dem metrischen System eines der zentralen Modelle der Standardisierung selbst fehlte. Deutsch-Neuguinea verfügte über einen weltweit beispiellosen Reichtum an ökonomischen Institutionen, nicht allerdings über eine Währung, über Schrift, kodifiziertes Recht oder einheitliche Maße und Gewichte. Die Verhaltensweisen der dort lebenden Bevölkerungsgruppen waren weder rechtlich noch durch exakt quantifizierende Verfahren normiert. Verhältnisse, die die preußischen Amtmänner zu ändern hatten was diesen Prozess einer ,Erststandardisierung' heterogener Kulturgefüge für den Zusammenhang der Standardisierungstheorie so wertvoll macht. Denn, wie Susan Leigh Star und Martha Lampland erinnern, ist dieses Fundament industrialisierter Gesellschaften in ihnen selbst wenig sichtbar: „Yet the standards, numbers, and models tend to be black boxes in their own right." ${ }^{15} \mathrm{Da}$ es sich bei diesen Verdeckungen und Überdeckungen keinesfalls um gewaltfreie Prozesse handelt, wird an dieser Stelle weder die Rechtsgeschichte der Stan-

cyclopedia of Philosophy, online unter: http://plato.stanford.edu/archives/sum2015/entries/ measurement-science, zuletzt aufgerufen am 09.01.2019.

10 Mario Schmidt, Wampum und Biber. Fetischgeld im kolonialen Nordamerika. Eine Mauss'sche Kritik des Gabeparadigmas, Bielefeld, 2014; David Akin/Joel Robbins (Hg.), Money and Modernity. State and Local Currencies in Melanesia, Pittsburg, PA, 1999; Jonathan Parry/Maurice Bloch (Hg.), Money and the Morality of Exchange, Cambridge, 1989; Marilyn Strathern, The Gender and the Gift. Problems with Women and Problems with Society in Melanesia, Berkeley, CA, 1988.

11 Nicolas Rowland/Jan-Hendrik Passoth, ,Infrastructure and the State in Science and Technology Studies“, in: Social Studies of Science 45, 1 (2015), S. 137-145; Dirk van Laak, Imperiale Infrastruktur. Deutsche Planungen für eine Erschließung Afrikas 1880 bis 1960, Paderborn, 2004; Urs Stäheli, „Infrastrukturen des Kollektiven: alte Medien - neue Kollektive?“ in: $Z M K, 2$ (2012), S. 99-116; Gabriele Scharbacher, „Medium Infrastruktur. Trajektorien soziotechnischer Netzwerke in der ANT", in: ZMK, 2 (2013), S. 129-148.

12 Miloš Vec, Recht und Normierung in der Industriellen Revolution. Neue Strukturen der Normsetzung in Völkerrecht, staatlicher Gesetzgebung und gesellschaftlicher Selbstnormierung, Frankfurt/M., 2006.

13 Simon Schaffer, „Les cérémonies de la mesure. Repenser l'histoire mondiale des sciences“, in: Annales. Histoire, Sciences Sociales, 2 (2015), S. 409-435; Theodore M. Porter, Trust in Numbers. The Pursuit of Objectivity in Science and Public Life, Princeton, NJ, 1996.

14 Witold Kula, Measures and Men, übers. v. Richard Szreter, Princeton, NJ, 1986 [poln. OA 1970]; Aashish Velkar, Markets and Measurements in Nineteenth-Century Britain, Cambridge, 2012; Jean-Claude Hocquet (Hg.), Der Staat und das Messen und Wiegen, St. Katharinen, 1992; Harald Witthöft, Umrisse einer Historischen Metrologie zum Nutzen der wirtschafts- und sozialgeschichtlichen Forschung: Maß und Gewicht in Stadt und Land Lüneburg, im Hanseraum und im Kurfürstentum/Königreich Hannover vom 13. bis zum 19. Jahrhundert, Göttingen, 1979.

15 Martha Lampland/Susan Leigh Star, „Reckoning with Standards“, in: dies. (Hg.), Standards and Their Stories. How Quantifying, Classifying, and Formalizing Practices Shape Everyday Life, Ithaca, NY, 2009, S. 9. 
dardisierung noch die Ethnologie der Infrastruktur die entscheidenden Impulse geben, sondern das in der Standardisierungsforschung unerprobte konzeptuelle Vokabular der bildwissenschaftlichen Ikonoklasmustheorie.

$\mathrm{Zu}$ diesem Zweck wird zunächst der typische Verlauf eines vom Staat ausgehenden Ikonoklasmus geschildert, der sich gegen die Masken der Loma richtete. Erst in einem zweiten Schritt wird das religions- und kunstgeschichtliche Konzept für den Bereich metrischer Standards erstmalig fruchtbar gemacht. Hierzu werden im zweiten Teil bestehende Ansatzpunkte wie Angriffe auf Maßnormale vorgestellt und schließlich die koloniale Standardisierung in Deutsch-Neuguinea als Metroklasmus konzeptionalisiert. Hierzu ist es dienlich, zunächst genau auf den Prozess der Zerstörung künstlerisch-sakraler Symbole einzugehen:

\section{Staatlicher Ikonoklasmus: Die Masken der Loma (Guinea)}

Mit der 1958 erreichten Unabhängigkeit von Frankreich stellte sich der Republik Guinea das Problem der Regierung der Animismen. Der entschieden modernistische Kurs der Regierung unter Sékou Touré richtete sich nicht nur gegen das, was Jacques Rivière bei den Loma noch als ,pure paradise of fetishes' geschildert hatte ${ }^{16}$, sondern zugleich gegen den hinter vielen Ritualen stehenden Initiations- und Geheimbund Poro. Die als ,Demystification Campaign' bekannt gewordenen Welle staatlicher Gewalt gegen die Anhänger des Poro bediente sich unterschiedlicher Mittel. Einige dieser Interventionen lassen sich mit dem dänischen Ethnologen Christian Kordt Højbjerg als geschickten aber letztendlich erfolglosen Ikonoklasmus beschreiben. ${ }^{17}$ Die Zerstörung der Masken führt nicht zum intendierten Statusverlust der Objekte. Diese Unregierbarkeit ikonoklastischer Prozesse, die zuweilen aktivieren und pluralisieren, was doch ernüchtert und standardisiert werden sollte, ist entscheidend.

Ziel der Regierungskampagne in Guinea waren die Masken, die in den Ritualen des Geheimbundes Poro die Geister verkörperten. Wie so oft handelt es sich bei den bekämpften Bildern also nicht in erster Linie um Gemälde, sondern um Ikonen, die öffentlich bekannt, wenn auch nicht sichtbar sind. Wie im ersten umfänglich diskursivierten Ikonoklasmus - dem byzantinischen Bilderstreit - richtete sich die Aggression zudem gegen ikonische Objekte von hoher sakraler und zeremonieller Bedeutung.

16 Christian Kordt Højbjerg, Resisting State Iconoclasm among the Loma of Guinea, Durham, 2007, S. 43. Sékou Touré, der erste Präsident Guineas, war wie Nkrumah in Ghana oder Cabral in Guinea-Bissau Gegner der Ideen der Négritude. Ebd., S. 50.

17 Im Jahr 1991 nahm Højbjerg an einer Begräbnisfeierlichkeit teil - umgeben von bemerkenswerter Stille in den Zelten der Frauen, die die Masken selbst nicht sehen durften, ihren geheimen Status jedoch durch ihr Wissen mitproduzieren. Ebd., S. 46. 
Da die Masken der Loma geheim waren und einer strengen Genderzuteilung unterlagen, hatte bereits ihre Präsentation vor der gesamten Dorfversammlung einen de-sakralisierenden Effekt. Wie ein Informant Højbjergs berichtet, forderte die Polizei zunächst die Masken auf, aus dem Haus unter die Augen aller zu treten. Sie erklärte sodann, dass Männer kein Recht hätten, mehr Masken als Frauen zu besitzen. Die ausgezogenen Masken der Männer wie der Frauen wurden sodann aufgefordert - entgegen jeglicher Regel durcheinander zu sprechen. Diese geradezu ,im Bild oder innerhalb seiner angestammten Funktionsweise produzierten Widersprüche beschädigten die Illusion. Sie wurden von drastischeren Maßnahmen flankiert: Denn im Anschluss an ihre letzte transgressive Aufführung wurden die Masken verbrannt. Jedem, der dagegen Einspruch erhob, drohte physische Gewalt seitens des Ordnungspersonals, worin sich bereits andeutet, dass der objektfeindlichen Kulturpolitik der Staatsikonoklasten viele Mittel zur Verfügung stehen: Gesetze, Polizeigewalt, Gefängnisse, erhebliche Ressourcen, sowie zu gewissem Grad die Massenmedien.

Ein weiteres Beispiel für das desakralisierende Spiel mit dem zu entwertenden Ritual waren satirische Aufführungen junger Theatergruppen, welche die hochgeachteten Ritualexperten des Maskenkultes einem befreienden Lachen aussetzen sollten. Als Schönheitsfehler allerdings muss registriert werden, dass die Akteure zu diesem Theaterdienst verpflichtet worden waren. Oftmals wurden die Wächter der Masken im Vorfeld von der Polizei gewarnt und auch die sozialistische Jungendbewegung (JRDA) nahm nicht immer freiwillig an der Kampagne teil, obwohl es doch die Jugend war, der man staatlicherseits die Zwangsmitgliedschaft in dem Geheimbund mit seiner langen und schmerzhaften Initiationszeit (Beschneidung der Mädchen) ersparen wollte. ${ }^{18}$ Auffällig war zudem das entschiedene Eintreten christlicher Missionare für Aufklärung und Fortschritt, denen es jedoch nicht gelang, die andauernde Furcht der Bevölkerung vor der Rache der verbrannten Masken zu zerstreuen. ${ }^{19}$ Heilige Haine wurden umgepflügt und bepflanzt, nicht aber aus der Erinnerung gelöscht. ${ }^{20}$ Letztlich geben diese trotz ihrer Zerstörung wirksamen Orte ein Beispiel für ,inneren Ikonoklasmus' vor. Hier beginnt der Geheimbund selbst, die Bindungen seines Wertsystems an zerstörbare Objekte zu lösen, ohne jedoch die symbolische Ordnung hierdurch zu schwächen.

Ikonoklasmus lässt sich mithin als eine öffentliche Operation beschreiben, deren Besonderheit darin liegt, ein ikonisches Objekt, ein Bild oder Staatssymbol anzugreifen, hiermit aber zugleich stellvertretend ein ganzes System oder eine symbolische Ordnung zu treffen. Hierin liegt die außerordentliche Möglichkeit: Die Negation eines religiösen oder politischen Wertsystems lässt

18 Højbjerg (2007), Resisting State Iconoclasm, S. 58.

19 Ebd., S. 60.

20 Ebd., S. 63. Andere Elemente des Glaubens, so wie Ahnen- und Wasserkulte, blieben in der Kampagne zwischen 1959 und 1961 unberührt. 
sich durch Hände, Feuer oder Werkzeuge bewerkstelligen. Wie Bruno Latour beobachtet: „[T]he iconoclast's hammers [have] always seemed to strike sideways". ${ }^{21}$ Von der Irritation eines Wertsystems durch das Verbrennen der Masken ab, ist der Ausgang des ikonoklastischen Prozesses offen und genuin unkontrollierbar. Von der Obrigkeit initiiert, bleibt das Verfahren abhängig von den Reaktionen der Beteiligten: Tänzer, Ritualexperten, Jugendliche, Polizei, Beobachter, Leser und Politiker. Ein gewisser Automatismus muss also greifen, bevor sich entscheidet, ob die Zerstörung die Gemüter verletzt, die Meinungen spaltet, Vergeltungsmaßnahmen fordert oder ob die Öffentlichkeit ungerührt über das Ereignis hinweggeht.

Die Gewalt gegen Bilder, etwa der Angriff einer Suffragette auf den liegenden Akt der „Venus vor dem Spiegel“ von Velázquez, hat die Verletzung eines bestimmten Frauenbildes und zugleich die Befreiung der inhaftierten Emmeline Pankhurst zum erklärten Ziel, kann aber in der Öffentlichkeit auch konträre Energien mobilisieren. James Simpson betont für die Kinesis des Ikonoklasmus einen wellenförmigen Verlauf, wobei Anfangszwecke und Folgen immer weiter divergieren können. ${ }^{22}$ Für das paradoxale Verhältnis von Aufklärung und Ikonoklasmus spricht die Tatsache, dass die Akteure Gewaltmonopole usurpieren, und als vereinzelte Terroristen, Aufständische oder als Staatsterrorismus auftreten. Auch wenn sich die frühesten Beispiele des Ikonoklasmus an religiösen Fragen entzündet haben: Zerstört wird seit der Französischen Revolution oftmals im Namen der Demokratie und der Säkularisierung, ja als Signatur der Avantgarde immer eigenständiger innerhalb der modernen Kunst. ${ }^{23}$ In ihren typischen Varianten bewegt sich letztere in Richtung abstrakter Formen, die zwar einer Standardisierung nicht gleichzusetzen sind, sich dennoch aber dem geometrischen Repertoire zuordnen lassen. Unter den fünf von Latour klassifizierten Typen des Ikonoklasmus ${ }^{24}$ listet er auch

21 Bruno Latour, „What Is Iconoclash? Or Is there a World beyond the Image Wars?“, in: ders./Peter Weibel (Hg.), Iconoclash. Beyond the Image Wars in Science, Religion, and Art, Karlsruhe, 2002, S. 14-37: 17.

22 „A striking feature of iconoclasm, then, whether in Constantinople or in England, is this: it comes in waves. Once started, it's difficult to stop. [...] Each wave detects contagion and infection less from the original source of infection, and more [...] from the previous, failed effort to cultural hygiene. [...] This kinesis of iconoclasm continues, with ever purer, narrower historical affiliations, and it continues until the logic of destruction is stabilized." James Simpson, Under the Hammer. Iconoclasm in the Anglo-American Tradition, Oxford, 2010, S. 85 .

23 Ebd.

24 Zu Latours Typologie: ,Typ A‘: Die Gläubigen sollen von allen Bildern befreit werden, da sie Idole sind und nicht in der Lage, essentielle Zugänge zu vermitteln: „Free the believers [...] of their false attachments to idols of all sorts and shapes ... They believe it is not only necessary but also possible to entirely dispose of intermediaries and to access truth, objectivity, and sanctity.“, Typ B“: Die Ikonoklasten fordern hartnäckig bessere, neuere, aktivere Ikonen ein: "[They] do not believe it possible nor necessary to get rid of images. What they fight is freeze-framing, that is, extracting an image out of the flow, and becoming fascinated by it, as if it were sufficient, as if all movement had stopped." (Latour [2002], What Is Iconoclash?, S. 21.) Beim Bildersturm vom, Typ C` kämpft eine religiöse oder politische Gruppe gegen die 
unwissende Bildzerstörer auf, etwa die Stadtplaner, die Ikonen en passant einreißen ohne ihrer gewahr geworden zu sein und die Skeptiker, denen Bilderstürmer wie Ikonophile gleichermaßen suspekt erscheinen. Nicht einmal in der distanzierten Meinungslosigkeit gibt es ein Entrinnen: Selbst noch diejenigen, die den Bildern keine Bedeutung zumessen wollen, sind ikonoklastisch in ihrer Missbilligung der Bilder.

Für den formalen Zusammenhang der metrischen Standardisierung mit dem Ikonoklasmus ist aufschlussreich, dass immer wieder eine Logik der Kommodifizierung, der Verbreitung der Warenförmigkeit, konstatiert wird. Hierzu zählt etwa die manifeste Deflation der Bilder, die David Joselit im digitalen Zeitalter konstatiert, dass Kunst zu einer globalen Währung entwickelt. ${ }^{25}$ Die Kaskade von verfügbaren Bildern wirkt sich ebenso neutralisierend aus, wie die Dekontextualisierung von Artefakten in Museen die Möglichkeit des emphatisch Ikonischen durch eine schlichte Politik der Relokalisierung reduziert. ${ }^{26}$ Für Jan Assmann ist das Vergessen eine der wichtigsten und wirksamsten Ressourcen der Bilderfeindlichkeit. Es sind immer wieder Figuren der Neutralisierung und des Verschwindens, die auftreten - zur Dynamik des Bildersturms gehört auch die Produktion vermeintlich leerer Flächen. ${ }^{27}$ Trotz erheblichen Aufwands zeigt sich, dass selbst noch zerstörte Statuen als Bruchstücke musealisiert werden, dass den bekämpften Symbolen eine wiedergängerische Fähigkeit zukommt, dass ihre Semiotiken geradezu als zäh charakterisiert werden dürfen, selbst wenn sich die Bedeutung deformierter Objekte erzwungenermaßen wandelt.

Selbst bei der vollständigen Annihilation des materiellen Trägers ist nichts erreicht, denn die Bedeutungen migrieren in immer unerreichbarere Zeichen. Im Fall der gesprengten Buddha Statuen im afghanischen Bamiyan produzie-

Bilder der anderen um die Einsetzung und Würdigung der eigenen Standards. Letztlich fügt Latour noch das unwissende Zerbrechen der Bilder als ,Typ D“ hinzu, sowie die Spötter vom ,Typ E', die Ikonoklasten wie Ikonophile gleichermaßen verspotten. Insgesamt gilt: „What is so terrible for idol smashers is that there is no way to decide for good whether they are As, Bs oder Cs. [...] We don't know for sure. Ah, but that is why it is called Iconoclash" [ebd., S. 30].

25 „Medium or Postmedium are not good analytic tools for describing the hybridity of such chains or ,currencies' of different states of form. Here we may take a lesson from late capitalist business practices in which virtually anything, from trash to home mortgages, may be ,monetized ${ }^{*}$ - in other words exchanged on an international market in an abstracted representational form." David Joselit, After Art, Princeton, NJ, 2013, S. 3.

26 „Not only that, but, more interestingly, the Enlightenment is itself an iconoclastic movement in three profound ways. After 150 years or so of failed iconoclasm, Northern Europeans were exhausted. They invented three alternatives to literal iconoclasm. In the first place, the scientific Enlightenment exercised a philosophical iconoclasm by describing ideology as false consciousness, an idol that enthralls the naive and that must be broken. Secondly, the sentimental Enlightenment neutralized the image by placing it in the museum and by calling it Art. And thirdly, Enlightenment taste commodified the image under the market's hammer." Simpson (2010), Under the Hammer, S. 117.

27 Gottfried Boehm, „Ikonoklasmus. Auslöschung - Aufhebung - Negation“, in: ders., Wie Bilder Sinn erzeugen. Die Macht des Zeigens, Berlin, 2007, S. 54-71. 
ren die nun evakuierten Aushöhlungen in der Felswand eine intensive und unübersehbare Leere. Bedeutungen lassen sich auch im Falle der LomaMasken nicht einfach abstreifen: „C'est une singulière illusion que de croire atteindre le paganisme en saccageant ses supports les plus visibles. Les croyances subsistent en devenant clandestines ou en recourant à un symbolisme moins vulnerable“. ${ }^{28}$ Højbjerg berichtet hingegen in Guinea und den Nachbarländern über Fälle, in denen die staatlichen Ikonoklasmen der Modernisten erfolgreich waren und die bekämpften ontologischen Ordnungen an Halt verloren. ${ }^{29}$ Verschiebungen und Turbulenzen, Vergessen und Desemantisierung münden letztlich in der Durchsetzung homogener, naturalisierter Wertsphären und ,symbolfeindlicher Semantiken'. All diese Analysen beschränkten sich auf den Bereich der bildenden Kunst und religiösen Symbole und sie sind noch nicht hinreichend auf die typischen Kernelemente der metrischen Standardisierung bezogen worden.

\section{Staatlicher Metroklasmus: Die Standards von ,Deutsch-Neuguinea“}

Im äußersten Norden der Kolonie Deutsch-Neuguinea ${ }^{30}$, der entlegenen Inselkette der Marianen, ${ }^{31}$ ließ der Bezirksamtmann Georg Fritz seinen Inselbewohnern im September 1904 folgendes Zirkular mitteilen:

Vom 1. April 1905 ab soll im inneren Verkehr auf den Marianen das deutsche Mass- und Gewichtssystem in Anwendung kommen. Ich empfehle daher schon jetzt den Gewerbetreibenden, sich statt der seither üblichen englischen und spanischen mit deutschen (Meter-) Massen und (Kilo-) Gewichten zu versehen. Alle

28 „Es ist eine einzige Selbsttäuschung zu glauben, dass sich das Heidentum durch Verwüstung seiner sichtbarsten Objekte auslöschen ließe. Der Glaube überdauert indem sich verbirgt oder zu einer Symbolik Zuflucht nimmt, die weniger angreifbar und verletzlich ist.“ Højbjerg (2007), Resisting State Iconoclasm, S. 65; unter Bezug auf Georges Balandier, Afrique Ambiguë, Paris, 1957.

29 Ramon Sarró, The Politics of Religious Change on the Upper Guinea Coast. Iconoclasm Done and Undone, Edinburgh, 2009.

$30 \mathrm{Zu}$ den deutschen Kolonien gehörten unfreiwillig die Karolinen, die Marianen, die Marshallinseln (Mikronesien), ein Teil des polynesischen Samoa, die nördlichsten Ausläufer der Salomo-Inseln, der nordöstliche Teil der Insel Neuguinea (Kaiser-Wilhelms-Land) sowie die vorgelagerten, großflächigen Inseln Neu-Mecklenburg und Neu-Pommern mit der GazelleHalbinsel.

31 Dirk H. R. Speenemann, „Combining Curiosity with Political Skill. The Antiquarian Interests and Cultural Politics of Georg Fritz", in: Micronesian Journal of the Humanities and Social Sciences, 5 (2006), S. 495-504; Gerd Hardach, König Kopra. Die Marianen unter deutscher Herrschaft 1899-1914, Stuttgart, 1990; Hermann Joseph Hiery (Hg.), Die deutsche Südsee 1884-1914. Ein Handbuch, 2. Aufl., Paderborn, 2002. 
fremden Masse und Gewichte, die nach dem 1. April 1905 in Gebrauch gefunden werden, unterliegen der Einziehung. ${ }^{32}$

Angesichts der patriarchalen Strenge, mit der Fritz in seinem Regierungsbezirk aufzutreten wusste, kann es als sehr wahrscheinlich gelten, dass die erwähnte „Einziehung“ der vorgängigen Maße und Gewichte auch in die Tat umgesetzt wurde. Als die zentrale Kolonialverwaltung Deutsch-Neuguineas einige Jahre darauf per Umfrage eruierte ${ }^{33}$, ob eine Einführung des deutschen Maß- und Gewichtssystems mit unüberwindlichen Schwierigkeiten zu rechnen hätte, war die Antwort aus Saipan, man habe sich bereits „mit Maßen und Waagen versehen" lediglich die ,Eingeborenen" bedienten sich noch des spanischen Maßes „Ganta“. ${ }^{34}$ Widerstand gegen die Metrisierung ist direkt nicht belegt, wenn auch der Aufstand der Sokehs auf Ponape (1910/11) sich gegen die neu eingeführte und bereits verdoppelte Kopfsteuer richtete. ${ }^{35}$ Global gesehen gehören Angriffe auf die Standardmaße fest zur Geschichte der Metrisierung. ${ }^{36}$ Der mexikanische Wirtschaftssoziologe Héctor Vera verwendet für diese Angreifer auf Messobjekte bereits den Begriff der „Mesuroclasts“. Bei der Quebra-Quilo-Revolte in Nordbrasilien (1874) drückt sich dieser Appell bereits im Namen aus, da die Landbevölkerung die neu eingeführten Kilogrammgewichte zerschlug. ${ }^{37}$

32 Gez. Fritz, Kaiserliches Bezirksamt Saipan, den 21. September 1904 Bundesarchiv BArch R 1001/2555 (Akten Masse und Gewichte in Neu-Guinea von November 1907 bis August 1913), S. 22 (vorhanden ist nur eine maschinenschriftliche Abschrift des Briefes).

33 Votum des Gouvernementsrats Deutsch-Neuguinea auf Grundlage der Umfrage in den Bezirken (Bundesarchiv BArch R 1001/2555, S. 4). Der Brief erwähnt die Sitzung vom 29. Oktober 1907, datiert aber vom 2. November 1907. Die Kolonien sind zu unterschiedlichen Zeitpunkten der Maß-und Gewichtsordnung des Deutschen Reiches unterworfen worden: Togo (1897), Kamerun (1894), Deutsch-Südwestafrika (1899), Deutsch-Neuguinea und Deutsch-Ostafrika (1912).

34 Bundesarchiv BArch R 1001/2555/Nr. 21: Akten Masse und Gewichte in Neu-Guinea von November 1907 bis August 1913, Schreiben Saipan, 8. Februar 1908.

35 Alexander Krug, Der Hauptzweck ist die Tötung von Kanaken. Die deutschen Strafexpeditionen in den Kolonien der Südsee 1872-1914, Tönning, 2005.

36 Richard Sheldon/Adrien Randall/Andrew Charlesworth/David Walsh, „Popular Protest and the Persistence of Customary Corn Measures. Resistance to the Winchester Bushel in the English West", in: Adrian Randall/Andrew Charlesworth (Hg.), Markets, Market Culture and Popular Protest in Eighteenth-Century Britain and Ireland, Liverpool, 1996, S. 25-45: 27.

37 Héctor Vera, The Social Life of Measures. Metrication in the United States and Mexico, 1789-2004, Ann Arbor, MI, 2012, Dissertation, online unter: https://pqdtopen.proquest.com/ doc/924487292.html?FMT=AI, zuletzt abgerufen am 09.01.2019, S. 414. Die spanische Originalversion erschien als Héctor Vera, A peso el kilo. Historia del sistema métrico decimal en México, México, 2007; vgl. ders., „The Social Construction of Units of Measurement: Institutionalization, Legitimation and Maintenance in Metrology“, in: Lara Huber/Oliver Schlaudt (Hg.), Standardization in Measurement. Philosophical, Historical and Sociological Issues, London, 2015, S. 173-187; der Aufstand steht auch im Zusammenhang mit der gleichzeitigen Umstellung der Steuern. Vgl. Roderick J. Barman, „The Brazilian Peasantry Reexamined. The Implications of the Quebra-Quilo-Revolt, 1874-1875“, in: Hispanic American Historical Review, 53 (1977), S. 401-424. 
Will man die Metrisierung Deutsch-Neuguineas als staatlichen Metroklasmus betrachten, so sind Machtkämpfe an zwei Fronten zu berücksichtigen: In ihrer Eigenschaft als Dinge des täglichen Gebrauchs stehen die metrischen Waagen und Gewichte vor Ort als Signale der nationalstaatlichen Ansprüche des Deutschen Reichs sowie dessen wirtschaftspolitischer Vormachtstellung, die im Pazifik zumeist Behauptung blieb. Weitestgehend abgestreift hat das metrische System die politischen Ansprüche der Französischen Revolution. Während die naturalistische und universalistische Grundierung erhalten blieb, hat sich das metrische System im Laufe des 19. Jahrhunderts zu einem Trägersystem marktliberaler Werte entwickelt, das Reminiszenzen an die Egalitätsforderungen der Ersteinführung zu wahren und umzunutzen verstand. ${ }^{38}$

Georg Fritz muss in seinem Regierungsbezirk zwei Typen von abweichender Metrik bekämpfen: Die indigenen Zähl- und Kalkulationsformen einerseits sowie die Standards der konkurrierenden Handelsmächte andererseits. Das 1825 eingeführte System der British Imperial Standards war im ganzen britischen Commonwealth obligatorisch und in der ozeanischen Region aufgrund der Handelsbeziehungen zu Australien und weiterer britischer Kolonien mehr und mehr die logistische Verkehrssprache. Im Hinterland der Inseln waren durch die spanische Missionstätigkeit die spanischen Maße sowie ihre vorzüglichen , peruanischen' und ,chilenischen' Silbermünzen bereits wesentlich länger verankert. ${ }^{39}$ Mit den chinesischen und japanischen Maß-Systemen, die ebenfalls im Schutzgebiet auftreten ${ }^{40}$, ist zunächst eine erste Ebene pluralisierter Standards benannt, die in Teilen nicht-westliche Universalismen vertreten. Die Zwecke und Effekte der Standardisierung bleiben jedoch unter all diesen imperialen metrischen Systemen vergleichbar: Sie sind auf die unmerkliche Kanalisierung der internationalen Handelsströme zu den eigenen Gunsten ausgelegt. Die Mühen der Buchhaltung, die Hafengebühren und Zollkontrollen bilden hierbei die Zugriffspunkte einer Direktion qua Buchungs- und Maßeinheit. Die Quantifizierung ist Ausdruck und Form der Logistik und der Zollbestimmungen ${ }^{41}$ Mit Latour ließe sich die Ersetzung des britischen Pfund durch den Meter oder des spanischen Ganta durch 300 Gramm als Ikonoklasmus vom ,Typ C` auffassen, bei dem es

38 Simon Schaffer, „Metrology, Metrication, and Victorian Values“, in: Bernard Lightman (Hg.), Victorian Science in Context, Chicago, IL, 1997, S. 438-475.

39 Miguel Aguilar-Robledo, „Contested Terrain. The Rise and Decline of Surveying in New Spain 1500-1800“, in: Journal of Latin American Geography, 8, 2 (2009), S. 23-47; Manuel Carrera Stampa, „The Evolution of Weights and Measures in New Spain“, in: Hispanic American Historical Review, XXXIX (1949), S. 2-24.

40 Vgl. hierzu George Sarton/J. R. Ware, ,Were the Ancient Chinese Weights and Measures Related to Musical Instruments?“ in: Isis 1, 2 1947, S. 73; Hans Ulrich Vogel, „Weights and Measures in China“, in: Helaine Selin (Hg.), Encyclopaedia of the History of Science, Technology, and Medicine in Non-Western Cultures, Dordrecht, Boston, MA, London, 1997, S. 1010-1012. Zu Japan vgl. Shigeo Iwata, „Japanese Scales and Weights“, in: Equilibrium (1983), S. 319-326.

41 Monika Dommann, Materialfluss. Eine Geschichte der Logistik an den Orten ihres Stillstands, Frankfurt/M., im Druck. 
zur Ersetzung der Fetische der anderen durch die eigenen kommt. ${ }^{42}$ Dieses Durchwechseln internationaler Systeme ist in erster Linie Wirtschaftspolitik.

Die Umfrage zur Metrisierung in Deutsch-Neuguinea dokumentiert jedoch deutlich eine zweite Wirkungsebene der Standardisierung, wo direkt koloniale Gewalt ausgeübt wird. Dies ist der Fall, wo indigene Systeme der Quantifizierung und Messung angegriffen werden. Der staatliche Ikonoklasmus mag hier bis zu einem gewissen Grad zu Latours ,Typ D‘, den unabsichtlichen Ikonoklasmen, zuzurechnen sein.

Umso folgenreicher allerdings sind die Irritationen innerhalb der getroffenen Ordnung einzustufen: Die Reform betraf und entmachtete lokale Wertungs- und Messungsobjekte ausgerechnet in einer Weltregion, die aufgrund der schieren Überfülle monetärer Institutionen seit Bronislaw Malinowski immer wieder wichtige Beiträge zur Wirtschaftsethnologie hervorgebracht hat und noch immer der aktuellen Debatte um die ,multiplicities of money ${ }^{\text {' zent- }}$ rales argumentatives Terrain bietet. ${ }^{43}$ Kaum ein Gebiet ist so reich an Teil- und Zeremonialwährungen. Kaum eine Region ist in der Pluralität der sozialstrukturierenden Wertsphären und ihrer Repräsentation durch die sozialen Medien quantifizierender Objekte so heterogen. ${ }^{44}$ Für Standardisierungsprozesse bietet sich ein fast unendliches Gefälle möglicher Stabilisierungen.

Diese besondere Konstitution der monetären Sphäre ist in zweierlei Hinsicht entscheidend für die Frage der Standardisierung der Maße und Gewichte. Am einen Ende der Skala liegen große Regionen, in denen Geld unbekannt ist. Mengen verbreiteter Waren (Feldfrüchte, Gewebe, Werkzeuge) erfüllen erfolgreich die Funktion eines Tauschmediums. Bei den Warengeldern kommt alles auf die verwendeten Maße an. Am anderen Ende der Skala liegen in Deutsch-Neuguinea oftmals unwahrscheinliche Formen von Zeichengeldern. So zählen auf den Marshallinseln Fledermaus- oder Hundezähne als Naturalgeld; am Mittellauf des Sepik werden Urheberrechte an Liedgut oder Werkzeugen übertragen. ${ }^{45}$ Direkt neben prämonetären Gebieten liegen Enklaven, in

42 Latour (2002), What Is Iconoclash?, S. 30.

43 Akin/Robbins (Hg.) (1999), Money and Modernity.

44 Für Überblicksdarstellungen vgl. noch immer: A. Hingston Quiggin, A Survey of Primitive Money. The Beginnings of Currency, London, 1949; Paul Einzig, Primitive Money in its Ethnological, Historical and Economic Aspects, London, 1949. William J. D. Mira, From Cowrie to Kina. The Coinages, Currencies, Badges, Medals, Awards, and Decorations of Papua New Guinea, Sydney, 1986.

45 Alexis Themo von Poser, „Trommeln und Masken. Handelsbeziehungen in den Mündungsgebieten von Sepik und Ramu“, in: Christian Kaufmann/Philippe Peltier/Markus Schindlbeck (Hg.), Tanz der Ahnen. Kunst vom Sepik in Papua-Neuguinea, München, 2015, S. 30-38: 30: „Zwar gibt es ein strenges Urheberreicht für viele Dinge, so zum Beispiel für Melodien und Liedtexte, für Tänze, Namen, Schnitzmuster und Körperschmuck, es kann aber zu unterschiedlichen Anlässen und aus verschiedenen Gründen übertragen werden. Solche oft virtuellen und abstrakten Werte zählten zu den wichtigsten und am höchsten geschätzten Gaben; sie mochten als Mitgift bei Hochzeiten oder zur Wiedergutmachung nach Konflikten dienen, aber auch zur Bezahlung für Land und damit für das wichtigste Gut. Mit der Weitergabe eines bestimmten 
denen das soziale Gefüge von Geldformen geradezu überdeterminert ist - wie beispielsweise auf der Insel Palau, unweit der Marianen. Das dortige Scherben- oder Perlengeld wird nicht für Haus, Nahrung und Kleidung eingesetzt. Doch alles, was an sozialer Interaktion vor sich geht bis hin zur ehelichen Umarmung, wird durch 53 Klassen eines Perlengeldes geregelt. ${ }^{46}$ Dieses Geld lässt sich vor allem in der Erzeugung von Beziehungen und Hierarchien verdienen. ${ }^{47}$

Gerade im Bereich der Zeichengelder wird offensichtlich, dass die zur Wertmessung eingesetzten Objekte nicht wie Münzen numerische Werte angeben und dass ihre Quantifizierungsleistung sich nicht ausschließlich auf ökonomische Werte bezieht. Die alternierenden Routinen der Quantifizierung in nicht-industrialisierten Ökonomien weichen in mehrfacher Hinsicht ab. Zunächst sind politische, medizinische, zeremonielle, ästhetische oder strafrechtliche Kontexte der Wertmessung ebenso abgebildet wie ökonomische Werte. Hinzu kommen die sprachlich verankerten Quantifizierungssemantiken, wie die oftmals sehr abweichenden Zählsysteme, die auf dem Körper, der 3 , der 5, der 12 oder der 20 beruhen können. Jane I. Guyer hat darauf hingewiesen, dass die Verwendung unterschiedlicher Wertungsskalen in Abhängigkeit von der jeweiligen Situation stark differiert. ${ }^{48}$ Quantifizierung kennt also serielle Beiordnung in lediglich numerischen Aggregaten. Die Ordnung bleibt horizontal und ist weitaus weniger hierarchisch gedacht als in den Ordinalskalen. Diese privilegieren wie das olympische Komitee die ersten drei Plätze und spiegeln mühelos soziale Hierarchien. Erst der Typus der metrisch stabilen Intervallskalen allerdings, ermöglicht Messung und Quantifizierung im technisch stabilen Sinn. Die europäische Bewertung metrischer Maße und Geldtypen ist demgegenüber vom Repertoire her auf die letzte Variante eingeschränkt. Sie stehen zudem für eine abstrahierte und reduzierte Fassung der monetären Sphäre, die oftmals zu schnell mit der Quantifizierung gleichge-

Urheberrechts schuf man feste Bindungen, die sich durch die gemeinsame Nutzung der betreffenden Sache, die gemeinsame Aufführung oder Ausübung anderen gegenüber vertieften."

46

„Der Mensch, als Tier aufgefasst, hat hier genug zum Lebensunterhalte, will er aber eine Frau haben, Familie gründen, Mitglied eines Staates sein, so muss er Geld besitzen." Dabei hat der Einzelne unter Umständen „,weit mehr Sorgen als ein fleissiger Arbeiter bei uns.“ Richard Parkinson, Dreißig Jahre in der Südsee. Land und Leute, Sitten und Gebräuche im Bismarckarchipel und auf den deutschen Samoainseln, Stuttgart, 1907, S. 19.

47 „Udoud can be used to purchase commodities, to pay for labor services, to cement or break off personal friendship and political alliance, to reciprocate affinal food prestations, to make and terminate marriage, to conclude peace between villages, to ward off illness, to elevate a man to a chiefly title, to resolve fines imposed by chiefly councils, to pass inheritance through the generations, and to coerce the spirits. The various classes of udoud have well established focal usages. [...] [F]or titleholders the more respectable method of obtaining udoud was to control the labor, behavior, and marriages of others." Richard Parmentier, „Money Walks, People Talk. Systemic and Transactional Dimensions of Palauan Exchange“, in: L'Homme, 162 (2002), S. 49-80: 55.

48 Jane I. Guyer, Marginal Gaines. Monetary Transactions in Atlantic Africa, Chicago, IL, 2004, S. $47 \mathrm{f}$. 
setzt wird, die in sich wesentlich größere Spielräume bietet. Der metrische Prototyp Deutschlands (Nr. 22) stand bei seiner Einführung für ein spezifisches symbolisches Regime der Quantifizierung von Werten. Da die Ermittlung von Preisen immer an Mengenangaben gekoppelt ist, liegen in jeder Währungsangabe Elemente dieses Standards mit vor.

Auffällig ist jedoch, dass diese Verschränkung von Preis und physischer Form oder Menge bei den ozeanischen Zeichengeldern noch enger einzustufen ist. Denn in diesen zumeist nicht-numerisch lesbaren Objekten, findet die Quantität des Wertes ihren Ausdruck. Dies kann durch Alter, Bekanntheitsgrad, Schönheits- oder Seltenheitswert geschehen - aber durchaus auch durch schiere Größe oder Menge. Diese wird in Ozeanien jedoch nicht in Meter und Kilogramm, sondern in vor-metrischen Maßen ermittelt, wodurch in der Kolonie ein weiterer Standardisierungskonflikt entsteht. Die Historische Metrologie deutet diesen jedoch selbst als Indikator für den Industrialisierungsgrad und damit für die wirtschaftliche Verfassung einer Gesellschaft. Handel und Logistik, Buchhaltung und Zollwesen lösen vormals lokalspezifische Maße von ihren konkreten Prozessorientierungen ab und erzeugen eine abstrakte Matrix der exakten Beschreibung.

Der Vergleich der metrischen und monetären Standards in Europa und Ozeanien zeigt zwei Unterschiede: Die Menge eines Stoffes muss in Ozeanien nicht notwendig in den messbaren Raumkoordinaten Größe und Schwere angegeben sein, sondern kann durch symbolische Gegenstände, Schätzungen und ästhetische Formgewohnheiten reguliert werden, und geldähnliche Objekte können Bereiche sozialen Handelns betreffen, die in Europa nicht gezählt würden. Diese Tatsachen machen plausibel, inwiefern die Metrisierung der Kolonie die sozialen Strukturen mit einiger Schärfentiefe ergreift. Diese hohe Passung der Wertmesser in das soziale Gefüge der Gesellschaft lässt sich am vieldiskutierten Steingeld der Insel Yap zeigen, die in der Nachbarschaft von Palau und unweit der Marianen gelegen ist. ${ }^{49}$ Diese zeremonielle Währung wird „Fä“ genannt und besteht aus Agonitplatten von der Größe und Anmutung ganzer Mühlsteine. Sie können nur von mehreren Personen gemeinsam überhaupt bewegt werden. Der Geldwert wird in ungefähren Maßen taxiert: „Sein Wert wird auch bei nicht ganz runden Stücken nach der Weite des größten Durchmessers durch Handspannen bestimmt, die von der Daumen- bis zur Zeigefingerspitze gemessen werden." ${ }^{\text {"50 }}$ Besonders alte oder große Exemplare tragen Eigennamen und damit idiosynkratrische Wertelemente. Ein sechs Handspannen großes Stück ist nach seinem ersten westlichen Erforscher Jan Kubary benannt; subalterne Mitglieder der Inselgesellschaft dürfen keine Steinplatten besitzen, die größer als vier Spannen sind. ${ }^{51}$

49 Vgl. Arno Senfft, „Das Geld der Yaper“, in: Deutsches Kolonialblatt, 12 (1901), S. 870-872.

50 Theodor Helmreich, Das Geldwesen in den deutschen Schutzgebieten, 2. Teil, Mikronesien, Fürth, 1913, S. 96.

51 Ebd., S. 97 und S. 101. 
Die Steingeldwährung „Fä“ von der Insel Yap steht für die Interdependenz metrischer Formate. Denn um die Platten auf der Insel Ponape aus einem Steinbruch zu schlagen, mussten die ausgesandten Gruppen 500 Kilometer über den Ozean navigieren. Erneut ist die orientierende Messung nicht ausschließlich von abstrakt-numerischer Natur. ${ }^{52}$ Jedes „Fä“ zeugt von den bestandenen Gefahren des Rücktransports mit erheblicher Fracht nach geleisteter, oft monatelanger Arbeit in den Steinbrüchen. All diese Kosten und Risiken bei der Geldherstellung, die Abenteuer und Gemeinschaftsleistung, und nicht zuletzt die Navigationskünste, die immer wieder zu den elaboriertesten Formen nicht-westlichen Wissens gezählt werden, wurden von unerwarteter Seite entwertet. Nicht durch Gesetz, sondern vielmehr durch die Idee des Händlers O'Keefe, ein Schiff zu erwerben und den Inselbewohnern gegen Steingeld den Transport technisch zu erleichtern.

Die dadurch einsetzende Inflation der Steinplatten entwertete diese allerdings nicht vollständig, was sowohl der Bezirksregierung als auch O'Keefe selbst die Möglichkeit gab, sich an den indigenen Wertmessungsobjekten zu bereichern:

Auch die deutsche Regierung erkennt das Fä als Zahlungsmittel an und pfändet Gemeinden und Einzelbesitzern, die gegen ihre Anordnungen verstoßen haben, die Geldsteine. Sie werden in diesem Falle zwar oft an ihrem Standorte belassen, aber der eingeborene Gerichtsvollzieher malt mit schwarzer Farbe nicht zu klein die Buchstaben B.A. (Bezirksamt) auf einen oder mehrere. ${ }^{53}$

Der Behörde erschlossen sich durch diese Anerkennung der fremden Währung erhebliche Druck- und Einflussmittel, die an den höchsten Werten der lokalen Kultur ansetzen konnten. Zwar wurde manche Schuld eingelöst und die Behörde strich mit schwarzer Farbe die Lettern auf dem gepfändeten Stein wieder durch. Wo immer aber die Auslösung nicht erfolgte, ging das Objekt in den Besitz der Regierung über, für die zu jeder Zeit die Möglichkeit bestand, Fä gegen Copra einzutauschen - gegen den lukrativsten Rohstoff der Region, die ölhaltige Frucht der Kokosnusspalme. ${ }^{54}$ Die Entwertungsroutinen, die an den unterschiedlichen Messungs- und Wertmessungsverfahren ansetzen, erweisen sich als milder Inflationsprozess mit gravierenden Folgen für die vielfältigen Kompetenzen, die sich mit dieser ungewöhnlichen monetären Institution verknüpfen.

Die Steingeldwährung wird in erster Linie durch das Profitinteresse eines Händlers erschüttert. Die technische Modernisierung trifft lokale Messungskünste jedoch ins Herz, denn was durch diesen Wandel überflüssig wird, sind

52 Vgl. David Turnbull, Mapping the World in the Mind. An Investigation of the Unwritten Knowledge of the Micronesian Navigators, Geelong, 1991; Matthias Schemmel, Spatial Thinking and External Representation. Towards a Historical Epistemology of Space, Berlin, 2016.

53 Helmreich (1913), Das Geldwesen, S. 105.

54 Ebd., S. 106. 
die berühmten mikronesischen Navigationskünste. Allerdings legten die Leute aus Yap ihre Gewohnheit nicht vollends ab. Noch die australische Kolonialregierung verbot die riskante Seefahrt, die sich an Abfolgen von Stern- und Küstenkonstellationen ohne Kompass orientierte. Auch das Steingeld wurde von seiner inflationären Verfügbarkeit verändert, aber nicht beseitigt. Es änderte jedoch seine Zuordnung zu sozialen Schichten und Ritualen. In der Konkurrenz zu westlichen, rein monetär gedachten Wertmaßstäben verloren die Steinplatten an Wert, aber nahmen in ihrer Zahl zu. Metroklastisch ist dieser Prozess insofern, als die veränderten Objekte die symbolische Ordnung aktivierten und die soziale Hierarchie der Insel herausforderten. Auf diese Gewalt folgte jedoch keine schlichte Ersetzung durch andere Standards.

In der jüngeren Wirtschaftsethnologie wird oftmals diskutiert, ob nicht die Austauschsituation zwischen unterschiedlichen sozioökonomisch strukturierten Gruppen geradezu eine Blüte und neue Entwicklung der Naturalwährungen hervorruft. In Deutsch-Neuguinea war eine interessierte Appropriation des Steingeldes von Yap seitens der Kolonialregierung zu verzeichnen. Diese nutzte das Steingeld zur Verpfändung und zur Zahlung von Strafen. Die Appropriation der „Naturalgelder“ durch die Kolonisatoren bedeutet allerdings keine Übernahme all der Bedeutungen, die diese Objekte in der Herkunftskultur repräsentieren. Es darf vermutet werden, dass diese Aneignung oberflächlich blieb, bzw. dass im Umgang mit dem Zeichengeld vielmehr metrische Quantifizierungs- und Wertvorstellungen die indigene Institution überschrieben und es als ,modernisiert verstanden wurde.

In anderen Regionen des ehemaligen Deutsch-Neuguinea ist exakt dieser ,innere' Ikonoklasmus, der den Wertmesser verwendet, ihm aber die Quantifizierungsroutinen der Gegenseite zuschreibt, in Feldforschungen jüngeren Datums bestätigt worden. Den Abschied vom Muschelgeld im Zentralmassiv Neuguineas schildern Pamela J. Stewart und Andrew Strathern als aktive Wahl der Bevölkerung, da die Weißen, die das Muschelgeld überhaupt erst in die Region gebracht hatten, in der Wahrnehmung der Bevölkerung das ,echte“ Münzgeld trickreich verheimlicht hatten. Die Übernahme allerdings erfolgt durch eine Umcodierung der Wertungsroutinen. Auch Banknoten können in zeremoniellen Situationen zum Einsatz kommen: „The Duna, like the Hageners, use money as both a ceremonial valuable and a medium for commodity exchange, and they no longer employ shells in their transactions. [...] [The banknotes; A. E.] have been given a purely local set of values. "“55

55 Pamela J. Stewart/Andrew Strathern, „Transformations of Monetary Symbols in the Highlands of Papua New Guinea“, in: L'Homme 162 (2002), S. 137-156: 153. 


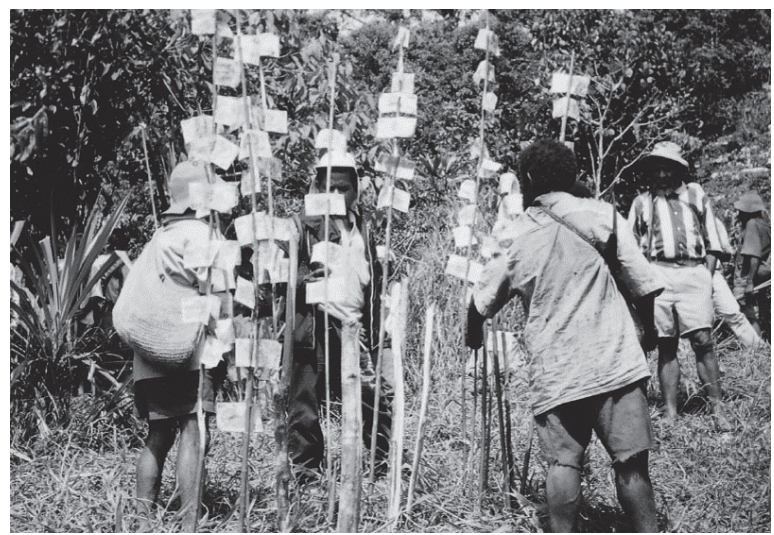

3.1 - Zeremonie im Hochland von Papua-Neuguinea:

Ritual, bei dem ,Kina'-Banknoten die Perlmuschelgelder ersetzt haben, die sonst auf den Stäben präsentiert wurden.

,Kina' bedeutet ,Perlmuschel' in der Sprache der Melpa, die im Hochland Papua-Neuguineas um Mount Hagen leben und durch den Handel vor allem mit Kolonisatoren das Muschelgeld, später Banknoten zu schätzen lernten.

Das Foto zeigt angehörige der Duna, die Papiergeld wie früher die Muschelgelder auf Stecken aufreihen (1999).

Geldobjekte werden in dieser Szene zu binären Medien, die sowohl die Industrialisierung als auch die Gegenposition zu verwalten vermögen. Stewart und Strathern legen nahe, dass diese kultische Einbindung der Banknoten in den älteren zeremoniellen Tausch eine gelungenere Zähmung und reappropriation des Geldes darstellt als der Red Box Money-Kult. ${ }^{56}$

Die prinzipielle Beweglichkeit und Bedeutung sozialer Medien, ihre Eigenheit, von pluralen Wertvereinbarungen getragen $\mathrm{zu}$ werden, wird durch die beispiellose Erfolgsgeschichte des Meters und des ,Black Box Money-Kults“ als Standards mit der größten globalen Verbreitung leicht verdeckt. Das damit einhergehende Anheimfallen ganzer Kulturen an eine unregierbare Wette, die Etablierung einer Ebene vergessener monetärer Symbolik und die Ent-semiotisierung des Vertrauens im Geldverkehr - all dies scheint der Tendenz nach unaufhaltsam. Nicht jedoch in dem durch Gouverneur Georg Fritz metrisierten Bezirk. Die Vereinigten Staaten von Mikronesien gehören neben Samoa zu den sechs Staaten ${ }^{57}$, die sich dem Systeme Internationale, dem Nachfolger des

56 „In this way they have at least partially tamed it and so, for the time being, having made it a supreme object of value in their cult, also set it to work in the service of their own social values." Stewart (1980), Red Box Money-Cult, S. 174.

57 Nach Hector Veras Zählung erfolgte die Metrisierung Papua-Neuguineas 1970, da die Kolonien im Ersten Weltkrieg an Australien gingen und wieder aus dem metrischen System ausstiegen. Auch heute noch gehören Samoa (nie eingeführt), Palau, die Marshallinseln und die Vereinigten Staaten von Mikronesien zu den Ländern, die der Meterkonvention nicht beigetreten sind, wie die vielleicht bekannteren Verweigerer der Vereinigten Staaten von Amerika, Myanmar und Sierra Leone/Liberia. Vera (2012), The Social Life of Measures, S. 494-497. 
metrischen Systems und gültigen Reglement der Standardisierung von Maßen und Gewichten, nicht angeschlossen haben.

\section{Literatur}

Aguilar-Robledo, Miguel, „Contested Terrain. The Rise and Decline of Surveying in New Spain 1500-1800“, in: Journal of Latin American Geography 8, 2 (2009), S. 23-47.

Akin, David/Robbins, Joel (Hg.), Money and Modernity. State and Local Currencies in Melanesia, Pittsburg, PA, 1999.

Alder, Ken, The Measure of the World, Washington, D.C, 2003.

Balandier, Georges, Afrique Ambiguë, Paris, 1957.

Barman, Roderick J., „The Brazilian Peasantry Reexamined. The Implications of the Quebra-Quilo-Revolt, 1874-1875“, in: Hispanic American Historical Review, 53 (1977), S. 401-424.

Berz, Peter, 08/15. Ein Standard des 20. Jahrhunderts, München, 2001.

Boehm, Gottfried, „Ikonoklasmus. Auslöschung - Aufhebung - Negation“, in: ders., Wie Bilder Sinn erzeugen. Die Macht des Zeigens, Berlin, 2007, S. 54-71.

Bundesarchiv BArch R 1001/2555 (Akten Masse und Gewichte in Neu-Guinea von November 1907 bis August 1913).

Cahan, David, An Institute for an Empire. The Physikalisch-Technische Reichsanstalt, 1871-1918, Cambridge, 1989.

Chang, Hasok, Inventing Temperature. Measurement and Scientific Progress, New York, NY, 2004.

Dommann, Monika, Materialfluss. Eine Geschichte der Logistik an den Orten ihres Stillstands, Frankfurt/M., im Druck.

Einzig, Paul, Primitive Money in Its Ethnological, Historical and Economic Aspects, London, 1949.

Gooday, Graeme/Sumner, James, By Whose Standards? Standardization, Stability and Uniformity in the History of Information and Electrical Technologies, History of Technology, Vol. 28, London, 2008.

Guyer, Jane I., Marginal Gaines. Monetary Transactions in Atlantic Africa, Chicago, IL, 2004.

Hardach, Gerd, König Kopra. Die Marianen unter deutscher Herrschaft 1899-1914, Stuttgart, 1990.

Helmreich, Theodor, Das Geldwesen in den deutschen Schutzgebieten, 2. Teil, Mikronesien, Fürth, 1913.

Hiery, Hermann Joseph (Hg.), Die deutsche Südsee 1884-1914. Ein Handbuch, 2. Aufl., Paderborn, 2002.

Hind, Dieter/Kochsiek, Manfred, Herausforderung Metrologie. Die PhysikalischTechnische Bundesanstalt und die Entwicklung seit 1945, Bremerhaven, 2002.

Hocquet, Jean-Claude (Hg.), Der Staat und das Messen und Wiegen, St. Katharinen, 1992.

Højbjerg, Christian Kordt, Resisting State Iconoclasm among the Loma of Guinea, Durham, 2007. 
Iwata, Shigeo, „Japanese Scales and Weights“, in: Equilibrium (1981), S. 319-326.

Joselit, David, After Art, Princeton, NJ, 2013.

Krug, Alexander, Der Hauptzweck ist die Tötung von Kanaken. Die deutschen Strafexpeditionen in den Kolonien der Südsee 1872-1914, Tönning, 2005.

Kula, Witold, Measures and Men, übers. v. Richard Szreter, Princeton, NJ, 1986 [poln. OA 1970].

Laak, Dirk van, Imperiale Infrastruktur. Deutsche Planungen für eine Erschließung Afrikas 1880 bis 1960, Paderborn, 2004.

Lampland, Martha/Leigh Star, Susan, „Reckoning with Standards“, in: dies. (Hg.), Standards and Their Stories. How Quantifying, Classifying, and Formalizing Practices Shape Everyday Life, Ithaca, IL, 2009, S. 9.

Latour, Bruno, Science in Action. How to Follow Scientists and Engineers through Society, Cambridge, MA, 1987.

Ders., „What Is Iconoclash? Or is there a World beyond the Image Wars?“, in: ders./Peter Weibel (Hg.), Iconoclash. Beyond the Image Wars in Science, Religion, and Art, Karlsruhe, 2002, S. 14-37.

Meyer-Stoll, Cornelia, Die Maß- und Gewichtsreformen in Deutschland im 19. Jahrhundert unter besonderer Berücksichtigung der Rolle Carl August Steinheils und der Bayerischen Akademie der Wissenschaften, München, 2010.

Mira, William J. D., From Cowrie to Kina. The Coinages, Currencies, Badges, Medals, Awards, and Decorations of Papua New Guinea, Sydney, 1986.

Owens, Kay, History of Number. Evidence from Papua New Guinea and Oceania, Heidelberg, 2018.

Parkinson, Richard, Dreißig Jahre in der Südsee. Land und Leute, Sitten und Gebräuche im Bismarckarchipel und auf den deutschen Samoainseln, Stuttgart, 1907.

Parmentier, Richard J., ,Money Walks, People Talk. Systemic and Transactional Dimensions of Palauan Exchange“, in: L'Homme 162 (2002), S. 49-80.

Parry, Jonathan/Bloch, Maurice (Hg.), Money and the Morality of Exchange, Cambridge, 1989.

Pickering, Andrew, „Islands of Stability. Engaging Emergence from Cellular Automata to the Occupy Movement", in: ZKM 5, 1 (2014), S. 124-134.

Polanyi, Karl, „Über den Stellenwert wirtschaftlicher Institutionen in der Antike am Beispiel Athen, Mykene und Alalakh“, in: ders. (Hg.), Ökonomie und Gesellschaft, übers. v. Heinrich Jelinek, Frankfurt/M., 1979 [engl. OA 1957], S. 387-413.

Porter, Theodore M., Trust in Numbers. The Pursuit of Objectivity in Science and Public Life, Princeton, NJ, 1996.

Poser, Alexis Themo von, ,,Trommeln und Masken. Handelsbeziehungen in den Mündungsgebieten von Sepik und Ramu“, in: Christian Kaufmann/Philippe Peltier/Markus Schindlbeck (Hg.), Tanz der Ahnen. Kunst vom Sepik in PapuaNeuguinea, München, 2015, S. 30-38.

Quiggin, A. Hingston, A Survey of Primitive Money. The Beginnings of Currency, London, 1949.

Quinn, Terry, From Artefacts to Atoms. The BIPM and the Search for Ultimate Measurement Standards, Oxford, 2012.

Rowland, Nicolas/Passoth, Jan-Hendrik, „Infrastructure and the State in Science and Technology Studies“, in: Social Studies of Science 45, 1 (2015), S. 137-145.

Sarró, Ramon, The Politics of Religious Change on the Upper Guinea Coast. Iconoclasm Done and Undone, Edinburgh, 2009.

Sarton, George/Ware, J. R., ,Were the Ancient Chinese Weights and Measures Related to Musical Instruments?" in: Isis 1, 2 (1947), S. 73. 
Schaffer, Simon, „Metrology, Metrication, and Victorian Values“, in: Bernard Lightman (Hg.), Victorian Science in Context, Chicago, IL, 1997, S. 438-475.

Ders., „Les cérémonies de la mesure. Repenser l'histoire mondiale des sciences“, in: Annales. Histoire, Sciences Sociales, 2 (2015), S. 409-435.

Scharbacher, Gabriele, „Medium Infrastruktur. Trajektorien soziotechnischer Netzwerke in der ANT", in: ZMK, 2 (2013), S. 129-148.

Schemmel, Matthias, Spatial Thinking and External Representation. Towards a Historical Epistemology of Space, Berlin, 2016.

Schmidt, Mario, Wampum und Biber. Fetischgeld im kolonialen Nordamerika. Eine Mauss 'sche Kritik des Gabeparadigmas, Bielefeld, 2014.

Senfft, Arno, „Das Geld der Yaper“, in: Deutsches Kolonialblatt, 12 (1901), S. 870872.

Sheldon, Richard/Randall, Adrian/Charlesworth, Andrew/Walsh, David, „Popular Protest and the Persistence of Customary Corn Measures. Resistance to the Winchester Bushel in the English West, " in: Adrian Randall/Andrew Charlesworth (Hg.), Markets, Market Culture and Popular Protest in Eighteenth-Century Britain and Ireland, Liverpool, 1996, S. 25-45.

Simpson, James, Under the Hammer. Iconoclasm in the Anglo-American Tradition, Oxford, 2010.

Speenemann, Dirk H. R., „Combining Curiosity with Political Skill. The Antiquarian Interests and Cultural Politics of Georg Fritz", in: Micronesian Journal of the Humanities and Social Sciences, 5 (2006), S. 495-504.

Stäheli, Urs, „Infrastrukturen des Kollektiven: alte Medien - neue Kollektive?“ in: ZMK, 2 (2012), S. 99-116.

Stampa, Manuel Carrera, „,The Evolution of Weights and Measures in New Spain“, in: Hispanic American Historical Review, XXXIX (1949), S. 2-24.

Stewart, Pamela J./Strathern, Andrew, „Introduction. Latencies and Realizations in Millennial Practices“, in: Ethnohistory 47, 1 (2000), S. 3-27.

Dies., „Transformations of Monetary Symbols in the Highlands of Papua New Guinea“, in: L'Homme 162 (2002), S. 137-156.

Strathern, Andrew, „The Red Box Money-Cult in Mount Hagen 1968-71. (Part I)“, in: Oceania 50, 2 (1979), S. 88-102.

Ders., „The Red Box Money-Cult in Mount Hagen 1968-71. (Part II)“, in: Oceania 51, 3 (1980), S. 162-175.

Strathern, Marilyn, The Gender of the Gift. Problems with Women and Problems with Society in Melanesia, Berkeley, CA, 1988.

Tal, Eran, „Measurement in Science“, auf: The Stanford Encyclopedia of Philosophy, online unter: http://plato.stanford.edu/archives/sum2015/entries/measurement-science, zuletzt aufgerufen am 09.01.2019.

Turnbull, David, Mapping the World in the Mind. An Investigation of the Unwritten Knowledge of the Micronesian Navigators, Geelong, 1991.

Vec, Miloš, Recht und Normierung in der Industriellen Revolution. Neue Strukturen der Normsetzung in Völkerrecht, staatlicher Gesetzgebung und gesellschaftlicher Selbstnormierung, Frankfurt/M., 2006.

Velkar, Aashish, Markets and Measurements in Nineteenth-Century Britain, Cambridge, 2012.

Vera, Héctor, A peso el kilo. Historia del sistema métrico decimal en México, México, 2007.

Ders., The Social Life of Measures. Metrication in the United States and Mexico, 1789-2004, Ann Arbor, MI, 2012, Dissertation, online unter: https://pqdtopen.pro 
quest.com/doc/924487292.html?FMT=AI, zuletzt abgerufen am 09.01.2019.Ders., „The Social Construction of Units of Measurement: Institutionalization, Legitimation and Maintenance in Metrology", in: Lara Huber/Oliver Schlaudt (Hg.), Standardization in Measurement. Philosophical, Historical and Sociological Issues, London, 2015, S. 173-187.

Vogel, Hans Ulrich, „Weights and Measures in China“, in: Helaine Selin (Hg.), Encyclopaedia of the History of Science, Technology, and Medicine in Non-Western Cultures, Dordrecht, Boston, MA, London, 1997, S. 1010-1012.

Winkler, Hartmut, „Black Box und Blackboxing - Zur Einführung. Vortrag im Graduiertenkolleg ,Automatismen', Universität Paderborn, 14.10.2014“, auf: Open Desk, online unter: http://homepages.uni-paderborn.de/winkler/gk-black.pdf zuletzt aufgerufen am 20.05.2019

Witthöft, Harald, Umrisse einer Historischen Metrologie zum Nutzen der wirtschaftsund sozialgeschichtlichen Forschung. Mass und Gewicht in Stadt und Land Lüneburg, im Hanseraum und im Kurfürstentum/Königreich Hannover vom 13. bis zum 19. Jahrhundert, Göttingen, 1979. 



\author{
STEFAN RIEGER \\ STILLE POST. \\ AUTOMATISMEN DER FORMERZEUGUNG
}

\begin{abstract}
Beim Anschauen regelmäßiger geometrischer Linieen, Schnecken- Kreis- und Wellenlinieen, symmetrischer Gestalten, Zierrathen, Schnörkeln, wo überhaupt Gesetz und Nothwendigkeit herrscht, fühlt sich das Auge unwillkürlich von den Umrissen der Gegenstände fortgezogen, die Bewegungen sind erleichtert, ja halb automatisch, so daß sie auf die angeschauten Gegenstände übertragen werden in denen nun ein eigenes Leben und Bewegen erscheint, was einen eigenthümlichen Eindruck gewährt, und ebenfalls von leisen Spannungsgefühlen am Augapfel begleitet ist. Es wäre der Mühe werth diese Art Augenmusik die uns allenthalben aus der Natur und Kunstwelt entgegenwinkt als einen eigenen Kunstgegenstand zu bearbeiten. Gewiß würde hier für das schaffende Genie eine neue Bahn gebrochen wenn die Ausführungen hinlänglich ins Große getrieben würden. ${ }^{1}$
\end{abstract}

\title{
I. Im Außenbereich bewusster Planung
}

Der Beitrag setzt an einem Schwerpunkt des Graduiertenkollegs Automatismen an und diesen in Szene. Situiert ist er nämlich dort, wo Automatismen als Dynamiken einer Strukturentstehung gefasst werden, die sich jenseits bewusster Planung vollziehen. Solche Prozesse sollen stellvertretend am Fall von Bildern und ihrer zunehmenden Automatisierung in den Blick genommen werden. Die verwendeten Bilder oder genauer noch Bildtypen sind dabei so unterschiedlich wie die Anlässe, an denen diese Verarbeitung jeweils stattfindet. Bei all dieser Streuung gibt es aber dennoch einen gemeinsamen Fluchtpunkt, der die unterschiedlichen Teilaspekte fokussiert. Für die Benennung dieses Fluchtpunkts bietet sich das im Titel genannte Kinderspiel von der Stillen Post an - und zwar als Modell für die Beschreibung von Prozessen der Transformation, das Momente von Intentionalität und Gesteuertheit, kurz, die bewusste Planung und Kontrolle gezielt außer Kraft setzt. An Beispielen aus sprachlicher, gezeichneter, fotografierter und nicht zuletzt filmischer Darstellung soll im Prozess der allmählichen Verfertigung von Bildern mit deren transrationaler Konstruiertheit zugleich das Unterlaufen stabiler Zuordnungen zu Natur und Kultur sichtbar werden. ${ }^{2}$

Johann Purkinje, Beiträge zur Kenntnis des Sehens in subjektiver Hinsicht, Prag, 1819, S. $161 \mathrm{f}$.

2 Das eröffnet regelrechte Schauplätze der Transrationalisierung. Vgl. dazu stellvertretend Willy Hellpach, „Psychotechnik des Unbewußtseins“, in: Walther Moede (Hg.), Industrielle Psychotechnik. Der Mensch. Eignung - Leistung - Charakter - Verhalten, 13. Jahrgang 
Hinter diesen Beispielen steckt ein für die kultur- und medienwissenschaftliche Analyse unabdingbarer Fragenkomplex: Wie stellt man sich vor, dass es so etwas wie Konstanz und Persistenzen überhaupt geben kann, die es erlauben, Transformationen, also Veränderungen jedweder Art, an Bildern als solche überhaupt wahrzunehmen? Die Beobachtung von Veränderung setzt einen wie auch immer gearteten Überlieferungszusammenhang, einen wie auch immer gearteten Übertragungsraum voraus, der die Folie für die vielfältigen Veränderungen bereitstellt. Wie kann man also an individuellen, aber auch an kollektiv organisierten Überlieferungszusammenhängen (etwa in Form von Institutionen, Archiven, Bildsammlungen, Archetypenlehren u. Ä.) solche Folien plausibilisieren? Was für ein Konzept von kulturellem Gedächtnis kann das leisten? Wer ist für die Formüberlieferung zuständig, wer also sind die Agenten und wo sind die Agenturen? Man gerät auf der Suche nach Antworten schnell an sehr großräumige Ansätze, wie etwa dem der Kulturtheorie Aby Warburgs. Neben solchen universalen Theorieangeboten steht eine eher kleinteilig vorgehende Praxis, die sich an der Operationalisierung von Persistenzen und Konstanz in einem Überlieferungsgeschehen versucht, das keiner bewussten Kontrolle unterliegt. Von diesem Außerkraftsetzen intendierter Steuerung durch Prozesse einer technischen Automatisierung handeln die folgenden fünf Fallgeschichten. Sie sollen zeigen, wie und wo das Durchhaltevermögen von Formen überhaupt verhandelt wird, welche Rolle dabei Aspekten zukommt, denen sich die Forschung des Graduiertenkollegs verschrieben hat - Aspekten der Normalisierung, der Standardisierung und nicht zuletzt der Automatisierung. Die fünf Fallgeschichten spielen aufeinanderfolgend in der Sprachwissenschaft, der Kunstgeschichte, der Neurologie, der Wissenschaftsgeschichte und der Neurowissenschaften. Abgeschlossen werden sie durch Warburgs Kulturtheorie. In allen Fällen geht es um eine Kulturtheorie, die wissenschaftliche Argumentationen und Experimentalanordnungen heranzieht, um Persistenz und Variation sowohl beobachten als auch erklären zu können. Für wie plausibel diese der Sache nach im Einzelnen erachtet werden, tut dabei ihrer Verwendung als kulturtheoretischer Begründung keinen Abbruch.

\section{Probanden müssen Linien zeichnen}

Auch die Sprache ist, als Einheit genommen, eine Welt der Gegenstände und so können wir auch ihr gegenüber eine mehr sachlich-begriffliche oder eine mehr physiognomische Fassung vollziehen. Die sachliche Fassung der Sprache in höchstmöglicher Vollendung wird in der theoretischen Philosophie und Wissenschaft erreicht. Hier ist Sprache, ist jedes Wort ,Zeichen' eines Dinges oder Begriffes. Je naiver aber das Spracherlebnis ist, um so weniger trägt Wort und Satz

(1936), Berlin, S. 104-116, sowie Friedrich Giese, Das außerpersönliche Unbewußte. Theoretische Bemerkungen zum intuitiven Denken, Braunschweig, 1924. 
Gesicht und Ausdruck. Menschen, die diese innige Nähe zur Sprache haben, sind auch noch in unserem Bereiche imstande, die Sprache gesichthaft zu erleben. ${ }^{3}$

Bei dem Schreiber dieses Zitats handelt es sich um den Hamburger Psychologen Heinz Werner, einen Kollegen Ernst Cassirers und Gewährsmann für dessen Philosophie der symbolischen Formen. ${ }^{4}$ In Erscheinung trat Werner immer wieder mit Arbeiten zur sogenannten Sprachphysiognomik, ein Ansatz, der, wie es der Titel schon sagt, Sprache und Physiognomik direkt aneinander koppeln und, über die bloße Behauptung hinaus, diese Kopplung vor allem experimentell überprüfen will. ${ }^{5}$ Dieses gesichthafte Erleben von Sprache ist daran interessiert, Formen zu finden, wo man sonst die Beschäftigung mit sprachwissenschaftlich einschlägigen Kategorien wie etwa der Bedeutung erwarten würde. Umsetzung findet das Ganze in aufwendigen Experimentalreihen, in denen Werner ,die sinnlichen Erscheinungsformen sprachlicher Ausdrücke in verschiedenen Sprachen graphisch fixieren“ ließ. ${ }^{6}$ Diese Erscheinungsformen haben, um gleich einem Missverständnis vorzubeugen, nichts mit der wissenschaftlichen Grafologie zu tun, beziehen sie sich doch über die individuelle Handschrift als deren genuinen Gegenstandsbereich hinaus auf sämtliche Formen der schriftlichen Darbietung, damit eben auch auf Drucktypen und Maschinenschrift, also auf die technischen Standards eines Schriftverkehrs und nicht nur auf die Besonderheiten eines individuellen Ausdrucks.

Zur physiognomischen Wortgrammatik

Ebenso "spitz" in deutscher und lateinischer Schreibschrift.

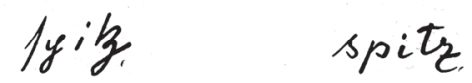

Für eine solche Versuchsreihe stellten sich eine Anzahl Lehrer des plattdeutschen Gebiets zur Verfügung. Ausgehend von onomatopöetischen Ausdrücken, zeichnete der Vl. an eine Tafel eine „lustige" und ,traurige" Linie.
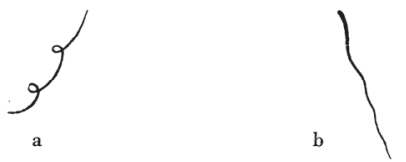

4.1 und 4.2 - Sprachphysiognomische Proben

3 Heinz Werner, „Über Sprachphysiognomik als einer neuen Methode der vergleichenden Sprachbetrachtung“, in: Zeitschrift für Psychologie, 109 (1929), S. 337-363: 338.

4 Vgl. dazu Stefan Rieger, Schall und Rauch. Eine Mediengeschichte der Kurve, Frankfurt/M., 2009.

5 Zur Würdigung aus linguistischer Sicht und unter Berücksichtigung des Auditiven vgl. Stefan Volke, Lautphysiognomik. Grundlagen einer leibphänomenologischen Beschreibung der Lautwahrnehmung, Freiburg, 2007.

6 John Michael Krois, „Cassirer und die Politik der Physiognomik“, in: Claudia Schmölders (Hg.), Der exzentrische Blick. Gespräch über Physiognomik, Berlin, 1996, S. 213-226: 222. 
Eine Arbeit des Psychologen Richard Krauss mit dem Titel „Über graphischen Ausdruck. Eine experimentelle Untersuchung über das Erzeugen und Ausdeuten gegenstandsfreier Linien" von 1930, die sich bei Werner orientiert, informiert über dessen Vorhaben wie folgt?

Auf das Ziel und die Einzelheiten dieser Untersuchung kann hier nicht weiter eingegangen werden, sondern es sei nur berichtet, daß sich eine Tendenz bei einzelnen Vpn. herausstellte, Wortbilder in einem anderen als dem dargebotenen Schriftzug zu erleben, der den Inhalt des Wortes besonders adäquat ausdrückt. So ging es nicht nur mit Eigenschaftswörtern (wie spitz oder rund) sondern auch mit Dingwörtern und sogar mit Materialien. ${ }^{8}$

Bestimmte Wörter, so lautet eine der Grundannahmen, bewahren die Form des Spitzen, des Runden bis hin zur Beibehaltung dinglicher oder materialer Qualitäten. Lässt sich die von Werner behauptete Physiognomik im Experiment nachstellen? Kann man das überindividuell verhandeln? Lässt sich eine objektive, weil inter- oder sogar asubjektive Gültigkeit für dieses Formenrepertoire feststellen? Kurz: Gibt es nachweisbare Mechanismen der Standardisierung und Normalisierung? ${ }^{9}$ Die Überprüfung dieser Fragen führt zu Nachstellungen, wie derjenigen von Richard Krauss, bei denen die Versuchspersonen Reflexion und Intention so weit wie nur immer möglich ausschalten sollen, um sich also völlig zu Medien der Form bzw. der Formwiedererkennung zu machen. Einen Eindruck über die Eigenlogik solcher Experimentalanordnungen vermittelt folgende Selbstreflexion ihres Versuchsleiters:

Natürlich kann ich Ihnen nicht sagen, Sie dürfen nichts denken, sonst würden Sie die ganze Zeit dasitzen und denken: ,O Gott, ich darf nichts denken. 'Aber Sie sollen Ihre Gedanken nicht damit beschäftigen: Wie mache ich eine Linie, die fröhlich aussieht, sondern wenn Sie schon durchaus etwas denken müssen, so soll es in die Richtung gehen:, Wie ist mir zu Mute, wenn ich fröhlich bin, wenn ich einmal ganz lustig bin, ich bin schon ganz fröhlich, ganz vergnügt. ${ }^{10}$

7 Für die Nachstellung hier ist folgende Studie einschlägig, auf die in diesem Zusammenhang allerdings nur angespielt wird: Richard Krauss, „Über graphischen Ausdruck. Eine experimentelle Untersuchung über das Erzeugen und Ausdeuten gegenstandsfreier Linien“, Leipzig, 1930 (Beihefte zur Zeitschrift für angewandte Psychologie; 48).

8 Ebd., S. 1.

9 Heinz Werner, der dazu die Statistik bemüht, gesteht den letztendlich den subjektiven Stellenwert solcher Befunde durchaus ein. Zum Verlust des exakt-wissenschaftlichen Charakters vgl. ders. (1929), Über Sprachphysiognomik, S. 346.

10 Krauss (1930), Über graphischen Ausdruck, S. 5. 

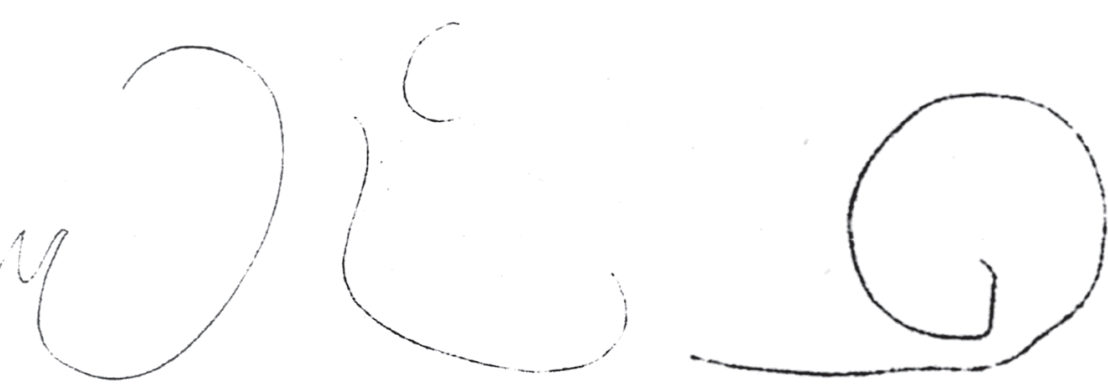

4.3, 4.4 und 4.5 - Sprachphysiognomisch lesbare Linienzüge; von links nach rechts: fröhlich, traurig, angespannter Wille

Auf der Suche nach Erklärungsmodellen für die Bedeutung bestimmter Linienzüge kommt ein Argumentationstopos der Moderne ins Spiel, nämlich die Verschränkung von Ethnologie und Entwicklungspsychologie. ${ }^{11}$ Als einen geradezu mechanischen Erklärungsansatz zieht Krauss das sogenannte Partizipationsgesetz des französischen Ethnologen Lucien Lévy-Bruhl (1857-1939) heran. Es handelt sich um ein Gesetz, das dem Erforscher gegenstandsfreier Linien im Rückgriff auf den Entwicklungspsychologen und Sprachphysiognomen Heinz Werner nicht weniger als die Konstatierung einer physiognomischen Umwelterfassung erlaubt. ${ }^{12}$ Diesem Gesetz zufolge kommt es im primitiven und - so jedenfalls ergänzt Werner den Ansatz von Lévy-Bruhl unter Rekurs auf weitere ethnologische Kompetenz und namentlich mit Blick auf Theodor-Wilhelm Danzel, der mit seiner Ethnologischen Kulturkunde immerhin den Versuch einer universalen Systematik der Kulturwissenschaften unternommen hat - im künstlerischen Denken zu einer Angleichung an die Umwelt, zu einer Wandlung und Verwandlung, die bis zur Behauptung einer regelrechten Wesensidentität reicht. ${ }^{13}$ Dazu zitiert Krauss die Einschätzung Danzels durch Ernst Vatter in dessen Religion und Plastik der Naturvölker von 1916: „Mit feinem Gefühl hat DANZEL erkannt, daß die Partizipation mit dem Außermenschlichen, die Ausweitung des Ichbewußtseins und Ichgefühls auf die Materie, die sozusagen ein Stück des Menschen wird, am ehesten

11 Verwiesen wird auf einschlägige Arbeiten, etwa Felix Krueger, Über Entwicklungspsychologie. Ihre sachliche und geschichtliche Notwendigkeit, Leipzig, 1915 (Arbeiten zur Entwicklungspsychologie, Bd. 1, Heft 1); Heinz Werner, Einführung in die Entwicklungspsychologie, Leipzig, 1926.

12 Dazu Lucien Lévy-Bruhl, Das Denken der Naturvölker, Wien, Leipzig, 1926, sowie in der Übertragung auf die Sprache: Werner (1929), Über Sprachphysiognomik und ders., Grundfragen der Sprachphysiognomik, Leipzig, 1932.

13 Unmittelbar im Kontext der Danzel'schen Erweiterung von Lévy-Bruhls Ansatz, die darin besteht, bloß beschreibende Ergebnisse durch eine Art der Erklärung zu ergänzen, taucht in einer Fußnote Kassner auf: „Es sei darauf hingewiesen, daß bei Kassner für ähnliche Probleme der Begriff der ,Verwandlung“ des ,Sichverwandelns“ zentral ist.“ (Werner [1929], Über Sprachphysiognomik, S. 70.) 
das außerordentlich entwickelte Empfinden des primitiven Künstlers für materialgerechte Formengestaltung zu erklären vermag. ““'14

Um die Sprachphysiognomik zu plausibilisieren, wird ein Schichtenmodell mit unterschiedlichen zeitlichen Tiefen unterstellt. In den genetisch tiefer liegenden Schichten hätte der physiognomische Sinn seinen angestammten Ort, dort verharren die Persistenzen bis zu ihrer Reaktivierung. Zugänge dazu bieten neben Entwicklungspsychologie und Ethnologie die Kunst: ,[Z]wingt doch der wahre Künstler durch sein Werk den Betrachter in jene ursprünglichen Schichten seiner selbst hinabzusteigen und sie in sich lebendig werden zu lassen" ". ${ }^{15}$ Unterstellt wird also ein Mechanismus der Vorzeitigkeit, der die physiognomische Bedeutung absichern und der durch Erfahrungen etwa der Kunst zutage treten soll - als überindividuell gültiges Repertoire.

\section{Naivität der Medien: die Stille Post kopierender Kinder}

Für den zweiten Überlieferungszusammenhang steht ein Kinderspiel Pate, nämlich das der Stillen Post. Eine Stille oder Flüster Post funktioniert nicht nur mit kleinen narrativen Sequenzen, deren Veränderung man ausgehend von einem Original im Prozess der Mitteilung beobachtet, sondern es funktioniert auch mit Bildern als Träger von Formen. ${ }^{16}$ So fand das Prinzip Stille Post Eingang in eine Debatte über kunstgeschichtliche Überlieferungen, wie sie namentlich der Physiologe (und nebenbei auch als Archäologe tätige) Max Verworn (1863-1923) entwickelt hat. Der Anlass ist ein Vortrag Verworns aus dem Jahr 1914 mit dem Titel Ideoplastische Kunst. Um zu klären, wie es zu bestimmten realen Effekten der Formveränderung in lang angelegten Etappen der Malerei ausgehend von der Steinzeit hat kommen können, und noch konkreter, wie es zum Übergang von einer älteren physioplastischen zu einer neueren ideoplastischen Kunst hat kommen können, versucht er, den Prozess malerischer Überlieferung nachzustellen und kurzerhand zu simulieren.

14 Krauss (1930), Über graphischen Ausdruck, S. 70.

15 Werner nach Krauss (1930), Über graphischen Ausdruck, S. 124. Vgl. zum Verhältnis von Ästhetik, Experiment und Linie: Sabine Mainberger, Experiment Linie. Künste und ihre Wissenschaften um 1900, Berlin, 2010 (Kaleidogramme; Bd. 53).

16 Ernst Ketzner, „Zur Analyse der Gestaltperseveration an gezeichneten und gelegten Figuren“, in: Archiv für die gesamte Psychologie 97 (1936), S. 435-449. 

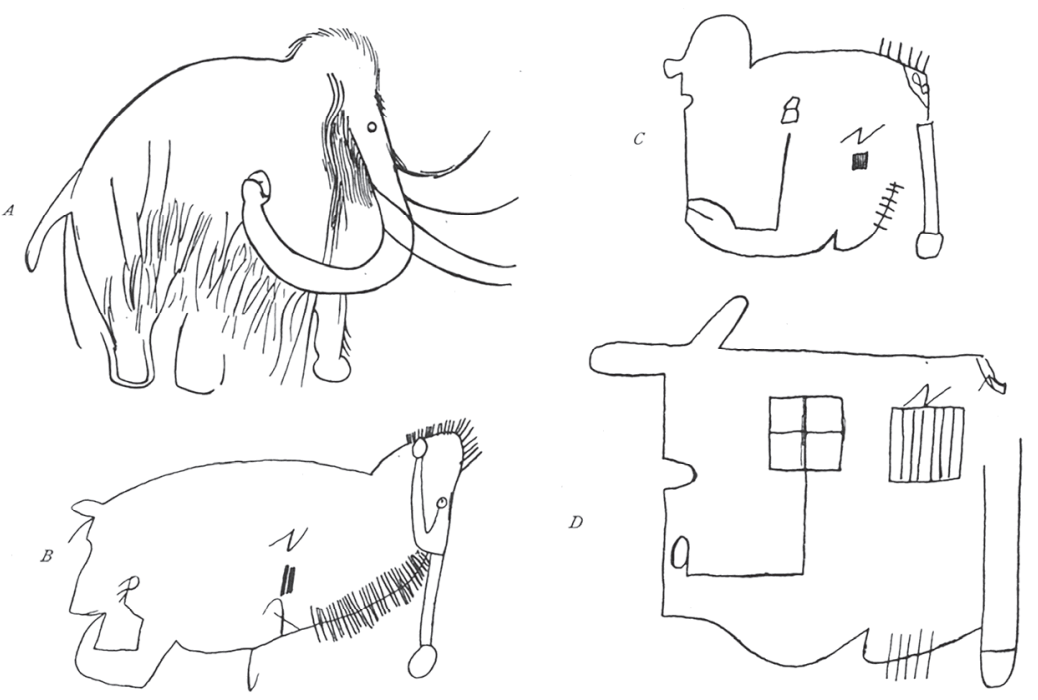

4.6 und 4.7 - Umgestaltende Wirkung fortgesetzten Kopierens.

A: Originalvorlage, B: zehnte Kopie, C: achtzehnte, D: siebenundzwanzigste Kopie

Dazu legt er einer mit Bedacht ausgewählten Gruppe von Schulkindern Zeichnungen mit dem Sujet der Höhlenmalereien vor und fordert die Kinder auf, diese wiederholt und unter Vermeidung des originalen Originals immer weiter abzumalen und so jene Mechanismen sichtbar werden zu lassen, die im Realen der Bildwerdung den einzelnen Agenten ihr Malwerkzeug führte. ${ }^{17}$ Jene gleichermaßen simulierten wie stimulierten Transformationen, die im allmählichen Prozess der unwissentlichen Bildverfertigung bei den Kindern zutage treten, versucht Verworn für eine Theorie kunstwissenschaftlicher Formveränderung und damit für die Beschreibung von Sachverhalten zu bemühen, die einem sehr langen Prozess entstammen. Der Versuch mündet, kurz gesagt und schnell gezeigt, in einen Prozess der zunehmenden Abstraktion, genauer noch, der ornamentalen Umformung figuraler Motive, die Verworn für die nachpaläolithischen Perioden und damit für die ideoplastische Kunst geltend macht. Wie er - performativ stimmig - ausgerechnet an einem Mammut veranschaulicht, werden dabei ,die ornamental wirksamen Elemente des figuralen Gegenstandes“" zunehmend betont. Die visuelle Umsetzung seiner Stillen Post beschreibt Verworn wie folgt:

Die Vorlage bildete eine genaue Kopie des Bildes eines Mammuts aus der Höhle von Combarelles. Die Kopien wurden angefertigt von 9- bis 12-jährigen Kindern in verschiedenen Dörfern. Die erste Kopie diente als Vorlage für die zweite, die

17 Zu den Details vgl. Stefan Rieger, „Ungewollte Abstraktion. Zur Auflösung in der optischen Datenverarbeitung“, in: Claudia Blümle/Armin Schäfer (Hg.), Struktur - Figur - Kontur. Abstraktion in Kunst und Lebenswissenschaften, Zürich, Berlin, 2007, S. 159-171. 
zweite als Vorlage für die dritte usf., so daß jedesmal ein anderes Kind kopieren mußte. Das Resultat war das Beifolgende (Fig. 6) [Abb. 4.6 und 4.7; S. R.]. Aus dem Bilde eines Mammuts, das sehr bald entstellt und unverständlich wurde, war schließlich ein hausähnliches Gebilde geworden. ${ }^{18}$

Dieser Versuch einer Operationalisierung von Persistenzen hat Methode und erschöpft sich keineswegs in der bunten Beliebigkeit solcher Experimente Methode vor allem hinsichtlich der Auswahl der Agenten. Kinder, noch dazu solche, die in entlegenen Bergdörfern aufgewachsen sind, taugen für Verworns Stille Post als Posten im Transformationsgeschehen deswegen so gut, weil sie, ohne es selbst zu wissen und deswegen intentional steuern zu können, ihrerseits Wissen preisgeben bzw. produzieren. ${ }^{19}$ Sie sind somit Agenten einer positiv, weil als Erkenntnisgenerator angesetzten Naivität. „Das moderne Kind“", also dasjenige das den Städten und nicht irgendwelchen Dörfern entstammt, so heißt es bei Verworn über den Regelkreis zwischen Wahrnehmung und kognitiver Verarbeitung und damit zur Motivation seiner Agentenwahl, „zeichnet gar nicht, was es gesehen hat, sondern was es gelernt hat und weiß.“" ${ }^{20}$ Diese Dorfkinder aber stellen in der Stillen Post etwas nach, was man im Großen sucht: nämlich einen Mechanismus für Formbildungsprozesse, ein nicht in Einzelindividuen und in deren Sozialisation begründetes operationales Wissen, ein implizites Wissen über Formen, ein unbewusstes, aber zugleich sicheres Wissen über Form. ${ }^{21}$

18 Max Verworn, Ideoplastische Kunst. Ein Vortrag, Jena, 1914, S. 11.

19 In einem anderen Text heißt es zur Auswahl von Kinderprobanden: „Die Kunst der Kinder ist von Anfang an durch und durch ideoplastisch. Ich habe meine Experimente gerade an Bauernkindern aus entlegenen Gebirgsdörfern angestellt, die mehr Gelegenheit zur Beobachtung der Natur haben und weniger mit Vorstellungsmaterial durch die Erziehung überfüttert werden, weil ich sehen wollte, ob man hier nicht wenigstens in einem früheren Entwicklungsstadium physioplastische Charaktere der Zeichnung finden würde.“ Max Verworn, „Zur Psychologie der primitiven Kunst", in: Naturwissenschaftliche Wochenschrift, Neue Folge, VI. Bd., Nr. 46, 17. November 1907, S. 721-728: 724.

20 Verworn (1914), Ideoplastische Kunst, S. 45.

$21 \mathrm{Zu}$ einer Formalisierung der Auflösung aus Sicht der Informationstheorie vgl. Karl Steinbuch, Automat und Mensch. Auf dem Weg zu einer kybernetischen Anthropologie, 4., neubearb. Aufl., Berlin (u. a.), 1971. 

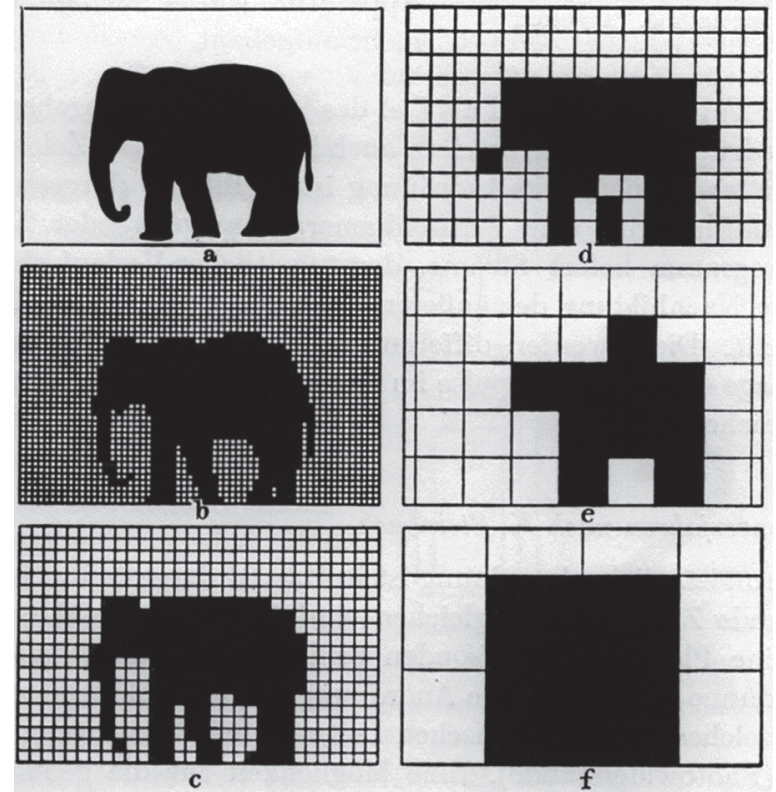

4.8 - Rasterung eines Elefanten

IV. Unwissentlichkeit der Medien: die Geometrie der optischen Treue

Die dritte Fallgeschichte bringt, weil sie im Umfeld der Psychoanalyse spielt, mit deren Tiefensemantik dann doch noch die Archäologie ins Spiel. ${ }^{22}$ Wie lassen sich Formpersistenzen im Unbewussten und damit fernab aller Intention der Beteiligten nachstellen? Um dieses anspruchsvolle Unterfangen geht es dem Wiener Psychiater Otto Pötzl. Sein Text „Experimentell erregte Traumbilder in ihren Beziehungen zum indirekten Sehen" stammt aus dem Weltkriegsjahr 1917 und aus dem psychologischen Laboratorium der neurologischen Station für Kopfschussverletzungen in Wien. Was im Zentrum seiner Mitteilung steht, ist weniger das Trauma von Weltkriegsteilnehmern, als vielmehr der Traum; ein experimenteller Zugriff auf den Traum oder genauer seine experimentelle Modellierung. Und so verlässt Pötzl schon nach zwei Seiten das Verhältnis von Kopfschüssen zur Pathologie der Sehsphäre und wendet sich 70 Seiten lang den experimentell erregten Traumbildern zu. Den Theoriestand der Psychoanalyse von 1917 berücksichtigend, hat das sehr konkrete Folgen auf die Auswahl der Versuchspersonen.

22 Vgl. Michael Rohrwasser/Gisela Steinlechner/Juliane Vogel/Christiane Zintzen (Hg.), Freuds pompejanische Muse. Beiträge zu Wilhelms Jensens Novelle, Gradiva', Wien, 1996. 
Experimentiert wurde im streng unwissentlichen Verfahren. Zur Exposition wurde eine Serie von Diapositiven benützt, die für die Firma Reichert hergestellt worden waren; sie waren der Öffentlichkeit bisher unbekannt geblieben und auch Verf. hat sie erst bei den Versuchen kennengelernt; jedes Bild wurde im allgemeinen nur zu diesem einzigen Versuch verwendet; die Vp. [Versuchspersonen] wurden aus möglichst verschiedenen Kreisen gewählt und es wurde mit jeder, eine einzige ausgenommen, nur ein einziger Versuch gemacht. [...] Im allgemeinen wurden Personen, die sich selbst mit Traumanalysen im Sinne der Freudschen Schule beschäftigten, vermieden, da die Versuche Personen betreffen sollten, die möglichst wenig in die Mechanismen des Traumes eingeweiht sind. ${ }^{23}$

Die technische Umsetzung des Experimentes wird prekär, stellt sie doch an das exponierte Bildmaterial die Anforderung einer vollständigen Ungeläufigkeit für alle Beteiligten. Wie aber gelangt man unter den Bedingungen einer massenmedial eingespielten Bildpolitik an Bilder, die keiner visuellen Geläufigkeit, keiner visuellen Topik entsprechen? Als Bildmaterial wurde eine Serie mit Diapositiven benutzt, die eigens für eine Wiener Firma hergestellt wurde und die bis zum Einsatz ihrer Uraufführung selbst ihrem Versuchsleiter unbekannt blieb. Theoretische Blindheit und visuelle Ungeläufigkeit stellen sicher, dass Pötzls Experimente tatsächlich im streng unwissentlichen Verfahren stattfinden konnten. Pötzl nimmt das Ergebnis der Versuchsreihen vorweg und hält fest, dass von seinen insgesamt zwölf Versuchspersonen neun „eine deutliche Beeinflussung ihrer Traumvisionen durch die tachistoskopische Exposition" 24 zeigten. Um das nachzuweisen, bedarf es der Schrift und so werden im Verlauf des Experiments insgesamt drei unterschiedliche Protokolle und im Anschluss daran Skizzen angefertigt. Um diesen Übergang von der Schrift zum technisch erzeugten Bild zu veranschaulichen, sei eine von Pötzls Versuchsreihen skizziert. Am 19. Februar 1917 blitzt für die Dauer einer Hundertstelsekunde ein Diapositiv auf, das bestimmte Tempelruinen von Theben enthält. Im Traumprotokoll des nächsten Tages gibt die Versuchsperson an, sich nicht an das exponierte Bild erinnern zu können; nach unruhigem Schlaf träumt sie davon, eine bestimmte Person in einem bestimmten Garten im Vorübergehen gesehen zu haben. Pötzl fordert seinen Informanten nun auf, die Situation zu zeichnen:

23 Otto Pötzl, „Experimentell erregte Traumbilder in ihren Beziehungen zum indirekten Sehen“, in: Zeitschrift für die gesamte Neurologie und Psychiatrie 37, (1917), S. 278-349: 283.

24 Ebd. 


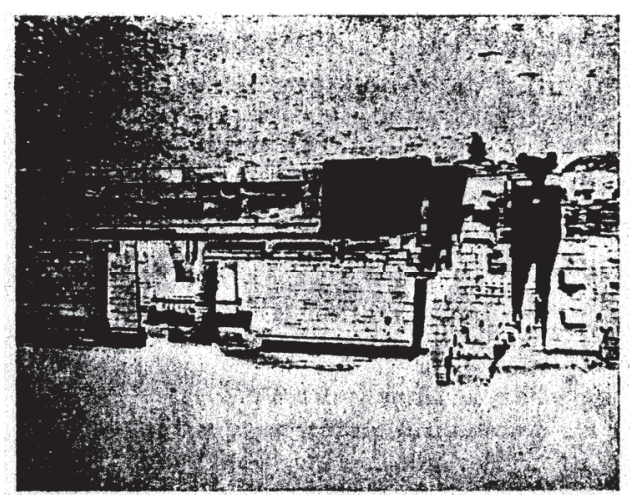

Fig. 1.

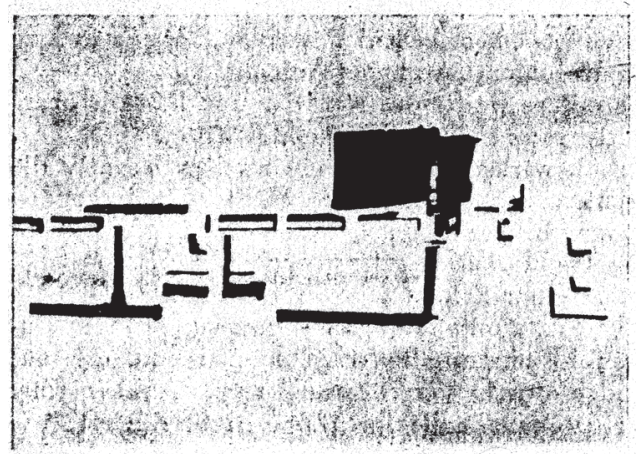

Fig. 2.

\section{9 - Tempelruinen}

[D]ie Zeichnung reproduziert in absoluter Formentreue die lang über das ganze Bild verlaufende Grundmauer der Tempelruine mit der Andeutung ihres Quaderwerks. Nur die schwarze viereckige Fläche des fahnenartigen Schattens, der gesehen worden war (,Buchstabe, oben breit ...') findet sich nicht; sie ist vom Traumbild exkludiert, schon im Wachen entwickelt gewesen; dafür erscheint der Schatten, der einer menschlichen Figur ähnlich ist; dieser war unbemerkt geblieben; jetzt erscheint er [...] verspätet im Traumbild nachgeliefert.

Y., die geträumte Person, ist hoch, schlank, brünett. Y. trägt eine Frisur, die den Eindruck vollendet, daß der Schatten in der Exposition ganz gut der Schatten von Y. auf einer Mauer sein könne. Die Zeichnung [...] reproduziert alle Einzelheiten dieses Schattens in einer Weise, die nur von der Bildfigur, nicht von der Vorstellung oder Silhouette von Y. herstammen kann. Y. ist eine Frau. Sie wird anders dargestellt $[\ldots]^{25}$

Die Tempelruine wird zur Gartenmauer, die Schattengestalt zu einer Person aus dem biographischen Umfeld des Träumers. Das Resultat bestätigt Pötzls Hypothese: Es gibt eine Reihe von Deckungsstellen und Decksituationen, die

25 Ebd., S. 286. 
das Gefüge des Traums ausmachen, die im Traum als Form persistieren. Die Überlagerung von unbewusst Erlebtem und bewusst Aufgenommenem ist „durch eine besondere Konstellation hier eindeutig nachweisbar". Wenn - wie Pötzl schreibt - kongruente geometrische Formen die Deckung vermitteln, liegt es nahe, diesen Vorgang nun seinerseits illustrieren zu wollen. „Die geometrisch-optische Treue vieler Deckungsstellen zwischen Traumbild und Exposition [...] ließ es als verhältnismäßig leicht erscheinen, die Versuche auf rein photographischem Weg zu illustrieren. "“26 Dafür zuständig ist ein Fotograf, der nach den strengen Angaben Pötzls versucht, mittels ausschließlich fotografischer Verfahren, nämlich mit Unter- und Überexposition sowie mit Retusche die Wirkung der tachistoskopisch eingespielten Fotos zu veranschaulichen. Mit dieser Verbundschaltung unterschiedlicher optischer Medien wird das Unbewusste selbst experimentell zugänglich und figurierbar - als persistente Momentaufnahme im Modus des Unwissentlichen.

\section{Körnung und Evolution: Standards für die Bewegungserfassung}

Die vierte Fallgeschichte setzt bei den bewegten Bildern an. Dieses Arrangement soll nicht einer Medienevolution von Schrift, Bild, Foto, Film und Computersimulation das Wort reden, sondern auf ein grundsätzliches Problem hinweisen, das unterschiedliche Teilbereiche durchzieht. Diese Fallgeschichte ist angesiedelt in der Wissenschaftsgeschichte und betrifft die in Medienwissenschaftskreisen berühmte Encyclopaedia Cinematographica. ${ }^{27}$ Unter ihrem Gründungsdirektor Gotthard Wolf hat sich die Encyclopaedia Cinematographica seit 1952 dem Versuch verschrieben, bewegte Bilder enzyklopädisch zu erfassen. Der Hintergrund ist eine großangelegte medienpädagogische Initiative, die auf die Bereitstellung wissenschaftlicher Dokumentationsfilme für Schulen und Universitäten abzielt und zu diesem Behufe ein Archiv bewegter Bilder anlegen will, um Dinge sichtbar zu machen, die man sonst nicht sehen kann: Weil sie zu schnell oder zu langsam verlaufen, etwa Prozesse in der Biologie oder in der Botanik, aber auch in den Bewegungsformen technischer Apparate; um - etwa im Rahmen der Ethnologie - Bewegungsformen zu erhalten, die davon bedroht sind, auszusterben und damit für immer unerfasst zu bleiben. Als Beispiele werden soziale Rituale (Tänze, Initiationsriten) und bestimmte historische Produktionstechniken genannt. Dieses Archiv soll universalen Charakter haben, soll übernational und über mehrere Jahrzehnte an-

26 Ebd., S. 295. Pötzl ist bemüht, die Mathematik stark zu machen und die Deckungsstellen nicht zuletzt über Wahrscheinlichkeiten abzusichern. Zu einer Variation des Grundanliegens vgl. auch Jaromir Lhotsky, Der Film als Experiment und Heilmethode. Mit einem Beitrag ,Vergleichspunkte zwischen Film und Traum'von Univ.-Professor Dr. Otto Pötzl, Wien, 1950.

27 Gotthard Wolf, Der wissenschaftliche Dokumentationsfilm und die Encyclopaedia Cinematographica, München, 1967. 
gelegt sein, wobei es seinem Begründer als ein offenes Projekt ohne ein absehbares Ende gilt - ein gigantisches Unterfangen mit Zügen der Hypertrophie. Als Plattform dient das Institut für wissenschaftlichen Film in Göttingen, hervorgegangen aus der Reichstelle für den Unterrichtsfilm. Dort findet dieses Projekt einer Bewegungsinventarisierung seine Heimstatt, dort werden die Filme archiviert, von dort aus erfolgt die koordinierte Anschaffung entsprechenden Filmmaterials und dort werden auch selbst entsprechende Filme produziert. Damit diese ihren Anspruch einlösen, nämlich Bewegungsformen vor Augen zu halten und somit auch vergleichbar zu machen, müssen sie standardisiert sein. Und dieser Standardisierung ist das ganze Projekt gewidmet. Es geht also in weiten Teilen um die methodisch zentrale Frage, wie solche Filme überhaupt anzufertigen sind und wie sie mit einer ebenfalls standardisierten Begleitpublikation zu versehen sind - so, als ob man der Evidenz des Films dann doch nicht so ganz trauen würde.

\begin{tabular}{|c|c|c|c|c|}
\hline & $\begin{array}{l}\text { Putórius } \\
\text { putorius }\end{array}$ & $\begin{array}{c}\text { Rattus } \\
\text { norvegicus }\end{array}$ & $\begin{array}{c}\text { Mustela } \\
\text { nivalis }\end{array}$ & Tierarten \\
\hline \multicolumn{5}{|l|}{ Lokomotion } \\
\hline \multicolumn{5}{|l|}{ Rivalenkampf } \\
\hline Beuteerwerb & $\begin{array}{l}\text { kleinste } \\
\text { themat. } \\
\text { Einheit. }\end{array}$ & \multicolumn{3}{|c|}{$\begin{array}{l}\text { Horizontal } \\
\text { Vergleich mit Beuteerwerb } \\
\text { bei anderen Tierarten }\end{array}$} \\
\hline \multicolumn{5}{|l|}{ Nahrungsaufnahme } \\
\hline Paarbildung & \multirow{5}{*}{ 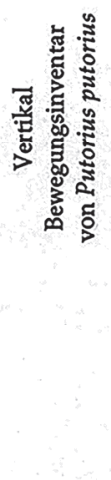 } & & & \\
\hline Kopulation & & & & \\
\hline Geburt & & & & \\
\hline Spiel der Jungtiere & & & & \\
\hline 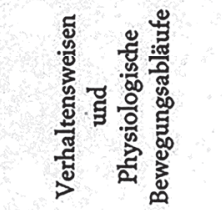 & & & & \\
\hline
\end{tabular}

4.10 - Enzyklopädie-Schema-Zoologie

Im Rahmen dieser technischen und institutionell gesicherten Standardisierung werden Formveränderungen sichtbar. Um etwa zu sehen, ob ein Tier besser an das Wasser angepasst ist als ein anderes, werden die Bewegungsformen beider Tiere standardisiert aufgezeichnet und nebeneinandergehalten. An den jeweiligen Abläufen werden so Momente der Evolutionsgeschichte selbst sichtbar. 
Anhand zweier Filme: $E 4$ über das Wasserschwein (Hydrochoerus capybara) und $E 3$ über den Sumpfbiber (Myocastor coypus) werden aufgrund technischer Gleichheit - dreifache Zeitdehnung, Naheinstellung in einem Aquarium - die Unterschiede deutlich.

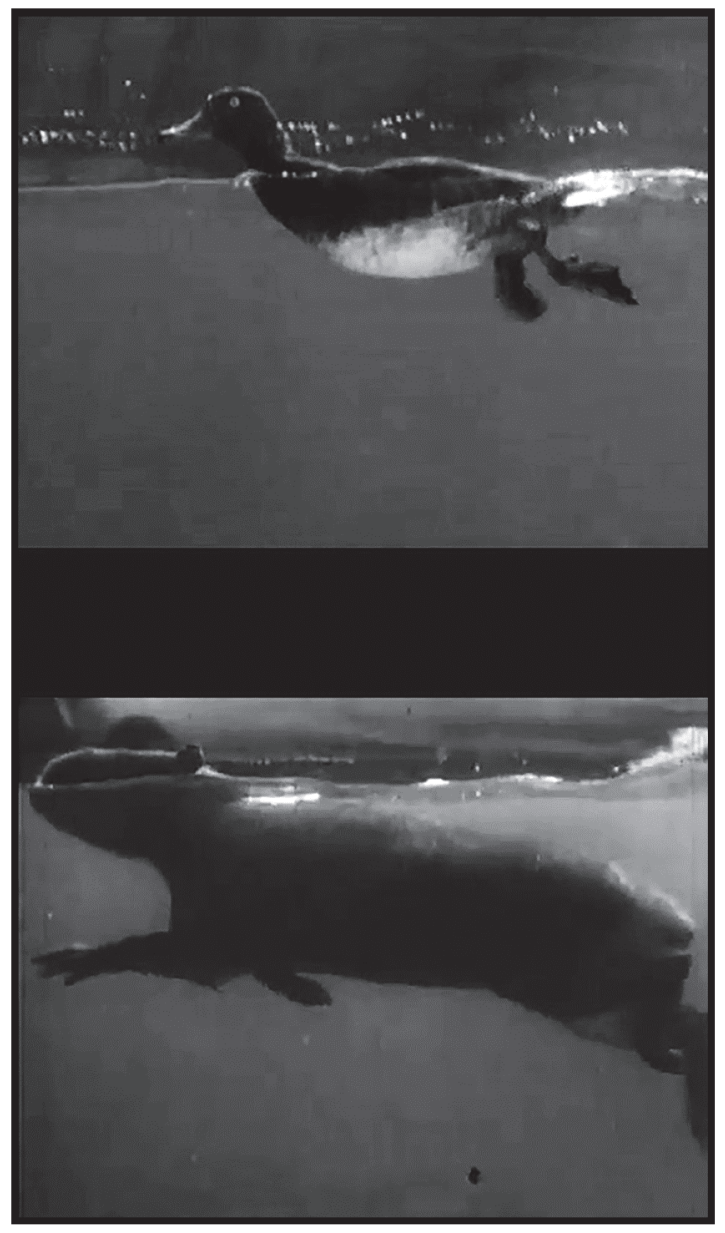

4.11 - Tiere in Bewegung

Wir wollen hier einmal genauer betrachten, wie ein solcher Vergleich mit Hilfe des Filmes durchzuführen ist. Es sei etwa die Aufgabe gestellt, das Schwimmen und Tauchen des Wasserschweins und des Sumpfbibers zu vergleichen. [...] Während das Wasserschwein seine Bewegungen in der Art eines schwimmenden Landtieres vollführt, ist der Sumpfbiber an das Leben im Wasser offensichtlich besser angepaßt. ${ }^{28}$

28 Ebd., S. 21. 
Das länger im Wasser sozialisierte Tier kommt mit diesem Medium besser zurecht als ein vorrangig landbewohnendes Tier, das sich nur gelegentlich ins Wasser verirrt. Was in den Horizontalanordnungen und in den Vertikalanordnungen jeweils sichtbar wird, sind Aspekte evolutionärer Formveränderung unter der Bedingung möglichst weitgehender formaler Konstanz. Und selbstredend gilt das Interesse nicht nur den Bewegungsformen der Tiere: Schwimmen, Schweben, Fliegen, sondern einem Kosmos an Bewegungsweisen, also von Pflanzen, Tieren, Menschen und nicht zuletzt von Maschinen. Diese auf ein Format zu bringen - dem Enzyklopädie-Schema - setzt voraus, dass man aus dem Kontinuum von Bewegungsflüssen Enzyklopädie-Einheiten isoliert. Dieses Finden, dieses Isolieren kleinster thematischer Einheiten und ihre Betitelung ist die Voraussetzung dafür, Bewegungsformen in ihrer Persistenz, aber auch in ihrem Wandel sichtbar zu machen. Das Erfassen von Grundbewegungsvorgängen geht dem Inventar voraus. Auf welche Detailfragen die Macher geraten, wird an einer Begebenheit um die Gangart von Pferden deutlich.

Konrad Lorenz machte in der Anfangszeit der Enzyklopädie, als man sich mit der tierischen Lokomotion beschäftigte, den Vorschlag, bei der Lokomotion des Pferdes die Gangarten auch im Zusammenhang mit der ,Hohen Schule“ aufzunehmen. Er argumentierte damals, daß diese Dressurerfolge nicht erzielt werden könnten, wenn nicht im Tier die Anlage für die entsprechende Bewegungsweise vorhanden wäre. Wir haben damals die ,Hohe Schule“ nicht aufgenommen, aber als zehn Jahre später das Paarungsverhalten von Wildpferden der Dülmener Herde dokumentationsmäßig erfaßt wurde, konnten die Lorenzschen Gedankengänge laufbildmäßig bestätigt werden. Der Hengst zeigte in seinem Verhalten Bewegungsweisen, die auch in der ,Hohen Schule“ vorkommen. ${ }^{29}$

Dieser Befund ist besonders bemerkenswert, verortet oder diskutiert er doch die Frage nach der Stabilität und der Varianz von Formen ausgerechnet an der Schnittstelle von natürlichen und dressierten Bewegungsformen. Was die Encyplopaedia Cinematographica sichtbar macht, und zwar gegen die Intuition ihrer Veranstalter und damit nachträglich, ist die Übergängigkeit zwischen Instinkt und Dressur, zwischen Natur und Kultur. Was sie aber vor allem sichtbar macht, ist die Tatsache, dass hier neben Unwissentlichkeit und Naivität, wie in den Fällen zuvor, wiederum eine neue Option zu den Beobachtungsermöglichungen von Persistenz und Wandel hinzutritt: Erst die Sequenzierung und damit die Kleinteiligkeit der Einheiten ermöglicht die Sichtbarkeit von Persistenzen.

\section{Gehirnkino: Reprojektionen aus der Blackbox}

Natürlich zuständig für diese letzte Episode des Wissens sind, und das ist wenig erstaunlich, die Neurowissenschaften zuständig. Einem Team amerikani-

29 Ebd., S. 46 f. 
scher Wissenschaftler um Jack L. Gallant von der University of California in Berkeley scheint etwas gelungen, was in den populärwissenschaftlich gehaltenen Rezeptionen reflexartig die Rede vom Gedankenlesen in den Raum stellt und damit entsprechenden Spekulationen Vorschub leistet. Florian Rötzer etwa kommentiert diese Forschung für Teleopolis unter dem Titel „Weiterer Erfolg im ,Gedankenlesen“", wobei er typografisch eine Form der Distanzierung unternimmt und auch sonst die futuristischen Erwartungen der Forscher einigermaßen dämpft. ${ }^{30}$ Und Markus Becker fasst für Spiegel Online vielversprechend unter dem Titel „Computer rekonstruiert Filme aus Gedanken“ die Befunde wie folgt zusammen: „Das Experiment ist spektakulär, das Ergebnis gespenstisch: Forscher haben erstmals allein aus der Gehirnaktivität Filme rekonstruiert, die Testpersonen zuvor gesehen hatten. Ist das der Durchbruch zum Gedankenlesen?"“31

Ein Text der Forschergruppe mit dem Titel „Reconstructing Visual Experiences from Brain Activity Evoked by Natural Movies“, veröffentlicht in der Zeitschrift Current Biology im Oktober 2011, gibt über das Verfahren Auskunft. ${ }^{32}$ Die Forscher um den Neurowissenschaftler Gallant weisen darauf hin, dass es ihnen gelungen sei, eine grundlegende Begrenzung in entsprechenden Untersuchungen zu umgehen: Sie könnten mit ihrem Verfahren endlich auch Bewegtbildern Rechnung tragen. Damit unterscheiden sie sich von bisherigen Verfahren auf Grundlage der funktionellen Magnetresonanztomogorafie (fMRT), die auf statische Bilder und auf die Logik ihrer Lokalisation fokussiert waren - allen voran die berühmte Studie von Tom M. Mitchell et al. mit dem Titel „Predicting Human Brain Activity Associated with the Meanings of Nouns" von 2008.33

Auf der Grundlage der funktionellen Kernspintomographie könnten mithilfe neuer algorithmischer Verfahren aus den Aktivitätsmustern der Hirnzellen Rückschlüsse auf den Dateninput gegeben werden, also in einer Art reverse engineering das Gehirn beim Wahrnehmen beobachtet werden. Anders und einfacher, nämlich mit einer Überschrift der Wochenzeitschrift Die Zeit gesagt: Wir sehen, was Du siehst. Spektakulär wird das Ganze dort, wo das exponierte Material - Trailer von Hollywoodfilmen - mit dem aus dem Gehirn

30 Florian Rötzer, „Weiterer Erfolg im ,Gedankenlesen““, auf: Telepolis vom 24.11.2011, online unter: http://www.heise.de/tp/artikel/35/35552/1.html, zuletzt aufgerufen am 03.01.2019.

31 Markus Becker, „Computer rekonstruiert Filme aus Gedanken“, auf: Spiegel online vom 23.09.2011, online unter: http://www.spiegel.de/wissenschaft/mensch/hirnstroeme-computerrekonstruiert-filme-aus-gedanken-a-787867.html, zuletzt aufgerufen am 03.01.2019.

32 Yuval Benjamini/Jack L. Gallant/Thomas Naselaris/Shinji Nishimoto/An T. Vu/Bin Yu, „Reconstructing Visual Experiences from Brain Activity Evoked by Natural Movies“, auf: Current Biology vom 22.09.2011, online unter: https://www.cell.com/currentbiology/fulltext/S0960-9822(11)00937-7, zuletzt aufgerufen am 03.01.2019.

33 Tom M. Mitchell et al., „Predicting Human Brain Activity Associated with the Meanings of Nouns“, in: Science, 320 (2008), S. 1191-1195. Grundlegend zu den Erkenntnismöglichkeiten dieses bildgebenden Verfahrens Nikos K. Logothetis, „What We Can Do and What We Cannot Do with fMRI“, in: Nature, 453 (2008), S. 869-878. 
ausgelesenen und entsprechend aufgearbeiteten Material gegenübergestellt wird.
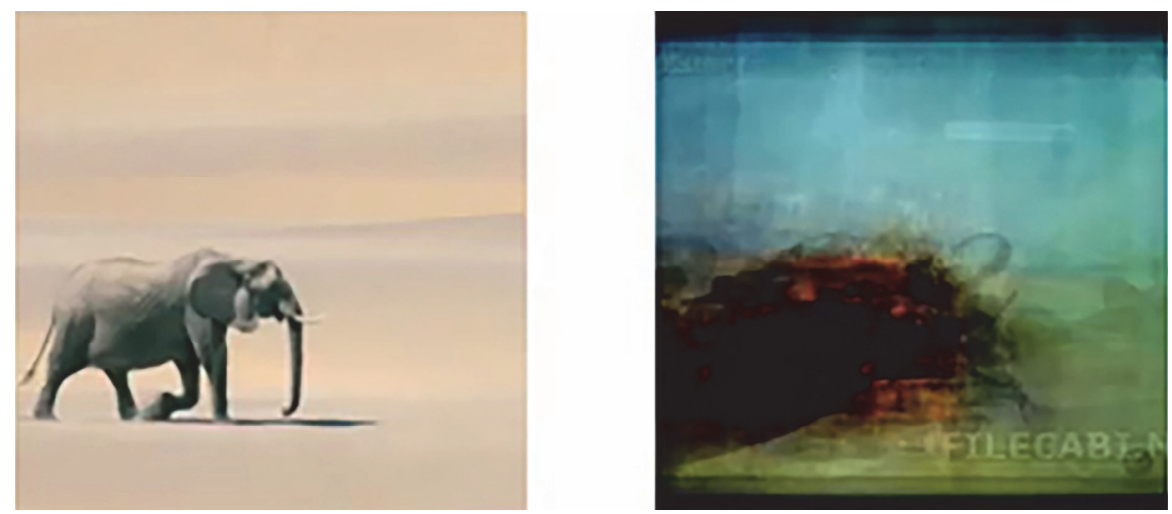

4.12 - Foto und ausgelesenes Gedankenbild

Zwei Dinge sind bemerkenswert: zum einen die direkte Gleichsetzung von Forschungsqualität und Datenverarbeitung, die Gallant in einem fast schon an Friedrich Kittler erinnernden Duktus folgendermaßen auf den Punkt bringt: "Schnellerer Datenzugriff beschleunigt die Forschung, so einfach ist das." ${ }^{\text {"34 }}$ Anlass für diesen Befund, der Gallant als Gewährsmann derart zu Wort kommen lässt, ist eine Fallstudie des Speicherherstellers Thecus, die unter dem Titel „Thecus N5200XXX Case Study by UC Berkeley. Hirnforscher beschleunigen Wissenschaften mit Thecus-Speichergeräten“ ihre Technik nobilitieren. Einer quantitativen Logik ist es vorbehalten, von nicht bewegten Bildern - mit denen sich die Gruppe um Gallant vorher beschäftigt hatte - auf bewegte Bilder überzugehen.

Bemerkenswert ist zum anderen ein Moment der Evidenz, welches die fraglichen Dinge nicht mehr nur nach abstrakten Lokalisationsmustern, sondern im Modus einer direkten Ähnlichkeit sichtbar und auch vergleichbar macht: Im Wortsinne spektakulär an der Geschichte ist, direkt sehen zu können, wie die Körnung als Ausbund eines quantitativen Moments in Qualität umschlägt. So kann ein laufendes Bild des gezeigten Films wiedergegeben und gefragt werden, wie sich das Original zu dem aus den Hirnprozessen abgeleiteten verhält. Die Suche nach der Persistenz gründet in der technischen Möglichkeit von Simultaneität von gesehenem und errechnetem Bild.

34 Thecus N5200XXX Case Study by UC Berkeley, „Hirnforscher beschleunigen Wissenschaften mit Thecus-Speichergeräten“, auf: Thecus vom 21.05.2012, online unter: http://german. thecus.com/media_news_page.php?NEWS_ID=4659, zuletzt aufgerufen am 03.01.2019. 


\section{Warburgs Bildbruch}

Wollte man diese fünf Fälle und ihre Figuren (Ontologie, Naivität, Unwissentlichkeit, Körnung und Simultaneität) typologisieren, so hätte man folgende Befundlage: In der Sprachphysiognomik Werners liegt die Persistenz in der Dingqualität von Schrifttypen, die die Qualitäten der Dinge, die sie bezeichnen, in der Form wiederholen. Bei Verworn und seinen Kinderkopisten führt dagegen eine Persistenzanordnung zum Befund von Varianten, wobei die Persistenz im Versuchsaufbau liegt. Bei Pötzls Experimentalträumern werden die medialen Bedingungen von Persistenzen sichtbar, indem der Traum medial und unwissentlich figuriert wird. Und im Projekt der Encyplopaedia Cinematographica werden Bewegungen medial inszeniert, wobei die feine Körnung des Mediums, die eine Zerlegung in Elementarbewegungen ermöglicht, die Sichtbarkeit der Persistenz erzeugt. Und in der letzten Anordnung scheint gar das Versprechen der Einsichtnahme in die Blackbox auf Grundlage von Ähnlichkeitsrelationen vorzuliegen, die eine Gleichzeitigkeit ermöglichen. In den Wissensgeschichten darüber, wie Ähnlichkeit und wie aus Ähnlichkeit Variation entsteht, verschaffen sich unterschiedliche operative wie argumentative Züge Geltung: Einmal als Befund, der in genetische Tiefenschichten verweist, dann wiederum als Gebot, das Probanden unwissentlich im Zuge ihres unablässigen Kopierens erfüllen sollen, und schließlich als Momentaufnahme eines Unbewussten, das aus einer Geometrie der optischen Treue abgeleitet wird, als Normierung analog aufgezeichneter Bewegungsfolgen in der Standardisierung der Encyplopaedia Cinematographica und schließlich als eine simultan sichtbar gemachte Ähnlichkeitsrelation auf der Grundlage aufwendig betriebener Bildverarbeitung.

Wie gehen die kleinmaschigen Befunde der fünf Fallgeschichten zusammen mit den Erklärungsangeboten der Kulturtheorie? Ein Angebot für das Durchhaltevermögen von Formen liegt den Pathosformeln Aby Warburgs zugrunde. Wie aber ist der Überlieferungsraum angelegt, in dem solche Formen überleben und im Mnemosyne Atlas entsprechend kartografiert werden können? Was ermöglicht Prozesse der Persistenz und Variation und was ermöglicht ihre Beobachtung? Der vollständige Titel von Warburgs Bildatlas ist programmatisch, verspricht er doch eine Bilderreihe zur Untersuchung der Funktion vorgeprägter antiker Ausdruckswerte bei der Darstellung bewegten Lebens in der Kunst der europäischen Renaissance. Umsetzung findet das in den schwarz bespannten Tafeln als Ort der Begegnung unterschiedlicher Bildtypen - vom Tafelbild über Fotografien von Statuen bis hin zu Briefmarken und Werbebildern.

Warburg organisiert die Möglichkeit seines entsprechenden Überlieferungsraums paradox, weil im Modus des Bildbruchs. ${ }^{35} \mathrm{Im}$ Warenlager gängiger

35 Vgl. dazu Stefan Rieger, ,Richard Semon und/oder Aby Warburg: Mneme und/oder Mnemosyne“, in: DVjs, 72 (1998), Sonderheft (Medien des Gedächtnisses), S. 245-263. 
Gedächtniskonzepte - so jedenfalls rekonstruiert es Warburgs Biograf Ernst H. Gombrich - finden sich ganz unterschiedliche Dinge, die Warburg unbeschadet logischer Kohärenzen zusammenfügt: Dynamogramme, Urprägewerke, Energiekonserven, Eindrucksstempel und nicht zuletzt jene mnemischen Wellen und Engramme, die Warburg der seiner Zeit einschlägigen Gedächtnistheorie Richard Semons entnimmt. Die Präferenz für Semon und nicht etwa für den auf den ersten Blick nahe liegenden Ansatz von Carl Gustav Jung mit den Archetypen eines kollektiven Unbewussten begründet sein Biograf Gombrich theoretisch mit einer intellektuellen Tendenz Warburgs und pragmatisch mit einem aktuellen Bücherkauf: „Getreu seiner ,monistischen Tendenz' hielt er sich mehr an Richard Semon, einen begeisterten Anhänger von Hering, dessen Buch über Die Mneme als erhaltendes Princip im Wechsel des organischen Geschehens (2. Aufl., Leipzig, 1908) Warburg 1908 erworben hatte." ${ }^{36}$ Statt auf Subjekte und deren individuelle Merklebensgeschichten setzt Semon eine hochgradige Formalisierung in Szene, deren Schemata veranschaulichen sollen, wie etwa Gedächtnisinhalte aus dem Zustand der Latenz in den der Manifestation gelangen - ohne dazu ein menschliches Unbewusstes als intentional agierenden Merkwart bemühen zu müssen. Stattdessen ist ein physikalischer Automatismus im Gang, der nach den strengen Vorgaben der Reizsummation und einer Mathematik von Schwellwerten verfährt. Dabei gewährt die Hypertrophie des organischen Modells seiner Mneme nicht zuletzt die Annahme einer weitreichenden Verlustfreiheit von Information, die Warburgs Theoriebildung Vorschub leistet.

36 Ernst H. Gombrich, Aby Warburg. Eine intellektuelle Biographie, Frankfurt/M., 1981, S. 326. 

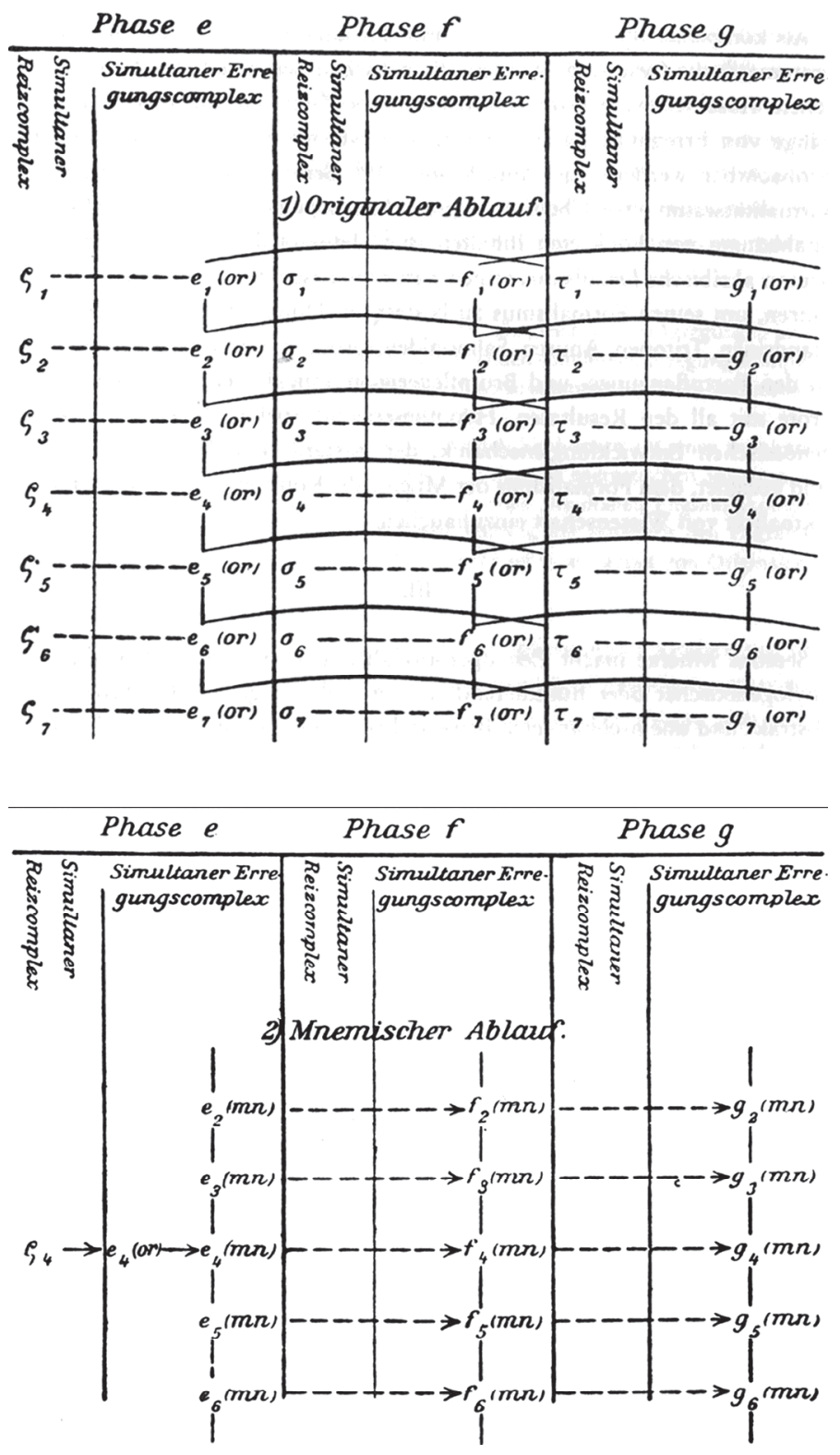

4.13 und 4.14 - Originaler und mnemischer Ablauf

In Warburgs Theoriebildung sind es neben den Engrammen mnemische Wellen, die zum Übertragungsmedium all dessen werden, was in dieser Welt an Formen jeher der Fall war und ist. Im Anschluss an diese Vorgaben wird es theoretisch plausibel, dass ein Kulturweltfunk auf Sendung geht, der nur von 
ausgewählten Empfängern wie Warburg selbst auch tatsächlich empfangen wird. Warburg steht damit in einer Reihe von Typen, die ein implizites Wissen um Formen verbindet: Kinder, Naive, Künstler, Hirnverletzte, Träumer und Warburg als Theoretiker sind unbewusste Medien der Form. Diese doch weitgehend als anomisch geltende Personengruppe dient der Moderne immer wieder als gern benutzte Faszinationsfigur. Doch hier steht etwas anderes im Vordergrund: nicht ihr Zugang zu einer diffusen Alterität, sondern ihre Leistung als Wissensfigur.

Was Warburgs Kulturtheorie leistet, ist der Versuch, Konstanz und Änderung von Formen auf ein übergreifendes Gedächtnismodell zurückzuführen. Bemerkenswert daran ist, dass seine Beleihungen Natur und Kultur gleichermaßen bemühen, so als ob diese Differenz für die Erklärung eines entsprechenden Überlieferungszusammenhangs innerhalb der Kultur keine Rolle zu spielen brauchte. Vielleicht, so steht zu vermuten, ist der Bildbruch, also die Fügung von logisch sich ausschließenden Gedächtnismodellen, die einzige Möglichkeit, die Persistenz von Formen überhaupt zu beschreiben. Um sie allerdings nachzustellen und zu betreiben, ist der Einsatz von technischen Medien ebenso unablässig wie die unterschiedlichen Begründungsfiguren und Experimentalanordnungen aus den Einzelwissenschaften. Der Versuch, für die Geschichte der Form eine Kohärenz herzustellen und zu plausibilisieren, warum es so etwas wie Persistenz überhaupt gibt oder geben können soll, ist ein hypertrophes Unterfangen. Derlei Unbescheidenheit hat ihren Preis: Gelingen kann sie nur im stetigen Rekurs auf wissenschaftliche Begründungsfiguren und in der Performanz von Kohärenz- und Bildbrüchen.

In den fünf Teilgeschichten oder in ihrer Fügung zu einer Kulturtheorie selbst spielen Einzelwissenschaften als Erklärungsangebote eine zentrale Rolle. Der Beschäftigung mit Wissenschaftsgeschichte käme damit ein anderer Stellenwert zu: Fachwissenschaften und das, was sie jeweils treiben, wäre nicht mehr länger Gegenstand für eine Kulturwissenschaft, die auf der Ebene ihrer Sujets alles glaubt umfassen zu können und daher auch der Geschichte von Einzelwissenschaften Raum gewährt. Vielmehr würde die Wissenschaftsgeschichte mit den jeweiligen Argumentationsfiguren und den Versuchsanordnungen ihrer Einzeldisziplinen zu jenem Ort, der eine Kulturtheorie als solche überhaupt erst zu begründen vermag. Oder noch deutlicher gesagt: Weil die Experimentalanordnungen erklären, wie kulturelle Formüberlieferung funktioniert, sind die zuständigen Wissenschaften nicht Beiwerk zur Kulturtheorie, sondern deren Fundament. Die Wissenschaftsgeschichte wäre so die argumentative Operationsbasis einer jeden Theorie von Kultur. ${ }^{37}$

37 Der vorliegende Text über die „Automatismen der Formerzeugung“ ist eine überarbeitete Fassung von: Stefan Rieger, „Persistenz. Eine Kulturtheorie der Form“, in: Ludwig Jäger/ Dietrich Boschung (Hg.), Formkonstanz und Bedeutungswandel, Paderborn, 2014 (Morphomata, Bd. 19), S. 267-292. 


\section{Literatur}

Becker, Markus, „Computer rekonstruiert Filme aus Gedanken“, auf: Spiegel online vom 23.09.2011, online unter: http://www.spiegel.de/wissenschaft/mensch/ hirnstroeme-computer-rekonstruiert-filme-aus-gedanken-a-787867.html, zuletzt aufgerufen am 03.01.2019.

Benjamini, Yuval/Gallant, Jack L./Naselaris, Thomas/Nishimoto, Shinji/Vu, An T./Yu, Bin, „Reconstructing Visual Experiences from Brain Activity Evoked by Natural Movies“, auf: Current Biology vom 22.09.2011, online unter: https://www.cell.com/ current-biology/fulltext/S0960-9822(11)00937-7, zuletzt aufgerufen am 03.01.2019.

Gombrich, Ernst H., Aby Warburg. Eine intellektuelle Biographie, Frankfurt/M., 1981.

Ketzner, Ernst, „Zur Analyse der Gestaltperseveration an gezeichneten und gelegten Figuren“, in: Archiv für die gesamte Psychologie97, (1936), S. 435-449.

Krauss, Richard, „Über graphischen Ausdruck. Eine experimentelle Untersuchung über das Erzeugen und Ausdeuten gegenstandsfreier Linien“, Leipzig, 1930 (Beihefte zur Zeitschrift für angewandte Psychologie; 48).

Krois, John Michael, „Cassirer und die Politik der Physiognomik“, in: Claudia Schmölders (Hg.), Der exzentrische Blick. Gespräch über Physiognomik, Berlin, 1996, S. 213-226.

Krueger, Felix, Über Entwicklungspsychologie. Ihre sachliche und geschichtliche Notwendigkeit, Leipzig, 1915 (Arbeiten zur Entwicklungspsychologie, Bd. 1, Heft 1).

Lévy-Bruhl, Lucien, Das Denken der Naturvölker, Wien, Leipzig, 1926.

Lhotsky, Jaromir, Der Film als Experiment und Heilmethode. Mit einem Beitrag ,Vergleichspunkte zwischen Film und Traum 'von Univ.-Professor Dr. Otto Pötzl, Wien, 1950.

Logothetis, Nikos K., „What We Can Do and What We Cannot Do with fMRI“, in: Nature, 453 (2008), S. 869-878.

Mainberger, Sabine, Experiment Linie. Künste und ihre Wissenschaften um 1900, Berlin, 2010 (Kaleidogramme, Bd. 53).

Mitchell, Tom M., et al., „Predicting Human Brain Activity Associated with the Meanings of Nouns“, in: Science, 320 (2008), S. 1191-1195.

Pötzl, Otto, „Experimentell erregte Traumbilder in ihren Beziehungen zum indirekten Sehen“, in: Zeitschrift für die gesamte Neurologie und Psychiatrie 37, (1917), S. 278349.

Rieger, Stefan, „Ungewollte Abstraktion. Zur Auflösung in der optischen Datenverarbeitung“, in: Claudia Blümle/Armin Schäfer (Hg.), Struktur - Figur - Kontur. Abstraktion in Kunst und Lebenswissenschaften, Zürich, Berlin, 2007, S. 159-171.

Ders., Schall und Rauch. Eine Mediengeschichte der Kurve, Frankfurt/M., 2009.

Ders., „Richard Semon und/oder Aby Warburg: Mneme und/oder Mnemosyne“, in: DVjs, 72 (1998), Sonderheft (Medien des Gedächtnisses), S. 245-263.

Rohrwasser, Michael/Steinlechner, Gisela/Vogel, Juliane/Zintzen, Christiane (Hg.), Freuds pompejanische Muse. Beiträge zu Wilhelms Jensens Novelle ,Gradiva;, Wien, 1996.

Rötzer, Florian, „Weiterer Erfolg im ,Gedankenlesen““, auf: Telepolis vom 24.11.2011, online unter: http://www.heise.de/tp/artikel/35/35552/1.html, zuletzt aufgerufen am 03.01.2019.

Steinbuch, Karl, Automat und Mensch. Auf dem Weg zu einer kybernetischen Anthropologie, 4., neubearb. Aufl., Berlin (u. a.), 1971. 
Thecus N5200XXX Case Study by UC Berkeley, „Hirnforscher beschleunigen Wissenschaften mit Thecus-Speichergeräten“, auf: Thecus vom 21.05.2012, online unter: http://german.thecus.com/media_news_page.php?NEWS_ID=4659, zuletzt aufgerufen am 03.01.2019.

Verworn, Max, Ideoplastische Kunst. Ein Vortrag, Jena, 1914.

Ders., „, „Zur Psychologie der primitiven Kunst“, in: Naturwissenschaftliche Wochenschrift, Neue Folge, VI. Bd., Nr. 46, 17. November 1907, S. 721-728.

Volke, Stefan, Lautphysiognomik. Grundlagen einer leibphänomenologischen Beschreibung der Lautwahrnehmung, Freiburg, 2007.

Werner, Heinz, Einführung in die Entwicklungspsychologie, Leipzig, 1926.

Ders., „Über Sprachphysiognomik als einer neuen Methode der vergleichenden Sprachbetrachtung“", in: Zeitschrift für Psychologie, 109 (1929), S. 337-363.

Ders., Grundfragen der Sprachphysiognomik, Leipzig, 1932.

Wolf, Gotthard, Der wissenschaftliche Dokumentationsfilm und die Encyclopaedia Cinematographica, München, 1967. 



\section{SUSANNE JANY \\ DiE FABRIKATION DES BETRIEBSUNFALLS}

Auf einer Warntafel, die in einer Fabrik in den 1920er Jahren aufgestellt ist, wird auf die Konsequenzen eines Arbeitens an den Maschinen mit offenem Haar und ohne Schutzmütze hingewiesen. ${ }^{1}$ Mittig zwischen zwei Fotografien gesetzt, ist folgender kurzer Text zu lesen: „Wichtige Bekanntmachung. Auf den nebenstehenden beiden Bildern sind die Folgen der Zuwiderhandlung gegen die nachstehende Vorschrift ersichtlich. Der Arbeiterin wurden die losen Haare von der Transmission erfasst und zum Teil mitsamt der Kopfhaut von der Schädeldecke getrennt. Die Haare wachsen nicht mehr nach." In der beigefügten Vorschrift wird den Arbeiterinnen streng untersagt, „die Haare offen oder in herabhängenden Zöpfen zu tragen." Rechts neben dem Text findet sich das frontale Portrait einer Frau. Auf dem Bild links sieht man ihren Hinterkopf, der mit Narben bedeckt ist, die von einer schweren Kopfverletzung zeugen. Dieses drastische Ausstellen eines Einzelfalls mahnt zum Unterlassen gefährlicher Gewohnheiten, die einen spezifischen und häufigen Unfalltypus provozieren: In Produktionsbetrieben des 19. Jahrhunderts wird die aus Dampf- oder Wasserkraft gewonnene Energie mittels offener Riemengetriebe durch die Werkhallen hindurch auf die Arbeitsmaschinen übertragen. Geraten die Arbeiter_innen mit Haaren, Kleidung oder Körperteilen zwischen Teile der Anlage, hat dies schwerwiegende Verletzungen zur Folge, die nicht selten zum Tod der Verunfallten führen. ${ }^{2}$ Betriebsunfälle wie diese gehören in den Fabriken der Jahrhundertwende zum Alltag. Sie geschehen mit einer Regelmäßigkeit und Vorhersehbarkeit, die der Routine der Arbeitsabläufe kaum nachstehen. Gerade deswegen lassen sich Arbeitsunfälle nicht als singuläre Unglücksfälle, katastrophale Ausnahmezustände oder fatale Einbrüche in ein anderweitig funktionierendes System bestimmen. ${ }^{3}$ Als Betriebsunfälle sind sie nicht die Kehrseite des Betriebs, sondern ihm wesentlich. Entsprechend möchte ich sie im Folgenden nicht in Kategorien des Dysfunktionalen, sondern aus

1 Die Warntafel ist abgedruckt in: Friedrich Syrup (Hg.), Handbuch des Arbeiterschutzes und der Betriebssicherheit, Berlin, 1927, S. 547.

2 Vgl. Sophie Kritzler, Der Betriebs-Unfall der Fabrikarbeiterin (mit Untersuchungen in der Textil-, Nahrungsmittel und Chemischen Industrie), Chemnitz, 1933, S. 57; Jamie L. Bronstein, Caught in the Machinery: Workplace Accidents and Injured Workers in Nineteenth-Century Britain, Stanford, CA, 2008, S. 16.

3 „Wie es die englische Homonymie accident nahelegt", so Nicolas Pethes, ,ist ein Unfall zunächst nichts anderes als ein Zufall, d. h. ein kontingentes und nicht planbares Ereignis, das durch eine spezifische Abweichung vom Erwarteten, Regelhaften oder Normalen auffällt.“ Nicolas Pethes, „Accidental Experiments“, in: Christian Kassung (Hg.), Die Unordnung der Dinge. Eine Wissens- und Mediengeschichte des Unfalls, Bielefeld, 2009, S. 381-398: 385. 
ihrem betrieblichen Funktionieren heraus beschreiben. ${ }^{4}$ Paul Virilio hat auf den Zusammenhang zwischen der Serialisierung als industriellem Prinzip und der Serialität des industriellen Unfalls aufmerksam gemacht. ${ }^{5}$ Ich werde zeigen, unter welchen Umständen im letzten Drittel des 19. Jahrhunderts der Betriebsunfall neben anderen Unfalltypen zur Erscheinung kommt. ${ }^{6}$ Im Unterschied zum technischen Unfall, der seine Ursprungsszene in der Dampfkesselexplosion hat, oder zum Verkehrsunfall von Schiffen, Eisenbahnen oder Automobilen liegt das Spezifische des Betriebsunfalls darin, dass er nicht allein auf technische Fehler, menschliches Versagen oder eine Verkettung unglücklicher Umstände zurückzuführen ist. ${ }^{7}$ Er resultiert vielmehr aus einem betrieblichen Komplex, der sich aus Arbeitsabläufen, Maschinen, Menschen und Architekturen zusammensetzt. Mit der Normalisierung industrieller Arbeit in der europäischen Hochindustrialisierung geht die Normalisierung von Arbeitsunfällen einher. ${ }^{8}$ In dieser Perspektive rücken die infrastrukturellen Voraussetzungen des Unfalls in den Vordergrund, die zu einer gewissen Stabilisierung betrieblicher Unfallszenen um 1900 führen. Zum unerwünschten Zwischenfall, zur Störung oder zum Unglück wird der Arbeitsunfall schließlich nicht auf struktureller Basis, sondern erst durch die Produktion einer symbolischen Differenz zum Normalbetrieb, die, so die These, seit den 1880er Jahren durch Warnhinweise, Verhaltensvorschriften, Sicherheitsvorkehrungen und Unfallversicherungen umgesetzt wird. Diese Maßnahmen führen den Unfall als neuartigen Ereignistypus ein, um ihn als Realität in den Betrieben um 1900 möglichst zu eliminieren.

1.

Die Gefahren für die Arbeiter_innen in industriellen Produktionsbetrieben sind derart eng mit den Anlagen und ihren betrieblichen Abläufen verbunden, dass gelegentlich von der „Gefährlichkeit der Betriebe an sich“ gesprochen

4 Vgl. Perrows Darstellung von Unfällen in technischen Systemen: Charles Perrow, Normale Katastrophen. Die unvermeidbaren Risiken der Großtechnik, Frankfurt/M., 1988.

5 Vgl. Paul Virilio, „Der integrale Unfall“, in: Kassung (2009), Die Unordnung der Dinge, S. 7-8.

6 Zum Unfall aus kulturwissenschaftlicher Perspektive: Kassung (2009), Die Unordnung der Dinge; Lars Koch/Christer Petersen/Joseph Vogl (Hg.), Zeitschrift für Kulturwissenschaften: Störfälle, Bielefeld, 2011.

7 Zu diesen Faktoren: Eva Horn, „Die Verkettung unglücklicher Umstände. Über unwahrscheinliche Unfälle“, in: Stefan Rieger/Manfred Schneider (Hg.), Selbstläufer/Leerläufer. Regelungen und ihr Imaginäres im 20. Jahrhundert, Zürich, 2012, S. 199-217.

8 Der Begriff der Normalisierung zur Jahrhundertwende, darauf weist Jürgen Link hin, kommt dem nahe, was heute Standardisierung heißt. Vgl. Jürgen Link, „,Normativ“ oder ,Normal‘? Diskursgeschichtliches zur Sonderstellung der Industrienorm im Normalismus, mit einem Blick auf Walter Cannon“, in: Werner Sohn/Herbert Mehrtens (Hg.), Normalität und Abweichung. Studien zur Theorie und Geschichte der Normalisierungsgesellschaft, Wiesbaden, 1999, S. 31-34. 
wird. ${ }^{9}$ Besonders häufig und folgenschwer treten Betriebsunfälle im Minenwesen, im Eisenbahnbetrieb und in der Metallverarbeitung auf. Im Jahresbericht des Hamburgischen Gewerbeaufsichtsamtes findet sich folgender Bericht:

In mehreren Fällen entstanden wieder schwere oder tödliche Quetschungen dadurch, daß Arbeiter zwischen feste Gebäudeteile und den fahrenden Kran oder die beförderte Last gerieten; auch schwere Unfälle durch ungenügende Befestigung und den hierdurch herbeigeführten Absturz der Last waren wieder zu beklagen. - In einem Kohlenbunkerungsbetrieb wurden weibliche Kontorangestellte mit dem Aufschreiben der im Kranbetrieb beförderten Kohlenmengen beschäftigt; als hierbei eine Kranschreiberin ihren Arbeitsplatz im Führerstand des Krans auf unvorschriftsmäßigem Wege zu erreichen suchte, geriet sie in das Getriebe und wurde tödlich verletzt[.] ${ }^{10}$

Gefährdungen gehen auch in Schmieden, Bergwerken, Spinnereien, Brauereien, Holz- und Metallwerkstätten, Gießereien und Schlachthöfen von ungesicherten Plattformen aus, von rotierenden Maschinenteilen, sich bewegenden Kränen und herabfallenden Lasten. Unfälle geschehen, wenn Arbeiter_innen bei der Reinigung in laufende Maschinen fassen, wenn ihre Kleidung von Transmissionen erfasst wird oder wenn sie versehentlich auf Schienen geraten und von Förderwagen überrollt werden. Ferner zählen zu den Unfallursachen Nachlässigkeiten, Regelverstöße oder gefährliche Angewohnheiten. Die Gleichförmigkeit von Routinearbeiten birgt ebenso Unfallpotenzial wie Zeitdruck durch enge Arbeitsvorgaben. ${ }^{11}$ Der Sozialhistoriker Klaus Weinhauer hat die Arbeitsbedingungen von Arbeitern und Arbeiterinnen im Hamburger Hafen zur Jahrhundertwende rekonstruiert und festgestellt, dass allein technische Vorkehrungen zur Gefahrenkontrolle nicht ausreichten: „Was nützen die bestüberprüften Seile und Ketten, wenn [die Arbeiter] in Winden oder Kränen arbeiteten, mit deren Hilfe eine möglichst rasche Schiffsabfertigung erreicht werden sollte, und die Arbeiter kaum genügend Zeit hatten, die Hieven fachgerecht zusammenzustellen." ${ }^{\prime 2}$ Die konkreten Unfallorte sind diejenigen Stellen, an denen bewegliche und unbewegliche Elemente, Maschinenteile und Architektonisches aufeinandertreffen. Entsprechend entstehen Gefährdungen

9 Georg Bitta, Die Betriebsunfälle in der Eisen- und Stahlindustrie von Posen, Mittel- und Niederschlesien in den Jahren 1910-1920, Breslau, 1925, S. 18.

10 Rasch, Jahresbericht des Hamburgischen Gewerbeaufsichtsamts über das Jahr 1922. Sonderabdruck aus dem vom Reichsarbeitsministerium herausgegebenen Jahresberichten der Gewerbeaufsichtsbeamten, Hamburg, 1923, S. 37.

11 Entsprechend wurde ein Zusammenhang zwischen den Maßnahmen der Rationalisierung zu Beginn des 20. Jahrhunderts - höhere Taktung der Betriebsprozesse, engere Stellung der Maschinen, Reduktion der Arbeitsschritte und daraus resultierende Monotonie - und der (weiteren) Zunahme an Betriebsunfällen festgestellt (vgl. Kritzler (1933), Der Betriebs-Unfall der Fabrikarbeiterin, S. 54). Evident wird dies jedoch bereits im 19. Jahrhundert.

12 Klaus Weinhauer, „Unfallentwicklung und Arbeitsprozeß im Hamburger Hafen 1896/971936: Ein Beitrag zu vernachlässigten Perspektiven der Arbeiter(innen)geschichte“, in: Karl Lauschke/Thomas Welskopp (Hg.), Mikropolitik im Unternehmen. Arbeitsbeziehungen und Machtstrukturen in industriellen Großbetrieben des 20. Jahrhunderts, Essen, 1994, S. 107122: 119 . 
auch, wenn aufgrund enger Raumverhältnisse ein Ausweichen eingeschränkt oder unmöglich wird. ${ }^{13}$ Das Problem des Arbeitsunfalls ist so kein ausschließlich maschinelles, sondern in gleichem Maße ein architektonisches. Festzustellen, dass die Arbeiter_innen lediglich an Maschinen verunglücken, greift also vor dem Hintergrund des hier Gesagten in vielerlei Hinsicht zu kurz. ${ }^{14}$ Denn der industrialisierte Betrieb stellt sich als Dispositiv aus Arbeitsoperationen, maschinellen Einrichtungen, architektonischen Elementen, Raumdispositionen, menschlichen Akteuren, Verkehrsmitteln, betriebswirtschaftlichen Vorgaben, Betriebsabläufen und Zeitplänen zusammen. All diese Elemente sind in ihrem Zusammenspiel daran beteiligt, dass die Fabrik zum gefährlichen Ort werden kann. Insofern wäre auch Roger Cooters und Bill Luckins Beobachtung weiter zu präzisieren. Die Historiker schreiben:

It is important to recall that accidents became normalized and legitimated in the nineteenth century in synchronization with the extension of automatically driven machinery. This was a process which went hand in hand with claims that the sites where mishaps would most likely to occur were inherently predictable and manipulable. ${ }^{15}$

Was Cooter und Luckin hier als ,machinery“ bezeichnen, sind also nicht nur die technischen Anlagen der Fabrik, sondern ebenso die infrastrukturellen Voraussetzungen, die in ihrem Dispositivcharakter den Betrieb als solchen ausmachen.

Um 1880 entdecken Architekten und Bauingenieure den Zusammenhang zwischen funktionalen Architekturen und ihren betrieblichen Abläufen und machen dieses Bedingungsgefüge für die Gestaltung der Gebäude produktiv. Zweckbauten geben Arbeitsprozessen eine Form und erhalten durch sie zugleich ihre architektonische Gestalt. Viele der hier erwähnten Betriebe, darunter Produktionsanlagen, mechanisierte Wäschereien, industrielle Schlachthäuser oder Bahnhöfe, stellen im 19. Jahrhundert neuartige Bauaufgaben dar. Folglich sehen sich die Baupraktiker und Planer mit der Herausforderung konfrontiert, diese Bauten ihrem Betrieb entsprechend zu entwerfen. Verhandelt wird dies über den Diskurs der ,zweckmäßigen Anlage“.16 So heißt es im Handbuch der Architektur über landwirtschaftliche Betriebe von 1884: „Zur Zweckmäßigkeit der Wirthschaftsgebäude gehört eine der Benutzung entspre-

13 Vgl. John Calder, The Prevention of Factory Accidents: A Practical Guide to the Law on the Safe-Guarding, Safe-Working, and Safe-Construction of Factory Machinery, Plant and Premises, London, New York, NY, 1899, S. 236.

14 Ähnlich sieht dies auch François Ewald, wenn er schreibt, es sei ein Trugschluss anzunehmen, die Arbeitsunfälle des 19. Jahrhunderts würden durch Maschinen verursacht, vgl. François Ewald, Der Vorsorgestaat, Frankfurt/M., 1993, S. 17.

15 Roger Cooter/Bill Luckin, „Accidents in History: An Introduction“, in: Roger Cooter (Hg.), Accidents in History: Injuries, Fatalities and Social Relations, Amsterdam, 1997, S. 1-16: 5.

16 Um ein Beispiel unter vielen zu nennen: Julius Koch, „Mittheilungen über Fabriks-Anlagen (Vortrag, gehalten in der Fachgruppe für Architektur und Hochbau und der Maschinen-Ingenieure, am 29. März 1882“, in: Zeitschrift des österreichischen Ingenieur- und ArchitektenVereins, 34 (1882), S. 74-81: 74. 
chende Größe und Stellung zu einander, so wie eine solche innere Einrichtung derselben, welche der Arbeitsförderung nach Möglichkeit Vorschub leistet".${ }^{17}$ Ziel ist die bauliche Umsetzung der Betriebe, so dass sie über ihre architektonische Disposition Arbeitsprozesse auf ideale, d. h. wirtschaftliche Weise ablaufen lassen. Verarbeitungen, Verteilungen oder Montagen sollen, so die Vorstellung der Verantwortlichen, mit möglichst geringem Aufwand an Kosten, Personal, Material und Zeit umgesetzt werden. Letztlich geht es darum, Betriebsprozesse mit architektonischen Mitteln zu strukturieren und als reibungslose Abläufe zu realisieren. Für dieses neuartige architektonische Konzept habe ich an anderer Stelle den Begriff „Prozessarchitekturen“ vorgeschlagen. ${ }^{18}$ Das zugrundeliegende Wissen über die entsprechenden Arbeitsprozesse, über ihre Ablauflogiken sowie über ihre zeitlichen, räumlichen, technischen und personellen Voraussetzungen wird zeitgenössisch in Ingenieur- und Architekturhandbüchern, Zeitschriftenaufsätzen und Monografien diskutiert und vermittelt. Das Konzept der Prozessarchitekturen impliziert dabei ein infrastrukturelles Dispositiv, dessen einzelne betriebliche Elemente in den Publikationen ausführlich beleuchtet werden. Die Autoren beabsichtigen, verallgemeinerbare bauliche Richtlinien zu entwickeln, die auf unterschiedliche Kontexte übertragbar sind. Auf der Basis der Texte und Zeichnungen, der entwickelten Raumprogramme, Idealanordnungen und Mustergrundrisse können konkrete Gebäude umgesetzt werden. Derart in eine räumliche Ordnung überführt, werden die Anlagen architektonisch auf Dauer gestellt. Diese Normalisierung von Betrieb im ausgehenden 19. Jahrhundert korrespondiert mit der zeitgleichen Normalisierung von Unglücksfällen - die Zwangsläufigkeit architektonisch strukturierter Betriebsabläufe geht mit zwangsläufigen Unfällen einher. Das Schiff zu erfinden, heißt, so Virilio in einem Gespräch mit Sylvère Lotringer, dessen potenziellen Untergang zu erfinden; die Innovation des Zuges bringt die Entgleisung mit sich; diejenige des Flugzeugs den Absturz. ${ }^{19}$ Industrielle Anlagen als Prozessarchitekturen durchzubilden, hieße dann, den Betriebsunfall zu fabrizieren.

17 Friedrich Engel/Eduard Schmitt/Georg Osthoff/Albert Geul, Handbuch der Architektur, Vierter Teil, 3. Halbband: Landwirthschaftliche Gebäude und verwandte Anlagen. Ställe für Arbeits-, Zucht- und Luxuspferde; Wagen-Remisen. Gestüte und Marstall-Gebäude. Rindvieh-, Schaf-, Schweine- und Federviehställe. Feimen, offene Getreideschuppen und Scheunen. Magazine, Vorraths- und Handelsspeicher für Getreide. Größere landwirthschaftliche Gebäude-Complexe. Schlachthöfe und Viehmärkte. Markthallen und Marktplätze. Brauereien, Mälzereien und Brunnereien, 1. Aufl., Darmstadt, 1884, S. 3.

18 Susanne Jany, Prozessarchitekturen: Medien der Betriebsorganisation (1880-1936), Konstanz, 2019.

19 Vgl. Sylvère Lotringer/Paul Virilio, The Accident of Art, Cambridge, MA, London, 2005, S. 88. 
2.

Prozessarchitektonisch organisierte Betriebe entwickeln spezifische Unfallpotenziale, die sich einerseits aus dem Betrieb der Anlagen, andererseits aus ihrer raumgreifenden und offenen Struktur ergeben. Über den Eisenbahnunfall schreibt der Historiker Ernst Krafft in den 1920er Jahren: „Das eigentliche Problem bei der Schöpfung der Eisenbahn, so merkwürdig uns das heute auch klingen mag, lag nicht in der Lokomotive, sondern im Schienenstrang. " 20 Dass die Schiene - im Sinne der Maschinentheorie Franz Reuleaux'21 - Teil des Eisenbahnsystems ist, macht vor allem der Unfall deutlich. Denn die gravierenden Verletzungen, die Betroffene von Eisenbahnunfällen erleiden, ereignen sich genau an jenem gefährlichen Punkt, an dem die Räder der tonnenschweren Eisenbahn auf die Schienen treffen und dort, falls etwas zwischen sie gerät, ihre, wie es heißt, zermalmende, zerstückelnde und zerreißende Kraft entfalten. ${ }^{22}$,Dampfkraftwagen und Schienenstrang gehören zusammen, erst aus der Ehe beider konnte das länderverbindende Verkehrsmittel des 19. Jahrhunderts werden“"23 - und der Eisenbahnbetrieb sein spezifisches Unfallpotenzial entwickeln. Denn viel häufiger als katastrophale Entgleisungen oder Zusammenstöße stellen sich Bahnunfälle als Betriebsunfälle dar ${ }^{24}$, etwa bei alltäglichen Bau- und Rangierarbeiten oder bei Arbeitsroutinen im Bahnhofsbereich, wie ein willkürlich herausgegriffenes Beispiel aus dem Jahr 1916 zeigt:

Um bei dem von Erkner nach Charlottenburg verkehrenden Güterzug 7716 Postsachen ein- und auszuladen, wurde mit dem Postkarren regelmäßig das erste Gleis des Bahnhofs Friedrichshagen überquert. Am 7. Dezember 1916 kam dieser Zug gegen 8 Uhr abends verspätet an. Die vier mit der Aufgabe beauftragten Postbeamten (3 männliche und 1 weibliche) wollten diesen Weg gerade in dem Augenblick machen, als auf dem Gleis der D-Zug 38 durchfuhr. Sie wurden alle 4 überfahren und getötet; der Postkarren zertrümmert. ${ }^{25}$

Stellt sich das Unfallereignis für die Geschädigten als fatale oder gar letale Störung vorgesehener Abläufe dar, zeigt sich die maschinell-architektonische

20 Ernst Krafft, 100 Jahre Eisenbahnunfall, Berlin, 1925, S. 9.

21 Vgl. Franz Reuleaux, Theoretische Kinematik. Grundzüge einer Theorie des Maschinenwesens, Braunschweig, 1875, S. 164.

22 Vgl. Ludwig Stockert, Eisenbahnunfälle (Neue Folge): Ein weiterer Beitrag zur Eisenbahnbetriebslehre, Band 1: Chronik einiger in den Jahren 1913-1918 bekanntgewordenen grösseren Eisenbahnunfälle, Berlin, Wien, 1920, S. 65 f.

$23 \mathrm{Krafft}$ (1925), 100 Jahre Eisenbahnunfall, S. 12.

24 So heißt es 1886: „Als besonders dringlich war schon bei den Verhandlungen des Reichstages die Ausdehnung der gesetzlichen Unfallfürsorge auf die in den Transportbetrieben beschäftigten Arbeiter bezeichnet worden. Diese Betriebe sind in der That erfahrungsgemäß besonders gefährlich. Unter ihnen nimmt der Betrieb der Eisenbahnen eine hervorragende Stellung ein.“ Carl Doehl, Die Unfall-Versicherung der gewerblichen, Fabrik- und Betriebs-Arbeiter nach den Materialien des Gesetzes vom 6. Juli 1884, den erlassenen Ausdehnungs- und Ergänzungs-Gesetzen, den ergangenen Ausführungsverordnungen und den Beschlüssen, Entscheidungen und Mittheilungen des Reichs-Versicherungsamtes, Leipzig, 1886, S. IX.

25 Stockert (1920), Eisenbahnunfälle (Neue Folge), S. 66. 
Anlage den Verunfallten ebenso wie dem Unfall gegenüber weitgehend indifferent. Der Unfall bringt meist weder Maschinen noch automatisierte Arbeitsprozesse zum Stillstand - geschweige denn D-Züge. Selbst wenn sich schwere Unfälle ereignen, arbeiten die Anlagen oft weiter und müssen manuell gestoppt werden, um den Verunglückten zu Hilfe kommen zu können. Erst diese nachträgliche Unterbrechung des Betriebs inauguriert den Unfall als Ereignis. Aus struktureller Perspektive kommt ihm zunächst eine eigentümliche NichtEreignishaftigkeit zu; der Betrieb führt zum Betriebsunfall und bleibt doch von ihm nahezu unberührt.

Treten betriebliche Anlagen derart als Unfallmaschinen auf und nehmen sie dabei architektonische Ausmaße $a^{26}$, kann der Mensch in sie hinein geraten: d. h. auf die Gleise der Bahnhöfe, zwischen rotierende Räder oder in das Riemengetriebe der Transmissionsanlage. Charlie Chaplin hat dazu in seinem Film Modern Times die passenden Bilder gefunden"27: Die Hauptfigur des Fabrikarbeiters fällt aufgrund akuter Überforderung auf das Fließband und gerät zwischen die übergroßen Zahnräder der Fabrikmaschinerie. Erst wenn das Subjekt derart in der Anlage verunglücken kann, tut sich eine Differenz auf: Hat die prozessarchitektonische Infrastruktur vorher lediglich die Voraussetzungen dafür geliefert, dass sich Abläufe jeglicher Art ereignen können, macht die unbeabsichtigte Intervention des Subjekts aus den normalen Arbeitsroutinen das Geschehen des Betriebsunfalls. Erst angesichts der Gefahren für das Individuum, das in die laufenden Anlagen hineingerät, wird eine Bedeutungsdifferenz zwischen Normalbetrieb und Betriebsunfall etabliert, die es auf struktureller Ebene zunächst nicht gibt. Martin Heidegger hat festgestellt, ein ,Zeug' würde erst dann als solches in den Sinn kommen, wenn es seine Funktion versagt oder in medienwissenschaftlicher Wendung: ,[I]mmer dort, wo eine Störung auftritt, [wird] das Medium selbst thematisiert". ${ }^{28}$ Dieser medientheoretische Topos findet sich auch in Bezug auf den Raum ${ }^{29}$ und auf Infrastrukturen formuliert: ,[S]ie treten in der Regel nur im Moment der Bildstörung, des Systemfehlers, des Verkehrsstaus überhaupt in die Alltagserfahrung" ". ${ }^{30}$ Diese Aisthetisierung von Infrastrukturen im Moment ihres funktionalen Versagens ist dem Akt einer (subjektiven) Bedeutungszuschreibung geschuldet. Es ließe sich auch anders argumentieren: Zwischen Rauschen und Information kann allein aus den medialen Voraussetzungen des Kommunikationskanals, so eine andere medienwissenschaftliche Erkenntnis, nicht ohne

26 Zur Referenz auf die Maschine im Kontext prozessarchitektonischer Anlagen: Susanne Jany, „Making Buildings Work“, in: Laurent Stalder/Moritz Gleich (Hg.), Architecture/Machine, Zürich, 2017, S. 70-81.

27 Modern Times, USA 1936, 87 Minuten, Regie und Buch: Charles Chaplin.

28 Albert Kümmel, „Störung“, in: Bernd Stiegler/Alexander Roesler (Hg.), Grundbegriffe der Medientheorie, München, 2005, S. 229-236: 230.

29 Vgl. Stephan Günzel, „Medialer Raum: Bilder - Zeichen - Cyberspace“, in: ders. (Hg.), Raum. Ein interdisziplinäres Handbuch, Stuttgart, Weimar, 2010, S. 219-233: 222.

30 Gabriele Schabacher, „Medium Infrastruktur. Trajektorien soziotechnischer Netzwerke in der ANT“, in: Zeitschrift für Medien- und Kulturforschung 4, 2 (2013), S. 129-149: 129. 
Weiteres unterschieden werden. Ähnliches gilt für betriebliche Infrastrukturen: Sie stellen zunächst nichts weiter als die Voraussetzungen dafür her, dass Prozesse ablaufen können. Die Symbolisierung als ,Störung' oder ,Unfall' ist eine nachträgliche, die vom Subjekt ausgehend entworfen ist.

3.

Ist der Unfall derart subjektiviert, können Disziplinierungen als Schutzmaßnahmen veranlasst werden. In den 1880er Jahren entwirft man bei der Bahn Betriebsrichtlinien und ab 1907 Fahrdienstvorschriften, die die Bahnarbeiter in Sicherheitsfragen unterrichten und besondere Verhaltensweisen vorschreiben. Vermieden werden soll, dass Menschen, Tiere oder Gegenstände zwischen Züge und Elemente der Bahnhofsarchitektur - Gleise etwa, Bahnsteige, Tunnelwände, Barrieren, Schranken, Prellböcke oder Rampen - geraten. Bei der Reichs-Eisenbahn Elsass-Lothringen spricht man dafür eine ganze Reihe an Verboten aus:

Insbesondere ist untersagt:

a) Die Geleise kurz vor einem in Bewegung befindlichen Zuge oder Fahrzeug zu überschreiten;

b) innerhalb eines Geleises zu stehen oder zu gehen, sofern dies die dienstliche Verrichtung nicht unbedingt nothwendig macht;

c) über stehende Wagen zu klettern oder unter solchen durchzukriechen, wenn eine Lokomotive vor oder hinter denselben steht, oder wenn auf dem betreffenden Geleise rangirt wird;

d) zwischen stillstehenden Wagen hindurch zu gehen, wenn dieselben weniger als eine Wagenlänge auseinander stehen;

e) während der Fahrt einen unsicheren Platz einzunehmen, von welchem das Herabgleiten oder Herabfallen möglich ist;

f) bei stillstehenden Wagen an die Buffer oder sonstigen Wagentheile zu lehnen;

g) auf einen in Bewegung befindlichen Zug resp. auf Lokomotiven, Wagen oder Schiebebühnen auf- bezw. davon herunter zu springen;

h) die Decke eines bewegten Wagens zu betreten und während der Fahrt von der Decke des einen Wagens auf einen anderen zu klettern;

i) Materialien, Geräthe, Ladungsstücke u.s.w. zwischen den Geleisen sowie neben denselben auf eine Entfernung von weniger als ein Meter von dem nächsten Gestänge liegen zu lassen;

k) bei in Bewegung befindlichen Dampfschiebebühnen sich in den von den vorstehenden Auflauframpen bestrichenen Bereich zu begeben. ${ }^{31}$

31 Reichs-Eisenbahnen in Elsass-Lothringen, Anleitung zur Instruirung der im äusseren Dienste beschäftigten Eisenbahn-Beamten und Arbeiter behufs Verhütung von Unfällen, Strassburg, 1880, S. 12 f. Ähnliche Hinweise gelten auch für die Eisenbahnwerkstätten: Reichs-Eisenbahnen in Elsass-Lothringen, Instruktion zur Verhütung von Unfällen in den Werkstätten, Strassburg, 1882. 
Neben sicherheitstechnischen Verhaltensrichtlinien in diversen Betrieben und Fabriken $^{32}$ werden materielle Abschirmungen vor allem der gefährlichen Bereiche zwischen fixen und beweglichen Teilen der Anlage vorgeschrieben. ${ }^{33}$ Unfallprävention wird zur architektonischen Aufgabe. An Bahnhöfen wird empfohlen, riskante Bahnübergänge durch Über- und Unterführungen zu ersetzen. ${ }^{34}$ In Produktionsanlagen und mechanisierten Betrieben kommen teils raumgreifende Vergitterungen, Geländer, Distanzhalter und Abdeckungen (der Transmissionen etwa) zum Einsatz. Ebenso wie die zu sichernden Strukturen, nehmen auch die sicherheitstechnischen Anpassungen architektonische Ausmaße an und entfalten sich entlang der prozessarchitektonischen Anlage. Die Umwandlung von dysfunktionalen in möglichst funktionale Konstellationen verläuft in den meisten Fällen nicht konfliktfrei, sondern lässt sich nur als Aushandlungsprozess im Modus des trial-and-error charakterisieren. ${ }^{35}$

Das Unfallversicherungsgesetz von 1884 überführt betriebliche Unglücksfälle in eine politisch-juristische Sichtbarkeit. ${ }^{36}$ Dem Erlass des Unfallversicherungsgesetzes gehen ausführliche Diskussionen im Reichstag bezüglich staatlicher Fürsorge bei Erwerbsunfähigkeit oder Todesfall als Folge betrieblicher Unfälle voraus. Beim 1871 eingeführten Haftpflichtgesetz muss der oder die Verunfallte noch selbst nachweisen, dass es sich um einen Arbeitsunfall gehandelt hat. ${ }^{37} 1876$ gibt es eine erste Ordnung zum Schutz von Fabrikarbeitern vor Krankheit und Unfall, die jedoch keinen allgemein verbindlichen Rechtsstatus hat und daher auch nur sporadisch umgesetzt wird. 1881 scheitert eine erste Vorlage des Unfallversicherungsgesetzes, das am 6. Juli 1884 schließlich verabschiedet wird. Es gilt zunächst ausschließlich für Produktionsanlagen, bevor es 1885 auf Post- und Verkehrsbetriebe, 1886 auf den Soldatenstand und die Landwirtschaft und 1887 auf das Bauwesen und die Schifffahrt ausgeweitet wird. Monetäre Absicherungen bei Schadensfällen werden nun im öffentlichen Recht verankert. Der Gesetzestext hebt folgendermaßen an:

32 Vgl. Calder (1899), The Prevention of Factory Accidents, S. 46.

33 Konkrete Sicherheitsmaßnahmen, die in den Betrieben umzusetzen sind, werden durch die Gewerbeordnung vorgeschrieben, die 1891 vom Reichstag verabschiedet wird. Vgl. Arne Andersen, „Arbeiterschutz in Deutschland im 19. und frühen 20. Jahrhundert“, in: AfS, 31 (1991), S. 61-83: 75.

34 Vgl. Hans Wegele, Bahnhofsanlagen, Berlin, Leipzig, 1931, S. 17.

35 Nachzuverfolgen bei Calder (1899), The Prevention of Factory Accidents.

36 Vgl. das Argument Ewalds, der am Beispiel Frankreichs den Arbeitsunfall nicht als ein an sich neuartiges Phänomen beschreibt, sondern als eines, das um 1880 erstmals im Medium des Rechts verhandelt wird. Das dem deutschen Unfallversicherungsgesetz vergleichbare französische Gesetz ,über die Haftung für Unfälle, denen die Arbeiter während ihrer Arbeit zum Opfer fallen“ tritt erst am 9. April 1898 in Kraft. Ewald (1993), Der Vorsorgestaat, S. 280.

37 Vgl. Dietrich Milles, „What Are Occupational Diseases? Risk and Risk Management in Industrial Medicine in Germany, c. 1880-1920“, in: Cooter (1997), Accidents in History, S. 179195: 184 . 
$\S 1$. Alle in Bergwerken, Salinen, Aufbereitungsanstalten, Steinbrüchen, Gräbereien (Gruben), auf Werften und Bauhöfen sowie in Fabriken und Hüttenwerken beschäftigten Arbeiter und Betriebsbeamte, letztere, sofern ihr Jahresverdienst an Lohn oder Gehalt zweitausend Mark nicht übersteigt, werden gegen die Folgen der bei dem Betriebe sich ereignenden Unfälle nach Maßgabe der Bestimmungen dieses Gesetzes versichert. [...] Die in Abs. 1 aufgeführten gelten im Sinne dieses Gesetzes diejenigen Betriebe gleich, in welchen Dampfkessel oder durch elementare Kraft (Wind, Wasser, Dampf, Gas, heiße Luft u.s.w.) bewegte Triebwerke zur Verwendung kommen [...]. ${ }^{38}$

Hauptkriterium für die Feststellung eines Betriebsunfalls und die Gewährung von Zahlungen ist der zeitliche, räumliche und kausale Zusammenhang mit dem Betrieb, in dem sich der Unfall ergeben hat. Dieser Zusammenhang ist im Gesetzestext von 1884 noch recht lose als ,,in einem versicherten Betriebe vorkommende[r] Unfall“ bestimmt und vom explodierenden Dampfmaschinenkessel aus gedacht. Als Fabriken gelten ,im Sinne dieses Gesetzes insbesondere diejenigen Betriebe, in welchen die Bearbeitung oder Verarbeitung von Gegenständen gewerbsmäßig ausgeführt wird." ${ }^{39}$ Spätere juristische Schriften versuchen sich an einer näheren Bestimmung und meinen mit ,Betrieb“ nicht mehr den Ort des Unfalls, die industrielle Anlage, sondern die Abläufe, die unauflöslich mit ihr verbunden sind:

Betriebsunfall im Sinne der Unfallversicherungsgesetze ist das Ereignis der mit dem Betriebe in Verbindung stehenden, plötzlichen und abnormen Einwirkung eines äußeren Vorganges oder Zustandes auf einen freiwillig oder gesetzlich Versicherten mit der von Letzterem nicht beabsichtigten Folge von Körperverletzung oder Tod. ${ }^{40}$

Der „Betriebsunfall“ wird hier als unbeabsichtigte und ,abnorme[]“ Störung des Normalbetriebs bewertet. Seiner Ablauflogik wird ein eigenständiger Status zugesprochen. Als juristischer Sachverhalt wird der Unfall so dem regulären Betriebsgeschehen enthoben. Über das Unfallversicherungsgesetz wird das Unfallereignis nicht nur rechtlich adressierbar, sondern auch analysierbar. Der Gesetzeskonzeption gehen 1881 via amtlicher Anweisung vom Reichskanzler statistische Erhebungen voraus, um Vergleichbarkeiten herstellen zu können und eine Basis für die Berechnung der Entschädigungsleistungen zu gewinnen. ${ }^{41}$ Fabriken, Bergwerke, Salinen, Werften, Bauhöfe, Aufbereitungsanstalten, Eisenbahn-, Schifffahrts- und andere Betriebe haben über einen Zeitraum von vier Monaten des Jahres 1881 ,statistisches Material“ über Betriebsunfäl-

38 Doehl (1886), Die Unfall-Versicherung, S. 3-5.

39 Ebd., S. 5.

40 Friedrich Meyer, Land- und forstwirtschaftlicher Betriebsunfall, München, 1893, S. 12.

41 Vgl. o.A., „Die Statistik und das Unfallversicherungsgesetz. Teildruck aus Volkszeitung Nr. 238 vom 8. Oktober 1881 (Quelle Nr. 8)“, in: Karl Erich Born/Hansjoachim Henning/Florian Tennstedt (Hg.), Quellensammlung zur Geschichte der Deutschen Sozialpolitik 1867 bis 1914. II. Abteilung: Von der Kaiserlichen Sozialbotschaft bis zu den Februarerlassen Wilhelms II. (1881-1890). 2. Band, 1. Teil: Von der zweiten Unfallversicherungsvorlage bis zum Unfallversicherungsgesetz vom 6. Juli 1884, Stuttgart, Jena, New York, NY, 1995, S. 23-25. 
le und ihre Folgen zu liefern, d. h. Verletzungsarten und Todesfälle anzuzeigen. ${ }^{42}$ Später wird den Betrieben über das Unfallversicherungsgesetz die Meldung sämtlicher Unglücksfälle vorgeschrieben. Über Formularvordrucke veranlasst man, die Unfallarten entsprechend ihrer Ursachen zu klassifizieren: durch Explosionen von entweder unter Druck stehenden Apparaten oder explosiven bzw. brandgefährlichen Stoffen; durch glühende Metallmassen, ätzende Flüssigkeit oder giftige Dämpfe; durch bewegte Maschinenteile; durch Einsturz oder Herabfallen von Gegenständen; durch den Fall von Leitern, Treppen, Galerien etc.; durch Fahrzeuge und bei Ladearbeiten; durch sonstige Ursachen. ${ }^{43}$ Der dem deutschen Unfallversicherungsgesetz verwandte englische Factory and Workshop Act von 1895 legt zur besseren Dokumentierbarkeit von Unglücken eine Ordnung fest, die an möglichen Verletzungsarten orientiert ist:

The nature of the injury should be clearly described under one or other of the heads in the following classification: (a) Causing death; (b) loss of right hand or arm; (c) loss of left hand or arm; (d) loss of part of right hand; (e) loss of part of left hand; (f) loss of any part of leg or foot; (g) fracture of limbs or bones of trunk; (h) fracture of hand or foot; (i) loss of sight of one or both eyes; (j) injuries to head and face; (k) burns and scalds; (l) lacerations, contusions, and other injuries not enumerated above. ${ }^{44}$

Die juristische Sichtbarmachung des Betriebsunfalls erfolgt über die Standardisierung dessen, was man als seine Ursachen und Konsequenzen ausmacht. Vorindustrielle Formen des Unfalls werden gemeinhin über das Moment der Kontingenz bestimmt. Im ausgehenden 19. Jahrhundert führen Standardisierungspraktiken und Versicherungskalküle industrielle Unfälle als eine neue Form von Ereignishaftigkeit ein, durch die das mit statistischer Regelmäßigkeit auftretende Unfallrisiko als Möglichkeit immer schon vorweggenommen ist. ${ }^{45}$ Zwar kommt es zu einer juristischen Differenzierung zwischen Unfallereignis und regulärem Betrieb mit den Mitteln der Statistik, dabei stellt aber gerade die Statistik den Unfall als genauso regulär heraus wie die prozessarchitektonisch normalisierten Arbeitsabläufe:

The rise of statistics in the mid-nineteenth century secularized accidents as expected events [...]. Man-made industrial accidents in particular were increasingly seen as a part of the expected and ,normal' flow and structure of everyday social life - endogenous rather than exogenous to human motivations, actions and processes. ${ }^{46}$

42 Ebd., S. 23 f.

43 Vgl. Doehl (1886), Die Unfall-Versicherung, S. 356 f.

44 Calder (1899), The Prevention of Factory Accidents, S. 38.

45 Vgl. Wolfgang Schäffner, „Das Trauma der Versicherung. Das Ereignis im Zeitalter der Wahrscheinlichkeit“, in: Inka Mülder-Bach (Hg.), Modernität und Trauma. Beiträge zum Zeichenbruch des Ersten Weltkrieges, Wien, 2000, S. 104-120: 111.

46 Cooter/Luckin (1997), Accidents in History, S. 3. 
Die Statistik identifiziert und produziert den Unfall als ein neuartiges nicht aber besonderes Ereignis, das in seiner Vorhersehbarkeit den Routinen der Arbeitsabläufe in Nichts nachsteht. Der Unfall ist ein normaler Störfall, ein über betriebliche Routinen normalisiertes Ereignis. Erst über diese Identifizierung und Etablierung regelmäßiger Unfallszenarien kann ein Zugriff auf den Betrieb und dessen Unfallpotenzial umgesetzt werden, der regelhafte Gegenmaßnahmen als Sicherheitsvorkehrungen wirksam werden lässt. Erst auf dieser Basis kann Unfallprävention als solche zur Norm werden, sind also Reaktionen auf Betriebsunfälle nicht mehr zwangsläufig nachträglich.

4.

Virilio hat festgestellt, dass die ,,industrielle Serialisierung des Unfalls zwangsläufig zu einer Infragestellung des Begriffs des Zu-Fälligen oder Katastrophischen führt. In der Tat wird der Unfall, sobald er systemisch wird, einem Programm oder Kalkül ähnlich. “" ${ }^{47}$ Die Statistik macht aus dem jähen Unfall nicht nur ein absehbares, da berechenbares Ereignis, sondern bindet diesen von seiner inhärenten Nachträglichkeit los. Sie macht Unfallgeschehen für zukunftsgerichtete Planungen verfügbar und wirkt daher strukturbildend..$^{48}$ In Anlehnung an Virilios Argumentation spricht Eva Horn von einem dem Unfall inhärenten Futurismus. ${ }^{49}$ Aus dem unfalltechnischen „Störungs-Wissen“"50 lässt sich daher nicht nur Schutz-, sondern Innovations- und Optimierungspotenzial schlagen. Normale Unfälle stellen keine Abweichungen von Regelfällen dar, sondern stellen die Akteure vielmehr vor unerwartete und „,neue Situationen, für deren Handhabung es eben gerade noch keine Regeln gibt", deren Etablierung sie jedoch anstoßen. ${ }^{51}$ Betriebsunfälle wiederum bringen eine spezifische Eigendynamik und Produktivität mit sich, die es erlaubt, neuartiges arbeitsorganisatorisches Wissen zu produzieren, das betrieblich implementierbar ist. Dabei geht es nicht primär um das körperliche oder zumindest monetäre Wohl der Arbeiter_innen. R. C. Richards argumentiert in seinem Bericht „Railway Accidents and ,Safety First"“ von 1915:

We recognized that every time a capable, experienced employee was killed or injured it not only brought suffering and sorrow to himself and his family, but necessitated the employment of a new and inexperienced man in his place, thereby

47 Virilio (2009), Der integrale Unfall, S. 7.

48 Vgl. Lotringer/Virilio (2005), The Accident of Art, S. 63 f.; Stephen Graham/Nigel Thrift, „Out of Order: Understanding Repair and Maintenance“, in: Theory, Culture and Society 24, 3 (2007), S. 1-25: 4; Christian Kassung, „Einleitung“, in: ders. (2009), Die Unordnung der Dinge, S. 9-15: 9.

49 Vgl. Eva Horn, Zukunft als Katastrophe, Frankfurt/M., 2014, S. 250.

50 Ebd., S. 254.

51 Bettina Heintz, Die Herrschaft der Regel: Zur Grundlagengeschichte des Computers, Frankfurt/M., New York, NY, 1993, S. 247 [Herv. i. O.]. 
increasing the risk to the other men in the service and at the same time decreasing the efficiency of the organization, frequently very seriously. ${ }^{52}$

Der Arbeitsunfall, so die Erkenntnis der Betriebsplaner, ist nicht nur für Arbeitnehmer innen riskant, sondern auch für Arbeitgeber. In ökonomischer Hinsicht offenbart sich im Betriebsunfall ein Risiko zweiter Ordnung. Das Unfallversicherungsgesetz, das den finanziellen Ausgleich für Schäden als betriebswirtschaftlichen Faktor einführt, lässt den Unfall auf die Bilanz des Betriebs zurückwirken und ihn nicht nur als menschliche Tragödie, sondern auch als Störmoment im ökonomischen Funktionieren des Betriebs auftreten. Indem der Betriebsunfall eine Versicherungsmaschinerie in Gang setzt, kommt dem Unfall der Status eines betriebswirtschaftlich relevanten Ereignisses zu. Verletzungen, Traumata und Todesfälle in den Produktionsbetrieben der Jahrhundertwende etablieren den Unfall als juristischen Sachverhalt und Problem von Haftbarkeiten, Entschädigungen und Rentenansprüchen. Umfangreiche Schutzmaßnahmen dienen letztlich auch dazu, den Betrieb in ökonomischer Hinsicht abzusichern und als möglichst unfallfrei und reibungslos zu rekonstituieren: ,It was determined [...] to inaugurate a movement to reduce such accidents, both as a matter of humanity and to increase the efficiency of the organisation." ${ }^{53}$ Der subjektivierte Betriebsunfall arbeitet so dem ursprünglichen Imperativ zur zweckmäßigen Anlage der Funktionsbauten und dem Ideal reibungsloser Betriebsabläufe zu. ${ }^{54}$ Auch in der Sicherung der Betriebe geht es letztlich einmal mehr um die Kriterien der Produktivität und Effizienz, um die Umsetzung betriebswirtschaftlicher Vorgaben, die man, so die Erkenntnis, ebenfalls mit Mitteln des Arbeitsschutzes erreichen kann. Der Betriebsunfall - dies macht die infrastrukturelle Perspektive deutlich - ist zugleich Normalisierungseffekt und Normalisierungsinstrument. Man begegnet dem Betriebsunfall also nicht als singuläre Begebenheit, aufgrund seiner medialen und epistemischen Nachträglichkeit scheint dies ein vergebliches Unterfangen, sondern auf infrastruktureller Ebene: über Betriebsvorschriften, Sicherheitsarchitekturen und Unfallversicherungsgesetze, mit denen man das betriebliche Dispositiv von innen heraus, d. h. über die Manipulation seiner Elemente, abzusichern beabsichtigt.

52 Vgl. R. C. Richards, „Railway Accidents and ,Safety First““, in: Journal of Political Economy 23, 1 (1915), S. 49-60: 55.

53 Ebd.

54 Dass Unfälle und reibungslose Abläufe keine Gegensätze darstellen, meint auch Esther FischerHomberger, „Der Eisenbahnunfall von 1842 auf der Paris-Versailles-Linie. Traumatische Dissoziation und Fortschrittsgeschichte", in: Kassung (2009), Die Unordnung der Dinge, S. 4988: 80 . 


\section{Literatur}

o.A., „Die Statistik und das Unfallversicherungsgesetz. Teildruck aus Volkszeitung Nr. 238 vom 8. Oktober 1881 (Quelle Nr. 8)“, in: Karl Erich Born/Hansjoachim Henning/Florian Tennstedt (Hg.), Quellensammlung zur Geschichte der Deutschen Sozialpolitik 1867 bis 1914. II. Abteilung: Von der Kaiserlichen Sozialbotschaft bis zu den Februarerlassen Wilhelms II. (1881-1890). 2. Band, 1. Teil: Von der zweiten Unfallversicherungsvorlage bis zum Unfallversicherungsgesetz vom 6. Juli 1884, Stuttgart, Jena, New York, NY, 1995, S. 23-25.

Andersen, Arne, „Arbeiterschutz in Deutschland im 19. und frühen 20. Jahrhundert“, in: AfS, 31 (1991), S. 61-83.

Bitta, Georg, Die Betriebsunfälle in der Eisen- und Stahlindustrie von Posen, Mittelund Niederschlesien in den Jahren 1910-1920, Breslau, 1925.

Bronstein, Jamie L., Caught in the Machinery: Workplace Accidents and Injured Workers in Nineteenth-Century Britain, Stanford, CA, 2008.

Calder, John, The Prevention of Factory Accidents: A Practical Guide to the Law on the Safe-Guarding, Safe-Working, and Safe-Construction of Factory Machinery, Plant and Premises, London, New York, NY, 1899.

Cooter, Roger/Luckin, Bill, „Accidents in History: An Introduction“, in: Roger Cooter (Hg.), Accidents in History: Injuries, Fatalities and Social Relations, Amsterdam, 1997, S. 1-16.

Doehl, Carl, Die Unfall-Versicherung der gewerblichen, Fabrik- und Betriebs-Arbeiter nach den Materialien des Gesetzes vom 6. Juli 1884, den erlassenen Ausdehnungsund Ergänzungs-Gesetzen, den ergangenen Ausführungsverordnungen und den Beschlüssen, Entscheidungen und Mittheilungen des Reichs-Versicherungsamtes, Leipzig, 1886.

Engel, Friedrich/Schmitt, Eduard/Osthoff, Georg/Geul, Albert, Handbuch der Architektur, Vierter Teil, 3. Halbband: Landwirthschaftliche Gebäude und verwandte Anlagen. Ställe für Arbeits-, Zucht- und Luxuspferde; Wagen-Remisen. Gestüte und Marstall-Gebäude. Rindvieh-, Schaf-, Schweine- und Federviehställe. Feimen, offene Getreideschuppen und Scheunen. Magazine, Vorraths- und Handelsspeicher für Getreide. Größere landwirthschaftliche Gebäude-Complexe. Schlachthöfe und Viehmärkte. Markthallen und Marktplätze. Brauereien, Mälzereien und Brunnereien, 1. Aufl., Darmstadt, 1884.

Ewald, François, Der Vorsorgestaat, Frankfurt/M., 1993.

Fischer-Homberger, Esther, ,Der Eisenbahnunfall von 1842 auf der Paris-VersaillesLinie. Traumatische Dissoziation und Fortschrittsgeschichte“, in: Christian Kassung (Hg.), Die Unordnung der Dinge. Eine Wissens- und Mediengeschichte des Unfalls, Bielefeld, 2009, S. 49-88.

Graham, Stephen/Thrift, Nigel. „Out of Order: Understanding Repair and Maintenance", in: Theory, Culture and Society 24, 3 (2007), S. 1-25.

Günzel, Stephan, „Medialer Raum: Bilder - Zeichen - Cyberspace“, in: ders. (Hg.), Raum. Ein interdisziplinäres Handbuch, Stuttgart, Weimar, 2010, S. 219-233.

Heintz, Bettina, Die Herrschaft der Regel: Zur Grundlagengeschichte des Computers, Frankfurt/M., New York, NY, 1993.

Horn, Eva, Zukunft als Katastrophe, Frankfurt/M., 2014. 
Dies., „Die Verkettung unglücklicher Umstände. Über unwahrscheinliche Unfälle“, in: Stefan Rieger/Manfred Schneider (Hg.), Selbstläufer/Leerläufer. Regelungen und ihr Imaginäres im 20. Jahrhundert, Zürich, 2012, S. 199-217.

Jany, Susanne, Prozessarchitekturen: Medien der Betriebsorganisation (1880-1936), Konstanz, 2019.

Kassung, Christian (Hg.), Die Unordnung der Dinge. Eine Wissens- und Mediengeschichte des Unfalls, Bielefeld, 2009.

Ders., „Einleitung“, in: ders. (Hg.), Die Unordnung der Dinge. Eine Wissens- und Mediengeschichte des Unfalls, Bielefeld, 2009, S. 9-15.

Koch, Julius, „Mittheilungen über Fabriks-Anlagen (Vortrag, gehalten in der Fachgruppe für Architektur und Hochbau und der Maschinen-Ingenieure, am 29. März 1882)“, in: Zeitschrift des österreichischen Ingenieur- und ArchitektenVereins, 34 (1882), S. 74-81.

Koch, Lars/Petersen, Christer/Vogl, Joseph (Hg.), Zeitschrift für Kulturwissenschaften: Störfälle, Bielefeld, 2011.

Krafft, Ernst, 100 Jahre Eisenbahnunfall, Berlin, 1925.

Kritzler, Sophie, Der Betriebs-Unfall der Fabrikarbeiterin (mit Untersuchungen in der Textil-, Nahrungsmittel und Chemischen Industrie), Chemnitz, 1933.

Kümmel, Albert, „Störung“, in: Bernd Stiegler/Alexander Roesler (Hg.), Grundbegriffe der Medientheorie, München, 2005, S. 229-236.

Link, Jürgen, „,Normativ“ oder ,Normal“? Diskursgeschichtliches zur Sonderstellung der Industrienorm im Normalismus, mit einem Blick auf Walter Cannon“, in: Werner Sohn/Herbert Mehrtens (Hg.), Normalität und Abweichung. Studien zur Theorie und Geschichte der Normalisierungsgesellschaft, Wiesbaden, 1999, S. 30-44.

Lotringer, Sylvère/Virilio, Paul, The Accident of Art, Cambridge, MA, London, 2005.

Meyer, Friedrich, Land- und forstwirtschaftlicher Betriebsunfall, München, 1893.

Milles, Dietrich, „What are Occupational Diseases? Risk and Risk Management in Industrial Medicine in Germany, c. 1880-1920“, in: Roger Cooter (Hg.), Accidents in History: Injuries, Fatalities and Social Relations, Amsterdam, 1997, S. 179-195.

Perrow, Charles, Normale Katastrophen. Die unvermeidbaren Risiken der Großtechnik, Frankfurt/M., 1988.

Pethes, Nicolas, „Accidental Experiments“, in: Christian Kassung (Hg.), Die Unordnung der Dinge. Eine Wissens- und Mediengeschichte des Unfalls, Bielefeld, 2009, S. 381-398.

Rasch, Jahresbericht des Hamburgischen Gewerbeaufsichtsamts über das Jahr 1922. Sonderabdruck aus dem vom Reichsarbeitsministerium herausgegebenen Jahresberichten der Gewerbeaufsichtsbeamten, Hamburg, 1923.

Reichs-Eisenbahnen in Elsass-Lothringen, Anleitung zur Instruirung der im äusseren Dienste beschäftigten Eisenbahn-Beamten und Arbeiter behufs Verhütung von Unfällen, Strassburg, 1880.

Dies., Instruktion zur Verhütung von Unfällen in den Werkstätten, Strassburg, 1882.

Reuleaux, Franz, Theoretische Kinematik. Grundzüge einer Theorie des Maschinenwesens, Braunschweig, 1875.

Richards, R. C., „Railway Accidents and ,Safety First““, in: Journal of Political Economy 23, 1 (1915), S. 49-60.

Schabacher, Gabriele, „Medium Infrastruktur. Trajektorien soziotechnischer Netzwerke in der ANT", in: Zeitschrift für Medien- und Kulturforschung 4, 2 (2013), S. 129-148. 
Schäffner, Wolfgang, „Das Trauma der Versicherung. Das Ereignis im Zeitalter der Wahrscheinlichkeit“, in: Inka Mülder-Bach (Hg.), Modernität und Trauma. Beiträge zum Zeichenbruch des Ersten Weltkrieges, Wien, 2000, S. 104-120.

Stockert, Ludwig, Eisenbahnunfälle (Neue Folge): Ein weiterer Beitrag zur Eisenbahnbetriebslehre, Band 1: Chronik einiger in den Jahren 1913-1918 bekanntgewordenen grösseren Eisenbahnunfälle, Berlin, Wien, 1920.

Syrup, Friedrich (Hg.), Handbuch des Arbeiterschutzes und der Betriebssicherheit, Berlin, 1927.

Virilio, Paul, „Der integrale Unfall“, in: Christian Kassung (Hg.), Die Unordnung der Dinge. Eine Wissens- und Mediengeschichte des Unfalls, Bielefeld, 2009, S. 7-8.

Wegele, Hans, Bahnhofsanlagen, Berlin, Leipzig, 1931.

Weinhauer, Klaus, „Unfallentwicklung und Arbeitsprozeß im Hamburger Hafen 1896/971936: Ein Beitrag zu vernachlässigten Perspektiven der Arbeiter(innen)geschichte“, in: Karl Lauschke/Thomas Welskopp (Hg.), Mikropolitik im Unternehmen. Arbeitsbeziehungen und Machtstrukturen in industriellen Großbetrieben des 20. Jahrhunderts, Essen, 1994, S. 107-122. 


\section{NICOLE M. WILK \\ „DAS IST KEIN NEUER KALTER KRIEG“ - ZUM ZUSAMMENHANG VON METADISKURS UND STANDARDBILDUNG AUS DISKURSLINGUISTISCHER SICHT}

Der vorliegende Beitrag setzt Grundannahmen des Automatismen-Konzepts ein, um Fragen der Herausbildung, Sichtbarkeit und Belegbarkeit sprachlicher Standards auf den Ebenen der verhältnismäßig stark normierten und kodifizierten Grammatik und der eher schwach normierten und nur teilweise kodifizierten Lexik zu behandeln. Nach einer Rekapitulation prominenter Standardbegriffe der Varietäten- und Medienlinguistik, wie sie kondensiert in den Termini Standardsprache, standardsprachliche Norm, standardnahe Varietät und (De-) Standar-disierung auftreten, werden diese im Hinblick auf die automatismenrelevanten Kriterien Gebrauchshäufigkeit und metasprachliche Thematisierung betrachtet, wobei der Standard einmal als Folge einer Verfestigung sprachlicher Muster und einmal als Ergebnis von Entautomatisierung in Prozessen normreflektierender und normbildender Sprachaufmerksamkeit in Erscheinung tritt. Dabei kann die grammatische Variantenbildung aufgefasst werden als Zusammenspiel der auf sprachsystematischen Abstraktionen beruhenden Automatismen, die sprachgeschichtlich als ,Kräfte“ innerhalb der Sprache als langue (z. B. als Ausgleich) oder auf kognitiver Ebene (z. B. als Analogiebildung) beschrieben werden, sowie einer Normierung durch (sprachpflegerische) Norminstanzen, die Varianten mit Stigma bzw. Prestige versehen.

Anschließend sollen an einem framesemantischen Fallbeispiel Standardisierungsprozesse korpuslinguistisch transparent gemacht werden, so dass anhand der Schema-Aktualisierung (Kalter Krieg) im Diskurs zur russischen Annexion der Krim die Herausbildung re-standardisierter Werte und ihre naturalisierende Wirkung als Teil eines semantischen Wandels in Diskursen exemplarisch nachvollzogen werden können. Die Problemstellung tangiert damit die übergeordnete Frage, wie (Be-)Deutung im Diskurs entsteht und wie sich Elemente des impliziten Wissens als Katalysatoren soziopolitischer Deutungsmuster erweisen, auch indem sie an andere diskursrelevante Frames, Topoi und Metaphern anschließen.

Wie entstehen standardsprachliche Varianten?

Bevor ich mich Standardisierungsprozessen von Bedeutungsattributen und ihrer Dynamik im Diskurs zuwende, wie sie die Framesemantik in Anlehnung 
an Schematheorie, Kasus- und Konstruktionsgrammatik modelliert hat, möchte ich den Begriffshorizont der sprachlichen Standards im Hinblick auf die beiden scheinbar konträren Standardverständnisse ,Soll ${ }^{\star}$ und ,Durchschnitt" abstecken, denen auch zahlreiche Wortbildungen mit Standard zugrunde liegen: Standardtänze, Standardsorte, Standardwerke im Sinne einer sozial begründeten Richtlinie und Standardkosten, Standardsituation, Standardabweichung in der Lesart eines empirisch begründeten Durchschnitts. Feilke hebt insbesondere hervor, dass letztere dem Topos der Normativität des Faktischen folgt, denn „Sprachen als geordnete Systeme sind keine von Menschenhand hervorgebrachten Artefakte und entwickeln ihre Formen und Normen oft unabhängig von, ja sogar gegen die Absichten der Beteiligten." ${ }_{1}$

In der Diskussion um die Standardvarietät(en) des Deutschen haben sich in den letzten Jahren einige Einsichten durchgesetzt, die die Vorstellung ablösen, ,die' Standardsprache sei eine schriftsprachnahe distanzsprachliche Leitvarietät des Deutschen, die den Eindruck von Neutralität in der überregionalen öffentlichen Kommunikation erweckt. ${ }^{2}$ Dazu zählen:

1. Standards sind Abgrenzungsbegriffe und negativ auf Vielfalt bezogen.

2. Standards sind relational und folgen einer flexiblen Norm

(Varietätenbezug).

3. Standards lassen Varianten zu (Varianz).

Sprachlicher Standard konstituiert sich in einem Kontinuum zu Gegenbegriffen wie Non-Standard, Substandard, Dialekt, Umgangssprache oder Fachsprachen. ${ }^{3}$ Somit ist der Standard immer schon eine Kategorie, die Varianz impliziert. Der Abhängigkeit des Standards von der medialen Performanz mit den für das Mündliche typischen Formen der Diskontinuität, Herausstellung oder Fokussierung, die sich unter den besonderen (multi-)modalen Bedingungen der Face-to-Face-Kommunikation herausbilden (Online-Prozessierung, räumlich-körperliche Koordination oder Kontextualisierung durch Stimme und Gestik), wird insbesondere in der Forderung nach einer mit dem schriftsprach-

1 Helmuth Feilke, „Schulsprache - Wie Schule Sprache macht“, in: Susanne Günthner/Wolfgang Imo/Dorothee Meer/Jan Georg Schneider (Hg.), Kommunikation und Öffentlichkeit: sprachwissenschaftliche Potenziale zwischen Empirie und Norm, Berlin, Boston, MA, 2012, S. 149-175: 152.

2 Vgl. Wolf Peter Klein, „Warum brauchen wir einen klaren Begriff von Standardsprachlichkeit und wie könnte er gefasst werden?“, in: Jörg Hagemann/Wolf Peter Klein/Sven Staffeld (Hg.), Pragmatischer Standard, Tübingen, 2013, S. 15-33: 17. Zur ,Standardsprachenideologie“ vgl. Matthias Hüning, „Standardsprachenideologie. Über Sprache als Mittel zur Abund Ausgrenzung", in: Emmeline Besamusca/Christine Hermann/Ulrike Vogl (Hg.), Out of the Box: Über den Wert des Grenzwertigen, Wien, 2013, S. 105-122.

3 Vgl. Heinrich Löffler, „Wieviel Variation verträgt die deutsche Standardsprache? Begriffsklärung: Standard und Gegenbegriffe“, in: Ludwig M. Eichinger/Werner Kallmeyer, Standardvariation. Wie viel Variation verträgt die deutsche Sprache?, Jahrbuch Institut für Deutsche Sprache, Berlin, 2005, S. 7-27: 21. 
lichen Standard überlappenden, aber flexibleren Norm für die gesprochene Sprache Rechnung getragen. ${ }^{4}$

Im Plural adressieren sprachliche Standards varietätenspezifische Normen mit unterschiedlich starker Verbindlichkeit auf den verschiedenen sprachlichen Ebenen (Aussprache-, Grammatik- oder Textsortennorm). Durch Sprachwandel, Sprachkontakt, über Dialekte, Fachsprachen oder durch Regelkonflikte im System kommt es zur freien, funktionalen oder regionalen Variation in der Aussprache (benutzen/benützen), der Flexion (downgeloaded/gedownloaded; backte/buk; bin/habe gesessen) oder der Lexik (Apfelsinel Orange; Sonnabend/Samstag). Während sich die faktische Gebrauchsnormalität oft der Kenntnis der Sprecher/innen entzieht, können diese bei Doppelformen/Dubletten in Zweifel geraten, welches Wort, welche Wortform, welcher Satz standardsprachlich als korrekt zu gelten hat. ${ }^{5}$ Zweifel setzt die Entautomatisierung der Formulierungsroutine voraus und führt zur Metabetrachtung: "In der Regel sind sich Sprecher des Deutschen des komplexen Deklinationssystems ihrer Sprache nicht oder kaum bewusst, sondern bilden die Formen mehr oder weniger automatisiert. Bewusstheit tritt vor allem dann auf, wenn ein sprachlicher Fall aus der Selbstverständlichkeit der regelmäßigen Verwendung hervortritt." ${ }^{6}$ Die Regeln sind prinzipiell bewusstseinsfähig bzw. vorbewusst und nicht im Freud'schen Verständnis unbewusst im Sinne von verdrängt. Zweifelsfälle müssen sogar definitorisch ,über eine gewisse metasprachliche Komponente verfügen".7 Die Formen können sprachfunktional (extern) verschiedenen Varietäten (Fachsprache - Umgangssprache) oder Medien (mündlicher/schriftlicher Sprachgebrauch) angehören, seltener gehen sie aus verschiedenen Strukturlogiken des Sprachsystems hervor. Durch das Wir-

4 Vgl. Jan Georg Schneider/Georg Albert, „Medialität und Standardsprache - oder: Warum die Rede von einem gesprochenen Gebrauchsstandard sinnvoll ist", in: Hagemann/Klein/Staffeld (2013), Pragmatischer Standard, S. 49-60: 54.

$5 \mathrm{Zu}$ dieser Definition des Zweifelsfalls vgl. Wolf-Peter Klein, „Sprachliche Zweifelsfälle als linguistischer Gegenstand. Zur Einführung in ein vergessenes Thema der Sprachwissenschaft", auf: Linguistik Online 16, 4 (2003), online unter: http://www.linguistik-online. de/16_03/klein.html, zuletzt aufgerufen am 03.01.2019, der darauf hinweist, dass die beiden Varianten eines Zweifelsfalls formseitig oft teilidentisch sind. Als Beispiele nennt er dubios/ dubiös, lösbar/löslich, des Automat/des Automaten, Rad fahren/radfahren, Staub gesaugt/ staubgesaugt/gestaubsaugt. Standardwerke wie die verschiedenen Duden-Bände, auf die Sprecher in solchen Fällen zurückgreifen können, enthalten dann lediglich die sprachwandelbereinigte, mit Konsistenz und Legitimität ausgestattete, oft auch ästhetisch begründete Zielnorm; vgl. dazu auch Dietrich Busse, „Sprachnorm, Sprachvariation, Sprachwandel. Überlegungen zu einigen Problemen der sprachwissenschaftlichen Beschreibung des Deutschen im Verhältnis zu seinen Erscheinungsformen“, in: Deutsche Sprache 34, 4 (2007), S. 314333: 329 .

6 Corinna Peschel, „Grammatische Zweifelsfälle als Thema des Deutschunterrichts? Das Beispiel der ,schwachen Maskulina““, in: Mathilde Hennig/Christoph Müller (Hg.), Wie normal ist die Norm? Sprachliche Normen im Spannungsfeld von Sprachwissenschaft, Sprachöffentlichkeit und Sprachdidaktik, Kassel, 2009, S. 39-59: 51.

7 Klein (2003), Sprachliche Zweifelsfälle, o. S. 
ken von Normvermittlungsinstanzen (Schule, Lehrwerke, Ämter oder Modelltexte) ${ }^{8}$ können solche Varianten zum Index sozialer Differenzierung werden.

Die stilistische Variation der kodifizierten Norm in den Bereichen Morphologie und Syntax wird nicht selten Ziel sprachpflegerischer Aktivitäten, so dass mitunter ,freie Varianten, die das Sprachsystem zulässt, als Normverstoß behandelt werden, beispielsweise wenn behauptet wird, dass die indirekte Rede ausschließlich im Konjunktiv realisiert werden dürfe ${ }^{\text {"ब }}$ oder aber, wenn die Duden-Grammatik über Jahrzehnte hinweg für zwei koordinierte attributive Adjektive ohne vorangehendes Artikelwort im Dat.Sg.Mask./Neutr. wie in aus kontrolliertem biologischem Anbau Parallelflexion empfiehlt, wenngleich in vermündlichten Domänen konstant Wechselflexion (aus kontrolliertem biologischen Anbau) überwiegt und die Verteilung der beiden Varianten in schriftlichen Texten mit 57 Prozent Parallel- und 43 Prozent Wechselflexion Flexionsschwankungen in diesem Bereich als klaren Zweifelsfall ausweisen. ${ }^{10}$ Sprachpflegerischer (Über-)Regulierung ist es wohl beispielsweise auch geschuldet, dass das Verb backen noch nicht vollständig zu den schwachen Verben übergewechselt, d. h. die Präteritalvariante buk noch immer gebräuchlich ist.

Stigmatisiert wird aus der Perspektive eines Standards, der sich am formellen Schriftsprachgebrauch (Qualitätsmedien) mit öffentlich publizierten Modelltexten, weniger aber an der alltäglichen Sprechsprache mit ihren unterschiedlichen Sprachformen orientiert. Denn die geforderte Norm entspricht nicht immer dem normalen, unauffälligen' Sprachgebrauch, wie sich am Beispiel der Partizipialform gewinkt verdeutlichen lässt. Diese Variante wird vom Dudenband „Richtiges-und-gutes-Deutsch“ als Norm gefordert, während die stark flektierte, erstmals im Mittelhochdeutschen durch Analogiebildung zu starken Verben wie sinken, stinken und trinken aufgetretene Variante gewunken als ,normal' Form erscheint, insofern sie die derzeit gebräuchlichere von beiden ist. ${ }^{11}$ Die Varianz folgt somit verschiedenen Regelhaftigkeiten: Zunahme von Irregularität durch (sozial motivierte?) Analogie auf der einen und Ausgleich von Irregularität bzw. Abbau von Markiertheit auf der anderen Seite, wobei sprachsystematische Ausgleichsprozesse immer von der Verwen-

8 Vgl. Busse (2007), Sprachnorm, Sprachvariation, Sprachwandel, S. 320 f.

9 Christoph Müller, „Wat ihr normal nennt ...- Ein didaktisches Dilemma und die Chance, aus der Not eine Tugend zu machen“, in: Hennig/Müller (2009), Wie normal ist die Norm?, S. 6083: 64 .

10 Vgl. Damaris Nübling, „Unter großem persönlichem oder persönlichen Einsatz? Der sprachliche Zweifelsfall adjektivischer Parallel- vs. Wechselflexion als Beispiel für aktuellen grammatischen Wandel", in: Klaus-Michael Köpcke/Arne Ziegler (Hg.), Grammatik - Lehren, Lernen, Verstehen, Zugänge zur Grammatik des Gegenwartsdeutschen, Berlin, Boston, MA, 2011, S. 175-196: 183.

11 Vgl. Lucia Zahradníček, „Gewinkt oder gewunken? Wie wird winken ,normal“ flektiert?“, in: Hennig/Müller (2009), Wie normal ist die Norm?, S. 130-149. 
dungsfrequenz abhängig sind ${ }^{12}$ und für einzelne Gattungen unterschiedlichen Konventionalisierungsprozessen unterliegen. Die Entwicklung von Präferenzen für Flexionsformen kann Ergebnis des Zusammenwirkens verschiedener sprachimmanenter Strategien sein, wie auch das Beispiel der Zunahme von $\ddot{o}-$ Formen für den Konjunktiv II zeigt (stöhle, gewönne). Diese jüngeren Konjunktivformen erhöhen sprachsystematisch den morphologischen Kontrast zum Präsenz - stähle ist in der gesprochenen Sprache nur noch in einzelnen Dialekten von stehle zu unterscheiden -, verstoßen jedoch gleichzeitig gegen das Prinzip der Morphemkonstanz. „Dass sich die Variation hier so lange hält, erklärt sich also auch aus dem Konflikt der beiden lokalen Optimierungen Distinktivität vs. Morphemkonstanz". ${ }^{13}$ Sprachlicher Wandel folgt somit schon intern verschiedenen Prinzipien und einzelne „Entwicklungen wie der präteritale Numerusausgleich (ich sang - wir sungen > ich sang - wir sangen) oder die Herausbildung der vereinfachten Ablautalternanz X-o-o sind nie nur Komplexitätsreduktion, sondern immer auch Systematisierung" ${ }^{\text {"14 }}$, die gerade nicht von Normautoritäten gesteuert und intendiert ist, und „die Sprache als kognitives und kommunikatives Werkzeug gebrauchsfertig" erhält. ${ }^{15}$

Diese deskriptive Fundierung des Standards, die nicht die soziale Akzeptanz zum Angelpunkt erhebt, wird eingelöst in der Ermittlung der standardsprachlichen Normen als emergente Gebrauchsnormen auf der Basis quantitativer Verteilungen in verschiedenen Varietäten. Standardsprache umfasst somit auch Varianten (Standardvariation) im Grenzbereich zu anderen Varietäten. ${ }^{16}$

12 Nübling weist insbesondere für verbalmorphologische Schwach-Stark-Sprünge darauf hin, dass diese nur unter der Bedingung von Hochfrequenz zustande kommen (vgl. Damaris Nübling „Der alemannische Konjunktiv II zwischen Morphologie und Syntax: Zur Neuordnung des Konjunktivsystems nach dem Präteritumschwund“, in: Arno Ruoff/Peter Löffelad (Hg.), Syntax und Stilistik, Beiträge der 12. Arbeitstagung zur alemannischen Dialektologie, Idiomatica 18, Tübingen, 1997, S. 107-121: 120.

13 Antje Dammel, „Die schönen alten Formen ... Grammatischer Wandel der deutschen Verbalflexion - Verfall oder Reorganisation?“ in: Albrecht Plewnia (Hg.), Sprachverfall?: Dynamik - Wandel - Variation, Jahrbuch Institut für Deutsche Sprache, Berlin, 2014, S. 5170: 66.

14 Ebd., S. 51 [Herv. i. O.].

15 Müller (2009), Wat ihr normal nennt ..., S. 61. Dabei spielt es keine Rolle, ob sprachlichen Automatismen kognitiver oder sprachimmanenter Status zugesprochen wird. Um Spekulationen über die kognitive Organisation und Repräsentation sprachlicher und deiktischer Einheiten zu vermeiden, bietet es sich an, ,die' sprachliche Praxis als mustergenerierende fiktionale Größe aufzufassen, die immer auch Normdiskurse über Sprachpraktiken umfasst.

16 Auch Daten-Variation, vgl. dazu Löffler (2005), Wieviel Variation verträgt die deutsche Standardsprache?, S. 24. Natürlich ist die faktische Varianz bezogen auf den Wertebereich im jeweils betrachteten Datenmaterial wesentlich höher. 


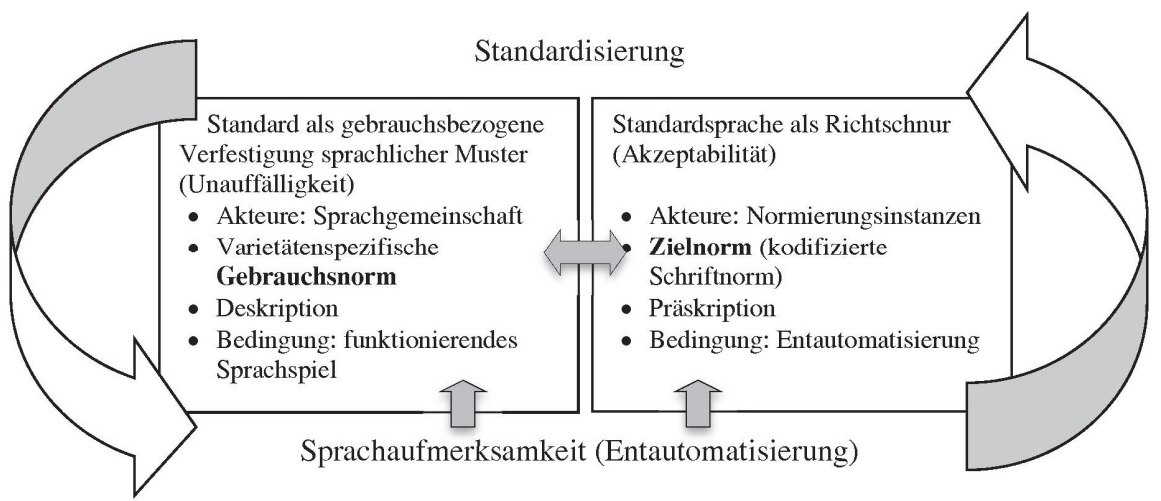

6.1 - Standardisierung im Spannungsfeld zwischen Gebrauchsnorm und Kodifizierung

Nicht nur, dass jede Frequenzerhebung Deutung voraussetzt und auf der Vorentscheidung beruht, aus dem Datenstrom konkrete Formen zu segmentieren und statistisch zu erfassen. Unter der Prämisse, dass im Standard soziale und sprachliche Automatismen zusammenwirken, geht auch in den aus authentischen Daten abgeleiteten De-facto-Standard die Wirkung eines kodifizierten Standards als institutionalisierte Vorschrift oder auch als Toleranz gegenüber sprachlicher Variation ein. Standard bildet sich somit auf der Grundlage verschiedener Automatismen, wobei selbst die Bildung einer metasprachlichen Norm Züge eines solchen trägt, da zwar die Varianten und ihre Verteilung bewusst verhandelt und offen gelegt werden, nicht aber die Motive für die Formulierung der einen oder anderen Zielnorm (soziale Differenzierung).

Wenn der Duden unter dem Eintrag Standarddeutsch standardnahes Sprechen und Schreiben so definiert, dass es bedeutet, ,sich unauffällig und sicher in verschiedenen eher formellen Kontexten bewegen (zu) können" ${ }^{17}$, werden Sprachintuition und Angemessenheitsempfinden im sozialen Kontext zum Gradmesser auch für Prozesse der Standardisierung und Destandardisierung. Letztere tendiert häufig zu einer normorientierten Lesart, die mit Sprachverfallsprognosen einhergeht. So bezeichnet sie vielfach die Auflösung sprachtypologischer Besonderheiten des Deutschen durch Sprachkontakt mit Migranten-, insbesondere Balkansprachen. ${ }^{18}$ Neuanalytische Züge würden im Deutschen mit seinen vier Kasus, dem synthetischen Komparativ und der Komposition sogar „besonders offen und schroff zutage(treten), weil sie heute hoch-

17 Munzinger Online/Duden - Das Wörterbuch der sprachlichen Zweifelsfälle; 8., vollst. überarb. und erw. Aufl., Bibliographisches Institut GmbH, Berlin, 2016 (abgerufen von Universitätsbibliothek Paderborn am 15.10.2018).

18 Zum Abbau der Kasusmorphologie als ,aktuell-beschleunigte Drift-Phase in Richtung Analytismus“ vgl. Uwe Hinrichs, „Sprachwandel oder Sprachverfall? Zur aktuellen Forschungssituation im Deutschen“, in: Muttersprache 119, 1 (2009) S. 47-57: 53. 
gradig beschleunigt auftauchen und das Normgefüge des Standards fühlbar erschüttern." 19

Standardisierung wird dagegen als Terminus uneinheitlich verwendet. Koch und Oesterreicher beschreiben die Standardisierung der Schriftsprache als einen der Stabilität dienenden Prozess der Selektion und Kodifizierung, bei dem , auch Abwahlen getroffen (werden), die den sozialen und situativ-kommunikativen Anforderungen der Distanzsprache Rechnung tragen“" ${ }^{20}$ und der Gefahr läuft, in Sprachpurismus umzuschlagen, je nach Durchlässigkeit der kodifizierten Norm. So sei es nicht verwunderlich, dass Selektionsprozesse nur außersprachlich motiviert sind, etwa durch ,politische(n) Machtzuwachs, ethnische Selbstbehauptung, Zentralismus, ökonomische Stärke, kulturelle Strahlkraft oder religiöses Engagement. Das sprachinterne Kriterium, nach dem als Schriftsprache diatopische Kompromißvarietäten bevorzugt werden, ist daher nirgendwo zwingend". ${ }^{21}$

Die Herausbildung eines schriftsprachlichen Gebrauchsstandards in einem nicht normativen Sinne wird von Koch und Oesterreicher unter dem Oberbegriff Ausbau behandelt und umfasst morphologische und syntaktische Besonderheiten der kompakten Satzformate, der Textphorik, der semantischen Progression, der Textgliederung und der Notwendigkeit zur expliziten Verkettung. Die Verbindung zwischen grammatischer Form und sprachlicher Handlung wird im Sinne einer Grammatik als frozen pragmatics im Sozialkonstruktivismus bei Berger und Luckmann und in der frühen Pragmatik bei Ehlich und Rehbein gezogen. Dort kommt der Standardisierung sprachlicher Formen als verfestigter Muster der Sinn zu, sprachliche Handlungsfähigkeit herzustellen und zu garantieren: „Sprachliche Handlungsmuster, oder abkürzend gesagt, Muster, sind also die Formen von standardisierten Handlungsmöglichkeiten, die im konkreten Handeln aktualisiert und realisiert werden. [...] Jedes Muster ist auf einen spezifischen Zweck potentieller Handelnder bezogen: es wird durch diesen Zweck strukturiert". ${ }^{22}$

Beide Traditionen konvergieren in der diskurslinguistischen Theoriebildung mit einem pragmatischen Sprachbegriff als Fundament. Dieser ,verlangt aber den Bezug zu außersprachlichen Faktoren, und diskurslinguistische Konzepte zeichnen sich vor allem dadurch aus, dass sie immer schon über rein sprachliche Faktoren hinausweisen und sich als Effekt von Diskursen in Vergegenständlichungen manifestieren. ${ }^{{ }_{223}}$ Diese Parole-Perspektive führt letztlich zu

19 Ebd.

20 Peter Koch/Wulf Oesterreicher, „Funktionale Aspekte der Schriftkultur, Schriftlichkeit und Sprache", in: Hartmut Günther/Otto Ludwig (Hg.), Schrift und Schriftlichkeit: ein interdiziplinäres Handbuch internationaler Forschung, Berlin, New York, NY, 1994,: S. 587-604: 598.

21 Ebd.

22 Konrad Ehlich/Jochen Rehbein, „Sprachliche Handlungsmuster“, in: Hans-Georg Soeffner (Hg.), Interpretative Verfahren in den Sozial- und Textwissenschaften, Stuttgart, 1979, S. 243274: 250 .

23 Constanze Spieß, „Linguistische Genderforschung und Diskurslinguistik. Theorie - Methode - Praxis“, in: Susanne Günthner/Dagmar Hüpper/Constanze Spieß (Hg.), Genderlinguistik. 
einem dynamischen Grundverständnis sprachlicher Formen. Die Vorstellung von fixierten, kontextlosen Form-Funktionspaaren weicht der Annahme auch diskontinuierlich realisierter Konstruktionen, in denen kontextspezifisch über Modalitätsgrenzen hinweg bildliche oder andere außersprachliche Elemente konstellativ zusammenwirken. Günthner nennt hier in Bezug auf gesprochensprachliche Daten prosodische, lexiko-semantische, sequenzielle und räumliche Merkmale und schlägt daher vor,

Konstruktionen als Orientierungsmuster zu betrachten, deren Instantiierung im Hier und Jetzt der Interaktion erfolgt. Interagierende stellen somit Beziehungen zwischen der sich momentan entfaltenden Interaktion und vergangenen Erfahrungen her, indem sie sedimentierte Muster re-aktualisieren. Zwischen sedimentiertem Wissen und dem tatsächlichen Gebrauch im betreffenden Kontext liegt eine bi-direktionale Beziehung vor: Das Wissen um Konstruktionen und Muster steuert einerseits die Produktion und Rezeption sprachlicher Formen und Funktionen, zugleich beeinflussen die aktuellen Gebrauchsweisen wiederum deren Formen und Funktionen. ${ }^{24}$

Diese wechselseitigen Veränderungen treten auch bei Schema-/Konzeptmischungen (blending) auf, wenn beispielsweise eine Leitmetapher (wie Fußball) zur Beschreibung politischer oder kultureller Zusammenhänge eingesetzt wird und durch diese Übertragung selbst einen Schemawandel erfährt.25 Winkler weist in diesem Zusammenhang darauf hin, dass jede Schema-Aktualisierung Abstraktionen voraussetzt, die Wahrnehmungen filtern, und sich in wiederholten und perspektivischen Instantiierungen Schemata (stetig) verändern. ${ }^{26}$

Bezogen auf begriffliche und durch sprachliche Muster geprägte Wahrnehmungsbedingungen gehen Berger und Luckmann davon aus, dass die Wahrnehmung von Phänomenen der alltäglichen Wirklichkeit durch sprachliche Objektivationen bereits ,vor-arrangiert“ ist. ${ }^{27}$ Mittels der ihr inhärenten Perspektivität vergegenständlicht Sprache Erfahrung und macht sie als Wissensobjekt zugänglich ${ }^{28}$, so dass Weltausschnitte mit (diskursiv bedingter) wechselnder, Wirklichkeitsdichte" entstehen.

Sprachliche Konstruktionen von Geschlechtsidentität, Berlin, New York, NY, 2012, S. 5485: $63 \mathrm{f}$.

$24 \mathrm{Zu}$ dieser Kritik an der Konstruktionsgrammatik vgl. Susanne Günthner, „Von Konstruktionen zu kommunikativen Gattungen: Die Relevanz sedimentierter Muster für die Ausführung kommunikativer Aufgaben“, in: Deutsche Sprache 34, 1/2 (2006), S. 173-190: 185.

25 Vgl. Alexander Ziem, „Lexikalische Felder, konzeptuelle Metaphern und Domänenmischungen im Interdiskurs Fußball“, in: Zeitschrift für Semiotik 34, 3/4 (2010), S. 305-328.

26 Vgl. Hartmut Winkler ,Schemabildung - Eine Maschine zur Umarbeitung von Inhalt in Form“, in: Tobias Conradi/Gisela Ecker/Norbert Otto Eke/Florian Muhle (Hg.), Schemata und Praktiken, München, 2012, S. 15-35: 21 f. und 25.

27 Peter L. Berger/Thomas Luckmann, Die gesellschaftliche Konstruktion der Wirklichkeit. Eine Theorie der Wissenssoziologie, 3. Aufl., Frankfurt/M., 1972, S. 24.

28 Ebd., S. 72. 


\section{Standardisierung als , semantischer Kampf ${ }^{\star}$}

In diskurssemantischer Sicht wird verstehensrelevante ,Wirklichkeit' als Prozess des Relevantsetzens semantischer Aspekte erfasst. Dieser soll im Folgenden am Beispiel der durch die Ereignisbezeichnung Kalter Krieg im KrimDiskurs ab März 2014 evozierten, framebezogenen Standardwerte betrachtet werden, um schließlich die Verbindung zwischen der (Re-)Standardisierung und seiner Naturalisierungsdimension zu bestimmen. Den Anlass für diesen Diskurs markiert das Ereignis der russischen Besetzung der ukrainischen Schwarzmeer-Krim, die aus westlicher Perspektive als völkerrechtliche Annexion interpretiert wurde. Weil das Szenario Erinnerungen an die imperiale Machtpolitik der Sowjetunion wachruft, ist in den Massenmedien bald von zurückgekehrten alten Schreckgespenstern die Rede ( $S Z$ vom 18. März 2014, „Krim-Annexion - Putins neues Russland“), und so entfaltet sich die Deutungsfolie des Kalten Kriegs entlang semantischer Standardwerte, die an der sprachlichen Oberfläche durch Verbindungen mit den Lexemen Block, Feind, Ost-West-X, Krise und Konflikt aktualisiert werden. Schließlich setzt ein öffentlicher Metadiskurs über den Ereignisnamen ein, ein kollektives, entautomatisierendes Zweifeln darüber, ob das „Erklärmuster der Blockkonfrontation" deskriptiv adäquat ist und welche Gefahr seine Wiederbelebung hinsichtlich eines konstruktiven Wirklichkeitseffektes birgt. Überschriften wie „Das Gerede vom Kalten Krieg“, „Die Mär vom neuen Kalten Krieg“ oder „Ein neues Spielfeld für Kalte Krieger", wertende Prädikate in Bezug auf die Einsetzung des Ereignisnamens wie ,gefährlich“, „,falsch“, „,zu befürchten“, „gespenstisch" dokumentieren den normativen Zug der Argumentation.

Um zu ermitteln, wie der Diskurs in einem Zeitraum von sechs bis acht Wochen die Blackbox des historischen Ereignisnamens öffnet und Standardwerte umbildet, wurden in einem ersten Teilkorpus zu dieser Schema-Aktualisierung 34 Artikel aus überregionalen deutschen Zeitungen zum Suchstichwort Kalter Krieg im Kontext der Krim-Krise im Zeitraum vom 1. März 2014 bis 16. Mai 2014 zusammengestellt. Der Diskurs folgt in diesem Stadium einer allgemeinen Krisenrhetorik und gerät in ein Wechselspiel aus Dramatisieren und Bagatellisieren, das durch die komplexitätsreduzierende Wirkung des Framings einen vorerst ,abstrakten' Schrecken (Blockbildung) auf den Plan ruft und das reale Leid der ukrainischen Bevölkerung in der Darstellung reduziert. Zudem stellen die konzeptuell vorgebahnten Frames und Topoi geschichtlich-politischer Diskurse kommunikative Anschlusspotenziale dar ${ }^{29}$, die - selbst wenn sich in den Ausschnitten einzelne Kommentatoren zu Wort melden oder einzelne Politiker zitiert werden - Spuren sprachlich-diskursiver

29 Vgl. Klaus-Peter Konerding, „Grundlagen einer linguistischen Schematheorie und ihr Einsatz in der Semantik“, in: Inge Pohl (Hg.), Methodologische Aspekte der Semantikforschung, Frankfurt/M. (u. a.), 1997, S. 57-84. mit Bezug auf Dietrich Busse, Textinterpretation, Sprachtheoretische Grundlagen einer explikativen Semantik, Opladen, 1992 und Hans-Jürgen Heringer, Lesen, Lehren, Lernen. Eine rezeptive Grammatik des Deutschen, Tübingen, 1989. 
Automatismen erkennen lassen. Die Ereignisbezeichnung Kalter Krieg weist in dem betrachteten Diskursausschnitt Kennzeichen einer diskurssemantischen Grundfigur auf, die von Ziem bestimmt wird durch metakommunikative Behandlung, frequentes Auftreten in bestimmten Diskursausschnitten bzw. -zeiträumen und die Re-Aktualisierung verhältnismäßig konstanter Standardwerte:

Von einer diskurssemantischen Grundfigur kann man genau dann sprechen, wenn (i) es sich dabei um ein Diskurselement handelt, auf das häufig metasprachlich Bezug genommen wird, (ii) dasselbe Element zumindest temporär signifikant häufig innerhalb eines diskursiven Zusammenhangs auftritt und (iii) die Inhaltsseite des Diskurselements eine Reihe von zeitlich persistenten Standardwerten aufweist, so dass dasselbe Diskurselement auch in anderen Diskursen wirksam werden kann. ${ }^{30}$

Im Folgenden möchte ich am Beispiel der auf der politischen Wärme-KälteMetaphorik aufruhenden Nominalphrase Kalter Krieg als semantischer Grundfigur im Diskurs um die Annexion der Krim zeigen, dass in der Entfaltung des Diskurses Deutungsschemata als Automatismen der Herstellung eines öffentlichen Diskursgegenstands wirksam werden (Objektivierung), selbst dann, wenn eine metakommunikative Zurückweisung der politischen Ereignisbezeichnung dazu führt, dass das Konzept Kalter Krieg drei Monate später kaum mehr explizit genannt wird. Um diese Annahme zu überprüfen, wurde ein zweites Teilkorpus mit 76 Artikeln aus überregionalen Zeitungen zum Suchstichwort Krim zwischen dem 17. Juli 2014 und dem 10. August 2014 erhoben, das seine Intensität aus dem diskursauslösenden Ereignis des Absturzes der Passagiermaschine MH17 über der umkämpften Ostukraine gewinnt. In der Analyse stellt sich heraus, dass das einmal aktualisierte Schema das Feld des Sagbaren für den weiteren Verlauf dieses Diskurses mit den (angepassten) Standardwerten der Frame-Attribute absteckt, wenngleich es vereinzelt noch explizit aufgegriffen wird, wie im Falle des durch eine Journalistennachfrage provozierten und dabei negierten Obama-Zitats „Das ist kein neuer kalter Krieg“. 31

\section{Die Datenanalyse im Einzelnen: zur Rolle von Standardwerten im Diskurs}

Im Diskursbeispiel tritt das politische Ereignis der kriegerischen Auseinandersetzungen auf der Krim durch die Wahrnehmung der musterhaft instantiierten Standardwerte in das Kalte-Krieg-Schema ein. Das implizite Wissen erweist sich dabei als prinzipiell bewusstseinsfähig und erscheint im Falle der diskurssemantischen Grundfigur des Kalten Kriegs sogar anfällig für metadiskursive

30 Alexander Ziem, Frames und sprachliches Wissen. Kognitive Aspekte der semantischen Kompetenz, Berlin, New York, NY, 2008, S. 400 f.

${ }^{31}$ Die Welt online, 30.07.2014, „Ukraine-Krise. MAN-Chef unterstützt harte Sanktionen gegen Putin“. 
Verhandlungen, deren Abschluss den diskursiv modifizierten Frame wieder in Funktion bringt. Dem entfalteten Schema als epistemologische Größe bleibt eine hermeneutische Perspektive inhärent, womit insbesondere über die metaphorische Kontextbildung Naturalisierungseffekte entstehen. ${ }^{32}$

$\mathrm{Zu}$ den Bedingungen, unter denen der Ereignisname als Deutungsmuster aufgerufen wird, gehört das Auftreten salienter Frameelemente, d. h. hochfrequenter Füllwerte: Standardwerte wie beispielsweise Ost-West-Konflikt für das Attribut Art des Ereignisses, nukleare Bedrohung für die Ereignischarakteristika oder Friedensdividende für die Ereignisfolgen. Aber welche Position nehmen Standardwerte in der Architektur instantiierter Frames ein? Standardwerte oder default values gehören neben Attributen (Slots) und Füllwerten (filler) zu den miteinander verbundenen Strukturelementen von Frames, die als Repräsentations- und Organisationsformate verstehensrelevanten Wissens ${ }^{33}$ in der deutschsprachigen Framesemantik diskursbezogen und korpusbasiert vor allem von Busse, Ziem, Wengeler und Fraas modelliert und in ihrer rekursiven Vernetzung beschrieben wurden. Slots werden als Leerstellen gefüllt durch sinnvolle Fragen, die der frameevozierende Ausdruck aufwirft, Füllwerte ergeben sich in einem konkreten Wertebereich in Form von Wörtern, Syntagmen oder Prädikationen aus dem betrachteten Datenmaterial. Ebenso wie die Salienz bzw. Zentralität der Slots auf Basis der Menge der instantiierten Füllwerte (Type-Frequenz) ermittelt wird, können hochfrequente Füllwerte (Token-Frequenz) als Standardwerte eines Slots inferiert werden. Slots sind Produkte von Abstraktionsprozessen, die ausgewählte Aspekte eines Frames in den Vordergrund der Wahrnehmung rücken ${ }^{34}$, während es sich bei den Standardwerten meist um musterhaft im Diskurs realisierte Lexeme/Prädikationen handelt. Sinken diese salienten Wissenselemente ins kollektive Gedächtnis ab, müssen sie ausdrucksseitig nicht mehr erscheinen und können als nicht-verbalisierter, durchschnittlich erwartbarer Füllwert eines Frameattributs für das Verständnis eines Diskursausschnitts vorausgesetzt werden. Explizierungsbedürftig ist meist nur die Abweichung von diesem Standardverständnis.

Konkrete Füllwerte verfestigen sich vor allem durch hohe Auftretenshäufigkeit innerhalb eines Diskurses zu Standardwerten. „In der Folge“, resümiert Ziem, ,etabliert sich eine ,kognitive Routine“ (Langacker 1987:163), hier: eine rekurrent wirksame Verbindung zwischen einem Frageaspekt (einer Leerstelle) und einem Inhaltsaspekt (einem Standardwert)." ${ }^{\text {"35 }}$

32 Beispiele aus dem Teilkorpus II sind u. a. neue Eiszeit, ökonomische Eiszeit, Eiszeit zwischen Russland und dem Westen, abgekühlte Beziehungen sowie Abkühlung der russischen Konjunktur.

33 Vgl. Kathrin Beckers, Kommunikation und Kommunizierbarkeit von Wissen. Prinzipien und Strategien kooperativer Wissenskonstruktion, Berlin, 2012, S. 76-83.

34 Vgl. Konerding (1997), Grundlagen einer linguistischen Schematheorie, S. 58.

35 Alexander Ziem, „Frame-Semantik und Diskursanalyse - Skizze einer kognitionswissenschaftlich inspirierten Methode zur Analyse gesellschaftlichen Wissens", in: Ingo H. Warnke/ Jürgen Spitzmüller (Hg.), Methoden der Diskurslinguistik. Sprachwissenschaftliche Zugänge zur transtextuellen Ebene, Berlin, 2008, S. 89-116: 108. Frames und ihre Elemente stellen 
Es entstehen musterhaft konfigurierte Strukturen innerhalb eines Frames, die rekursiv selbst wiederum Frames bilden können oder umgekehrt den frameevozierenden Ausdruck (beispielsweise Kalter Krieg) als Standardwert (etwa des Frames Blockbildung) enthalten. Die Einbettungsverhältnisse werden durch morphosyntaktische Relationen und zwischen frameevozierendem Schlüsselwort und Standardwert bestimmt. Semantisches Wissen wird über die Transkription von Schlüsselwörtern in neuen Diskurszusammenhängen reorganisiert, die sich framesemantisch als Verfestigung neuer Default-Werte beschreiben lässt, d.h. „im selben Prädikationstyp wird nunmehr standardmäßig ein anderer Wert instantiiert. “"36

Wie lassen sich nun konkrete Standardwerte im Konzeptframe Kalter Krieg ermitteln? Der Ereignisname ist 1946 erstmals dokumentiert, gebraucht von Herbert B. Swobe, einem Mitarbeiter des US-amerikanischen Präsidentenberaters Bernard Baruch, und steht in einer Tradition von Wetter- und Naturmetaphern, die für die politische Kommunikation einschlägig sind (Deutscher Herbst, Prager/Arabischer Frühling, Tauwetterperiode). Er hat sich in den folgenden Jahrzehnten als Ereignisname ${ }^{37}$ für die permanente Situation des „Nicht-Friedens“"38 bzw. für den „Systemkonflikt zwischen dem kommunistischen Modell der staatssozialistischen ,Volksdemokratie' auf der einen und dem westlichen Modell der liberalkapitalistischen parlamentarischen Demokratie auf der anderen Seite" ${ }^{39}$ etabliert. Kennzeichnend für diese bipolare Situation der Konfrontation, die mit der Wiedervereinigung 1989 und dem Zusammenbruch der Sowjetunion endet, war die Blockbildung um die beiden Führungsmächte Sowjetunion und USA. In diese knappe Beschreibung gehen bereits viele Standardwerte der Frameattribute Beteiligte, Art des Konflikts, Ursache und Folge ein. Die metaphorische Kälte des Namensattributs verweist auf den Slot Bedrohungsart mit Prädikationen zu nuklearer Abschreckung, Atomwaffen, Wettrüsten, Eiserner Vorhang oder Wirtschaftsspionage, wobei die Bedeutungsaspekte ,nuklear' und ,atomar' hier zentral sind. Einen Anhaltspunkt zur Ermittlung von Standardwerten liefern die Kookkurrenzlisten zur Nominalphrase Kalter Krieg, für die das öffentliche Archiv des Deutschen Referenzkorpus (DeReKo) in Cosmas II ${ }^{40}$ insgesamt 31.911 Belege

dabei immer zugleich kognitive Einheiten und Einheiten der Theoriebildung dar bzw. sind „Formate der Organisation und der Rekonstruktion des verstehensrelevanten Wissens“ (Dietrich Busse, Frame-Semantik. Ein Kompendium. Einführung - Diskussion - Weiterentwicklung, Berlin, New York, NY, 2012, S. 539-540).

36 Ebd., S. 106.

37 Die Onymisierung zeichnet sich an der Großschreibung des Adjektivs ab, die nach Durchsicht der Konkordanzen in Cosmas II etwa ab 1992 überwiegt. Das kleingeschriebene Adjektiv im für den Titel des Beitrags gewählten Zitat bildet somit eine Ausnahme bzw. mag typisch für den Negationskontext sein.

38 Bernd Stöver, Der Kalte Krieg, 4. Aufl., München, 2012, S. 8.

39 Ebd., S. 7.

40 Vgl. http://www.ids-mannheim.de/cosmas2/web-app. Das DeReKo umfasst 42 Milliarden Wörter (Stand: 03.02.2018). 
zwischen 1949 und 2013 liefert (Eingabe: kalt* Krieg*), wobei die Treffermenge ab 1990 kontinuierlich steigt (was auch mit der Zunahme der Gesamttextmenge im Referenzkorpus zusammenhängt). Das Kookkurrenzprofil belegt eine Salienz des Folgen- und Wirkungslots (Friedensdividende, Zusammenbruch der Sowjetunion) sowie ausgeprägte Spuren metasprachlicher Verwendung: Als zentraler Slot stellt sich Deutungsmuster/Logik heraus (mit Füllwerten wie Schwarz-Weiß, Freund-Feind, anti-, Fronten, Block-), wobei das Lexem Logik in beiden Teilkorpora am häufigsten durch Genitivattribute erweitert wird (ermittelt über AntConc 3.2.4m), darunter (Logik) des nuklearen Aufrüstens, des Siegs und des Wettrüstens. Dass der Kalte-Krieg-Frame vom Ende her perspektiviert wird, belegen die Nomen, die in das belegstärkste syntagmatische Muster des Kalten Krieg(e)s eintreten: Ende, Relikte, Überbleibsel und Erbe.

\begin{tabular}{|l|l|l|l|}
\hline Zeitraum & neue $^{*}$ Kalte $^{*}$ Krieg & Kalte $^{*}$ Krieg $^{*}$ & $\begin{array}{l}\text { Anteil } \\
\text { (in Prozent) }\end{array}$ \\
\hline $1989-1991$ & 4 & 613 & 0,65 \\
\hline $1992-1997$ & 51 & 4980 & 1,02 \\
\hline $2000-2001$ & 16 & 2623 & 0,61 \\
\hline $2002-2003$ & 13 & 1807 & 0,72 \\
\hline $2004-2005$ & 24 & 1986 & 1,21 \\
\hline $2006-2007$ & 95 & 3262 & 2,91 \\
\hline $2008-2009$ & 148 & 4337 & 3,41 \\
\hline $2010-2011$ & 41 & 9868 & 0,42 \\
\hline $2012-2013$ & 21 & 2239 & 0,94 \\
\hline
\end{tabular}

6.2 - Tabelle 1: Häufigkeitsverteilung für die Attribuierung der Nominalphrase Kalter Krieg durch das Adjektiv neu, Korpusgrundlage: Belegsammlung aus dem

Deutschen Referenzkorpus (IDS Mannheim), ermittelt mit AntConc 3.2.4m

Die Adjektiverweiterung neue liefert einen Hinweis auf den metakommunikativen Einsatz als diskurssemantische Grundfigur, die, wie Tabelle 1 (Abb. 6.2) zeigt, vor allem 2008/09 einen hohen Anteil an den Gesamtverwendungen ausmacht. Anlass hierfür bot der Fünf-Tage-Krieg zwischen Russland und Georgien. Das Deutungsmuster wurde damals anhand explizierter Standardwerte diskutiert und überwiegend zurückgewiesen, wie der Textausschnitt aus Cosmas II exemplarisch zeigt:

Vor allem die Amerikaner fallen nun in die Rhetorik der Kalten Krieger zurück und wollen Moskau isolieren. Dem dürfen sich die Europäer - und vor allem die Deutschen - nicht anschließen. Sie müssen darauf drängen, dass die Nato-Staaten und Russland Kompromisse aushandeln. Dafür ist reden, reden und nochmal reden nötig. Der Westen muss selbstbewusst Flagge zeigen. Doch Drohgebärden sind vorerst überflüssig. (RHZ08/AUG.21592 Rhein-Zeitung, 26.08.2008; Dia$\log$ statt Isolation; Standardwerte hervorgehoben N. M. W.) 


\begin{tabular}{|c|c|c|}
\hline Standardwerte & $\begin{array}{l}\text { Anzahl und Belege } \\
\text { Teilkorpus I } \\
03-05 / 2014 \\
\end{array}$ & $\begin{array}{l}\text { Anzahl und Einzelbelege } \\
\text { Teilkorpus II } \\
07-08 / 2014\end{array}$ \\
\hline Kalt $*$ Krieg* $^{*}$ & 137 & 14 \\
\hline $\mathrm{X}$ des Kalten Kriegs/es & $\begin{array}{l}13 \\
\mathrm{X}=\text { Ende }(7), \text { Rückkehr }(1), \\
\text { Zeiten }(1), \text { Frontstellungen }(1)\end{array}$ & $\begin{array}{l}5 \\
\mathrm{X}=\text { Ende (2), Strukturen (2), } \\
\text { Zeiten (1) }\end{array}$ \\
\hline Bedrohung/bedrohen & 18 & 8 \\
\hline Atom-X & $\begin{array}{l}8 \\
\text { Atomwaffen }\end{array}$ & $\begin{array}{l} \\
\text { Atomwaffen (1), Atombomben } \\
\text { metaphor. (2), Atomrakete (1) }\end{array}$ \\
\hline Front/-/en & 3 & 6 \\
\hline Konfrontation & 20 & 7 \\
\hline $\begin{array}{l}\text { Ost-West-X } \\
\text { Ost und West }\end{array}$ & $\begin{array}{l}10 \\
\text { Konfrontation (4), Konflikt (3), } \\
\text { Achse (1), Gegensatz (1), Ost und } \\
\text { West (2), Ost gegen West (1) }\end{array}$ & $\begin{array}{l}3 \\
\text { Ost und West }\end{array}$ \\
\hline$\{k o n f l i k t\}$ & 69 & 111 \\
\hline$\{a n t i\}$ & $\begin{array}{l}17 \\
\text {-westlich (3), -amerikanismus (2), } \\
\text {-kommunismus (1), - russische (1) }\end{array}$ & $\begin{array}{l}14 \\
- \text { westlich (5),-faschistisch (2), } \\
\text {-kapitalistisch (1) }\end{array}$ \\
\hline$\{$ block $\}$ & $\begin{array}{l}12 \\
\text {-bildung (1), -frei (1), -denken (1) } \\
\text { - auseinandersetzung (1) }\end{array}$ & $\begin{array}{l}3 \\
\text { Macht- (2), -konfrontation (1) }\end{array}$ \\
\hline Spion/age & 5 & 7 \\
\hline$\{$ feind $\}$ & $\begin{array}{l}20 \\
\text { verfeindete Blöcke, Staatsfeinde, } \\
\text { feindselige Gruppierung, } \\
\text { Klassenfeind } \\
\end{array}$ & $\begin{array}{l}7 \\
\text { russlandfeindlichen Auslands, } \\
\text { innere Feinde, Freund-Feind- } \\
\text { Identifizierung }\end{array}$ \\
\hline$\{$ krise $\}$ & 125 & 109 \\
\hline Propaganda & 20 & $\begin{array}{l}13 \\
\text { bezogen auf Putin und Russland }\end{array}$ \\
\hline Symbol & $\begin{array}{l}11 \\
\text { Symbolpolitik (5) }\end{array}$ & $\begin{array}{l}4 \\
\text { darunter } 2 \text { symbolisch }\end{array}$ \\
\hline Sanktion/en & 59 & 311 \\
\hline$\{$ wirtschaft $\}$ & 63 & 232 \\
\hline
\end{tabular}

6.3 - Tabelle 2: Vergleich der Teilkorpora hinsichtlich der aktualisierten Standardwerte des Kalter-Krieg-Schemas

Tabelle 2 (Abb. 6.3) gibt einen Überblick über die Standardwerte des KalterKrieg-Frames, die im öffentlichen Diskurs über die Annexion der Krim revitalisiert (Konfrontation, Neutralität) werden, z. T. metaphorisch wie in der Nominalphrase Atombomben des Finanzkriegs. ${ }^{41}$ Das Beispiel illustriert auch die Standardwertumbildung von der Bedrohungsart des atomaren zum wirtschaftlichen Ruin. Es handelt sich dabei um eine Verschiebung, denn es hat bereits im Kalten Krieg - was im Metadiskurs der medialen Öffentlichkeit bestritten wird - wirtschaftliche Abschreckung durch Handelsbeschränkungen gegeben,

41 Als Atombomben des Finanzkriegs werden in einer Kolumne Zahlungssysteme bezeichnet, mit denen die Europäische Zentralbank Kredite an Russland verweigert und Konten sperrt, vgl. Spiegel Online vom 04. August 2014, „Die Spur des Geldes - Vom Finanz-Kriege“. 
die Wirtschaftsspionage und Wirtschaftsdiplomatie auf den Plan riefen (als Kookkurrenzpartner belegt).

Ebenso wie das Kriegsgeschehen in Georgien ein Jahr später nicht als Neuauflage des Kalten Kriegs interpretiert, sondern mit einer seiner Phasen als (neue) Eiszeit betitelt wird, entwickelt sich in Bezug auf die Ärabezeichnung während der Krim-Krise eine ähnliche Strategie, mit der sich eine Umdeutung zum Handelskrieg zwischen Russland und der EU vollzieht, ohne dass das Konzept (Kalter Krieg) weiterhin frequent aufgerufen wird. Auch diese Verschiebung hat Vorläufer, wie der nachfolgende Kommentar zu CIA-Chef Woolseys Äußerungen über das Ausmaß der Wirtschaftsspionage belegt:

Woolseys Eingeständnis macht deutlich, dass Washington die Abwehrmittel des Kalten Krieges jetzt für den ,Kalten Wirtschaftskrieg ' benutzt. Und die Feindlinien haben sich verschoben. Der neue Feind sind die Wirtschaftspartner der Vereinigten Staaten. Die ,nationalen Interessen' der USA sind nicht länger die bedrohte territoriale Integrität und die innere Sicherheit im klassischen Sinn: Die nationalen Interessen der Vereinigten Staaten sind die nationalen Wirtschaftsinteressen geworden. ${ }^{42}$

Die naturalisierende Wirkung des (Re-)Framings kann schließlich als Verselbstständigung der polarisierenden Semantik der Interpretationsfolie des Kalten Krieges und ihrer impliziten Kältemetaphorik beschrieben werden, die sich trotz der metakommunikativen Zurückweisung des Begriffs durchsetzt, festzumachen am Vorkommen zentraler Standardwerte des Konzeptframes Kalter Krieg, die aufgerufen, modifiziert und interdiskursiv verknüpft werden. Die in der Ereignisbezeichnung Kalter Krieg onymisierte Kälte-Metaphorik wird revitalisiert (Eiszeit) und verbindet sich durch Standardwert-Überschneidungen (Sieger, Gegnerschaft) insbesondere mit dem Interdiskurs des Spiels sowie einer allgemeinen Krisenrhetorik, für die der Singularitäts-Topos, der Topos der düsteren Zukunft und der 5-vor-12-Topos charakteristisch sind. ${ }^{43}$ Als prominent erweist sich zudem das Argumentationsmuster der an pädagogische Maßnahmen erinnernden Zuschreibung von Selbstverantwortlichkeit, die mit einer fußballsprachlichen Eigentor-Logik korrespondiert. Die beschriebenen Anschlüsse finden sich kondensiert in folgendem Beleg:

Und Wladimir Putin, Präsident ab dem Jahr 2000, wollte zum Westen vor allem wirtschaftliche Beziehungen aufbauen. Aber er dachte nicht daran, nach den politischen Regeln des Westens zu spielen. Nun drehen EU und USA den Spieß um. Sie wollen Putin zwingen, seinen politischen Kurs zu ändern mit wirtschaftlichen Sanktionen. Putin muss sich entscheiden. Für ihn haben geopolitische Interessen Vorrang vor wirtschaftlichen. Das hat er bereits mit der Annexion der Krim im März demonstriert, die Russlands Bevölkerung und Wirtschaft auch ohne Sanktionen schon teuer zu stehen kam. Und auch diesmal scheint Putin fest

42 V00/APR.17419 Vorarlberger Nachrichten vom 06. April 2000, S. A2, Ressort: Politik.

43 Vgl. Martin Wengeler/Alexander Ziem, ,,Wirtschaftskrisen“ im Wandel der Zeit. Eine diskurslinguistische Pilotstudie zum Wandel von Argumentationsmustern und Metapherngebrauch“, in: Achim Landwehr (Hg.), Diskursiver Wandel, Wiesbaden, 2010, S. 335-354. 
entschlossen, seine Politik der Abgrenzung zum Westen fortzusetzen. Die absehbaren wirtschaftlichen Schäden dieser Strategie nimmt er in Kauf. Doch ist auch die Bevölkerung dazu bereit? ${ }^{44}$

\section{Fazit}

In Bezug auf sprachliche Automatismen finden sich Bestätigungen für die Annahme, dass die beiden Standardbegriffe in Grammatik und (Frame-)Semantik, der Standard als Gebrauchsnorm und der Standard als Ergebnis kollektiver (normalisierender) Reflexion, miteinander zusammenhängen. Zweifelsfälle auf der semantischen Ebene entpuppen sich als Ausdrucks- und Bedeutungskonkurrenzen, in beiden Bereichen wird der Standard einmal über das Frequenzkriterium und einmal in Bezug auf eine mit Normierungsintentionen versehene metasprachliche Thematisierung definiert.

In der framesemantischen Beschreibung von Re-Standardisierungsprozessen im Sinne einer Umbildung und Anpassung von Standardwerten ergeben sich die Phasen der Transkription im Zuge einer diskursiven Wiederaufnahme und der Metakommunikation, d. h. der beschreibungssprachlichen Anpassung eines Schemas an eine neue diskursive Wirklichkeit, womit auch Anschlüsse an verwandte diskursspezifische Topoi und Metaphern entstehen. Standard erweist sich in diesem framesemantischen Bezug zunächst als Gebrauchsstandard. Eine bestimmte Konstellation von Standardwerten kann ein Schema evozieren, das diskursübergreifend modifiziert wird. Standardwerte sind dabei bevorzugte Kandidaten für eine metakommunikative Behandlung. Die Entautomatisierung schafft Schnittpunkte zwischen den scheinbar konträren Standardbegriffen: Der Normdiskurs verändert den Gebrauchsstandard.

Das spezifische Framing im Krim-Diskurs folgt Ein- und Ausschließungspraktiken mit der Besonderheit, dass das Vokabular der politischen Kälte, welche auf den Stand diplomatischer Beziehungen und auf die Bedrohungsart bezogen wird, den Diskurs strukturiert (Eiszeit, eisig, heiß, erwärmen). Dieser Mechanismus kann als ,Natürlichmachen“ auf zweierlei Weise verstanden werden: zum einen als Anschluss an einen Spenderbereich der Naturerscheinungen (Temperatur und Wetter), zum anderen an einen geschichtlichen Begriff, der metakommunikativ angepasst, d. h. restandardisiert wird und an andere Schemata anknüpft (etwa das Gewinner-Verlierer-Schema). Wenn man vom Naturalisierungsprozess als Mythenbildung sprechen möchte, wäre die ihres Sinns beraubte Form ${ }^{45}$ nicht mehr ,ausdrücklich' realisiert, vielmehr bliebe der Frame als Deutungsfolie über die transkodierten Standardwerte präsent und wirkt somit ,im Rücken` der am Diskurs beteiligten Subjekte. Zudem

44 Die WELT vom 4. August 2014, „Antiwestlicher Kurs - Europa wird Russland noch um Verzeihung bitten".

45 Roland Barthes, Mythen des Alltags, Frankfurt/M., 1987, S. 97. 
reproduziert das begriffliche Schema als semantischer Automatismus eine Relevanzstruktur, die den Konflikt im Hinblick auf eine mögliche Konfrontation der USA und Europas mit Russland perspektiviert. Das neue Ereignis wird typisiert als etwas Vertrautes: Dramatisierung (Spekulationen über die potenzielle Konfrontation politischer Machtblöcke) und Bagatellisierung (des Kriegsgeschehens und seiner Auswirkungen in der Ukraine) gehen Hand in Hand.

Abschließend lässt sich mit Blick auf das empirische Beispiel festhalten, dass sich das Kontextualisierungspotenzial des Ereignisnamens als Automatismus eines semantischen Schemas über einem konkreten Diskursausschnitt entfaltet. Was metadiskursiv aufgegriffen wird, schreibt sich in die Automatismen ein und verändert den Gebrauch grammatischer Varianten oder die Semantik gesellschaftlicher Schlüsselbegriffe. Insofern haben im Hinblick auf den Wandel sprachlicher Phänomene (moralische, präskriptive o. Ä.) Norm und empirischer Gebrauchsstandard eher den Charakter zweier Seiten einer Medaille, die - nach dem berühmten Diktum von de Saussure ${ }^{46}$ - nur insofern existiert als sie im Diskurs zirkuliert.

\section{Literatur}

Barthes, Roland, Mythen des Alltags, Frankfurt/M., 1987.

Beckers, Kathrin, Kommunikation und Kommunizierbarkeit von Wissen. Prinzipien und Strategien kooperativer Wissenskonstruktion, Berlin, 2012.

Berger, Peter L./Luckmann, Thomas, Die gesellschaftliche Konstruktion der Wirklichkeit. Eine Theorie der Wissenssoziologie, 3. Aufl., Frankfurt/M., 1972.

Busse, Dietrich, Textinterpretation, Sprachtheoretische Grundlagen einer explikativen Semantik, Opladen, 1992.

Ders., Frame-Semantik. Ein Kompendium. Einführung - Diskussion - Weiterentwicklung, Berlin, New York, NY, 2012.

Ders., ,Sprachnorm, Sprachvariation, Sprachwandel. Überlegungen zu einigen Problemen der sprachwissenschaftlichen Beschreibung des Deutschen im Verhältnis zu seinen Erscheinungsformen“, in: Deutsche Sprache 34, 4 (2007), S. 314-333.

Dammel, Antje, „Die schönen alten Formen ... Grammatischer Wandel der deutschen Verbalflexion - Verfall oder Reorganisation?“ in: Albrecht Plewnia (Hg.), Sprachverfall?: Dynamik - Wandel - Variation, Jahrbuch Institut für Deutsche Sprache, Berlin, 2014, S. 51-70.

Ehlich, Konrad/Rehbein, Jochen, „Sprachliche Handlungsmuster“, in: Hans-Georg Soeffner (Hg.), Interpretative Verfahren in den Sozial- und Textwissenschaften, Stuttgart, 1979, S. 243-274.

46 Ferdinand de Saussure, Linguistik und Semiologie. Notizen aus dem Nachlaß, gesammelt, übersetzt und eingeleitet von Johannes Fehr, Frankfurt/M., 1997, S. 107. 
Eichinger, Ludwig M./Kallmeyer, Werner, Standardvariation. Wie viel Variation verträgt die deutsche Sprache?, Jahrbuch Institut für Deutsche Sprache, Berlin, 2005.

Feilke, Helmuth, „Schulsprache - Wie Schule Sprache macht“, in: Susanne Günthner/ Wolfgang Imo/Dorothee Meer/Jan Georg Schneider (Hg.), Kommunikation und Öffentlichkeit: sprachwissenschaftliche Potenziale zwischen Empirie und Norm, Berlin, Boston, MA, 2012, S. 149-175

Fraas, Claudia/Meier, Stefan, „Multimodale Stil- und Frameanalyse - Methodentriangulation zur medienadäquaten Untersuchung von Online-Diskursen“, in: Kersten Sven Roth/Carmen Spiegel (Hg.), Angewandte Diskurslinguistik: Felder, Probleme, Perspektiven, Berlin, 2013, S. 135-162.

Günthner, Susanne, „Von Konstruktionen zu kommunikativen Gattungen: Die Relevanz sedimentierter Muster für die Ausführung kommunikativer Aufgaben“, in: Deutsche Sprache 34, 1/2 (2006), S. 173-190.

Heringer, Hans-Jürgen, Lesen, Lehren, Lernen. Eine rezeptive Grammatik des Deutschen, Tübingen, 1989.

Hinrichs, Uwe, ,Sprachwandel oder Sprachverfall? Zur aktuellen Forschungssituation im Deutschen“, in: Muttersprache 119, 1 (2009) S. 47-57.

Hüning, Matthias, „Standardsprachenideologie. Über Sprache als Mittel zur Ab- und Ausgrenzung“", in: Emmeline Besamusca/Christine Hermann/Ulrike Vogl (Hg.), Out of the Box: Über den Wert des Grenzwertigen, Wien, 2013, S. 105-122.

Klein, Wolf Peter, „Warum brauchen wir einen klaren Begriff von Standardsprachlichkeit und wie könnte er gefasst werden?“", in: Jörg Hagemann/Wolf Peter Klein/Sven Staffeld (Hg.), Pragmatischer Standard, Tübingen, 2013, S. 15-33.

Ders., „Sprachliche Zweifelsfälle als linguistischer Gegenstand. Zur Einführung in ein vergessenes Thema der Sprachwissenschaft“, auf: Linguistik Online 16, 4 (2003), online unter: http://www.linguistik-online.de/16_03/klein.html, zuletzt aufgerufen am 03.01.2019.

Koch, Peter/Oesterreicher, Wulf, „Funktionale Aspekte der Schriftkultur, Schriftlichkeit und Sprache“, in: Hartmut Günther/Otto Ludwig (Hg.), Schrift und Schriftlichkeit: ein interdiziplinäres Handbuch internationaler Forschung, Berlin, New York, NY, 1994, S. 587-604.

Konerding, Klaus-Peter, „Grundlagen einer linguistischen Schematheorie und ihr Einsatz in der Semantik“, in: Inge Pohl (Hg.), Methodologische Aspekte der Semantikforschung, Frankfurt/M. (u. a.), 1997, S. 57-84.

Langacker, Ronald W., Foundations of Cognitive Grammar. Vol. 1: Theoretical Prerequisites, Stanford, CA, 1987.

Löffler, Heinrich, „Wieviel Variation verträgt die deutsche Standardsprache? Begriffsklärung: Standard und Gegenbegriffe, in: Ludwig M. Eichinger/Werner Kallmeyer, Standardvariation. Wie viel Variation verträgt die deutsche Sprache?, Jahrbuch Institut für Deutsche Sprache, Berlin, 2005, S. 7-27.

Müller, Christoph, „Wat ihr normal nennt ...- Ein didaktisches Dilemma und die Chance, aus der Not eine Tugend zu machen“, in: Mathilde Hennig/Christoph Müller (Hg.), Wie normal ist die Norm? Sprachliche Normen im Spannungsfeld von Sprachwissenschaft, Sprachöffentlichkeit und Sprachdidaktik, Kassel, 2009, S. 60-83.

Munzinger Online/Duden - Das Wörterbuch der sprachlichen Zweifelsfälle; 8., vollst. überarb. und erw. Aufl., Bibliographisches Institut GmbH, Berlin, 2016 (abgerufen von Universitätsbibliothek Paderborn am 15.10.2018).

Nübling, Damaris, „Der alemannische Konjunktiv II zwischen Morphologie und Syntax: Zur Neuordnung des Konjunktivsystems nach dem Präteritumschwund“, in: Arno 
Ruoff/Peter Löffelad (Hg.), Syntax und Stilistik, Beiträge der 12. Arbeitstagung zur alemannischen Dialektologie, Idiomatica 18, Tübingen, 1997, S. 107-121.

Dies., „Unter großem persönlichem oder persönlichen Einsatz? Der sprachliche Zweifelsfall adjektivischer Parallel- vs. Wechselflexion als Beispiel für aktuellen grammatischen Wandel“", in: Klaus-Michael Köpcke/Arne Ziegler (Hg.), Grammatik Lehren, Lernen, Verstehen, Zugänge zur Grammatik des Gegenwartsdeutschen, Berlin, Boston, MA, 2011, S. 175-196.

Peschel, Corinna, „Grammatische Zweifelsfälle als Thema des Deutschunterrichts? Das Beispiel der ,schwachen Maskulina“", in: Mathilde Hennig/Christoph Müller (Hg.), Wie normal ist die Norm? Sprachliche Normen im Spannungsfeld von Sprachwissenschaft, Sprachöffentlichkeit und Sprachdidaktik, Kassel, 2009, S. 3959.

Saussure, Ferdinand de, Linguistik und Semiologie. Notizen aus dem Nachlaß, gesammelt, übersetzt und eingeleitet von Johannes Fehr, Frankfurt/M., 1997.

Schneider, Jan Georg/Albert, Georg, ,Medialität und Standardsprache - oder: Warum die Rede von einem gesprochenen Gebrauchsstandard sinnvoll ist"“, in: Jörg Hagemann/Wolf Peter Klein/Sven Staffeld (Hg.), Pragmatischer Standard, Tübingen, 2013, S. 49-60.

Spieß, Constanze, „Linguistische Genderforschung und Diskurslinguistik. Theorie Methode - Praxis“, in: Susanne Günthner/Dagmar Hüpper/Constanze Spieß (Hg.), Genderlinguistik. Sprachliche Konstruktionen von Geschlechtsidentität, Berlin, New York, NY, 2012, S. 54-85.

Stöver, Bernd, Der Kalte Krieg, 4. Aufl., München, 2012.

Wengeler, Martin/Ziem, Alexander, „',Wirtschaftskrisen“ im Wandel der Zeit. Eine diskurslinguistische Pilotstudie zum Wandel von Argumentationsmustern und Metapherngebrauch“, in: Achim Landwehr (Hg.), Diskursiver Wandel, Wiesbaden, 2010, S. 335-354.

Winkler, Hartmut, „Schemabildung - Eine Maschine zur Umarbeitung von Inhalt in Form“, in: Tobias Conradi/Gisela Ecker/Norbert Otto Eke/Florian Muhle (Hg.), Schemata und Praktiken, München, 2012, S. 15-35.

Zahradníček, Lucia, „Gewinkt oder gewunken? Wie wird winken ,normal“ flektiert?“, in: Mathilde Hennig/Christoph Müller (Hg.), Wie normal ist die Norm? Sprachliche Normen im Spannungsfeld von Sprachwissenschaft, Sprachöffentlichkeit und Sprachdidaktik, Kassel, 2009, S. 130-149.

Ziem, Alexander, Frames und sprachliches Wissen. Kognitive Aspekte der semantischen Kompetenz, Berlin, New York, NY, 2008.

Ders., „Frame-Semantik und Diskursanalyse - Skizze einer kognitionswissenschaftlich inspirierten Methode zur Analyse gesellschaftlichen Wissens", in: Ingo H. Warnke/ Jürgen Spitzmüller (Hg.), Methoden der Diskurslinguistik. Sprachwissenschaftliche Zugänge zur transtextuellen Ebene, Berlin, 2008, S. 89-116.

Ders., „Lexikalische Felder, konzeptuelle Metaphern und Domänenmischungen im Interdiskurs Fußball“, in: Zeitschrift für Semiotik 34, 3/4 (2010), S. 305-328. 



\section{ROLAND BLESS}

\section{STANDARDISIERUNG IM INTERNET - WER GESTALTET DAS INTERNET DER ZUKUNFT?}

Das Internet ist zu einem wesentlichen und sogar prägenden Bestandteil unserer modernen Informationsgesellschaft geworden. Der gesellschaftliche Einfluss wird einerseits nicht nur durch Firmen deutlich, die ohne das Internet keine Geschäftsgrundlage hätten (z. B. Amazon, Facebook, eBay, Google, Netflix, YouTube), sondern auch durch das Bedürfnis - vor allem der jüngeren Generation - mittels Smartphone permanent online zu sein, insbesondere, um Kontakte in Plattformen sozialer Netze wie Facebook, Instagram oder Twitter zu pflegen. Weiterhin hat das Internet einen starken Einfluss auf technologische Entwicklungen ausgeübt, der sich beispielsweise in der Ablösung der traditionellen leitungsvermittelten Telefonie-Infrastruktur durch die paketvermittelte Voice-over-IP-Technologie, basierend auf dem Internet-Protokoll IP, manifestiert.

Technisch gesehen ist das Internet ein Netz aus Netzen ${ }^{1}$ und ein damaliges Hauptziel der Entwicklungsingenieure war das Erreichen der sogenannten Interkonnektivität ${ }^{2}$, d. h. der Zusammenschluss verschiedenster Netze zu einem globalen Netz, in dem jedes Endgerät jedes andere angeschlossene Endgerät erreichen kann. Damit Kommunikation überhaupt gelingen kann, muss ein Protokoll festlegen, in welchem Format Daten ausgetauscht werden und wie der Ablauf der Kommunikation vonstattengeht. Solche Protokolle sind auch aus dem täglichen Leben bekannt. Damit sich zwei Menschen verständigen können, müssen sie sowohl über eine gemeinsame Sprache verfügen als auch bestimmten Regeln folgen, denn ein Gespräch läuft nach bestimmten Regeln ab, z. B. Begrüßung, abwechselnde Fragen und Antworten, Verabschiedung.

Kommunikation - egal ob technisch oder zwischenmenschlich - folgt bestimmten Regeln, die zwischen den Kommunikationspartnern vereinbart sein müssen. Üblicherweise betreffen die Regeln sowohl die Sprache (technisch: Protokollformate) als auch den Ablauf. Eine Einigung auf solche Regeln ist daher notwendig und erfolgt für technische Systeme meistens über Standardisierung. Damit möglichst viele Teilnehmer miteinander kommunizieren können, sollten die Standards offen, also nicht proprietär sein. Interessanterweise konnten sich in der Vergangenheit weder proprietäre Protokolle (wie z. B. IBMs SNA, Digital Equipments DecNet oder Novells IPX) noch alternative

In diesem Kontext sind digitale Kommunikationsnetze gemeint.

2 David D. Clark, „The Design Philosophy of the DARPA Internet Protocols“, in: Proc. SIGCOMM '88, Computer Communication Review, 18, 4 (1988), S. 106-114. 
Ansätze anderer Standardisierungsgremien (z. B. ISO/OSI, ATM) durchsetzen. Die Erfolgsfaktoren des Internets liegen daher in seiner Offenheit und der ,Einfachheit' seiner Kernprotokolle.

Im Bereich des Internets lassen sich im Wesentlichen zwei Organisationen nennen, die maßgeblich die Technik gestalten bzw. standardisieren: das W3C (World Wide Web Consortium) ${ }^{3}$, das sich primär um Protokolle und Technik bezogen auf das World Wide Web kümmert, sowie die IETF (Internet Engineering Task Force) $)^{4}$, die sich um die Protokolle der Internet-Infrastruktur kümmern, neben dem bereits erwähnten Internet-Protokoll beispielsweise auch weitere Kernprotokolle wie das zuverlässige Transportprotokoll TCP (Transmission Control Protocol), das Verzeichnisprotokoll DNS (Domain Name System), das Routingprotokoll BGP (Border Gateway Protocol), das Adressenzuteilungsprotokoll DHCP (Dynamic Host Configuration Protocol) oder das HTTP (Hypertext Transfer Protocol) zur Übertragung von WWWInhalten. Des Weiteren gibt es noch zahlreiche andere Standardisierungsgremien, die vor allem Kommunikationstechnik im Netzzugangsbereich entwickeln. Allen voran ist das IEEE (Institute of Electrical and Electronics Engineers $)^{5}$ zu nennen, welches u. a. Technik für lokale Netze wie Ethernet oder Wireless LAN entwickelt. Darüber hinaus sind noch das Broadband Forum für DSL-Technik, Cable Labs für kabelbasierte Zugänge oder $3 G P P$ für Mobilfunknetze zu nennen. Von den zuvor genannten Standardisierungsgremien haben sich die IETF, das W3C und die IEEE zu offenen Standards bekannt. ${ }^{6}$ Dies geschah insbesondere zur Abgrenzung zu staatlichen Technologiemandaten und politischer Einflussnahme auf die Standardisierung, wie es z. B. in der ITU-T (International Telecommunication Union - Telecommunication Sector) ${ }^{7}$ praktiziert wird. Die ITU-T ist eine von den Mitgliedsstaaten der UN (United Nations) legitimierte Organisation. Die „Open Stand“-Prinzipien umfassen das Bekenntnis zu einem fairen, transparenten und offenen Prozess, die Vorgabe, dass die Organisation nicht durch einzelne Unternehmen oder Gruppen dominiert wird und sie schließlich die Möglichkeit bietet Beschwerde einzulegen.

Im Folgenden wird primär auf die IETF eingegangen, da sie hauptsächlich für die technologische Weiterentwicklung im Internet und die offene Standardisierung der heutigen Internet-Protokolle verantwortlich ist. Das erklärte Ziel

3 „World Wide Web Consortium“, auf: W3C, April 2018, online unter: http://www.w3c.org, zuletzt aufgerufen am 28.11.2018.

4 „Internet Engineering Task Force“, auf: Internet Engineering Task Force, April 2018, online unter: https://ietf.org/, zuletzt aufgerufen am 28.11.2018.

5 „Institute of Electrical and Electronics Engineers“, auf: IEEE, April 2018, online unter: http:// www.ieee.org/, zuletzt aufgerufen am 28.11.2018.

6 „Open Standards“, auf: Open Stand, April 2018, online unter: http://open-stand.org/, zuletzt aufgerufen am 28.11.2018.

7 „International Telecommunication Union“, auf: ITU, Januar 2015, online unter: https://www. itu.int, zuletzt aufgerufen am 28.11.2018. 
der IETF8: Das Internet besser machen. Die ,Mission der IETF' formuliert die Organisation aus Freiwilligen selbst so: Hochqualitative, relevante technische Dokumente produzieren, die beeinflussen, wie das Internet entworfen, benutzt und verwaltet wird, um es zu verbessern.

Die IETF kümmert sich überwiegend um die Behebung aktueller Probleme, z. B. durch Schaffen notwendiger Erweiterungen und die Gestaltung kurzfristig umsetzbarer Lösungen. Sie erstellt gültige Internet-Standards in Form von RFCs (Request for Comments), die frei verfügbar sind (bei anderen Standardisierungsorganisationen kosten die Standarddokumente ggf. Geld). Die Verantwortung der IETF ist relativ groß, da die Stabilität des Internets von den eingesetzten Protokollmechanismen abhängt: Beispielsweise funktionieren die eingesetzten Staukontrollverfahren derzeit auf kooperativer Basis, d. h., die Protokolle aller Teilnehmer müssen sich in Stausituationen fair und kooperativ verhalten, damit es nicht zu einem staubedingten Kollaps im Internet kommt. Ähnlich verhält es sich mit Kernprotokollen zum Routing (d. h. Wegewahl) im Internet, denn sollten sie einen schwerwiegenden Fehler in der Spezifikation enthalten, würde das Internet nicht mehr stabil funktionieren.

Als zur IETF verwandte Organisationen zählen die Internet Research Task Force (IRTF), die Internet Society und die Internet Assigned Number Authority (IANA). Die IRTF betrachtet längerfristige Entwicklungen und führt Voruntersuchungen durch, wenn ein Problem beispielsweise noch nicht praktisch oder konkret genug ist, um eine standardisierte Lösung durch die IETF zu erfordern. Die Vorarbeiten durch die IRTF sind in kleineren Forschungsgruppen zu den jeweiligen Problemfeldern organisiert. Manchmal resultieren die Ergebnisse der Voruntersuchungen in einer späteren Gründung von Arbeitsgruppen in der IETF, wenn das Problem besser verstanden und konkretisiert wurde. Die Internet Society kümmert sich um die Entwicklung und Verbreitung des Internets, insbesondere in den Entwicklungsländern, sowie den gleichberechtigten Zugang (Motto: Das Internet ist für jeden). Gegründet wurde die Internet Society 1992 und fungierte auch als rechtliche Dachorganisation für die $I E T F^{9}$, um sich vor allem auch um nicht-technische (z. B. rechtliche, politische) Angelegenheiten zu kümmern. Die IANA schließlich kümmert sich um die Verwaltung von Protokollparametern, die oft eine begrenzte Ressource darstellen und einer koordinierten Vergabe bedürfen. Ein prominentes Beispiel hierfür stellen die freien IP-Adressenbereiche dar, die für die Version 4 des Protokolls bereits 2011 erschöpft waren. Da die korrekte Zusammenarbeit der Protokolle teilweise auch von passenden und eindeutigen ProtokollparameterWerten abhängt, ist diese Aufgabe ebenfalls essenziell für ein funktionierendes Internet.

8 Harald Alvestrand, „A Mission Statement for the IETF“, auf: IETF, BCP95, RFC3935, Oktober 2004, online unter: ftp://ftp.rfc-editor.org/in-notes/rfc3935.txt, zuletzt aufgerufen am 28.11.2018.

9 Erik Huizer, „IETF-ISOC relationship“, auf: IETF, RFC 2031, Oktober 1996, online unter: https://tools.ietf.org/html/rfc2031, zuletzt aufgerufen am 28.11.2018. 
Wer ist die IETF?

Die IETF ist eine Gemeinschaft aus Freiwilligen, die das Ziel haben, das Internet besser zu machen. Die IETF ist zwar offiziell eine organisierte Aktivität der Internet Society, sie existiert jedoch streng genommen nicht im rechtlichen Sinne, da sie keine Mitgliedschaft kennt und damit nicht über Mitglieder im eigentlichen Sinn verfügt. Dies hat vor allem zwei Konsequenzen zur Folge: Es gibt keine Mitgliedsgebühren, aus denen sich die IETF finanzieren könnte, und es gibt weder ein Wahlrecht noch formelle Abstimmungen. Letztere scheitern bereits an der Tatsache, dass keine Mehrheitsverhältnisse aufgrund fehlender Mitgliedschaft festgestellt werden können. Des Weiteren ist die IETF eine offene Gemeinschaft, d. h. eine Mitarbeit ist nicht an Bedingungen gebunden, lediglich ein entsprechender technischer Sachverstand ist erforderlich, um an den Diskussionen um technische Lösungen zu partizipieren. Diese Diskussionen erfolgen über ,offene" Mailinglisten, d. h. jeder Interessierte kann teilnehmen und aktiv Beiträge leisten. Wie viele Personen an IETFAktivitäten teilnehmen, lässt sich nur schwer feststellen. $\mathrm{Zu}$ den regelmäßigen Treffen aller IETF-Arbeitsgruppen kommen zwischen 1.000 und 1.500 Teilnehmer, in Spitzenzeiten Anfang 2000 waren es 2.800 Teilnehmer.

Die IETF wurde 1986 gegründet und entstand aus US-amerikanischen, ARPANET-bezogenen (Advanced Research Projects Agency Network) Regierungsaktivitäten. Beim ersten Treffen der IETF waren lediglich 21 Personen anwesend. Heute ist sie eine internationale offene Gemeinschaft aus Ingenieuren und Forschern, die bei Herstellern von Netzhardware (z. B. Router und Firewalls), Software-Herstellern, Internet-Dienstanbietern oder Forschungsinstituten arbeiten. Insbesondere sind auch Operatoren mit entsprechenden Erfahrungen aus dem praktischen Netzbetrieb beteiligt. Die Beteiligten nehmen an IETF-Aktivitäten vornehmlich als Personen und Individuen teil, damit treten Firmeninteressen eher in den Hintergrund. In der Tat gibt es langjährige IETF-Teilnehmer, die öfter ihren Arbeitgeber gewechselt, dabei ihre Arbeit aber zu den verschiedenen Themen weitergeführt haben.

\section{Arbeitsweise und Organisation der IETF}

Die Arbeit der IETF ist auf unterster Ebene in Form von Arbeitsgruppen (Working Groups $[W G \mathrm{~s}]$ ) organisiert. Die Arbeitsgruppen werden zu bestimmten Themen bzw. speziellen Problemen eingerichtet, nachdem sich zum einen genügend Gleichgesinnte finden, die an der Lösung des Problems mitarbeiten wollen, zum anderen muss die Einrichtung der Arbeitsgruppe von der IETFLenkungsgruppe (Internet Engineering Steering Group - IESG) befürwortet werden. Die Arbeitsgruppen arbeiten, wie zuvor bereits erwähnt, hauptsächlich über offene E-Mail-Verteilerlisten. Zudem treffen sich die Arbeitsgruppen normalerweise dreimal persönlich im Jahr bei den IETF-Meetings, bei Bedarf 
auch öfter. Jede Arbeitsgruppe hat üblicherweise zwei Vorsitzende ( $W G$ Chairs), welche die Arbeiten in der Arbeitsgruppe moderieren und sich um ihren Fortschritt bezüglich der Erreichung der gesetzten Ziele kümmern. Die Ziele werden üblicherweise in Form von noch zu erstellenden Dokumenten formuliert. Diese Dokumente (im Entwurfsstatus als Internet-Drafts bezeichnet) können beispielsweise Problembeschreibungen oder Protokollspezifikationen beinhalten, die ggf. später zu Internet-Standards (dann als RFC-Request for Comments bezeichnet) werden. Während sich meistens eine Gruppe von Autoren für diese Dokumente findet, um die eigenen Lösungen beizutragen, diskutiert die Arbeitsgruppe ebenfalls über den Inhalt der Dokumente und entscheidet über deren Fertigstellung. Dazu reicht ein grober Konsens aus, den die Vorsitzenden der Arbeitsgruppe üblicherweise erklären. Wie eingangs erwähnt, gibt es keine formalen Abstimmungen, da keine regulären Mehrheitsverhältnisse feststellbar sind. Dennoch finden manchmal Abstimmungen statt, bei denen dann häufig einfache Mehrheitsverhältnisse gelten, prinzipiell stehen jedoch technische Argumente im Vordergrund. Werden also beispielsweise durch einzelne Teilnehmer valide technische Gründe für einen Einwand genannt, so müssen die Autoren des Dokuments diese entsprechend berücksichtigen und es muss erneut über das Dokument abgestimmt werden.

Wie bereits erwähnt, müssen sich genügend Gleichgesinnte finden, bevor eine Arbeitsgruppe eingerichtet werden kann. Dies geschieht üblicherweise durch sogenannte BOF-Sitzungen bei den IETF-Treffen..$^{10} B O F$ steht für „Birds of a feather" und bezeichnet die Gruppe der Gleichgesinnten, die zunächst ein Problem formulieren, das eine Lösung erfordert. Im Wesentlichen wird dort diskutiert, ob das Problem konkret und fassbar genug ist, um in einer IETF-Arbeitsgruppe gelöst zu werden. Des Weiteren wird die potenzielle Satzung (WG Charter) einer solchen Arbeitsgruppe diskutiert, insbesondere erfolgt auch eine Abgrenzung, welche Probleme nicht von der Arbeitsgruppe betrachtet bzw. gelöst werden wollen, um die Arbeit möglichst fokussiert zu halten. Es ist möglich, zwei solche Treffen abzuhalten, bevor eine Arbeitsgruppe konstituiert wird. Vor diesen offiziellen $B O F$-Sitzungen gibt es oft noch informelle Bar- $B O F \mathrm{~s}^{11}$, bei denen erste Kontakte $\mathrm{z}$. B. bei einem Bier an der Hotelbar geknüpft werden.

Die ca. 120 Arbeitsgruppen sind weiterhin verschiedenen Themenbereichen (Areas) untergeordnet. Derzeit existieren folgende Themenbereiche: Anwendungen und Echtzeit (Applications and Real-Time), Generelles (General), Internet, Routing, Transport, Sicherheit (Security), Betrieb und Management (Operations and Management). Diesen Bereichen stehen Bereichsleiter (Area

10 Thomas Narten, „Considerations for Having a Successful Birds-of-a-Feather (BOF) Session“, auf: IETF, RFC 5434, Februar 2009, online unter: http://tools.ietf.org/html/rfc5434, zuletzt aufgerufen am 28.11.2018.

11 Lars Eggert/Gonzalo Camarillo, „Considerations for Having a Successful „Bar BOF“ Side Meeting“, auf: IETF, RFC 6771, Oktober 2012, online unter: http://tools.ietf.org/html/ rfc6771, zuletzt aufgerufen am 28.11.2018. 
Directors $[A D \mathrm{~s}]$ ) vor, die für die Aufsicht und eine gewisse Koordination der Arbeitsgruppen innerhalb des Bereichs sorgen. Die Arbeiten innerhalb eines Bereichs sollten sich idealerweise ergänzen und nicht zu stark überlappen. Die $A D$ s beobachten sowohl den Fortschritt der existierenden Arbeitsgruppen als auch die Initiativen zur Einrichtung neuer Arbeitsgruppen (BOFs). Des Weiteren sind alle $A D$ s Mitglied in der bereits zuvor erwähnten Lenkungsgruppe $I E S G$, dem wichtigsten Gremium der IETF, denn alle Standarddokumente müssen von der IESG verabschiedet werden. Daher sind sämtliche zu verabschiedenden Internet-Drafts von den $A D$ s genau zu lesen und zu kommentieren. Die Tätigkeit als $A D$ ist in der Regel so zeitaufwendig, dass sie gut die Hälfte der Arbeitszeit beansprucht. Dennoch gibt es genügend Firmen, die einen Mitarbeiter für die Tätigkeit in der IETF designieren, um einen Experten direkt in das Standardisierungsgeschehen einzubinden.

Die $A D$ s werden in einem aufwendigen Prozess von einem Nominierungskomitee $^{12}$ für zwei Jahre gewählt, wobei die technische Kompetenz der Kandidaten eine wesentliche Rolle spielt. Das Nominierungskomitee (Nominations Commitee - NomCom) besteht aus einer möglichst zufälligen Auswahl von Freiwilligen der IETF-Teilnehmer' ${ }^{13}$, wobei maximal zwei Freiwillige von der gleichen Organisation sein dürfen, um eine einseitige Einflussnahme auszuschließen. Eine bestimmte regelmäßige Teilnahme an IETF-Meetings ist jedoch Voraussetzung, um sich als Mitglied für das NomCom zu qualifizieren. Die Nomcom-Mitglieder sammeln und sichten Kandidatenvorschläge und führen Interviews mit den Kandidaten durch. Die Liste der Kandidaten wird veröffentlicht.

Die IETF-Teilnehmer wählen nicht nur ihre Führungsriege selbst, sondern sie legen auch den Standardisierungsprozess und ihre Organisation selbst fest. Änderungen erfolgen ebenfalls über offene Diskussion und speziell dafür eingerichtete Arbeitsgruppen. Neben den $A D$ s wird noch der Vorsitzende der IETF (IETF Chair) gewählt, der ebenfalls Mitglied und Vorsitzender der IESG ist und praktisch als offizieller Repräsentant und Sprecher für die IETF dient, sich aber auch um alle generellen Belange der IETF kümmert, weshalb er auch immer zugleich $A D$ für die General Area ist. Im Gegensatz zu einem $A D$ Posten, ist der Posten des IETF-Vorsitzenden eine Vollzeitbeschäftigung.

Ein weiteres Gremium in der IETF ist das Internet Architecture Board (IAB), dessen Mitglieder ebenfalls vom NomCom gewählt werden und zu dessen Aufgaben die architekturelle Begleitung der Arbeiten in der IETF, sowie die Aufsicht und Aufnahme von Verbindungen zu anderen Standardisierungsorganisationen gehören. Das $I A B$ veranstaltet gelegentlich Workshops zu bestimmten

12 Murray S. Kucherawy, „IAB, IESG, and IAOC Selection, Confirmation, and Recall Process: Operation of the Nominating and Recall Committees", auf: IETF, RFC 7437, Januar 2015, online unter: http://tools.ietf.org/html/rfc7437, zuletzt aufgerufen am 28.11.2018.

13 Rob Austein/Bert Wijnen, „Structure of the IETF Administrative Support Activity (IASA)“, auf: IETF, RFC 4071, April 2005, online unter: http://tools.ietf.org/html/rfc4071, zuletzt aufgerufen am 28.11.2018. 
(überwiegend technischen) Themen und verfasst Dokumente über die Ergebnisse solcher Workshops. Die Arbeitslast eines $I A B$-Mitgliedes ist geringer als die eines $A D$ s.

Damit die IETF-Meetings abgehalten werden können, existiert ein IETFSekretariat, das sich um die Organisation und Ausrichtung der Treffen sowie den Betrieb der Mailinglisten und Webseiten kümmert. Des Weiteren gibt es einen administrativen Direktor (IETF Administrative Director - IAD), der für alle administrativen Belange der IETF zuständig und Teil der als IASA (Internet Administration Support Activity) bezeichneten Aktivität im Rahmen der Internet Society ist. Die IASA nimmt keinen direkten Einfluss auf die Standardisierung. Der $I A D$ ist hauptberuflich tätig und von der Internet Society angestellt. Im Rahmen der IASA wurde ein Aufsichtsgremium (IETF Administration Oversight Committee) geschaffen, welches verantwortlich für Finanzen ist und damit sowohl das Budget der IETF festlegt als auch die Ausgaben der IETF kontrolliert. ${ }^{14}$ Das IAOC schließt auch Verträge z. B. mit dem Sekretariat oder den Tagungshotels und evaluiert die entsprechenden Leistungen. Das $I A O C$ besteht aus den Vorsitzenden von IETF und IAB sowie aus dem Präsidenten der Internet Society und zwei durch das NomCom gewählten Mitgliedern.

Abbildung 7.1 veranschaulicht noch einmal die Zusammenhänge der verschiedenen Gremien und Funktionen innerhalb der IETF.

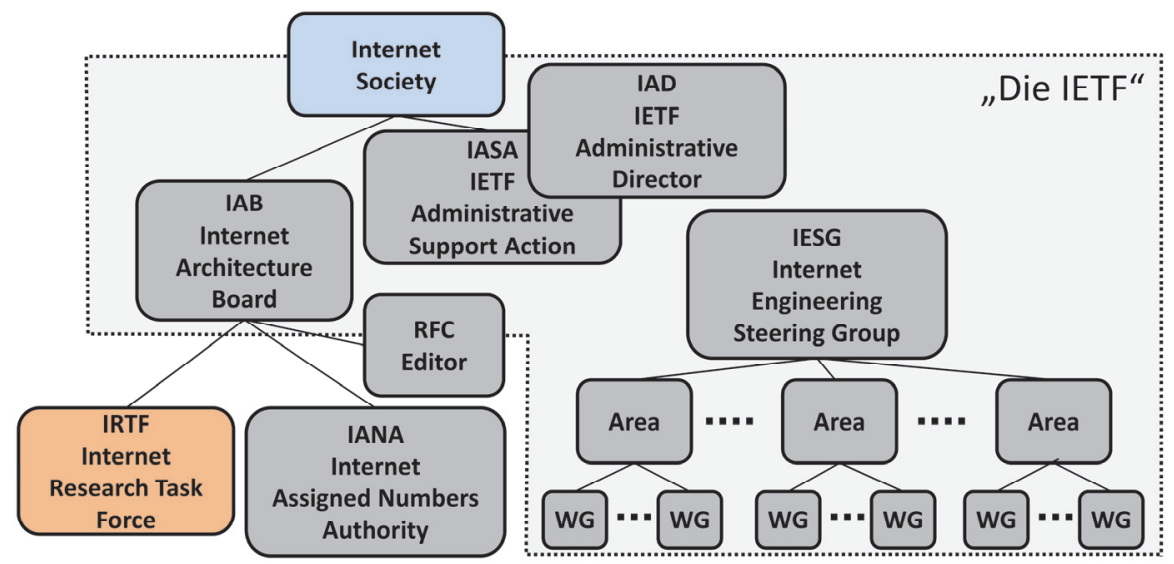

7.1 - Die Organisation der IETF

Üblicherweise finden die Treffen abwechselnd in Nordamerika, Asien oder Europa statt. Für die Treffen werden Teilnahmegebühren erhoben, aus denen die IETF einen Großteil der organisatorischen Unkosten deckt, zudem werden

14 Donald Eastlake 3rd, „Publicly Verifiable Nominations Committee (NomCom) Random Selection“, auf: IETF, RFC 3797, Juni 2004, online unter: http://tools.ietf.org/html/rfc3797, zuletzt aufgerufen am 28.11.2018. 
Sponsoren gesucht. Die restlichen Unkosten werden größtenteils über Spenden der Internet Society gedeckt. Die Internet Society verfügt seit 2003 durch Betrieb der .org-Domänennamen-Registratur über eine Einkommensquelle. Die Kostenaufstellungen der IETF sind öffentlich und damit für jeden einsehbar und somit transparent. Abgesehen vom Sponsoring der IETF-Meetings sind direkte Spenden an die IETF sind nicht möglich, da die Unabhängigkeit gewahrt bleiben soll, es ist jedoch indirekt über die Internet Society möglich, die IETF zu unterstützen. Die Unabhängigkeit der IETF ist wichtig, weshalb langfristig versucht wird, die Finanzierung über eine unabhängige Stiftung (IETF Endowment ${ }^{15}$ ) sicherzustellen - bislang jedoch nur mit mäßigem Erfolg.

\section{Standards und Standardisierungsprozess}

Die IETF-Standards werden als $R F C$ s veröffentlicht und sind im Gegensatz zu formalen und legitimierten Standardisierungsorganisationen (z. B. DIN, ETSI, ITU, ISO) nicht gesetzlich bindend. Des Weiteren gibt es keine formale Anerkennung von IETF-Standards durch Regierungen oder formale Standardisierungsorganisationen und IETF-Standards werden nicht als Standards bei anderen Organisationen eingereicht (z. B. bei der ISO).

Die RFCs sind eine Dokumentenreihe (ISSN 2070-1721) von inzwischen mehr als 8.500 Dokumenten, die sowohl Standarddokumente in zwei Stufen ${ }^{16}$ umfassen (Proposed Standard, Internet-Standard) sowie weitere Dokumenttypen, die keine Standards im eigentlichen Sinn darstellen, sondern eher beschreibenden Charakter (Informational, Best Common Practice) oder experimentellen Charakter besitzen (Experimental). Das Format der RFCs ist ebenfalls offengehalten, denn es sind bislang Dokumente, die im ASCII-Format mit festem Zeilen- und Seitenumbruch formatiert sind und somit kein spezielles Programm zum Anzeigen benötigen. Abbildungen und Formeln sind damit jedoch recht mühsam zu beschreiben und derzeit erfolgt ein erneuter Versuch ${ }^{17}$ auf modernere Ausgabeformate umzustellen (u. a. HTML sowie das Portable Document Format - PDF). Diese erfüllen jedoch nicht immer die Anforderungen nach Stabilität, vollständiger Offenheit, größtmöglicher und unbegrenzter Nutzbarkeit über verschiedenste Geräte hinweg ${ }^{18}$ - schließlich sind die ersten $R F C$ s nach über 45 Jahren immer noch lesbar. Als Quellformat ist

15 https://www.sustainietf.org/, zuletzt aufgerufen am 28.11.2018.

16 Russ Housley/Erik Burger/Dave Crocker, „Reducing the Standards Track to Two Maturity Levels“, auf: IETF, RFC 6410, Oktober 2011, online unter: http://tools.ietf.org/html/rfc6410, zuletzt aufgerufen am 28.11.2018.

17 Heather Flanagan, „RFC Format Framework“, auf: IETF, RFC 7990, Dezember 2016, online unter: https://tools.ietf.org/html/rfc7990, zuletzt aufgerufen am 28.11.2018.

18 Heather Flanagan/Nevil Brownlee, „RFC Series Format Requirements and Future Development", auf: IETF, RFC 6949, Mai 2013, online unter: https://tools.ietf.org/html/rfc6949, zuletzt aufgerufen am 28.11.2018. 
daher XML (Extensible Markup Language) vorgesehen, welches verschiedene Ausgabeformate erzeugen kann.

Der Standardisierungsprozess in der IETF ${ }^{19}$ ist offen und transparent angelegt. Er ist offen, weil die Mailinglisten und Arbeitsgruppen jedem zur Teilnahme offenstehen. Er ist transparent, weil Diskussionen und Entscheidungen, auch die der IESG, offen einsehbar sind. Die Ziele des IETF-Standardisierungsprozesses sind unter anderem technische Exzellenz, vorherige Implementierung und Testen sowie klare, kurze und leicht verständliche Dokumentation..$^{20}$

Dave Clark hat einmal das Credo der IETF so beschrieben: „We reject: kings, presidents, and voting. We believe in: rough consensus and running

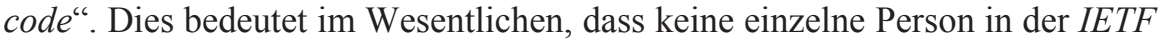
die Macht hat, über die Geschicke der IETF oder die Annahme bzw. Ablehnung von Standards zu entscheiden, dass aber auch keine formalen Abstimmungen über Standards stattfinden. Ein bekanntes Beispiel über die Unsinnigkeit von Abstimmungen bei Standards ist die Verabschiedung des $100 \mathrm{MBit} / \mathrm{s}$ IEEE-Standards 100VG-AnyLAN, den u. a. der Hersteller Hewlett Packard unbedingt als Konkurrenz zum $100 \mathrm{MBit} / \mathrm{s}$-Ethernet durchsetzen wollte und dies aufgrund einer großen Anzahl stimmberechtigter Mitglieder bewerkstelligen konnte; Akzeptanz fand der Standard im Markt aber nicht.

Der grobe Konsens in der IETF kann sehr unterschiedlich ausfallen. Mal kann es sein, dass eine Stimme Mehrheit als ausreichend angesehen wird, mal kann ein fast gleiches Verhältnis als nicht ausreichender Konsens gewertet werden. Bei den IETF-Treffen wird häufiger ein grobes Meinungsbild innerhalb der Arbeitsgruppen über Zustimmung oder Ablehnung über Vorschläge oder Vorgehensweisen der Teilnehmer durch ein Summen (Humming) ermittelt. Entscheidungen bei den Treffen müssen jedoch auf den Mailinglisten bestätigt werden, damit auch Arbeitsgruppenmitglieder, die nicht an den Treffen teilnehmen konnten, noch die Möglichkeit haben, ihre Meinung zu äußern. Die Entscheidung für einen Standard muss somit nicht einhellig sein, aber jeder hat die Möglichkeit seine Meinung zu äußern. Der Zusatz ,running code“ im obigen Zitat von Clark bedeutet, dass ein starkes Argument für eine Protokollspezifikation eine funktionierende Implementierung ist. Gibt es beispielsweise konkurrierende Vorschläge für bestimmte Protokollspezifikationen, wird der Vorschlag mit einer funktionierenden Implementierung eher positiv bewertet.

Wie bereits zuvor beschrieben, beginnen die Arbeiten zu einem Standard in der IETF oft mit einem informellen Treffen von Gleichgesinnten, die dann eine $B O F$-Sitzung bei einem $A D$ beantragen. Bereits in diesem Stadium wer-

19 Scott Bradner, „The Internet Standards Process - Revision 3“, auf: IETF, RFC 2026, Oktober 1996, online unter: https://tools.ietf.org/html/rfc2026, zuletzt aufgerufen am 28.11.2018, und Housley/Burger/Crocker (2011), Reducing the Standards Track.

20 Ebd. 
den Mailinglisten eingerichtet, um über das Thema und die Arbeitsinhalte zu diskutieren. Die Bekanntgabe solcher Initiativen erfolgt meist in anderen Arbeitsgruppen, die themenverwandt sind. Um eine $B O F$-Sitzung zu beantragen, ist eine erste grobe Beschreibung der Problemstellung, Zielsetzung und der Arbeitsinhalte einer möglichen Arbeitsgruppe erforderlich. Diese $B O F$-Sitzungen können ein- oder zweimal stattfinden, bevor eine Arbeitsgruppe eingerichtet wird. Dies erfolgt nur mit Zustimmung der IESG, nachdem die Satzung der Arbeitsgruppe verabschiedet wurde. In der Satzung sind neben Problemstellung und Arbeitsinhalten bereits Zwischenziele in Form von Zeitpunkten für die Fertigstellung von Arbeitsgruppendokumenten definiert.

Bereits in der frühen Phase der BOF-Initiative werden erste Dokumente als Diskussionsgrundlage verfasst. Diese Internet-Drafts genannten Dokumente im RFC-Format dienen dazu, bestimmte Themen ausführlicher und strukturierter zu behandeln als dies in längeren E-Mail-Konversationen möglich ist. So verfassen meist einige wenige Autoren erste individuelle Dokumente, die andere Teilnehmer lesen und kommentieren, woraufhin die Autoren meistens Änderungen an dem Dokument vornehmen und es in einer neuen Version veröffentlichen. Internet-Drafts sind reine Arbeitsdokumente und verlieren ihre Gültigkeit nach sechs Monaten, d. h. sie werden dann vom IETF-Server gelöscht. Da jedoch bei aktiver Weiterentwicklung schnell neue Versionen der Internet-Drafts erstellt werden, existiert in der Regel immer ein aktueller gültiger Internet-Draft. Im Verlauf der Zeit einigt sich die Arbeitsgruppe mittels grober Konsensfindung darauf, welche Internet-Drafts als offizielle Arbeitsgruppendokumente akzeptiert werden. Fortschritte bezüglich der Dokumente werden sowohl auf der Mailingliste als auch bei den IETF-Meetings diskutiert. Ziel der Arbeitsgruppe ist es, die Dokumente in einen Zustand zu bekommen, dass sie bei der IESG zur Durchsicht eingereicht werden können. Irgendwann besteht Konsens durch einen letzten Aufruf (WG Last Call) zur Kommentierung innerhalb der Arbeitsgruppe, dass dieser Zustand erreicht ist. Kommentare in dieser letzten Phase werden dann noch eingearbeitet, bevor der Vorschlag über den zuständigen $A D$ bei der $I E S G$ eingereicht wird. Der $A D$ führt zuvor eine Durchsicht des Internet-Drafts durch und kann eine erneute Überarbeitung durch die Arbeitsgruppe verlangen. IESG-Mitglieder lesen den eingereichten Internet-Draft, beurteilen ihn bezüglich Klarheit, technischer Qualität und können Zustimmung, Enthaltung oder Diskussionsbedarf äußern. Zeitgleich beginnt ein letzter Aufruf durch die IESG an die IETF-Gemeinschaft (IETF Last Call), den Entwurf zu kommentieren. Bei schwerwiegenderen Einwänden muss die Arbeitsgruppe das Dokument nochmal überarbeiten und erneut die IESG-Durchsicht passieren. Ergebnisse der IESG-Evaluierung sind öffentlich einsehbar und dokumentiert. Verabschiedet die IESG schließlich das Dokument, wird es zur Veröffentlichung durch den $R F C$-Editor freigegeben. Der $R F C$-Editor vergibt eine eindeutige $R F C$-Nummer und überprüft das Dokument auf sprachliche Klarheit und Formatierung. Die Autoren haben dann noch einmal 48 Stunden Zeit, um die durch den $R F C$-Editor durchgeführten 
Änderungen $\mathrm{zu}$ überprüfen, ob z. B. durch sprachliche Umformulierungen keine technischen Änderungen eingeführt wurden. Erst nach expliziter $\mathrm{Zu}-$ stimmung durch die Autoren wird der $R F C$ veröffentlicht, was der IETF-Gemeinschaft ebenfalls bekanntgegeben wird.

Ein $R F C$, der einen Protokollstandard definiert, wird zuerst als $R F C$ der Stufe Proposed Standard verfasst. Als Standard dieser Stufe ist er insgesamt stabil, hat wohldefinierte Entwurfsentscheidungen, erfuhr eine ausführliche Durchsicht durch die IETF-Gemeinschaft und erhielt genug Interesse der Gemeinschaft, um als wertvoll erachtet zu werden. Er bildet somit eine gute Grundlage zur Implementierung eines Protokolls. Zur Erreichung des Proposed Standard ist keine Implementierungs- oder Betriebserfahrung erforderlich, aber erwünscht - dies spricht im Sinne des ,running code“ für eine implementierbare und funktionierende Implementierung. Spätere Erfahrungswerte können jedoch Änderungen oder sogar das Zurückziehen der Spezifikation zur Folge haben, bevor eventuell der Standard die nächste Stufe erreicht. Diese zweite und letzte Stufe ist der Internet-Standard, der sich durch einen hohen technischen Reifegrad auszeichnet sowie die generelle Ansicht, dass das spezifizierte Protokoll oder der Dienst von signifikantem Nutzen für die InternetGemeinschaft ist. Die Stufe kann erreicht werden, wenn mindestens zwei unabhängige interoperable Implementierungen mit weiter Verbreitung und erfolgreicher Erfahrung aus dem Betrieb existieren. Des Weiteren existieren keine bekannten Fehler der Spezifikation, welche die Interoperabilität einer neuen Implementierung mit den bereits im Einsatz befindlichen fehlschlagen lässt.

Der Standardisierungsprozess und die Arbeit in der IETF werden inzwischen durch einige Werkzeuge unterstützt. Es existieren beispielsweise Werkzeuge, um die Internet-Drafts zu verwalten und deren aktuellen Status im Standardisierungsprozess zu verfolgen sowie um die Beiträge bei den IETFMeetings zu verwalten oder um Internet-Drafts zu verfassen. Des Weiteren sind die Entscheidungen und Diskussionen der IESG dokumentiert und archiviert, ebenso wie sämtliche Mailinglisten.

Generell ist festzuhalten, dass bei den Standards der IETF Interoperabilität im Vordergrund steht und nicht die Konformität von Implementierung. Die IETF standardisiert im Gegensatz zu anderen Standardisierungsorganisationen keine Architekturen, sondern Protokolle mit dem Ziel größtmöglicher technischer Exzellenz und Interoperabilität. Die IETF definiert auch keine Konformitätstests für Implementierungen, da eine Befolgung der Protokollspezifikation als ausreichend erachtet wird. Die Dauer des Standardisierungsprozesses eines Protokolls beträgt oft zwei bis drei Jahre, kann aber manchmal auch deutlich länger oder kürzer ausfallen. Die Energie der Arbeitsgruppen ist nicht immer konstant. Oftmals ist das Engagement der Teilnehmer kurz nach Einrichtung der Arbeitsgruppe am höchsten, kommen im Verlauf der Zeit jedoch weitere interessante Themen in neuen Arbeitsgruppen hinzu, schwindet nicht selten die Energie in älteren Arbeitsgruppen. 
Dispute werden normalerweise über die Mailinglisten oder bei den IETFMeetings ausgetragen, dennoch existiert ein formaler Beschwerdeprozess. Offiziell sind zunächst die $W G$-Vorsitzenden zu kontaktieren, danach der $A D$. Weitere Beschwerdeschritte laufen über die IESG und das $I A B$, die jeweils öffentlich und offiziell dazu Stellung nehmen und der Beschwerde stattgeben oder sie ablehnen. Eine Beschwerde über den Prozess an sich (also nicht dessen Befolgung) einzulegen, ist auch möglich, eine solche muss dann an die ISOC gerichtet werden. Beschwerden kommen gelegentlich vor, der Prozess ist aber aufwendig und langsam.

\section{IETF-Kultur}

Die IETF-Kultur ist zum einen von Offenheit geprägt, zum anderen sehr stark durch den technischen Fokus. Politische oder wirtschaftliche Diskussionen werden weitestgehend vermieden. Dennoch gibt es die Notwendigkeit, sich mit Patenten und Schutzrechten auseinanderzusetzen. Es kommt nicht selten vor, dass Protokolle oder Mechanismen durch Firmen als geistiges Eigentum geschützt werden. Dies widerspricht eigentlich dem Ziel einer möglichst offenen Kommunikation, an der jeder teilnehmen kann, wenn der Einsatz bestimmter Protokolle als geistiges Eigentum geschützt ist. Die Haltung der IETF ist daher eher ablehnend gegenüber Patentschut $\mathrm{z}^{21}$, d. h. normalerweise werden patentfreie Verfahren bevorzugt. Sollten Beiträge in der IETF geschützte Inhalte enthalten, so ist die IETF umgehend darüber zu informieren diese Richtlinie ist auf Mailinglisten und bei den IETF-Meetings zur Kenntnis zu nehmen. Liegen Schutzrechte vor, wird im Einzelfall entschieden, wie weiter verfahren wird. Weniger problematisch sind Fälle, in denen der Rechteinhaber eine lizenzfreie Nutzung einräumt.

Die recht speziellen Gepflogenheiten der IETF, insbesondere bei den Meetings, sind im sogenannten „Tao der IETF“ dokumentiert. ${ }^{22}$ Beispielsweise finden bei einem IETF-Meeting auch viele Diskussionen in den Pausen und Gängen zwischen den Sitzungen statt. Insbesondere wird davon abgeraten, sich in den Pausen so ungeschickt zu positionieren, dass man einem hungrigen IETFTeilnehmer den Zugriff auf die wichtige Pausenverpflegung (z. B. in Form von Cookies) erschwert oder gar verwehrt.

21 Scott Bradner/Jorge L. Contreras, „Rights Contributors Provide to the IETF Trust“, auf: IETF, RFC 5378, November 2008, online unter: https://tools.ietf.org/html/rfc5378, zuletzt aufgerufen am 28.11.2018.

22 Paul Hoffman/Susan Harris, „The Tao of IETF: A Novice's Guide to the Internet Engineering Task Force“, auf: IETF, RFC 4677, September 2006 online unter: https://tools.ietf.org/html/rfc 4677, zuletzt aufgerufen am 28.11.2018, sowie Paul Hoffman, „The Tao of IETF: A Novice's Guide to the Internet Engineering Task Force“, auf: IETF, November 2012, online unter: https:// www.ietf.org/tao.html, zuletzt aufgerufen am 28.11.2018. 
Da die IETF sich für eine breite und offene Partizipation einsetzt, bemüht sie sich, durch verschiedene Aktivitäten neue Teilnehmer zu integrieren. So gibt es ein Mentoring-Programm bei den IETF-Meetings, Reisestipendien durch die Internet Society, spezielle Veranstaltungen und Training für Neuankömmlinge, um sie mit der IETF-Gemeinschaft vertraut zu machen.

\section{Resümee}

Die IETF ist eine sehr offene Gemeinschaft, die das Ziel verfolgt, das Internet besser zu machen. Sie entwickelt Internet-Standards in einem offenen und transparenten Prozess nach dem Credo „Rough consensus and running code“. Die IETF standardisiert keine Architekturen, sondern Protokolle mit dem Ziel größtmöglicher technischer Exzellenz und Interoperabilität. Trotz des offenen Prozesses und gewählter IESG, ist der effektive politische Einfluss der $A D$ s relativ hoch. Auch ist zu beobachten, dass bestimmte Hersteller versuchen, sich Einfluss in der Standardisierung zu sichern.

Erfolg kann die IETF für sich proklamieren, wenn ihre Standards eingesetzt werden und das Internet dadurch ,besser" wird. Der IETF gelingt es jedoch nicht immer, rechtzeitig und schnell genug auf aktuelle Entwicklungen zu reagieren. So besteht die Gefahr, dass bestimmte Hersteller De-facto-Standards schaffen, die breiten Einsatz finden, denen aber die technische Exzellenz oder der breite Konsens fehlen. Die Regel, dass zwei $B O F$ s notwendig sind, um eine Arbeitsgruppe zu gründen, kann zugunsten einer schnelleren Reaktion gelockert werden - eventuell ist kein BOF erforderlich, wenn die IESG von der Nützlichkeit der vorgeschlagenen WG überzeugt ist.

Eine weitere Problematik ist die Fülle von $R F C$-Dokumenten: Hier ist Expertenwissen notwendig, um die relevanten und zusammengehörigen $R F C \mathrm{~s}$ zu finden - manchmal existieren $R F C$ s, die eine Übersicht über relevante Standards zu einem Thema bzw. Protokoll geben. Dies korrespondiert auch mit dem Problem, dass zwar generell die IETF offen gegenüber Teilnehmern ist, jedoch entsprechendes (technisches) Wissen notwendig ist, um in der IETF sinnvoll beitragen zu können.

In jüngster Zeit wurde auch vorgeschlagen ${ }^{23}$, dass die IETF sich bewusst sein sollte, dass ihre Standards als Institution wirken: Sie geben vor wie die Kommunikation im Internet abläuft bzw. ablaufen kann und greifen damit regelnd in unser Leben ein, d. h., sie ermöglichen, strukturieren oder beschränken zwischenmenschliche Interaktionen. Die von Lawrence Lessig formulier-

23 Mark Nottingham, „Representing Stakeholder Rights in Internet Protocols“, auf: IETF, Internet Draft: Best Current Practice, Oktober 2014, online unter: https://tools.ietf.org/html/draftnottingham-stakeholder-rights, zuletzt aufgerufen am 28.11.2018. 
ten Beobachtungen „Code Is Law“24 gilt eben auch insbesondere für die im Internet eingesetzten Protokolle. Obwohl die IETF sich überwiegend mit technischen Aspekten auseinandersetzt, muss sie realisieren, dass sie zugleich auch immer politisch wirkt - eine Verbindung der Mechanismen im Internet mit Menschenrechten wurde ebenfalls diskutiert.25 Jüngste IAB-Empfehlungen $^{26}$ zur Vertraulichkeit und Wahrung der Privatsphäre durch Protokolle verdeutlichen den Handlungsbedarf in dieser Richtung.

\section{Literatur}

Alvestrand, Harald. „A Mission Statement for the IETF“, auf: IETF, BCP95, RFC3935, Oktober 2004, online unter: ftp://ftp.rfc-editor.org/in-notes/rfc3935.txt, zuletzt aufgerufen am 28.11.2018.

Austein, Rob/Wijnen, Bert, „Structure of the IETF Administrative Support Activity (IASA)“, auf: IETF, RFC 4071, April 2005, online unter: http://tools.ietf.org/html/ rfc4071, zuletzt aufgerufen am 28.11.2018.

Bradner, Scott, „The Internet Standards Process - Revision 3“, auf: IETF, RFC 2026, Oktober 1996, online unter: https://tools.ietf.org/html/rfc2026, zuletzt aufgerufen am 28.11.2018.

Ders./Contreras, Jorge L., „Rights Contributors Provide to the IETF Trust“, auf: IETF, RFC 5378, November 2008, online unter: https://tools.ietf.org/html/rfc5378, zuletzt aufgerufen am 28.11.2018.

Clark, David D. „The Design Philosophy of the DARPA Internet Protocols“, in: Proc. SIGCOMM '88, Computer Communication Review, 18, 4 (1988), S. 106-114.

Eastlake 3rd, Donald, „Publicly Verifiable Nominations Committee (NomCom) Random Selection“, auf: IETF, RFC 3797, Juni 2004, online unter: http://tools.ietf. org/html/rfc3797, zuletzt aufgerufen am 28.11.2018.

Eggert, Lars/Camarillo, Gonzalo, „Considerations for Having a Successful „Bar BOF“ Side Meeting“, auf: IETF, RFC 6771, Oktober 2012, online unter: http://tools.ietf. $\mathrm{org} / \mathrm{html} / \mathrm{rfc} 6771$, zuletzt aufgerufen am 28.11.2018.

Flanagan, Heather, „RFC Format Framework“, auf: IETF, RFC 7990, Dezember 2016, online unter: https://tools.ietf.org/html/rfc7990, zuletzt aufgerufen am 28.11.2018.

24 Lawrence Lessig, „Code Is Law: On Liberty in Cyberspace“, auf: Harvard Magazine, Januar 2000, online unter: https://harvardmagazine.com/2000/01/code-is-law-html, zuletzt aufgerufen am 28.11.2018.

25 Joy Liddicoat/Avri Doria, „Human Rights and Internet Protocols: Comparing Processes and Principles“, auf: Internet Society, Dezember 2012, online unter: http://www.internetsociety.org/ sites/default/files/Human\%20Rights\%20and\%20Internet\%20Protocols\%20Comparing\%20Processes\%20and\%20Principles.pdf, zuletzt aufgerufen am 28.11.2018

26 „IAB Statement on Internet Confidentiality“, auf: Internet Architecture Board, November 2014, online unter: https://www.iab.org/2014/11/14/iab-statement-on-internet-confidentiality/, zuletzt aufgerufen am 28.11.2018. 
Dies./Brownlee, Nevil, „RFC Series Format Requirements and Future Development“, auf: IETF, RFC 6949, Mai 2013, online unter: https://tools.ietf.org/html/rfc6949, zuletzt aufgerufen am 28.11.2018.

Hoffman, Paul, „The Tao of IETF: A Novice's Guide to the Internet Engineering Task Force“, auf: IETF, November 2012, online unter: https://www.ietf.org/tao.html, zuletzt aufgerufen am 28.11.2018.

Ders./Harris, Susan, „The Tao of IETF: A Novice's Guide to the Internet Engineering Task Force", auf: IETF, RFC 4677, September 2006, online unter: https://tools.ietf. org/html/rfc4677, zuletzt aufgerufen am 28.11.2018.

Housley, Russ/Burger, Erik/Crocker, Dave, ,,Reducing the Standards Track to Two Maturity Levels“, auf: IETF, RFC 6410, Oktober 2011, online unter: http://tools.ietf. org/html/rfc6410, zuletzt aufgerufen am 28.11.2018.

Huizer, Erik, „IETF-ISOC relationship“, auf: IETF, RFC 2031, Oktober 1996, online unter: https://tools.ietf.org/html/rfc2031, zuletzt aufgerufen am 28.11.2018.

„IAB Statement on Internet Confidentiality“, auf: Internet Architecture Board, November 2014, online unter: https://www.iab.org/2014/11/14/iab-statement-on-inter net-confidentiality/, zuletzt aufgerufen am 28.11.2018.

„Institute of Electrical and Electronics Engineers“, auf: IEEE, April 2018, online unter: http://www.ieee.org/, zuletzt aufgerufen am 28.11.2018.

„Internet Engineering Task Force“, auf: IETF, April 2018, online unter: https://ietf.org/, zuletzt aufgerufen am 28.11.2018.

„International Telecommunication Union“, auf: ITU, Januar 2015, online unter: https:// www.itu.int, zuletzt aufgerufen am 28.11.2018.

Kucherawy, Murray S., „IAB, IESG, and IAOC Selection, Confirmation, and Recall Process: Operation of the Nominating and Recall Committees“, auf: IETF, RFC 7437, Januar 2015, online unter: http://tools.ietf.org/html/rfc 7437, zuletzt aufgerufen am 28.11.2018.

Lessig, Lawrence, „Code Is Law: On Liberty in Cyberspace“, auf: Harvard Magazine, Januar 2000, online unter: https://harvardmagazine.com/2000/01/code-is-law-html, zuletzt aufgerufen am 28.11.2018.

Liddicoat, Joy/Doria, Avri, „Human Rights and Internet Protocols: Comparing Processes and Principles“, auf: Internet Society, Dezember 2012, online unter: http:// www.internetsociety.org/sites/default/files/Human $\% 20$ Rights $\% 20$ and $\% 20$ Internet $\% 2$ 0Protocols-\%20Comparing\%20Processes\%20and\%20Principles.pdf, zuletzt aufgerufen am 28.11.2018.

Narten, Thomas. „Considerations for Having a Successful Birds-of-a-Feather (BOF) Session“, auf: IETF, RFC 5434, Februar 2009, online unter: http://tools.ietf.org/html/ rfc5434, zuletzt aufgerufen am 28.11.2018.

Nottingham, Mark. „Representing Stakeholder Rights in Internet Protocols“, auf: IETF, Internet Draft: Best Current Practice, Oktober 2014, online unter: https://tools. ietf.org/html/draft-nottingham-stakeholder-rights, zuletzt aufgerufen am 28.11.2018.

„Open Standards“, auf: Open Stand, April 2018, online unter: http://open-stand.org/, zuletzt aufgerufen am 28.11.2018.

„World Wide Web Consortium“, auf: W3C, April 2018, online unter: http://www.w3c. org, zuletzt aufgerufen am 28.11.2018. 

EFFEKTE DER NATURALISIERUNG: LEBEN, KÖRPER, PRAKTIKEN 



\title{
ANTONIO LUCCI UND THOMAS MACHO
}

\author{
„VIVETE SANI E AMATEMI“. \\ Paolo MantegazZA und das GesPenst deR BioPolitiK
}

1.

Als Paolo Mantegazza am 28. August 1910 starb, trug eine der vielen Todesanzeigen den Titel „Tod eines Optimisten“.' Charakteristisch für seine Persönlichkeit waren tatsächlich ein unerschütterlicher Optimismus - nicht ohne Naivität - gegenüber der Menschheit und ihrer Fähigkeit zum Fortschritt, aber auch die Neigung zu vielen Wissenschaften, die ihn dazu brachte, sich selbst als ,poligamo di molte scienze“ ${ }^{\text {“2 }}$, zu bezeichnen.

Paolo Mantegazza wurde am 31. Oktober 1831 in Monza geboren. Seine Mutter, Laura Solera Mantegazza (1813-1873), war eine Freundin Garibaldis, engagierte Parteigängerin des Risorgimento und philanthropische Sozialreformerin, die vor allem für die Frauenbildung kämpfte. 1850 gründete sie die erste Tagesstätte für die Kinder der Armen, und 1870 die Scuola professionale femminile d'Italia, eine frühe Berufsschule für Frauen. Drei Jahre nach ihrem Tod publizierte Paolo ihre Biografie unter dem Titel La mia mamma. ${ }^{3}$ Sein Vater, Giovan Battista Mantegazza (gestorben 1867), war ein wohlhabender Sohn des Bürgermeisters von Monza; von ihm wissen die Biografien sonst fast nichts.

In Pisa und Mailand studierte Mantegazza Medizin; 1854 schloss er das Studium in Pavia ab. Danach reiste er nach Südamerika ${ }^{4}$, praktizierte in Argentinien und Paraguay als Arzt, und entwickelte ein ausgeprägtes Interesse für Anthropologie, Ethnologie und die alimenti nervosi, die ,Nervennahrungen', die wir heute als Rauschmittel und Drogen bezeichnen. Mit Akribie erforschte er zunächst vor allem die Früchte des Kokastrauchs ${ }^{5}$, die er selbst in bemerkenswert hohen Dosen konsumierte ${ }^{6}$; in seinen Schriften unterschied er

1 Luciano Zuccoli, „La morte di un ottimista“, in: Paolo Mantegazza, L'uomo e gli uomini. Antologia di scritti antropologici, hg. v. Giulio Barsanti und Fausto Barbagli, Florenz, 2010, S. 265-268.

${ }^{2}$ Giulio Barsanti, „Un poligamo di molte scienze. L'antropologia a tutto campo di Paolo Mantegazza“, in: Mantegazza (2010), L'uomo e gli uomini, S. 5-29.

3 Vgl. Paolo Mantegazza, La mia mamma. Laura Solera Mantegazza, Mailand, 1876.

4 Vgl. ebd., Sulla America Meridionale. Lettere Mediche, Mailand, 1869.

5 Vgl. ebd., „Sulle virtù igieniche e medicinali della coca e sugli alimenti nervosi in generale“, in: Annali Universali di Medicina 167, 501 (1859), S. 449-519.

6 Vgl. Antonio Aimi, „Mantegazza e la coca: una ricerca da rivalutare“, in: Cosimo Chiarelli/ Walter Pasini (Hg.), Paolo Mantegazza e l'evoluzionismo in Italia, Florenz, 2010, S. 163-175. 
bald zwischen coca und cocaina, weshalb vermutet wird, dass er das Alkaloid Kokain bereits um 1859 aus den Kokablättern extrahiert hatte. Doch Mantegazza analysierte und klassifizierte auch die Wirkungen von Alkohol, Mate, Guarana, Opium, Haschisch, Kava oder Ayahuasca, ein halluzinogener Lianentrank, dessen ritueller Gebrauch vor allem in der Amazonasregion verbreitet war. 7 Nach seiner Rückkehr aus Südamerika wurde er - im Alter von 29 Jahren - als Professor für Pathologie an die Universität von Pavia berufen; zehn Jahre später besetzte er den ersten Lehrstuhl für Anthropologie in Italien am Istituto di Studi Superiori in Florenz, wo er auch ein anthropologischethnologisches Museum einrichtete. Mantegazza wirkte als Pionier der Hydrotherapie: Er gründete und verwaltete - ab 1871 - ein Jahrzehnt lang die hydrotherapeutische Badeanstalt von Riminis; er betätigte sich als Sexualwissenschaftler und Sozialhygieniker und trug somit entscheidend zur zeitgenössischen Etablierung von Körperstandards bei. Darüber hinaus unterstützte er - gegen den Widerstand der katholischen Kirche - die Bemühungen um Ehescheidung und künstliche Befruchtung. Er unternahm ethnologische Feldforschungen bei den Lappen ${ }^{9}$ und den Todas in Indien ${ }^{10}$, und nutzte in diesem Kontext die Fotografie in durchaus avantgardistischer Manier für Zwecke der ethnologischen Dokumentation. Seit 1865 war er Parlamentsabgeordneter und ab 1876 Senator des italienischen Königreiches ${ }^{11}$; daneben reüssierte er auch als Romanschriftsteller und Verfasser zahlreicher populärwissenschaftlicher Bücher, die in die wichtigsten europäischen Sprachen übersetzt wurden. Er führte einen Briefwechsel mit Charles Darwin, dessen Werk er in Italien verbreitete; und bis zu seinem Tod gab er die jährlich erscheinenden Almanacchi d'Igiene Popolare heraus.

Kurzum, während Paolo Mantegazza heute allenfalls als eine Art von ,Hippie-Professor', als Vorreiter der Sexual- und Drogenforschung, erinnert wird, war er zu Lebzeiten (und noch bis zum Ende der Zwischenkriegszeit) eine prominente Autorität auf verschiedenen wissenschaftlichen Gebieten, ein populärer Aufklärer und vielgelesener Autor (mit erstaunlich hohen Auflagenzahlen, auch in Deutschland), ein politisch engagierter Intellektueller und Protagonist eines zeitgenössischen Hedonismus, dessen Plädoyers für den Genuss, etwa in der Fisiologia del piacere (1854), zugleich dessen Kritik an

7 Vgl. Paolo Mantegazza, „Degli alimenti nervosi narcotici I“, in: L'Igea, 23 (1864), S. 354355: 354 f.; ders., „Degli alimenti nervosi narcotici II“, in: L'Igea, 1 (1865), S. 3-7; ders., Quadri della natura umana. Feste ed ebbrezze, Mailand, 1871.

8 Vgl. Monika Antes, Die Vermessung der Liebe. Paolo Mantegazza (1831-1910) und seine bahnbrechenden Entdeckungen, Würzburg, 2012, S. 20 f.

9 Vgl. ders., Un viaggio in Lapponia coll'amico Stephen Sommier, Mailand, 1881; Paolo Mantegazza/Stephen Sommier, Studi antropologici sui Lapponi, Florenz, 1880.

10 Vgl. Paolo Mantegazza, India, Mailand, 1884; ders., Studi sull'etnologia dell'India, Florenz, 1886.

11 Vgl. Walter Pasini, „Paolo Mantegazza, deputato e senatore del Regno“, in: Cosimo Chiarelli/ Walter Pasini (Hg.), Paolo Mantegazza e l'evoluzionismo in Italia, Florenz, 2010, S. 121132. 
einer heuchlerischen bürgerlichen Doppelmoral, explizit in Il secolo tartufo (1888) - neben Nietzsche und Freud - einen nicht unerheblichen Einfluss auf den Zeitgeist ausübten. Mantegazza exponierte sich als ein moderner Epikureer, nicht nur in Epicuro, saggio di una filosofia del bello (1891), sondern schon in der Vorrede zur Neuauflage der Physiologie der Wonne (1870), die er mit dem „Dekalog des Epikur“ und im Habit des Propheten beschloss:

[So] nehme auch ich das monumentale Wesen des Gesetzgebers und Propheten an; und, herab von der Höhe meiner Gesetztafeln, der Zukünftigen meinen Gruß entbietend, setze ich auf die Stirn meines Buches folgenden Dekalog des Epikur, mit welchem jedermann ein glücklicher Mensch sein kann, wenn er es nur sein will.

I. Immer arbeiten.

II. Immer lieben.

III. Die Frau mehr als sich selbst lieben.

IV. Niemals auf der Seite seines Habens im Leben die fremde Dankbarkeit setzen.

V. Erziehen statt hassen; statt verachten lächeln.

VI. Aus der Distel die Faden, aus dem Wermut die Medizin ziehen.

VII. Sich nie beugen, es denn, um den Gefallenen Hilfe zu leisten.

VIII. Immer mehr Verstand haben, als Ehrgeiz.

IX. Sich jeden Abend fragen: ,Was habe ich heut Gutes gethan?

$\mathrm{X}$. In seiner Bibliothek stets ein neues Buch, in seinem Kredenzschrank eine volle Flasche, in seinem Garten eine frische Blume haben. ${ }^{12}$

Dennoch blieb der ,Prophet" und epikureische Ratgeber Mantegazza, dessen fröhlicher Appell zur Lebenskunst auch und gerade im Kontrast zur ,schwarzen Romantik" wahrgenommen werden muss, die der italienische Kulturhistoriker Mario Praz so ausführlich erforscht hat ${ }^{13}$, stets ein Anthropologe und Arzt, der in den ausgedehnten Feldern seiner vielfältigen Interessen und Tätigkeiten konsequent zwei Maximen verfolgte: die Maxime der medizinischen Beurteilung und Normierung menschlicher Handlungen und Lebensformen, und die aufklärerische Maxime einer faktisch normativen, nicht bloß deskriptiven Übertragung wissenschaftlich relevanten Wissens und das Ideal des Natürlichen auf das Alltagsleben. Mantegazza verfolgte eine ,politica come ampliamento, estensione del suo esser medico"14, so hat es Walter Pasini in seiner Studie über die politischen Ambitionen Mantegazzas zusammengefasst. Auch unsere eigene These stellt diesen Aspekt in den Mittelpunkt: Dass die Werke Mantegazzas - sowohl die belletristischen und populärwissenschaftlichen als auch die wissenschaftlichen Schriften - gelesen und betrachtet werden können im Kontext gouvernementaler Konzepte und Praktiken der Biopolitik. Und allgemeiner noch: in einem Denkraum, der durch die Koordinaten jenes ,pen-

12 Paolo Mantegazza, Die Physiologie der Wonne, übers. v. Graf August Wilding, Berlin, Leipzig, 1870 [ital. OA 1854], S. 11.

13 Vgl. Mario Praz, La carne, la morte e il diavolo nella letteratura romantica, Mailand, Rom, 1930.

14 Pasini (2010), Paolo Mantegazza, deputato e senatore del Regno, S. 122. 
siero vivente" ${ }^{15}$ definiert wird, dem der italienische Philosoph Roberto Esposito 2010 eine wichtige Untersuchung gewidmet hat; in dieser Untersuchung wird der Lebensbegriff als tragende Kategorie der italienischen Philosophie tout court ausgelegt.

Mantegazza hat nicht nur in seinen wissenschaftlichen bzw. medizinischen Werken, sondern auch in der Belletristik sowie in seiner politischen Tätigkeit ständig den Versuch unternommen, pädagogisch und physiologisch ein Ideal des Natürlichen im Sinne eines konstruierten Körperstandards zu entwerfen und etablieren. Dieser Prozess der Standardisierung wird durch einen exnegativo Aufruf des von der Regel abweichenden Falls unterbreitet.

\section{2.}

Eine wichtige Brücke zwischen den literarischen, populärwissenschaftlichen und wissenschaftlichen Texten Mantegazzas schlagen seine Romane, in denen der Wille zur medizinisch-hygienischen Standardisierung und Alphabetisierung der Bevölkerung einen einzigartigen Ausdruck fand. Der Briefroman Un giorno a Madera ${ }^{16}$ stellt in diesem Sinn einen entscheidenden Kreuzungspunkt dar: Erzählt wird die Liebesgeschichte eines jungen englischen Paars - Emma und William - die aufgrund der Krankheit des Mädchens, die an Tuberkulose leidet, eine tragische Wendung nimmt. So weit ist der Stoff gut bekannt; er erinnert an Opern wie La Bohème und an die ubiquitäre Romantisierung der Schwindsucht, die noch Thomas Manns Roman vom Zauberberg beherrscht. Bis zur Entdeckung des Tuberkulose-Erregers durch Robert Koch im Jahr 1882 waren die Ursachen der Krankheit unbekannt: Manche Ärzte erklärten sie als Effekt mangelnder Hygiene (wie die Cholera), klimatischer Verhältnisse oder eines ungesunden Lebenswandels (etwa durch zu viel Arbeit), andere hielten sie für eine Erbkrankheit - und so auch Mantegazza. Er entwickelt seine Erzählung aus dem Wunsch Williams, mit Emma ein Kind zu zeugen. Doch Emma ist die einzige Überlebende einer Familie, die von der Tuberkulose vernichtet wurde; sie versprach ihrem Vater am Sterbebett kein Kind zu bekommen, um die Erbkrankheit nicht zu verbreiten. So schreibt Emma an ihren Geliebten:

Mein William, mein lieber William, muß ich Dir wirklich sagen, für wen mein Herz schlägt, - nach so vielen Monaten gemeinsamen Kummers, nach so vielen gemeinsamen Schmerzen? [...] Aber Emma kann weder Dir noch einem andern angehören; sie ist durch einen heiligen Schwur gebunden, allein zu leben und allein zu sterben. Mein Blut ist verflucht, ist verhängnisvoller Weise bestimmt, in sich selbst zu erlöschen; und Deine Liebe sowohl, wie die meinige, und alle menschlichen Kräfte zusammen, könnten dieses unerbittliche Urteil, vor wel-

15 Vgl. Roberto Esposito, Pensiero Vivente: Origine e attualità della filosofia italiana, Turin, 2010.

16 Vgl. Paolo Mantegazza, Un giorno a Madera. Una pagina dall'Igiene dell'amore, Mailand, 1868. 
chem Deine Emma schon vor mehreren Jahren, - noch ehe sie Dich kannte - das Haupt gebeugt hat, beschwören. Ich schwor meinem Vater, mich nie zu verheiraten, als ich noch nicht wußte, was Liebe ist und als die Liebe zu meinem Vater mein ganzes Herz erfüllte. Ich schwor, nie ein Kind auf meinen Knieen zu halten, das mich zärtlich anblickte und mich lächelnd Mama nannte, zu einer Zeit, als ich selbst noch wenig mehr als ein Kind war. Jetzt weiß ich, was Liebe ist: ich weiß, daß Lieben mehr ist als Leben; ich errate jetzt, was es heißen will, Mutter zu sein: aber ich werde nie Gattin und nie Mutter sein, ich werde meinen Eid nie lösen können. ${ }^{17}$

Der Konflikt zwischen dem Versprechen, das Emma ihrem sterbenden Vater gegeben hat, und der Sehnsucht nach Liebe und Mutterschaft, im Wechselspiel mit dem verzehrenden Begehren des männlichen Helden, führen die Liebesgeschichte zu einem tragisch-pathetischen Ende. Die Erzählung schließt mit dem Abschiedsbrief der sterbenden Emma, kurz nachdem sie - nach vielen ärztlichen Untersuchungen - zur Überzeugung gelangt war, Kinder risikofrei auf die Welt bringen zu können. Sie schreibt:

William, ich fühle, daß ich sterben muß. Ich habe es weder der Tante noch dem Arzte gesagt, denn ich fühle, daß doch alles umsonst sein würde. Das sanfte Klima von Madeira hatte einen leichten Schleier auf meine Wunde gelegt, aber die Nebel von London haben sie wieder geöffnet, und grausamer als je. Ich kann nicht mehr leben, und es schmerzt mich nur, daß ich sterben werde ohne Dich gesehen zu haben. Jede Stunde, jede Minute schaue ich Dein Bild an, und ich schaue Dich mit solchem Verlangen an, daß es mir scheint, Du müßtest meine Sehnsucht stillen, Du müßtest kommen, um mich zum letzten male zu sehen. Aber Du wirst nicht kommen. - Und dann erschreckt mich noch der Gedanke, so plötzlich sterben zu müssen. Ich fühle ein glühendes Feuer in meiner Brust; mir ist, als fühlte ich dort etwas, das von einem Augenblicke zum andern platzen müßte. ${ }^{18}$

Mantegazza weist seinen Wählern von Monza bereits in der Widmung den Weg, auf den die Erzählung geführt wird; er will, dass der Roman die Menschen zu einem medizinisch aufgeklärten und unterrichteten Selbstbewusstsein bewegt: Sie sollen leben und lieben, ohne die biopolitischen Imperative der Hygiene und der Rücksicht auf die Gesundheit zu übertreten. Aus diesem Grund wiederholt die Widmung der italienischen Fassung (die nicht in die deutsche Übersetzung aufgenommen wurde) den Abschiedssatz Emmas: „Lebe, und liebe mich" ${ }^{19}$, allerdings in einer signifikant veränderten Fassung, die geradezu als Motto einer biopolitisch inspirierten Aufklärung interpretiert werden kann: „,vivete sani e amatemi“, lebt gesund und liebt mich, empfiehlt Mantegazza seiner Leserschaft. In dem „lebt gesund und liebt mich“ verbirgt

17 Paolo Mantegazza, Einen Tag in Madeira. Ein Kapitel aus der Hygiene der Liebe, ohne Übersetzungsangabe, Leipzig, 1882, S. 39 f.

18 Ebd., S. 105.

19 Ebd., S. 107. 
sich jene kulturelle Praxis, die zu einem idealtypischen Lebensstandard als prozessuale Konstruktion einer gesunden Natürlichkeit hinarbeiten soll.

Der dunkle Kern, die unheimliche Seite dieses Kapitels aus einer Hygiene der Liebe - wie Mantegazza selbst seine Novelle unter Bezug auf ein geplantes umfangreiches Werk zur Igiene dell'amore $(1877)^{20}$ benannt hatte - besteht wohl in der ärztlichen Vorschrift, die an Emmas Verzicht exemplifiziert wird, sich als kranker Mensch nicht fortzupflanzen, um die Krankheit nicht zu vererben. Relevant ist dabei nicht der wissenschaftliche Irrtum, die Fehleinschätzung der Tuberkulose als erbliches Leiden statt als Infektionskrankheit, sondern die biopolitisch-eugenische Grundhaltung, die in Igiene dell'amore vielfach bezeugt wird. Ausführlich werden in diesem Werk Francis Galtons Untersuchungen über die Erblichkeit des Genies - Hereditary Genius von 1869 - referiert ${ }^{21}$; eben dieses Buch wurde übrigens im Todesjahr Mantegazzas von Anna Schapire-Neurath und Otto Neurath, dem späteren Kultusminister der Münchner Räterepublik, Mitglied des Wiener Kreises und Erfinder der Bildstatistik, ins Deutsche übersetzt, mit einem geradezu enthusiastischen Vorwort der Übersetzer, in dem es hieß, Galtons Forschungen hatten

[...] von Anfang an ein Problem vor Augen: Wie kann man eine menschliche Rasse züchten, die unseren Idealen am meisten entspricht? [...] Wer mit offenem Auge die Entwicklung der Zukunft vorauszuschauen versucht, sieht als die größten Probleme, welche die Menschheit in immer stärkerer Weise bewegen werden, die Verbesserung der sozialen Ordnung und die Verbesserung unserer Rasse, zwei Ziele, die eng miteinander zusammenhängen. Der Ruhm aber, in entscheidendem Maße die Bewegung für die systematische Verbesserung der Rasse in unserem Zeitalter eingeleitet zu haben, gebührt Francis Galton und seiner Eugenik.22

Dem Kapitel zu Galton in Igiene dell'amore ließ Mantegazza ein weiteres Kapitel über die Erblichkeit von Krankheiten folgen. Darin zitierte er Platon, der verlangt habe,

[...] daß vor der Hochzeit die Gatten ganz nackt untersucht würden, und die Bräute bis zum Gürtel; wir aber erlauben Mädchen die Ehe, welche nur mit Hilfe des Kaiserschnitts gebären können und beruhigen uns mit dem elenden Trost, daß schon manches Opfer von dem Messer des Geburtshelfers glücklich davon gekommen ist. Man nennt dies Achtung vor der persönlichen Freiheit, aber ich nenne es fatalistische Brutalität. ${ }^{23}$

\footnotetext{
20 Vgl. Paolo Mantegazza, Die Hygiene der Liebe, übers. v. Reinhold Teutscher, 11. Aufl., Berlin, 1910.

21 Ebd., S. 348-360.

22 Vorwort der Übersetzer zu Francis Galton, Genie und Vererbung, übers. v. Otto Neurath und Anna Schapire-Neurath, Leipzig, 1910 [engl. OA Hereditary Genius. An Inquiry into its Laws and Consequences, 1869], S. VI f. [Herv. i. O.].

23 Mantegazza (1910), Die Hygiene der Liebe, S. 362.
} 
Zwar betont Mantegazza, „nicht alle Krankheiten sind gleich erblich“"24, was an der Diskussion über die Erblichkeit der Taubstummheit belegt wird; doch zählt er kurz danach folgende Erbkrankheiten auf: Fettleibigkeit, Herzkrankheiten, Hämorrhoiden, Nasenbluten, Bluterkrankheit, Rheumatismus, Gicht, Harnsteine, Rachitis (hält er für zweifelhaft), Krebs, Skrofeln und Tuberkeln, nervöse Krankheiten und den Wahnsinn, der mindestens zu fünfzig Prozent erblich sei, Hautkrankheiten, Albinismus und die meisten Missbildungen (,Monstruositäten"). ${ }^{25}$ Die Notwendigkeit einer strengen Anwendung medizinisch-biopolitischer Normen auf den menschlichen und sozialen Körper als Prozess eines bewusst angestrebten Ideals des Natürlichen scheint ihm so evident, dass die Möglichkeit des Irrtums gar nicht in Erwägung gezogen wird; stattdessen schwelgt Mantegazza in Ironie: „Wenn Ihr also Mut habt, Ihr Tuberkulösen, Skrofulösen und Krebskranken, so könnt Ihr diese herrlichen Pflanzen, die Tuberkeln, die Skrofeln, den Krebs ins Unendliche vermehren“". ${ }^{26}$

Das positivistiche Ideal Mantegazzas, das durch den Nexus zwischen medizinischer Praxis, politischer Handlung und Populärwissenschaft eine ,Orthopädie' der Gesellschaft anstrebt, findet in diesen polemischen Aussagen seinen vollkommenen Ausdruck. Er träumt einerseits von einer Gesellschaft, in der das Bewusstsein von den medizinischen Imperativen regiert wird, und er verfolgt andererseits eine propagandistische Tätigkeit, die tatsächlich in diese Richtung geht. Die Idee der Normalisierung der ,natürlichen“ Triebe wird vor allem in den Schriften zur Sexualwissenschaft präsent sein, mit beeindruckenden Nachwirkungen auf das damalige Publikum.

\section{3.}

Die sozialen Rückkopplungseffekte der populärwissenschaftlichen Aufklärungstätigkeit Mantegazzas erscheinen überaus deutlich in einigen Briefen, die Mantegazza in die elfte Auflage von Gli amori degli uomini27 eingeführt hatte. Dieses Werk über Die Geschlechtsverhältnisse des Menschen war zu seiner Zeit sehr erfolgreich und wurde vielfach übersetzt und nachgedruckt. Es besteht aus einer ethnologischen Beschreibung der Sitten und Gewohnheiten verschiedener Völker in Hinblick auf Initiations- und Heiratsrituale, sexuelle Praktiken, Frauenkauf und Frauentausch, Prostitution und sogenannte „Verirrungen der Liebe“, von der Masturbation und Sodomie bis zu Geschlechtsverstümmelungen. Im zuletzt genannten Abschnitt wurde auch die Homosexualität thematisiert, freilich mit kritischem Furor: „Die Liebe zwischen Männern ist eine der schrecklichsten Erscheinungen in der menschlichen Psychologie

24 Ebd., S. 363.

25 Ebd., S. 363-365.

26 Ebd., S. 366.

27 Paolo Mantegazza, Gli amori degli uomini, Bd. 1 und 2, hg. v. Gabriella Armenise, Lecce, Brescia, 2012 [1885], S. $119 \mathrm{f}$. 
und war und ist zu allen Zeiten und in allen Ländern ein viel verbreiteteres Laster als man denkt. ${ }^{\text {'28 }}$ Nach dem Erfolg der ersten Ausgabe erhielt Mantegazza einige Briefe von Homosexuellen, die über ihre eigene Sexualität berichteten und oft nach Erklärungen, Antworten und Empfehlungen fragten; sie wollten ihre sexuelle Orientierung als Krankheit rechtfertigen, um der sozialen und kulturellen Missbilligung zu entgehen.

Die bewegenden Briefe, die Mantegazza wiedergegeben hat, und die ein außerordentliches psychologisches und kulturelles Dokument dieser Zeit darstellen, scheinen den Autor mit einer theoretischen Schwierigkeit zu konfrontieren: Mantegazza ist einerseits erfüllt von Empathie gegenüber den Leiden und den Liebeserzählungen der Briefschreiber, andererseits gelingt es ihm nicht, sich dem Zeitgeist zu entziehen, und folglich setzt er die Beschreibung der Homosexualität als verwerfliche ,Leidenschaft' fort: Die Homosexualität sei eine ,passione colpevole, schifosa, ributtante quanto volete: ma passione" ${ }^{\prime 29}$, eine schuldhafte, widerliche, was immer ihr wollt abstoßende Leidenschaft, aber eben eine Leidenschaft. Um den Tonfall und die Effekte der biopolitischen Aussagen Mantegazzas gegenüber einem Teil seines Publikums darzustellen, lohnt es sich, eines der interessantesten Zeugnisse zu übertragen, das an Mantegazza geschickt wurde:

Ich bin einundzwanzig Jahre alt und bin überhaupt kein effeminiertes Individuum. Ich bin mittelgroß, meine Konstitution ist ziemlich wohlgenährt (obwohl beinahe fettleibig), meine Stimme ist gewissermaßen baritonal, mein Bart ist sehr dicht und meine Geschlechtsorgane sind absolut gesund, gut gebaut mit angemessenen Proportionen. Sowohl die Schönheiten der Natur als auch die schönen Künste und insbesondere die Musik und die Dichtung üben auf mich eine mächtige Anziehungskraft aus. Mein einziger Zeitvertreib in der Stadt sind die Theater und Konzerte, und auf dem Land die Bergwanderungen.

Beim Analysieren meiner erotischen Triebe finde ich in ihnen keine Perversion, sondern eher eine Inversion. Tatsächlich lässt mich die Schönheit der weiblichen Gestalten völlig gefühlskalt, während der Anblick eines herkulischen Torsos oder schöner athletischer Beine eine tiefe Bewunderung in mir hervorruft, die von übermächtigem sinnlichem Verlangen begleitet wird.

Diese Neigung zu Dingen männlicher Schönheit stellt sich aber nicht nur in den fleischlichen Begierden dar, sondern wohl in allen Ausdrucksformen meines ästhetischen Gefühls.

So gerate ich ins ekstatische Schwärmen vor einer Gebirgslandschaft mit schrecklichen Schluchten, mit reißenden Wildbächen und schneebedeckten Bergspitzen, während ich eine Abneigung empfinde gegen den brianzolischen Hügel mit seinen grünen Anhöhen, mit seinen blühenden Beeten, mit seinen kleinen Kaskaden und Bächlein.

Ebenso bevorzuge ich in der Musik die breiten und majestätischen Rhythmen mit zahlreichen Akkorden, Arpeggien und Tonänderungen, während mir die fröhlichen brillanten Filigranrhythmen nahezu gleichgültig bleiben. So liebe ich

28 Ders., Die Geschlechtsverhältnisse des Menschen, ohne Übersetzungsangabe, Berlin, 1900 [ital. OA Gli amori degli uomini, 1886], S. 122.

29 Mantegazza (2012), Gli amori degli uomini, S. 118. 
von all den prosodischen Metren nur den reimlosen Elfsilber, der am flüssigsten und imposantesten ist, während all die anderen Metren, so scheint es mir, nur fähig sind, den Ideen von Säuglingen und Ähnlichem Ausdruck zu verleihen.

Kurz gesagt, wenden sich also alle meine ästhetischen Gefühle nur kräftigen, prächtigen und grandiosen Konzepten zu, während im Gegensatz dazu die graziösen, feinen und anmutigen Konzepte keine Resonanz in meiner Seele finden.

Welch Wunder also, wenn für mich das Vorbild der sinnlichen Schönheit eher von Herkules und Mars verkörpert wird, als von Venus und den drei Grazien?

Wenn ich nun von meinen Bestrebungen in Bezug auf den fleischlichen Kontakt sprechen soll, würde ich sagen, dass sie sich in einer sehr lebendigen Lust äußern, den geliebten Mann an die Brust zu drücken, und mich mit ihm zu vereinen, wie der Mann mit der Frau oder wie die Frau mit dem Manne.

Ich wünschte, dass einer der beiden (egal welcher) eine Einrückung hätte, dort wo er eine Ausbuchtung zeigt (männlicher Tribadismus). Meine Begierde ist also nicht sodomitischer Natur: sie ist kein sexuell pervertierter Trieb, sie ist doch vielmehr ein sexuell invertierter Trieb.

Die von mir bis jetzt konsultierten Ärzte waren einer Meinung, als sie mir mitteilten, dass ich sogar sehr schnell und einfach den Strom meiner erotischen Neigungen in den richtigen Kanal leiten könnte, wenn ich versuchen würde, all meine Geschmäcker umzukehren und mich mit Kontakt zum Weiblichen vertraut zu machen.

Aber habe ich das Recht eine solche Kur zu unternehmen? Und wenn ich nach der Heilung Unglückliche zeugen würde, die das traurige Erbe dieser meiner psychischen Anomalie in sich tragen würden?! Wie sehr müsste ich dann meine egoistische Unachtsamkeit verdammen??? ${ }^{30}$

Die Schlussfragen, die der anonyme Autor in seinem Brief stellt, belegen den überaus erschreckenden Einfluss jener medizinischen Populärwissenschaft, die Mantegazza so wortgewaltig vertreten hat. Da der Absender seine Sexualität als krankhaft akzeptiert hat, fragt er sich, ob er denn das Recht habe, sie sogar in heterosexuellen Beziehungen zu praktizieren, sofern er dabei riskiere, ein Kind zu zeugen, das dieselbe Krankheit erben könnte. Im Prinzip fragt der Autor des Briefs also nach der biopolitisch-eugenischen Erlaubnis - wie in $U n$ giorno a Madera - zur eigenen Fortpflanzung, unabhängig von der Möglichkeit fundamentaler medizinischer Irrtümer. Diese Frage nach einer ,Erlaubnis ‘ ließ Mantegazza, der die persönliche Freiheit des Individuums stets respektieren wollte, vermutlich zweifeln; doch blieb er befangen von seinen Vorurteilen, er schwieg und erteilte den leidenschaftlich aufgeworfenen Fragen keine Antwort.

4.

Doch werden schon in dem utopischen Roman L'anno 3000, den Mantegazza 1897 veröffentlicht hat, auch die dystopischen Merkmale einer radikalen Me-

30 Ebd., S. 119 f. [ins Deutsche übers. v. Antonio Lucci] [Herv. i. O.]. 
dikalisierung der Gesellschaft verdeutlicht. In diesem Roman wird eine futuristische Welt beschrieben, die von den beiden Protagonisten Paolo und Maria bereist wird, um die Hauptstadt der Welt zu erreichen und die rechtliche und ärztliche Zustimmung eines hygienischen Weltgerichts für ihre Partnerschaft $\mathrm{zu}$ erhalten. Besonders unheimlich können einer heutigen Leserschaft zwei Abschnitte erscheinen: Der erste findet sich im achten Kapitel des Buches, der zweite auf den letzten Seiten des Romans.

Im achten Kapitel beschreibt Mantegazza das ärztliche Verfahren, dem alle Säuglinge unterworfen werden: eine Art von genetischer Untersuchung, die mithilfe einer verbesserten Version der Röntgenstrahlen durchgeführt wird. Diese Untersuchung soll - wie unsere DNA-Analysen - mit höchstmöglicher Sicherheit die Lebensfähigkeit oder Lebensunfähigkeit der Neugeborenen bestimmen. Nach der Analyse werden die physischen und psychischen Charakteristika des Kindes zusammengefasst und die kritischen Punkte protokolliert, die mit angemessenen Erziehungsmaßnahmen verstärkt oder entkräftet werden müssen. Wenn aber die Neugeborenen nur über eine missgebildete, schwächliche (,gracilissima“) oder lungenkranke (,tubercolotica“) Konstitution verfügen, sprechen die Ärzte das Urteil: „lebensunfähig“. Nach dem Urteil muss die Mutter die Genehmigung für die Beseitigung des Kindes erteilen oder gegen die Meinung der Ärzte das Kind mit sich nach Hause nehmen.

Jedoch als das Kind Nr. 20, ein sehr schwächliches Wesen, das bereits vor 8 Monaten geboren worden war, dem Examen unterworfen wurde, runzelte der Arzt die Stirn und rief durch ein Glockenzeichen zwei andere Ärzte aus einem Nebenzimmer herbei, und einer nach dem andern nahmen die Untersuchung des armen Kindes kopfschüttelnd und mit schmerzlichen Mienen vor. Die drei Ärzte kamen in folgendem Urteilsspruch überein: „Schwächliches, lungenkrankes, lebensunfähiges Kind“. Als die Mutter diesen traurigen Entscheid vernahm, brach sie in Schluchzen aus und fragte die Ärzte: „Könnte denn mein Kind nicht durch eine geeignete Kur gerettet werden?“ „Nein“, antworteten die drei Ärzte wie aus einem Munde. Dann wandte sich der Hygieniker zu der Mutter: „Und nun?“ Die Mutter weinte noch heftiger und antwortete, indem sie das Kind den Ärzten zurückgab, mit kaum vernehmbarer Stimme: „Ja!“ Dieses „Und nun“ wollte sagen: „Erlauben Sie also, daß Ihr Kind beseitigt wird?" Nun nahm in der Tat ein Hilfsarzt das Kind, öffnete einen schwarzen Verschlag in der Wand des Saales, schob es hinein und verschloß ihn wieder. Er ließ eine Feder schnappen, man hörte einen von einem kleinen Knall begleiteten Seufzer. Das Kind, von einem 2000 Grad heißen Luftstrom umflutet, war verschwunden, und es blieb nichts als ein Häuflein Asche übrig. Die Mutter hatte gleich nach dem Urteilsspruch den Saal verlassen, und der Hygieniker, mit trauriger, aber ruhiger Miene, rief nun „Nummer 21“ auf. ${ }^{31}$

Wenig später weigert sich eine andere Mutter, ihr Kind exterminieren zu lassen; der Arzt - und mit ihn wohl auch der allwissende Erzähler - charakteri-

31 Ders., Das Jahr 3000. Ein Zukunftstraum, übers. v. Willy Alexander Kastner, Lüneburg, 2012 [ital. OA 1897], S. 92. 
siert sie indes als „unbarmherzige“ und folglich „schlechte“ Mutter: „Armes Weib! Wie oft wird sie dieses Nein! noch bereuen. Sie hält sich für eine gute Mutter und ist doch grausam. Die Beseitigung der zum Leiden oder zu vorzeitigem Tode bestimmten Kinder, das allein ist die echte Barmherzigkeit." ${ }_{32}$ Kurzum, die biopolitisch-eugenische Doktrin findet ihren vollendeten Ausdruck in der literarischen Narration, die es dem Autor gestattet, sich nicht nur von den Zwängen der Wahrscheinlichkeit zu befreien, sondern auch einen Raum für Ambivalenz und Ungewissheit aufzubauen: Maria und Paolo - die fiktionalen Alter Egos des Autors und seiner geliebten Contessa Maria Fantoni - sind immerhin ,tief erschüttert' von der offensichtlich inhumanen Prozedur der Hygieniker.

Die Idee einer Gemeinschaft, die von außen durch eine rigide hygienischorthopädische Praxis normiert werden und die über das Leben und den Tod der Individuen entscheiden kann, bleibt das janusköpfige Gespenst, das die hygienisch-medizinische Theorie der Gesellschaft Mantegazzas unterstützt.

Gerade aus dieser ambivalenten Perspektive erscheint der Preis so besonders unheimlich, den Paolo am Ende des Romans erringt: den Preis für das „Psychoskop“, das er erfunden hat und das als die wichtigste und nützlichste Erfindung der Welt beschrieben wird; eine Art von Fernglas, durch das man die Gedanken der Menschen lesen kann.

Wenn wir alle wissen werden, daß jeder in unserm Gehirn lesen kann, werden wir bestrebt sein, daß unsere Handlungen und Gedanken einander nicht widersprechen, und unser Denken wird dieselbe gute Richtung nehmen, wie wir sie für unsere Handlungen suchen. Es ist zu hoffen, daß durch das Psychoskop die Lüge von der Erde verbannt oder wenigstens eine seltene Erscheinung wird, die sich allmählich ganz verliert, wie alle Organe und Funktionen, deren Übung nicht mehr notwendig und nützlich ist. Sehen wir von all den Vorteilen ab, die uns das neue Instrument in der Diagnose der Seelenkrankheiten, in der Erziehung und Psychologie bieten wird, so wird auch der Wissenschaft des Denkens eine neue Welt erschlossen, und sicherlich ist es dem Menschen nützlicher, sich selbst zu kennen, als das Innere der Erde oder die Bewohner der andern Planeten..$^{33}$

Mantegazza suggeriert die Fortschrittlichkeit eines solchen Apparats, der buchstäblich alles vor die Augen aller stellen würde, wie in einer Universalisierung des ,Panopticons' von Jeremy Bentham, das Michel Foucault bekanntlich zum Sinnbild der Disziplinargesellschaften erklärt hat. Noch einmal wird die Kreuzung zwischen Wissenschaft, Erzählung und sozialer Normierung zum dunklen Gelenkspunkt einer biopolitischen Spekulation, die - auch bei Cesare Lombroso (der übrigens mit Mantegazza in Kontakt stand) - am Ende des 19. Jahrhunderts einen wichtigen Standort in der italienischen Ideengeschichte gefunden zu haben schien. Die Ambivalenz bleibt uns selbst, den

32 Ebd., S. 94.

33 Ebd., S. 133. 
Kennern neuerer Überwachungs- und Kontrollgesellschaften, überlassen: Wie sollten wir auch den liebenswürdigen Epikureer und Drogenkenner, mit voller Flasche in der Kredenz und einem neuen Buch im Regal, mit dem strengen Hygieniker und Propagandisten des „Psychoskops“ verbinden?

\section{Literatur}

Aimi, Antonio, „Mantegazza e la coca: una ricerca da rivalutare“, in: Cosimo Chiarelli/ Walter Pasini (Hg.), Paolo Mantegazza e l'evoluzionismo in Italia, Florenz, 2010, S. $163-175$.

Antes, Monika, Die Vermessung der Liebe. Paolo Mantegazza (1831-1910) und seine bahnbrechenden Entdeckungen, Würzburg, 2012.

Esposito, Roberto, Pensiero Vivente: Origine e attualità della filosofia italiana, Turin, 2010.

Galton, Francis, Genie und Vererbung, übers. v. Otto Neurath und Anna SchapireNeurath, Leipzig, 1910 [engl. OA Hereditary Genius. An Inquiry into its Laws and Consequences, 1869].

Mantegazza, Paolo, Un giorno a Madera. Una pagina dall'Igiene dell'amore, Mailand, 1868.

Ders., Die Physiologie der Wonne, übers. v. Graf August Wilding, Berlin, Leipzig, 1870 [ital. OA 1854.]

Ders., Sulla America Meridionale. Lettere Mediche, Mailand, 1869.

Ders., Quadri della natura umana. Feste ed ebbrezze, Mailand, 1871.

Ders., La mia mamma. Laura Solera Mantegazza, Mailand, 1876.

Ders., Un viaggio in Lapponia coll'amico Stephen Sommier, Mailand, 1881.

Ders., Einen Tag in Madeira. Ein Kapitel aus der Hygiene der Liebe, ohne Übersetzungsangabe, Leipzig, 1882.

Ders., India, Mailand, 1884.

Ders., Studi sull'etnologia dell'India, Florenz, 1886.

Ders., Die Geschlechtsverhältnisse des Menschen, ohne Übersetzungsangabe, Berlin, 1900 [ital. OA Gli amori degli uomini, 1886].

Ders., Die Hygiene der Liebe, übers. v. Reinhold Teutscher, 11. Aufl., Berlin, 1910.

Ders., L'uomo e gli uomini. Antologia di scritti antropologici, hg. v. Giulio Barsanti/ Fausto Barbagli, Florenz, 2010.

Ders., Gli amori degli uomini, Bd. 1 und 2, hg. v. Gabriella Armenise, Lecce, Brescia, 2012 [1885].

Ders., Das Jahr 3000. Ein Zukunftstraum, übers. v. Willy Alexander Kastner, Lüneburg, 2012 [ital. OA 1897].

Ders., ,Sulle virtù igieniche e medicinali della coca e sugli alimenti nervosi in generale“, in: Annali Universali di Medicina 167, 501 (1859), S. 449-519.

Ders., „Degli alimenti nervosi narcotici I“, in: L'Igea, 23 (1864), S. 354-355.

Ders., ,Degli alimenti nervosi narcotici II“, in: L'Igea, 1 (1865), S. 3-7.

Ders.,/Sommier, Stephen, Studi antropologici sui Lapponi, Florenz, 1880. 
Pasini, Walter, „Paolo Mantegazza, deputato e senatore del Regno“, in: Cosimo Chiarelli/Walter Pasini (Hg.), Paolo Mantegazza e l'evoluzionismo in Italia, Florenz, 2010, S. 121-132.

Praz, Mario, La carne, la morte e il diavolo nella letteratura romantica, Mailand, Rom, 1930.

Zuccoli, Luciano, „La morte di un ottimista“, in: Paolo Mantegazza, L'uomo e gli uomini. Antologia di scritti antropologici, hg. v. Giulio Barsanti und Fausto Barbagli, Florenz, 2010, S. 265-268. 



\section{ANNE SCHREIBER \\ STANDARDS FOR GROUP ACTION. \\ ANFÄNGE DES US-AMERIKANISCHEN MANAGEMENTS \\ ZWISCHEN BIOCHEMIE, SOZIALTHEORIE UND \\ WISSENSCHAFTSGESCHICHTE}

Unconsciously, in the minds of all, business was taking on the elemental quality of a profession, that is, standards for group action. ${ }^{1}$

\section{Einleitung}

Mehr per Zufall denn Planung stieß der US-Biochemiker Lawrence Joseph Henderson im Verlauf der 1920er Jahre auf eine Methode, mit der er die komplexen physikalisch-chemischen Wechselbeziehungen im Puffersystem von Säugetierblut, die den $\mathrm{pH}$-Wert konstant halten, vermittels einer einzigen Grafik darstellen und berechnen konnte. Die zahlreichen Anpassungsmechanismen sowohl an die Vorgänge im Innern des Organismus als auch in der Umwelt versuchte er zunächst anhand von Vergleichen zwischen einer Vielzahl kartesischer Koordinatensysteme, Tabellen sowie mathematischen Formeln zu berechnen. Indem er die rechtwinkligen Grafiken anschließend neben- und übereinanderlegte, entstand eine Darstellung aus parallel zueinander verlaufenden Achsen, mit der die Interdependenzen auf einen einzigen Blick sichtbar wurden. Wie er im Gespräch mit Kollegen erfuhr, ähnelte die Darstellung einem Nomogramm, ein Ende des 19. Jahrhunderts durch den französischen Ingenieur und Mathematiker Maurice d'Ocagne entwickeltes grafisches Verfahren, das der Kalkulation mit mehr als zwei Variablen diente. ${ }^{2}$ Mithilfe des Nomogramms stellte Henderson die komplexen Reaktionen im Blut jetzt in einem einzigen Bild dar. Diese Ansicht, so meinte er, veranschaulichte nicht nur die im Blut herrschenden Gesetzmäßigkeiten, sondern die des Lebens schlechthin ${ }^{3}$ : Schon in den 1910er Jahren argumentierte er, dass der pH-Wert ausschlagegebend für die Entstehung von Leben sei. In den naturphilosophi-

\footnotetext{
1 Owen D. Young, „Dedication Address“, in: Dedication Addresses: George F. Baker Foundation, Boston, MA, 1927, S. 388.

2 Thomas L. Hankins, „Blood, Dirt, and Nomograms: A Particular History of Graphs“, in: Isis 90, 1 (1999), S. 50-80.

3 Lawrence Joseph Henderson, Blood. A Study in General Physiology, New Haven, MA, 1928.
} 
schen Schriften The Fitness of the Environment und The Order of Nature entwarf er ein biozentrisches Weltbild, mit dem er die Evolution als einen Prozess der wechselseitigen Anpassung zwischen Systemen und ihrer Umwelt beschrieb und damit die allein auf dem Gedanken der Konkurrenz und Anpassung an die Umwelt fußende darwinistische Theorie umkehrte. ${ }^{4}$

Bis Ende der 1920er Jahre setzte er sich mit dem pH-Wert auseinander, den er bei verschiedenen Zuständen des Körpers, bei Ruhe und Arbeit, bei Gesundheit und Krankheit und bei unterschiedlichen klimatischen Verhältnissen untersuchte. Von den Möglichkeiten der Nomografie überzeugt, überlegte er nicht nur, wie die Methode für die Physiologie zu standardisieren sei. Seine Gedanken gingen vielmehr über die Grenzen der Physiologie hinaus. Von der Nomografie, so Henderson, könnten auch andere Disziplinen profitieren. Hier dachte er sowohl an die Physik als auch die Soziologie, die es wie die Physiologie mit der Analyse von komplexen Systemen zu tun haben. ${ }^{5}$

\section{Entdeckung des Faktors Mensch: \\ Die Anfänge der Harvard Business School}

Hendersons Gedanken fanden Anklang bei Wallace Donham, seit 1919 zweiter Dean der 1908 gegründeten Harvard School of Business Administration. In den beginnenden 1920er Jahren sah sich Donham einer zunehmenden Kritik an den Arbeitsbedingungen, der massiver auftretenden Arbeitsermüdung, der sogenannten industrial fatigue und dem Erstarken der Gewerkschaften gegenübergestellt. Diese Situation nutzte Donham für den Entwurf einer Rhetorik des Notstandes und argumentierte, dass die Industrie dringend aufgefordert sei, sich der Notwendigkeit ihres gesellschaftlichen Leaderships bewusst zu werden. Schon kurz nach seinem Amtsantritt plante er daher ein umfangreiches Forschungsvorhaben, mit dem Zweck der Erforschung der Faktoren guter Beziehungen am Arbeitsplatz. Hierzu nahm er Kontakt zu Henderson und dem Industriepsychologen Elton Mayo auf, denen er die Leitung seines Forschungsvorhabens überantwortete. 1927 wurde Henderson Gründungsdirektor des Harvard Fatigue Laboratory (HFL), ein eigens in der Business School eingerichtetes Labor zur Untersuchung der Faktoren der körperlichen Ermüdung, das eines der weltweit ersten sportphysiologischen Labore darstellte. Zur selben Zeit übernahm Mayo eine Reihe an schon seit 1924 in den Werkstätten des Telekommunikationsunternehmens AT\&T in Chicago laufenden Untersuchungen, die sogenannten Hawthorne-Experimente.

4 Lawrence Joseph Henderson, The Fitness of the Environment, New York, NY, 1913; ders., The Order of Nature, Cambridge, MA, 1917.

5 John Parascandola, „Organismic and Holistic Concepts in the Thought of L. J. Henderson“, in: Journal of the History of Biology 4, 1 (1971), S. 63-113. 
Trotz seiner Arbeit am HFL standen Henderson und Mayo in engem Austausch über die Ergebnisse der Hawthorne-Experimente. Schon kurz nach Beginn der Experimente wollten sie erkannt haben, welche Relevanz positive zwischenmenschliche Beziehungen am Arbeitsplatz haben. ${ }^{6}$ In dieser ersten Phase wurden in dem von der normalen Produktion abgetrennten Relay Assembly Test Room eine Gruppe aus sechs Mitarbeiter_innen beim Zusammenbau von Telefonrelais beobachtet und dabei variierenden Produktionsbedingungen ausgesetzt; neben der Lichtintensität war dies die Pausenanzahl, die Länge des Arbeitstages oder der Lohnanreiz. Indifferent gegenüber den sich variierenden Faktoren war der Output im Verlauf der Untersuchungen kontinuierlich gestiegen. Den Grund für die gestiegene Produktivität wollten Mayo und Henderson daher in den entstanden sozialen Beziehungen entdecken. Während der Dauer der Experimente sei aus der Gruppe der vormals einander unbekannten Mitarbeiter_innen ein ,self governing team“ geworden. ${ }^{7}$ Hierbei waren Bande aus Sympathien und Freundschaften entstanden, die sich jenseits der Vorgaben des Managements informell ergeben hatten. Diese positiven sozialen Beziehungen, die auf einem Austausch gemeinsamer Werte und Gefühlslagen basierten und durch die wechselseitige Angleichung der Einstellungen stabil gehalten wurden, wirkten sich positiv auf die Produktivität aus. Den gestiegenen Output führten sie zudem auf das Verhalten der die Experimente leitenden Supervisoren zurück, deren konstruktive Haltung von Seiten der Mitarbeiter_innen als Wertschätzung aufgefasst worden sei.

Die Hawthorne-Experimente stellten nicht nur den Anfang der ,HumanRelations-Schule' dar, mit der erstmals die Bedeutung des Faktors Mensch voll anerkannt wurde, auch veränderten sie von Grund auf die Sicht auf die Vorgänge in einem Unternehmen: Infolge dessen wurde der Output nicht mehr kausal und gemäß einem maschinellen Verständnis mit der Variation einzelner Faktoren begründet, sondern als Ergebnis einer nicht linear erfassbaren und damit komplexen Gemengelage aus Wechselbeziehungen zwischen sozialen, technologischen und ökonomischen Faktoren betrachtet. ${ }^{8}$

Ihre Entdeckung verleitete Mayo zu der Annahme, dass die Untersuchungen eine weitere industrielle Revolution auslösen würden. Tatsächlich markierten die Verhaltensexperimente nicht allein den Auftakt der Human-Relations-Schule; sie begründeten zugleich das zentrale Selbstverständnis des modernen Managementdenkens, das sich entsprechend dem Zeitgeist der Demokratisierung am Anfang einer grundlegenden Transformation sah: der Humanisierung der Arbeit. Die Hawthorne-Experimente führten damit zu einer

6 Eine umfassende Darstellung der Geschichte der Hawthorne-Experimente bieten: Richard Gillespie, Manufacturing Knowledge. A History of the Hawthorne Experiments, Cambridge, New York, NY, Melbourne, 1991; Emil Walter-Busch, Das Auge der Firma. Mayos Hawthorne-Experimente und die Harvard Business School, 1900-1960, Stuttgart, 1989.

7 Elton Mayo, Hawthorne and the Western Electric Company. The Social Problems of an Industrial Civilization, Boston, MA, 1945, S. 82.

8 Walter-Busch (1989), Das Auge der Firma. 
Infragestellung autoritärer Denkstrukturen und hierarchischer Typen der Organisation, wie sie sich im 19. Jahrhundert herausgebildet hatten, wie etwa im Bereich der Bürokratie und des Militärs, zugunsten eines auf wechselseitiger Abstimmung zwischen dem Management und den Mitarbeiter_innen beruhenden horizontalen und netzwerkartigen Typus der Organisation. Infolge dessen wurden die Techniken der Disziplinierung der Körper durch die gouvernementalen Techniken der Organisation der Kommunikation, den Praktiken der Selbst- und Fremdreflexion, wie z. B. das Gruppenfeedback ersetzt. Anstatt die Subjekte zu isolieren, wurden die Mitarbeiter_innen zu Gruppen zusammengeschlossen, über die wiederum das Verhalten der Einzelnen gesteuert und kontrolliert werden konnte. Damit wurden schon die HawthorneExperimente zum Schauplatz der Entdeckung einer bislang wenig beachteten und jenseits des rationalen Handelns vonstattengehenden Ökonomie, wie sie gegenwärtig unter dem Begriff des „Plattformkapitalismus“ diskutiert wird. Einer Ökonomie der sozialen Netzwerke, eines informellen und auf dem Austausch immaterieller Werte beruhenden Tauschgeschäfts. ${ }^{9}$

2. Subjekte der Naturalisierung und Standardisierung: Verfahren der Normalisierung in Medizin, Biologie und Arbeitssoziologie

Mit den Ende der 1920er Jahre in den USA entwickelten Managementtechniken beschäftigte sich auch der französische Wissenschaftshistoriker Georges Canguilhem. In einer Rezension von 1947, in der sich Canguilhem mit der kurz zuvor erschienenen Publikation Der Mensch in der mechanisierten Produktion des Soziologen Georges Friedmann auseinandersetzte, ging er auf die Bedeutung der Hawthorne-Experimente ein. In den Chicagoer Experimenten wollte er eine Fortführung von Diskursen und wissenschaftlichen Verfahren entdecken, wie sie in der modernen Medizin und Biologie aufgekommen waren. ${ }^{10}$ So beschäftigte sich Canguilhem in den 1940er Jahren mit der Unterscheidung zwischen dem Normalen und dem Pathologischen, die er als Effekte von im Labor und insofern künstlich erzeugten Werten betrachtete. Was als durchschnittlich gesund oder krank angesehen wurde, war daher nach Canguilhem nicht mit jenen Werten gleichzusetzen, die wiederum im je einzelnen Organismus vorherrschten und für diesen als normal galten.

Wie Canguilhem in seinem Aufsatz 1947 argumentierte, war daher auch kein wesentlicher Unterschied zwischen den Methoden des Scientific Management, wie sie Frederick Taylor zuvor in den 1910er Jahren entwickelt hatte, und denen des Industriepsychologen Mayo auszumachen, wenngleich beide auf einem jeweils unterschiedlichen Menschenbild beruhten. Taylor, so Can-

9 Nick Srnicek, Plattform-Kapitalismus, Hamburg, 2018.

10 Georges Canguilhem, „Milieu et normes de l'homme au travail“, in: Cahiers Internationaux de Sociologie, 3 (1947), S. 120-136. 
guilhem, habe sich den Menschen noch wie eine Maschine vorgestellt, die an andere Maschinen zu koppeln ist, oder wie ein sehr einfaches Lebewesen, dessen Bedürfnisse aus nichts weiter bestünden als Zuckerbrot und Peitsche. Dahingegen sprach sich Mayo zwar für das ,well being“ der Mitarbeiter_innen aus, allerdings setzte er dieses mit den unter laborartigen Bedingungen ermittelten Werten gleich und ignorierte dabei, dass es sich hierbei nur um eine Angleichung zwischen den Werten des Unternehmens - die Maximierung des ökonomischen Gewinns - und denen der Mitarbeiter_innen handelte. Damit offenbarten die Experimente, dass die Mitarbeiter_innen gar nicht als Subjekte ihrer Arbeit begriffen wurden. In diesem Fall hätten sie ihre Werte selbst erschaffen und wären damit im eigentlichen Sinn erst produktiv geworden, das heißt zu Produzenten ihrer Arbeit, denn: „Tout homme veut être sujet de ses normes.“11

Wie der vorliegende Aufsatz zeigt, war es allerdings weniger das Verhalten des einzelnen Subjekts beziehungsweise die Widerständigkeiten von sich den objektiven Gesetzen entziehenden Subjektivitäten, auf die sich die in dieser Zeit entstehende Managementtechniken bezogen. Mit den um die Jahrhundertwende gegründeten Gewerkschaften und der Zunahme organisierter Streiks waren es vielmehr die Techniken der Gruppenorganisation, die zu einem zunehmenden Problem für das Management wurden. Die den Experimenten unterliegende Frage war daher nicht, wie der Einzelne zum Zweck der Steigerung der Produktivität zu mehr Effizienz angehalten werden konnte. Vielmehr ging es nun darum, eben jene Werte und Bedingungen zu ermitteln, mit denen Gruppen gelenkt werden konnten, jenen ,standards for group action“ also. ${ }^{12}$

Anders als es in der Forschung meist dargestellt wird - indes nicht allein die Konzepte des Industriepsychologen Elton Mayo, die den Verlauf der Experimente bestimmten. Vielmehr waren es die über Henderson einwandernden harten Methoden der modernen Naturwissenschaft, die die Validität der Ergebnisse belegten und die Arbeitsweisen standardisierten. Die hierbei verwendeten Konzepte wie Umwelt, System und Gleichgewicht dienten als Strategien der Naturalisierung, indem sie die beobachteten Phänomene mit natürlichen Gesetzmäßigkeiten begründeten. Wie im Folgenden gezeigt wird, wurden die aus der Biochemie kommenden Methoden nicht allein auf die Untersuchung der physiologischen Zustände angewendet; bei den Hawthorne-Experimenten dienten sie nun als Erklärungsmodelle auch für das Verhalten der Mitarbeiter. Auf diese Weise wurden Konzepte wie Umwelt, System und Gleichgewicht nun nicht mehr nur zur Analyse von Organismen, sondern der Kommunikation, der Sprechweisen und Zirkulationsweisen von Einstellungen und Affekten angewendet. Die Hawthorne-Experimente stellten darin nicht nur ein Vorspiel der späteren Kybernetik dar, die Sprache als sich selbst stabilisierendes, homöosta-

11 Ebd.

12 Young (1927), Dedication Address. 
tisches System betrachtet. ${ }^{13}$ Sie bedeuteten zudem eine Fortsetzung eben jener Vergleiche zwischen Chemie und Soziologie, wie sie bereits um 1800 aufkamen und nun in den Kreuzungen zwischen Industrieforschung, Soziologie und Biochemie des 20. Jahrhunderts erneut in Erscheinung traten. So wurden während der Hawthorne-Experimente die ersten soziogrammatischen Darstellungen entworfen. Ähnlich denen, die kurz darauf der Soziologe Jacob Levy Moreno entwickeln sollte - Visualisierungen, in denen die Kommunikation in der Form eines Schaltkreises dargestellt ist und soziale Prozesse homolog zu Prozessen in physikalisch-chemischen Systemen modelliert werden. ${ }^{14}$

\section{Anpassung an extreme Umwelten: \\ Anfänge des Managementdenkens zwischen Soziologie, Physiologie und Systemwissenschaft}

Die Untersuchungen in den Hawthorne-Werken wurden nur zu Beginn von den Interessenfeldern und Konzepten Mayos geleitet. Um das Verhalten der Mitarbeiter innen verständlich zu machen, bezog er sich auf Ansätze der französischen Soziologen Le Play und Émile Durkheim, der funktionalistischen Schule der Sozialanthropologen Alfred Radcliffe-Brown und Bronisław Malinowski sowie der Entwicklungspsychologie Jean Piagets. Zur selben Zeit leitete Henderson die Untersuchungen im HFL, wo er den pH-Wert bei körperlicher Belastung wie Ausdauersport und unterschiedlichen Klimabedingungen wie Hitze und Kälte untersuchte. ${ }^{15}$

Bei den im HFL durchgeführten Experimenten diente die Nomografie zur Diagnostik des Energiestoffwechsels und der Leistungsfähigkeit. ${ }^{16}$ Die Untersuchungen knüpften an die Fragestellungen der Physiologie des 19. Jahrhunderts an, die die Ermüdung erstmals im Zusammenhang mit der Leistung erforschte, um daraus Instrumente für die Arbeitswissenschaften abzuleiten. ${ }^{17}$ Auf der Grundlage von Modellen aus der Mechanik, der Physiologie und der Psychologie wurden in den Laboren Objektivitätskriterien ermittelt, um „die Normen und Bedingungen der Produktion festzulegen." ${ }^{18}$ Im HFL vollzog sich

13 Lily E. Kay, Who Wrote the Book of Life? A History of the Genetic Code, Stanford, CA, 2000, S. 294-296.

14 Sebastian Gießmann, „Drawing the Social. Jacob Levy Moreno, Sociometry, and the Rise of Network Diagrammatics“, online unter: https://netzeundnetzwerke.de/, zuletzt aufgerufen am 05.11.2018.

15 Elton Mayo, The Humans Problems of Administration, New York, NY, 1933; ders. (1945), Hawthorne and the Western Electric Company

16 Steven M. Horvath/Elizabeth C. Horvath, The Harvard Fatigue Laboratory. Its History and Contributions, Englewood Cliffs, NJ, 1973.

17 Anson Rabinbach, „Ermüdung, Energie und der menschliche Motor“, in: Philipp Sarasin/ Jakob Tanner (Hg.), Physiologie und industrielle Gesellschaft, Frankfurt/M., 1998, S. 286-312.

18 François Vatin, „Arbeit und Ermüdung. Entstehung und Scheitern der Psychophysiologie der Arbeit", in: Philipp Sarasin/Jakob Tanner (Hg.), Physiologie und industrielle Gesellschaft. 
ein Wandel hinsichtlich der Erklärungsmodelle, der Deutungsweisen und Kulturtechniken, mit denen die Ermüdung bemessen und dargestellt wurde: Hier wurde der Körper nicht mehr als ,Human Motor' und damit analog zur Maschine beschrieben und über die muskuläre Leistung definiert, sondern anhand des Verhaltens eines Gesamtsystems, das sich gegenüber seiner Umwelt selbst organisiert. ${ }^{19}$ Aufgrund seines Interesses für die Fragestellungen Mayos beschäftigte sich Henderson zunehmend auch mit den Methoden und Problemstellungen der Arbeitssoziologie.

War Hendersons Beschäftigung mit den Fragestellungen der Arbeitssoziologie anfangs noch von den aus der Biochemie kommenden Konzepten und Methoden bestimmt, so überlegte er anknüpfend an die Arbeit im HFL, wie er das Nomogramm nun zur Analyse auch des sozialen Verhaltens verwenden konnte. Während er diese Herangehensweise wieder verwarf, war es schließlich die Lektüre der soziologischen Schriften des Ingenieurs und Ökonomen Vilfredo Pareto, in denen Henderson die für seine Überlegungen geeigneten Konzepte entdeckte.

\section{Begriffe in Arbeit: \\ Hendersons „System“ und Cannons „Homöostase“}

$\mathrm{Zu}$ Beginn seiner Beschäftigung mit dem $\mathrm{pH}-$ Wert arbeitete Henderson noch in Nachbarschaft zu Walter Bradford Cannon. Beide begreifen sich als Erben des französischen Lebenswissenschaftlers Claude Bernard, der die Methoden der Physik und Chemie auf die Untersuchung von Organismen übertrug und damit die Physiologie zu einer modernen Wissenschaft machte. Zugleich grenzte Bernard die Physiologie von der Physik und Chemie ab, indem er argumentierte, dass die Logiken des lebendigen Organismus zu eigensinnig seien, als dass sie mittels der naturwissenschaftlichen Gesetze vollständig berechnet werden könnten. Die physiologische Forschung begriff er daher als einen offenen Prozess, der der Emergenz der biologischen Phänomene gleich war. Die Methode selbst wurde damit zu einem Teil des zu untersuchenden Objekts. Sie erlaubte die Aufhebung der künstlichen Trennung zwischen dem Subjekt und dem Objekt, die in der modernen Wissenschaft eingeführt wurde.

Dieser „Ethik“ - wie Canguilhem sie später bezeichnete - des wissenschaftlichen Arbeitens, verschrieb sich auch der Physiologe Cannon. Anknüpfend an Bernard widmete er seine Auseinandersetzung den Bedingungen, die das innere Milieu des Organismus konstant hielten. ${ }^{20} \mathrm{Um}$ die komplexen Mechanismen

Studien zur Verwissenschaftlichung des Körpers im 19. und 20. Jahrhundert, Frankfurt/M., 1998, S. 347-368: $355 \mathrm{f}$.

19 Philipp Felsch, Laborlandschaften. Physiologische Alpenreisen im 19. Jahrhundert (Reihe: „Wissenschaftsgeschichte“, hg. v. Michael Hagner/Hans-Jörg Rheinberger), Göttingen, 2007.

20 Wolf Lepenies (Hg.), Georges Canguilhem. Wissenschaftsgeschichte und Epistemologie. Gesammelte Aufsätze, Frankfurt/M., 1979. 
des physiologischen Gleichgewichts von denen der Physik und Chemie zu unterscheiden, prägte Cannon den Begriff der „Homöostase“. Denn während das Gleichgewicht in der Physik und in der Chemie einen Zustand der stabilen Endlage beschrieben, der daher auch präzise berechnet werden konnte, war mit dem physiologischen Gleichgewicht, bei dem sich der Organismus über verschiedene Feedbackprozesse stabil hielt, ebengerade nicht ein sich in Ruhe befindender Körper gemeint, sondern umgekehrt ein System in Arbeit, dessen Stillstand einen Zustand jenseits des Gleichgewichts bedeutete. Mit dem physiologischen Gleichgewicht, so Cannon, war vielmehr eine Bandbreite an Werten bezeichnet, innerhalb derer die biologischen Prozesse um einen normalen oder durchschnittlichen Wert oszillierten, dem sie sich immer nur relativ annäherten und dessen Dynamiken daher nicht exakt zu bestimmen waren. Wenn auch Cannon damit der exakten Bestimmbarkeit und Vorhersage der biologischen Prozesse kritisch gegenüberstand, wurde seine Forschung von Seiten der Kybernetik wiederum zur Entwicklung von sich selbst regulierenden technischen Geräten herangezogen, die bekanntermaßen der Abwehr von Fliegerangriffen dienen sollten, indem sie deren wahrscheinliche Flugbahn im Voraus berechneten..$^{21}$

\section{Technische Epistemologie: \\ Anfänge der US-Wissenschaftsgeschichte und Reform der Humanwissenschaften}

Anders als der Mediziner Cannon, der seine Untersuchungen wie Bernard in vivo - am lebendigen Objekt - unternahm, arbeitete der aus der Chemie kommende Henderson in vitro, mit über verschiedene instrumentelle Verfahren präparierten Blutproben. ${ }^{22}$ Das Blut untersuchte er damit nicht in seiner natürlichen Umgebung und aus dem dynamischen Geschehen biologischer Abläufe heraus, sondern in der kontrolliert-künstlichen Umgebung des Reagenzglases. Und anders als Cannon war Henderson zudem bestrebt, eine mathematische Darstellung der Prozesse auszumachen. Insofern betrachtete er das Blut als ein von seiner natürlichen Umwelt isoliertes System, wodurch er die Veränderungen des pH-Werts in Bezug auf eine reduzierte Anzahl von Messgrößen betrachtete und einfacher berechnen konnte. Bei dieser Herangehensweise orientierte er sich neben Bernard zudem an der Arbeitsweise des US-Physikers Josiah Willard Gibbs. Dieser führte die Arbeit mit dem Konzept des geschlossenen Systems ein, um Gleichgewichtsbedingungen in komplexen physikalisch-chemischen Systemen berechenbar zu machen.. ${ }^{23}$ Wie Gibbs betrachtete

\footnotetext{
21 Steven J. Cooper, „From Claude Bernard to Walter Cannon. Emergence of the Concept of Homeostasis“, in: Appetite 51, 3 (2008), S. 419-427.

22 Garland E. Allen, Life Science in the Twentieth Century, New York, NY, 1975.

23 Henderson (1928), Blood, S. 7.
} 
auch Henderson das Blut als ein physikalisch-chemisches System. Dessen verschiedene Adaptionsmechanismen, die infolge einer Störung des Gleichgewichts auftraten, suchte er in der Form einer mathematischen Gleichung darzustellen. Mithilfe des Nomogramms entwickelte er schließlich ein Instrument, mit dem er die im Blut vorherrschenden allgemeinen Gesetzmäßigkeiten

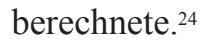

Hendersons Ziel, die biologischen Vorgänge in der Form einer mathematischen Formel wiederzugeben, betrachtete Cannon folglich kritisch. In der Arbeit seines Kollegen sah er Bernards Konzept des „milieu intérieur" missinterpretiert..$^{25}$ Bernards Errungenschaft sei es gewesen, die moderne Physiologie gerade dadurch von der Physik und Chemie zu unterscheiden, indem sie dem Leben eine gewisse Eigenständigkeit zuschrieb, durch die es sich dem Zugriff von Seiten der Umwelt bis zu einem bestimmten Grad unabhängig machte. Zwar beruhte auch Hendersons Auseinandersetzung nicht mehr auf dem in der Industriegesellschaft dominierenden Bild vom Körper als einer von außen regelbaren Maschine - mit dem Konzept des Systems wurde dieses vielmehr durch ein netzwerkartiges, sich selbst organisierendes und dynamisch anpassendes Modell abgelöst. Hendersons Arbeitsweise stütze sich zugleich noch auf die Methoden der Physik und Chemie, die den Körper auf eine „thermodynamische Maschine" reduzierten, indem sie davon ausgingen, dessen Mechanismen mathematisch beschreiben zu können. ${ }^{26}$

Hendersons Herangehensweise gründete auf einer sich auf technische Instrumente und naturwissenschaftlich-empirische Methoden stützenden Epistemologie. Wie er in der Einleitung zu seinem Hauptwerk von 1929 darlegte, sollte es die Aufgabe der Physiologie des 20. Jahrhunderts sein, ihre Methoden auf rationale Grundlagen zu stellen. Die Physiologie habe sich dazu mathematischer Methoden zu bedienen. Seiner Einschätzung nach würden Forschungsrichtungen wie die Biochemie, die sich der Methoden und Konzepte der Physik und Chemie bediente, der Biologie im 20. Jahrhundert zu einer ähnlichen Größe verhelfen, wie sie die Physik und die Chemie im 19. Jahrhundert erlangten. Schon in den Anfangsjahren seiner Arbeit als Biochemiker beschäftige sich Henderson zudem mit wissenschaftsphilosophischen Strömungen der Zeit. 1911 hielt er einen Kurs in „History of Science“, ein zu dieser Zeit noch nicht existierendes Fach, der damit das vermutlich erste Seminar in dieser Disziplin in der Geschichte von Harvard darstellte. 1924 gründete er die History of Science Society gemeinsam mit dem Mathematiker und Chemiker George Sarton, den er Jahre zuvor schon nach Cambridge holte. Hendersons Interesse galt den Ansätzen des logischen Empirismus, mit denen sich zeit-

24 Ebd.

25 Cooper (2008), From Claude Bernard to Walter Cannon.

26 Jakob Tanner, ,,Weisheit des Körpers‘ und soziale Homöostase. Physiologie und das Konzept der Selbstregulation“, in: Philipp Sarasin/Jakob Tanner (Hg.), Physiologie und industrielle Gesellschaft. Studien zur Verwissenschaftlichung des Körpers im 19. und 20. Jahrhundert, Frankfurt/M., 1998, S. 129-169: 160. 
gleich auch der Physiker Percy Bridgman, der Psychologe Burrhus Frederic Skinner und der Philosoph Willard Quine auseinandersetzten. Sie verband die Kritik an den als bloß spekulativ abgetanen Methoden des kantischen Transzendentalismus. An die Stelle der Vernunft rückten nun technische Geräte, die dem empirischen Beleg theoretischer Annahmen dienten. ${ }^{27}$

Die US-amerikanische Rezeption des logischen Empirismus wurde befördert durch eine in den 1930er Jahren voragetriebene Bildungsreform des Präsidenten der Universität, James Bryan Conant. Unter Conant sollte die Einführung empirischer Methoden weiterentwickelt werden, allen voran auch in den Humanwissenschaften, wozu Fächer wie die Soziologie, die Anthropologie, die Sozialpsychologie, die Analytische Philosophie, die Wissenschaftsgeschichte sowie auch die neu entstehenden Managementtheorien zählten..$^{28}$

Die Bildungsreform bildete einen Hintergrund für die Versuche Hendersons, biochemische Konzepte und naturwissenschaftliche Methoden auf die Fragestellungen Mayos zu übertragen. Ein weiterer Grund stellte die gegenüber der Physik zunehmende Bedeutung der Biologie dar: Während zur selben Zeit - und das heißt kurz nach dem Ausbruch der Weltwirtschaftskrise - auch Cannon darüber nachdachte, inwieweit die Biologie Modelle für das Verständnis einer sich immer komplexer darstellenden Gesellschaft liefern konnte, lagen beiden Überlegungen, wenngleich konträre, politische Ansichten zugrunde. Der Physiologe Cannon, der sich für die demokratischen Programme des New Deal stark machte, entwarf ein korporatistisches Organisationsmodell. Die flexiblen, sich selbst steuernden Anpassungs- und Interaktionsmechanismen in biologischen Organismen betrachtete er als Modell für das Funktionieren der modernen Demokratie, die auf einem Kräftespiel zwischen den Institutionen aus Industrie, Politik und Wissenschaft beruhte. ${ }^{29}$ Dagegen stand Henderson der Programmatik des New Deal skeptisch gegenüber. Sein Interesse galt der Funktionsweise eines einzigen Systems und der Anpassung an relativ starr bleibende Werte. Seine Auseinandersetzung mit den Techniken des modernen Managements zeugte vom Interesse einer industriellen Elite, die in Zeiten der ökonomischen und politischen Krisen der 1930er Jahre an der Aufrechterhaltung des Status quo interessiert war. ${ }^{30}$

27 Joel Isaac, Working Knowledge. Making the Human Sciences from Parsons to Kuhn, Cambridge, 2012, S. 23.

28 Ebd.

29 Jakob Tanner, „,Weisheit des Körpers' und soziale Homöostase. Physiologie und das Konzept der Selbstregulation“, in: Philipp Sarasin/Jakob Tanner (Hg.), Physiologie und industrielle Gesellschaft. Studien zur Verwissenschaftlichung des Körpers im 19. und 20. Jahrhundert, Frankfurt/M., 1998, S. 129-169: 160.

30 Barbara S. Heyl, „The Harvard ,Pareto Circle““, in: Journal of the History of the Behavioural Sciences 4, 4 (1968), S. 316-334; Steve Fuller, Thomas Kuhn. A Philosophical History for Our Times, Chicago, IL, 2000, S. 164. 


\section{Objektivierung des Verhaltens:}

Ermessung sozialer Gleichgewichte

Sowohl in Hendersons naturwissenschaftlicher Arbeitsweise als auch in dessen Denkweise entdeckte Donham einen für die Aufgabenstellungen der Harvard Business School geeigneten Wissenschaftler. Nachdem er die Rockefeller Stiftung für seine Vorhaben gewann - die Familie war in den 1910er Jahren aufgrund von Streiks in den zu ihrem Eigentum gehörenden Ludlow-Werken in die Kritik von Seiten der Öffentlichkeit geraten -, wurden die HawthorneExperimente ab 1927 mit einer jährlichen Summe von 30.000 USD gefördert, zudem gingen 35.000 USD einmalig in die Ausstattung des HFL ein. 1930 wurden die Gelder zusammengeführt. Für die Dauer von sieben Jahren wurden die Untersuchungen dadurch mit 125.000 USD jährlich finanziert, womit die Fördersumme das größte Forschungsbudget der Business School in den 1930er Jahren darstellte. ${ }^{31}$

In der Rezeptionsgeschichte der Human-Relations-Bewegung ist die Bedeutung des HFL sowie der Anteil von Hendersons Arbeit der von Mayo nachgeordnet. ${ }^{32}$ Nichtsdestoweniger gingen aus der Arbeits- und Denkweise des Biochemikers Henderson eben jene Erklärungsmodelle, Methoden und (Medien-)Techniken hervor, die die Untersuchungen in den HawthorneWerken maßgeblich bestimmten. So war die Verschiebung von der Einfaktorenanalyse, wie sie noch den Taylorismus kennzeichnete, zur Betrachtung mehrerer, miteinander interagierender Faktoren letztlich auf Hendersons physiologische Denkweise zurückzuführen. ${ }^{33}$

Um die Natur der zwischenmenschlichen Beziehungen zu verstehen, griff auch Mayo auf die von Henderson entwickelte Nomografie zurück. ${ }^{34}$ Mit der 1884 durch d'Ocagne entwickelten grafischen Kalkulationstechnik wurden die Wechselbeziehungen zwischen einer Vielzahl an Faktoren entlang von parallel zueinander verlaufenden Achsen auf einen Blick erfasst. Die Vorteile dieses „bird's eye view“"35 führten zu seiner raschen Verbreitung im Militär, in der Geologie und im Ingenieurswesen. Durch Hendersons Arbeit wurde das Nomogramm auch in der Physiologie erstmals verwendet. Anders als die in der Physiologie des 19. Jahrhunderts entwickelten Messinstrumente, die die physiologischen Veränderungen noch in der Form von Kurvenverläufen darstellten, ließ die Nomografie allerdings optisch keine Ähnlichkeiten oder Verweise

31 Jeffrey L. Cruikshank, A Delicate Experiment. The Harvard Business School 1908-1945, Boston, MA, 1987, S. 125.

32 Eine Ausnahme bildet Walter-Busch (1989), Das Auge der Firma.

33 Ebd.

34 Gillespie (1991), Manufacturing Knowledge.

35 Thomas L. Hankins, „Blood, Dirt, and Nomograms: A Particular History of Graphs“, in: Isis 90, 1 (1999), S. 50-80: 77; siehe auch Bruno Latour, „Drawing Things Together. Die Macht der unveränderlichen mobilen Elemente", in: Andréa Belliger/David J. Krieger (Hg.), ANThology. Ein einführendes Handbuch zur Akteur-Netzwerk-Theorie, Bielefeld, 2006, S. 259-308. 
mehr zu den körperlichen Vorgängen zu. Zugleich waren auch die Kurvenverläufe in ihrer Regelmäßigkeit weniger ein Ausdruck der Natur gewesen, sondern entsprachen mehr dem wissenschaftlichen Ideal der „mechanischen Objektivität“"36, das in der Präzision der Messinstrumente eine Entsprechung fand. Wurden hierdurch sowohl die Natur als auch die wissenschaftliche Beobachtung mechanisiert und standardisiert, so galt dies nicht minder für die Nomografie. Denn während Bernard mit der Vivisektion zugleich eine Ethik des Forschens begründete, war das Nomogramm als Schließung des experimentellen Vorgangs zu begreifen. Als „operatives Bild“ stellte das Nomogramm nicht nur die Wechselbeziehungen zwischen einer festgelegten Anzahl von Faktoren dar, es gab auch die Regeln und Operationen vor, mit denen die physiologischen Vorgänge zu berechnen waren. ${ }^{37}$ Auf diese Weise wurde die Arbeit des Physiologen zur reinen Kalkulation, zur mechanischen Anwendung einer Regel. An die Stelle einer konkreten Epistemologie, einer noch bei Bernard als organisch vorgestellten Weise der Betrachtung, trat das ,technische Apriori“" eines maschinenförmigen, „bewusstlosen Denkens“. .38

Bis in die 1930er Jahre tendierten Hendersons Überlegungen dahin, die exakten Methoden der Biochemie auch in den Sozialwissenschaften einzuführen. Henderson betrachtete es als Ziel der Hawthorne-Experimente, die Faktoren der Arbeitsproduktivität über die Ermittlung von objektiven Indikatoren des Verhaltens messbar zu machen. Auch Mayo verwendete in den Anfangsjahren noch medizinische Methoden wie Pulsmessungen. Währenddessen suchte Henderson mithilfe des Nomogramms nach denjenigen Variablen, mit denen sich die auf die Produktivität Einfluss nehmenden sozialen Faktoren quantitativ bestimmen ließen. Im Verlaufe der Experimente musste er jedoch erkennen, dass er die Messgrößen für die Gleichgewichtswerte sozialer Systeme nicht präzise ermitteln konnte..$^{39}$

\section{Animal Spirits:}

Entstehung des Systemdenkens zwischen Ameisenforschung, Texthermeneutik und Managementdenken

Mit der Einsicht in die Problematik, die Gesetzmäßigkeiten zwischenmenschlicher Interaktionen ebenso präzise wie die der biologischen bestimmen zu wollen, wendete Henderson sich den Möglichkeiten der sozialwissenschaftli-

36 Soraya de Chadarevian, „Die ,Methode der Kurven“ in der Physiologie zwischen 1850 und 1900", in: Michael Hagner (Hg.), Ansichten der Wissenschaftsgeschichte, Frankfurt/M., 2001, S. 161-190; siehe auch Lorraine Daston/Peter Galison, Objektivität, Frankfurt/M., 2007.

37 Sybille Krämer, „Punkt, Strich, Fläche. Von der Schriftbildlichkeit zur Diagrammatik“, in: dies./Cancik-Kirschbaum, Eva/Trotzke, Rainer (Hg.), Schriftbildlichkeit. Über Wahrnehmbarkeit, Materialität, Operativität von Notationen, Berlin, 2012, S. 79-101: 82.

38 Ebd., S. 91.

39 Walter-Busch (1989), Das Auge der Firma, S. 129. 
chen Analyse zu. Bereits 1926 machte ihn ein Kollege, der Ethnologe William Morton Wheeler auf das sozialwissenschaftliche Werk des italienischen Ingenieurs und Ökonomen Vilfredo Pareto aufmerksam und sein 1916 erschienenes Trattato di Sociologia Generale. Obgleich es Pareto war, der die Mathematisierung der schon bei Adam Smith aufgestellten ökonomischen Annahmen vorantrieb, wuchsen ihm zunehmend Zweifel an der Tragweite der Modelle. So erkannte er, dass die Theorie des rational handelnden homo oeconomicus wenig mit dem realen Verhalten gemein habe. Dieses erschien ihm vielmehr von nur halb bewussten Glaubensüberzeugen, Gewohnheiten und Affekten gesteuert. Dennoch wollte er auch in diesem eine Gesetzmäßigkeit erkennen. Auch das reale Verhalten betrachtete er als Prozess der wechselseitigen Interaktion, ähnlich den Preisanpassungen am Markt. Aus den wechselseitigen Beeinflussungen gingen gemeinsam geteilte Werte und Normen hervor, die das System in Gleichgewicht und damit stabil hielten. Trotz seiner Abkehr von der Annahme rationalen Verhaltens stellten die soziologischen Überlegungen damit eine Kontinuität der Gleichgewichtstheorie dar. ${ }^{40}$

Paretos Überlegungen fußten allerdings nicht auf einer empirischen Beobachtung. Da sich die Ursachen für die jeweilige Handlung erst nachträglich, in Form einer auf diese folgenden Erklärungen manifestierten, wendete sich Pareto der Sprache zu. Die objektiven Fakten seiner Theorien wollte er in einem Konvolut aus Schriften aus unterschiedlichen historischen Zeiten entdecken, in kollektiven Erzählungen, Mythen und Legenden, in historischen, philosophischen und theologischen Abhandlungen, die er als Archive eines kollektiven Wissens betrachtete, aus denen sich die Gesetze menschlichen Verhaltens rekonstruieren ließen. ${ }^{41}$

Den Ethologen Wheeler, der sich mit den Verhaltensgewohnheiten von Insekten beschäftigte, verleiten die Theorien Paretos dazu, Ameisengesellschaften als Modelle der menschlichen Gesellschaft zu begreifen. ${ }^{42}$ Henderson wiederum fand in Paretos Überlegungen brauchbare Konzepte für die Analyse des zwischenmenschlichen Verhaltens im Unternehmen. ${ }^{43}$ In Pareto sah er den Gibbs der Sozialwissenschaften. Über seinen Befund tauschte er sich mit dem Statistiker und Ökonomen Edwin Bidwell Wilson aus, der sich in etwa zeitgleich mit Paretos mathematischer Ökonomie auseinandersetzte. Aus Wilsons Sicht erleichterte das Konzept des „Sozialen Systems“ die Arbeit der Soziologen und Ökonomen. Seiner Meinung nach half es, von der Untersuchung der Gesellschaft als Ganzes abzusehen. Um die Vielzahl der sozialen und ökonomischen Faktoren unter Kontrolle zu bringen, ginge es zunächst darum, die

\footnotetext{
40 Maurizio Bach, Jenseits des rationalen Handelns. Zur Soziologie Vilfredo Paretos, Wiesbaden, 2004, S. 12.

41 Ebd.

42 Niels Werber, Ameisengesellschaften: Eine Faszinationsgeschichte, Frankfurt/M., 2013.

43 Heyl (1968), The Harvard ,Pareto Circle'.
} 
Gesellschaft in der Form kleinerer, überschaubarer Gruppen zu untersuchen, „small, manageable, closed systems". ${ }^{44}$

Die über Henderson eingebrachten Konzepte, wie das des „sozialen Systems", wirkten daher in zwei Richtungen: In der wissenschaftlichen Arbeit diente es dem Management der Vielzahl der beobachteten Faktoren - im Unternehmen einer immer größer werdenden Zahl an Mitarbeiter_innen. Denn mit der zunehmenden Dynamisierung, der Veränderung und dem Wachstum der Belegschaft war das Management nicht mehr in der Lage, sich mit dem einzelnen Mitarbeiter, oder gar dem Unternehmen als Ganzes zu beschäftigen. Konzepte, wie das des sozialen Systems, dienten der Entwicklung von Methoden, mit denen das Verhalten Vieler gesteuert werden konnte, wie die der Teamarbeit und des Gruppenfeedbacks. Bei der Zusammenstellung der Gruppe ging es zudem nicht mehr darum, den Ablauf der Tätigkeiten im Voraus festzulegen, wie noch im Scientific Management, sondern lediglich darum, die richtigen Rahmenwerte zu platzieren, an die sich die Mitarbeiter im Folgenden von selbst anpassten und damit wiederum auf das Verhalten anderer im Unternehmen einwirkten.

Von der Relevanz von Paretos Überlegungen überzeugt, hielt Henderson 1932 ein Seminar, das als Einführung in die Denkweise des Sozialwissenschaftlers angelegt war. $\mathrm{Zu}$ den Teilnehmern zählten neben Elton Mayo und den, bei den Hawthorne-Experimenten mitarbeitenden, Wissenschaftlern Fritz Roethlisberger, Thomas Whitehead und dem Leiter der Forschungsabteilung Personalmanagement William Dickson, auch die Soziologen Talcott Parsons, Robert Merton und George Homans, der Ideenhistoriker Crane Brinton, der Rechtswissenschaftler und Anwalt Charles Curtis, der Unternehmer Chester Barnard, die Anthropologen Eliot Chapple und Conrad Arensberg sowie zeitweilig der Ökonom Joseph Schumpeter. ${ }^{45}$ Dieses und auch die weiteren von ihm gegründeten soziologischen Seminare und wissenschaftlichen Zirkel, die den Charakter interdisziplinärer Thinktanks hatten, nahmen hierin einen wissenschaftlichen Stil vorweg, wie er prägend für die Zeit der Kybernetik wurde: die Arbeit mit Disziplinengrenzen überschreitenden und als universal gültig betrachteten Konzepten.

Das Konzept des sozialen Systems bestimmte insofern auch die Auswertung der bei den Hawthorne-Experimenten erhobenen Daten. Zwar dachte Henderson, wie auch Donham und Mayo, dass der Manager zunächst ein Praktiker sein müsse, einer jener „men of affairs“, die Entscheidungen auf Erfahrung und Intuition gründeten. ${ }^{46}$ In der systemischen Betrachtungsweise wollte er jedoch zugleich ein theoretisches Instrument entdeckt haben, mit

44 Juan Carvajalino, „E. B. Wilson and the Rise of Mathematical Economics in United States of America: A Trip into the ,No Man's Land“, 1920-1940“, online unter: https://hope.econ.duke. edu/node/1241, zuletzt aufgerufen am 05.11.2018.

45 Heyl (1968), The Harvard ,Pareto Circle'.

46 Lawrence Joseph Henderson, Pareto's General Sociology. A Physiologist's Interpretation, Cambridge, MA, 1935. 
dem das Sozialverhalten in den meisten Fällen erklärbar sei. Die in das Unternehmen einwandernden Konzepte der Biochemie dienten von da an nicht mehr nur zur Untersuchung der physiologischen Faktoren, wie noch im HFL, sondern dem Verständnis der Kommunikationsweisen, die in der Form eines Systems sich wechselseitig stabilisierender Interaktionen betrachtet wurde.

\section{Management des Wissens:}

Die Hawthorne-Experimente als Auftakt der Wissensgesellschaft

Die AT\&T wurden auf diese Weise zum Schauplatz der Entwicklung von zentralen Medientechniken und Theorien der Kommunikation des 20. Jahrhunderts: In den Werkstätten der Western Electric Company der AT\&T, ein aus der Bell Telephone Company hervorgegangenes Unternehmen der Telekommunikationsindustrie, 1877 durch Alexander Graham Bell gegründet, wurde das für die Telefonie gebrauchte technische Equipment, die Telefone, Kabel und Schaltgeräte, in hochgradig spezialisierten Produktionseinheiten hergestellt. Die AT\&T erlangten um die Jahrhundertwende Monopolstellung, das Wachstum in den Werkstätten erforderte eine Neuorganisation der Produktion. In der Anwendung der Methoden des Taylorismus wurde die Western Electric führend. ${ }^{47}$ Das Zusammenspiel aus der Standardisierung der Produktion und technologischen Innovationen führte wiederum zu einer zunehmenden Komplexität, da es die wiederholte Standardisierung von immer neuen Arbeitsabfolgen erforderte. 1920 richtet die Western Electric das „Time Standards Department" ein. Die dort arbeitenden Mitarbeiter_innen hatten die Aufgabe, die Arbeitsdauer mithilfe von Stoppuhren und einer Mikrobewegungen aufzeichnenden Kamera festzulegen. Während dort gefertigte technische Geräte wie das Relais im Alltag der Menschen zu einer zunehmenden Technisierung der Kommunikation führten, wurde mit den Hawthorne-Experimenten wiederum die Bedeutung der mündlichen Kommunikation als zentraler Faktor der Produktivität erkannt. Und nur wenige Jahre später wurden die Bell Laboratories wiederum zum Ort, an dem Claude Shannon seine mathematische Theorie der Information entwickelte.

Um die mündliche Kommunikation messbar zu machen, wurde zu Beginn der Hawthorne-Experimente zunächst das in der Psychiatrie und Analyse entwickelte Verfahren der Befragung angewendet. Ende der 1920er wurden die ersten Interviews durchgeführt, bereits 1929 waren es mehr als 10.000. Nachdem auch das Management deren Relevanz bestätigte, wurden diese ab den 1930er Jahren sukzessive auf sämtliche Organisationseinheiten ausgeweitet. ${ }^{48}$ Zur besseren Analyse der Kommunikationsweisen wurden die Aussagen der

47 Gillespie (1991), Manufacturing Knowledge, S. 12.

48 Fritz Roethlisberger/William Dickson, Management and the Worker. An Account of a Research Program Conducted by the Western Electric Company, Chicago, IL, 1939, S. 183. 
Mitarbeiter_innen Kategorien zugeordnet und zu quantitativen Größen zusammengefasst. Hierbei erhielten solche Aussagen einen Wert, die samt Indizes Informationen über das soziale Feld beinhalteten, wie die Aussagen über die sozialen Beziehungen am Arbeitsplatz oder auch das Privat- und Freizeitleben. ${ }^{49}$ Die einzelnen Abteilungen wurden hierbei als Teile eines Systemganzen betrachtet. Störungen in dem einen Teil führten demnach zu Anpassungsreaktionen in einem anderen, so dass die Vielzahl der Unterhaltungen als Teil eines fortlaufenden und sich dynamisch anpassenden Gleichgewichtsmechanismus betrachtet wurde. ${ }^{50}$ Die Aufgabe der Manager war es sodann, Störungen auszugleichen, indem sie unproduktive Werte wie störende Kommunikationsweisen blockierten und an die Werte des Unternehmens anpassten. ${ }^{51}$

Während der Hawthorne-Experimente wurden auf diese Weise die bislang von Seiten der Unternehmensführung vernachlässigten immateriellen und impliziten Faktoren der Produktivität sichtbar gemacht, die nur halb bewussten Einstellungen, Glaubensüberzeugungen und Gefühle. Für die Verhaltensstudien interessierte sich auch Chester Barnard, ein Spitzenmanager der AT\&T, der sich nach einem Besuch von Hendersons Seminar von dessen Überlegungen überzeugt zeigte. Zugleich erschienen ihm die Interviewbefragungen ungeeignet, um die Werte des Unternehmens zu vermitteln, da dies nur auf dem theoretischen Weg erfolgte. Im Unternehmensalltag müssten Manager vielmehr unmittelbar verkörpern, was sie von den Mitarbeiter_innen erwarteten. Die Manager seien Vorbilder, die die Werte des Unternehmens zuallererst vorzuleben hätten und deren Verhaltensweisen die Mitarbeiter_innen dann unbewusst nachahmten und sich hierdurch aneigneten.

Nach 1945 gingen die Ansätze der Human-Relations-Bewegung wiederum in Theorien des kybernetischen Managements ein. So basierte auch Herbert Simons Theorie der Entscheidung auf den Vorarbeiten von Mayo, Henderson und Barnard. Zwar betrachtete Simon unternehmerische Entscheidungen als rational, zugleich räumte er den unbewussten Prozessen eine gewisse Relevanz ein.

Barnards Überlegungen - die er in einer griffigen Formel fasste „progress of what they want before they know themselves" ${ }^{\text {s52 }}$ - spitzten zu, was sich während der Hawthorne-Experimente bereits ankündigte und wenige Jahre später unter dem Begriff der „Wissensgesellschaft“ gefasst wurde: die zunehmende Bedeutung von Kopf- versus Handarbeit und damit einhergehend die Bedeutung immaterieller und impliziter Formen des Wissens. Moderne Theorien des Managements, wie sie in der Human-Relations-Bewegung entwickelt wurden, nahmen damit vorweg, was im späteren practice turn der Wissensgeschichte der 1970er Jahre theoretisch reflektiert wurde. Die Sichtweise, wonach Wissen

49 Ebd., S. 282.

50 Ebd., S. 567.

51 Stephen B. Adams/Orville R. Butler, Manufacturing the Future: A History of Western Electric, Cambridge, MA, 1999, S. 127.

52 Walter-Busch (1989), Das Auge der Firma. 
eben nicht aus theoretischen Setzungen, sondern konkreten Praktiken und Handlungen, Materialien und Medien hervorgeht, war eine Erkenntnis, auf der auch das Management der Zwischenkriegsära basierte. ${ }^{53}$ Während mit den praxeologischen Ansätzen die Kontingenzen und Instabilitäten der Wissensproduktion sichtbar gemacht werden sollen, zielten die Managementansätze hingegen auf deren Stabilisierung ab.

Mit den Hawthorne-Experimenten wurden die Techniken der Disziplinierung der Körper, die Praktiken der Beobachtung, Aufzeichnung und Effizienzsteigerung der Bewegungen, wie sie den Taylorismus kennzeichneten, durch gouvernementale Techniken der Lenkung von Gruppen und damit einer Organisation der in ihnen zirkulierenden Kommunikation und Affekte ersetzt. ${ }^{54}$ Hier bildete sich nicht nur einfach der Übergang von der Hand- zur Kopfarbeit, von einer Industrie- in die Wissensgesellschaft ab. Vor allem hatte man es mit der Erscheinung eines veränderten ökonomischen Wissens und damit eines neuen Typus von Macht zu tun. Mit der Infragestellung einer zentralen Annahme der politischen Ökonomie seit Adam Smith - der Theorie des rationalen Handelns - erschien nun erstmals der Faktor Mensch in der Gesamtheit seiner sozialen Beziehungen. ${ }^{55}$ Zugleich wurde damit den irrationalen Faktoren ein neues Gewicht gegeben, den Einstellungen und Glaubensüberzeugungen sowie den nur schwer kontrollierbaren sozialen Affekten. ${ }^{56}$ Die Hawthorne-Experimente sind von daher auch als Vorformen einer gegenwärtigen Erscheinung des Ökonomischen neu zu entdecken - dem Handel mit den in sozialen Netzwerken entstehenden und auf dem Tausch von Einstellungen, Meinungen und Affekten basierenden digitalen Daten, wie im sogenannten „Plattformkapitalismus“57 - und damit nicht zuletzt als frühe Erscheinung eines Typus von Macht, wie er aktuell virulent wird: der Kopplung von auf Gruppendynamiken und Affektmanipulationen basierenden Strukturen des autoritären Regierens und Marktliberalismus.

53 Ausgehend von u. a: Galison/Dostan (2007), Objektivität; Bruno Latour/Steven Woolgar, Laboratory Life. The Construction of Scientific Facts, 2. Aufl., Princeton, NJ, 1986; HansJörg Rheinberger, Experimentalsysteme und epistemische Dinge. Eine Geschichte der Proteinsynthese im Reagenzglas, Frankfurt/M., 2001.

54 Michel Foucault, Überwachen und Strafen. Die Geburt des Gefängnisses, Frankfurt/M., 1977; ders., Geschichte der Gouvernementalität II. Die Geburt der Biopolitik, 1978-1979, Frankfurt/M., 2006.

55 Joseph Vogl, Kalkül und Leidenschaft. Poetik des ökonomischen Menschen, München, 2002.

56 Urs Stäheli, ,Poststrukturalismus und Ökonomie: Eine programmatische Skizze der Affektivität ökonomischer Prozesse“, in: Caroline Arni (Hg.), Der Eigensinn des Materials. Erkundungen sozialer Wirklichkeit, Festschrift für Claudia Honegger zum 60. Geburtstag, Frankfurt/M., Basel, 2007, S. 503-520.

57 Srnicek (2018), Plattform-Kapitalismus. 


\section{Literatur}

Adams, Stephen B./Butler, Orville R., Manufacturing the Future. A History of Western Electric, Cambridge, MA, 1999.

Allen, Garland E., Life Science in the Twentieth Century, New York, NY, 1975.

Bach, Maurizio, Jenseits des rationalen Handelns. Zur Soziologie Vilfredo Paretos, Wiesbaden, 2004.

Canguilhem, Georges, „Milieu et normes de 1'homme au travail“, in: Cahiers Internationaux de Sociologie, 3 (1947), S. 120-136.

Carvajalino, Juan, „E. B. Wilson and the Rise of Mathematical Economics in United States of America: A Trip into the ,No Man's Land", 1920-1940", online unter: https://hope.econ.duke.edu/node/1241, zuletzt aufgerufen am 05.11.2018.

Cooper, Steven J., „From Claude Bernard to Walter Cannon. Emergence of the Concept of Homeostasis", in: Appetite 51, 3 (2008), S. 419-427.

Cruikshank, Jeffrey L., A Delicate Experiment. The Harvard Business School 19081945, Boston, MA, 1987.

Daston, Lorraine/Galison, Peter, Objektivität, Frankfurt/M., 2007.

De Chadarevian, Soraya, „Die ,Methode der Kurven“ in der Physiologie zwischen 1850 und 1900“, in: Michael Hagner (Hg.), Ansichten der Wissenschaftsgeschichte, Frankfurt/M., 2001, S. 161-190.

Felsch, Philipp, Laborlandschaften. Physiologische Alpenreisen im 19. Jahrhundert (Reihe: „Wissenschaftsgeschichte“, hg. v. Michael Hagner/Hans-Jörg Rheinberger), Göttingen, 2007.

Foucault, Michel, Überwachen und Strafen. Die Geburt des Gefängnisses, Frankfurt/ M., 1977.

Ders., Geschichte der Gouvernementalität II. Die Geburt der Biopolitik, 1978-1979, Frankfurt/M., 2006.

Fuller, Steve, Thomas Kuhn. A Philosophical History for Our Times, Chicago, IL, 2000.

Gillespie, Richard, Manufacturing Knowledge. A History of the Hawthorne Experiments, Cambridge, New York, NY, Melbourne, 1991.

Gießmann, Sebastian, „Drawing the Social. Jacob Levy Moreno, Sociometry, and the Rise of Network Diagrammatics“, online unter: https://netzeundnetzwerke.de/, zuletzt aufgerufen am 05.11.2018.

Hammond, Debora, The Science of Synthesis. Exploring the Social Implications of General Systems, Boulder, CO, 2003.

Hankins, Thomas L., „Blood, Dirt, and Nomograms: A Particular History of Graphs“, in: Isis 90, 1 (1999), S. 50-80.

Henderson, Lawrence Joseph, The Fitness of the Environment, New York City, NY, 1913.

Ders., The Order of Nature, Cambridge, MA, 1917.

Ders., Blood. A Study in General Physiology, New Haven, MA, 1928.

Ders., Pareto's General Sociology. A Physiologist's Interpretation, Boston, MA, 1935.

Ders./Mayo, Elton, „The Effects of Social Environment“, in: ders./Bernard Barber (Hg.), L. J. Henderson on the Social System. Selected Writings, Chicago, IL, 1970, S. 214-234.

Heyl, Barbara S., „The Harvard ,Pareto Circle“", in: Journal of the History of the Behavioural Sciences 4, 4 (1968), S. 316-334. 
Horvath, Steven M./Horvath, Elizabeth C., The Harvard Fatigue Laboratory, Its History and Contributions, Englewood Cliffs, NJ, 1973.

Kay, Lily E., Who Wrote the Book of Life? A History of the Genetic Code, Stanford, CA, 2000, S. 294-296.

Krämer, Sybille, „Punkt, Strich, Fläche. Von der Schriftbildlichkeit zur Diagrammatik“, in: dies./Eva Cancik-Kirschbaum/Rainer Trotzke (Hg.), Schriftbildlichkeit. Über Wahrnehmbarkeit, Materialität, Operativität von Notationen, Berlin, 2012, S. 79101.

Isaac, Joel, Working Knowledge. Making the Human Sciences from Parsons to Kuhn, Cambridge, 2012.

Latour, Bruno, „Drawing Things Together. Die Macht der unveränderlichen mobilen Elemente“, in: Andréa Belliger/David J. Krieger (Hg.), ANThology. Ein einführendes Handbuch zur Akteur-Netzwerk-Theorie, Bielefeld, 2006, S. 259-308.

Ders./Woolgar, Steven, Laboratory Life. The Construction of Scientific Facts, 2. Aufl., Princeton, NJ, 1986.

Lepenies, Wolf (Hg.), Georges Canguilhem. Wissenschaftsgeschichte und Epistemologie. Gesammelte Aufsätze, Frankfurt/M., 1979.

Link, Jürgen, Versuch über den Normalismus. Wie Normalität produziert wird, Göttingen, 1997.

Mayo, Elton, The Humans Problems of Administration, New York, NY, 1933.

Ders., Hawthorne and the Western Electric Company, The Social Problems of an Industrial Civilization, Boston, MA, 1945.

Muhle, Maria, Eine Genealogie der Bio-Politik. Eine Untersuchung des Lebensbegriffs bei Michel Foucault und Georges Canguilhem, Paderborn, 2013.

Parascandola, John, „Organismic and Holistic Concepts in the Thought of L. J. Henderson“", in: Journal of the History of Biology 4, 1 (1971), S. 63-113.

Rabinbach, Anson, „Ermüdung, Energie und der menschliche Motor“, in: Philipp Sarasin/Jakob Tanner (Hg.), Physiologie und industrielle Gesellschaft. Studien zur Verwissenschaftlichung des Körpers im 19. und 20. Jahrhundert, Frankfurt/M., 1998, S. 286-312.

Rheinberger, Hans-Jörg, Experimentalsysteme und epistemische Dinge. Eine Geschichte der Proteinsynthese im Reagenzglas, Frankfurt/M., 2001.

Roethlisberger, Fritz/Dickson, William, Management and the Worker. An Account of a Research Program Conducted by the Western Electric Company, Chicago, IL, 1939.

Srnicek, Nick, Plattform-Kapitalismus, Hamburg, 2018.

Stäheli, Urs, „Poststrukturalismus und Ökonomie. Eine programmatische Skizze der Affektivität ökonomischer Prozesse“, in: Caroline Arni (Hg.), Der Eigensinn des Materials. Erkundungen sozialer Wirklichkeit. Festschrift für Claudia Honegger zum 60. Geburtstag, Frankfurt/M., Basel, 2007, S. 503-520.

Tanner, Jakob, „,Weisheit des Körpers“ und soziale Homöostase. Physiologie und das Konzept der Selbstregulation“, in: Philipp Sarasin/Jakob Tanner (Hg.), Physiologie und industrielle Gesellschaft. Studien zur Verwissenschaftlichung des Körpers im 19. und 20. Jahrhundert, Frankfurt/M., 1998, S. 129-169.

Vatin, François, „Arbeit und Ermüdung. Entstehung und Scheitern der Psychophysiologie der Arbeit", in: Philipp Sarasin/Jakob Tanner (Hg.), Physiologie und industrielle Gesellschaft. Studien zur Verwissenschaftlichung des Körpers im 19. und 20. Jahrhundert, Frankfurt/M., 1998, S. 347-368.

Vogl, Joseph, Kalkül und Leidenschaft. Poetik des ökonomischen Menschen, München, 2002. 
Walter-Busch, Emil, Das Auge der Firma. Mayos Hawthorne-Experimente und die Harvard Business School, 1900-1960, Stuttgart, 1989Werber, Niels, Ameisengesellschaften. Eine Faszinationsgeschichte, Frankfurt/M., 2013.

Young, Owen D., „Dedication Address“, in: Dedication Addresses: George F. Baker Foundation, Boston, MA, 1927, S. 388. 


\section{LAURA MOISI \\ ZURÜCK IN DIE ZUKUNFT: \\ THEORIE UND GESCHICHTE DER FRANKFURTER KÜCHE}

„Eine Küche ist eigentlich nichts anderes als ein Laboratorium“" stellung vom Haushalt als Bereich exakter Wissensproduktion setzt die Architektin Margarete Schütte-Lihotzki ein historisches Denkmal mit der von ihr 1926 entwickelten Frankfurter Küche. Nicht nur bewegt man sich in dieser Küche wie in einem Labor, sie ist auch in experimenteller Weise entstanden, durch genaue Messungen von Abständen, Schritten und Bewegungsmustern. Die Standardisierungen, aus denen die Frankfurter Küche hervorgeht, bezeugen spannungsreiche Verflechtungen zwischen Abstraktion und Verkörperung, Technik und Naturalisierung. Ziel des Entwurfs war es, ausgehend von normierten Körpermaßen und Imaginationen von weiblicher Physiognomie, Prinzipien der Leistungssteigerung, wie man sie aus Fabriken und Betrieben kannte, auf die Hausarbeit zu übertragen.

Dieser Beitrag beschäftigt sich mit den kulturellen Imaginationen von Geschlecht und Effizienz, von Instruktion und Verausgabung, die den Diskurs der Haushaltsführung zu Beginn des 20. Jahrhunderts prägen. Wann und wie werden biologische Vorgänge und geschlechtsspezifische Körper-Bilder in dem Frankfurter Wohnprojekt relevant? Wie vollzieht sich dabei die Grenzziehung zwischen natürlichen und technischen Abläufen? Und welche Vorstellungen von Verschwendung und Effizienz liegen den Visionen neuer Bewegungsökonomien zugrunde? Ziel des Beitrags ist es, zu analysieren, inwiefern die Entwicklung von standardisierten Räumen Hausarbeit als feminine Tätigkeit codiert und als Dienstarbeit naturalisiert. Zunächst soll ein kurzer Blick auf den US-amerikanischen Entstehungskontext geworfen werden, der das Design der Frankfurter Küche anregte. Anschließend geht es um die Modellierung der rationellen Küche nach hygienischen, digestiven und raumökonomischen Prinzipien und das ambivalente Verhältnis zu Geschlechterordnungen, das sich darin äußert.

\footnotetext{
1 Margarete Lihotzki, „Einiges über die Einrichtung österreichischer Häuser unter besonderer Berücksichtigung der Siedlungsbauten“, in: Das Schlesische Heim, 8, 1921, S. 217-222: 221.
} 


\section{Das Zuhause als Ingenieursarbeitsplatz}

Mit der Frage nach der Organisation des Haushaltes verhandelt die US-amerikanische Ratgeberliteratur eine Reihe verschiedener Themen: Sauberkeit und Hygiene, Arbeitserleichterung und Leistungssteigerung, aber auch Erziehung, Bildung und Modernisierung. So versteht Catherine E. Beecher in ihrem einflussreichen Treatise on Domestic Economy (1841) den Bereich des Häuslichen als Kern allen gesellschaftlichen Lebens. Ein ausgeglichener Haushalt ist für Beecher die Grundlage des Wohlergehens der US-amerikanischen Bevölkerung. Es ist die Idee einer Optimierung des Menschen durch Veränderungen der Umwelt - im Sinne der häuslichen ,Umwelt', in der das Leben in seiner ganzen Spannweite stattfindet. Beeinflusst von Beechers Treatise, entwickelt Christine Frederick mit ihrem 1912 erstmals publizierten The New Housekeeping: Efficiency Studies in Home Management ein Standardwerk der Ratgeberliteratur zum Thema Modernisierung und Effizienzsteigerung im Haushalt.

$\mathrm{Zu}$ einer Zeit, in der die Steigerung von Effizienz als Universalmaßnahme für die Modernisierung der amerikanischen Gesellschaft gilt, proklamiert Frederick die Befreiung von den Lasten und Strapazen der Hausarbeit durch Prinzipien der Standardisierung nach Vorbild von Frederick Taylor. Es sind Vorstellungen von Rentabilität und Effizienz, die sich an der analytischen Zergliederung komplexer Arbeitsprozesse in einzelne Arbeitsschritte orientieren. Dazu entwickelt Frederick ein prototypisches Küchenlabor: die Applecroft Home Experiment Station in Greenlawn, New York. Mittels Zeit- und Bewegungsstudien misst Frederick die Abstände zwischen Arbeitsplatten, Spüle und Schränken und berechnet die Zeit und die Schritte, die nötig sind, um Mahlzeiten zu kochen oder Geschirr abzuräumen. Frederick wandelt den häuslichen Alltag in einen Rhythmus von Stufen und Etappen, um die im Haus verbrachte Zeit genau zu messen, zu teilen und zu ordnen. Es ist eine Transformation der Küche in einen Raum von exakter Wissenschaft. ${ }^{2}$ Das erklärte Ziel ist, Hausarbeit nicht länger als „Dienstarbeit“ zu betrachten, sondern als frei gewählten Beruf, als eine Form der Ingenieursarbeit. ${ }^{3}$ Exakte Berechnungen von Arbeitsschritten sollen überflüssige (,wasteful“") Bewegungen im Raum verhindern und die alltäglichen Reinigungs- und Versorgungsarbeiten von der Mühseligkeit, Zeit und Energie, die sie kosten, befreien. Im Zentrum von Fredericks Visionen steht die Idee, die Küche in eine Fabrik umzuwandeln - eine Fabrik, die müheloses Arbeiten und erfüllende Tätigkeiten garantieren soll. ${ }^{4}$

2 Christine Frederick, The New Housekeeping: Efficiency Studies in Home Management, New York, NY, 1919 [1913], S. 101.

3 Vgl. Christine Frederick, Household Engineering: Scientific Management in the Home, Chicago, IL, 1920.

4 Frederick charakterisiert das Haushalten als einen selbstständigen Beruf: „Housework, the science of home-making and motherhood, if followed out on an efficient plan, can be the most 


\section{Dienen und Herrschen}

Ausgangspunkt der Ratgeberzeitschriften und Bücher zur Haushaltsführung ist immer wieder die sogenannte Dienstbotenfrage. Ausgehend von einem weithin proklamierten Mangel an Dienstangestellten, befassen sich Zeitschriften wie das Ladies' Home Journal mit der Umgestaltung von Hausarbeit. Damit bleibt die Annahme unausgesprochen, dass Hausarbeit, vor allem dann, wenn sie mühevoll ist, eine Dienstarbeit ist; etwas, das andere erledigen - und zwar jene, die von Geburt an mit einem niederen sozialen Status versehen sind. In dem Moment, als die US-amerikanischen home economists den Haushalt in eine Sphäre der zeit- und angeblich arbeitssparenden Profession umwandeln wollen, tauchen Dienstboten als rhetorische Figuren auf, um den Bruch mit der Vergangenheit zu thematisieren. Auch Frederick führt den sozialen Status und die Dienstarbeit als Ausgangsproblematik in ihrem Ratgeber an.

The home problem for the woman of wealth is simple: it is solved. Money, enough of it, will always buy service, just as it can procure the best in any other regard. The home problem for the women of the very poor is also fairly simple. The women of the poor themselves come from the class of servants. Their homemaking is far less complex, their tastes simple, and society demands no appearance-standard from them. [...] The problem, the real issue, confronts the middle-class woman of slight strength and still slighter means, and of whom society expects so much - the wives of ministers on small salary, wives of bank clerks, shoe salesmen, college professors, and young men in various businesses starting to make their way. ${ }^{5}$

In dieser Passage aus The New Housekeeping macht Frederick unmissverständlich klar, dass sich ihre Ratschläge zum modernen Haushalten nicht an alle richten. Hausarbeit wird gemäß Frederick erst dann zu einem Problem, wenn sie von Ehefrauen der weißen amerikanischen Mittelschicht ausgeübt wird. Die soziale Anerkennung von Hausarbeit soll da ansetzen, wo die Erfahrungen von denjenigen, denen über Jahrhunderte hinweg nichts anderes blieb als häusliche Arbeiten zu erledigen, weil sie in ärmeren Verhältnissen geboren worden sind, für unbedeutend, defizitär und der Vergangenheit angehörend erklärt werden. Die kulturellen Imaginationen von Armut und Privileg, von pathologischer und gesunder Hauswirtschaft, von Herrschen und Dienen, die sich in der Dienstbotenfrage abzeichnen, bleiben Dreh- und Angelpunkt der Rationalisierungsbewegungen.

Die historische Verflochtenheit von sozialer Herkunft, Rassifizierung und Geschlecht, wenn es um häusliche Pflege- und Reinigungsarbeiten geht, hebt

glorious career open to any woman - one that will not stultify nor degrade, but which offers her peculiar talents their widest and most varied scope." Frederick (1919), The New Housekeeping, S. 101.

5 Ebd., S. $11 \mathrm{f}$. 
Angela Davis in ihrem Buch Women, Race and Class hervor. ${ }^{6}$ Nicht vorgesehen in den Ratgebern zum Haushalten war das Leben afro-amerikanischer Frauen, die oftmals neben ihrem eigenen Haushalt noch den von weißen Familien erledigten. Die Dienstboten, Haushälterinnen, Mägde und Haussklav_inen prägen das Narrativ der Rationalisierung durch eine geisterhafte Abwesenheit. Die an weiße Frauen der US-amerikanischen Mittelschicht gerichteten Lehren zum richtigen Haushalten sind Gebote und Privilegien zugleich, die letztlich diesen Frauen ein strukturelles Erbe der Hausarbeit aufbürden, wie Annegret S. Ogden in The Great American Housewife schreibt: „[T]he typical white middle-class women still worked as many hours in the home as her grand-

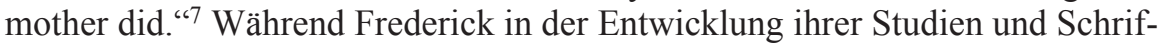
ten häusliche und betriebliche Wissensbereiche durchquert, schreibt sie die Trennung in weibliche und männliche Arbeits- und Existenzbereiche fort. Inmitten der Frauenbewegung der 1920er Jahre dienen Fredericks Ratgeberkolumnen dem Schutz traditioneller Geschlechterordnungen und der Aufrechterhaltung rassistischer Hegemonien. Mit neuen Methoden sollen alte Hierarchien bewahrt werden.

Mit Blick auf den europäischen Kontext zeigt Regina Schulte in ihrem historischen Abriss über Dienstarbeit auf, wie im 18. Jahrhundert eine zunehmende „Verweiblichung des Dienens“ entsteht. ${ }^{8}$ Davor bezeichnet Dienstarbeit eher ein Verhältnis als eine Tätigkeit. Schulte beschreibt die häusliche Dienstleistung als eine Beziehung, die verschiedene soziale Strukturen, normative Verhältnisse und Machtstrukturen miteinander verbindet. Hatten Wohnräume im Frankreich des 17. Jahrhunderts beispielsweise noch keine funktionalen Differenzierungen und gingen offen ineinander über, so dass „häufiger körperlicher Kontakt" zwischen Dienstangestellten, Familienmitgliedern und Besuchern den innerhäuslichen Alltag in wohlhabenden Familien kennzeichnete, wandelte sich die häusliche Gestaltung im 18. Jahrhundert dahingehend, dass nun zunehmend Wert gelegt wurde auf die ,private Intimität" von einzelnen Familienmitgliedern. ${ }^{9}$ Dies ging einher mit einem Vorgang der Trennung und Aufteilung der Körper, Klassen und Geschlechter. Es entsteht eine „,neue Topografie“ des Häuslichen, die den Dienstangestellten spezifische Plätze ,in den Küchen, den Hallen, den Vorzimmern“ zuweist. ${ }^{10}$ Es kommen dabei Verflechtungen zwischen Herrschaft, Arbeit und Geschlecht zum Vorschein, die sich auch in die architektonischen Strukturen von Wohnräumen und Häusern einschreiben.

\footnotetext{
6 Angela Davis, Women, Race and Class, New York, NY, 1983, S. 222.

7 Annegret S. Ogden, The Great American Housewife: From Helpmate to Wage Earner, 17761986, Westport, CT, 1986, S. 148.

8 Regina Schulte, „Häusliche Dienste“ in: Gisela Ecker/Claudia Lillge (Hg.), Kulturen der Arbeit, Paderborn, 2011, S. 155-168: 158.

9 Ebd., S. 159.

${ }^{10}$ Ebd.
} 


\section{Die Frankfurter Küche}

Auch in Deutschland beschäftigen sich Hausfrauenverbände mit der Erleichterung und Optimierung von häuslichen Arbeiten, als 1921 die von Irene Witte übersetzte Version von Fredericks Scientific Management in the Home unter dem Titel Rationelle Haushaltsführung erscheint. ${ }^{11}$ Eine materiell und architektonisch zugespitzte Ausdrucksform dieser Vorstellungen eines rationalisierten Haushaltes stellt Margarete Schütte-Lihotzkys Frankfurter Küche dar (Abb. 10.1). Es handelt sich dabei um eine vollständig ausgestattete Kücheneinrichtung auf 5 bis 6 Quadratmetern. Die österreichische Architektin, die oft als ,Mutter' der Einbauküche bezeichnet wird - wobei damit manchmal das von ihr entworfene Küchenmodell gemeint ist, und manchmal, zu ihrem Ärgernis, sie selbst -, hat die Frankfurter Küche im Rahmen des Massenwohnungsbaus in Frankfurt in der Zeit von 1925 bis 1930 entwickelt. „Ich bin keine Küche“, sagt sie in einem Interview. Die Bezeichnung missfällt ihr auch deshalb, weil sie ein Missverständnis ihrer Arbeiten als Architektin zum Ausdruck bringt.

Für Schütte-Lihotzky ist die von ihr konzipierte Küche in erster Linie ein Baukonzept für preisgünstige Arbeiterwohnungen, und kein Möbelstück. Sie beschäftigt sich nämlich mit einer ganzheitlichen Vorstellung von Gesellschaft und sieht die von ihr entworfene Küche im Verhältnis zu den Infrastrukturen der Stadt. Nachdem sie von 1915 bis 1919 als erste und damals einzige Frau an der Kunstgewerbeschule in Wien Architektur studiert, gewinnt SchütteLihotzky mit einem Entwurf für seriell fabrizierte Fertigteile 1920 einen Wettbewerb für eine Siedlungsanlage in Wien. ${ }^{12}$ Sie beginnt in Wiener Architekturbüros an preisgünstigen Wohnungsentwürfen zu arbeiten, und stößt um die gleiche Zeit auf die deutsche Übersetzung von Fredericks Buch zur ,rationellen Haushaltsführung“. Sie sagt später, sie sei von den Methoden der USAmerikanerin beeindruckt gewesen und wollte diese gerne auf Fragen des Sozialbaus übertragen. Als man sie im Alter von 30 Jahren als Leiterin der „Unterabteilung Hausrat“ im Frankfurter Hochbauamt mit der Umgestaltung der häuslichen Küche beauftragt, liefert die Buchvorlage zur Effizienzsteigerung im Haushalt einen Anstoß, „die dort angeführten Prinzipien auch beim Wohnbau anzuwenden". ${ }^{13}$ Ziel dieses Entwurfes war es, im Einklang mit den von Frederick propagierten Prinzipien der Leistungssteigerung im Haushalt, „die Grundsätze arbeitssparender, wirtschaftlicher Betriebsführung, deren Verwirklichung in Fabriken und Büros zu ungeahnten Steigerungen der Leistungsfähigkeit geführt haben, auf die Hausarbeit [zu] übertragen“. ${ }^{14}$ Als Be-

${ }^{11}$ Irene Witte, Die rationelle Haushaltsführung. Betriebswissenschaftliche Studien, Berlin, 1921.

12 Margarete Schütte-Lihotzky, Warum ich Architektin wurde, Salzburg, 2004, S. 40.

13 Ebd., S. 89.

${ }^{14}$ Margarete Schütte-Lihotzky, „Rationalisierung im Haushalt“, in: Das Neue Frankfurt 1, 5 (1927), S. 120-123: 120. 
standteil der in Frankfurt geschaffenen Wohnungen in Arbeitersiedlungen eröffnet die Frankfurter Küche als materieller Zeitzeuge einen Blick in eine Zukunft, wie sie von Architekten und Planern damals imaginiert wurde.

Eine prototypische Frankfurter Küche besteht aus zwölf Aluminiumschütten, einer Zeile mit Ober- und Unterschränken, einem Abtropfbrett, zwei Ausziehplatten darunter, acht Schubladen mit Holzgriffen, einer Spüle, einer Arbeitsplatte, und dem an der Wand befestigten Bügelbrett, das jederzeit heruntergeklappt werden kann. In ihrem Zentrum steht ein höhenverstellbarer Drehstuhl, mit dem alle Tätigkeiten im Sitzen verrichtet werden können. Merkmal der Frankfurter Küche sind die eingebauten Küchenzeilen, die Fächer, die sich öffnen und schließen lassen, damit mehr Bewegungsfreiheit herrscht. Grundprinzip dabei: Alles in Reichweite. Alles soll mit einem Handgriff erledigt werden können. Die Höhe des Arbeitsstuhls ließ sich je nach Körpergröße verstellen, und die Maße der Küche waren insgesamt genau an typisierte Merkmale (Gewicht, Größe, Haltung) von normierten Frauenkörpern angepasst. Es handelt sich um ein System, das es ermöglichen soll, alle Gerätschaften in dem kleinen Raum zu platzieren - von Bügelbrett und Tisch bis hin zu Vorratsschränken und Abfallrinne. Sämtliche Arbeitsabläufe sind bereits antizipiert. So hatten manche Versionen der Küche am Rand eine Aussparung, in die man die Gemüseabfälle mit einem Griff hineinwerfen konnte. Und dies ohne dabei einen Blick in den Mülleimer werfen zu müssen, als Einsparung von Raum, in dem die Reste der Küchenarbeit und der Reinigungsarbeit verschwinden.

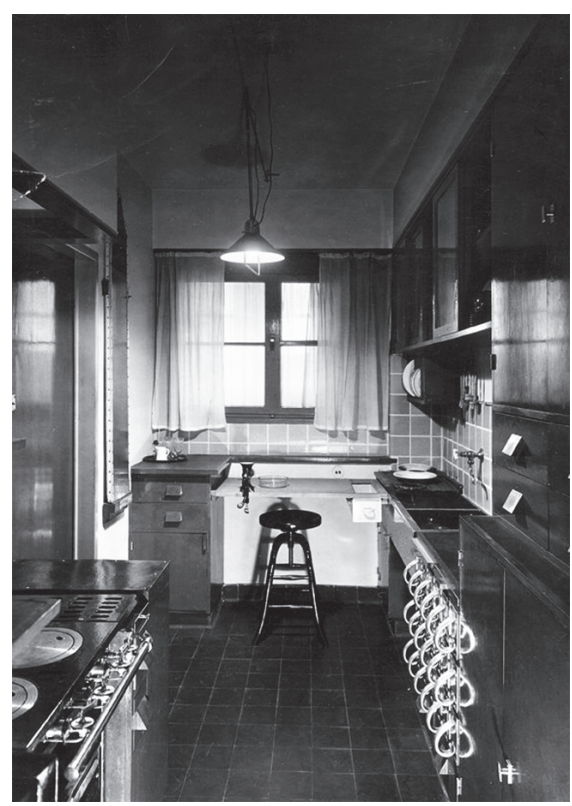

10.1 - Prototyp einer Frankfurter Küche (1926) 
Die Küche, die in Frankfurt entsteht, hängt mit grundlegenden Fragen über die Umstrukturierung des häuslichen Lebens zusammen. ${ }^{15}$ Architekt Ernst May, der 1925 sämtliche Ämter für Bauaktivitäten in Frankfurt übernimmt - vom Siedlungsamt bis zum Hochbauamt, Tiefbauamt und der Baupolizei - verfolgt dabei das Ziel, ,vom Kochtopf zur Fassade [zu] bauen“. ${ }^{16}$ Dabei soll die Wohnungsgestaltung von innen nach außen geschehen und die Küche und die Hauswirtschaft das „Herzstück“ im Siedlungsprojekt bilden. ${ }^{17}$ Im Zuge des sozialen Wohnungsbaus setzen sich die Frankfurter Architekten das Ziel, mit der reduzierten Gestaltung der Frankfurter Küche soziale Unterschiede zu nivellieren. ${ }^{18}$ Im Kontext von Visionen über das „neue Wohnen“ und den „neuen Menschen“ geht es darum, die Ästhetik des Ornaments zugunsten einer Ästhetik des Schlichten und der seriellen Produktion zu verabschieden. Die kostengünstig hergestellten Einbauküchen werden zum Grundbestandteil von Wohnungen, deren Miete den Wochenlohn eines Arbeiters nicht übersteigen sollte. ${ }^{19}$ In Serienproduktion entstehen zwischen 1926 und 1930 in Frankfurt im sozialen Wohnungsbau ungefähr 10.000 solcher Küchen. ${ }^{20}$

Die funktionale Ästhetik der Frankfurter Küche bricht mit dem bürgerlichen Wohnstil der Zeit. Als „Arbeitsküche“ verstanden, soll die Frankfurter Küche die Wohnküche ablösen - in ideeller wie pragmatischer Hinsicht. In seinem Text Die neue Wohnung wendet Bruno Taut sich gegen jede Form von Erinnerungsstücken und „historischen Plunder“. ${ }^{21}$ Mit dem Schnörkel soll die Vergangenheit selber entsorgt werden. Erna Meyer schreibt dazu: „Jetzt geht's ums Ganze, der neue Mensch sucht seine neue Haut." ${ }^{22}$ Man sieht sich am „Ende einer sentimentalen Periode“ und strebt einen „Bruch mit der Vergangenheit" an. ${ }^{23}$

Diese ästhetischen Fragen sind eng verflochten mit Vorstellungen von Sauberkeit und Hygiene im Wohnraum. Margarete Schütte-Lihotzky äußert sich dazu, indem sie sagt, dass ,die Wohnküche eine in unseren Augen niedrigere Wohnform war, weil alles, der Schmutz, der Dreck, das Gemüseputzen, die Schalen alle, der Abfall, das alles war im Wohnzimmer, nicht wahr. So war

\footnotetext{
15 Joachim Krausse, „Vom Kochtopf zur Fassade bauen“, in: Renate Flagmeier/Werkbundarchiv Museum der Dinge (Hg.), Die Frankfurter Küche. Eine museale Gebrauchsanweisung, Berlin, 2012, S. 19-34: 27.

${ }^{16}$ Ebd.

17 Ebd.

${ }^{18}$ Flagmeier/Werkbundarchiv - Museum der Dinge (2012), Die Frankfurter Küche, S. 11.

${ }^{19}$ Krausse (2012), Vom Kochtopf zur Fassade bauen, S. 19.

${ }^{20}$ Ebd., S. 20.

${ }^{21}$ Vgl. Flagmeier/Werkbundarchiv - Museum der Dinge (2012), Die Frankfurter Küche, S. 15.

22 Erna Meyer, „Wohnungsbau und Hausführung“, in: Der Baumeister, 6 (1927), S. 89-94: 89. Vgl. auch: Flagmeier/Werkbundarchiv - Museum der Dinge (2012), Die Frankfurter Küche, S. 15 .

${ }^{23}$ Schütte-Lihotzky (2004), Warum ich Architektin wurde, S. 65.
} 
das eine niedrigere Form.“" ${ }^{24}$ Für Schütte-Lihotzky war Krankheit auch persönlich ein zentrales Motiv. Ihre Eltern starben an Tuberkulose und sie selbst erkrankte daran Ende 1924 schwer und konnte sich erst ein Jahr später wieder erholen. Diese biografischen Elemente zeichnen sich in dem Versuch ab, eine Wohnform zu konstruieren, welche die darin lebenden Personen vor Krankheiten schützt - zum Beispiel durch die Absonderung von Schmutz und Abfall in dafür vorgesehene Räume und Behälter. Die schmutzabweisenden Aluminiumschütten symbolisieren ebenso diesen Anspruch von Hygiene und Aufgeräumtheit durch ihre klaren Formen und ihr metallisches Material.

In ihrer historischen Rückschau auf Küchen und Badezimmer zur Jahrhundertwende beschreiben Ellen Lupton und J. Abbott Miller, inwiefern neu aufkommende Vorstellungen von der Entstehung und Verbreitung von Krankheiten die Wohnarchitekturen maßgeblich prägen. Während man früher davon ausging, dass schlechte Gerüche die Auslöser von Krankheit waren, entwickelt sich im 19. Jahrhundert ein Verständnis von unsichtbaren Keimen und von Ansteckung. ${ }^{25}$ Das neue Verständnis von Sauberkeit und Körperpflege manifestiert sich dabei in flachen, schmutz- und wasserabweisenden Waschanlagen, Fassaden, Badewannen, Toiletten. ${ }^{26}$ Im Zuge dessen erhalten Ideen von Sauberkeit im Haus eine neue Bedeutung. „At the core of popular sanitarian writings about the home was a vision of life as an intimate process of respiration, consumption, excretion, and decay, in which the individual body figured prominently as a pollutant. “" ${ }^{27}$ Der Körper wird, so wie das Haus, als eine Quelle von Gefahr codiert - Gefahren im gesundheitlichen Sinne wie auch im sozialen oder kulturellen. Zugleich werden soziale Fragen im 20. Jahrhundert zunehmend medikalisiert. Vor diesem Hintergrund gelten Körper als hygienische und medizinische Probleme: „[B]odies [are] construed as objects of therapeutic intervention or as problems to be solved." ${ }^{28}$ Körper gestalten sich zunehmend zu einer Frage der öffentlichen, Gesundheit', die institutionell verhandelt wird.

\footnotetext{
${ }^{24}$ Krausse (2012), Vom Kochtopf zur Fassade bauen, S. 28.

${ }^{25}$ Ellen Lupton/J. Abbott Miller, The Kitchen, the Bathroom, and the Aesthetics of Waste: A Process of Elimination, New York, NY, 1992.

${ }^{26}$ Ebd., S. 7.

${ }^{27}$ Nancy Tomes, „The Private Side of Public Health: Sanitary Science, Domestic Hygiene, and the Germ Theory, 1870-1900“, in: Judith W. Leavitt/Ronald L. Numbers (Hg.), Sickness and Health in America. Readings in the History of Medicine and Public Health, Wisconsin, WI, 1997, S. 506-528: 512.

${ }^{28}$ Robert Heynen, Degeneration and Revolution: Radical Cultural Politics and the Body in Weimar Germany, Leiden, Boston, MA, 2015, S. 4.
} 


\section{Stoffwechsel und Spurenbeseitigung}

Walter Benjamin hat über Adolf Loos und die Architekten des funktionalen Wohnens gesagt, sie hätten „Räume geschaffen, in denen es schwer ist, Spuren zu hinterlassen". ${ }^{29}$ Die Frankfurter Küche symbolisiert mit ihrer sterilen Optik einen derartigen Raum, bewohnt von einem ,neuen Menschen“, wie es die Architekten ersehnten - von Menschen, denen Ornamente und Schmuck nichts bedeuten, und deren Spuren sofort beseitigt und in spezifischen Behältern verborgen werden. Das hängt auch damit zusammen, dass die Visionen des Wohnungsbaus, aus dem die Frankfurter Küche hervorgeht, von der Vorstellung inspiriert waren, dass die häuslichen Räume, allen voran die Küche, analog zum menschlichen Körper Prozesse des Stoffwechsels betreiben; dass sich die Küche gewissermaßen selbst verzehrt. Es handelt sich hierbei um ein ganz spezifisches Verhältnis von Haushalt und Architektur, das auf dem Vorbild einer natürlichen Digestion beruht, und den Haushalt als einen stofflichen Austausch mit der Umgebung, mit der Natur, versteht..$^{30}$ Wie Joachim Krausse feststellt, ist die Frankfurter Küche ,eine exemplarische Lösung für die Verkleinerung eines Raumes mit den zentralen metabolischen Funktionen, dem Stoffwechsel mit der Natur: Heizen und Kochen, Bevorratung, Belichtung und Belüftung, Wasserversorgung und -entsorgung, Sanitäreinrichtungen und Hygiene". ${ }^{31}$ Ein zentrales Motiv ist dabei die Idee eines natürlichen Wertstoffkreislaufs, eines kontinuierlichen Kreises der Erzeugung, des Erwerbs und des Verbrauchs von Speisen und Gütern - einem Wertstoffkreislauf der Küche.

Im Jahr 1989 entwirft der Künstler William Stumpf das Modell eines „metabolischen Hauses", mit dem Hinweis darauf, dass die Architekten des 20. Jahrhunderts die Küche mit Blick auf Prozesse des Verbrauchens eingerichtet haben, ohne aber Spuren und Abfälle effektiv zu entfernen. ${ }^{32}$ Zwar zeichnen sich moderne Küchen durch eine Ästhetik des Verschwindens aus, doch ist der Abfall damit zunächst nur aus dem Blickfeld verbannt. Stumpf zufolge bestehe die Aufgabe zukünftiger Designer darin, Wege zu finden, um die Küchenräume zu effektiveren Abbauprozessen zu befähigen. Müll, so Stumpf, sei das zentrale Problem der Küchendesigner der Zukunft: „Our bodies do a good job of taking in oxygen, food, and water, getting nutrition, and

\footnotetext{
${ }^{29}$ Walter Benjamin, „Literarische und ästhetische Essays. Erfahrung und Armut“, in: Gesammelte Schriften, unter Mitwirkung von Theodor W. Adorno und Gershom Scholem, hg. v. Rolf Tiedemann und Hermann Schweppenhäuser, Bd. II.1, Frankfurt/M., 1977, S. 213-219.

${ }^{30}$ Vgl. Joachim Krausse, ,Eine Architektur der Raum-Zeit. Joachim Krausse im Gespräch mit Renate Flagmeier", in: Renate Flagmeier/Werkbundarchiv - Museum der Dinge (Hg.), Die Frankfurter Küche. Eine museale Gebrauchsanweisung, Berlin, 2012, S. 34-57: 36.

${ }^{31}$ Ebd.

${ }^{32}$ Vgl. Patricia Leigh Brown, „Space for Trash: A New Design Frontier“, in: The New York Times, 27. Juli 1989, S. C1.
} 
dispelling waste. Our houses don't do that very well. They should have a digestive system just like we do." ${ }^{\text {33 }}$

Zwar haben die Arbeitsküchen, die im Rahmen des Frankfurter Wohnprojektes zwischen 1926 und 1930 entstanden, Schmutz und Reste nicht endgültig beseitigt, doch sie haben das organische Stoffwechselmodell, das Stumpf hier propagiert, zur Grundlage genommen für die Entwicklung von Räumen, in denen Abbauprozesse und die Vulnerabilität von Körpern von Beginn an einen festen Platz haben. Die auf Sauberkeit und Hygiene ausgelegten Standardisierungen fungieren dabei als Kulturtechniken der Transformation des Häuslichen. So wie Körper Fäkalien hinterlassen, sollten Häuser und Wohnungen Müll herausgeben. Die Entsorgungsinfrastruktur des Wohnens ist als visionäres Projekt der Zukunft angelegt worden. Dabei wird das Leben im Frankfurter Wohnungsbau inventarisiert und eine Bilanz gezogen: Was braucht der Mensch zum Leben? Von zentraler Bedeutung ist die Trennung jener häuslichen Bereiche, in denen Schmutz entsteht, von denen des Wohnens - eine Trennung zwischen Wohnen und Arbeiten, Sauberkeit und Schmutz, die in einem gemauerten Müll-und Besenschrank zwischen Küche und Wohnzimmer verkörpert wird. Ein weiteres Detail im Hinblick auf die Einrichtung von Öffnungen, Übergängen und Kanälen für Abfälle, das die Küche damals zu einer Kuriosität machte, erscheint heute als visionäres Vorbild: Der Müll verschwindet in einer Abfallrinne. Die eingebaute Abfallrinne symbolisiert auf besondere Weise die ambitionierten Vorstellungen von steriler Sauberkeit und einer Logik des Verschwindens. Die Frankfurter Küche antizipiert Abbauprozesse, die Öffnungen des Hauses und des Körpers, und macht die Entsorgung von Abfall zu einem integralen Bestanteil häuslichen Lebens - das Wegwerfen wird zu einer zweiten Natur.

\section{Zeit-Raum-Ökonomien}

Mit der Frankfurter Küche entsteht eine enge Verflechtung von Raum und Zeit, die zur Grundlage einer neuen Raumökonomie wird. Dabei handelt es sich um eine Ökonomie, die den Raumverlust als Mehrwert propagiert, als Zunahme von Komfort, Effizienz und Entlastung, nach dem Motto „Weniger ist mehr" ${ }^{34}$ Grundrisse und Arbeitsplatzstudien der Frankfurter Küche zeigen, mit welcher Überzeugung die Entwürfe darauf abzielten, Raum zu sparen, Leerflächen und überflüssige Wege zu vermeiden. Es handelt sich um ein spezifisches Verständnis davon, dass weniger Raum mehr Effizienz, weniger Platz mehr Freiheit bedeutet. ${ }^{35}$ Das hat auch mit Vorstellungen von Verausga-

${ }^{33}$ Ebd.

${ }^{34}$ Krausse (2012), Vom Kochtopf zur Fassade bauen, S. 28.

${ }^{35}$ Die Konzeptualisierung der Küche als Bewegungsraum hängt auch mit den Entwicklungen des Films zusammen. Die Ingenieurin Lillian Gilbreth, die sich ebenfalls mit Bewegungsstudien 
bung und Verschwendung zu tun, in denen sich Bilder von physischen Resten, wie Abfall und Schmutz, mit Narrativen von überflüssigen Handhabungen und unnötigen Bewegungen verbinden.

Etymologisch geht das deutsche Wort Verschwendung auf „verswenden, zerbrechen, vernichten, verzehren“ zurück, was dann zu ,verswinden“ wird, was so viel bedeutet, wie „machen, daß etw. verschwindet". ${ }^{36}$ Damit gehen bestimmte Narrationen über das Vergehen von Zeit einher. Wenn beispielsweise die Rede davon ist, dass Dinge ihren Dienst getan haben, dann wird das Vergehen von Zeit, das sich anhand von Abfall manifestiert, deutlich. Und umgekehrt ist die Frage nach dem Wert der Zeit selbst eng geknüpft an das, was als wertlos, überflüssig und unnötig gilt.

Die Doppelbedeutung des englischen Worts waste - die zeitliche Bestimmung des Überflüssigen und die materielle Verwertung von Zeitlichkeit kommt in den Management-Theorien deutlich zum Ausdruck. Denn waste kann sich ebenso auf die Wertlosigkeit von Dingen beziehen wie auf die Sinnlosigkeit von Tätigkeiten. To "waste" movement bedeutet im rationellen Haushalten zu viele Bewegungen zu machen, sich an zu vielen Orten zugleich aufzuhalten und damit die Zeit selbst zu Abfall zu machen. Die Optimierung von Hausarbeit besteht darin, Tätigkeiten wie Putzen, Kochen, Abräumen auf einer Zeitachse anzugliedern und durch Beobachtung ,sinnlose“ Bewegungen $\mathrm{zu}$ vermeiden. ${ }^{37}$ Die efficiency-Bewegung selbst ist freilich schon immer eine Theorie der Verausgabung und der Einsparung, in der es um die Beseitigung von überflüssigen Bewegungen und Zeitkosten geht. Dabei werden die Bewegungen und die Orientierung im häuslichen Raum zum Kern der Visionen von Erneuerung und Modernisierung.

So überrascht es wenig, dass die Frankfurter Küche nicht nur auf neu aufkommende Vorstellungen von Schmutz und Sauberkeit zurückgeht, sondern auch maßgeblich von Bewegungsökonomien und Transporträumen inspiriert ist. Schütte-Lihotzky hatte die Küche ausgehend von dem Modell eines Speisewagens im Zug entworfen. Mobilität und Beweglichkeit waren zentrale Vorbilder. Die Bewegungsstudien orientierten sich dabei an biometrischen Maßstäben von normierten, weiblichen Körpern. Der größere Trend von Ergonomie und Effizienz am Arbeitsplatz, auf den die australische Kulturwissenschaftlerin Melissa Gregg hinweist, und der sich beispielsweise im Kontext

beschäftigte, entwickelte in filmischen Studien eine Reorganisation von Arbeitsabläufen. Wie Joachim Krausse mit Blick auf die Arbeiten von Gilbreth feststellt, macht die zu der Zeit entstehende Kinematografie die Beobachtung des Bewegungshaushaltes möglich. Vgl. Krausse (2012), Vom Kochtopf zur Fassade bauen, S. 39.

$36 \mathrm{http} / / /$ drieschverlag.blogspot.de/2012/05/vergeuden.html, zuletzt aufgerufen am 30.09.2018.

${ }^{37}$ Frederick (1920), Household Engineering, S. 21. 
von typewriting und Telefonieren manifestierte, hat auch die KüchenForschung geprägt. ${ }^{38}$

Vorstellungen von Überfluss, Verschwendung und Geschlecht spielten eine gewichtige Rolle im deutschen Haushaltsdiskurs. Zwar wurden viele Prinzipien der ,Rationalisierung' aus dem US-amerikanischen Kontext übernommen, aber die Themen Verschwendung und Sparsamkeit wurden in Deutschland grundsätzlich anders bewertet als in der US-amerikanischen Haushaltsliteratur. Christine Frederick prägte in ihren Ratgeberbüchern zum Haushalten den Begriff der kreativen Verschwendung und sie adressierte weiße Frauen der Mittelklasse in ihrer Rolle als Konsumentinnen. Anders sah dies im deutschen Kontext aus: Hier wurde die Unterscheidung zwischen Verschwendung und Effizienz in ein Narrativ von Sparsamkeit übersetzt.

Der Aufwand, der mit Hausarbeit verbunden war, galt nicht als Verschwendung, wenn dadurch der Kauf von Gütern verhindert werden konnte. Die wirtschaftliche Not und Güterknappheit während des Ersten Weltkrieges machte Sparsamkeit gewiss zu einer Notwendigkeit. Die kulturelle Bedeutung von Sparsamkeit ging aber über rein pragmatische Gründe hinaus. Wie Nancy Reagin in Sweeping the German Nation argumentiert, war sparsames Haushalten eine Weise, seine Zugehörigkeit zur imaginären Gemeinschaft zu zeigen. Dabei bestanden viele der sparsamen Methoden der Haushaltsführung, die von Hausfrauenverbänden in der Weimarer Republik vorgebracht wurden, in einem erhöhten Aufwand. Günstig und sparsam bedeutete oft zusätzliche Arbeit. So griffen die Hausfrauenverbände auf ältere, arbeitsintensivere Modelle von Hausarbeit und Nahrungszubereitung zurück, die den Frauen abverlangten, dass sie Lebensmittel einmachten, um diese länger haltbar zu machen, anstatt importierte Produkte einzukaufen. Aus dem Ausland importierte Lebensmittel zu kaufen, Orangen oder Bananen, galt als unbedacht, faul und bequem. Überhaupt war Komfort an und für sich etwas Schmutziges - ein Zeichen von Trägheit und Faulheit. ${ }^{39}$ Der Imperativ der Sparsamkeit richtete sich zwar an alle Haushalte; sozial und kulturell sanktioniert wurden aber besonders Haushalte mit niedrigem Einkommen. So wurden als weiblich markierte Körper im Zuge der Rationalisierung des Haushaltes zu Beginn des 20. Jahrhunderts in den USA, und anschließend in Deutschland, kulturell auf verschiedene Weisen zu Akteurinnen der Sicherstellung von Sparsamkeit, Gesundheit, Sauberkeit und Ordnung erklärt.

\footnotetext{
${ }^{38}$ Melissa Gregg, „The Athleticism of Accomplishment. Speed in the Workplace“, in: Judy Wajcman/Nigel Dodd (Hg.), The Sociology of Speed: Digital, Organizational, and Social Temporalities, Oxford, 2017, S. 102-114.

${ }^{39}$ Nancy Reagin, Sweeping the German Nation: Domesticity and National Identity in Germany, 1870-1945, New York, NY, 2007, S. 42.
} 


\section{Narrative von Fortschritt und Emanzipation}

Die Imagination von Hausarbeit als weibliche Tätigkeit materialisiert sich in der Frankfurter Küche - obwohl die Architektin selbst ihren Entwurf als eine Intervention in Geschlechterordnungen versteht. Das erklärte Ziel von Margarete Schütte-Lihotzki war es, berufstätigen Frauen zu ermöglichen, neben ihren häuslichen Verpflichtungen auch einer Erwerbsarbeit nachzugehen. Folge der Raumgestaltung war aber, dass der Person, deren Lebensqualität durch den Entwurf dieser Küche verbessert werden sollte, die Rolle einer Bediensteten zugeteilt wird:

Sie kauft ein, verschwindet in der Küche, kocht, trägt das Essen auf, während der Mann sich in der Zeitung vertieft und die Kinder bei laufendem Fernseher am Esstisch, der nicht zur Küche gehört, warten. Nach dem Essen geht wiederum die Frau in die Küche, in der ohnehin nur Platz für eine arbeitende Person ist, wäscht ab und räumt auf. ${ }^{40}$

Es sind Narrative von Fortschritt und Emanzipation, die eine intrinsische Nähe zwischen weiblichen Köpern und der Sphäre des Häuslichen voraussetzen. „Die Hausfrau sollte nach diesen Vorstellungen entlastet werden, um ihr letztlich noch mehr aufzubürden. “"41 Lothar Binger und Susann Hellemann bringen diesen Punkt zum Ausdruck, wenn sie über den Architekten Bruno Taut und seine Vision von der Arbeitsküche schreiben: „Taut wies der Hausfrau am Eßtisch seines Hauses sogar einen bestimmten Platz zu, von dem aus sie noch müheloser die anderen Familienmitglieder bedienen sollte." ${ }^{42}$ Noch bevor das Wohnungsbauprojekt begann, hatte Taut seiner Frau einen Schrittzähler gegeben. Er zeigte sich äußert überrascht über die vielen Schritte, die sie täglich machte. Er war überzeugt, dass da etwas nicht stimmte.

Die rationelle Küche beruht auf hegemonialen Vorstellungen von Rationalität und Effektivität. Jeder Schritt wird berechnet, jeder Millimeter und jede Sekunde gezählt; jede erdenkliche Handlung vermeintlich vorweggenommen. Es herrscht eine völlige Abwesenheit von Leere, alle Plätze sind vergeben, alle Aufgaben verteilt. Das, was die Küche verhindern sollte, war zu viel Bewegung. Aber vor der Rationalisierung hatte niemand so genau die Bewegungen gemessen. Wenn die standardisierte Arbeit in Produktionsbetrieben die Energie und Zeit der Arbeiter maximal ausschöpfen sollte, so haben die Rationalisierungen von Küchen eine maximale Verwertung und Kontrolle der Zeit, Energie und Bewegungsraums weiblicher Arbeitskraft im Privaten beansprucht. Prozesse der Standardisierung, so wie sie in der Frankfurter Küche

\footnotetext{
${ }^{40}$ Ines Heindl, „Kulinarische Diskurse als Indikatoren sich wandelnder Gesellschaften“, in: Manfred Blohm/Sara Burkhardt/Christine Heil (Hg.), Tatort Küche: Kunst, Kulturvermittlung, Museum. Die Küche als Lebens- und Erfahrungsraum, Flensburg, 2009, S. 65-77: 69.

${ }^{41}$ Lothar Binger/Susann Hellemann, Küchengeister. Streifzüge durch Berliner Küchen, Berlin, 1996, S. 116.

${ }^{42}$ Ebd.
} 
zum Ausdruck kommen, unterstellen eine natürliche Zugehörigkeit weiblicher Körper in den Bereich des Hauses - und damit einhergehend eine natürliche Exklusion männlicher Körper von den Sorgearbeiten im Privaten. Die rationelle Küche ist so gesehen eine Kulturtechnik der Naturalisierung von Zweigeschlechtlichkeit und der Trennung zwischen Sorge- bzw. Erwerbsarbeit.

Bereits in Schütte-Lihotzkys eigenen Darstellungen kommen die Ambivalenzen in diesem Projekt zwischen Befreiung und Bürde, Loslösung und Bewahrung zum Ausdruck. Sie erzählt, wie der damalige Architekt Ernst May sie als zuständige Leiterin für die Entwicklung der Küche einsetzte, um zu vermitteln, die Küche sei von einer Frau für Frauen geschaffen. In ihrer Autobiografie Warum ich Architektin wurde, schreibt sie:

Es kam den damaligen bürgerlichen und kleinbürgerlichen Vorstellungen entgegen, daß die Frau im wesentlichen am häuslichen Herd arbeitet. Deshalb wisse auch eine Frau als Architektin am besten, was für das Kochen wichtig ist. Das machte sich eben damals propagandistisch gut. Aber, um der Wahrheit Ehre zu geben, ich habe bis zur Schaffung der Frankfurter Küche nie einen Haushalt geführt, nie gekocht und keinerlei Erfahrungen im Kochen gehabt. ${ }^{43}$

Das Frankfurter Wohnprojekt und die Frankfurter Küche sind ein zeithistorisches Dokument für den Versuch, Geschlechterordnungen aufzubrechen, indem man sie aufrechterhält. Schließlich bleibt die Frage offen, was Hausarbeit eigentlich ist. „Homework is quite simply work you are asked to do when you are at home, usually assigned by those with authority outside the home" ${ }^{64}$, schreibt die Kulturwissenschaftlerin und feministische Autorin Sara Ahmed in Living a Feminist Life. Hausarbeit im Sinne der Frankfurter Küche ist die Arbeit der Lebenserhaltung, es ist die Herstellung der Bedingungen von bedeutsameren Tätigkeiten. Die optimierten Bewegungsabläufe innerhalb des Haushaltes sollten andere Bewegungen ermöglichen, andere soziale Orientierungen erleichtern - die außerhalb des Hauses. In Interviews und Gesprächen hat Schütte-Lihotzki immer wieder betont, dass sie die Frankfurter Küche für alleinlebende und berufsstätige Frauen entwickelt hat. Die Arbeit in der Küche soll Zeit für andere Dinge zulassen - die Anwesenheit in der Küche als Bedingung für die Abwesenheit aus der Küche. Man könnte mit Ahmed von einem maskulinen Verständnis von produktiver Arbeit sprechen, bedingt von der Abwesenheit und der Distanz zu reproduktiver Arbeit: „A masculinist model of creativity is premised on withdrawal. She is there; there she is: engaged in the endless repetitive cycle of housework." ${ }^{45}$

Dahinter stehen kulturelle Vorstellungen davon, welche Bewegungsmuster und Orientierungen im Raum sich auf welche Weise lohnen. Nach dem Prinzip: Wenn alles in Reichweite ist, mit einem Handgriff erledigt, dann wandelt sich die endlose Schleife von Sorgearbeit in einen kontrollierbaren Rhythmus.

\footnotetext{
${ }^{43}$ Schütte-Lihotzki (2004), Warum ich Architektin wurde, S. 150.

${ }^{44}$ Sara Ahmed, Living a Feminist Life, Durham, 2017, S. 7.

${ }^{45}$ Ebd., S. 158.
} 
Das eigentliche Ziel der Frankfurter Küche war in der Tat radikal: Letzten Endes ging es darum, die Küche selbst gewissermaßen abzuschaffen, und reproduktive Tätigkeiten, wie Kochen und Reinigen, auf ein Minimum zu reduzieren. Aber die Schritte, die man geht, erschaffen Fußpfade - persönliche und kollektive Wege, die passiert und tradiert werden. Die Bewegungsanalysen der Frankfurter Küche sind mehr als nur Orientierungen im Raum. Sie stellen nicht nur optimierte Abläufe der Hausarbeit bereit, sondern eine soziale Anordnung von Körpern und Geschlecht, von Lebenswegen und Laufbahnen. Über dieses kulturelle Erbe von Sorgearbeit im Alltag bemerkt Ahmed: „A way is cleared that enables or eases the progression of some bodies. And that way is cleared by requiring that others do less-valued work, housework; the work that is required for the reproduction of their existence." ${ }^{46}$

\section{Fazit}

In der Rückschau stellt die Frankfurter Küche ein wichtiges Zeugnis dar für die Übertragung von Prinzipien der Effizienz und der Standardisierung in den Bereich des privaten Wohnens. Zwar hat die Frankfurter Küche keine „neuen Menschen" hervorgebracht, aber sie hat deutliche Spuren hinterlassen in der gegenwärtigen Wohnkultur, besonders mit Blick auf die Entsorgungsstruktur. Ohne einen Platz für die Reste, die im Alltag übrigbleiben, ohne einen fest integrierten Platz für Müll - unter der Spüle, hinter einem unteren Regalschrank - wäre eine moderne Küche heute nicht zu denken. Historische Spuren dieses Aufbaus von Einbauküchen mit einer integrierten Logik der Entsorgung, einer „Ästhetik des Verschwindens“, finden sich in den Rationalisierungsbewegungen des Haushaltes $\mathrm{zu}$ Beginn des 20. Jahrhunderts. ${ }^{47}$ Schütte-Lihotzkys Entwurf der Frankfurter Küche kehrte in den 1950er Jahren in Form der modernen Einbauküche nach Deutschland zurück und fand sich fortan in deutschen Haushalten wieder, wenn auch ohne die radikal reduzierte Ästhetik.

Am Beispiel der Frankfurter Küche deutet sich an, wie Prozesse der Normierung und der technischen Standardisierung mit der Legitimation von Geschlechterordnungen einhergehen. Die Frankfurter Küche wurde als sozialpolitischer Bauplan entworfen, der es Arbeitern und Arbeiterinnen mit geringem Einkommen ermöglichen sollte, platzsparend und hygienisch $\mathrm{zu}$ wohnen unter der Bedingung, dass weibliche Körper die Räume des Privaten verwalten und sauber halten. Der Blick auf die politische Ästhetik von materieller Alltagskultur erlaubt es, grundlegende Auf- und Zuteilungen von sozialen Positionen, Pflichten und Aufgaben im Alltag kritisch zu beleuchten und potenziell zu unterwandern. Die Frankfurter Küche lebt fort: als Zukunftsvision der Ver-

\footnotetext{
${ }^{46}$ Ebd., S. 158.

${ }^{47}$ Lupton/Miller (1992), The Kitchen, the Bathroom, and the Aesthetics of Waste, S. 7.
} 
gangenheit und als kulturelle Vermessung von Ungleichheit im Gewand von Freiheit.

\section{Literatur}

Ahmed, Sara, Living a Feminist Life, Durham, 2017.

Benjamin, Walter, „Literarische und ästhetische Essays. Erfahrung und Armut", in: Gesammelte Schriften, unter Mitwirkung von Theodor W. Adorno und Gershom Scholem, hg. v. Rolf Tiedemann und Hermann Schweppenhäuser, Bd. II.1, Frankfurt/M., 1977, S. 213-219.

Binger, Lothar/Hellemann, Susann, Küchengeister. Streifzüge durch Berliner Küchen, Berlin, 1996.

Brown, Patricia L., „Space for Trash: A New Design Frontier“, in: The New York Times, 27. Juli 1989, S. C1.

Davis, Angela, Women, Race and Class, New York, NY, 1983.

Flagmeier, Renate/Werkbundarchiv - Museum der Dinge (Hg.), Die Frankfurter Küche. Eine museale Gebrauchsanweisung, Berlin, 2012.

Frederick, Christine, The New Housekeeping: Efficiency Studies in Home Management, New York, NY, 1919 [1913].

Dies., Household Engineering: Scientific Management in the Home, Chicago, IL, 1920.

Gregg, Melissa, „The Athleticism of Accomplishment. Speed in the Workplace“, in: Judy Wajcman/Nigel Dodd (Hg.), The Sociology of Speed: Digital, Organizational, and Social Temporalities, Oxford, 2017, S. 102-114.

Heindl, Ines, „Kulinarische Diskurse als Indikatoren sich wandelnder Gesellschaften“, in: Manfred Blohm/Sara Burkhardt/Christine Heil (Hg.), Tatort Küche: Kunst, Kulturvermittlung, Museum. Die Küche als Lebens- und Erfahrungsraum, Flensburg, 2009, S. 65-77.

Heyen, Robert, Degeneration and Revolution: Radical Cultural Politics and the Body in Weimar Germany, Leiden, Boston, MA, 2015.

Krausse, Joachim, „Vom Kochtopf zur Fassade bauen“, in: Renate Flagmeier/ Werkbundarchiv - Museum der Dinge (Hg.), Die Frankfurter Küche. Eine museale Gebrauchsanweisung, Berlin, 2012, S. 19-34.

Ders., „Eine Architektur der Raum-Zeit. Joachim Krausse im Gespräch mit Renate Flagmeier", in: Renate Flagmeier/Werkbundarchiv - Museum der Dinge (Hg.), Die Frankfurter Küche. Eine museale Gebrauchsanweisung, Berlin, 2012, S. 34-57.

Lihotzki, Margarete, „Einiges über die Einrichtung österreichischer Häuser unter besonderer Berücksichtigung der Siedlungsbauten“, in: Das Schlesische Heim, 8, 1921, S. 217-222.

Lupton, Ellen/Miller, J. Abbott, The Kitchen, the Bathroom, and the Aesthetics of Waste: A Process of Elimination, New York, NY, 1992.

Meyer, Erna, „Wohnungsbau und Hausführung“, in: Der Baumeister, 6 (1927), S. 89-95.

Ogden, Annegret S., The Great American Housewife: From Helpmate to Wage Earner, 1776-1986, Westport, CT, 1986. 
Reagin, Nancy, Sweeping the German Nation: Domesticity and National Identity in Germany, 1870-1945, New York, NY, 2007.

Schulte, Regina, „Häusliche Dienste“ in: Gisela Ecker/Claudia Lillge (Hg.), Kulturen der Arbeit, Paderborn, 2011, S. 155-168.

Schütte-Lihotzky, Margarete, „Rationalisierung im Haushalt“, in: Das Neue Frankfurt 1, 5 (1927), S. 120-123.

Dies., Warum ich Architektin wurde, Salzburg, 2004.

Tomes, Nancy, „The Private Side of Public Health: Sanitary Science, Domestic Hygiene, and the Germ Theory, 1870-1900“, in: Judith W. Leavitt/Ronald L. Numbers (Hg.), Sickness and Health in America. Readings in the History of Medicine and Public Health, Wisconsin, WI, 1997, S. 506-528.

Witte, Irene, Die rationelle Haushaltsführung. Betriebswissenschaftliche Studien, Berlin, 1921. 



\author{
TOBIAS EICHINGER
}

\title{
AUTHENTISCHE AMPUTATIONEN. ZuM UMGANG MIT EXTREMEN WÜNSCHEN IN DER MEDIZIN ZWISCHEN KÖRPERLICHER INTEGRITÄT UND NORMALITÄT
}

Dass die Medizin mit ihren Möglichkeiten, auf Körper und Geist des Menschen zuzugreifen und diese mithilfe von Medikamenten und Operationen zu verändern, auch ganz ohne das Vorliegen von Krankheitszuständen oder Verletzungen zum Einsatz kommen kann und kommt, ist seit einiger Zeit nicht nur mehr und mehr behandlungspraktische Realität, sondern auch Gegenstand kritischer Reflexion und Diskussion geworden. Unter den Stichworten der Optimierung, des Enhancement, der Verbesserung und Gestaltung des eigenen Selbst mit medizinischen Mitteln werden Verfahren und Aktivitäten verhandelt, die sich auch auf den Begriff der wunscherfüllenden Medizin bringen lassen. ${ }^{1}$ War ärztliches Handeln in einem traditionellen Sinne vornehmlich und zentral an einem Bündel therapeutischer Ziele orientiert - die im Wesentlichen Maßnahmen in kurativer, präventiver, palliativer und rehabilitativer Absicht umfassen -, so wird Medizin heute zunehmend auch als Technik und Praxis der individuell angepassten und wunschgemäßen Lebensgestaltung und gezielten Selbstverbesserung verstanden und nachgefragt.

\section{Lebenslange Optimierung}

An die Seite des traditionellen Konzeptes, wonach Medizin als humane Hilfestellung für Menschen in Not und Bedrängnis die Beseitigung von Krankheit und Leiden bezweckt und verfolgt, ist ein Paradigma getreten, das eher gesunde Menschen adressiert und Medizin als wertneutrale ,Humantechnik“" begreift. Die Palette der Angebote, die entsprechend zur Verfügung stehen, um Umstände und Bedingungen der je eigenen Lebensführung den persönlichen Vorlieben anzupassen und dabei angenehmer, effektiver und erfolgreicher zu gestalten, erstreckt sich über den gesamten Lebensverlauf, von Maßnahmen

1 Vgl. Matthias Kettner, „Enhancement als wunscherfüllende Medizin“, in: Ada Borkenhagen/ Elmar Brähler (Hg.), Die Selbstverbesserung des Menschen. Wunschmedizin und Enhancement aus medizinpsychologischer Perspektive, Gießen, 2012, S. 13-31; Tobias Eichinger, Jenseits der Therapie. Philosophie und Ethik wunscherfüllender Medizin, Bielefeld, 2013.

2 Dieter Birnbacher, „Die ethische Ambivalenz des Enhancement“, in: Michael Quante/Erzsébet Rózsa (Hg.), Anthropologie und Technik. Ein deutsch-ungarischer Dialog, München, 2012, S. 111-125: 111 . 
vorgeburtlicher Manipulation bis hin zur Kontrolle und Beeinflussung von Sterben und Tod: Wer sich Kinder wünscht, sich aber nicht auf natürlichem Wege fortpflanzen kann (weil der Partner unfruchtbar ist oder demselben Geschlecht angehört; oder weil es gar keinen Partner gibt), kann mithilfe der Reproduktionsmedizin eigene Kinder bekommen, während Menschen, die sich fortpflanzen können, das aber nicht wollen, unerwünschten Nachwuchs mit ärztlicher Unterstützung verhindern können. Wer hingegen ungewollt schwanger geworden ist, kann die Schwangerschaft von einem Arzt abbrechen lassen. Wer hingegen - gewollt schwanger - die Geburt wunschgemäß terminieren oder den Strapazen einer natürlichen Geburt aus dem Weg gehen will, kann sein Kind mittels einer Wunschoperation zur Welt bringen. Wer das Risiko minimieren will, dass das eigene Kind nicht behindert sein wird oder wer sich ein Kind mit einem bestimmten Geschlecht wünscht, kann sich diese Wünsche dank modernster Pränataldiagnostik und Reproduktionsmedizin erfüllen. Wer unter dem Geschlecht, mit dem er selbst geboren worden und aufgewachsen ist, übermäßig leidet, kann dieses auf medizinischem Wege wechseln. Genauso kann, wer mit seinem äußeren Erscheinungsbild nicht zufrieden ist, seine Gestalt durch operative Eingriffe wunschgemäß formen lassen, sich die Haut straffen, überschüssige Körperpartien entfernen und fehlende ergänzen lassen. Wer gerne leistungsfähiger wäre, kann seine motorischen und kognitiven Fähigkeiten mithilfe von Medikamenten und Implantaten erheblich steigern. Wer sich emotional nicht mehr von äußeren Einflüssen und unberechenbaren Launen bestimmen lassen möchte, kann seine Stimmung mit pharmakologischen Mitteln oder gar neurostimulierenden Interventionen kontrollieren und auf Knopfdruck heben. Wessen Kinder sich nicht planmäßig und diszipliniert genug verhalten, kann den zappeligen Nachwuchs mit Tabletten ruhigstellen. Und wer schließlich im Sterben liegt, kann sich zur völligen Bewusstlosigkeit sedieren lassen, um das Leiden des allerletzten Lebensabschnitts zu umgehen - von der Möglichkeit, auf Wunsch mithilfe medizinischer Unterstützung aus dem Leben zu scheiden, ganz zu schweigen.

Bei all diesen Optionen, gerade mit medizinischen Mitteln die psychophysische Verfassung den je eigenen Vorlieben und Idealen anzupassen und somit sich selbst wunschgemäß zu gestalten, geht es in aller Regel darum, bestimmte Eigenschaften und Fähigkeiten so zu manipulieren und zu steuern, dass der durch den fraglichen Eingriff erreichte Zustand nach allgemein geteilten und nachvollziehbaren Gesichtspunkten als besser eingeschätzt werden kann etwa wenn das Ziel ist, mehr Informationen in kürzerer Zeit aufnehmen, verarbeiten und memorieren zu können; oder wenn das Ziel ist, schneller laufen, höher springen oder länger wach und aufmerksam bleiben zu können; oder wenn man einen jugendlicheren und attraktiveren Körper haben möchte. Das schließt freilich nicht aus, dass die im Einzelnen verfolgten Ziele auch kritisiert werden können (und mitunter auch sollten), doch lassen diese sich zunächst durchweg als Verbesserungen charakterisieren, da sie eine Steigerung und Intensivierung von als positiv und wünschenswert eingeschätzten Fähig- 
keiten und Eigenschaften betreffen. Mithilfe wunscherfüllender Medizin hoffen und beabsichtigen ihre Nutzer, schöner, besser, stärker, schneller, jünger, gesünder, wacher, aufmerksamer, leistungsfähiger, produktiver und reproduktiver, konzentrierter, zufriedener und letztendlich glücklicher zu werden alles Enhancement zielt in diesem komparativischen Sinne auf die Optimierung bereits vorhandener oder das Erreichen fehlender positiver Eigenschaften. Zwar ist es eine keineswegs triviale Frage, was eigentlich ,besser ' bedeuten soll und nach welchen Kriterien sich bemessen lässt, ob etwa eine rein quantitative ,Verbesserung' auch wirklich besser ist, das heißt, ob sie in einem umfangreichen und tiefgreifenden, qualitativen Sinne auch langfristig erstrebenswert ist - und diese Frage stellt sich umso dringlicher, je invasiver, risikoreicher und irreversibler das Vornehmen des fraglichen Eingriffs ist. Gleichwohl handelt es sich bei dem überwiegenden Anteil der derart diskutierten Veränderungen um Veränderungen, deren Attraktivität - zumindest für andere - meist relativ problemlos nachvollziehbar ist. Nicht nur wird das angestrebte Ziel von dem Optimierungswilligen selbst so klar und eindeutig als Verbesserung gesehen, dass dafür auch die unvermeidlichen Risiken einer Körperverletzung (wie im Falle einer Operation) oder gesundheitlichen Beeinträchtigung (wie im Falle übermäßigen Dopings) in Kauf genommen werden, auch außenstehende Beobachter, so kritisch und ablehnend sie auch den eingesetzten Mitteln gegenüber sein mögen, können meist dem angestrebten Resultat des Enhancement, als Ziel für sich genommen, durchaus etwas abgewinnen.

\section{Extreme wunscherfüllende Medizin}

Am Rand des sehr breiten und beständig wachsenden Spektrums derartiger Optimierungswünsche existieren aber auch Wünsche, bei denen nicht nur die Risiken der Durchführung zu denken geben, sondern das jeweils angestrebte Ziel selbst hoch fragwürdig erscheint. Die Medizin sieht sich auch mit Forderungen nach ärztlicher Unterstützung konfrontiert, die alles andere als nachvollziehbar, plausibel oder gar rational zu sein scheinen und dementsprechend zuallererst auf Unverständnis und intuitive Ablehnung stoßen. So gibt es Fälle, in denen potenzielle Medizinklienten Eingriffe wünschen, die nicht nur durch die notwendigen Verfahrensschritte ihrer Durchführung gesundheitliche Risiken und die Gefahr unerwünschter Nebenwirkungen bedeuten - als negative Mittel zum positiven Zweck -, sondern deren bezwecktes Ziel nach gängiger Auffassung selbst eine eindeutige Schädigung bedeutet - der Eingriff mithin als negatives Mittel zu einem negativen Zweck aufgefasst werden muss. Zu dieser Gruppe von Schädigungswünschen, das heißt von Wünschen, die sich auf eine bewusste und gezielte Beeinträchtigung des eigenen Körpers richten (bemerkenswerterweise beziehen sich derartige Wünsche nur auf den Körper und nicht auf die geistig-seelische Dimension des Selbst), lassen sich umstrittene Praktiken wie religiös motivierte Beschneidungen, Lebendorganspenden, 
die gezielte Zeugung eines gehörlosen Kindes (mittels PID) oder extreme Formen ästhetisch-kosmetischer Chirurgie und so genannter extreme body modification wie das Anschleifen von Zähnen, das subkutane Implantieren von Metallplatten oder auch das künstliche Spalten der Zunge rechnen. So unterschiedlich diese Beispiele jeweils beschaffen sind und so verschieden die für eine ethische Beurteilung relevanten Umstände im Einzelnen gelagert sind, all diese an die Ärzteschaft herangetragenen Forderungen zielen darauf ab, ohne das Vorliegen einer medizinischen Notwendigkeit den Körper eines gesunden Menschen mit medizinisch-technischen Mitteln bewusst zu beeinträchtigen, zu verletzen, zu versehren. Diese Maßnahmen lassen sich somit nur schwerlich unter den Begriff der Optimierung bringen, da sie ja gerade eine im medizinisch-physiologischen Sinne unzweideutige Verschlechterung der eigenen körperlichen Verfassung bezwecken. Insofern stellen solche Fälle selbstverlangter Schädigung auf der Skala von an die Medizin gerichteten Veränderungswünschen gewissermaßen das diametrale Gegenüber zu positiv (und hyper-positiv) angelegten Enhancement-Begehrlichkeiten dar. Gleichzeitig aber teilen derartige Wünsche nach , grundloser' Verletzung, künstlicher Behinderung und freiwilliger Verstümmelung mit medizinischen Verbesserungswünschen die Schwierigkeit, die jeweils angefragten Behandlungen mit dem herkömmlichen ärztlichen Ethos und der moralisch-professionellen Integrität der Medizin zu vereinbaren. Wie bei Maßnahmen zur Verbesserung des körperlichen oder geistigen Befindens gesunder Menschen liegt auch bei Forderungen nach Selbstschädigung keine medizinische Indikation vor. Diese aber ist die notwendige Bedingung zur nicht nur ethisch, sondern auch rechtlich legitimen Durchführung medizinischer Leistungen. ${ }^{3}$ Demzufolge lassen sich auch die mitunter befremdlich anmutenden Anliegen nach Selbstschädigung unter das Label der wunscherfüllenden Medizin fassen, da hier aus-

\footnotetext{
So stellt etwa der Medizinethiker Gerald Neitzke klar: „Heute dürfen weder diagnostische noch therapeutische Maßnahmen begonnen werden, ohne dass zuvor eine Indikation gestellt wurde. Nicht indizierte oder gar kontraindizierte ärztliche Maßnahmen scheiden von vornherein aus dem Bereich rationaler, verantwortungsvoller Medizin aus.“ Gerald Neitzke, „Unterscheidung zwischen medizinischer und ärztlicher Indikation. Eine ethische Analyse der Indikationsstellung", in: Ralph Charbonnier/Klaus Dörner/Steffen Simon (Hg.), Medizinische Indikation und Patientenwille. Behandlungsentscheidungen in der Intensivmedizin und am Lebensende, Stuttgart, 2008, S. 53-66: 53. Wie weit dabei der Bereich einer als indiziert geltenden Maßnahme gesteckt sein kann, ist einer Definition aus einem medizinrechtlichen Handbuch zu entnehmen: „Indizierte Heileingriffe sind ärztliche Eingriffe und andere Behandlungen, die am Körper eines Menschen vorgenommen werden und die nach den Erkenntnissen und Erfahrungen der ärztlichen Heilkunde und den Grundsätzen eines gewissenhaften Arztes angezeigt sind und vorgenommen werden, um Krankheiten, Leiden, Körperschäden, körperliche Beschwerden oder seelische Störungen zu verhüten, zu erkennen, zu heilen oder zu lindern und damit alle auf die Besserung eines Leidens gerichteten ärztlichen Maßnahmen, gleichgültig ob der ärztliche Eingriff der Behandlung selbst, der Diagnose oder der Prophylaxe dient.“ Nine Joost, „Schönheitsoperationen - die Einwilligung in medizinisch nicht indizierte ,wunscherfüllende" Eingriffe", in: Claus Roxin/Ulrich Schroth (Hg.), Handbuch des Medizinstrafrechts, Stuttgart, 2010, S. 383-443: 395 f.
} 
schließlich aufgrund eines geäußerten Wunsches ohne Vorliegen medizinischärztlicher Notwendigkeit medizinisches Wissen und Können zum Einsatz kommen soll. Um das sowohl empirisch als auch ethisch Außergewöhnliche solcher Maßnahmen zu markieren, soll hier der Begriff extremer wunscherfüllender Medizin herangezogen werden.

Um nun die ethisch-anthropologische Herausforderung derartiger extremer wunscherfüllender Medizin für die ärztliche Praxis und Profession zu verdeutlichen, bietet sich als ein konkretes Wunschfeld, das nicht nur in den Medien für Aufmerksamkeit sorgt, sondern auch in medizinethischen Kreisen bereits diskutiert wird, das Phänomen der gewünschten Amputation physiologisch gesunder Gliedmaßen an. Dieses Phänomen wird in der medizinischen und medizinethischen Literatur auch als Körper-Integritäts-Identitäts-Störung (Body Integrity Identity Disorder, BIID) diskutiert. Die Betroffenen empfinden dabei ein Körperteil - meist eine Extremität - als nicht zu ihrem eigenen Körper gehörig, berichten von einer charakteristischen und gravierenden Entfremdungserfahrung, wonach das betreffende Glied ihres Körpers für sie komplett überflüssig und störend ist. Dieses Gefühl geht so weit, dass die eigene körperliche Integrität als fragmentiert, empfindlich gestört und unvollständig erlebt wird, was wiederum schwerwiegende Auswirkungen auf die Identitätsbildung und das Selbstwertgefühl haben kann. Dieser Zustand, der zu einem erheblichen Leidensdruck führen kann, besteht dabei bereits oft seit vielen Jahren, nicht selten seit der Kindheit oder Adoleszenz. Aus Sicht der Betroffenen stellt die Entfernung des betreffenden Körperteils und damit die gezielte Selbstschädigung die einzige Möglichkeit der Linderung oder Heilung ihres Leidens dar. Ein zentrales Kennzeichen von BIID ist das intensive und anhaltende Verlangen nach einer Veränderung des bestehenden Körpers und dem Erlangen des Wunschkörpers. Im ,als überwältigend empfundenen Wunsch [...], sich durch eine fundamentale und irreparable Beschädigung des eigenen Körpers eine ,neue“ Identität zu verschaffen "“4 wird die Verheißung auf ein neues, integres und leidfreies Leben gesehen. Nur auf diesem Wege, so hoffen die Betroffenen, sei es ihnen möglich, ,zu einem vollständigen Körperselbst zu gelangen". 5 Mit derselben Begründung - zur Wiederherstellung einer als erheblich gestört empfundenen körperlichen Integrität - wünschen in anderen Fällen gesunde Menschen sehnsüchtig die elektive Durchtrennung des Rückenmarks zur Herbeiführung einer Querschnittslähmung, wieder andere verspüren den sehnlichen Wunsch zu erblinden. Der überwiegende Teil der von BIID be-

4 Arnd Pollmann, „Ein Recht auf Unversehrtheit? Skizze einer Phänomenologie moralischer Integritätsverletzungen“, in: Sibylle an der Walt/Christoph Menke (Hg.), Die Unversehrtheit des Körpers: Geschichte und Theorie eines elementaren Menschenrechts, Frankfurt/M., 2007, S. 214-236: 214.

5 David Holzer/Thomas Stompe, ,Körpermodifikation - (sub-)kulturelle und psychopathologische Aspekte“, in: Spectrum Psychiatrie, 2 (2014), S. 34-39: 38. 
troffenen Menschen wünscht sich allerdings die Amputation eines Beines. ${ }^{6}$ Aus medizinischer Perspektive ist bis heute nicht geklärt, worin die Ursachen dieses Phänomens liegen und worin eine effektive Therapie bestehen könnte.? Was hierbei aber offensichtlich und zweifelsfrei eine so wirksame wie radikale Lösung zu sein verspricht, ist die tatsächliche Umsetzung des Wunsches nach Entfernung der Extremität, die elektive Amputation bzw. die intendierte Verletzung mit dem Ergebnis einer schwerwiegenden körperlichen Behinderung.

Bei der Realisierung von Amputations- und Verstümmelungswünschen handelt es sich jedoch um Eingriffe, die dem traditionellen ärztlichen Auftrag so weit entgegenstehen wie es kaum radikaler vorstellbar scheint. Primum nil nocere lautet der klassische Leitsatz der ärztlichen Kunst seit der Antike. Dieses ethische Grundprinzip der Medizin, Schaden zu vermeiden, war dabei aber freilich nie als Warnung vor mutwilligen und (medizinisch) grundlosen Schädigungen gemeint. Stets handelte es sich um die negativen, aber unvermeidlichen Nebenwirkungen therapeutisch intendierter Heileingriffe, die demnach so minimal wie möglich zu halten sind. Dass gesunde Menschen nicht medizinischen Maßnahmen ausgesetzt werden dürfen, die diesen beabsichtigt und ausschließlich Schaden zufügen, verstand sich dabei stets von selbst. Der so grundsätzlichen wie eklatanten Diskrepanz von BIID-Wünschen zum herkömmlichen ärztlichen Auftrag und Selbstverständnis entsprechen dann auch typische Reaktionen und Einschätzungen, die das Phänomen des Amputationswunsches als „obszön“ oder „abstoßend“ bezeichnen (so kommentierte ein schottischer Politiker zwei Ende der 90er Jahre bekannt gewordene Fälle erfolgter Wunschamputationen). Ähnlich unmissverständlich in seiner Ablehnung findet der renommierte Medizinethiker Arthur Caplan das Anliegen von BIID-Betroffenen ,absolut verrückt“ und hält es für ,äußersten Irrsinn“, auf derartige Wünsche nach Verstümmelung einzugehen. ${ }^{8}$ Diese Äußerungen sowie die intuitiv zurückweisende Reaktion, die die allermeisten Menschen, konfrontiert mit der Einschätzung derartiger Wünsche, zeigen dürften, scheinen zu bestätigen, was bereits die Einordnung ihrer Erfüllung als extreme wunscherfüllende Medizin nahelegt: dass das Verlangen nach einer erheblichen Behinderung, nach der Entfernung gesunder Gliedmaßen in einer eskalierenden Abfolge mit gebräuchlicheren Praktiken ästhetischer Körper- und Selbstveränderung steht, dabei aber über den Bereich des Üblichen und des in

6 Siehe Aglaja Stirn/Aylin Thiel/Silvia Oddo, Body Integrity Identity Disorder (BIID). Störungsbild, Diagnostik, Therapieansätze, Weinheim, 2010, S. 2.

7 Diskutiert werden u. a. psychologische, psychiatrische, kognitiv-verhaltenstherapeutische sowie neurobiologische Erklärungsmodelle, vgl. Sabine Müller, „Body Integrity Identity Disorder (BIID) - Lassen sich Amputationen gesunder Gliedmaßen ethisch rechtfertigen?“, in: Ethik in der Medizin 20, 4 (2008), S. 287-299 und Stirn/Thiel/Oddo (2010), Body Integrity Identity Disorder (BIID).

8 Alle Zitate aus Randy Dotinga, „Out on a Limb“, auf: salon, online unter: http://www.salon. com/2000/08/29/amputation, zuletzt aufgerufen am 03.01.2019. 
der Sphäre des Privaten akzeptierten Verhaltens hinausgeht. Amputations- und Selbstschädigungswünsche lassen sich somit durchaus als Teil des weiten Spektrums wunscherfüllender Medizin verstehen, stellen aber gleichzeitig einen besonderen Extremfall dar.

Aus medizinethischer Perspektive fallen zunächst die bedenklichen Gemeinsamkeiten ins Auge: medizinisch assistierte bzw. durchgeführte Körperveränderungen, die aus rein ästhetischen Gründen gewünscht werden und dabei keiner medizinischen Notwendigkeit geschuldet sind, sind zwar meist weitaus harmloser als die Entfernung von Extremitäten und mögen mittlerweile auch weithin akzeptiert sein, sind aber aus medizinethischer Perspektive weiterhin als fragwürdig einzustufen bis abzulehnen. Auch chirurgische Eingriffe zur - fachlich nicht indizierten - Brustvergrößerung, Nasenmodellierung oder Faltenbeseitigung verfolgen keinerlei therapeutisches Ziel, setzen den Klienten bzw. die Klientin aber einem nicht unerheblichen gesundheitlichen Risiko aus, um auf Wünsche zu reagieren, die kaum mit einer medizinisch zu nennenden Notwendigkeit begründet werden können, sondern vielmehr kontingente Selbstverwirklichung und individuelle Geschmackssache sind. Und wie bei Amputationswünschen zur Wiederherstellung der körperlichen Integrität und personalen Identität stellt sich auch bei schönheitsmedizinischen Maßnahmen notorisch die Frage, ob mit der Durchführung der gewünschten Veränderungen die, eigentliche" Ursache des Leidens und beklagten Zustandes denn überhaupt tangiert, geschweige denn behoben werden kann. Was unbedingt zu vermeiden ist, so diese Skepsis und Kritik, ist „Psychotherapie mit dem Skalpell“". ${ }^{9}$ Dass bei vielen kosmetisch-ästhetischen Eingriffen aber genau diese Gefahr beständig droht, dass es sich letztlich um psychische oder soziale Probleme handelt, die durch Operationen am äußeren Erscheinungsbild gelöst werden sollen, liegt an einigen Merkmalen der Wünsche und Vorstellungen, die hier im Spiel sind.

\section{Normalität, Schönheit und Identität}

Schönheitsoperationen richten sich klarerweise auf Äußerlichkeiten und damit auf körperliche Eigenschaften, die für andere sichtbar sind und sein sollen. Somit sind auch die entsprechenden Motive wesentlich durch den Blick von außen, den Blick der Anderen, das heißt extern bewirkt und geformt. Schon der medizinischen Praxis, aus der die kosmetisch-ästhetische Chirurgie hervorgegangen ist, der rekonstruktiven plastischen Chirurgie, liegt diese externalistische Motivation sozialer Visibilität zugrunde. Neben der Wiederherstel-

9 Vgl. Kurt Bayertz/Kurt W. Schmidt, „Es ist ziemlich teuer, authentisch zu sein...!' Von der ästhetischen Umgestaltung des menschlichen Körpers und der Integrität der menschlichen Natur", in: Johann S. Ach/Arnd Pollmann (Hg.), no body is perfect. Baumaßnahmen am menschlichen Körper - Bioethische und ästhetische Aufrisse, Bielefeld, 2006, S. 43-62: 55. 
lung durch Unfälle und Verletzungen gestörter oder zerstörter Körperfunktionen geht es der rekonstruktiven Medizin beinahe unvermeidlich immer auch um die äußere Erscheinung und Gestalt deformierter Organe und Gewebeteile, die es wieder in den Zustand vor der Beschädigung zu bringen gilt. Dabei ist ein zentrales Motiv der rekonstruktiven medizinischen Arbeit an der äußerlichen Erscheinung das Streben nach Normalität. Sichtbar entstellte und dadurch auch sozial beeinträchtigte Menschen wünschen sich meist nichts mehr, als ,wieder normal' auszusehen und nicht aufgrund ihres beschädigten Äußeren übermäßig beachtet oder darauf reduziert zu werden. Dieser Form von Normalisierung durch medizinisches Handeln stehen die gewünschten Eingriffe bei BIID diametral entgegen. Hier soll ja gerade die (äußerlich) normale und intakte körperliche Erscheinung verändert werden, um eine offensichtliche - und das heißt meist auch eine nicht zu übersehende - Abweichung von der Norm des gesunden und funktionsfähigen Körpers zu erreichen. ${ }^{10}$ Ziel der plastisch-rekonstruktiven Medizin dagegen ist es, den Patienten „Zu einem so weit wie möglich ,normalen“ Niveau an Aufmerksamkeit von anderen" ${ }^{\prime 11} \mathrm{zu}$ verhelfen. So intuitiv plausibel diese Zielrichtung medizinischen Handelns ist und so sehr sie sich mit dem traditionellen ärztlichen Ethos vereinbaren lässt, so ist auch unbestreitbar, dass die Übergänge zu anderen, weniger eindeutigen Formen ästhetischer Selbstgestaltung mit medizinischen Mitteln fließend sind und es unmöglich ist, hier eine klare Grenze zu ziehen. Denn wenn eine bei einem Unfall größtenteils zerstörte Nase wieder hergestellt werden soll, muss freilich nicht exakt dieselbe Form rekonstruiert werden, die die Nase vor dem Unfall hatte. Die neue Nase kann problemlos den persönlichen Wünschen gemäß modelliert und ästhetisch gestaltet werden, so dass das Ergebnis schließlich als Verbesserung gegenüber der natürlichen, dann versehrten Nase empfunden wird. Genaugenommen ist es also unmöglich, plastisch-chirurgisch zu rekonstruieren, ohne ästhetische Gesichtspunkte zu berücksichtigen. An diesem Übergang von der rekonstruktiven zur ästhetischen plastischen Chirurgie lässt sich ein Moment feststellen, das charakteristisch ist für die Genese und Logik von Enhancement-Maßnahmen im Allgemeinen. Stets ist begründungsbedürftig, warum die Durchführung effektiver medizinischer Maßnahmen bei dem Wiedererreichen eines Normalmaßes was häufig mit einem gesunden Zustand gleichgesetzt wird - enden soll und nicht zur direkten Verbesserung und Steigerung über diesen normalen Zustand

10 Darin ist dann auch eine Umkehrung der üblichen Dynamik von Medikalisierungsprozessen zu sehen, wie sie etwa Peter Conrad beschreibt, wonach Abweichungen vom Normalen, die bis dahin keine medizinische Relevanz besaßen, neu in den Definitions- und Zuständigkeitsbereich der Medizin geraten, um sie dort mit den entsprechenden Mitteln zu beschreiben, zu disziplinieren und schließlich zu eliminieren. Vgl. Peter Conrad/Joseph W. Schneider, Deviance and Medicalization. From Badness to Sickness, Philadelphia, PA, 1992.

11 Urban Wiesing, „Die ästhetische Chirurgie: Eine Skizze der ethischen Probleme“, in: Zeitschrift für medizinische Ethik 52, 2 (2006), S. 139-154: 144. Ganz ähnlich schlägt Dieter Birnbacher vor, zwischen kompensatorischem und erweiterndem Enhancement zu unterscheiden: Birnbacher (2012), Die ethische Ambivalenz des Enhancement, S. $113 \mathrm{ff}$. 
hinaus weitergeführt werden kann. Bis auf wenige Ausnahmen entstammen sämtliche Mittel und Methoden, die als medizinisches Enhancement propagiert, diskutiert und kritisiert werden, dementsprechend auch aus therapeutischen Kontexten und sind meist zunächst zur Krankheitsbekämpfung entwickelt worden.

Die plastische Chirurgie untersteht in ihrer konkreten Anwendung notwendigerweise ästhetischen Kriterien und bewegt sich damit im Spannungsfeld von individuellen und sozialen Vorstellungen von Schönheit und Normalität. Sie ist damit immer auch zu einem gewissen Teil mit Einflussfaktoren der Mode konfrontiert, die ihrerseits freilich historisch und kulturell variabel sind. Die konkrete Wunschform und -proportion, die eine zu verändernde Körperpartie durch einen schönheitsmedizinischen Eingriff annehmen soll, lässt sich somit analog zu Kleidung und Schmuck als Mittel der individuellen Gestaltung der äußeren und sichtbaren Seite des Selbst verstehen. Freilich handelt es sich dabei um eine besondere Dimension der Selbstformung, eine Form von Selbstgestaltung, die zu Ergebnissen führt, die man nicht einfach wieder ablegen und wechseln kann, eine Form von Selbstgestaltung, die nicht nur sprichwörtlich unter die Haut geht. Ob Gewebe entfernt, unterspritzt, gedehnt, durchstochen, gespalten, mit Tinte getränkt oder künstlich vernarbt wird stets werden hierbei Körpermanipulationen gewünscht und durchgeführt, die invasiv und irreversibel sind. Und so ist es gerade der spezifische Clou an medizinisch-kosmetischer Veränderung der äußeren Erscheinung, dass die eigenen Vorstellungen nicht nur wunschgemäß umgesetzt werden, sondern diese auch dauerhaft und verlässlich bleiben. Damit kommen Körpermodifikationen den Möglichkeiten und Bedürfnissen individueller Identitätsbildung sehr entgegen. Als zentrale Kriterien für die Herausbildung und Kultivierung eines unverwechselbaren eigenen Selbst, lassen sich Permanenz und Persönlichkeit identifizieren. Indem Tätowierungen, Piercings, Schönheitsoperationen und andere Formen von body modification bis hin zu Selbstverstümmelungen „dauerhafte physische Veränderungen darstellen und zumeist individuell ausgewählt und gestaltet werden"12, erfüllen sie diese Anforderungen in besonderem Maße. Allerdings ist ein Wunsch nach ästhetischer Umgestaltung des eigenen Körpers immer - mehr oder weniger - von externen Einflussfaktoren bestimmt, die ihrerseits nicht unbedingt von Dauer sein müssen, und so ist bei invasiven und irreversiblen Eingriffen stets die Wandelbarkeit der eigenen Wünsche und Vorstellungen hinsichtlich des erstrebten Körperideals zu berücksichtigen. Entsprechend wird auch aus juristischer Perspektive die Unterscheidung zwischen der „Langzeitpräferenz“ des eigenen Gesundheitsschutzes und der „Kurzzeitpräferenz Aussehen“ plausibel, um im Rahmen der Risikoaufklärung für eine klare Gewichtung zugunsten der langfristig relevanten Dimension der Unversehrtheit des Körpers zu plädieren. ${ }^{13}$

12 Holzer/Stompe (2014), Körpermodifikation, S. 36.

13 Siehe Joost (2010), Schönheitsoperationen, S. 433. 
So sehr in Gesellschaften westlicher Prägung in Zeiten der Spät- oder Postmoderne nun der Körper zunehmend in den Mittelpunkt des identitätsbildenden Interesses rückt und angesichts der beständig fortschreitenden technischen Möglichkeiten der Manipulation und Formung einerseits und aufgrund des gesellschaftlich-moralischen Pluralismus und Individualismus andererseits auch als ein solches Medium der Selbstbestimmung und -expression im Dienste des „Identitätsmanagement[s]“"14 gelebt und praktiziert wird, so wenig kann noch von einer einheitlichen Motivlage hinter dieser Entwicklung gesprochen werden. Ein wichtiges Merkmal zur weiteren Differenzierung der unterschiedlichen Körpermodifikationsformen - vom kleinen Tattoo bis hin zur künstlichen Querschnittslähmung - ist dann auch in den motivationalen Einflussfaktoren auszumachen. Während Eingriffe wunscherfüllender Medizin, die ihren Empfänger und dessen Körper schöner, stärker und fitter machen sollen, wesentlich extern motiviert sind und mehr oder weniger stark von sozialen Faktoren wie Status, Kommunikation und Außenwirkung abhängig sind, scheint bei Amputationswünschen das Gegenteil der Fall zu sein. BIID-Betroffene sehnen sich nach extremen Körperveränderungen nicht wegen ihres Umfelds und der dort dominanten Bilder und Normen, sondern trotz ihres ja nie wertneutralen sozialen Kontextes. Sämtliche Fallberichte deuten einhellig darauf hin, dass Menschen mit einer Körper-Integritäts-Identitäts-Störung sehr wohl bewusst ist, dass ihr Anliegen keineswegs den kulturell und medial vermittelten Körperidealen ihrer Lebenswelt entspricht, dass die angestrebten Ergebnisse von niemandem sonst als ästhetischer Gewinn bewertet werden und dass von den Operationen kaum gesellschaftlicher Nutzen oder soziale Vorteile zu erwarten sind. Insofern verläuft die Identitätsbildung durch die Erfüllung von Amputationswünschen genau umgekehrt zu derjenigen durch Selbstformungspraktiken wie Bodybuilding, Brustvergrößerung, Hautstraffung oder Hirndoping, die alle wesentlich abzielen auf gesellschaftlich vermittelte und propagierte Werte wie Jugendlichkeit, Leistungsfähigkeit, Schönheit sowie - körperliche Unversehrtheit.

Authentische Verstümmelungswünsche

$\mathrm{Zu}$ dem eklatant nonkonformen Wesenszug des Selbstschädigungswunsches kommt hinzu, dass das gestörte Körperbild bzw. die Diskrepanz zwischen dem idealen Körperbild und der realen Körperwirklichkeit, unter der die Betroffenen leiden, meist sehr lange, oft seit Jahrzehnten besteht, ohne an Intensität abzunehmen oder sich zu wandeln. Bemerkenswert ist hier, dass häufig sehr „präzis[e] Vorstellungen bezüglich der ,Demarkationslinie‘, welche akzeptier-

14 Holzer/Stompe (2014), Körpermodifikation, S. 37. 
te von nicht akzeptierten Körperabschnitten trennt" ${ }^{\text {"15 }}$, bestehen - Amputationswillige können zentimetergenau angeben, wo und wie etwa ihr nicht integrierter Unterarm abgetrennt werden soll. Außerdem simulieren viele über lange Zeiträume hinweg immer wieder den erwünschten Zustand, indem sie sich etwa ein Bein abbinden und sich in der Öffentlichkeit auf Krücken oder im Rollstuhl fortbewegen. Dies geschieht allerdings meist in fremder Umgebung, Betroffene führen häufig aus Angst vor Unverständnis und zurückweisenden bis ausgrenzenden Reaktionen ein Doppelleben, um zumindest ihrem Verlangen nach einem zeitweisen Vortäuschen der gewünschten Behinderung nachgehen zu können. ${ }^{16}$ Dieses pretending genannte Simulationsverhalten wird in aller Regel als höchst befreiend und befriedigend erlebt, was den ohnehin starken Wunsch nach Amputation und Selbstschädigung dann bestätigt, noch weiter vertieft und verfestigt. ${ }^{17}$ Von kurzlebigen und oberflächlichen Präferenzen, die mithilfe der Medizin umgesetzt werden sollen, die dabei aber auch immer unter dem Verdacht stehen, von nur begrenzter Dauer zu sein und infolge absehbar wechselnder Moden und Trends aufzutauchen und wieder zu verschwinden, kann bei Amputationswünschen offenbar keine Rede sein. Gerade durch das detailliert praktizierte und oft wiederholte Simulieren des gewünschten Zustandes mit Behinderung scheinen wichtige Grundanforderungen erfüllt, die für gewöhnlich an Wünsche gestellt werden, deren Erfüllung schwerwiegende medizinische Eingriffe verlangt, welche mit nicht unerheblichen Risiken verbunden sind und die in kaum bis gar nicht mehr umkehrbaren Körperveränderungen resultieren. Gleichzeitig können in der Mehrzahl der Fälle psychotische Symptome oder körperdysmorphe Störungen ausgeschlossen werden. ${ }^{18}$

Dass Menschen bei klarem Verstand, bei voller Zurechnungs- und Urteilsfähigkeit, bei Kenntnis aller alternativen Optionen und vor allem mit langjähriger Erfahrung im imaginierten Erleben des antizipierten Wunschzustandes trotz überwiegend irritierender und ablehnender Reaktionen wohlüberlegt und konstant die Entfernung eines intakten Körperteils ersehnen, macht deutlich, dass derartige Wünsche nach Körpermodifikation für die Betroffenen einen existenziellen Stellenwert einnehmen. Damit stellen sie einen Sonderfall medizinisch nicht indizierter Eingriffe zur Selbstgestaltung dar. Gerade der Umstand, dass eine schwerwiegende, freiwillig und gezielt herbeigeführte Behinderung, wie sie die Amputation von Extremitäten ist, ganz offensichtlich allen verbreiteten Vorstellungen von Funktionstüchtigkeit, Gesundheit und Schönheit zuwiderläuft, vermag die Intensität und Identifikationskraft des Verlangens beweisen. Stimmig und glaubhaft scheint dann auch zu sein, dass die

15 Peter Brugger, „Der Wunsch nach Amputation. Bizarre Macke oder neurologische Störung?“, in: Ars Medici, 2 (2011), S. 59-63: 61.

16 Siehe Stirn/Thiel/Oddo (2010), Body Integrity Identity Disorder (BIID), S. 2 ff.

17 Vgl. Erich Kasten, „Body Integrity Identity Disorder - Körperidentität durch erwünschte Behinderung“, in: Lege artis 3, 1 (2013), S. 165-177.

18 Siehe Stirn/Thiel/Oddo (2010), Body Integrity Identity Disorder (BIID), S. 19. 
Betroffenen in nicht unerheblichem Maße unter dem nicht-amputierten $\mathrm{Zu}$ stand leiden und ,ihre Funktionstüchtigkeit als Person eben gerade durch das Vorhandensein der Gliedmaße eingeschränkt" ${ }^{\text {"19 }}$ sehen. Somit ist bei Menschen mit BIID die Umkehrung der üblichen Vorstellung körperlicher Integrität zu konstatieren. Nicht das intakte Vorhandensein und uneingeschränkte Funktionieren aller zur typischen physiologisch-anatomischen Ausstattung des Menschen gehörigen Körperteile wird als Bedingung eines ganzheitlichen Integritätsgefühls vorausgesetzt, sondern erst durch das Fehlen bestimmter Teile und damit das Abweichen vom üblichen Schema wird der spezifische Zustand von Unversehrtheit, Selbsttreue und Authentizität als Person erreichbar. ${ }^{20}$ Insofern korrespondieren derartige Wünsche nach dem Abtrennen von Gliedmaßen zur ultimativen Selbstfindung weniger mit einem Verständnis vom „Körper als Projekt" als mit der gegensätzlichen Auffassung, wonach der physische Körper den ,letzte[n] Hort von Authentizität und unhintergehbare[n] Bezugspunkt von Identität" darstellt. ${ }^{21}$

Wenn Wünsche nach medizinisch grundloser Verstümmelung nun bestehen und im Sinne aufgeklärter Rationalität, Wohlerwogenheit und Dauerhaftigkeit sich stimmig in das umfassende Gesamt aus persönlichen Wertvorstellungen, Überzeugungen und Präferenzen des Betroffenen einfügen - und gleichzeitig das Vorliegen von mentaler Einschränkung, Zwang oder Wahn ausgeschlossen werden kann -, so kann davon ausgegangen werden, dass es sich um authentische Wünsche nach spezifischen Formen der Selbstgestaltung handelt.22 Dass Authentizität bzw. psychophysische Integrität im Einzelfall und aus Sicht der betroffenen Person ein höheres Gewicht einnehmen kann als die körperliche (äußerliche) Unversehrtheit, beweisen die berichteten Fälle von Körper-Integritäts-Identitäts-Störungen, die gleichzeitig den zunächst als „bizarre Macke“23 erscheinenden Wunsch als ,echtes“ und ernst zu nehmendes Verlangen eines leidenden Menschen sichtbar werden lassen. Wenn außerdem aufgrund der tiefsitzenden Sehnsucht und des korrespondierenden Leidensdrucks, der nur mehr durch die Erfüllung des Amputationswunsches gelindert und beseitigt zu werden vermag, bei verwehrter professioneller Herbeiführung der

19 Brugger (2011), Der Wunsch nach Amputation, S. 62.

20 Vgl. zu den verschiedenen Dimensionen des Integritätsbegriffs Pollmann (2007), Ein Recht auf Unversehrtheit?

21 Ada Borkenhagen, „Gemachte Körper: Die Inszenierung des modernen Selbst mit dem Skalpell. Aspekte zur Schönheitschirurgie“, in: Psychologie und Gesellschaftskritik 25, 1 (2001), S. 55-67: 55.

22 Hinzu kommt, dass es sich bei den BIID-Betroffenen ,in der Regel [um] intelligente, autonome und erfolgreiche Menschen" handelt, siehe Stirn/Thiel/Oddo (2010), Body Integrity Identity Disorder (BIID), S. 19. Zur Idee und Anforderungen einer kohärenten Wunschaufklärung siehe Peter Stemmer, „Was es heißt, ein gutes Leben zu leben“, in: Holmer Steinfath (Hg.), Was ist ein gutes Leben? Philosophische Reflexionen, Frankfurt/M., 1998, S. 47-72, zur identitätsbildenden Dimension von Wünschen siehe Eichinger (2013), Jenseits der Therapie, S. $63 \mathrm{ff}$.

23 Brugger (2011), Der Wunsch nach Amputation. 
verlangten Behinderung durch eine Ärztin oder einen Arzt als Alternative schließlich die tatsächliche Automutilation, das heißt die Verstümmelung in Eigenregie als letzter Ausweg bleibt; und wenn diese ,Selbsthilfe ' wegen des anhaltenden Leidens und der klaren (Er-)Lösungsvision durch Amputation auch mit einiger Wahrscheinlichkeit zu erwarten ist, dabei dieser selbst unternommene Lösungsversuch aber in aller Regel erheblich höhere gesundheitliche Risiken birgt als ein Eingriff von fachlich versierten und autorisierten Experten $^{24}$, dann muss doch auch und gerade aus medizinethischer Sicht eine ernsthafte Nutzen-Schaden-Abwägung vorgenommen werden, die diese Option miteinbezieht. Im Zuge solch einer Beurteilung kann dann durchaus der Grundsatz des Nichtschadens (auch als primum nil nocere, s. o.) auch auf die Verhinderung gefährlicher Selbstverstümmelung bezogen werden und ein ärztlich verantwortungsvolles Handeln im äußersten Ausnahmefall - als angemessene Hilfe zur Re-Integration eines auseinanderklaffenden Körper-SelbstBildes - das Umsetzen des Wunsches nach Verstümmelung bedeuten. ${ }^{25}$

Diese drastische Konsequenz, die zunächst klarerweise sowohl fundamentale Überzeugungen des individuellen Arztes als auch generelle ethische Grundprinzipien der Medizin in Frage und auf den Kopf zu stellen scheint, ist bei näherer Betrachtung doch nicht so weit vom Kernauftrag der jahrhundertealten ärztlichen Praxis entfernt. So besteht doch eine der ältesten und basalsten Aufgaben der Medizin darin, dort, wo keine Heilung möglich ist, Schmerz und Leid zu lindern. ${ }^{26}$ Und dass Menschen mit einer Körper-Integritäts-IdentitätsStörung in nicht unerheblichem Maße unter einem Zustand leiden, der von dem „subjektiven Gefühl einer leiblichen Nicht-Vollständigkeit angesichts eines gesunden physikalischen Körpers" geprägt ist, kann als unzweifelhaft gelten. ${ }^{27}$ Solange weder überzeugende Erklärungen der Ursachen, Prävalenz und Klassifizierung von BIID vorliegen noch effektive Therapiemöglichkeiten bekannt sind, darf aus ethischer Sicht angesichts des Leidens der Betroffenen, welches zweifelsfrei und real existiert, die Möglichkeit der elektiven Amputation nicht von vornherein ausgeschlossen werden. Andernfalls droht auch in diesen extremen Fällen die Gefahr, den leidenden Menschen zu bevormunden

24 Vgl. Elliot D. Sorene/Carlos Heras-Palou/Frank D. Burke, ,Self-Amputation of a Healthy Hand: A Case of Body Integrity Identity Disorder", in: Journal of Hand Surgery (British and European Volume) 31, 6 (2006), S. 593-595.

25 Vgl. Neil Levy, „Autonomy is (Largely) Irrelevant“, in: The American Journal of Bioethics 9 , 1 (2009), S. 50-51.

26 Vgl. exemplarisch die Bestimmung von Hippokrates: „Und zwar will ich zuerst definieren, was nach meiner Ansicht die ärztliche Kunst ist: die Kranken gänzlich von ihren Leiden befreien“. Hans Diller (Hg.), Hippokrates: Ausgewählte Schriften, Stuttgart, 1994, S. 229 sowie die einschlägige Formulierung der "Ziele der Medizin“ des großen internationalen Projektes des Hastings Centers Mitte der 90er Jahre: Daniel Callahan, „The Goals of Medicine: Setting New Priorities“, in: Hastings Center Report 26, 6 (1996), S. 1-21.

27 Hans-Peter Kapfhammer, „Fremdkörper im Leib“, in: Psychopraxis 15, 1 (2012), S. 15-17: 16. So heißt es etwa in der ersten bisher erschienenen Monografie zum Thema: „Der Leidensdruck der Betroffenen aufgrund der Nichtumsetzbarkeit des Wunsches ist immens." Stirn/Thiel/Oddo (2010), Body Integrity Identity Disorder (BIID), S. 2. 
und in paternalistische Muster zurückzufallen. ${ }^{28}$ Dass dies eine große Herausforderung für Grundfeste des ärztlichen Ethos bedeuten mag, liegt auf der Hand und darf ebenfalls nicht heruntergespielt werden. Doch darf die durch das Phänomen BIID ausgelöste Verunsicherung herkömmlicher medizinethischer Prinzipien und ärztlicher Standards andererseits freilich kein Grund sein, eine differenzierte und ergebnisoffene Prüfung und Beurteilung des Umgangs mit diesen wenigen Extremfällen von Körper-Integritäts-Identitäts-Störungen zu verweigern.

Vieles spricht dafür, dass das Grundprinzip des Nichtschadens unter bestimmten Voraussetzungen durchaus dem Ziel der Leidenslinderung untergeordnet bzw. eingeschränkt werden sollte. In Einzelfällen kann die höchstpersönliche psychophysische Integrität einen höheren Stellenwert einnehmen als die körperliche Unversehrtheit, und es wäre in verkürzender Weise unzutreffend $\mathrm{zu}$ behaupten, durch die Erfüllung des Amputationswunsches würden Menschen ihre Gesundheit gegen eine Behinderung eintauschen. Nimmt man die tragische Situation BIID-Betroffener ernst, muss doch konstatiert werden, dass diese vielmehr verlangen, das Leiden an ihrem unerfüllten Wunsch gegen das Leiden an der resultierenden körperlichen Beeinträchtigung eintauschen zu können. ${ }^{29}$ Allerdings stellt sich angesichts der großen Hoffnung auf den antizipierten Zustand mit Behinderung sowie vor allem angesichts der Glücksgefühle, die für die Betroffenen schon mit der nur imaginierten Realisierung verbunden sind (etwa im Rahmen des pretending, aber auch in psychotherapeutischen Gesprächen ${ }^{30}$ ), die Frage, ob der Wunschzustand nach der ersehnten Amputation individuell überhaupt als Behinderung gesehen und negativ empfunden wird. Dies ist aufgrund der spezifischen Umstände des hier vorliegenden Verlangens stark zu bezweifeln. So sprechen die typische langfristige Genese und kontinuierliche Prüfung sowie das große und tiefgehende identitätsbildende Gewicht des entsprechenden Wunsches viel eher dafür, dass der Zustand mit Behinderung als ganz und gar leidfrei erlebt werden kann. Demnach würde die Erfüllung eines derartigen Amputationswunsches nicht nur den Übergang bedeuten von einem äußerlich intakten Körper bei einem (von außen unsichtbaren) mentalen Leidenszustand hin zu einem äußerlich behinderten Körper ohne ein korrespondierendes mentales Leiden; eine elektiv herbeigeführte Schädigung könnte der betreffenden Person darüber hinaus auch noch den enormen Gewinn eines (wieder-)hergestellten Integritäts- und Ganzheitsgefühls verschaffen, welcher zudem eine beträchtliche positive Wirkung für die eigene Identitäts- und Selbstfindung entfalten kann. Vieles spricht dafür, dass die Durchführung der gewünschten Amputation der betroffenen Person, die vorher unter dem Zustand leiden musste, ,als Amputierter in einem

28 Vgl. Thomas Schramme, „Freiwillige Verstümmelung. Warum eigentlich nicht?“, in: Ach/ Pollmann (2006), no body is perfect, S. 165.

29 Vgl. Jozsef Kovacs, „Whose Identity Is it Anyway?“, in: The American Journal of Bioethics 9, 1 (2009), S. 44-45: 45.

30 „Vgl. Stirn/Thiel/Oddo (2010), Body Integrity Identity Disorder (BIID), S. 11. 
nicht behinderten Körper zu leben“"31, die Möglichkeit eröffnen kann, zu sich selbst zu finden und nicht mehr in einem als fremd empfundenen Körper gefangen sein zu müssen.

\section{Normativität der Medizin}

Die Erörterung eines sorgsamen und differenzierten Umgangs mit KörperIntegritäts-Identitäts-Störungen scheint, wenn man dies in einen größeren kulturhistorischen Rahmen stellt, auf nicht weniger hinzudeuten als auf eine fundamentale Verschiebung im ethischen Fundament der Medizin. Mit dem Aufkommen und Siegeszug von Aufklärung und neuzeitlicher Wissenschaft seit dem 17. und 18. Jahrhundert hielten auch im Feld der Medizin die mächtigen Kräfte der Rationalisierung und Objektivierung, der Entzauberung und Verwissenschaftlichung Einzug und führten im Zuge dieser Revolution des Welt- und Menschenbildes zu einer folgenreichen Entwicklung der ärztlichen Heilkunst. Die Rolle des Arztes, der sich bis dahin in erster Linie als kurativer Therapeut versuchte, wandelte sich grundlegend. Zu der Funktion des reinen Praktikers, der pragmatisch am Einzelfall herumlaborierte, gesellte sich die Tätigkeit des forschenden Wissenschaftlers, der ganz ohne Patientenkontakt systematisch im Labor und unter Einsatz experimenteller Methodik allgemeinen medizinischen Erkenntnissen und neuartigen Einsichten über den menschlichen Körper und Geist auf der Spur war. Die medizinischen Wissenschaften führten zu einem ungeahnten Wissenszuwachs über physiologische Wirkzusammenhänge, über Merkmale, Entstehungsbedingungen und Umwelteinflüsse von Erkrankungen und Heilungsvorgängen. So konnten auch für den Menschen speziestypische Parameter ermittelt und aufgestellt werden, deren Vorliegen und uneingeschränktes Funktionieren zur Definition von Gesundheit und gesundheitlicher Normalität wurden. ${ }^{32}$ Im Zuge dieser Entwicklung wuchs der Medizin eine gewaltige Definitions- und Normierungsmacht nicht nur über die körperlich-seelischen Zustände des Menschen zu, sondern auch über den adäquaten Umgang damit. ${ }^{33}$ Die sich so entfaltende normierende Kraft des medizinisch-wissenschaftlichen Modells konnte sich fortan durch das immer weiter reichende Durchdringen, Erklären und Klassifizieren, vor allem aber durch die enormen Fortschritte und Heilungserfolge als unmittelbare Effekte

31 Avi Craimer, ,The Relevance of Identity in Responding to BIID and the Misuse of Causal Explanation", in: The American Journal of Bioethics 9, 1 (2009), S. 53-55: 55.

32 Vgl. zu diesem historisch-normativen Komplex Georges Canguilhem, Das Normale und das Pathologische, Berlin, 2013 [frz. OA 1972].

33 Welche Bedeutung dies für das gesamte Feld ärztlichen Tuns hat, macht Petra Gelhaus klar: „Ohne Normalbereiche, Normwerte und Vorstellungen vom normalen Funktionieren wäre die moderne Medizin mit dem Ziel der Wiederherstellung der Gesundheit nicht denkbar." Petra Gelhaus, „Wie groß ist zu groß? Zur Funktionalität des Normalen“, in: Dominik Groß/Sabine Müller/Jan Steinmetzer (Hg.), Normal - anders - krank? Akzeptanz, Stigmatisierung und Pathologisierung im Kontext der Medizin, Berlin, 2008, S. 33-49: 34. 
der Verwissenschaftlichung und Rationalisierung des Lebendigen, immer weiter verbreiten und etablieren.

Mit dem Beginn des 21. Jahrhunderts scheint nun die Epoche der generalisierenden Rationalisierung und Verallgemeinerung der psychophysischen Normativität in dieser Dominanz an ihr Ende zu kommen. ${ }^{34}$ Es fragt sich, ob die wertbeladenen Vorstellungen von Normalität und Abweichung, die durch eine als objektivistische Naturwissenschaft des menschlichen Körpers und Geistes verstandene Medizin geprägt und die über das Begriffspaar gesund/ krank operationalisiert worden waren, noch länger ihren umfassenden Anspruch auf generelle Gültigkeit erheben können. Dies wird zum einen unabweisbar durch die wachsenden Anfragen nach einer Inanspruchnahme medizinischer Leistungen und Maßnahmen nach Belieben, zur indikationslosen Erfüllung individueller Wünsche (und durch deren ebenfalls zunehmenden Realisierungen); zum anderen machen Phänomene extremer medizinischer Wünsche wie die von BIID-Betroffenen deutlich, dass auch innerhalb des herkömmlichen Auftrags der Medizin der Leidenslinderung klar abgegrenzte Definitionen von gesund und krank sowie von normal und abweichend nicht mehr durchgängig praktikabel und akzeptabel sind. Dies soll nicht bedeuten, dass der Krankheitsbegriff und die Gesundheitsidee ihren Wert als regulative Ideale und Orientierungspunkte gänzlich verloren hätten und schon bald verschwinden würden; und die gänzliche Aufgabe des therapeutischen Paradigmas als orientierendes und normierendes Gerüst für die Medizin als moralische Praxis, als Profession mit besonderer Verantwortung und Integrität hätte auch bedenkliche Folgen zu gewärtigen. ${ }^{35}$ Doch werden wohl an die Seite der traditionellen Krankheitsorientierung neue Kriterien und Konzepte treten müssen, die der tatsächlichen Realität einer liberalen Gesellschaft und eines weltanschaulichen Pluralismus besser Rechnung zu tragen vermögen. Hier sind verschiedene medizinisch-ärztliche Kriterien und Leitwerte denkbar - und erst ein breiter Diskurs, der noch lange nicht abgeschlossen ist, wird hier die bestimmenden normativen Größen ergeben und von weniger relevanten und auch weniger konsensfähigen unterscheiden können. Unbedingt dazu gezählt werden müssen aber sicherlich Ziel- und Orientierungsgrößen wie Leidensfreiheit, Integrität, Authentizität, Lebensqualität und Wohlbefinden. Dass diese Werte dabei einen ebenso starken Normativitätsanspruch hinsichtlich der Anwendung medizinischen Wissens und Könnens entfalten können, wie es der Krankheitsbegriff lange Zeit getan hat, führen Fälle von BIID mitsamt den dadurch aufgeworfenen ethischen Fragestellungen zum richtigen Maß der Ver-

34 Gleichzeitig ist aktuell im Zeichen der Quantify Yourself-Bewegung zwar ein neuer Schub einer Rationalisierung von Körperlichkeit und psychophysischer Funktionalität zu verzeichnen, allerdings steht dieses Paradigma ganz im Zeichen individueller und personalisierter Vermessung und Kontrolle und damit etwas quer zu der Idee speziestypischer Durchschnittsund Mittelwerte.

35 Siehe Eichinger (2013), Jenseits der Therapie, S. 204 ff. 
fügung über den eigenen Körper und zu angemessenen Formen individueller Selbstgestaltung plastisch vor Augen. ${ }^{36}$

Dass diese Verschiebung der grundlegenden Werte und Orientierungsgrößen medizinischen Handelns, welches ja weiterhin limitierungs- und legitimierungsbedürftig ist, nun aber nicht ein völlig freigegebenes und beliebiges anything goes ohne sinnvolle Steuerungsmöglichkeit zur Folge haben muss, zeigen bei näherer Betrachtung bereits die genannten Kandidaten für zeitgemäße Kriterien selbst, die den herkömmlichen Stützpfeilern des therapeutischen Paradigmas in mancher Hinsicht überlegen scheinen. So sind Gesichtspunkte wie Leidensfreiheit, Integrität und Authentizität weit davon entfernt, dem schrankenlosen Belieben des einzelnen Individuums anheim zu stehen. Ärztliches Handeln würde deswegen nicht zur Sache kritikloser und willfähriger Erfüllung kontingenter und idiosynkratischer Wünsche zur freien Selbstgestaltung und Lebensführung je nach persönlichem Geschmack. Auch wenn die Einschätzung von individuellen Leidenszuständen letztlich nur von dem Betroffenen selbst vorgenommen werden kann und selbst wenn die dringende Notwendigkeit medizinischer Leistungen zur subjektiven Integritätsfindung oder Leidvermeidung sich freilich schnell reklamieren lässt, wird doch eine entsprechende, dabei bloß strategische' Behauptung geäußert in der Absicht, medizinische Maßnahmen in Anspruch nehmen zu können, einer ernsthaften Prüfung durch einen unabhängigen Fachmann nicht standhalten können. Eine vergleichbare Schwierigkeit tritt notorisch bei Enhancement-Begehrlichkeiten in Erscheinung, deren verbessernder Charakter häufig als selbsterklärend suggeriert wird, während bei genauer Betrachtung das Gegenteil der Fall ist: Was ,besser' im Einzelfall bedeuten soll, worin die ,Optimierung' eines Zustandes, einer Eigenschaft oder Fähigkeit eigentlich bestehen soll, ist „weder evident noch per se konsensfähig“".37

Die Urteilskraft des Mediziners ist damit weiterhin gefordert, wenn nicht sogar in höherem und komplexerem Maße als dies im objektivistischen Körper-Funktions-Paradigma der Wiederherstellung einer funktionalistisch verstandenen Gesundheit (resp. der Bekämpfung von Krankheit) der Fall ist. Um Kriterien wie Integrität, Authentizität und individuelles Wohlbefindens adäquat einzuschätzen, bedarf es dann auch Überlegungen und Beurteilungen, die weniger einen material-funktionalen Normalzustand als vielmehr eher vage und offene Konzepte wie das eines guten Lebens anvisieren. Hierfür verspre-

36 Hier ist auch das analoge Beispiel der schwierigen Einstufung von Anorexie zwischen pathologischer Zwangsstörung und tolerierbarem Ausdruck individueller Autonomie im Zeichen von Selbstoptimierung aufschlussreich. Vgl. Gala Rebane, „Anorexia nervosa: psychische Störung oder Selbstoptimierung?"“, in: Anna Sieben/Katja Sabisch-Fechtelpeter/Jürgen Straub (Hg.), Menschen machen. Die hellen und die dunklen Seiten humanwissenschaftlicher Optimierungsprogramme, Bielefeld, 2012, S. 211-233.

37 Peter Wehling, „Biopolitik in Zeiten des Enhancements. Von der Normalisierung zur Optimierung", in: Sascha Dickel/Martina Franzen/Christoph Kehl (Hg.), Herausforderung Biomedizin. Gesellschaftliche Deutung und soziale Praxis, Bielefeld, 2011, S. 233-250: 241. 
chen narrativ-hermeneutische Zugänge eine fruchtbare Methode zu sein, um die individuelle Vorgeschichte, die Einbettung und Verarbeitung von Störungen, Auffälligkeiten und Einschnitten innerhalb der psychophysischen Biografie der betreffenden Person angemessen und differenziert erfassen zu können. So scheint ein narrativer Ansatz besonders aussichtsreich zu sein, wenn es darum geht, für einen gelingenden Lösungsweg die Bedeutung eines ungewöhnlichen Wunsches nach Körperveränderung (wie eines Amputationswunsches) zu erschließen. ${ }^{38}$ Damit geraten Dimensionen wie Lebensqualität, Glück, Identität, Authentizität und andere Parameter in den Blick, die ursprünglich nicht unbedingt und explizit zur fachlichen Domäne der ärztlichen Profession gehören. Vielmehr ist hiermit dem Urteilsvermögen und der Entscheidungsmacht des je einzeln Betroffenen die bestimmende Kompetenz und Funktion zuerkannt. Denn letztlich kann nur derjenige Mensch selbst, der leidet, der in seiner Integrität grundlegend gestört ist, der in seiner authentischen Selbstfindung empfindlich beeinträchtig ist, dies beurteilen. Medizinhistorisch stellt dies sicherlich keine nebensächliche Entwicklung dar. So führt für manchen Beobachter die „Forderung nach Autonomie des einzelnen in der Frage der Beurteilung und Pflege seiner Gesundheit“ gar zu einem „Wiedererstarken prä-rationaler Medizin“"39 - ob man mit Georges Canguilhem darin nun eine Wiedererweckung vorwissenschaftlicher Grundzüge ärztlichen Tuns erkennen mag oder nicht, die prinzipielle Deutungshoheit des Hilfsbedürftigen über seinen Zustand und (so weit möglich) auch über die Wege zur Abhilfe scheint ethisch kaum bestreitbar zu sein. Letztlich liegt darin der entscheidende Grund, weshalb es so wichtig ist, gegenüber leidenden Menschen bevormundendes und paternalistisches Verhalten im Zeichen überkommener Konzepte von Natürlichkeit und Normalität zu vermeiden - auch wenn es in extremen Fällen kontraintuitiv sein und gerade Ärzten schwerfallen mag: „Die Bedeutung der Freiheit, unsere eigene Vorstellung eines guten Lebens zu entwickeln und umzusetzen, verlangt, dass Ärzte auch unvernünftige Entscheidungen respektieren und, so es die Ressourcen erlauben, die Originalität und Diversität des menschlichen Daseins unterstützen." ${ }^{\text {"40 }}$

38 Vgl. Jenny Slatman/Guy Widdershoven, „Being Whole after Amputation“, in: American Journal of Bioethics 9, 1 (2009), S. 48-49.

39 Georges Canguilhem, „Macht und Grenzen der Rationalität in der Medizin“, in: ders. (Hg.), Grenzen medizinischer Rationalität: historisch-epistemologische Untersuchungen, Tübingen, 1989, S. 41-68: 56.

40 Julian Savulescu, „Autonomy, the Good Life, and Controversial Choices“, in: Rosamond Rhodes/Leslie P. Francis/Anita Silvers (Hg.), The Blackwell Guide to Medical Ethics, Malden, MA, 2007, S. 17-37: 35 . 


\section{Literatur}

Bayertz, Kurt/Schmidt, Kurt W., ,„Es ist ziemlich teuer, authentisch zu sein...!' Von der ästhetischen Umgestaltung des menschlichen Körpers und der Integrität der menschlichen Natur", in: Johann S. Ach/Arnd Pollmann (Hg.), no body is perfect. Baumaßnahmen am menschlichen Körper - Bioethische und ästhetische Aufrisse, Bielefeld, 2006, S. 43-62.

Birnbacher, Dieter, „Die ethische Ambivalenz des Enhancement“, in: Michael Quante/ Erzsébet Rózsa (Hg.), Anthropologie und Technik. Ein deutsch-ungarischer Dialog, München, 2012, S. 111-125.

Borkenhagen, Ada, „Gemachte Körper: Die Inszenierung des modernen Selbst mit dem Skalpell. Aspekte zur Schönheitschirurgie“, in: Psychologie und Gesellschaftskritik 25, 1 (2001), S. 55-67.

Brugger, Peter, „Der Wunsch nach Amputation. Bizarre Macke oder neurologische Störung?", in: Ars Medici, 2 (2011), S. 59-63.

Callahan, Daniel, „,The Goals of Medicine: Setting New Priorities“, in: Hastings Center Report 26, 6 (1996), S. 1-21.

Canguilhem, Georges, „Macht und Grenzen der Rationalität in der Medizin“, in: ders. (Hg.), Grenzen medizinischer Rationalität: historisch-epistemologische Untersuchungen, Tübingen, 1989, S. 41-68.

Ders., Das Normale und das Pathologische, Berlin, 2013 [frz. OA 1972].

Conrad, Peter/Schneider, Joseph W., Deviance and Medicalization. From Badness to Sickness, Philadelphia, PA, 1992.

Craimer, Avi, „The Relevance of Identity in Responding to BIID and the Misuse of Causal Explanation", in: The American Journal of Bioethics 9, 1 (2009), S. 53-55.

Diller, Hans (Hg.), Hippokrates: Ausgewählte Schriften, Stuttgart, 1994.

Dotinga, Randy,,Out on a Limb“, auf: salon, online unter: http:/www.salon.com/2000/ 08/29/amputation, zuletzt aufgerufen am 03.01.2019.

Eichinger, Tobias, Jenseits der Therapie. Philosophie und Ethik wunscherfüllender Medizin, Bielefeld, 2013.

Gelhaus, Petra, „Wie groß ist zu groß? Zur Funktionalität des Normalen“, in: Dominik Groß/Sabine Müller/Jan Steinmetzer (Hg.), Normal - anders - krank? Akzeptanz, Stigmatisierung und Pathologisierung im Kontext der Medizin, Berlin, 2008, S. 3349.

Holzer, David/Stompe, Thomas, „Körpermodifikation - (sub-)kulturelle und psychopathologische Aspekte“, in: Spectrum Psychiatrie, 2 (2014), S. 34-39.

Joost, Nine, ,Schönheitsoperationen - die Einwilligung in medizinisch nicht indizierte ,wunscherfüllende" Eingriffe", in: Claus Roxin/Ulrich Schroth (Hg.), Handbuch des Medizinstrafrechts, Stuttgart, 2010, S. 383-443.

Kapfhammer, Hans-Peter, „Fremdkörper im Leib“, in: Psychopraxis 15, 1 (2012), S. 15-17.

Kasten, Erich, „Body Integrity Identity Disorder - Körperidentität durch erwünschte Behinderung", in: Lege artis 3, 1 (2013), S. 165-177.

Kettner, Matthias, „Enhancement als wunscherfüllende Medizin“, in: Ada Borkenhagen/Elmar Brähler (Hg.), Die Selbstverbesserung des Menschen. Wunschmedizin und Enhancement aus medizinpsychologischer Perspektive, Gießen, 2012, S. 13-31.

Kovacs, Jozsef, „Whose Identity Is it Anyway?“, in: The American Journal of Bioethics 9, 1 (2009), S. 44-45. 
Levy, Neil, „Autonomy is (Largely) Irrelevant“, in: The American Journal of Bioethics 9, 1 (2009), S. 50-51.

Müller, Sabine, „Body Integrity Identity Disorder (BIID) - Lassen sich Amputationen gesunder Gliedmaßen ethisch rechtfertigen?", in: Ethik in der Medizin 20, 4 (2008), S. 287-299.

Neitzke, Gerald, „Unterscheidung zwischen medizinischer und ärztlicher Indikation. Eine ethische Analyse der Indikationsstellung“, in: Ralph Charbonnier/Klaus Dörner/Steffen Simon (Hg.), Medizinische Indikation und Patientenwille. Behandlungsentscheidungen in der Intensivmedizin und am Lebensende, Stuttgart, 2008, S. 53-66.

Pollmann, Arnd, „Ein Recht auf Unversehrtheit? Skizze einer Phänomenologie moralischer Integritätsverletzungen“, in: Sibylle an der Walt/Christoph Menke (Hg.), Die Unversehrtheit des Körpers: Geschichte und Theorie eines elementaren Menschenrechts, Frankfurt/M., 2007, S. 214-236.

Rebane, Gala, „Anorexia nervosa: psychische Störung oder Selbstoptimierung?“, in: Anna Sieben/Katja Sabisch-Fechtelpeter/Jürgen Straub (Hg.), Menschen machen. Die hellen und die dunklen Seiten humanwissenschaftlicher Optimierungsprogramme, Bielefeld, 2012, S. 211-233.

Savulescu, Julian, „Autonomy, the Good Life, and Controversial Choices“, in: Rosamond Rhodes/Leslie P. Francis/Anita Silvers (Hg.), The Blackwell Guide to Medical Ethics, Malden, MA, 2007, S. 17-37.

Schramme, Thomas, „Freiwillige Verstümmelung. Warum eigentlich nicht?“, in: Johann S. Ach/Arnd Pollmann (Hg.), no body is perfect. Baumaßnahmen am menschlichen Körper - Bioethische und ästhetische Aufrisse, Bielefeld, 2006, S. 163-184.

Slatman, Jenny/Widdershoven, Guy, „Being Whole after Amputation“, in: American Journal of Bioethics 9, 1 (2009), S. 48-49.

Sorene, Elliot D. et al., „Self-Amputation of a Healthy Hand: A Case of Body Integrity Identity Disorder", in: Journal of Hand Surgery (British and European Volume) 31, 6 (2006), S. 593-595.

Stemmer, Peter, „Was es heißt, ein gutes Leben zu leben“, in: Holmer Steinfath (Hg.), Was ist ein gutes Leben? Philosophische Reflexionen, Frankfurt/M., 1998, S. 47-72.

Stirn, Aglaja/Thiel, Aylin/Oddo, Silvia, Body Integrity Identity Disorder (BIID). Störungsbild, Diagnostik, Therapieansätze, Weinheim, 2010.

Wehling, Peter, „Biopolitik in Zeiten des Enhancements. Von der Normalisierung zur Optimierung", in: Sascha Dickel/Martina Franzen/Christoph Kehl (Hg.), Herausforderung Biomedizin. Gesellschaftliche Deutung und soziale Praxis, Bielefeld, 2011, S. 233-250.

Wiesing, Urban, „Die ästhetische Chirurgie: Eine Skizze der ethischen Probleme“, in: Zeitschrift für medizinische Ethik 52, 2 (2006), S. 139-154. 


\title{
Körper Bei der Arbeit. Geste, Norm und TeChnik
}

\begin{abstract}
Wenn wir von Körpern bei der Arbeit sprechen, meinen wir nicht so sehr Körper, die arbeiten, oder die Arbeit von Körpern, sondern eher, wie Körper bearbeitet werden, wie sie mit Arbeit Körper werden. Es wäre interessant, die verschiedenen Körpertypen - Körper von Tieren, Pflanzen, Bakterien, physische Körper, künstliche Körper (aber sind das überhaupt noch Körper?) - miteinander zu vergleichen und zu sehen, was die Körper können, die unseren, aber auch jene, die wir erschaffen, die wir herstellen, oder die wir in den kommenden Jahren herstellen werden. Die Frage wäre dann aber, was den Körper macht. Uns interessiert hier, was den menschlichen Körper mit seinen Grenzen, seinen Fähigkeiten, seinen Werkzeugen und seinen Transformationen macht. Den ,offenen', technisch gegliederten Körper, den wir auch als ,Technokörper bezeichnen könnten. Ausgangspunkt ist der nackte Körper, der normale Körper ,in Form', der Körper und nichts anderes. Wir wissen aber auch, dass der menschliche Körper nicht zu denken ist ohne seine Werkzeuge und Prothesen. Von daher diese erste Frage: Was ist ein normaler Körper?
\end{abstract}

\section{Der normale Körper}

Ich erinnere mich an eine Diskussion mit einem Tscherkessen, einem ungefähr 20 Jahre alten Akrobaten, der sich wie ein Blatt Papier verbiegen konnte und einen Mast hochkletterte, als wäre es eine Treppe. Als ich ihm meine Bewunderung für seine mühsam erworbene Geschmeidigkeit und Beweglichkeit ausdrücken wollte, erklärte er mir, dass er für seine Leidenschaft einen hohen Preis zu zahlen hätte, dass er bereits völlig zerschlagen und gebrochen sei. Jeden Tag musste er seinen Körper über seine Grenzen hinaus belasten, wodurch er bereits jetzt an unzähligen Muskel-Knochen-Leiden litt. Er wusste, dass ihm seine Gelenke für den Rest seines Lebens Schmerzen bereiten würden. Das gleiche galt und gilt für seine Kollegen oder für die Athleten, die so hart trainieren, dass ihre Körper buchstäblich deformiert werden. De-formiert, das heißt, dass er seine Form verloren hat. Was aber genau ist die Form eines Körpers? Im Französischen wie im Deutschen sagt man, wenn man sich wohl fühlt, ,ich bin in Form'; aber in Form wovon? Was ist die Form eines Körpers ,in Form"?

In Die Existenzweise technischer Objekte erwähnt Gilbert Simondon die „déformations professionnelles“ der Handwerker der vorindustriellen Zeit. Er entwickelt seine Theorie anhand des Gegensatzes zwischen dem universellen, 
rationalen Wissen des Ingenieurs und dem ,Experten'-Wissen des Hirten oder des Bergmanns; letztere „haben Teil an der lebendigen Natur der Sache, die sie kennen, und ihr Wissen ist ein Wissen der tiefgehenden, direkten Teilhabe, die eine ursprüngliche Symbiose erfordert und eine Art Fraternität mit einem geschätzten und geeigneten Aspekt der Welt umfasst." "Das gleiche gilt für den Handwerker, der „durch seinen Körper die innere Aufteilung und die Selbstregulierung der Aufgabe sicherstellt" und der sein Wissen - im Gegensatz zu den Tafeln der Enzyklopädie oder den Handbüchern der Ingenieure vermittels seiner Erfahrung, seiner Tätigkeit und der Sprache weitergibt. Für Simondon ist eine technische Geste eine notwendigerweise beherrschte Geste; sie stellt „die Würde der Handwerksarbeit“ dar. ${ }^{2}$ Der Körper des Handwerkers bildet sich im Umgang mit dem Werkstoff durch einen langen Lernprozess heraus, er „individualisiert sich technisch“ und macht dadurch die technische Operation möglich.

Die Relation Mensch-Maschine wird verwirklicht, wenn der Mensch durch die Maschine auf die natürliche Welt einwirkt, [...] diese Relation ist also teilweise mit der der Werkzeug-Maschine vergleichbar, wenn man unter WerkzeugMaschine die Maschine versteht, die keine Selbstregulation umfasst. Es ist noch der Mensch, der in dieser Relation im Mittelpunkt des assoziierten Milieus steht: Die Werkzeug-Maschine ist die Maschine, die keine autonome innere Regulierung hat, und die eines Menschen bedarf, damit sie funktioniert. Der Mensch greift hier als lebendiges Wesen ein; er gebraucht, ohne dass dies bewusst formuliert würde, seinen eigenen Sinn für die Selbstregulierung, um jene der Maschine auszulösen. ${ }^{3}$

Wenn man aus seinem eigenen Körper ein mit technischen Objekten (Werkzeugen und/oder Maschinen) assoziiertes technisches Mittel macht, prägt man in die tiefste Tiefe des eigenen Selbst eine Technizität ein, die zu einer Identität wird. Das Ohr des Musikers, das Auge des Fotografen, der Gaumen des Kochs macht sie zu „Experten“ auf ihrem Gebiet. Wie aber verhält es sich mit den Körpern von Tänzern, Athleten, oder gar von Handwerkern, von Arbeitern, die durch die Lernprozesse geformt, aber auch verformt, verkrümmt, geschädigt wurden? Man spricht in diesem Fall von „déformations professionelles", von beruflichen Deformationen; Deformationen aber in Bezug worauf? Auf einen Neutralitätszustand, eine ,Natürlichkeit‘ des Körpers? Jeder Körper deformiert sich auf natürliche Weise mit dem Alter, wenn man davon ausgeht, dass die Form eines Körpers, seine ,perfekte' Form dem vollen Umfang seiner Fähigkeiten entspricht, oder sagen wir, um es einfach zu machen, wenn man jung und bei guter Gesundheit ist. Demzufolge wäre jede Deformation eine auf das Älterwerden zurückzuführende Degradierung. Ist es also eine De-formation in Bezug auf eine Form, die man einmal erhalten hat? Ein al-

Gilbert Simondon, Du mode d'existence des objets techniques, Paris, 1989 [1958], S. 89 (dt.: Die Existenzweise technischer Objekte, Zürich, 2012, S. 82 f.).

Ebd., S. 77 (dt.: S. 71).

Ebd., S. 79 (dt.: S. 72 f.). 
ternder Körper ist kein deformierter Körper, sondern ein Körper, der der Verfallslogik eines jeglichen Lebewesen folgt. Ein deformierter Körper verliert dagegen einen Teil seiner Einheit aus Form und Funktion, denn er hat, in einem gewissen Maß, eine Gewalterfahrung gemacht. Die Gewalt eines Unfalls oder die Gewalt einer, widernatürlichen' Konditionierung.

\section{Wo hört die Ausbildung auf und wo fängt die Gewalt an?}

Kann das Erlernen einer Technik als eine auf den menschlichen Körper ausgeübte Form von Gewalt angesehen werden? Wenn man bedenkt, dass der Körper im wesentlichen undeterminiert ist, bis er beginnt, Werkzeuge abzusondern, ohne die er sich seiner Umgebung nicht anpassen könnte, dann wird der Körper erst durch diese künstlichen Prothesen menschlich, die er herzustellen und zu gebrauchen lernt, indem er seine Gesten an die Materie anpasst. Ein Körper ist menschlich, wenn er in der Lage ist, sich zu beherrschen, wenn er mit der Welt, die er trans-formiert, kon-form geht. Seine Eigentümlichkeit besteht darin, die Grenzen, die ihm durch die Natur gegeben sind, zu überschreiten.

Indem er seine biologische Individualität der technischen Organisation eines Berufs widmet, wird der Mensch „Werkzeugträger“, und diese Funktion geht mit einer Deformation seines Körpers und seines Geistes einher, eine „Ursache der Entfremdung“ nach Simondon, der daran erinnert, wie sehr die Handwerker und Bauern an Berufskrankheiten und starken Deformierungen litten, wie z. B. die Lungenkrankheiten der Bergarbeiter, die Bleivergiftung der Glasmaler, die Arthrose der Bauern usw. Er fügt sogar hinzu: „In den Abscheu, den der Honnête homme gegenüber den Handwerksleuten empfindet, geht vielleicht auch ein Teil des Unbehagens ein, das man verspürt, wenn man eine Monstrosität erblickt." ${ }^{4}$ Die Bemerkung, so wie sie formuliert ist, ist zwiespältig. Es gäbe somit einen „Honnête homme“, einen „Mann von Welt, angenehm und kultiviert aufgrund seiner Umgangsformen wie auch aufgrund seiner Geisteskultur und seiner Kenntnisse" (nach der Definition des Petit Robert), der in einem Gegensatz zu denen steht, die einen Beruf ausüben. Ein Mensch, dessen Körper keinerlei berufliche Deformation erfahren hat, da er sich nicht in die praktischen Künste verirrt hat, sondern sich damit beschäftigt $\mathrm{zu}$,erkennen'. Ein Liberaler also. Ist seine Bemerkung die Wiederaufnahme einer aus der Vergangenheit übernommenen Unterscheidung zwischen den Honnêtes hommes, die die freien Künste anstelle der praktischen Künste praktizieren oder handelt es sich um das Zeichen einer kaum verhüllten Verachtung gegenüber den „Handwerksleuten'?5 Abgesehen davon, ist das ,Unbehagen“

4 Ebd., S. 104 (dt.: S. 95).

5 In Die Hoffnung der Pandora erwähnt Bruno Latour die sprachliche Vieldeutigkeit des Adjektivs „technisch“, wenn es insbesondere auf einen Beruf angewendet wird und dabei sowohl 
tatsächlich mit einer Monstrosität konfrontiert? Man kann sich fragen, ob die Handwerker früher wirklich so unförmig wurden, dass man ,Abscheu' vor ihnen hätte empfinden müssen. Die Einstellung des Autors in Bezug auf die Handarbeit bleibt doppeldeutig, denn er hebt an anderer Stelle hervor, dass trotz der schwierigen Lebensbedingungen und der schlimmen Ausbeutung der Handwerksleute durch die extrem hierarchisierten sozialen und politischen Systeme die Arbeiter einen unveräußerlichen Stolz auf ihre Fertigkeiten bewahrten. Einen Beruf zu haben bedeutete, Teil eines Wertesystems zu sein, wo jeder eine Rolle und einen Platz hatte und wo der Handwerker eine wesentliche Funktion in der Gesellschaft ausfüllte.

Vom Standpunkt des Paläontologen aus stellt André Leroi-Gourhan fest, dass sich bis zur Maschinisierung und der industriellen Programmierung der Produktionsmittel die operativen Verhaltensweisen der Menschen allmählich erweitert haben, ohne ihr Wesen zu verändern:

Vom Pithekanthropus bis zum Schreiner des 19. Jahrhunderts erfuhr die Gestalt
der Operationsketten keine Veränderung. Der Arbeiter hat seinen Werkstoff vor
sich, er nutzt die besonderen Mängel und Eigenschaften, die er ihm bietet, kom-
biniert den Ablauf der möglichen Tätigkeitsketten aufgrund eines traditionellen
Wissens, er gestaltet den Fertigungsprozeß, korrigiert und gelangt schließlich zu
dem Produkt, dessen Urheber er ist, in einer ausgeglichen Verausgabung musku-
lärer und gedanklicher Bewegungen. ${ }^{6}$

Diese effektive Synthese der Operationsketten lässt sich nicht nur auf alle Techniker aller Techniken anwenden, sie gilt auch für alle nur denkbaren Mittel bis hin zur industriellen Revolution, die die Menschen nach und nach ihrer Technizität beraubte, die sie bis dahin unter Beweis gestellt hatten und die ihren technologischen Aufstieg garantierte. Mit oder ohne Maschinen war die manuelle Tätigkeit so abwechslungsreich, dass die Verbindung mit den $\mathrm{Ge}-$ hirnbereichen, mit denen diese Tätigkeit eng verbunden ist, sichergestellt war. Nachdem aber die Mehrzahl unserer technischen Gesten an Maschinen übertragen wurde, können wir uns legitimer Weise fragen, was nicht nur aus unseren Händen, sondern aus der Gesamtheit unseres 40.000 Jahre alten physiologischen Apparats werden wird, dem Erbe jenes ,überständigen Säugetiers', das wir geworden sind.

eine Fähigkeit als auch eine Begabung bezeichnet, zudem aber auch eine untergeordnete Funktion: „Techniker, technische Objekte oder Fertigkeiten sind gleichzeitig untergeordnet (weil die Hauptaufgabe im Anschluss wieder aufgenommen wird), unentbehrlich (weil ohne sie das Ziel nicht zu erreichen ist) und in gewissem Sinn auch unberechenbar, geheimnisvoll, unsicher (weil sie von einem höchst spezialisierten und nicht klar umschriebenen Talent abhängig sind)." L'espoir de Pandore. Pour une version réaliste de l'activité scientifique, Paris, 2007, S. 202 (dt.: Die Hoffnung der Pandora. Untersuchungen zur Wirklichkeit der Wissenschaft, Frankfurt/M., 2002, S. 234).

6 André Leroi-Gourhan, Le geste et la parole II: La mémoire et les rythmes, Paris, 1965, S. 60 (dt.: Hand und Wort, Frankfurt/M., 1980, S. 318). 
Befreit von seinen Werkzeugen, seinen Gesten und Muskeln, von der Programmierung seiner Handlungen und seines Gedächtnisses, befreit von der Einbildungskraft, an deren Stelle die Perfektion des Fernsehens getreten ist, befreit auch von der Tier- und Pflanzenwelt, vom Wind, von der Kälte, den Mikroben und dem Unbekannten der Gebirge und Meere, steht der homo sapiens der Zoologie wahrscheinlich am Ende seiner Laufbahn. ${ }^{7}$

Bis zum 19. Jahrhundert folgte der technische Evolutionsprozess einem Rhythmus, der mit dem der Entwicklung unserer Bedürfnisse noch eng verbunden war. Dadurch konnte ein für das Funktionieren unseres neuromotorischen Systems unverzichtbares Gleichgewicht zwischen unseren physischen und geistigen Aktivitäten aufrechterhalten werden. In dem Rhythmus jedoch, in dem sich inzwischen die Wissenschaften und Techniken entwickeln, entgeht uns ein ganzer Teil der Evolution: die Evolution unserer Gattung.

Einerseits haben wir somit ein menschliches Werden, das über Tätigkeiten verläuft, die immer weiter perfektioniert werden und uns ermöglichen, die Welt zu transformieren und Werkzeuge, Prothesen und Objekte herzustellen. Andererseits gibt es einen Körperapparat, der tendenziell neutral, glatt und unbestimmt bleibt und eine Menschheit, die sich in der Entwicklung ihrer ,Umgangsformen“ und ihrer ,Kenntnisse“ sucht. Darin liegt das ganze Paradox des technischen Aufstiegs: Zunächst haben wir ein ungeheures Ausmaß an Geschicklichkeit, Erfindungsgeist und Kraft entfaltet, um uns von den Naturgesetzen zu befreien, um die Welt zu transformieren und sie unseren Bedürfnissen zu unterwerfen, und dies dank der Gesten der Handwerker, die - zusammen mit den Wissenschaften und der Entwicklung der Kenntnisse - die ersten Säulen dieses Tempels erbaut haben. Dann aber waren wir damit so erfolgreich, dass wir fast wieder bei unserer ersten physischen Unbestimmtheit angekommen sind. Wir sind gegenwärtig umgeben von Objekten, die von mechanisierten Technik-Ensembles realisiert werden, deren Funktionsweise uns so fremd ist wie noch nie.

Von daher die Notwendigkeit, nach Bruno Latour, die wechselseitigen Beziehungen zwischen den ,Menschlichen“ und den ,Nichtmenschlichen “ zu vertiefen, zwischen den verschiedenen Agenten der technischen Vermittlung. Latour zeigt in der Tat, dass die Artefakte ebenso von uns hergestellt sind, wie wir von ihnen, und dass ,wir lernen müssen, Handlungen sehr viel mehr Agenten zuzuschreiben - und auf sie zu verteilen -, als es in materialistischen oder soziologischen Erklärungen vorgesehen ist."

Nur weil er Hersteller und Werkzeugträger ist, hat sich der Mensch unabhängig machen können von seinen natürlichen Lebensbedingungen. Ohne diese Anpassungsleistung wäre ihm seine Schwäche, ein wenig spezialisiertes

7 Ebd., S. 266 (dt.: S. 496 f.). Vielleicht sollte man diese alarmistische Feststellung etwas nuancieren: Es ist nicht sicher, dass uns das Fernsehen ausnahmslos von unserer Einbildungskraft „,befreit" hat. Das Kino und die auf Video- und Digitaltechnik basierenden Künste bieten imaginäre Explorationen der Verbindung zwischen dem Auditiven und dem Visuellen.

8 Latour (2007), L'espoir de Pandore, S. 189 (dt.: (2002), Die Hoffnung der Pandora, S. 219). 
Tier zu sein, wohl kaum verziehen worden. Er ist Werkzeugträger und technisches Individuum von Natur aus, eine Frucht seiner besonderen Evolution. Alles in allem ist auch die Fähigkeit, die Materie mit dem Körper und den Werkzeugen zu transformieren, zu bearbeiten, Teil seiner Lebensbedingungen. Der Mensch produziert, also arbeitet er. Seine Arbeit ist das Ergebnis des technischen Wissens, erworben durch eine körperliche, den Eigenschaften der Materie gehorchenden Dressur. ,Travailler' heißt ursprünglich quälen, Leid zufügen, das heißt den Körper einer Behandlung zu unterwerfen, die ihn zugrunde richtet (von Lateinisch trepalium: Folterinstrument). Von daher rühren die beruflichen Deformationen, von denen Simondon etwas weiter spricht, von daher rühren aber auch die besonderen Eigenschaften eines jeden Technikers: das Gehör, der Tastsinn, die Kraft, die Präzision. Jedes Lernen und jede Praxis erzeugt unterschiedliche rezeptive Verhaltensweisen, besondere Sensibilitäten. In einem gewissen Ausmaß erwirbt der Körper sinnliche oder technische Eigenschaften, die ihm fehlten.

\section{Ist jede Geste zunächst eine technische Geste?}

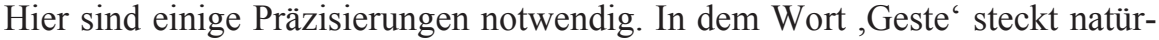
lich die Vorstellung einer körperlichen Bewegung, vor allem der Arme und der Hände, es liegt darin aber auch dier Idee eines ,In-sich-Tragens' (gestatio), also der Vorstellung von etwas, das sich vorbereitet und Zeit braucht. Genau dies spielt sich in der Geste ab, eine gewisse Beziehung zum Körper und zur Zeit. Es ist ein Geschehen, das auf den technisch zugerichteten Körper einwirkt, dabei aber - Durchgangs- und Deutungsort der Welt - für die Empfindung, für die der Formierung vorangehende In-formierung offen bleibt. Die Authentizität und der Daseinsgrund der Geste liegen in diesem Zwischenraum, der von den Begriffen der Technik, der Kunst und der Arbeit gebildet wird. Und diese besondere Beziehung zwischen dem Projekt und der Ausführung läuft notwendigerweise über den Körper bei der Arbeit. Man begegnet hier wieder der Metapher des Austragens, der doppelten Dimension von Ausführung und Ausgesetztheit.

In Corpus spricht Jean-Luc Nancy von einer Welt, in der die - offenen, stets offenen - Körper technisch vernetzt und gegliedert sind: Er nennt das „Ökotechnie“. Für ihn wäre eine Welt ohne Technik - oder eine vortechnische Welt - dies:

Ausgangspunkt könnte sein: eine abgekapselte, verschlossene Welt, eine volle, total immanente Welt, eine Welt oder ein Ding, das spielt keine Rolle, die so sehr an sich, so sehr in sich wäre, dass sie sich nicht einmal berührte und die 
man auch nicht berühren könnte, eine Welt, die allein wäre, an sich und in sich, eine solche Welt wäre kein Körper. ${ }^{9}$

Die Welt vor der Technik ließe sich als ein geschlossener Kreislauf vorstellen, als eine ungeschiedene Masse, als Grund der Welt, als ein Ding an sich, gebunden an sein biologisches Funktionieren, etwas, das sich nach den immer gleichen und unveränderlichen natürlichen Gesetzen produziert und reproduziert. Nancy stellt dieser Welt die Idee eines Körpers entgegen, der ,das Offene' ist, ,die Erweiterung', die Ausgesetztheit' in der Welt. Die Welt wird Körper durch das, was ihn sich selbst gegenüber exteriorisiert. „Wenn der Körper nicht Masse ist, wenn er nicht verschlossen und von sich durchdrungen ist, ist er außerhalb von sich. Er ist das Außerhalb-von-sich-Sein." ${ }^{10}$ Er ist der Ort des Ereignisses, er ist das In-der-Welt-Sein, berührend und berührt, empfindend und denkend in ein und demselben Raum, der die Grenze der Existenz ist. Es ist klar ersichtlich, dass es diese Vorsilbe, dieses ,ex ' ist, das uns in Bezug auf den Rest des Lebendigen situiert. Angefangen bei unseren ersten Tätigkeiten, durch die die Materie entdeckt, transformiert und ihrem FormWerden ausgesetzt wurde, bis zu den hochentwickelten technischen Objekten von heute entwickeln wir uns in dieser Von-Innen-nach-Außen-Beziehung, und zwar in einem Modus, der derjenige der Existenz ist. Das heißt wir entwickeln uns im Rahmen einer Existenzweise, im Gegensatz, oder eher in Erweiterung zu einem Modus des Lebens, zu einer Lebensweise.

Nach Nancy setzt sich der Körper - des Menschen, der Welt - der Existenz als ,téchne der Körper' aus, einem System zur Hervorbringung von Körpern, die durch die Technik an die Welt angeschlossen sind. Kann man insofern sagen, dass die Technik den Körper ,macht', dass sie mit dem Menschlichen eine Einheit bildet? Muss man die mechanistische Metapher eines Körpers bemühen, der wie eine Maschine funktioniert, und gegebenenfalls ihre Teile und Mechanismen als technische Objekte untersuchen, oder muss umgekehrt der Körper als ein von der Natur determiniertes Element begriffen werden, das den Menschen in seine Bedingtheit als Lebewesen einschreibt? Ist der menschliche Körper ein Sonderfall, den man entsprechend einer ihm eigenen Organologie denken muss? Welche Beziehung unterhält er mit der Technik, die er produziert? Wo situiert sich die Geste als Bindeglied zwischen dem Körper und der Technik, die er außerhalb, aber auch ausgehend von sich, und dadurch durch sich, absondert?

Nach Nancy ist die Technik das, was den Körper, das Begehren, die Sprache und das Tun miteinander verfugt; Technik ist das, was zu Ausgesetztheit und Verwandlung führt. Man könnte somit die Technik als Mittel des pouvoir

\footnotetext{
9 Jean-Luc Nancy, Corpus, Paris, 2000, S. 108, (dt.: Corpus, Berlin, 2003, S. 106). Es handelt sich dabei um einen Vortrag, der am 8. April 1994 im Rahmen eines Kolloquiums mit dem Titel „Le poids du corps“ gehalten und anschließend verschriftlicht wurde.

10 Ebd., S. 113 (dt.: S. 110).
} 
ins Auge fassen, im Doppelsinn von Handlung und Herrschaft, aber auch als Potenzial: Was kann sie?

\section{Die Technik als Vermögen}

Wie Gaston Bachelard in L'eau et les rêves kann man sich vorstellen, dass der Klumpen Ton in den Händen bereits das künftige Gefäß enthält, dass er durch seine plastischen und metamorphischen Eigenschaften seine künftige, zu ent-deckende Form hervorruft. Es ist die Technizität der Menschen, die jene der Elemente weckt und offenbart: „Und wenn wir in der Erde wühlen könnten? Und wenn die Erde [...] enthalten könnte?" "11 Es ist bereits der Beginn einer Idee, die sich im Verlauf der Formgebung herausbildet. Es gibt, wie in einem Spiegel, eine Reflexion, ein Hin und Her zwischen der Materie und der Einbildungskraft, insbesondere durch den Tastsinn. Daher ist die Reflexivität der Materie nicht nur eine visuelle, sie ist auch eine körperliche, sie ist in die Gesten desjenigen eingeprägt, der mit ihr hantiert. Es handelt sich nicht um eine ,Intelligenz der Hand', wie man so sagt, eher um eine Rezeptivität, eine Verfügbarkeit. „Auch die Hand hat ihre Träume und ihre Hypothesen. Sie hilft, die Materie in ihrem Innersten zu erkennen. Sie hilft also zu träumen." 12 Eigentümliche Urlust des Knetens von Lehm und Ton, ,dynamische Hand", Organ der Energie, Organ der Formen: Die Hand hat ihre Gründe, die die Vernunft nicht kennt.

Die Technik schreibt sich in die Materie ein wie eine Möglichkeit, die bestimmten Bedingungen unterworfen ist. Zunächst muss sie als solche erkannt werden. Sie muss sich beim Nachdenken herausbilden, sie muss sich repräsentieren, erfinden. Gilbert Simondon nennt das ,die technische Einbildungskraft", die wir als „durch eine besondere Empfänglichkeit für die Technizität der Elemente definiert" betrachten können. ${ }^{13}$ Es ist nicht der Ton, der das Gefäß erahnen lässt, es ist seine Formbarkeit. Anders gesagt, die Technizität des Tons ist abhängig von mehreren Elementen, wie z. B. seine Konsistenz, die enthaltene Wassermenge, der mechanische Widerstand usw., die alle zusammen seine Formbarkeit bewirken. Erst dann wird er ein Element, das im Körper und Geist desjenigen Form annehmen kann, der ihn mit seinen Händen bearbeitet.

Die Erfindung, die zugleich Erschaffung des Individuums ist, setzt beim Erfinder die intuitive Kenntnis der Technizität der Elemente voraus; die Erfindung vollzieht sich auf dieser Zwischenebene zwischen dem Konkreten und dem Abstrakten, die die Ebene der Schemata ist. Sie setzt dabei die vorgängige Existenz und

11 Gaston Bachelard, L'eau et les rêves, Paris, 1942, S. 145 [Übersetzung Peter Geble].

12 Ebd. [Übersetzung Peter Geble]

13 Simondon (1989), Du mode d'existence des objets techniques, S. 74 (dt.: (2012), Die Existenzweise technischer Objekte, S. 68). 
Kohärenz von Vorstellungen voraus, welche die Technizität des Objekts mit Symbolen überziehen, die Teil einer imaginativen Systematik und Dynamik sind. ${ }^{14}$

„Zwischen dem Konkreten und dem Abstrakten“, oder zwischen dem Rationalen und dem Irrationalen gibt es die Intuition, eine ungeformte Eigenschaft des Geistes. Das lateinische intueri bedeutet ,aufmerksam betrachten'. Die Erfindung entsteht aus der Beobachtung, der Konzentration, dem Willen, da etwas zu sehen, wo es noch nichts gibt. Zumindest wenn man die Hypothese von Gaston Bachelard gelten lässt, dass es nicht die Wahrnehmung der Bilder ist, die den Prozess der schöpferischen Einbildungskraft bestimmt, und dass ,das wahrgenommene Bild und das erschaffene Bild zwei sehr unterschiedliche psychische Instanzen sind.“ Die imaginierten Bilder wären also „eher Sublimationen der Archetypen als Reproduktionen der Wirklichkeit" und diese Bilder kämen aus den „eigenen menschlichen Tiefen“. Indem sich Bachelard auf die Ursprünglichkeit der schöpferischen Einbildungskraft beruft, stellt er sich gegen die realistische Philosophie und die Psychologie, denen zufolge „man viel gesehen haben muss, um gut kombinieren zu können.“ Dieser Vorstellung des ,guten Sehens“ zieht er die Idee des ,guten Träumens“ vor, „eines Träumens, das der Traumwelt der im menschlichen Unbewussten verwurzelten Archetypen treu bleibt." ${ }^{15}$ Mit anderen Worten, man kann voraussetzen, dass die Formen der Technik nicht unbedingt in einer „Kohärenz der Vorstellungen“ entstehen, sondern in einer „Kohärenz der Träumereien der Materie“.

Der Rat gut zu sehen, der die Grundlage der realistischen Kultur darstellt, übertönt mühelos unseren paradoxen Rat gut zu träumen, das heißt so zu träumen, dass man der Traumwelt der im menschlichen Unbewussten verwurzelten Archetypen treu bleibt. ${ }^{16}$

Mit anderen Worten, man kann voraussetzen, dass die Formen der Technik nicht notwendigerweise aus einer „Kohärenz der Vorstellungen“ heraus entstehen, sondern eher aus einer „Kohärenz der Träumereien der Materie“. Die Hypothese von Bachelard hat den Vorzug, die Intuition und die Repräsentation um eine experimentelle und taktile Dimension zu ergänzen. Denn Intuition und Repräsentation eliminieren die experimentelle Phase der materiellen Imagination, eine Imagination, die im Kontakt mit der Materie entsteht, in einem annäherungsweisen und formgebenden Tasten.

Die zweite Möglichkeitsbedingung der Technik wäre jene ihrer Konkretisierung. ,Kann man?` Die Materie leistet Widerstand, sie überlässt sich nicht einfach so, der Körper muss in der Lage sein, zwischen ihr und der ursprünglichen Absicht eine Übereinstimmung herbeizuführen. Die Technik versteht sich als eine durch das Werkzeug bewerkstelligte Exteriorisierung. Marcel

14 Ebd., S. 73 (dt.: S. 67).

15 Gaston Bachelard, La terre et les rêveries de la volonté, Paris, 1947, S. 3 [Übersetzung Peter Geble].

16 Ebd. [Übersetzung Peter Geble; Herv. i. O.]. 
Mauss hält das jedoch für „eine grundsätzlich irrige Meinung“, denn „das erste und natürlichste technische Objekt und gleichzeitig technische Mittel des Menschen" ist der Körper. ${ }^{17}$ Die technischen Gesten nehmen im Körper Form an, in einem Körper, der sich den Erfordernissen der Materie in erster Linie deswegen beugt, um handeln und die Welt transformieren zu können.

\section{Der dressierte Körper}

Ausgehend von der Hypothese, nach der es „,beim Erwachsenen vielleicht gar keine ,natürliche Art" gibt", stellt Marcel Mauss eine inzwischen berühmt gewordene Liste körperlicher Haltungen auf, die man für angeboren oder persönlich hielt, wie die Art des Laufens, des Trinkens, des Gebärens, der Fortpflanzung, des Tanzens, des Schwimmens, ja sogar des Schlafens, die in Wirklichkeit alle von der Erziehung abhängig sind, und somit von der Überlieferung, das heißt von der Tradition. In dieser Hinsicht sind sie Techniken nach der Definition von Mauss aber auch deswegen, weil sie wirksam sind. Man muss bei dieser Aufzählung nicht in die Einzelheiten gehen, um erkennen zu können, in welchem Ausmaß noch unsere einfachsten Gesten einer Konditionierung unterworfen sind. Die Gesellschaften zwingen den Individuen einen bestimmten Gebrauch ihres Körpers auf und es wird dadurch nur allzu deutlich, wie wir uns, bewusst oder unbewusst, von einem In-der-Welt-Sein, das ,natürlich ${ }^{6} 18$ wäre, entfernt haben - zugunsten einer permanenten Anpassung unseres Körpers an den Gebrauch. Man kann, wie Marcel Mauss, von Dressur sprechen:

Die Dressur ist, wie beim Bau einer Maschine, das Streben nach oder der Erhalt einer Leistung. Hier handelt es sich um menschliche Leistung. Diese Techniken sind also die menschlichen Normen der menschlichen Dressur. Diese Vorgehensweisen, die wir bei Tieren anwenden, haben die Menschen freiwillig auf sich und ihre Kinder angewandt. ${ }^{19}$

Mauss führt hier in Bezug auf die Technik eine Reihe wichtiger Begriffe ein. Zunächst den der „menschlichen Leistung“. Er korrespondiert mit dem des Körpers als technisches Objekt bzw. als technisches Mittel. Mit anderen Wor-

17 Marcel Mauss, „Les techniques du corps“, in: Sociologie et anthropologie, Paris, 1950, 2004, S. 365-386: 372 (dt.: „Die Techniken des Körpers“, in: Soziologie und Anthropologie II, München, Wien, 1975, S. 189-222: 205 f.).

18 Obwohl es möglich war, bei verschiedenen Elefantengruppen spezifische Arten der Fortbewegung zu unterscheiden, bzw. bei Affengesellschaften derselben Art, die aber nicht am selben Ort leben, spezifische Arten des Handhabens von Gegenständen. Die Vorstellung eines ,natürlichen' Zustands ist somit mit Vorsicht zu betrachten, denn sie geht häufig mit einer Vorstellung von Kultur einher, selbst in der Tierwelt. Die Überlieferung bei Tieren variiert jedoch von einer Gruppe zur anderen hauptsächlich in Abhängigkeit von Umweltfaktoren und nicht entsprechend einem Willen oder einem Bewusstsein von ihrer Wirksamkeit.

19 Mauss (2004), Les techniques du corps, S. 372 (dt.: (1975), Die Techniken des Körpers, S. 208). 
ten, der Körper muss technisiert werden, um Technik, technische Objekte, aber auch, um eine soziokulturelle Identität hervorzubringen. Der Körper ist das erste Instrument, dessen sich der Mensch bedient, um sich zu exteriorisieren. Diese Erziehung oder Dressur, von Mauss mit dem Bau einer Maschine verglichen, ist vielleicht auch die erste Art, sich, außerhalb seiner selbst ${ }^{\star}$ oder außerhalb der Natur zu setzen, wenn Natur darin besteht, einer von den Naturgesetzen der Erhaltung und der Reproduktion diktierten Evolution zu folgen. Indem er seine Gesten einem Maß unterwirft, erneuert der Mensch seine Herrschaft über die Welt, und damit seine Exteriorisierungs- und Herrschaftsposition in Bezug auf sich selbst.

Für Jean-Luc Nancy können Körper nicht auf ,technische Objekte‘ reduziert werden. Sie sind Körper, ,einfach“ Körper, die als solche von der Welt erschaffen wurden, es sind aber auch Körper, die in ein System der Instrumentierung integriert sind: die „Ökotechnie“"

Die ,Schöpfung، ist die téchne der Körper. Unsere Welt erschafft eine Unzahl von Körpern, sie erschafft sich als Welt von Körpern (wobei sie zutage fördert, was stets auch ihre Wahrheit von Welt war). Unsere Welt ist die Welt der ,Technik', die Welt, in der sich der Kosmos, die Natur, die Götter, das vollständige System in seiner inneren Fügung als ,Technik' exponiert: die Welt einer Ökotechnie. Die Ökotechnie funktioniert mit technischen Apparaten, an die sie uns allseits anschließt. Sie macht unsere Körper, die sie zur Welt bringt und an dieses System anschließt, unsere Körper, die sie somit sichtbarer, wuchernder, polymorpher, gedrängter, mehr in ,Massen' und ,Zonen' erschafft, als sie es je waren. In der Erschaffung von Körpern findet die Ökotechnie den Sinn, den man ihr in den Resten des Himmels und des Geistes vergeblich zu geben versucht. ${ }^{20}$

Es handelt sich also um eine „Welt von Körpern“, die nicht immanent und nicht transzendent ist, sondern eine Welt von Konnexionen. Eine Welt, die für uns - menschliche Körper - nur als Welt der Technik existiert, das heißt als Welt der Relationen, der Instrumentierung, und doch produziert diese Welt, diese Ökotechnie, nur Körper. Die „téchne der Körper“ macht Körper und funktioniert mit technischen Apparaten. Eine technisch gegliederte „Welt der Körper". Diese Gliederung oder dieses ,innere Gefüge' kann als Kontakt und Bruch zugleich gedacht werden. Genau das macht eine Gliederung: Sie fugt zwei Glieder und hält sie zugleich auseinander.

Wenn wir für einen Augenblick zu Marcel Mauss und den Begriff der „menschlichen Norm“ zurückkehren, so sehen wir, dass der Sozialkörper Normen errichtet und jedes Individuum von Kindheit an dazu zwingt, sich den Forderungen eines Modells zu beugen. Genauso wie ein technisches Verhalten die Ausformung eines Korpus von Gesten und Haltungen nach sich zieht, denen sich das Individuum, um auf die Welt einwirken zu können, zu unterwerfen hat. Die systematische Setzung von Normen ist eines der Grundprinzipien der Technik, denn sowie sie zum Einsatz kommt, misst sie, wägt sie,

20 Nancy (2000), Corpus, S. 78 [Herv. i. O.] (dt.: (2003), Corpus, S. 77 f.). 
kalkuliert, evaluiert und reproduziert sie. Man darf jedoch nicht Norm mit Normalisierung verwechseln. Zu Beginn braucht es Messinstrumente, Richtmaße, um Operationsweisen festzulegen. Norma ist im Lateinischen der Winkel. Oder, nach Jean-Luc Nancy:

Wägen: Schöpfung. Das, wodurch eine Schöpfung beginnt, ohne einen Schöpfer vorauszusetzen. Subjekt vor jeglichem Subjekt, Wägen, ausgeübter, ausgehaltener Druck, ursprüngliche Gemeinschaft der Kräfte [...] Das Wägen verteilt das Ausgedehnte, die Extensionen und Intentionen. ${ }^{21}$

Die Welt, die Körper, die Objekte erschaffen sich in einer Waage, in der sich alles gegenseitig misst und wiegt; das Gewicht ist ein Maß, das zur Norm wird, das eine Wahl trifft und eliminiert. Das technische Instrument dient vor allem der Orientierung, es soll einen ständig weitergetriebenen Anspruch bestimmen, der seinerseits Rückwirkungen auf das Instrument hat. Man verfährt nach Normen, aber sie sind nicht in Stein gemeißelt. Sie sind bedingt durch die, abhängig vom Stand der Techniken, sich entwickelnde Forderung nach einem Ergebnis. Insbesondere sind sie vom Menschen zuvor festgelegt. „Der Mensch ist als Begründer von Normen und als Operateur ein normatives Wesen, das sich in seinen Operationen Normen unterwirft", schreibt Jean-Pierre Séris in seinem Werk über die Technik. ${ }^{22}$ Die Modelle wie die Normen schreiben Regeln vor, die zu befolgen sind, und die paradoxerweise verlangen, dass sie im Namen des Fortschritts - oder der Evolution - übertreten werden, damit neue Modelle eingeführt werden können, die ihrerseits befolgt und imitiert werden bis zu einer neuen Erfindung. Die Norm projiziert und antizipiert Gebrauchsweisen, sie ist stets ihrer Zeit voraus.

Der Körper ist der erste Ort dieser normativen Evaluierung, die zur Auswahl, Bewertung und Weiterentwicklung von Herstellungsprozessen führt. Die Normativität ist jeglicher Produktion inhärent, sie zielt auf Produktivität und Kohärenz. Jeder technische Lernvorgang verläuft notwendigerweise über eine Anpassungsphase, das heißt über einen Gesamtkomplex aufeinander abgestimmter und beherrschter Handgriffe, denen eine Methode zugrunde liegt und die ein bestimmte Ziel erreichen sollen.

Das ist vielleicht die einzige körperliche Dressur, der wir uns voll bewusst sind. Die berufsspezifischen Handgriffe werden gelernt, verinnerlicht und nach demselben Verfahren angewandt wie jede andere ,Technik des Körpers ‘ auch. Der Körper selbst wird zur formbaren Materie - in einer reflexiven Bewegung, die von der Materie zum Körper und vom Körper zur Materie geht. Das Können ist hier dasjenige, das die ,Formel' ${ }^{`}$ gibt, die auf die Körper anzuwenden ist, damit er seine Ziele erreicht - dieses Objekt, das man produziert hat, diese Partitur, die man entziffert hat, diese Geschwindigkeit, die man erreicht hat. Man kann dann von körperlicher Modellierung sprechen, denn sie

21 Ebd., S. 85 (dt.: S. 84).

22 Jean-Pierre Séris, La technique, Paris, 1994, S. 70 [Übersetzung Peter Geble]. 
führt $\mathrm{zu}$ einer unumkehrbaren Modifizierung der Wahrnehmung, und somit der Art und Weise des Seins. Jeder weiß, dass man die Welt nicht mehr in derselben Art und Weise wahrnimmt, nachdem man sich eine Technik inkorporiert hat.

So wie ein lichtempfindlicher fotografischer Film ist der Körper somit das erste Mess-, Hör- und Handlungsinstrument. Er empfängt den Druck, die Eindrücke und die Konsistenz der Stoffe, denen er Form gibt. Er kann nacheinander Meister und Knecht sein, geformter und formender, er ist offen:

Geht es um den Körper, dann sprechen wir von dem, was offen und unendlich ist, was das Offene des Schließens selbst, das Unendliche des Endlichen selbst ist. Das ist es, was ich erarbeiten möchte. Der Körper ist das Offene. Und damit es Öffnung geben kann, muss es etwas Geschlossenes geben, muss man an die Schließung rühren. An das Geschlossene zu rühren, ist bereits schon Öffnen. Vielleicht gibt es niemals Öffnung ohne ein Anrühren oder eine Berührung. Und Öffnen - Berühren - bedeutet nicht zerreißen, zerteilen, zerstören. ${ }^{23}$

Berühren heißt, etwas Geschlossenes oder Unbelebtes öffnen, wie es die Materie im Rohzustand sein kann. Durch das Berühren, das erst ein Erkennen und dann ein Verwandeln ist, entfaltet die Geste die in der Materie und in sich selbst enthaltenen Eigenschaften. Sie hat demiurgische Fähigkeiten, sie kann Räume und Orte schaffen, sie verfügt über die Technizität, die ,Ökotechnie der Körper', aber sie widersetzt sich der ungeschiedenen Masse eines Berührten, das sich mit einem Berührenden vermischt. Im Raum des Berührens entstehen die Technizität und die Formbarkeit, die Prothetizität und das Gefüge unserer Lage als Menschen ,ohne Eigenschaften“.

Übersetzung aus dem Französischen ${ }^{24}$ von Peter Geble

\section{Literatur}

Bachelard, Gaston, L'eau et les rêves, Paris, 1942.

Ders., La terre et les rêveries de la volonté, Paris, 1947.

Latour, Bruno, L'espoir de Pandore. Pour une version réaliste de l'activité scientifique, Paris, 2007, (dt.: Die Hoffnung der Pandora. Untersuchungen zur Wirklichkeit der Wissenschaft, Frankfurt/M., 2002).

Leroi-Gourhan, André, Le geste et la parole II: La mémoire et les rythmes, Paris, 1965, (dt.: Hand und Wort, Frankfurt/M., 1980).

23 Jean-Luc Nancy, „De l'âme“, in: ders. (2000), Corpus, S. 107-129: 107 (dt.: (2003), Corpus, S. 105).

24 Die Autorin dankt für die Unterstützung des Exzellenzclusters Matters of Activity. Image Space Material, gefördert durch die Deutsche Forschungsgemeinschaft (DFG) im Rahmen der Exzellenzstrategie des Bundes und der Länder - EXC 2025. 
Mauss, Marcel, „Les techniques du corps“, in: Sociologie et anthropologie, Paris, 2004 [1950], S. 365-386 (dt.: „Die Techniken des Körpers“, in: Soziologie und Anthropologie II, München, Wien, 1975, S. 189-222).

Nancy, Jean-Luc, Corpus, Paris, 2000, (dt.: Corpus, Berlin, 2003).

Ders., „De l'âme“, in: ders. (2000), Corpus, S. 107-129.

Séris, Jean-Pierre, La technique, Paris, 1994.

Simondon, Gilbert, Du mode d'existence des objets techniques, Paris, 1989 [1958], (dt.: Die Existenzweise technischer Objekte, Zürich, 2012). 


\section{UNIVERSALE KONSTRUKTEURE? VOM $\alpha$ $\tau o ́ \varsigma$ DES LEBENDIGEN ZUR AFFIRMATION DER SYNTHETISCHEN BIOLOGIE ALS UNIVERSALE INGENIEURSWISSENSCHAFT}

Der Organismus ist eine Maschine, die sich selbst aufbaut.

Jacques Monod [1970] ${ }^{1}$

„Biology is Technology“ ${ }^{{ }_{2}}$ - so lautet die ikonische Formel, in der die „Überschreitungsmedialität ${ }^{\text {“3 }}$ der synthetischen Biologie am deutlichsten zum Ausdruck kommt. In jenem Moment, in dem die auf die vermeintliche Universalität des genetischen Codes gründende Molekularbiologie immer mehr Elemente aus Design und Engineering aufnimmt, scheint es fast unausweichlich, von einer méta récit der synthetischen Biologie zu sprechen. Diese neue große Erzählung konstituiert sich wiederum aus einer bricolage jener Mikrogeschichten, die man im Rekurs auf Donna Haraway Engineering Tales nennen könnte. ${ }^{4}$ Im Mittelpunkt dieser Mikrogeschichten steht die Figur des BioIngenieurs.

Es ist höchst bemerkenswert, dass die meisten synthetischen Biologen in ihrer Tätigkeit eine Fortführung jener selbsttätigen molekularer Prozesse einer sich ohne Unterlass selbst-herstellenden Natur wähnen. ${ }^{5}$ Es gilt daher der Frage nachzugehen, unter welcher Selbstaffirmation das ingenieurstechnische Schaffen operiert, oder anders gewendet: Worin liegt die epistemische Möglichkeitsbedingung, welche das radikale Engineering biologischer Entitäten und Systeme als eine Art universelle Technologie erscheinen lässt? In Anbe-

Jacques Monod, Zufall und Notwendigkeit. Philosophische Fragen der modernen Biologie, 5. Aufl., München, 1982 [frz. OA 1970], S. 55.

2 Robert H. Carlson, Biology is Technology. The Promise, Peril, and New Business of Engineering Life, Cambridge, MA, 2010. Dazu ein kritisch-genealogischer Kommentar: Martin Müller, „Zoë als Téchne. Zum Paradox möglicher Menschen in der synthetischen Biologie“, in: Antonio Lucci/Thomas Skowronek (Hg.), Potential regieren. Zur Genealogie des möglichen Menschen, Paderborn, 2018, S. 239-252.

3 Kathrin Friedrich/Gabriele Gramelsberger, ,Techniken der Überschreitung. Fertigungsmechanismen,verlässlich lebensfähiger" biologischer Entitäten“, in: Zeitschrift für Medienwissenschaften, 4, (2011), S. 15-21.

4 Siehe Donna J. Haraway, Unruhig bleiben. Die Verwandtschaft der Arten im Chthuluzän, übers. v. Karin Harrasser, Frankfurt/M., 2018, S. 53.

5 Siehe Sophia Roosth, Synthetic. How Life Got Made, Chicago, IL, 2017, S. 56-60. 
tracht der nachfolgenden zwei Engineering Tales und im Hinblick auf die Wissensgeschichte der Molekularbiologie, so meine These, lassen sich Denkfiguren aus dem Register des (molekularen) Selbsttätigen erkennen, die heute für eine bedenkenswerte Affirmation des Bio-Engineerings herangezogen werden. Was bedeutet es, wenn der $\alpha$ vĩó $\varsigma$ des universellen, genetischen Codes als Herstellungstechnologie in Anschlag gebracht wird?

\section{Demiurgische Biologie?}

Stand das Humangenomprojekt noch unter der Ägide des genetischen Codes, den es zu lesen und zu enträtseln ${ }^{6}$ galt, so geht die synthetische Biologie noch einen bedeutenden Schritt weiter: Heute sollen ganze Genome editiert oder gleich neu geschrieben werden. Jenes vermeintliche Schreiben und die Logik der Schrift führten zu einer Art Explosion der Imagination biologischer Zukünfte, die sich als technische Verheißungen und prometheische Projekte Bahn brechen. ${ }^{7}$

Neben den „umprogrammierten Bakterien“" die nun etwa aus Zucker Medikamente oder kostbare Materialien herstellen, hat die synthetische Biologie ein mytho-poetisches Genre gewählt, in dem sich das fast uneingeschränkte Machbarkeitsdenken buchstäblich verkörpert: In den Laboren der Harvard Medical School und unter Aufsicht von George Church, einer der avantgardistischsten und einflussreichsten Biotechnologen unserer Tage, arbeitet man an der Auferstehung des Wollhaarmammuts. ${ }^{9}$ Die DNA des steinzeitlichen Tieres, die unlängst in der Arktis gefunden wurde, soll so aufbereitet werden, dass sie nach einer künstlichen Befruchtung von einer Elefantenkuh ausgetragen werden kann - ihres Zeichens eine entfernte Verwandte des seit Jahrtauenden ausgestorbenen und von Johann Friedrich Blumenbach klassifizierten Mammuthus primigenius. Das Ziel des durch die Methoden der synthetischen Bio-

6 Aus wissenskritischer Warte hatte Lily E. Kay - zurecht - bemerkt, dass es sich bei dem universellen, genetischen Code um eine epistemologische Erfindung handelt. In diesem Sinne wurde der Code nicht einfach entdeckt, sondern - dem Leben - eingeschrieben. Siehe: Lily E. Kay, Das Buch des Lebens. Wer schrieb den genetischen Code?, Berlin, 2005. Zur Logik der Einschreibung des genetischen Codes im Hinblick auf die Herstellung des (menschlichen) Körpers zeigt Hannelore Bublitz, was die synthetische Biologie für eine zeitgenössische Sozialtheorie bedeutet: Hannelore Bublitz, Das Archiv des Körpers. Konstruktionsapparate, Materialitäten und Phantasmen, Bielefeld, 2019, S. 111-120.

7 Siehe Martin Müller „,First Species Whose Parent Is a Computer“- Synthetic Biology as Technoscience, Colonizing Futures, and the Problem of the Digital“, in: Kristin Hagen/Margret Engelhard/Georg Toepfer (Hg.), Ambivalences of Creating Life. Philosophical Dimensions of Synthetic Biology, Heidelberg, 2016, S. 101-113

8 Siehe Stephen S. Fong, „Computational Approaches to Metabolic Engeneering Utilizing Systems Biology and Synthetic Biology“, in: Computational and Structural Biotechnology Journal 11, 18 (2014), S. 28-34.

9 Siehe Beth Shapiro, „Mammoth 2.0: Will Genome Engineering Resurrect Extinct Species?“, in: Genome Biology 16, 1 (2015), S. 1-3. 
logie ermöglichten Projektes ist eine ganz und gar anthropozäne Angelegenheit: Die majestätischen Wollhaarmammuts sollen aus dem Harvard-Labor zum Nordpol gebracht werden, wo sie dann, so erklärt Church, zum Schutz des gefährdeten arktischen Ökosystems zu Hunderten ihre Kreise ziehen sollen. ${ }^{10}$

Dass sich die Bio-Ingenieure nicht mehr mit der Neu-Konstruktion und der offenkundigen Optimierung des nicht-menschlichen Lebens zufriedengeben, lässt sich durch die folgenden Ereignisse um eine neue Technologie auf dem Feld der synthetischen Biologie andeuten: Im November des Jahres 2018 kamen Nana und Lulu auf die Welt. Es war eine normale Geburt ohne Komplikationen, trotzdem, so möchte ich behaupten, hat sich hier eine tiefe Zäsur, ein Einschnitt in die Geschichte der menschlichen Gattung ereignet. Das Genom und die Keimbahn der Babys wurden vom Biophysiker He Jiankui mithilfe von CRISPR/cas9, editiert'. He habe noch vor der Fertilisation einen Rezeptor im Genom ausgeschaltet, und die Zwillinge so immun gegen HIV gemacht. Der Privatdozent von der Southern University of Science and Technology im chinesischen Shenzhen will mit den Zwillingen die ersten genetisch editierten Menschenkinder zum Leben verholfen haben. Die Entrüstung war denkbar groß, als publik wurde, dass He die Eingriffe in die Keimbahn und die Fertilisation ohne Genehmigung der zuständigen Behörden und entgegen geltendem chinesischem Recht vorgenommen hatte. Noch vor der Veröffentlichung der dokumentierten Versuchsdaten, hatte er die inkognito durchgeführten Eingriffe am 25.11.2018 auf seinem Kanal bei YouTube bekannt gemacht.

Diese offenkundige technologische und ethische Grenzüberschreitung mag ein Déjà-vu bewirken: Der sogenannte Menschenpark-Streit zwischen Peter Sloterdijk und Jürgen Habermas feiert in diesem Jahr sein 20-jähriges Jubiläum. Die überstürzten und bestürzenden Ereignisse um Nana, Lulu und $\mathrm{He}$ Jiankui haben Sloterdijks Prognosen zunichte gemacht, welcher den Anbeginn einer neuen ingenieurstechnischen Biopolitik der menschlichen Gattung auf ein Äon nach unserer Zeit datierte.

Bei CRISPR (Clustered Regularly Interspaced Short Palindromic Repeats) handelt es sich ursprünglich um einen molekularen Mechanismus, mit dem Bakterien und Archaeen Angriffe von Viren erkennen und abwehren. Also eine Art Immunsystem, mit dem sich eine Zelle ständig selbst repariert, indem sie ,unerwünschte' Abschnitte eigenständig aus dem DNA-Strang schneidet und durch neue Sequenzen ersetzt. Im Jahr 2012 ist es Emmanuelle Charpentier und Jennifer Doudna gelungen, diesen in der Zelle ablaufenden molekula-

10 Unlängst hat Frédéric Neyrat - zurecht - argumentiert, dass der Ruf nach einem anthropozänen Terraforming am deutlichsten im Herstellungswillen der synthetischen Biologie zum Ausdruck kommt: ,[T] he production of life has become the principal piece of a will towards a limitless terrafroming“. In: Frédéric Neyrat, The Unconstructable Earth. An Ecology of Separation, New York, NY, 2019, S. 52. Ebenfalls dazu: Martin Müller, „Nach dem metabolischen Bruch“, in: Texte zur Kunst, 110 (2018), S. 154-159. 
ren Mechanismus in ein biotechnisches Werkzeug umzuwandeln. ${ }^{11}$ Mithilfe von CRISPR ließen sich ganze Genome mit noch nie dagewesener Präzision bearbeiten. Doudna erklärt in ihrer im Jahr 2017 zusammen mit dem Biochemiker Samuel H. Sternberg vorgelegten Monografie mit dem hyperbolischen Titel A Crack in Creation. The New Power to Control Evolution:

As long as the genetic code for a particular trait is known, scientists can use CRISPR to insert, edit, or delete the associated gene in virtually any living plant's or animal's genome. This process is far simpler and more effective than any other gene-manipulation technology in existence. Practically overnight, we have found ourselves on the cusp of a new age in genetic engineering and biological mastery - a revolutionary era in which the possibilities are limited only by our collective imagination. ${ }^{12}$

CRISPR gilt als neues Universalwerkzeug der synthetischen Biologie, denn es ist auf alle Lebewesen anwendbar - einschließlich des Menschen. Zudem lassen sich Veränderungen in der Keimbahn vornehmen, welche dann an die nachfolgenden Generationen vererbt werden. Dem Bio-Engineering kommt dabei zupass, dass auch fundamentale Änderungen des Erbguts, die mit CRISPR vorgenommen wurden, anschließend nicht mehr nachvollzogen werden können. Doudna und Sternberg versuchen, die biopolitische Ereignishaftigkeit von CRISPR ins Bild einer Fortschrittsgeschichte einzupassen, in der Naturgeschichte plötzlich in Technikgeschichte umschlägt, wenn sie schreiben:

For the roughly one hundred thousand years of modern humans' existence, the Homo sapiens genome has been shaped by the twin forces of random mutation and natural selection. Now, for the first time ever, we possess the ability to edit not only the DNA of every living human but also the DNA of future generations - in essence, to direct the evolution of our own species. This is unprecedented in the history of life on earth. It is beyond our comprehension. And it forces us to confront an impossible but essential question: What will we, a fractious species whose members can't agree on much, choose to do with this awesome power? ${ }^{13}$

Die postulierte „neue Macht zur Kontrolle der Evolution“ war führenden Akteuren des akzelerierenden Forschungsfeldes bereits im Mai 2015 unheimlich geworden. Man bemühte sich händeringend um ein globales Moratorium, um etwaige Off-Target-Effekte der neuen Technologie genauer zu untersuchen. Jedoch sollte der Aufruf Don't edit the Human Germ Line folgenlos verklingen. ${ }^{14}$

11 Jennifer A. Doudna/Emmanuelle Charpentier, „The New Frontier of Genome Engineering with CRISPR-Cas9“, in: Science 346, 6213 (2014), S. 1258096-1258096.

12 Jennifer A. Doudna/Emmanuelle Charpentier/Samuel H. Sternberg, A Crack in Creation. The New Power to Control Evolution, London, 2017, S. xiii.

13 Ebd., S. xvi.

14 Edward Lanphier, Fyodor Urnov, Sarah Ehlen Haecker, Michael Werner, Joanna Smolenski, „Don't Edit the Human Germ Line“, in: Nature 519, 7544 (2015), S. 410-411. Dazu kritisch: Martin Müller, „Wir müssen dringend reden“, in: Welt am Sonntag, Nr. 22, 28.05.2017, S. 59. 


\section{Schrödingers Code:}

„Gesetzbuch und ausübende Gewalt, Plan des Architekten und Handwerker des Baumeisters" zugleich

Welcher Lebensbegriff liegt der synthetischen Biologie zugrunde, mittels dessen ein vermeintlich uneingeschränktes Schalten und Walten auf der Ebene des Genoms möglich zu sein scheint? Was hier zum Tragen kommt, lässt sich innerhalb der Geschichte der Molekularbiologie bis in die Mitte des 20. Jahrhunderts zurückverfolgen: Es handelt sich um jenen diskurshistorischen Moment, in dem der Begriff des Lebens in den Einzugsbereich von Kybernetik und Informationstheorie gerät. Ein zentraler, genealogischer Moment des codebasierten und universellen Lebensbegriffs lässt sich bis zu Erwin Schrödingers Spekulationen zur Frage „What is Life?“ im Jahr 1943 - als eine Urszene der heutigen Formel von der Biologie als Technologie - identifizieren. Schrödingers Spekulationen über jenen materiellen, konstitutiven Grund lebender Entitäten stehen im Zeichen des Selbsttätigen und des Autogenerativen. Schrödingers wollte ,aufzeigen, daß es mit dem molekularen Bild des Gens nicht mehr unvereinbar ist, wenn der Miniaturcode einem hochkomplizierten und bis ins einzelne bestimmten Entwicklungsplan genau entspricht und irgendwie die Fähigkeit hat, seine Ausführung zu bewerkstelligen. " ${ }^{15}$ Der entscheidende Akteur in Schrödingers Suche nach den prima causa ist der operative Code selbst. So heißt es in der wohl ikonischsten Passage bei Schrödinger: „Die Chromosomstrukturen tragen gleichzeitig dazu bei, die Entwicklung, welche sie ahnen lassen, hervorzubringen. Sie sind zugleich Gesetzbuch und ausübende Gewalt, Plan des Architekten und Handwerker des Baumeisters. "'16 Aus theoretischer Perspektive ließe sich konstatieren: Die Chromosomstruktur wird von Schrödinger als operativ beschrieben. Den codegetriebenen Prozessen ist eine wundersame Selbstläufigkeit und Handlungsmacht eigen, wenn sie das Leben generieren und hervorbringen. Beachtenswert ist jene ,natürliche“ Technizität der Codes, die Schrödinger in paradoxaler Weise als Schrift und Struktur und damit in ihrer Agentivität und Generativität als eine Kulturtechnik und gleichsam als der Natur inhärenter Prozess begreift. Jener Code liegt außerhalb menschlicher Wirkmacht: Ihm eignet eher ein ,autorloses Schreiben' oder eine ,subjektlose Produktivität'. Das Leben, so ließe sich Schrödingers berühmte Passage verstehen, ist eine ,autogenerative Technologie'. Gene erscheinen somit als ,aktiv Handelnde, die nicht nur den Organismus beleben, sondern auch seine Entstehung in Gang setzen kön-

15 Erwin Schrödinger, Was ist Leben? Die lebende Zelle mit den Augen des Physikers betrachtet, München, 1989 [engl. OA 1944]. Die Monografie ist eine überarbeitete Fassung der im Jahr 1943 in Dublin gehaltenen, gleichnamigen Vorlesung.

16 Ebd., S. 41. 
nen “. ${ }^{17}$ Der Code ist hybriden Charakters, in dem Symbolisches, Zeichenhaftes und Natürliches sowie Materielles ein doppeldeutiges Verhältnis eingehen.

Schrödingers Code-Spekulationen rühren mithin an dem vielleicht fundamentalsten genealogischen Enigma des Lebensdenkens überhaupt: Welche Eigenaktivitäten, Kräfte und Automatismen wirken innerhalb der lebendigen Materie, die den individuellen belebten Körpern erzeugen und entwickeln? „Es geht um die Frage“, so Sigrid Weigel, „was einen Organismus zu dem disponiert, was er einmal werden soll, und was dafür verantwortlich ist, daß er sich dazu ausbildet oder eben nicht." 18 Diese Fragelinie reicht weit zurück und setzt zunächst mit Aristoteles' metaphysischen Spekulationen über die Erzeugung des Lebens und der Lebewesen ein, die vom Formungsprinzip eines allmächtigen Logos ausgeht, welcher dann jeweils durch seine belebende Aktivität die potenziell angelegte Möglichkeit des Lebendigen im Stoff aktualisiert und hervorruft. Noch vor der Geburt der Biologie um 1800 wurde die aristotelische Frage nach den Möglichkeitsbedingungen und den Ursachen des stofflichen Lebens unter dem Schlagwort der Epigenese neu verhandelt. Johann Friedrich Blumenbach setzte den Begriff des in der Materie wirkenden „Bildungstriebs" ${ }^{\prime 19}$ gegen die (antike und mittelalterliche) These der Präformation und Urzeugung. Sigrid Weigel erklärt:

Im Grunde genommen geht es in Schrödingers Untersuchungsanordnung um den alten und wiederholten Versuch, jene Mechanismen zu verstehen und zu erklären, nach denen Organismen ihre Form, ihre Gestalt oder Organisation ausbilden, erhalten, weiterentwickeln und vererben - ein Leitmotiv der Wissenschaft, das sich von Aristoteles', unbewegtem Beweger' über den Vis formativis der epigenetischen Theorie oder Lamarcks ,inneren Entwicklungstrieb', Maupertius’ ,Kristallisation“ und die ,molekularbiologische Organisation der Zelle' bis zur genetischen Information verfolgen läßt. ${ }^{20}$

Die Frage nach den Automatismen, dem av̉ ó weit zurück in die Wissensgeschichte des Lebensbegriffs. Heute erfährt die Genealogie vom sich selbst hervorbringenden Lebendigen eine radikale technowissenschaftliche Ausdeutung und praktische Wendung. Der universelle, kybernetische Lebensbegriff wird nun im Dispositiv der synthetischen Biologie zu einer Art universellem Organon erklärt. Die molekularen Automatismen des Lebendigen werden zu neuen Standards, Programmen und Protokollen einer Evolution in Menschenhand. Im Hinblick auf die agency lässt sich

17 Evelyn Fox, Das Leben neu denken. Metaphern der Biologie im 20. Jahrhundert, München, 1998, S. 13.

18 Sigrid Weigel, Die „innere Spannung im alphanumerischen Code“ (Flusser). Buchstabe und Zahl in grammatologischer und wissenschaftsgeschichtlicher Perspektive, Köln, 2006, S. 25.

19 Siehe Johann Friedrich Blumenbach, „Über den Bildungstrieb (Nisus formativus) und seinen Einfluß auf die Generation und Reproduction“, in: Georg Christoph Lichtenberg/Georg Forster (Hg.), Göttingisches Magazin der Wissenschaften und Litteratur 1, 5 (1780), S. 247-266.

${ }^{20}$ Weigel (2006), Die ,innere Spannung im alphanumerischen Code“, S. 25. 
erkennen, dass an die Stelle von Schrödingers universalem Baumeister die Figur des Lebensingenieurs rückt.

\section{Das Leben als Herstellungstechnologie}

Die Verfahren der synthetischen Biologie gründen auf einem impliziten Verständnis von der molekularen Performativität des Genoms, wie sie etwa in dem von George Church und Edward Regis verfassten Manifest Regenisis. How Synthetic Biology Will Reinvent Nature and Ourselves in opulenter Weise beschrieben wird: ,[B]iological organisms could be viewed as a kind of high technology, as nature's own versatile engines of creation." ${ }^{21}$ Die Autoren lassen es sich nicht nehmen, die Naturgeschichte des Genoms als eine große Erzählung zu entfalten. „It's the story of a once invisible being, nameless for eons, now called ,the genome'."22 Das Genom (im Singular) wird hier zum Subjekt einer außerordentlich langen Geschichte, die vor Milliarden Jahren mit der Emergenz des planetarischen Lebens - einsetzt:

The appearance of DNA some 3,900 million years ago makes it the most ancient of all ancient texts. [...] The original ancient text is written in the genomic DNA of every being alive today. That text is as old as life itself, and over 1030 copies of it are distributed around the earth, from 5 kilometers deep within the earth's crust to the edge of our atmosphere, and in every drop of the ocean. A version of this text is found in each nucleated cell of our bodies, and it consists of 700 megabytes of information (6 billion DNA base pairs). It contains not only a rich historical archive but also practical recipes for making human beings. ${ }^{23}$

In der Erzählung ihrer Ingenieursbiologie erscheint das DNA-basierte Leben als eine äonische, nicht-menschliche Technologie und wird beschrieben als eine Milliarden Jahre alte „Maschinerie der Herstellung“ - (diese Formel stellt eine deutliche Referenz zu Eric Drexlers gleichnamigen, im Jahr 1986 erschienen Manifest zum Produktions- und Maschinenbegriff in der Nanotechnologie her, welcher wiederum die "Molekulare Maschine“ zum Vorbild hat). ${ }^{24}$

Die Denkfigur vom ,Leben als Hochtechnologie' avanciert sogleich zum gravitätischen Mittelpunkt ihrer großen Erzählung der synthetischen Biologie.

21 George M. Church/Edward Regis, Regenesis. How Synthetic Biology Will Reinvent Nature and Ourselves, New York, NY, 2012, S. 4.

22 Ebd., S. 15.

23 Ebd., S. 38.

24 In Drexlers (Denk-)Figur der molekularen Maschine, die sich durch ihr Vermögen zur SelbstHerstellung auszeichnet, findet sich ein idealtypisches Vorbild für die Nanotechnologie: „In cells, molecular machines first transcribe DNA, copying its information to make RNA ,tapes'. Then, much as old numerically controlled machines shape metal based on instructions stored on tape, ribosomes build proteins based on instructions stored on RNA strands." Eric Drexler, Engines of Creation. The Coming Era of Nanotechnology, 2. Aufl., Oxford, 1990, S. 6. 
Die Rede vom Genom erlebt dabei eine Konkretisierung, wenn der Begriff des genetischen Programms ins Spiel kommt.

Just as computers were universal machines in the sense that given the appropriate programming they could simulate the activities of any other machine, so biological organisms approached the condition of being universal constructors in the sense that with appropriate changes to their genetic programming, they could be made to produce practically any imaginable artifact. ${ }^{25}$

Der Organismus wird von Church und Regis zu einer universellen Herstellungstechnologie erklärt, deren materieller Output durch den inhärenten, genetischen Programmcode gesteuert wird: „A living organism, after all, was a ready-made, prefabricated production system that, like a computer, was governed by a program, its genome. ${ }^{\text {2 } 26}$ Sie schreiben:

Synthetic biology and synthetic genomics, the large-scale remaking of a genome, were attempts to capitalize on the facts that biological organisms are programmable manufacturing systems, and that by making small changes in their genetic software a bioengineer can effect big changes in their output. ${ }^{27}$

In diesem Denken erscheint die Lebensherstellung als ein Diskurs von Industrie und Fabrikation. An die Stelle der eigentätigen, zellulären Reproduktion rückt die rationale Herstellung der von Ingenieuren ersonnenen Artefakte. Auf der Ebene des Genoms umprogrammierte biologische Entitäten sollen durch Menschen ersonnene Artefakte auf biologischem Wege - aus sich heraus herstellen. Artefakte werden in diesem Paradigma nicht von Maschinen, sondern von Organismen produziert:

Given the profusion and variety of biological organisms, plus the ability to reengineer them for a multiplicity of purposes, the question was not so much what they can be made to do but what they can't be made to do, in principle. After all, tiny life forms, driven solely by their own natural DNA, have, just by themselves, produced large, complex objects: elephants, whales, dinosaurs. A minuscule fertilized whale egg produces an object as big as a house. So maybe one day we can program an organism, or a batch of them, to produce not the whale but the actual house. ${ }^{28}$

Was man hier vorfindet, lässt sich als eine konsequente Appropriation des eingangs zitierten Satzes vom ,Leben als sich selbst aufbauende Maschine“ von Jaques Monod verstehen. Das Lebendige erscheint in dieser großen Erzählung des Ingenieurstechnischen nicht mehr als begrenzte Ressource, sondern als Produktionsmedium zur unlimitierten und unmittelbaren Materialisierung menschlicher Wünsche und Projekte.

\footnotetext{
25 Church/Regis (2012), Regenesis, S. 4.

26 Ebd., S. 15.

27 Ebd., S. 4.

28 Ebd., S. 7.
} 


\section{Platonische Implikationen}

Die synthetische Biologie steht für eine Biotechnologisierung gesellschaftlicher Zukünfte. Die visionären Versprechen und das Ethos der universellen Gestaltbarkeit zeitigen ihre Wirkung auf die Gegenwart. Sie beeinflussen die heutige Epistemologie und Praxis; sie bringen die Figur des Bioingenieurs in eine denkwürdige politische Position: als eine Agentur zur Bildung zukünftiger Utopien, aber auch zur Formierung von Weltbildern und Ethiken. Mit der Emphase für das Universale aktualisiert und re-inthronisiert sie das antike Schema von der ideellen Herrschaft des Symbolischen über die materielle Natur. Diese metaphysische Problematik hatte sich bereits im Zuge der Etablierung des kybernetischen Lebensbegriffs angekündigt. So zog Jacques Monod bereits im Jahr 1970 ein erstaunliches philosophisches Resümee zu den epistemologischen Implikationen des universellen genetischen Codes:

Den Biologen meiner Generation fiel es zu, die Quasi-Identität der Zellchemie in der gesamten Biosphäre zu enthüllen. Seit 1950 war man sich dessen gewiß, und jede neue Veröffentlichung brachte eine Bestätigung. Die Hoffnungen der überzeugtesten ,Platoniker' waren mehr als erfüllt. ${ }^{29}$

Mit der synthetischen Biologie ist aus der Code-Epistemologie eine Anwendungswissenschaft geworden, die sich nicht mehr damit aufhält, den genetischen Code nur zu erforschen, sondern darauf zielt, ihn gänzlich technisch zu kontrollieren und radikal umzuschreiben. In diesem Sinne steht die synthetische Biologie heute für eine molekulartechnische Aktualisierung jenes Mythos vom göttlichen Demiurgen aus Timaios, welcher die vergänglichen, lebendigen Körper aus ideellen, geometrischen Formen herstellen ließ.

Doch damit nicht genug: Angesichts der Ereignisse um CRISPR und die Editierung der menschlichen Keimbahn müssen wir uns dringend fragen: Für welche Biopolitik steht die synthetische Biologie? Im jenem Moment, in dem die menschliche Gattung selbst ins Zentrum des Bio-Engineering rückt, verwischt die Demarkationslinie zwischen Biotechnologien und Sozialtechnologien. Mit Politeía ist hoffentlich kein Staat mehr zu machen. ${ }^{30}$

29 Monod (1982), Zufall und Notwendigkeit, S. 99. Zur folgenreichen Geschichte vom Aufeinandertreffen von Philosophie und (molekularer) Biologie in Frankreich: Onur Erdur, Die epistemologischen Jahre. Philosophie und Biologie in Frankreich, 1960-1980, Zürich, 2018.

30 Der Autor dankt für die Unterstützung des Exzellenzclusters Matters of Activity. Image Space Material, gefördert durch die Deutsche Forschungsgemeinschaft (DFG) im Rahmen der Exzellenzstrategie des Bundes und der Länder - EXC 2025. 


\section{Literatur}

Blumenbach, Johann Friedrich, „Über den Bildungstrieb (Nisus formativus) und seinen Einfluß auf die Generation und Reproduction", in: Georg Christoph Lichtenberg/ Georg Forster (Hg.), Göttingisches Magazin der Wissenschaften und Litteratur 1, 5 (1780), S. 247-266.

Bublitz, Hannelore, Das Archiv des Körpers. Konstruktionsapparate, Materialitäten und Phantasmen, Bielefeld, 2019.

Carlson, Robert H., Biology is Technology. The Promise, Peril, and New Business of Engineering Life, Cambridge, MA, 2010.

Church, George M./Regis, Edward, Regenesis. How Synthetic Biology Will Reinvent Nature and Ourselves, New York, NY, 2012.

Doudna, Jennifer A./Charpentier, Emmanuelle „The New Frontier of Genome Engineering with CRISPR-Cas9“, in: Science 346, 6213 (2014), S. 1258096-1258096.

Dies./Sternberg, Samuel H., A Crack in Creation. The New Power to Control Evolution, London, 2017.

Drexler, Eric, Engines of Creation. The Coming Era of Nanotechnology, 2. Aufl., Oxford, 1990.

Erdur, Onur, Die epistemologischen Jahre. Philosophie und Biologie in Frankreich, 1960-1980, Zürich, 2018.

Fong, Stephen S., „Computational Approaches to Metabolic Engeneering Utilizing Systems Biology and Synthetic Biology", in: Computational and Structural Biotechnology Journal 11, 18 (2014), S. 28-34.

Friedrich, Kathrin/Gramelsberger, Gabriele, „Techniken der Überschreitung. Fertigungsmechanismen ,verlässlich lebensfähiger" biologischer Entitäten", in: Zeitschrift für Medienwissenschaften, 4, (2011), S. 15-21.

Haraway, Donna J., Unruhig bleiben. Die Verwandtschaft der Arten im Chthuluzän, übers. v.Karin Harrasser, Frankfurt/M., 2018.

Kay, Lily E., Das Buch des Lebens. Wer schrieb den genetischen Code?, Berlin, 2005.

Keller, Evelyn Fox, Das Leben neu denken. Metaphern der Biologie im 20. Jahrhundert, München, 1998.

Lanphier, Edward/Urnov, Fyodor/Haecker, Sarah Ehlen/Werner, Michael/Smolenski, Joanna, „Don’t Edit the Human Germ Line“, in: Nature 519, 7544 (2015), S. 410-411.

Monod, Jacques, Zufall und Notwendigkeit. Philosophische Fragen der modernen Biologie, 5. Aufl., München, 1982 [frz. OA 1970].

Müller, Martin, „First Species Whose Parent Is a Computer ${ }^{6}-$ Synthetic Biology as Technoscience, Colonizing Futures, and the Problem of the Digital“, in: Kristin Hagen/Margret Engelhard/Georg Toepfer (Hg.), Ambivalences of Creating Life. Philosophical Dimensions of Synthetic Biology, Heidelberg, 2016, S. 101-113.

Ders., „Wir müssen dringend reden“, in: Welt am Sonntag, Nr. 22, 28.05.2017, S. 59.

Ders., ,Zoë als Téchne. Zum Paradox möglicher Menschen in der synthetischen Biologie“, in: Antonio Lucci/Thomas Skowronek (Hg.), Potential regieren. Zur Genealogie des möglichen Menschen, Paderborn, 2018, S. 239-252.

Ders., „Nach dem metabolischen Bruch“, in: Texte zur Kunst, 110 (2018), S. 154-159.

Neyrat, Frédéric, The Unconstructable Earth. An Ecology of Separation, New York, NY, 2019.

Roosth, Sophia, Synthetic. How Life Got Made, Chicago, IL, 2017. 
Schrödinger, Erwin, Was ist Leben? Die lebende Zelle mit den Augen des Physikers betrachtet, München, 1989 [engl. OA 1944].

Shapiro, Beth, „Mammoth 2.0: Will Genome Engineering Resurrect Extinct Species?“, in: Genome Biology 16, 1 (2015), S. 1-3.

Weigel, Sigrid, Die „, innere Spannung im alphanumerischen Code“ (Flusser). Buchstabe und Zahl in grammatologischer und wissenschaftsgeschichtlicher Perspektive, Köln, 2006. 

Thesen:

Zum Eigenleben statistischer Instrumente und die Reduzierung des Ökologischen 



\section{THORBEN MÄMECKE}

\section{These 1: Automatismen sind unberechenbar.}

Naturalisierungen emergenter Prozesse sind Versuche, dies zu kaschieren.

Im Schnittfeld verschiedenster technologieaffiner Subkulturen, Maker- und Prosumer-Communities hat sich während der vergangenen Jahre ein durchwachsenes Experimentierfeld der systematischen, technologiebasierten Selbstbeobachtung entwickelt, welches Praktiken wie die des Lifelogging oder Personal Genome Project ebenso umfasst wie das inversive Enhancement der radikal posthumanistischen Body-Hacking-Szene. Über diese Extreme hinaus ist allerdings vor allem eine zunehmende Popularisierung des zahlenbasierten Self-Trackings festzustellen, welches in der Medienöffentlichkeit gemeinhin durch die Quantified Self Community repräsentiert wird. Für das Erkenntnisinteresse dieser Community ist charakteristisch, dass sie durch die experimentelle Entwicklung und Anwendung von (Selbst-)Vermessungsverfahren versucht, verborgene Prozesse und Gesetzmäßigkeiten zu ergründen, von denen angenommen wird, dass sie als Einflussfaktoren oder unabhängige Variablen bestimmte Lebensaspekte determinieren. Das Self-Tracking befragt die Routinen des Alltags dabei auf ihren ökonomischen Gehalt und sucht nach Verbesserungsmöglichkeiten jenseits der plattgetretenen Pfade täglicher Gewohnheiten. Der Quantified Self Community lässt sich demgemäß unterstellen, dass sie schwerpunktmäßig die Suche nach emergenten, eigendynamischen oder autopoietischen Abläufen organisiert und ihre Zugangsweisen zu Phänomenen dieser Art dem Konzept der Automatismen nicht unähnlich sind. Ein entscheidender Unterschied liegt jedoch darin, dass die Kontrollambitionen dieser Vermessungspraktiken, also die stets präsente Frage nach der planmäßigen Veränderbarkeit dezentraler, ungeplanter und eigendynamischer Prozesse, zumindest bei einem Teil der Community zu spezifischen Formen von Naturalisierung führen. Denn den Fluchtpunkt vieler Selbstvermessungspraktiken bildet ein ambivalentes Weltverständnis, nach dem der Naturzustand wahlweise als anzustrebendes Ideal oder als eine archaische, hemmende Kraft konstruiert wird. Ob das Ziel der numerischen Selbstbefragung nun eine Schlaftypbestimmung gemäß des ,Eule-Lerche-Prinzips“ oder der Versuch ist, der Evolution zurückgehaltene Entwicklungspotenziale abzuringen ${ }^{1}$, die epistemologische Basis beider Weltzuwendungen bildet die Annahme biologischer, physikalischer, aber auch sozialer Gesetzmäßigkeiten, die im Abseits des menschlichen Bewusstseins nach eigener Logik prozessieren und die durch

\footnotetext{
1 Siehe beispielsweise den aktuell in der Quantified Self Community rezitierten Artikel: „Your Brain Is Primed to Reach False Conclusions“ auf: FiveThirtyEight, vom 17.02.2015, online unter: http://fivethirtyeight.com/features/your-brain-is-primed-to-reach-false-conclusions/, zuletzt aufgerufen am 03.01.2019.
} 
den soziotechnischen Formalismus des Self-Trackings ,aufgedeckt' und geformt werden können.

Vor diesem Hintergrund lassen sich experimentelle Selbstbeobachtungen dieser Art auch als Versuche beschreiben: Durch Entautomatisierung, also durch die bewusste Beobachtung von eigenen Gewohnheiten, zugrundeliegende Ordnungsprinzipien aufzudecken, zu modifizieren und im Anschluss via Inkorporation wieder in einen vorreflexiven Zustand verminderter Komplexität zu überführen. Wobei das Ziel die Nutzbarmachung eigendynamischer Prozesse, im Sinne eines kontrollierten Prozessierenlassens von Abläufen unterhalb der Wahrnehmungsschwelle, darstellt. Die Metaphorik des Aufdeckens ist dabei nur einer unter zahllosen Hinweisen darauf, dass die hier dominanten Konzeptionen eigendynamischer Prozesse vornehmlich positivistische Wirklichkeitsverständnisse beerben, die wissensgeschichtlich immer wieder in der Allianz mit vergleichsweise einfach gehaltenen, quantifizierenden Methoden aufgetreten sind. Bereits seit den frühen Experimenten der Realisten des späten 19ten Jahrhunderts, welche sozialstatistische Erhebungen vor allem im Medium der Gauß'schen Normalverteilung naturalisierten, beziehen einfache Häufigkeitsauszählungen ihre Faszinationskraft aus vermeintlich natürlichen Gesetzmäßigkeiten, von denen angenommen wird, dass sie sich durch die Quantifizierung von zählbaren Einheiten zutage fördern lassen. Data-Mining-Verfahren scheinen so als systematische Suche nach dem besseren ,Ich' in den eigenen Datenspuren einen technologisch-kulturellen Kreuzungspunkt aus naturalisierender Quantifizierung und kritischen Selbstbefragungstechniken darzustellen. Viele der „N=1 Experimente“ ${ }^{“ 2}$ der avantgardistischen Self-Tracking Community beerben allein schon dadurch entsprechende Denkmuster, indem sich die Selbstvermesserin gleichermaßen als das eigene Gegenüber und das Gegenüber einer zu entdeckenden Natur konstruiert. Für die Methodizität dieser Weltzuwendungen sind vor allem Formen der Standardisierung konstitutiv, was sich sowohl in den charakteristischen Wiederholungszyklen der experimentellen Selbstvermessung als auch in der kollektiven Vermessung und der Aggregation von Daten in sogenannten Ökosystemen zeigt. Insbesondere die Langzeituntersuchungen basieren dabei häufig auf Annahmen über separierbare und durch Wiederholung aufzeigbare Phänomene, die sich selbst durch Wiederholung manifestieren und damit einer eigenen Logik folgen.

Dies zeigen exemplarisch aktuelle Versuche, durch die Verbindung von GPS-basierten Activity Trackern mit interaktiven Straßenkarten die besten Laufwege in Form sogenannter ,Desire Lines' zu ermitteln. Versuche dieser Art sind schon seit den Methoden des ,Organic Planning bekannt, das in den 1970er Jahren erstmalig eingesetzt wurde, um die Wegeführung auf dem Campus der Universität Oregon zu verbessern. Zu diesem Zweck ließ der Wiener Architekt Christopher Alexander auf weiten Teilen des Geländes Ra-

2 Vgl. dazu http://quantifiedself.com/n1/, zuletzt aufgerufen am 03.01.2019. 
sen aussäen. Das Muster aus Trampelpfaden, das Studierende und Angestellte der Universität in den Folgenden Monaten auf der Rasenfläche hinterließen, wurde im Anschluss als Vorlage für das neu entstehende Wegenetz des Campus verwendet. Alexander überführte damit Beobachtungen in einen experimentellen Aufbau, die schon während der 1960er Jahre durch den Soziologen Lewis Mumford im Zuge der Stadtentwicklung Brasilias formuliert wurden: "[The] slow curve is the natural line of the footwalker, as anyone can observe as he looks back at his tracks in the snow across an open field." ${ }^{33}$ Damit setzte Alexander durch Wiederholung und Quantifizierung auf eine Nutzbarmachung von Eigendynamiken, im Sinne eines kontrollierten Prozessierenlassens dezentraler Abläufe, wobei die naturalisierende Semantik dieser Verfahren die Bedingungen des experimentellen Aufbaus und alle übrigen Einflussfaktoren unsichtbar macht.

Die Automatismen-Bände ziert indes das Bild einer Schafherde, durch deren wiederholte Bewegungsabläufe eine verzweigte Struktur aus einzelnen, verflochtenen Trampelpfaden in den Schnee eines Feldes graviert wurde. Wie schon oft diskutiert wurde, ist dieses Bild gleichermaßen sinnbildlich für die strukturgenerierende Wirkung dezentraler, ungeplanter Prozesse als auch für die Abhängigkeit des Modells von bestimmten Perspektiven und Formen (wissenschaftlicher) Beschreibungspraxen, welche in diskursiver Weise zahlen-, bild- oder schriftförmige Repräsentationen sich selbst steuernder Prozesse zu erzeugen vermögen ${ }^{4}$, ohne dass sie als deckungsgleich mit einer dahinter liegenden Realität gelten müssen. Konstruktivistische Konzeptionen wie diese stellen die Steuerungseuphorie der Kybernetik oder der Quantified Self Community damit vor einige Schwierigkeiten, da sie den Wahrheitsanspruch ihrer Aussagen herausfordern. Dies mag mitunter einer der Gründe dafür sein, weshalb sich Naturalisierungen in technologischen oder wissenschaftlichen Diskursen immer wieder durchsetzen. Sie sind ein Versuch, eine Position außerhalb des sozialen und außerhalb jeder perspektivischen Befangenheit zu schaffen: Eine ,Beobachtung letzter Ordnung'.

Obgleich auch in der Automatismen-Forschung immer wieder Überlegungen dazu geäußert wurden, ob eine bedingte Kontrolle sich selbst steuernder Prozesse durch die Anwendung bestimmter Technologien denkbar ist ${ }^{5}$, bleibt eine Stärke des Automatismen-Konzepts gerade darin begründet, die Unhintergehbarkeit und damit auch Unberechenbarkeit von eigenständigen Logiken

3 Vgl. dazu http://bobulate.com/post/258332034/a-network-of-function-over-geometry, zuletzt aufgerufen am 03.01.2019.

4 Oliver Leistert, „Automatismen werfen das Problem der Beobachterin auf. Hiermit sind weitreichende epistemologische Fragen verbunden“, in: Hannelore Bublitz/Roman Marek/Christina L. Steinmann/Hartmut Winkler (Hg.), Automatismen, Paderborn, 2010, S. 99-102: 99 f.

5 Julius Othmer, „Durch mediale Repräsentationen wird ein kollektiver Automatismus auch für die an ihm beteiligten Individuen beobachtbar. Auf dieser Beobachtungsoption setzen Selbsttechnologien auf, welche ungeplante Strukturentstehung beeinflussen“, in: Hannelore Bublitz/ Irina Kaldrack/Theo Röhle/Mirna Zeman (Hg.), Automatismen - Selbst-Technologien, München, 2013, S. 134-138: 134 f. 
zu verdeutlichen, die sich aufgrund ihrer Komplexität (und der Perspektivengebundenheit der Betrachterin) einem willentlichen Zugriff notwendigerweise verwehren. ${ }^{6}$ Als theoretisches Konzept markieren Automatismen demnach gerade die Versuche, sozialen Phänomenen theoretisch habhaft zu werden, vor denen naturalistische, intentionalistische, behavioristische oder RationalChoice-Theoreme kapitulieren. Unkontrollierbarkeit ist mit dem Konzept der Automatismen dabei so fest verknüpft wie die Naturalisierung mit Wahrheitsansprüchen. Entsprechend würde sich das Konzept der Automatismen auch überall dort die Erklärungskraft selbst entziehen, wo es den Nachweis über die Kontrollierbarkeit dezentraler, emergenter und eigendynamischer Prozesse erbringt: Denn ein kontrollierbarer Automatismus ist kein Automatismus.

Auch die Vermessung führt demnach niemals zur ,Aufdeckung' von Phänomenen, sondern setzt ihrerseits eigenständige, in ihrem Ergebnis und der Art ihres Prozessierens unberechenbare Dynamiken in Kraft, was bereits als quantitative Seite von Automatismen beschrieben wurde.7 Demgemäß vollzieht sich Emergenz oft additiv und kann als Zusammenschluss von Daten zu neuen, nicht lokal steuerbaren und teilweise unvorhersehbaren Resultaten führen, die sich als Struktur einschreiben und selbstständig reproduzieren ohne dass sich ihr Effekt statistisch berechnen oder kontrollieren ließe. Wie Theo Röhle in Anlehnung an Victor Sklovskij ${ }^{8}$ schreibt, hat die Aggregation damit selbst einen ambivalenten Charakter, die sich aufgrund mangelnder innerer Verbundenheit lediglich als eine lose Verbindung von Elementen bildet, was durchaus auch unerwartet und unsystematisch erfolgen kann. Dies kann eine ungeplante Entstehung von Strukturen mit sich führen, indem Aufschichtungen vorgenommen werden, die nicht einer im Voraus geplanten Ordnung folgen. ${ }^{9}$ So erscheint auch die ehemals durch Naturalisten wie Quételet konstatierte Normalgesellschaft heute eher als Normalisierungsgesellschaft $^{10}$ im Sinne einer sich selbst erfüllenden Prophezeiung, indem sie Normalität (im Zuge ihrer statistischen Konstruktion) neben Normativität in die Funktionsstelle gesellschaftsuniverseller Wertbindung setzt. Dies lässt sich insofern auch als Automatismus beschreiben, als dass dieser Prozess wissens-

6 Hannelore Bublitz/Roman Marek/Christina L. Steinmann /Hartmut Winkler, „Automatismen. Einleitung“, in: dies. (Hg.), Automatismen, Paderborn, 2010, S. 9-16: 10.

7 Ebd., S. 13.

8 Victor Sklovskij, „Die Kunst als Verfahren“, in Jurij Striedter (Hg.), Russischer Formalismus. Texte zur allgemeinen Literaturtheorie und zur Theorie der Prosa, München, 1971 [1916], S. 4-35.

9 Vgl. Theo Röhle, ,Ad gregem agere - Digitales Mapping zwischen Akkumulation und Aggregation", in Thorben Mämecke/Jan-Hendrik Passoth/Josef Wehner (Hg.), Bedeutende Daten Modelle, Verfahren und Praxis der Vermessung und Verdatung im Netz, Wiesbaden, 2017, S. 71-90: 81.

10 Vgl. Jürgen Link, Versuch über den Normalismus. Wie Normalität produziert wird, Opladen, 1997; ders., „Wie das Kügelchen fällt und das Auto rollt. Zum Anteil des Normalismus an der Identitätsproblematik in der Moderne“, in: Herbert Willems/Alois Hahn (Hg.), Identität und Moderne, Frankfurt/M, 1999, S. 164-179; ders., „, The Normalistic Subject and its Curves. On the Symbolic Visualization of Orienteering Date“, in: Cultural Critique 57, 1, 2004, S. 47-67. 
geschichtlich erst durch die Versuche der ,Aufdeckung` gesellschaftlicher Strukturen anhand statistischer Instrumente in Gang gebracht wurde.

\section{Literatur}

Bublitz, Hannelore/Marek, Roman/Steinmann, Christina L./Winkler, Hartmut, „Automatismen. Einleitung“, in: dies. (Hg.), Automatismen, Paderborn, 2010, S. 9-16.

Leistert, Oliver, „Automatismen werfen das Problem der Beobachterin auf. Hiermit sind weitreichende epistemologische Fragen verbunden“, in: Hannelore Bublitz/Roman Marek/Christina L. Steinmann/Hartmut Winkler (Hg.), Automatismen, Paderborn, 2010, S. 99-102.

Link, Jürgen, Versuch über den Normalismus. Wie Normalität produziert wird, Opladen, 1997.

Ders., „Wie das Kügelchen fällt und das Auto rollt. Zum Anteil des Normalismus an der Identitätsproblematik in der Moderne“, in: Herbert Willems/Alois Hahn (Hg.), Identität und Moderne, Frankfurt/M, 1999, S. 164-179.

Ders., , The Normalistic Subject and its Curves. On the Symbolic Visualization of Orienteering Date', in: Cultural Critique 57, 1, 2004, S. 47-67.

Othmer, Julius, „Durch mediale Repräsentationen wird ein kollektiver Automatismus auch für die an ihm beteiligten Individuen beobachtbar. Auf dieser Beobachtungsoption setzen Selbsttechnologien auf, welche ungeplante Strukturentstehung beeinflussen“, in: Hannelore Bublitz/Irina Kaldrack/Theo Röhle/Mirna Zeman (Hg.), Automatismen - Selbst-Technologien, München, 2013, S. 134-138.

Röhle, Theo, „Ad gregem agere - Digitales Mapping zwischen Akkumulation und Aggregation“, in Thorben Mämecke/Jan-Hendrik Passoth/Josef Wehner (Hg.), Bedeutende Daten Modelle, Verfahren und Praxis der Vermessung und Verdatung im Netz, Wiesbaden, 2017, S. 71-90.

Sklovskij, Victor, „Die Kunst als Verfahren“, in Jurij Striedter (Hg.), Russischer Formalismus. Texte zur allgemeinen Literaturtheorie und zur Theorie der Prosa, München, 1971 [1916], S. 4-35. 



\section{PAUL BUCKERMANN}

\section{These 2: Die formelle Standardisierung von Maßeinheiten ermöglicht ungeplante Strukturbildung. Eine vergleichssoziologische Skizze zum Ecological Footprint.}

Vergleiche sind alltägliche und allgegenwärtige Operationen. Sie bieten sich in all ihren bewussten oder unbewussten Ausprägungen für Fragen nach Mechanismen der Strukturentstehung an, weil sie sich nicht nur auf bestehendes Wissen beziehen, sondern Ordnungsmuster stabilisieren, verändern oder neu anbieten können. Strukturell wirken dabei sowohl kommunikative Kategoriensysteme als auch Unterscheidungsfolien, welche soziale Verstehens- und Erwartungsstrukturen darstellen: So unterschiedlich Verglichenes auch sein mag, ist doch eine plausible, kategoriale Gleichheitsannahme notwendig, damit überhaupt etwas verglichen werden kann. Auch etwaige (In-)Differenzen zwischen Verglichenem können nur bezogen auf ein gemeinsames Tertium Comparationis festgestellt werden.

Jüngere soziologische Arbeiten zum Vergleich ${ }^{1}$ betonen über diese Einsichten und analytischen Implikationen hinaus insbesondere die gesellschaftliche Gemachtheit von kommunizierten Vergleichen und der Teilaspekte der "Gleichheitsunterstellung und Differenzbeobachtung".2 In dieser Perspektive ist die Annahme paradigmatisch, dass die Herstellung und Darstellung von Ordnung eine etwaige Realität nicht einfach abbildet, sondern selektiv Vergleichbarkeit herstellt, Unterscheidungsmodi anwendet und Zusammenhänge erst konstituiert. Dieses konstruktivistische Verständnis kommunikativer und kontingenter Ordnungsstiftung kann für eine These an der Schnittstelle von spezifischen Standardisierungsverfahren und der Automatismen-Forschung produktiv gemacht werden: Die formelle Standardisierung von Maßeinheiten ermöglicht ungeplante Strukturbildung.

In gegenstandsoffenen Vergleichskriterien wie etwa Länge oder Gewicht wird eine Unterscheidung und Relationierung von ganz unterschiedlichen Einheiten möglich. Durch formelle und bürokratische Standardisierung einer Metrik beziehen sich solche Vergleiche auf streng regulierte und objektiv prüfbare Maßeinheiten. Einheiten wie Meter oder Kilogramm können darüber

1 Vgl. Bettina Heintz, ,,Wir leben im Zeitalter der Vergleichung‘. Perspektiven einer Soziologie des Vergleichs“, in: Zeitschrift für Soziologie 45, 5 (2016), S. 305-323; Wendy Espeland/ Mitchell Stevens, „Commensuration as a Social Process“, in: Annual Review of Sociology, 24 (1998), S. 313-343; Bettina Heintz, „Numerische Differenz. Überlegungen zu einer Soziologie des (quantitativen) Vergleichs“, in: Zeitschrift für Soziologie 39, 3 (2010), S. 162-181; dies., „Welterzeugung durch Zahlen, Modelle politischer Differenzierung in internationalen Statistiken, 1948-2010“, in: Soziale Systeme 18, 1+2 (2012), S. 7-39; dies./Tobis Werron, „Wie ist Globalisierung möglich? Zur Entstehung globaler Vergleichshorizonte am Beispiel von Wissenschaft und Sport", in: Kölner Zeitschrift für Soziologie und Sozialpsychologie 63, 3 (2011), S. 359-394.

2 Heintz (2016), Zeitalter, S. 307. 
hinaus als allgemein bekannt vorausgesetzt werden, weil sie sich in der alltäglichen Anwendung als Ordnungskategorien einschleifen. Durch dauerhafte und formalisierte Standardisierung bilden sich so verbreitete Wissens- und Ordnungsstrukturen, die die Grundlage für eigenlogische Strukturbildung sein können. Genau solche Mechanismen der ungeplanten Strukturentstehung nimmt die Automatismen-Forschung in den Blick und postuliert „ein Entwicklungsmodell, das in Spannung zur bewussten Gestaltung und zu geplanten Prozessen steht.." ${ }^{\circ 3}$ Auf der einen Seite gerinnt die sukzessive Durchsetzung von standardisierten Maßeinheiten punktuell durch bewusst gestaltete Entscheidungsverfahren. Durch diese konventionale Festlegung, von oben ${ }^{6}$ stellt sich die Legitimität und allgemeine Verbindlichkeit der Entscheidungen her ${ }^{4}$, auf denen sich weitere Strukturbildung anschließen kann. Der politisch und rechtlich sichergestellte Maßstandard schafft universelle und extrem flexible Vergleichsmöglichkeiten, die andere Beobachtungs- und Ordnungsoperation ermöglichen, ohne sie dabei schon zu intendieren oder gar steuern.

Eine Kette von formeller Standardisierung und ungeplanter Strukturbildung lässt sich am Konzept des Ecological Footprint $(E F)^{5}$ nachvollziehen: Der $E F$ bezieht sich auf standardisierte Maßeinheiten, bildet neue, quasi-standardisierte Ordnungskategorien, welche wiederum anschließende Strukturbildung ermöglichen. Das „Buchhaltungssystems““6 $E F$ ist ein instruktiver Fall für die Vergleichssoziologie, da schon in der Grundidee des Indikators eine ultimative Anwendbarkeit mit planetarischem Ausmaß angelegt ist: Der $E F$ misst, verrechnet und vergleicht, wie der Ressourcenbedarf aller zivilisatorischen Vorgänge zu den ökologischen Ressourcen des Planeten Erde sich verhält. Der $E F$ operiert dabei auf Grundlage der standardisierten Längeneinheiten Meter, weil auf ihr ein neues Maß für komplexe Vergleiche konstruiert wurde: der globale Hektar ( $g h a)$. Ein Vertreter des EF sagt: „Das ist ja gerade der Trick: Dass es stets nur eine Größe gibt, worauf Dinge bezogen sind, nur ein tertium comparationis." ${ }^{7}$

Gesellschaftlich anschlussfähig wird die Einheit gha aber nicht nur, weil der Hektar eine alltagsweltliche Vorstellung von verständlichen Raumeinheiten abruft, sondern weil sich der gha auch auf eine numerische Größe reduzieren lässt. In einer Bildungsbroschüre heißt es: „Der Footprint kann für jede menschliche Aktivität angeben, wie viel produktive Fläche dafür benötigt

3 Norbert Eke/Lioba Foit/Timo Kaerlein/Jörn Künsemüller, „Logiken strukturbildender Prozesse. Automatismen“, in: dies. (Hg.), Logiken Strukturbildender Prozesse. Automatismen, Paderborn, 2014, S. 9-15: 9.

4 Vgl. Niklas Luhmann, Legitimation durch Verfahren, Frankfurt/M., 1983 [1969].

5 Zuerst in William Rees, ,Ecological Footprints and Appropriated Carrying Capacity: What Urban Economics Leaves Out", in: Environment and Urbanization 4, 2 (1992), S. 121-130; siehe standardmäßig Mathis Wackernagel/William Rees, Our Ecological Footprint: Reducing Human Impact on the Earth, Gabriola Island, 1996.

6 Mathis Wackernagel/Bert Beyers, Der Ecological Footprint. Die Welt neu vermessen, Hamburg, 2010, S. 7.

7 Ebd., S. 20. 
wird. Komplexe Dinge finden ihren Ausdruck somit in einer einzigen Zahl [...]. Damit lässt sich arbeiten“8, denn ,durch die Reduzierung auf die eine Einheit des gha wird es möglich, den Verbrauch natürlicher Ressourcen weltweit zu vergleichen." ${ }^{\text {"9 }}$ Das Konzept zielt somit auf einen globalen, universellen Vergleichshorizont, vor dem in einer extremen Komplexitätsreduktion alles Vorstellbare auf einen einzigen numerischen, vergleichsfähigen Wert reduziert wird. Besonders der Vergleichswert von Angebot und Bedarf ist dabei schon als handlungsinformierender Indikator ${ }^{10}$ angelegt, da mit ihm nicht nur gearbeitet werden kann, sondern soll.

Die Erfindung des $E F$ und all seine Implikationen beruhen auf der Standardisierung des Längenmaßes Meter und seiner universell eingeschliffenen Gebrauchsweise. Bevor globale Maßstandards durchgesetzt wurden, waren Maße historisch sehr vielfältig ${ }^{11}$ und oft stark in ihrem lokalen Kontext verwurzelt. ${ }^{12}$ Die heutige Elle des Schneider_innenhandwerks erinnert etwa daran, dass Maßeinheiten vor dem metrischen System oft einen Bezug zum omnipräsenten menschlichem Körper hatten. ${ }^{13}$ Die Feinheiten der Maße hingen von ortspezifischen Tätigkeiten sowie deren Relevanz für die soziale Reproduktion ab. Wenn etwa die Strecke zwischen Wasserquellen überlebenswichtig war, wurden genauere Unterschiede für Entfernungsangaben verwendet: Nomadische Gruppen in Wüstengebieten unterschieden hierfür u. a. zwischen der Hörweite der Stimme, der Distanz eines Pfeilschusses oder der menschlichen Blickweite von einem Tierrücken aus..$^{14}$

Mit der Ausbreitung von Handelsnetzwerken, Telekommunikationsinfrastrukturen und politischen Einflusssphären setzten sich dann auch überlokale Maßeinheiten sukzessive durch. ${ }^{15}$ Mit der formalen Standardisierung und Internationalisierung des „International System of Units“ (SI) hat sich bis heute zumindest dem Anspruch nach ein globales Einheitensystem für Messungen etabliert. Dem postrevolutionären Frankreich wird auch in diesem Modernisierungsprozess eine zentrale Rolle zugesprochen, da dort ein politischer Wille

8 Bert Beyers/Barbara Kus/Thora Amend/Andrea Fleischhauer, Großer Fuß auf kleiner Erde? Bilanzieren mit dem Ecological Footprint, Anregungen für eine Welt begrenzter Ressourcen. Deutsche Gesellschaft für Technische Zusammenarbeit, Nachhaltigkeit hat viele Gesichter, Nr. 10, Heidelberg, 2010, S. 16.

9 Ebd., S. 24.

10 Kevin Davis/Benedict Kingsbury/Sally Engle Merry, „Indicators as a Technology of Global Governance“, in: Law \& Society Review, 46, 1 (2012), S. 71-104.

11 Vgl. bspw. zur Vielfalt der prämetrischen Maße und Gewichte in Frankreich Ronald Zupko, French Weights and Measures Before the Revolution. A Dictionary of Provincial and Local Units, Bloomington, IN, 1978.

12 Vgl. David Hand, Measurement Theory and Practice. The World through Quantification, London, 2004, S. 11.

13 Witold Kula, Measures and Men, Princeton, NJ, 1986, S. 5.

14 Ebd., S. 5.

15 Ebd., Kap. 16. 
mit entsprechenden bürokratischen Strukturen zusammenfiel. ${ }^{16}$ Durch Widerstände im lokalen Vollzug und sich wandelnde machtpolitische Konstellationen dauerte eine offizielle Durchsetzung des metrischen Systems bis in die zweite Hälfte des 19. Jahrhunderts, als unter der Beteiligung von siebzehn Staaten 1875 die Meterkonvention ${ }^{17}$ verabschiedet und ein internationales Institutionengefüge zur Sicherung und Weiterentwicklung der Standards geschaffen wurde. ${ }^{18}$ Heute wird der Meter definiert als ,the length of the path travelled by light in vacuum during a time interval of 1/299 792458 of a se-

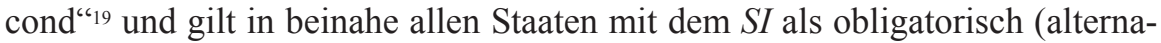
tive Längenmaße - prominent in den USA - werden mittlerweile durch metrische Einheiten definiert). Die naturwissenschaftlich fundierte, bürokratiegestützte und globale Standardisierung des Meters sowie der damit verbundene allgemeine Gebrauch ist die Grundlage des $g h a$, der zentralen Einheit des $E F$.

Der $E F$ soll zeigen, wie viel Biokapazität die menschliche Zivilisation braucht und wie viel dafür eigentlich zur Verfügung steht. Beide Werte - Bedarf und Angebot - werden pro Jahr als Produktivität pro Hektar in der Größe des gha gemessen. „Der globale Hektar entspricht einer quadratischen Fläche mit der Kantenlänge von 100 Metern [...] biologisch produktiver Fläche mit Weltdurchschnittsproduktivität.“" ${ }^{20}$ Zur Definition dieses Durchschnitts und der Umwandlung vom Hektar in gha werden Äquivalenzfaktoren für verschiedene Flächentypen sowie jährlich erhobene regionalspezifische Faktoren verrechnet. Bedarf (Fußabdruck) und Angebot (vorhandene Fläche) ${ }^{21}$ werden beide in der Größe des gha ausgedrückt und damit diskret kommensurabel. Diagrammatisch, grafisch und numerisch reduziert kann dann für jedes Individuum oder jeden Staat ein entsprechendes Verhältnis oder viel mehr die Differenz von Angebot und Bedarf abgebildet werden.

Der $E F$ hat als Indikator einen deutlichen Bezug zu kybernetischen Semantiken der weltgesellschaftlichen Planung vor dem Hintergrund einer planetaren Ökologie, was sich auch in einer leicht erkennbaren Analogie zu Buckminster Fullers Spaceship Earth ausdrückt: „Was nutzt ein Flugzeug ohne Navigationsinstrumente? Sicher, es fliegt. Aber wie hoch, wie schnell? Und wie lautet

16 Vgl. Roland Wenzlhuemer, „Die Geschichte der Standardisierung in Europa“, in: Europäische Geschichte Online, hg. v. Institut für Europäische Geschichte, 2010, Abschn. 3, online unter: http://www.ieg-ego.eu/wenzlhuemerr-2010-de, zuletzt aufgerufen am 07.11.2018.

17 Der Originaltext (französisch/englisch) ist online unter: http://www.bipm.org/utils/common/ documents/official/metre-convention.pdf, zuletzt aufgerufen am 07.11.2018.

18 Wenzlhuemer (2010), Geschichte, Kap. 2.

19 Definition des International Bureau of Weights and Measures, online unter: http://www.bipm.org/en/publications/si-brochure/metre.html, zuletzt aufgerufen am 07.11.2018.

20 Wackernagel/Beyers (2010), Footprint, S. 54.

21 Vgl. zur Methodologie des Ecological Footprint Michael Borucke/David Moore/Gemma Cranston/Kyle Gracey/Katsunori Iha/Joy Larson/Elias Lazarus/Juan Carlos Morales/Mathis Wackernagel/Alessandro Galli, „Accounting for Demand and Supply of the Biosphere's Regenerative Capacity: The National Footprint Accounts' Underlying Methodology and Framework", in: Ecological Indicators, 24 (2013), S. 518-533. 
seine genaue Position? Ohne Armaturen weiß der Pilot nicht einmal, wie viel Treibstoff sich noch in den Tanks befindet. [...] Nicht wesentlich anders geht es uns mit dem Naturverbrauch. [...] Und warum messen wir ihn dann nicht?"“22 Die totale Universalisierung im zivilisatorischen Wir fordert ein robustes Ordnungsverfahren, welches sich nur als globaler Mess- und Vergleichszusammenhang darstellen kann. Durch den $E F$ soll der gesamte Planet und die ganze Weltgesellschaft beobachtet werden, um steuernd in dieses umfassende Ökosystem eingreifen zu können. Während ältere Maße noch am Körper und an ortsspezifischen Reproduktionstätigkeiten orientiert waren, wird beim $E F$ und seinem gha deutlich, dass heute Maße immer noch an konkreten Problemstelllungen geschaffen werden. Aufbauend auf Semantiken des Ökosystems und breiten naturwissenschaftlichen Erkenntnissen ist die Reproduktion einer Gesellschaft nur vor dem Hintergrund eines planetarischen Maßstabs möglich, welcher entsprechende Beobachtungsinstrumente und Messtechniken zu erfordern scheint.

Das Verhältnis von selektiven Vergleichen und potenziell globalen Sinnzusammenzusammenhängen ist eine zentrale Pointe jüngerer Vergleichssoziologien. Allgemein kann die ,transformation of different qualities into a common metric“" ${ }^{23}$ als ein grundlegender Bestandteil des Sozialen bezeichnet werden. Neben solchen Kommensurationsverfahren und zahlenbasierten Vergleichen ${ }^{24}$ sind die Funktionen und Folgen von Vergleichen in allen medialen Formen ${ }^{25}$ eine extreme Komplexitätsreduktion ganz verschiedenster Phänomene und ihre kommunikative Relationierung durch den Vergleich. Bettina Heintz und Tobias Werron formulieren darauf aufbauend eine weltgesellschaftstheoretische These ${ }^{26}$ : Vergleiche sind durch Reduktion, Standardisierung und Vereinheitlichung nicht nur global denkbar, sondern stellen Globalität vielmehr her. Globalisierung realisiere sich so ,vor allem über Vergleiche, und damit meinen wir immer kommunizierte Vergleiche". ${ }^{27}$ Sich wiederholende, global verständliche und öffentlich kommunizierte Vergleichsresultate sind ein Globalisierungsmechanismus, da sie neben den direkten Verbindungsnetzwerken von Waren- und Personenverkehr, interaktiven Kontakten oder Infrastruktur die Beobachtungsseite von globalen Zusammenhängen ermöglichen und strukturieren.

Am $E F$ wird deutlich, wie Standardisierung andere Vergleichsoperationen ermöglicht, ohne jene dabei schon zu beabsichtigen. Besonders durch den eingeschliffenen Gebrauch ${ }^{28}$ von Maßeinheiten bei beständiger Nachprüfbarkeit

Wackernagel/Beyers (2010), Footprint, S. 7.

23 Espeland/Stevens (1998), Commensuration, S. 314.

24 Heintz (2010), Differenz, S. 169.

25 Heintz (2016), Zeitalter.

26 Heintz/Werron (2011), Globalisierung; Heintz (2012), Welterzeugung.

27 Heintz/Werron (2011), Globalisierung, S. 361 f. [Herv. i. O.].

28 Vgl. zum Stellenwert der Strukturbildung bei Automatismen Hannelore Bublitz, ,Automatismen beinhalten einen qualitativen Sprung: Aus der wiederholten Einschleifung durch Übung entsteht 
findet der $E F$ eine hohe alltagsweltliche und quasi-objektive Überzeugungskraft. Für meine These spricht nicht zuletzt, dass der $E F$ selbst als quasistandardisierter Indikator schon in die nächsten, unintendierten Standardisierungs- und Vergleichsverfahren eingeht. Im Happy Planet Index etwa wird die nationale Lebenserwartung mit der wiederum quantifizierten ,Lebenszufriedenheit' sowie dem $E F$ verrechnet, um anzuzeigen, in welchem Verhältnis Ressourcenverbrauch und gefühlte Lebensqualität stehen.. ${ }^{29}$ Meine These stärkt, dass es in der Tat wenig überraschend wäre, wenn hier wiederum die nächsten Vergleichshorizonte aufgespannt werden.

\section{Literatur}

Beyers, Bert/Kus, Barbara/Amend, Thora/Fleischhauer, Andrea, Großer Fuß auf kleiner Erde? Bilanzieren mit dem Ecological Footprint, Anregungen für eine Welt begrenzter Ressourcen. Deutsche Gesellschaft für Technische Zusammenarbeit, Nachhaltigkeit hat viele Gesichter Nr. 10, Heidelberg, 2010.

Borucke, Michael/Moore, David/Cranston, Gemma/Gracey, Kyle/Iha, Katsunori/Larson, Joy/Lazarus, Elias/Morales, Juan Carlos/Wackernagel, Mathis/Galli, Alessandro, ,Accounting for Demand and Supply of the Biosphere's Regenerative Capacity: The National Footprint Accounts' Underlying Methodology and Framework", in: Ecological Indicators, 24 (2013), S. 518-533.

Bublitz, Hannelore, „Automatismen beinhalten einen qualitativen Sprung: Aus der wiederholten Einschleifung durch Übung entsteht - paradoxerweise - gerade das Neue: spielerisch-mühelose Perfektion“, in: dies./Roman Marek/Christina L. Steinmann/Hartmut Winkler (Hg.), Automatismen, München, 2010, S. 23-26.

Davis, Kevin/Kingsbury, Benedict/Merry, Sally Engle, ,Indicators as a Technology of Global Governance“, in: Law \& Society Review 46, 1 (2012), S. 71-104.

Eke, Norbert/Foit, Lioba/Kaerlein, Timo/Künsemüller, Jörn, „Logiken Strukturbildender Prozesse. Automatismen“, in: dies. (Hg.), Logiken Strukturbildender Prozesse. Automatismen, Paderborn, 2014, S. 9-15.

Espeland, Wendy/Stevens, Mitchell, „Commensuration as a Social Process“, in: Annual Review of Sociology, 24 (1998), S. 313-343.

Hand, David, Measurement Theory and Practice. The World through Quantification, London, 2004.

Heintz, Bettina, „Numerische Differenz. Überlegungen zu einer Soziologie des (quantitativen) Vergleichs“, in: Zeitschrift für Soziologie 39, 3 (2010), S. 162-181.

Dies., ,Welterzeugung durch Zahlen, Modelle politischer Differenzierung in internationalen Statistiken, 1948-2010“, in: Soziale Systeme 18, 1+2 (2012), S. 7-39.

- paradoxerweise - gerade das Neue: spielerisch-mühelose Perfektion“, in: dies./Roman Marek/Christina L. Steinmann/Hartmut Winkler (Hg.), Automatismen, München, 2010, S. 23-26.

29 Daten, Ergebnisse, Graphen und Formeln sind auf www.happyplanetindex.org/ einsehbar, zuletzt aufgerufen am 07.11.2018. 
Dies., „,Wir leben im Zeitalter der Vergleichung'. Perspektiven einer Soziologie des Vergleichs“, in: Zeitschrift für Soziologie 45, 5 (2016), S. 305-323.

Dies./Werron, Tobias, „Wie ist Globalisierung möglich? Zur Entstehung globaler Vergleichshorizonte am Beispiel von Wissenschaft und Sport", in: Kölner Zeitschrift für Soziologie und Sozialpsychologie 63, 3 (2011), S. 359-394.

Kula, Witold, Measures and Men, Princeton, NJ, 1986.

Luhmann, Niklas, Legitimation durch Verfahren, Frankfurt/M., 1983 [1969].

Rees, William, „Ecological Footprints and Appropriated Carrying Capacity: What Urban Economics Leaves Out", in: Environment and Urbanization 4, 2 (1992), S. 121-130.

Wackernagel, Mathis/Beyers, Bert, Der Ecological Footprint. Die Welt neu vermessen, Hamburg, 2010.

Wackernagel, Mathis/Rees, William, Our Ecological Footprint: Reducing Human Impact on the Earth, Gabriola Island, 1996.

Wenzlhuemer, Roland, „Die Geschichte der Standardisierung in Europa“, in: Europäische Geschichte Online, hg. v. Institut für Europäische Geschichte, 2010, online unter: http://www.ieg-ego.eu/wenzlhuemerr-2010-de, zuletzt aufgerufen am 07.11.2018.

Zupko, Ronald, French Weights and Measures before the Revolution. A Dictionary of Provincial and Local Units, Bloomington, IN, 1978. 



\section{ABBILDUNGSNACHWEISE}

Florian Sprenger

Abb. 2.1: Roger Twysden, Historiae Anglicanae Scriptores Decem, London, 1648, S. 339.

Abb. 2.2: Copyright Hamburger Kunsthalle, Fotonachweis Christoph Irrgang. Abb. 2.3: https://books.google.com/ngrams/, zuletzt aufgerufen am 14.03.2019.

\section{Anna Echterhölter}

Abb. 3.1: Pamela J. Stewart/Andrew Strathern, „Transformations of Monetary Symbols in the Highlands of Papua New Guinea“, in: L'Homme 162 (2002), S. 137-156: 143.

Nicole M. Wilk Abb. 6.1, 6.2 und 6.3: (C) Nicole M. Wilk.

Abb. 6.2 und 6.3: Die Tabellen wurden erstellt durch Nicole M. Wilk.

Roland Bless

Abb. 7.1: (C) Roland Bless.

Stefan Rieger

Abb. 4.1 und 4.2: Heinz Werner, Grundfragen der Sprachphysiognomik, Leipzig, 1932, S. 146 und S. 147.

Abb. 4.3 bis 4.5: Richard Krauss, Über graphischen Ausdruck. Eine experimentelle Untersuchung über das Erzeugen und Ausdeuten gegenstandsfreier Linien, Leipzig, 1930 (Beihefte zur Zeitschrift für angewandte Psychologie; 48), Tafeln im Anhang.

Abb. 4.6 und 4.7: Max Verworn, Ideoplastische Kunst. Ein Vortrag, Jena, 1914, S. 12, Figuren 6a und 6b.

Abb. 4.8: Karl Steinbuch, Automat und Mensch. Auf dem Weg zu einer kybernetischen Anthropologie, 4., neubearb. Aufl., Berlin (u. a.), 1971, S. 111, Bild 51.

Abb. 4.9: Otto Pötzl, „Experimentell erregte Traumbilder in ihren Beziehungen zum indirekten Sehen", in: Zeitschrift für die gesamte Neurologie und Psychiatrie, 37 (1917), S. 278-349, hier: Figur 1 und 2.

Abb. 4.10: Gotthard Wolf, Der wissenschaftliche Dokumentationsfilm und die Encyclopaedia Cinematographica, München, 1967, S. 40.

Abb. 4.11: Bildsequenzen aus der Encyplopaedia Cinematographica (Quelle: YouTube).

Abb. 4.12: Gegenüberstellung von Original und Rekonstruktion unter Verwendung der Originalarbeit von Gallant nach Florian Rötzer, „Weiterer Erfolg im 
,Gedankenlesen““, auf: Telepolis vom 24.11.2011, online unter: http://www. heise.de/tp/artikel/35/35552/1.html, zuletzt aufgerufen am 03.01.2019.

Abb. 4.13 und 4.14: Richard Semon, Die Mneme als erhaltendes Prinzip im Wechsel des organischen Geschehens, 4. und 5. unveränd. Aufl., Leipzig, 1920, S. 171 und S. 172.

\section{Laura Moisi}

Abb. 10.1: „Frankfurter Küche“, aus dem Archiv Margarete Schütte-Lihotzki, Wien. Nach: Peter Noever (Hg), Die Frankfurter Küche von Margarete Schütte-Lihotzki, 1992, S. 2. 


\section{ÜBER DIE AUTORINNEN UND AUTOREN}

DR. RoLAND BLESS ist Akademischer Oberrat am Institut für Telematik, Karlsruher Institut für Technologie (KIT). Nach dem Studium der Informatik an der Universität Karlsruhe (TH), promovierte er am Institut für Telematik zum Thema „Integriertes Management qualitätsbasierter Internetkommunikationsdienste". Die Habilitation erfolgte im Fach Informatik am KIT. Forschungsschwerpunkte: Dienstgüteunterstützung und Staukontrollverfahren im Internet, Hochgeschwindigkeitsnetze, Netzvirtualisierung und softwarebasierte Netze, Netzsicherheit sowie zukünftige Internet-Architekturen und -Protokolle. Er ist seit 1998 in der Internet-Standardisierung aktiv und Mitglied der GI, ACM, IEEE und Internet Society. Ausgewählte Veröffentlichungen: Sichere Netzwerkkommunikation (Hg. mit Stefan Mink/Erik-Oliver Blaß/Michael Conrad/Hans-Joachim Hof/Kendy Kutzner/Marcus Schöller) (2005); „Values and Networks - Steps toward Exploring Their Relationships“" (mit Carsten Orwat), in: Computer Communication Review 46, 2 (2016), S. 25-31; „Experimental Evaluation of BBR Congestion Control" (mit Mario Hock/Martina Zitterbart), International Conference on Network Protocols (ICNP) (2017), S. 1-10; „A Lower Effort Per-Domain Behavior (PDB) for Differentiated Services“ (mit Klaus Wehrle/Kathie Nichols), RFC 3662, IETF (2003); „Network Design“ (mit Susana Perez Sanchez), in: Luis Correia/Henrik Abramowicz/Martin Johnsson/Klaus Wünstel (Hg.), Architecture and Design for the Future Internet (2011), S. 59-87.

DR. DES. PAUl BUCKERMANN ist Soziologe an der Universität Luzern. Nach dem Studium an der Universität Bielefeld war er wissenschaftlicher Mitarbeiter am Graduiertenkolleg Automatismen an der Universität Paderborn und anschließend Forschungsmitarbeiter am „eikones NFS Bildkritik“ in Basel und Luzern. Seit 2017 war er wissenschaftlicher Assistent am soziologischen Seminar der Universität Luzern und ist dort seit 2019 Oberassistent. Seine Dissertation verfasste er zu pluralen Wissensarchitekturen und quantifizierenden Ordnungsverfahren im Kunstbetrieb. Aktuelle Veröffentlichungen: „Reactions, Reactivity, Rampant Reductions. On Self-Fulfilling Prophecies, the Matthew Effect, and Global Potentials of a New Gallery Ranking", in: Creative Industries Journal 11, 2 (2018), S. 197-202; „Warum eine Rangliste? Die Vorstellungen von Kunst hinter dem Künstler_innenranking Kunstkompass, 19702016“, in: Hannah Bennani/Martin Bühler/Sophia Cramer/Andrea Glauser (Hg.), Beobachtung und Vergleich. Soziologische Untersuchungen zur Weltgesellschaft (im Erscheinen). 
Prof. DR. ANNA ECHTERHÖLTER ist Professorin für Wissenschaftsgeschichte an der Universität Wien. Nach Fellowships am Max-Planck-Institut für Wissenschaftsgeschichte und dem Deutschen Historischen Institut in Washington folgten Vertretungsprofessuren an der Humboldt-Universität und der Technischen Universität Berlin. Sie ist Mitgründerin der Zeitschrift ilinx. Ihre Forschungsthemen umfassen die Geschichte der Quantifizierung, Rationierung und Planung, die Global- und Rechtsgeschichte der Vermessung sowie ökonomische Praktiken. Publikationen: Infrastrukturen der Asymmetrie. Vom ökonomischen Handwerk des Messens (Habilitation in Vorbereitung); Jenseits des Geldes. Aporien der Rationierung, (Hg. mit Hendrik Blumentrath/Frederike Felcht/Karin Harrasser) (2018); „Injury and Measurement. Jacob Grimm on Rural Quantification, Blood Money, and the Irritation of Equivalence", in: Social Analysis: The International Journal of Social and Cultural Practice 61, 4 (2017), S. 31-48; „Plantagenzeit. Gabe, Frist und Metroklasmus im Deutschen Pazifik", in: Michael Bies/Sebastian Giacovelli/Andreas Langenohl, Ästhetische Eigenzeiten von Tausch und Gabe (2018), S. 187-217.

DR. TOBIAS EICHINGER ist Oberassistent am Institut für Biomedizinische Ethik und Medizingeschichte der Universität Zürich. Studium der Philosophie und Filmwissenschaft, Promotion $\mathrm{zu}$ philosophischen und ethischen Fragen der wunscherfüllenden Medizin. Am Zürcher Institut ist er Lehrkoordinator und leitet ein Projekt zur Entwicklung eines E-Learning-Tools für Medizinethik. Forschungsinteressen: ethische Fragen von Enhancement, wunscherfüllender Medizin und Medikalisierung, philosophische Deutungen von Gesundheit und Krankheit sowie die Darstellung von medizinethischen Problemen im Film. Ausgewählte Publikationen: „Gesund machen oder Gesundheit machen? Philosophische Anmerkungen zu einem Grundbegriff der Medizin“, in: Brigitte Kepplinger/Florian Schwanninger (Hg.), Optimierung des Menschen (im Erscheinen); „Seelenermittlungen von Kannibalen, Psychiatern und Serienkillern - Das Schweigen der Lämmer", in: Martin Poltrum/Bernd Rieken (Hg.), Seelenkenner, Psychoschurken. Psychotherapeuten und Psychiater in Film und Serie (2017), S. 176-194; Jenseits der Therapie. Philosophie und Ethik wunscherfüllender Medizin (2013).

DR. SUSANNE JANY ist Postdoktorandin im Exzellenzcluster Matters of Activity. Image Space Material und wissenschaftliche Mitarbeiterin am Institut für Kulturwissenschaft (beides Humboldt-Universität zu Berlin). 2013 war sie Gastwissenschaftlerin an der Harvard University und von 2015 bis 2018 Mitarbeiterin am Exzellenzcluster Bild Wissen Gestaltung. Ein interdisziplinäres Labor (HU Berlin). Ihre Forschungsschwerpunkte sind medien- und kulturwissenschaftliche Architekturforschung, materielle Epistemologie und Theorien des Entwerfens. 2019 erscheint ihre Monografie Prozessarchitekturen: Medien der Betriebsorganisation (1880-1936) bei Konstanz University Press. Weitere Publikationen: „Making Buildings Work“, in: Laurent Stalder/Moritz 
Gleich (Hg.), Architecture/Machine (2017), S. 70-81; „Transgressions at the Post-Office Counter“, in: Interface Critique Journal, 1 (2018), S. 82-95.

DR. ANTONIO LUCCI hat Philosophie und Geschichte an der Universität Rom (La Sapienza) studiert und promovierte an der Universität in Triest im Bereich der Philosophie mit einer Arbeit über das Konzept von „Anthropotechnik“ von Peter Sloterdijk, die 2014 bei Aracne (Rom) veröffentlicht wurde. Derzeit ist er Fellow am Forschungsinstitut für Philosophie Hannover (FIPH). Fellowship am Internationalen Forschungszentrum Kulturwissenschaften Wien (SoSe 2018), Vertretung der Professur für „Kulturtheorie und kulturwissenschaftliche Ästhetik" an der Humboldt-Universität zu Berlin (SoSe 2016 und WiSe 2017/2018), wissenschaftlicher Mitarbeiter am Institut für Kulturwissenschaft der Humboldt-Universität (2015 bis 2017), Post-Doc am Exzellenzcluster Topoi (2013 bis 2015). Er ist Herausgeber diverser philosophischer und internationaler Zeitschriften wie Lo Sguardo und Azimuth. Zu seinen Veröffentlichungen zählen u. a.: Lacan, oggi. Sette conversazioni per capire Lacan (mit Sergio Benvenuto) (2014); Umano Post Umano (2016); Potential regieren. Zur Genealogie des möglichen Menschen, (Hg. mit Thomas Skowronek) (2018); Schmuckeremiten (voraussichtlich 2019).

DR. THORBEN MÄMECKE hat am Graduiertenkolleg Automatismen zum Thema Self-Tracking promoviert. Seine Forschungsschwerpunkte liegen in den Bereichen Subjektivierungs- und Gouvernementalitätsforschung, eParticipation, Medienwissenschaften sowie Medien- und Techniksoziologie. Zuletzt erschienen: Bedeutende Daten - Modelle, Verfahren und Praxis der Vermessung und Verdatung im Netz (Hg. mit Jan-Hendrik Passoth/Josef Wehner) (2017); „Benchmarking the self. Kompetitive Selbstvermessung im betrieblichen Gesundheitsmanagement", in: Stefanie Duttweiler/Robert Gugutzer/Jan-Hendrik Passoth/Jörg Strübing (Hg.), Leben nach Zahlen. Self-Tracking als Optimierungsprojekt? (2016), S. 99-118; „Die Statistik des Selbst - Zur Gouvernementalität der Selbstverdatung“, in: Stefan Selke (Hg.), Lifelogging - Digitale Selbstvermessung und Lebensprotokollierung zwischen disruptiver Technologie und kulturellem Wandel (2016), S. 97-125.

Prof. Dr. ThOmas Macho forschte und lehrte von 1993 bis 2016 als Professor für Kulturgeschichte am Institut für Kulturwissenschaft der HumboldtUniversität zu Berlin. 1976 promovierte er an der Universität Wien mit einer Dissertation zur Musikphilosophie; 1984 habilitierte er sich für das Fach Philosophie an der Universität Klagenfurt mit einer Habilitationsschrift über Todesmetaphern. Seit 2016 leitet er das Internationale Forschungszentrum Kulturwissenschaften (IFK) der Kunstuniversität Linz in Wien. Zu seinen neueren Monografien zählen: Das Leben ist ungerecht (2010); Vorbilder (2011); Schweine. Ein Portrait (2015); Das Leben nehmen. Suizid in der Moderne (2017). 
LAURA MOISI studierte Kulturwissenschaft an der Humboldt-Universität zu Berlin und war als wissenschaftliche Mitarbeiterin am Graduiertenkolleg $A u$ tomatismen an der Universität Paderborn tätig. In ihrer Dissertation Ordinary Waste. Szenen des Politischen in der alltäglichen Müllentsorgung hat sie sich mit der neueren Politisierung des Abfalls beschäftigt. Zu Ihren Forschungsinteressen zählen die kulturwissenschaftliche Müllforschung, politische Ideengeschichte sowie die Zusammenhänge von Geschlecht und Ungleichheit. Momentan beschäftigt sie sich mit der kulturellen Unsichtbarmachung von Gewalt, die sich im Privaten ereignet, und die Erzähl- und Schweigepraktiken, die damit einhergehen. Letzte Veröffentlichung: „Müll als Strukturfaktor gesellschaftlicher Ungleichheitsbeziehungen“, in: Bundeszentrale für politische Bildung (Hg.), Aus Politik und Zeitgeschichte: Müll (2018), S. 49-50.

MARTIN MÜLLER forscht als wissenschaftlicher Mitarbeiter am Exzellenzcluster Matters of Activity. Image Space Material und am Institut für Kulturwissenschaft der Humboldt-Universität zu Berlin. Zuvor war er am Exzellenzcluster Bild Wissen Gestaltung und am Paderborner Graduiertenkolleg Automatismen tätig. Forschungsschwerpunkte: Theorie der synthetischen Biologie, Geschichte der Bio- und Zoëpolitik, Selbst-Aktivität von Materialien, Genealogie und Ontologie des Techno- und Anthropozäns, Theorie und Geschichte des Postmetabolischen. Forschungsaufenthalte als Gastwissenschaftler: Universidad de Buenos Aires (2017); Université Paris 1 Panthéon-Sorbonne am Centre d'Etudes des Techniques, des Connaissances et des Pratiques (2013); Columbia University in New York (2012) und University of Cape Town (2009). Zuletzt erschienen: „Nach dem metabolischen Bruch“, in: Texte zur Kunst, 110 (2018), S. 154-159; „Zoë als Téchne. Zum Paradox möglicher Menschen in der synthetischen Biologie", in: Antonio Lucci/Thomas Skowronek (Hg.), Potential regieren. Zur Genealogie des möglichen Menschen (2018), S. 239-252; „,First Species Whose Parent Is a Computer ${ }^{6}$ - Synthetic Biology as Technoscience, Colonizing Futures, and the Problem of the Digital“, in: Kristin Hagen/Margret Engelhard/Georg Toepfer (Hg.), Ambivalences of Creating Life. Philosophical Dimensions of Synthetic Biology (2016), S. 101-113.

DR. Christoph NeuberT ist Akademischer Rat mit dem Schwerpunkt Mediengeschichte an der Universität Paderborn und Mitglied des Graduiertenkollegs Automatismen. Davor war er wissenschaftlicher Mitarbeiter am Lehrgebiet für Neuere deutsche Literaturwissenschaft und Medienästhetik der Fernuniversität Hagen und am Kulturwissenschaftlichen Forschungskolleg/SFB Medien und kulturelle Kommunikation an der Universität zu Köln.

Prof. Dr. PAtricia Ribault studierte Angewandte Kunst und Keramik an der École Nationale Supérieure des Arts Appliqués et des Métiers d'Art in Paris, bevor sie nach England, Venedig und Tunesien ging, um das Glasblasen 
zu erlernen. Während dieser Jahre arbeitete sie für Kulturorganisationen wie die UNESCO oder die Turquoise Mountain Foundation. 2000 ging sie zurück nach Paris, um Ästhetik an der Université Paris 1 Panthéon-Sorbonne zu studieren und schloss 2009 mit einem PhD in Kunst und Kunstwissenschaft ab. Ihre Doktorarbeit „Ontology of Craft“ (frz. „Pour une ontologie du geste“) ist ein Versuch, dem Sinn von Handwerksarbeit in unserer heutigen industrialisierten Welt nachzugehen. Von 2010 bis 2015 arbeitete sie als Head of Research an der École Supérieure d'Art et de Design de Reims in Frankreich. Sie leitet außerdem seit 2011 ein Seminar an der École Nationale Supérieure des Beaux-Arts in Paris. 2015 arbeitete sie zusammen mit dem Kunsthistoriker Thomas Golsenne an einer Sonderedition des französischen Journals Techniques \& Culture mit dem Titel Essais de Bricologie. Ethnologie de l'art et du design contemporains. Sie schreibt außerdem für zahlreiche wissenschaftliche Zeitschriften, Kataloge und Sammelwerke, wie The Journal of Modern Craft oder Appareil. Seit März 2015 ist sie Juniorprofessorin für Geschichte und Theorie der Gestaltung am Institut für Kulturwissenschaft und am Exzellenzcluster Bild Wissen Gestaltung (bis 2018) der Humboldt-Universität zu Berlin. Sie ist außerdem Mitglied des Hermann von Helmholtz-Zentrums für Kulturtechnik und forscht als Principal Investigator im neuen Exzellenzcluster Matters of Activity. Image Space Material der Humboldt-Universität.

Prof. Dr. Stefan Rieger, Studium der Germanistik und Philosophie. Promotion über barocke Datenverarbeitung und Mnemotechnik, Habilitationsschrift zum Verhältnis von Medien und Anthropologie (Die Individualität der Medien. Eine Geschichte der Wissenschaften vom Menschen) (2001). Heisenbergstipendiat der DFG. Seit 2007 Professor für Mediengeschichte an der RuhrUniversität Bochum. Aktuelle Arbeits- und Publikationsschwerpunkte: Wissenschaftsgeschichte, Medientheorie und Kulturtechniken. Zuletzt sind von ihm erschienen: Bunte Steine. Ein Lapidarium des Wissens (mit Benjamin Bühler) (2014); Kultur. Ein Machinarium des Wissens (mit Benjamin Bühler) (2014); Die Enden des Körpers. Versuch einer negativen Prothetik (2018).

ANNE SCHREIBER, Studium der Neueren deutschen Literatur, Philosophie und Volkswirtschaftslehre, Doktorandin der Humboldt-Universität zu Berlin. Ihre Dissertation untersucht die Anfänge moderner Managementtheorie, Wissenschaftsgeschichte und Sozialforschung zu Beginn des 20. Jahrhunderts in den USA. Sie war von 2014 bis 2017 wissenschaftliche Mitarbeiterin des Graduiertenkollegs Automatismen der Universität Paderborn. Zu ihren Publikationen zählen u. a. „The Secrets of Management. Mechanismen der Strukturentstehung und Zersetzung in der Physiologie Anfang des 20. Jahrhunderts", in: Patrick Hohlweck/Norbert Eke (Hg.), Zersetzung. Automatismen und Strukturauflösung (2018), S. 171-184; „Organisation durch Kommunikation. Medien des Managements in den USA Anfang des 20. Jahrhunderts", in: Zeitschrift für Medienwissenschaft 1 (2018), S. 28-36; „Distanz/Shared Answers: Anne 
Schreiber im Gespräch mit Karin Sander", in: Petra Reichensperger (Hg.), Begriffe des Ausstellens (von A - Z) (2014); „Gefahrensinn. Sense for Danger“, in: Zeitschrift für Germanistik, 1 (2011); „Netzkunstwerk = Netzwerkkunst?“ (zusammen mit Julia Schneider), in: Lydia Grün/Frank Wiegand (Hg.), musik netz werke. Konturen der neuen Musikkultur (2002), S. 176-197.

Prof. DR. Florian SPRENGER ist Juniorprofessor für Medienkulturwissenschaft an der Goethe-Universität Frankfurt. Forschungsschwerpunkte: Geschichte der Medientheorie, künstliche Environments im 20. Jahrhundert, Infrastrukturen der Überwachung in der Gegenwart. Letzte Buchpublikationen: Politik der Mikroentscheidungen. Edward Snowden, Netzneutralität und die Architekturen des Internets (2015); Internet der Dinge - Über smarte Objekte, intelligente Umgebungen und die technische Durchdringung der Welt (mit Christoph Engemann) (2015).

DR. NICOLE M. WILK ist seit 2018 wissenschaftliche Mitarbeiterin im DFGProjekt „Heterogene Widerstandskulturen. Sprachliche Praktiken des SichWidersetzens von 1933 bis $1945^{\text {“ }}$ an der Universität Paderborn. Nach dem Studium der Germanistischen Sprachwissenschaft und Sozialpsychologie an der (heute: Leibniz) Universität Hannover war sie wissenschaftliche Mitarbeiterin an der Stiftung Universität Hildesheim und hatte von 2008 bis 2018 die Juniorprofessur für Germanistische Sprachwissenschaft an der Universität Paderborn inne. Von 2013 bis 2017 war sie assoziiertes Mitglied im Graduiertenkolleg Automatismen. Ihre Forschungsschwerpunkte liegen in den Bereichen Kultursemiotik, Medien- und Diskurslinguistik, insbesondere Diskursgrammatik. In ihren Arbeiten thematisiert sie Körperbilder in Medien und Gesellschaft (Körpercodes. Die vielen Gesichter der Weiblichkeit in der Werbung) (2004); Leiblichkeit als Kategorie der linguistischen Semantik (Verstehen und Gefühle. Entwurf einer leiborientierten Kommunikationstheorie) (2004) sowie multimodales Spacing in raumgebundenen (mobilen) Medien (,,Gebäude erzählen Geschichte(n) “. Medienlinguistische und diskursgrammatische Untersuchung zur multimodalen Herstellung historischer StadtRäume durch Schilder, Pulte, Stelen, Mobile Tagging und Apps) (2015). 